\title{
Nutritional strategies to support muscle maintenance in clinical population
}

Citation for published version (APA):

Kouw, I. W. K. (2018). Nutritional strategies to support muscle maintenance in clinical population.

[Doctoral Thesis, Maastricht University]. Maastricht University. https://doi.org/10.26481/dis.20181205ik

Document status and date:

Published: 01/01/2018

DOI:

10.26481/dis.20181205ik

Document Version:

Publisher's PDF, also known as Version of record

\section{Please check the document version of this publication:}

- A submitted manuscript is the version of the article upon submission and before peer-review. There can be important differences between the submitted version and the official published version of record.

People interested in the research are advised to contact the author for the final version of the publication, or visit the DOI to the publisher's website.

- The final author version and the galley proof are versions of the publication after peer review.

- The final published version features the final layout of the paper including the volume, issue and page numbers.

Link to publication

\footnotetext{
General rights rights.

- You may freely distribute the URL identifying the publication in the public portal. please follow below link for the End User Agreement:

www.umlib.nl/taverne-license

Take down policy

If you believe that this document breaches copyright please contact us at:

repository@maastrichtuniversity.nl

providing details and we will investigate your claim.
}

Copyright and moral rights for the publications made accessible in the public portal are retained by the authors and/or other copyright owners and it is a condition of accessing publications that users recognise and abide by the legal requirements associated with these

- Users may download and print one copy of any publication from the public portal for the purpose of private study or research.

- You may not further distribute the material or use it for any profit-making activity or commercial gain

If the publication is distributed under the terms of Article $25 \mathrm{fa}$ of the Dutch Copyright Act, indicated by the "Taverne" license above, 
NUTRITIONAL STRATEGIES TO SUPPORT MUSCLE MAINTENANCE IN CLINICAL POPULATIONS 


\section{$\ddot{O}$ NUTRIM}

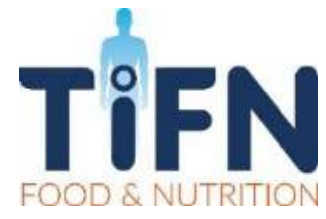

ISBN

978-94-6323-402-3

COVER AND ILLUSTRATIONS

Yvette Krist, www.yvettekrist.nl

PRINTED BY

Gildeprint

SUPPORTED BY

The studies presented in this thesis were performed within NUTRIM, School of Nutrition and Translational Research in Metabolism, accredited by the Royal Netherlands Academy of Arts and Sciences, and within the framework of TiFN.

(C) IMRE KOUW, MAASTRICHT 2018

ALL RIGHTS RESERVED. NO PART OF THIS THESIS MAY BE REPRODUCED, DISTRIBUTED, OR TRANSMITTED IN ANY FORM OR BY ANY MEANS, INCLUDING PHOTOCOPYING, RECORDING, OR OTHER ELECTRONIC OR MECHANICAL METHODS, WITHOUT THE PRIOR WRITTEN PERMISSION OF THE AUTHOR OR PUBLISHER, EXCEPT IN THE CASE OF BRIEF QUOTATIONS EMBODIED IN CRITICAL REVIEWS AND CERTAIN OTHER NON-COMMERCIAL USES PERMITTED BY COPYRIGHT LAW. 


\title{
NUTRITIONAL STRATEGIES TO SUPPORT MUSCLE MAINTENANCE IN CLINICAL POPULATIONS
}

\author{
DISSERTATION \\ To obtain the degree of Doctor at Maastricht University, \\ on the authority of the Rector Magnificus, Prof. dr. Rianne M. Letschert \\ in accordance with the decision of the Board of Deans, \\ to be defended in public \\ on Wednesday 5 December 2018, at 16:00 hours
}

by

Imre Willemijn Kehinde Kouw

Born 30 May 1986, Goes 


\section{PROMOTOR}

Prof. dr. L.J.C. van Loon

CO-PROMOTOR

Dr. L.B. Verdijk

\section{ASSESSMENT COMMITTEE}

Prof. dr. J.M.G.A Schols (chair)

Prof. dr. A.M.W.J. Schols

Dr. K. Lenaerts

Prof. dr. B.J.M. Witteman (WUR, Wageningen)

Dr. R. Koopman (University of Melbourne, Australia) 
"Sticks in a bundle are unbreakable" African proverb 



\section{CONTENTS}

CHAPTER ONE

CHAPTER TWO

CHAPTER THREE

CHAPTER FOUR

CHAPTER FIVE

CHAPTER SIX

CHAPTER SEVEN

CHAPTER EIGHT

CHAPTER NINE

CHAPTER TEN
General Introduction

One week of hospitalization following elective hip surgery induces

substantial muscle atrophy in older patients

Protein intake falls below $0.6 \mathrm{~g} / \mathrm{kg} / \mathrm{d}$ in healthy, older patients 53 admitted for elective hip or knee arthroplasty

Postprandial protein handling is not impaired in type 2 diabetes 75 patients when compared with normoglycemic controls

Basal and postprandial myofibrillar protein synthesis rates do not 101 differ between lean and obese males

Sodium nitrate co-ingestion with protein does not augment 131 postprandial muscle protein synthesis rates in older, type 2 diabetes patients

Protein ingestion before sleep increases overnight muscle protein 159 synthesis rates in healthy older men: a randomized controlled trial Physical activity performed in the evening increases the overnight 189 muscle protein synthetic response to pre-sleep protein ingestion in older men

General Discussion

Valorization

Summary

Samenvatting 250

Acknowledgements 254

About the author 




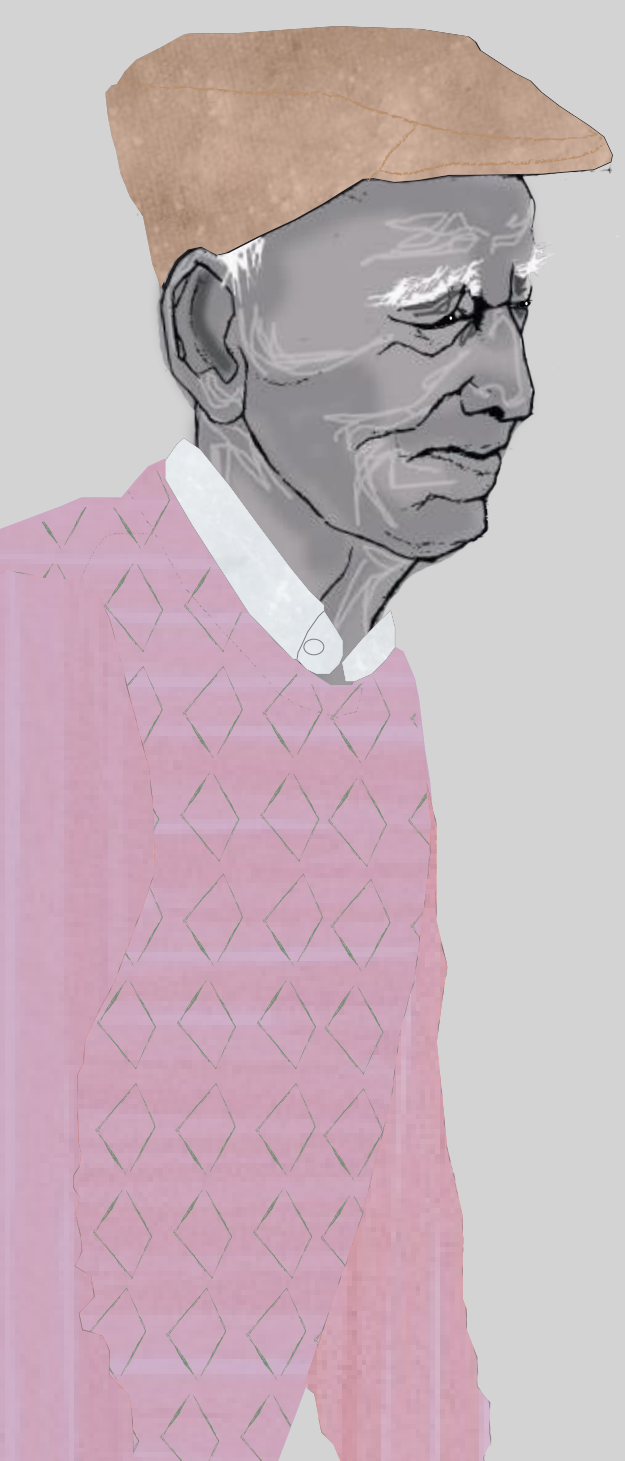




\section{CHAPTER ONE}

genERAl InTroduction 


\section{GENERAL INTRODUCTION}

Skeletal muscle tissue is of importance for ambulation, physical functioning, and overall metabolic health. Muscle mass maintenance is dictated by the net balance between muscle protein synthesis and muscle protein breakdown rates. Fluctuations in both basal and postprandial muscle protein synthesis rates seem to be key in the regulation of skeletal muscle maintenance throughout the lifespan. Physical activity and dietary protein intake are the two main anabolic stimuli that stimulate muscle protein synthesis [1]. Therefore, structural changes in physical activity and food intake can strongly affect muscle mass maintenance. Both a decline in physical activity level and a reduction in food intake can lead to a substantial decline in muscle mass [2-9]. Even a few days of physical inactivity and/or reduced food intake due to injury, hospitalization, and/or disease can strongly reduce muscle mass and strength [3-5, 9]. It has been proposed that the progressive loss of muscle mass throughout the lifespan can be largely attributed to the muscle and strength loss experienced during such short, successive periods of inactivity or muscle disuse $[10,11]$. In support, older individuals generally do not fully regain all muscle tissue that is lost during such short periods of reduced physical activity and/or food intake $[10,12]$. Skeletal muscle mass at hospital admission, as well as muscle mass loss during hospitalization are strongly associated with clinical outcome [13-16]. It thus seems clinically relevant to maintain skeletal muscle mass and strength in both health and disease. Intervention strategies to maintain muscle mass are warranted to attenuate muscle loss with aging and during acute and chronic disease. The present thesis focusses on nutritional strategies to support muscle mass maintenance in both healthy and more clinically compromised older populations.

\section{Muscle mass maintenance}

Skeletal muscle proteins are synthesized and broken down at a rate of approximately 1-2\% per day. Consequently, maintenance, growth, and loss of skeletal muscle tissue is regulated via the balance between muscle protein synthesis and breakdown rates. When net muscle protein balance is positive over a sustained period of time, muscle mass increases [1, 11]. Conversely, a substantial loss of skeletal muscle mass must be attributed to a structural negative net balance with the rate of muscle protein breakdown exceeding the rate of muscle protein synthesis $[1,17]$. To understand the proposed impairments in muscle protein metabolism leading to muscle loss with aging and disease, several research groups have assessed basal muscle protein synthesis and/or breakdown rates in both young and older subjects [18-20]. Studies assessing basal muscle protein synthesis rates show little or no differences between healthy young and older subjects [18-20]. However, it should be noted that even minor (undetectable) differences in basal muscle protein synthesis and/or breakdown rates may become clinically relevant when calculating their impact over one or more decades before sarcopenia becomes evident [1]. As physical activity and food intake are the key stimuli for muscle protein synthesis, more recent research has focused on whether 
derangements in the muscle protein synthetic response to those stimuli may be responsible for the greater loss of skeletal muscle mass with advancing age and chronic metabolic diseases.

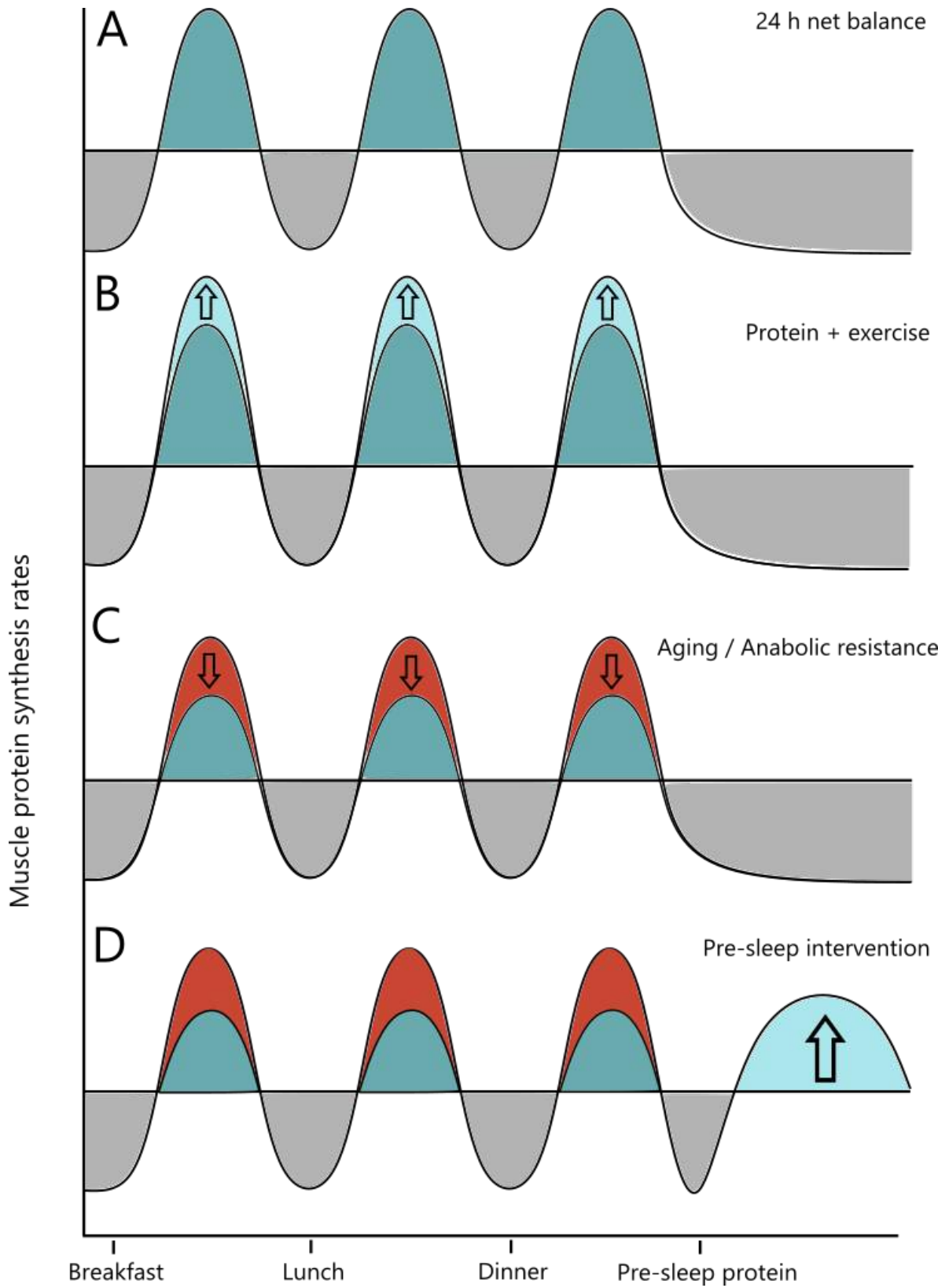

Figure 1 | A schematic representation of $24 \mathrm{~h}$ postprandial muscle protein synthesis rates in: A) a healthy condition; B) following a single bout of resistance exercise; C) during aging and/or anabolic resistance; and D) following a pre-sleep protein dose as a suggested strategy to increase overnight muscle protein synthesis rates. 


\section{Postprandial muscle protein synthesis}

Food intake, with dietary protein in particular, acutely increases muscle protein synthesis rates (Figure 1A) [1, 19, 21-23]. Following dietary protein ingestion, protein is digested and amino acids are absorbed by the gastrointestinal tract resulting in a rapid increase in plasma amino acid levels. The postprandial rise in circulating (essential) amino acids results in increased delivery to peripheral tissues, including muscle, resulting in increased tissue uptake and eventually increased muscle protein synthesis rates [23-25]. As such, protein digestion and amino acid absorption kinetics can have a major impact on the postprandial muscle protein synthetic response to meal ingestion. It has been well established that the muscle protein synthetic response to protein ingestion is dependent on multiple factors such as the amount [21, 26-29], type [30-32], source [27, 31, 33], and timing [34-36] of dietary protein ingestion.

Whereas the ingestion of a meal-like amount of protein $(20 \mathrm{~g})$ can substantially increase muscle protein synthesis rates in young individuals $[20,28,29]$, more protein seems to be required to substantially increase postprandial muscle protein synthesis rates in the older population [21, 23, 26, 37, 38]. Moreover, a dose-dependent relationship to stimulate muscle protein synthesis has been observed in older individuals following the ingestion of graded amounts of amino acids or dietary protein [21, 26, 37, 38]. Greater amounts of protein result in prolonged hyperaminoacidemia and, as such, may stimulate muscle protein synthesis for a more prolonged period $[21,26]$. The type of protein that is ingested forms another important factor in the postprandial stimulation of muscle protein synthesis. The ingestion of whey protein, which is commonly referred to as a 'rapidly digestible' protein source, results in a more rapid increase in postprandial amino acid levels and subsequent increase in muscle protein synthesis rates when compared with the more 'slowly digestible' milk protein fraction, casein $[30,32]$. Apart from the fact that differences in the postprandial muscle protein synthetic response to the ingestion of various protein sources is attributed to differences in protein digestion and amino acid absorption kinetics, the essential amino acid composition with leucine content in particular plays a key role. Essential amino acids do not only serve as precursors for muscle protein synthesis, but also act as signaling molecules that activate the mTOR signaling pathway, stimulating muscle protein synthesis [23, 24]. Previous work has shown that increasing the leucine content in a dose of protein/amino acids can augment the postprandial muscle protein synthetic response in older individuals [39-42]. For example, differences in the muscle protein synthetic response following the ingestion of animal-based protein vs plant-based protein sources or whey vs casein have been attributed to the lower essential amino acid/leucine content in these protein sources. In addition, the co-ingestion of free leucine with a single bolus of amino acids or protein has been shown to further increase muscle protein synthesis rates [39-41].

More recently, the distribution and timing of protein ingestion throughout the day has been suggested to modify net muscle protein balance on a 24 -hour basis $[34-36,43]$. While some research groups showed increased muscle protein synthesis rates and attenuated lean mass loss following a more evenly distributed protein intake pattern [7, 34, 35], others have failed 
to observe such differences in muscle mass maintenance and net protein balance between a balanced and a more skewed protein intake pattern [44-47]. To compensate for a suboptimal protein synthetic response to the ingestion of the main meals throughout the day, the overnight phase has been suggested as a window-of-opportunity for the simulation of muscle protein synthesis (Figure 1D) [48, 49]. Administration of dietary protein during sleep effectively increases plasma amino acid concentrations and muscle protein synthesis rates in healthy, older subjects [48]. Furthermore, in younger subjects the ingestion of protein in the hour(s) prior to sleep has been shown to stimulate overnight muscle protein synthesis, as well as, increasing the muscle mass gains during training intervention, supporting its potential as a strategy for muscle mass maintenance [48-50].

Under normal circumstances dietary protein is mainly consumed as part of a product or meal. The macronutrient composition in a meal likely modulates protein digestion and absorption kinetics and, as such, postprandial muscle protein synthesis rates [51]. The co-ingestion of carbohydrate and fat with protein delays protein digestion and amino acid absorption [52, 53]. However, this does not seem substantial enough to impair the postprandial muscle protein synthetic response to protein ingestion in older individuals [52-54]. Likewise, although the greater insulin response following carbohydrate co-ingestion could theoretically further stimulate postprandial muscle protein synthesis, this does not seem to happen [52, 54]. This could be explained by the idea that postprandial insulin levels are merely permissive and not modulatory for the postprandial rise in muscle protein synthesis rates $[52,55,56]$. Multiple other factors in a meal such as the protein matrix [57, 58], food density [37, 59], food texture $[60,61]$, food preparation (procedure and temperature) [60,61], mastication (chewing) [62], body posture [63, 64], micronutrients and other nutritional components (i.e. vitamins, polyphenols, $n$-3-polyunsaturated fatty acids (PUFA), nitrates, and fibers) [65] all have been suggested to influence gastric emptying, protein digestion and absorption kinetics, plasma amino acid availability, and/or postprandial muscle protein synthesis rates. To summarize, Figure 2 provides an overview of the potential factors that need to be taken into account when assessing the postprandial response to a meal. 


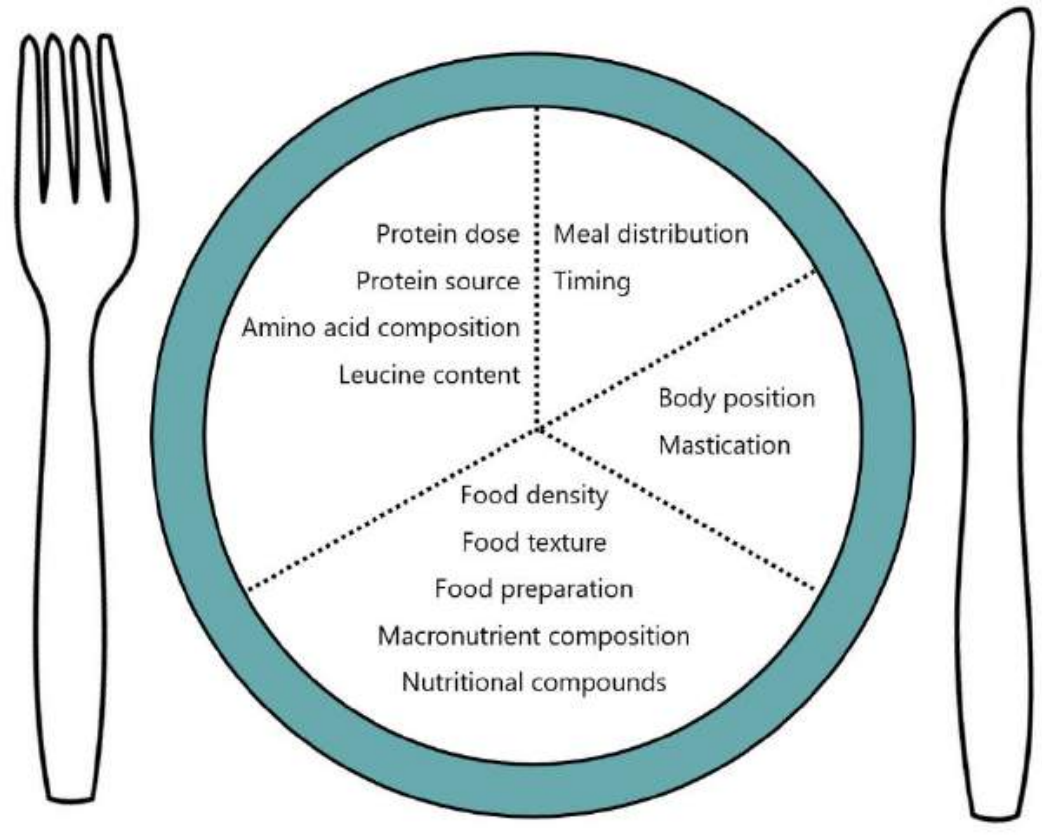

Figure 2 | Nutrition-related factors involved in the stimulation of postprandial muscle protein synthesis.

Apart from the nutrition-related factors described above, physical activity represents another key anabolic stimulus required to maintain skeletal muscle mass. A single session of physical activity increases post-absorptive muscle protein synthesis rates for up to 24-48 $\mathrm{h}$ [66]. However, the muscle protein net balance will remain negative in the absence of food intake [66]. Interestingly, physical activity performed prior to food intake further increases the postprandial rise in muscle protein synthesis rates and allows more of the ingested protein to be used for de novo muscle protein synthesis [67]. Physical activity sensitizes skeletal muscle tissue to the anabolic properties of the provided amino acids and, as such, further enhances the muscle protein synthetic response to food intake (Figure 1B) $[26,67,68]$. Since the level of physical activity and the anabolic properties of food intake have a synergistic effect, it is obvious that lifestyle changes over the lifespan are key aspects influencing skeletal muscle mass maintenance during healthy aging and disease. 


\section{Anabolic resistance}

Several studies have shown that older individuals display a reduced responsiveness to the anabolic properties of amino acid and protein administration [23, 69, 70]. In agreement, the muscle protein synthetic response to the ingestion of a single bolus of protein is lower in older individuals when compared with young $[20,38]$, a condition that is now referred to as anabolic resistance (Figure 1C) [17]. This anabolic resistance to food intake is suggested to represent a key factor responsible for the age-related muscle loss. Although the anabolic resistance to protein ingestion is most likely dependent on several factors such as health status, habitual physical activity level, and/or dietary habits, the mechanisms responsible for the blunted muscle protein synthetic response to protein ingestion remain unclear. Impairments in postprandial protein handling may reside at various levels $[17,71]$; including dietary protein digestion [72], amino acid absorption [73], the postprandial hormonal response [74] and subsequent microvascular perfusion [75], amino acid uptake in muscle [76], intramuscular signaling [23, 77], and/or myofibrillar protein synthesis [20,38]. For example, differences in protein digestion and absorption kinetics following the ingestion of a protein containing meal observed between young and older subjects may result in fewer amino acids becoming available in the circulation $[25,52,72]$. In addition, splanchnic retention of dietary proteinderived amino acids, which includes amino acid uptake by gut and liver tissue, may modulate postprandial muscle protein synthesis by affecting the postprandial availability of circulation amino acids. Moreover, impairments in the postprandial rise in insulin-mediated muscle tissue perfusion has been suggested to lower the availability of nutrients and growth factors and, as such, the postprandial stimulation of muscle protein synthesis in older and/or insulin resistant individuals $[56,78]$. Likely, one or more of these processes might be compromised to a certain extent with aging, physical inactivity, or the presence of chronic metabolic diseases, thus contributing to the accelerated loss of skeletal muscle mass.

Since physical activity increases the sensitivity of skeletal muscle to the anabolic properties of amino acids, physical inactivity likely lowers the anabolic response to protein ingestion. Therefore, anabolic resistance may be secondary to a lower level of habitual physical activity. In agreement, periods of limb immobilization, whole-body inactivity (bed rest), and periods of step reduction have been shown to lower both basal and postprandial muscle protein synthesis rates $[2,79,80]$. As such, lifestyle changes that come along with increased age and chronic metabolic disease (e.g. changes in daily physical activity levels, exercise, and habitual food intake) collectively contribute to the development of anabolic resistance, further supporting their role in the loss of skeletal muscle mass (Figure $\mathbf{3}$ ). 


\section{Physiological factors}

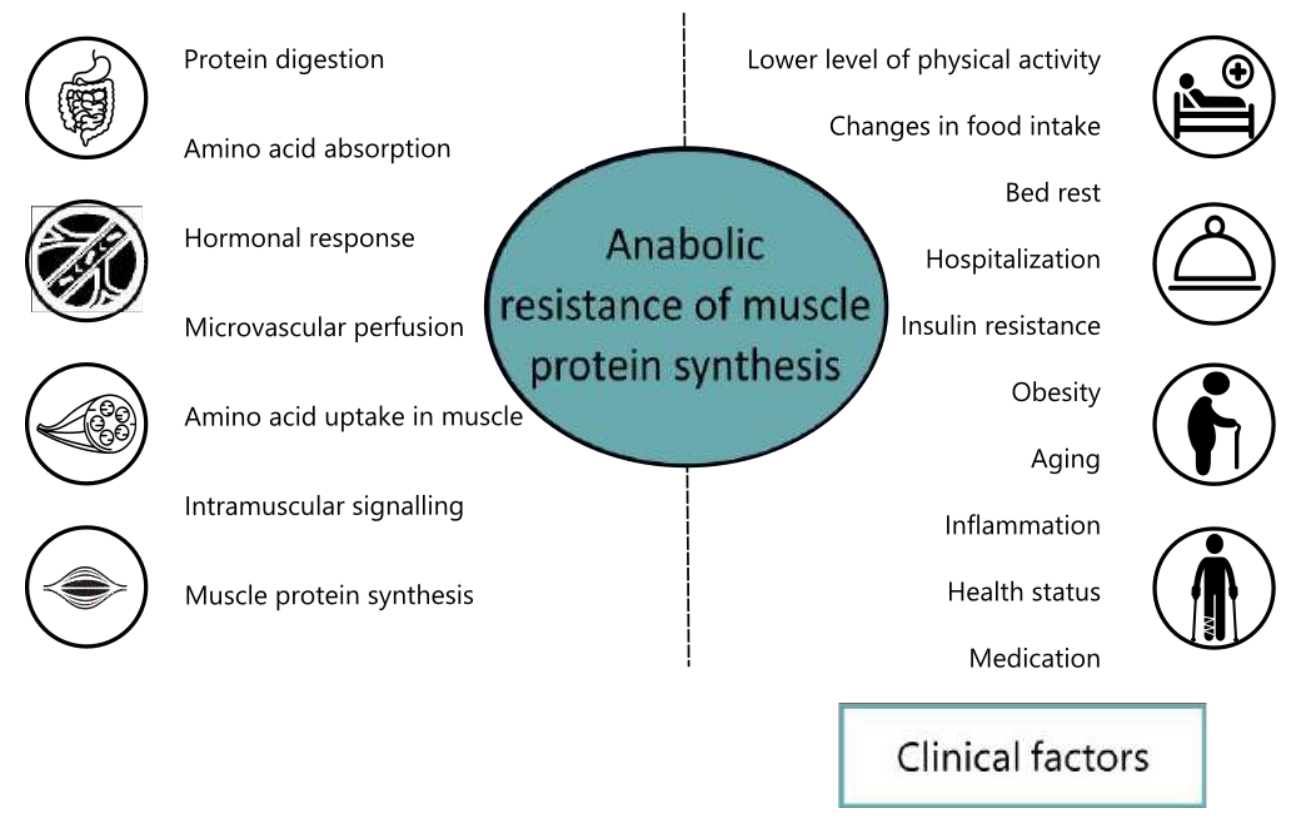

Figure 3 | Anabolic resistance can be attributed to impairments on various levels (left) due to changes in various conditions and/or the development of health issues (right).

\section{Clinical populations}

Hospitalization is generally accompanied by a reduction in food intake and a decline in physical activity level [81, 82]. Low levels of food intake during hospitalization increases the length of hospital stay, impairs functional outcome, increases the risk for infections, and is associated with a higher incidence of hospital readmissions and increased mortality [82-85]. Even a short period of hospitalization in older individuals can have detrimental effects, accelerating the age-related loss of skeletal muscle mass after discharge [86]. Moreover, hospitalization itself likely has a negative effect on muscle tissue, as 4-7 days of bed rest or immobilization have been shown to result in a decrease in muscle mass and muscle strength in both young and older individuals [3, 4, 87-89]. This muscle disuse atrophy is most rapid during the first few days of inactivity and, as such, can pose a major threat on clinical outcome during a period of hospitalization [3]. Furthermore, older individuals generally do not regain all muscle tissue lost following a period of disuse [90-92]. As such, short successive periods of muscle disuse atrophy due to injury or disease can contribute substantially to the overall agerelated loss of muscle mass and strength $[10,12]$.

Both the absolute amount of skeletal muscle mass at time of hospital admission as well as the amount of muscle loss during hospitalization affect clinical outcomes such as the length of hospital stay $[14,16,93]$, the ability to perform activities of daily living [81, 94], functional 
mobility [81, 93], the incidence of co-morbidities [14, 93], the risk for readmissions [14, 81, 93, 95], quality of life [96], and mortality rates [14, 81, 93, 95]. Furthermore, the loss of skeletal muscle mass, strength, and functional capacity following hospitalization often forms the tipping point for older patients to shift from a self-supporting living status to dependency [14, 86, 97].

\section{Interventional strategies to attenuate muscle loss}

To support muscle mass maintenance during healthy aging and periods of disease, effective interventional strategies should be established aimed at attenuating accelerated muscle loss. Muscle tissue loss has been shown to be more rapid in individuals consuming less energy than required during a period of bed rest when compared with volunteers who maintain energy balance [8]. Therefore, first we need to avoid overall undernutrition by ensuring energy balance. Besides energy intake, adequate protein intake is necessary to support muscle mass maintenance. Protein recommendations suggest a protein intake level of $1.2-1.5 \mathrm{~g} \cdot \mathrm{kg}^{-1} \cdot \mathrm{day}^{-1}$ for older individuals during hospitalization and illness $[98,99]$. Since daily protein consumption is generally sufficient in the community dwelling, older population [6, 100], habitual protein intake levels should be at least maintained or increased during periods of hospitalization. Increasing habitual protein intake can be achieved by providing a more protein-dense diet. For example, the use of protein-dense foods [101-103], fortification of meals [104, 105], and/or the use of oral nutrition supplements (ONS) [106-108] have been shown to effectively increase protein consumption in older individuals. Obviously, a proper choice of the ingested dietary protein component should be defined by the dose, amount, source, and timing as previously described.

Furthermore, several other nutritional compounds have been described to have anti-catabolic or anabolic properties [65]. Potential compounds may include: essential amino acids, branched-chain amino acids, specific amino acids such as leucine, arginine or glutamine, $\beta$ hydroxy- $\beta$-methylbutyric acid (HMB), creatine, PUFA, nitrates, vitamin $D$, and/or antioxidants $[65,109-111]$. Since physical activity sensitizes - and physical inactivity desensitizes - the muscle to the anabolic properties of food, optimizing the level of physical activity is essential to maximize the anabolic response to food ingestion $[2,67,79]$. Therefore, physical activity should be applied in both healthy conditions as well as during periods of muscle disuse and disease to increase the muscle protein synthetic response to protein ingestion. For example, pre-surgery exercise training, physiotherapy during hospitalization, and/or post-hospital rehabilitation programs have been shown to improve physical function and muscle mass before, during, and after a period of hospitalization $[112,113]$. However, physical activity is, at least in some conditions, not always feasible. Therefore, exercise mimetics including mobilization, passive training, massage, vibration training, and neuromuscular electrical stimulation (NMES) can be applied to further support muscle mass maintenance, strength, and functional capacity in patients $[114,115]$. Though beyond the scope of this thesis, there is also considerable interest in pharmacological anabolic stimulants (such as various androgens, $\beta 2-$ adrenergic agonists, statins, appetite stimulants, non-steroidal anti-inflammatory drugs, 
myostatin inhibitors, anabolic steroids, growth hormone, and other therapeutic interventions) to offset muscle mass and strength loss in both health and disease [109, 111]. Collectively, while there is extensive evidence available on the effect of different interventional strategies to support muscle mass maintenance in the older population, more research is required to develop effective interventional strategies that can be applied in a clinical setting to attenuate muscle mass and strength loss and/or regain muscle mass and functional capacity in older, more clinically compromised, populations. 


\section{AIM AND THESIS OUTLINE}

Since muscle mass maintenance is of great clinical relevance in both health and disease, the present thesis investigates aspects of muscle protein metabolism in healthy and more clinically compromised older populations. To determine the extent of muscle loss during short-term hospital admission, we assessed the impact of hospital admission in older patients showing substantial muscle atrophy in the 5 days following elective hip replacement surgery (chapter 2). In chapter 3 we recorded food intake in hospitalized older patients and compared the amount of protein that was provided with the amount of protein that was actually consumed in these patients. Since there is an accelerated loss of muscle mass in patients with metabolic diseases such as obesity, cardiovascular diseases, and type 2 diabetes, we examined our hypothesis that older type 2 diabetes patients show impairments in either basal and/or postprandial muscle protein synthesis rates (chapter 4). In chapter 5, we investigated whether the postprandial muscle protein synthetic response to protein ingestion is reduced in obese compared with healthy, lean males. In chapters 6-8, we propose several nutritional strategies to support muscle mass maintenance in healthy and more clinically compromised older populations. In view of the recent interest in dietary nitrate as a nutritional compound to increase vasodilation and improve muscle tissue perfusion, we investigated the impact of ingesting a single bolus of dietary nitrate with protein on postprandial muscle protein synthesis rates in older type 2 diabetes patients in chapter $\mathbf{6}$. In chapter 7 we assessed the dose-response relationship between the overnight muscle protein synthetic response to different amounts of protein ingested prior to sleep. We subsequently investigated the surplus benefits of physical activity performed in the evening to increase the overnight muscle protein synthetic response to pre-sleep protein ingestion (chapter 8). Finally, in chapter 9, the outcome of chapters 2 through 8 are discussed in the light of the existing literature. Additionally, the implications of this thesis are discussed and directions for future research are formulated. 


\section{REFERENCES}

1. Koopman, R. and L.J. van Loon, Aging, exercise, and muscle protein metabolism. Journal of applied physiology, 2009. 106(6): p. 2040-8.

2. Breen, L., K.A. Stokes, T.A. Churchward-Venne, D.R. Moore, S.K. Baker, K. Smith, P.J. Atherton, and S.M. Phillips, Two weeks of reduced activity decreases leg lean mass and induces "anabolic resistance" of myofibrillar protein synthesis in healthy elderly. J Clin Endocrinol Metab, 2013. 98(6): p. 2604-12.

3. Wall, B.T., M.L. Dirks, T. Snijders, J.M. Senden, J. Dolmans, and L.J. van Loon, Substantial skeletal muscle loss occurs during only 5 days of disuse. Acta Physiol (Oxf), 2014. 210(3): p. 600-11.

4. Dirks, M.L., B.T. Wall, B. van de Valk, T.M. Holloway, G.P. Holloway, A. Chabowski, G.H. Goossens, and L.J. van Loon, One Week of Bed Rest Leads to Substantial Muscle Atrophy and Induces WholeBody Insulin Resistance in the Absence of Skeletal Muscle Lipid Accumulation. Diabetes, 2016. 65(10): p. 2862-75.

5. Kortebein, P., A. Ferrando, J. Lombeida, R. Wolfe, and W.J. Evans, Effect of 10 days of bed rest on skeletal muscle in healthy older adults. JAMA, 2007. 297(16): p. 1772-4.

6. Houston, D.K., B.J. Nicklas, J. Ding, T.B. Harris, F.A. Tylavsky, A.B. Newman, J.S. Lee, N.R. Sahyoun, M. Visser, and S.B. Kritchevsky, Dietary protein intake is associated with lean mass change in older, community-dwelling adults: the Health, Aging, and Body Composition (Health ABC) Study. Am J Clin Nutr, 2008. 87(1): p. 150-5.

7. Farsijani, S., J.A. Morais, H. Payette, P. Gaudreau, B. Shatenstein, K. Gray-Donald, and S. Chevalier, Relation between mealtime distribution of protein intake and lean mass loss in free-living older adults of the NuAge study. Am J Clin Nutr, 2016. 104(3): p. 694-703.

8. Biolo, G., B. Ciocchi, M. Stulle, A. Bosutti, R. Barazzoni, M. Zanetti, R. Antonione, M. Lebenstedt, P. Platen, M. Heer, and G. Guarnieri, Calorie restriction accelerates the catabolism of lean body mass during 2 wk of bed rest. Am J Clin Nutr, 2007. 86(2): p. 366-72.

9. Mitchell, C.J., A.M. Milan, S.M. Mitchell, N. Zeng, F. Ramzan, P. Sharma, S.O. Knowles, N.C. Roy, A. Sjodin, K.H. Wagner, and D. Cameron-Smith, The effects of dietary protein intake on appendicular lean mass and muscle function in elderly men: a 10-wk randomized controlled trial. Am J Clin Nutr, 2017. 106(6): p. 1375-1383.

10. Wall, B.T., M.L. Dirks, and L.J. van Loon, Skeletal muscle atrophy during short-term disuse: implications for age-related sarcopenia. Ageing Res Rev, 2013. 12(4): p. 898-906.

11. Phillips, S.M., E.I. Glover, and M.J. Rennie, Alterations of protein turnover underlying disuse atrophy in human skeletal muscle. Journal of applied physiology, 2009. 107(3): p. 645-54.

12. English, K.L. and D. Paddon-Jones, Protecting muscle mass and function in older adults during bed rest. Curr Opin Clin Nutr Metab Care, 2010. 13(1): p. 34-9.

13. Gariballa, S. and A. Alessa, Sarcopenia: prevalence and prognostic significance in hospitalized patients. Clin Nutr, 2013. 32(5): p. 772-6.

14. Welch, C. K.Z. Hassan-Smith, A.C. Greig, M.J. Lord, A.T. Jackson, Acute Sarcopenia Secondary to Hospitalisation - An Emerging Condition Affecting Older Adults. Aging Dis, 2018. 9(1): p. 151-164.

15. de Hoogt, P.A., K.W. Reisinger, J.J.W. Tegels, J. Bosmans, F. Tijssen, and J. Stoot, Functional Compromise Cohort Study (FCCS): Sarcopenia is a Strong Predictor of Mortality in the Intensive Care Unit. World J Surg, 2017.

16. Sousa, A.S., R.S. Guerra, I. Fonseca, F. Pichel, and T.F. Amaral, Sarcopenia and length of hospital stay. Eur J Clin Nutr, 2016. 70(5): p. 595-601.

17. Burd, N.A., S.H. Gorissen, and L.J. van Loon, Anabolic resistance of muscle protein synthesis with aging. Exerc Sport Sci Rev, 2013. 41(3): p. 169-73.

18. Volpi, E., M. Sheffield-Moore, B.B. Rasmussen, and R.R. Wolfe, Basal muscle amino acid kinetics and protein synthesis in healthy young and older men. JAMA, 2001. 286(10): p. 1206-12. 
19. Paddon-Jones, D., M. Sheffield-Moore, X.J. Zhang, E. Volpi, S.E. Wolf, A. Aarsland, A.A. Ferrando, and R.R. Wolfe, Amino acid ingestion improves muscle protein synthesis in the young and elderly. Am J Physiol Endocrinol Metab, 2004. 286(3): p. E321-8.

20. Wall, B.T., S.H. Gorissen, B. Pennings, R. Koopman, B.B. Groen, L.B. Verdijk, and L.J. van Loon, Aging Is Accompanied by a Blunted Muscle Protein Synthetic Response to Protein Ingestion. PLoS One, 2015. 10(11): p. e0140903.

21. Pennings, B., B. Groen, A. de Lange, A.P. Gijsen, A.H. Zorenc, J.M. Senden, and L.J. van Loon, Amino acid absorption and subsequent muscle protein accretion following graded intakes of whey protein in elderly men. American journal of physiology. Endocrinology and metabolism, 2012. 302(8): p. E992-9.

22. Volpi, E., B. Mittendorfer, S.E. Wolf, and R.R. Wolfe, Oral amino acids stimulate muscle protein anabolism in the elderly despite higher first-pass splanchnic extraction. Am J Physiol, 1999. 277(3 Pt 1): p. E513-20.

23. Cuthbertson, D., K. Smith, J. Babraj, G. Leese, T. Waddell, P. Atherton, H. Wackerhage, P.M. Taylor, and M.J. Rennie, Anabolic signaling deficits underlie amino acid resistance of wasting, aging muscle. FASEB J, 2005. 19(3): p. 422-4.

24. Volpi, E., H. Kobayashi, M. Sheffield-Moore, B. Mittendorfer, and R.R. Wolfe, Essential amino acids are primarily responsible for the amino acid stimulation of muscle protein anabolism in healthy elderly adults. Am J Clin Nutr, 2003. 78(2): p. 250-8.

25. Koopman, R., S. Walrand, M. Beelen, A.P. Gijsen, A.K. Kies, Y. Boirie, W.H. Saris, and L.J. van Loon, Dietary protein digestion and absorption rates and the subsequent postprandial muscle protein synthetic response do not differ between young and elderly men. The Journal of nutrition, 2009. 139(9): p. 1707-13.

26. Yang, Y., L. Breen, N.A. Burd, A.J. Hector, T.A. Churchward-Venne, A.R. Josse, M.A. Tarnopolsky, and S.M. Phillips, Resistance exercise enhances myofibrillar protein synthesis with graded intakes of whey protein in older men. The British journal of nutrition, 2012. 108(10): p.1780-8.

27. Yang, Y., T.A. Churchward-Venne, N.A. Burd, L. Breen, M.A. Tarnopolsky, and S.M. Phillips, Myofibrillar protein synthesis following ingestion of soy protein isolate at rest and after resistance exercise in elderly men. Nutrition \& metabolism, 2012. 9(1): p. 57.

28. Moore, D.R., M.J. Robinson, J.L. Fry, J.E. Tang, E.I. Glover, S.B. Wilkinson, T. Prior, M.A. Tarnopolsky, and S.M. Phillips, Ingested protein dose response of muscle and albumin protein synthesis after resistance exercise in young men. The American journal of clinical nutrition, 2009. 89(1): p. 161-8.

29. Witard, O.C., S.R. Jackman, L. Breen, K. Smith, A. Selby, and K.D. Tipton, Myofibrillar muscle protein synthesis rates subsequent to a meal in response to increasing doses of whey protein at rest and after resistance exercise. Am J Clin Nutr, 2014. 99(1): p. 86-95.

30. Pennings, B., Y. Boirie, J.M. Senden, A.P. Gijsen, H. Kuipers, and L.J. van Loon, Whey protein stimulates postprandial muscle protein accretion more effectively than do casein and casein hydrolysate in older men. The American journal of clinical nutrition, 2011. 93(5): p. 997-1005.

31. Tang, J.E., D.R. Moore, G.W. Kujbida, M.A. Tarnopolsky, and S.M. Phillips, Ingestion of whey hydrolysate, casein, or soy protein isolate: effects on mixed muscle protein synthesis at rest and following resistance exercise in young men. J Appl Physiol, 2009. 107(3): p. 987-92.

32. Burd, N.A., Y. Yang, D.R. Moore, J.E. Tang, M.A. Tarnopolsky, and S.M. Phillips, Greater stimulation of myofibrillar protein synthesis with ingestion of whey protein isolate $\mathrm{v}$. micellar casein at rest and after resistance exercise in elderly men. Br J Nutr, 2012. 108(6): p. 958-62.

33. Gorissen, S.H., A.M. Horstman, R. Franssen, J.J. Crombag, H. Langer, J. Bierau, F. Respondek, and L.J. van Loon, Ingestion of Wheat Protein Increases In Vivo Muscle Protein Synthesis Rates in Healthy Older Men in a Randomized Trial. J Nutr, 2016. 146(9): p. 1651-9.

34. Areta, J.L., L.M. Burke, M.L. Ross, D.M. Camera, D.W. West, E.M. Broad, N.A. Jeacocke, D.R. Moore, T. Stellingwerff, S.M. Phillips, J.A. Hawley, and V.G. Coffey, Timing and distribution of protein ingestion during prolonged recovery from resistance exercise alters myofibrillar protein synthesis. J Physiol, 2013. 591(9): p. 2319-31. 
35. Mamerow, M.M., J.A. Mettler, K.L. English, S.L. Casperson, E. Arentson-Lantz, M. Sheffield-Moore, D.K. Layman, and D. Paddon-Jones, Dietary protein distribution positively influences $24-\mathrm{h}$ muscle protein synthesis in healthy adults. J Nutr, 2014. 144(6): p. 876-80.

36. Moore, D.R., J. Areta, V.G. Coffey, T. Stellingwerff, S.M. Phillips, L.M. Burke, M. Cleroux, J.P. Godin, and J.A. Hawley, Daytime pattern of post-exercise protein intake affects whole-body protein turnover in resistance-trained males. Nutr Metab (Lond), 2012. 9(1): p. 91.

37. Robinson, M.J., N.A. Burd, L. Breen, T. Rerecich, Y. Yang, A.J. Hector, S.K. Baker, and S.M. Phillips, Dose-dependent responses of myofibrillar protein synthesis with beef ingestion are enhanced with resistance exercise in middle-aged men. Appl Physiol Nutr Metab, 2013. 38(2): p. 120-5.

38. Moore, D.R., T.A. Churchward-Venne, O. Witard, L. Breen, N.A. Burd, K.D. Tipton, and S.M. Phillips, Protein ingestion to stimulate myofibrillar protein synthesis requires greater relative protein intakes in healthy older versus younger men. J Gerontol A Biol Sci Med Sci, 2015. 70(1): p. 57-62.

39. Wall, B.T., H.M. Hamer, A. de Lange, A. Kiskini, B.B. Groen, J.M. Senden, A.P. Gijsen, L.B. Verdijk, and L.J. van Loon, Leucine co-ingestion improves post-prandial muscle protein accretion in elderly men. Clinical nutrition, 2012.

40. Rieu, I., M. Balage, C. Sornet, C. Giraudet, E. Pujos, J. Grizard, L. Mosoni, and D. Dardevet, Leucine supplementation improves muscle protein synthesis in elderly men independently of hyperaminoacidaemia. J Physiol, 2006. 575(Pt 1): p. 305-15.

41. Katsanos, C.S., H. Kobayashi, M. Sheffield-Moore, A. Aarsland, and R.R. Wolfe, A high proportion of leucine is required for optimal stimulation of the rate of muscle protein synthesis by essential amino acids in the elderly. Am J Physiol Endocrinol Metab, 2006. 291(2): p. E381-7.

42. Kramer, I.F., L.B. Verdijk, H.M. Hamer, S. Verlaan, Y. Luiking, I.W. Kouw, J.M. Senden, J. van Kranenburg, A.P. Gijsen, M. Poeze, and L.J. van Loon, Impact of the Macronutrient Composition of a Nutritional Supplement on Muscle Protein Synthesis Rates in Older Men: A Randomized, Double Blind, Controlled Trial. J Clin Endocrinol Metab, 2015. 100(11):p.4124-32.

43. Bouillanne, O., E. Curis, B. Hamon-Vilcot, I. Nicolis, P. Chretien, N. Schauer, J.P. Vincent, L. Cynober, and C. Aussel, Impact of protein pulse feeding on lean mass in malnourished and at-risk hospitalized elderly patients: a randomized controlled trial. Clin Nutr, 2013. 32(2): p. 186-92.

44. Kim, I.Y., S. Schutzler, A.M. Schrader, H.J. Spencer, G. Azhar, R.R. Wolfe, and A.A. Ferrando, Protein intake distribution pattern does not affect anabolic response, lean body mass, muscle strength or function over 8 weeks in older adults: A randomized-controlled trial. Clin Nutr, 2017.

45. Kim, I.Y., S. Schutzler, A. Schrader, H. Spencer, P. Kortebein, N.E. Deutz, R.R. Wolfe, and A.A. Ferrando, Quantity of dietary protein intake, but not pattern of intake, affects net protein balance primarily through differences in protein synthesis in older adults. Am J Physiol Endocrinol Metab, 2015. 308(1): p. E21-8.

46. Adechian, S., M. Balage, D. Remond, C. Migne, A. Quignard-Boulange, A. Marset-Baglieri, S. Rousset, Y. Boirie, C. Gaudichon, D. Dardevet, and L. Mosoni, Protein feeding pattern, casein feeding, or milk-soluble protein feeding did not change the evolution of body composition during a short-term weight loss program. Am J Physiol Endocrinol Metab, 2012. 303(8): p. E973-82.

47. Farsijani, S., H. Payette, J.A. Morais, B. Shatenstein, P. Gaudreau, and S. Chevalier, Even mealtime distribution of protein intake is associated with greater muscle strength, but not with 3-y physical function decline, in free-living older adults: the Quebec longitudinal study on Nutrition as a Determinant of Successful Aging (NuAge study). Am J Clin Nutr, 2017. 106(1): p. 113-124.

48. Groen, B.B., P.T. Res, B. Pennings, E. Hertle, J.M. Senden, W.H. Saris, and L.J. van Loon, Intragastric protein administration stimulates overnight muscle protein synthesis in elderly men. American journal of physiology. Endocrinology and metabolism, 2012. 302(1): p. E52-60.

49. Res, P., B. Groen, B. Pennings, M. Beelen, G.A. Wallis, A.P. Gijsen, J.M.G. Senden, and L.J.C. Van Loon, Protein Ingestion before Sleep Improves Postexercise Overnight Recovery. 2012(1530-0315 (Electronic)).

50. Snijders, T., P.T. Res, J.S. Smeets, S. van Vliet, J. van Kranenburg, K. Maase, A.K. Kies, L.B. Verdijk, and L.J. van Loon, Protein Ingestion before Sleep Increases Muscle Mass and Strength Gains 
during Prolonged Resistance-Type Exercise Training in Healthy Young Men. J Nutr, 2015. 145(6): p. $1178-84$.

51. Gorissen, S.H., D. Remond, and L.J. van Loon, The muscle protein synthetic response to food ingestion. Meat Sci, 2015. 109: p. 96-100.

52. Gorissen, S.H., N.A. Burd, H.M. Hamer, A.P. Gijsen, B.B. Groen, and L.J. van Loon, Carbohydrate coingestion delays dietary protein digestion and absorption but does not modulate postprandial muscle protein accretion. J Clin Endocrinol Metab, 2014. 99(6): p. 2250-8.

53. Gorissen, S.H.M., N.A. Burd, I.F. Kramer, J. van Kranenburg, A.P. Gijsen, O. Rooyackers, and L.J.C. van Loon, Co-ingesting milk fat with micellar casein does not affect postprandial protein handling in healthy older men. Clin Nutr, 2017. 36(2): p. 429-437.

54. Hamer, H.M., B.T. Wall, A. Kiskini, A. de Lange, B.B. Groen, J.A. Bakker, A.P. Gijsen, L.B. Verdijk, and L.J. van Loon, Carbohydrate co-ingestion with protein does not further augment post-prandial muscle protein accretion in older men. Nutr Metab (Lond), 2013. 10(1): p. 15.

55. Trommelen, J., B. Groen, H. Hamer, L.C. de Groot, and L.J. van Loon, MECHANISMS IN ENDOCRINOLOGY: Exogenous insulin does not increase muscle protein synthesis rate when administrated systemically: a systematic review. Eur J Endocrinol, 2015.

56. Groen, B.B., A.M. Horstman, H.M. Hamer, M. de Haan, J. van Kranenburg, J. Bierau, M. Poeze, W.K. Wodzig, B.B. Rasmussen, and L.J. van Loon, Increasing Insulin Availability Does Not Augment Postprandial Muscle Protein Synthesis Rates in Healthy Young and Older Men. J Clin Endocrinol Metab, 2016. 101(11): p. 3978-3988.

57. Churchward-Venne, T.A., T. Snijders, A.M. Linkens, H.M. Hamer, J. van Kranenburg, and L.J. van Loon, Ingestion of Casein in a Milk Matrix Modulates Dietary Protein Digestion and Absorption Kinetics but Does Not Modulate Postprandial Muscle Protein Synthesis in Older Men. J Nutr, 2015. 145(7): p. 1438-45.

58. Soop, M., V. Nehra, G.C. Henderson, Y. Boirie, G.C. Ford, and K.S. Nair, Coingestion of whey protein and casein in a mixed meal: demonstration of a more sustained anabolic effect of casein. Am J Physiol Endocrinol Metab, 2012. 303(1): p. E152-62.

59. Burd, N.A., S.H. Gorissen, S. van Vliet, T. Snijders, and L.J. van Loon, Differences in postprandial protein handling after beef compared with milk ingestion during postexercise recovery: a randomized controlled trial. Am J Clin Nutr, 2015. 102(4): p. 828-36.

60. Barbe, F., O. Menard, Y. Le Gouar, C. Buffiere, M.H. Famelart, B. Laroche, S. Le Feunteun, D. Dupont, and $\mathrm{D}$. Remond, The heat treatment and the gelation are strong determinants of the kinetics of milk proteins digestion and of the peripheral availability of amino acids. Food Chem, 2013. 136(34): p. 1203-12.

61. Pennings, B., B.B. Groen, J.W. van Dijk, A. de Lange, A. Kiskini, M. Kuklinski, J.M. Senden, and L.J. van Loon, Minced beef is more rapidly digested and absorbed than beef steak, resulting in greater postprandial protein retention in older men. Am J Clin Nutr, 2013. 98(1): p. 121-8.

62. Remond, D., M. Machebeuf, C. Yven, C. Buffiere, L. Mioche, L. Mosoni, and P. Patureau Mirand, Postprandial whole-body protein metabolism after a meat meal is influenced by chewing efficiency in elderly subjects. Am J Clin Nutr, 2007. 85(5): p. 1286-92.

63. Holwerda, A.M., K. Lenaerts, J. Bierau, and L.J. van Loon, Body Position Modulates Gastric Emptying and Affects the Post-Prandial Rise in Plasma Amino Acid Concentrations Following Protein Ingestion in Humans. Nutrients, 2016. 8(4): p. 221.

64. Holwerda, A.M., K. Lenaerts, J. Bierau, W. Wodzig, and L.J.C. van Loon, Food ingestion in an upright sitting position increases postprandial amino acid availability when compared with food ingestion in a lying down position. Appl Physiol Nutr Metab, 2017. 42(7): p. 738-743.

65. Deane, C.S., D.J. Wilkinson, B.E. Phillips, K. Smith, T. Etheridge, and P.J. Atherton, "Nutraceuticals" in relation to human skeletal muscle and exercise. Am J Physiol Endocrinol Metab, 2017. 312(4): p. E282-E299.

66. Phillips, S.M., K.D. Tipton, A. Aarsland, S.E. Wolf, and R.R. Wolfe, Mixed muscle protein synthesis and breakdown after resistance exercise in humans. Am J Physiol, 1997. 273(1 Pt 1): p. E99-107. 
67. Pennings, B., R. Koopman, M. Beelen, J.M. Senden, W.H. Saris, and L.J. van Loon, Exercising before protein intake allows for greater use of dietary protein-derived amino acids for de novo muscle protein synthesis in both young and elderly men. The American journal of clinical nutrition, 2011. 93(2): p. 322-31.

68. Witard, O.C., M. Tieland, M. Beelen, K.D. Tipton, L.J. van Loon, and R. Koopman, Resistance exercise increases postprandial muscle protein synthesis in humans. Med Sci Sports Exerc, 2009. 41(1): p. 144-54.

69. Katsanos, C.S., H. Kobayashi, M. Sheffield-Moore, A. Aarsland, and R.R. Wolfe, Aging is associated with diminished accretion of muscle proteins after the ingestion of a small bolus of essential amino acids. Am J Clin Nutr, 2005. 82(5): p. 1065-73.

70. Volpi, E., B. Mittendorfer, B.B. Rasmussen, and R.R. Wolfe, The response of muscle protein anabolism to combined hyperaminoacidemia and glucose-induced hyperinsulinemia is impaired in the elderly. J Clin Endocrinol Metab, 2000. 85(12): p. 4481-90.

71. Groen, B.B., A.M. Horstman, H.M. Hamer, M. de Haan, J. van Kranenburg, J. Bierau, M. Poeze, W.K. Wodzig, B.B. Rasmussen, and L.J. van Loon, Post-Prandial Protein Handling: You Are What You Just Ate. PLoS One, 2015. 10(11): p. e0141582.

72. Dangin, M., C. Guillet, C. Garcia-Rodenas, P. Gachon, C. Bouteloup-Demange, K. Reiffers-Magnani, J. Fauquant, $\mathrm{O}$. Ballevre, and $\mathrm{B}$. Beaufrere, The rate of protein digestion affects protein gain differently during aging in humans. J Physiol, 2003. 549(Pt 2): p. 635-44.

73. Fujita, S. and E. Volpi, Amino acids and muscle loss with aging. J Nutr, 2006. 136(1 Suppl): p. 277S$80 \mathrm{~S}$.

74. Attaix, D., L. Mosoni, D. Dardevet, L. Combaret, P.P. Mirand, and J. Grizard, Altered responses in skeletal muscle protein turnover during aging in anabolic and catabolic periods. Int J Biochem Cell Biol, 2005. 37(10): p. 1962-73.

75. Timmerman, K.L., J.L. Lee, S. Fujita, S. Dhanani, H.C. Dreyer, C.S. Fry, M.J. Drummond, M. SheffieldMoore, B.B. Rasmussen, and E. Volpi, Pharmacological vasodilation improves insulin-stimulated muscle protein anabolism but not glucose utilization in older adults. Diabetes, 2010. 59(11): p. 2764-71.

76. Drummond, M.J., E.L. Glynn, C.S. Fry, K.L. Timmerman, E. Volpi, and B.B. Rasmussen, An increase in essential amino acid availability upregulates amino acid transporter expression in human skeletal muscle. Am J Physiol Endocrinol Metab, 2010. 298(5): p. E1011-8.

77. Fry, C.S., M.J. Drummond, E.L. Glynn, J.M. Dickinson, D.M. Gundermann, K.L. Timmerman, D.K. Walker, S. Dhanani, E. Volpi, and B.B. Rasmussen, Aging impairs contraction-induced human skeletal muscle mTORC1 signaling and protein synthesis. Skelet Muscle, 2011. 1(1): p. 11.

78. Keske, M.A., D. Premilovac, E.A. Bradley, R.M. Dwyer, S.M. Richards, and S. Rattigan, Muscle microvascular blood flow responses in insulin resistance and ageing. J Physiol, 2014.

79. Wall, B.T., M.L. Dirks, T. Snijders, J.W. van Dijk, M. Fritsch, L.B. Verdijk, and L.J. van Loon, Short-term muscle disuse lowers myofibrillar protein synthesis rates and induces anabolic resistance to protein ingestion. Am J Physiol Endocrinol Metab, 2016. 310(2): p. E137-47.

80. Drummond, M.J., J.M. Dickinson, C.S. Fry, D.K. Walker, D.M. Gundermann, P.T. Reidy, K.L. Timmerman, M.M. Markofski, D. Paddon-Jones, B.B. Rasmussen, and E. Volpi, Bed rest impairs skeletal muscle amino acid transporter expression, mTORC1 signaling, and protein synthesis in response to essential amino acids in older adults. Am J Physiol Endocrinol Metab, 2012. 302(9): p. E1113-22.

81. Brown, C.J., R.J. Friedkin, and S.K. Inouye, Prevalence and outcomes of low mobility in hospitalized older patients. J Am Geriatr Soc, 2004. 52(8): p. 1263-70.

82. Kruizenga, H., S. van Keeken, P. Weijs, L. Bastiaanse, S. Beijer, G. Huisman-de Waal, H. JagerWittenaar, C. Jonkers-Schuitema, M. Klos, W. Remijnse-Meester, B. Witteman, and A. Thijs, Undernutrition screening survey in 564,063 patients: patients with a positive undernutrition screening score stay in hospital 1.4 d longer. Am J Clin Nutr, 2016. 103(4): p. 1026-32. 
83. Hiesmayr, M., K. Schindler, E. Pernicka, C. Schuh, A. Schoeniger-Hekele, P. Bauer, A. Laviano, A.D. Lovell, M. Mouhieddine, T. Schuetz, S.M. Schneider, P. Singer, C. Pichard, P. Howard, C. Jonkers, I. Grecu, O. Ljungqvist, and T. NutritionDay Audit, Decreased food intake is a risk factor for mortality in hospitalised patients: the NutritionDay survey 2006. Clin Nutr, 2009. 28(5): p. 484-91.

84. Sullivan, D.H., M.M. Bopp, and P.K. Roberson, Protein-energy undernutrition and life-threatening complications among the hospitalized elderly. J Gen Intern Med, 2002. 17(12): p. 923-32.

85. Stratton, R.J. and M. Elia, Deprivation linked to malnutrition risk and mortality in hospital. British Journal of Nutrition, 2006. 96(5): p. 870-876.

86. Van Ancum, J.M., K. Scheerman, N.H. Jonkman, H.E. Smeenk, R.C. Kruizinga, C.G.M. Meskers, and A.B. Maier, Change in muscle strength and muscle mass in older hospitalized patients: $A$ systematic review and meta-analysis. Exp Gerontol, 2017. 92: p. 34-41.

87. Hvid, L.G., C. Suetta, P. Aagaard, M. Kjaer, U. Frandsen, and N. Ortenblad, Four days of muscle disuse impairs single fiber contractile function in young and old healthy men. Exp Gerontol, 2013. 48(2): p. 154-61.

88. Dirks, M.L., B.T. Wall, R. Nilwik, D.H. Weerts, L.B. Verdijk, and L.J. van Loon, Skeletal muscle disuse atrophy is not attenuated by dietary protein supplementation in healthy older men. J Nutr, 2014. 144(8): p. 1196-203.

89. Tanner, R.E., L.B. Brunker, J. Agergaard, K.M. Barrows, R.A. Briggs, O.S. Kwon, L.M. Young, P.N. Hopkins, E. Volpi, R.L. Marcus, P.C. LaStayo, and M.J. Drummond, Age-related differences in lean mass, protein synthesis and skeletal muscle markers of proteolysis after bed rest and exercise rehabilitation. J Physiol, 2015. 593(18): p. 4259-73.

90. Suetta, C., U. Frandsen, A.L. Mackey, L. Jensen, L.G. Hvid, M.L. Bayer, S.J. Petersson, H.D. Schroder, J.L. Andersen, P. Aagaard, P. Schjerling, and M. Kjaer, Ageing is associated with diminished muscle re-growth and myogenic precursor cell expansion early after immobility-induced atrophy in human skeletal muscle. J Physiol, 2013. 591(15): p. 3789-804.

91. Hvid, L., P. Aagaard, L. Justesen, M.L. Bayer, J.L. Andersen, N. Ortenblad, M. Kjaer, and C. Suetta, Effects of aging on muscle mechanical function and muscle fiber morphology during short-term immobilization and subsequent retraining. J Appl Physiol (1985), 2010.109(6): p.1628-34.

92. Pisot, R., U. Marusic, G. Biolo, S. Mazzucco, S. Lazzer, B. Grassi, C. Reggiani, L. Toniolo, P.E. di Prampero, A. Passaro, M. Narici, S. Mohammed, J. Rittweger, M. Gasparini, M. Gabrijelcic Blenkus, and B. Simunic, Greater loss in muscle mass and function but smaller metabolic alterations in older compared with younger men following 2 wk of bed rest and recovery. J Appl Physiol (1985), 2016. 120(8): p. 922-9.

93. Peterson, S.J. and C.A. Braunschweig, Prevalence of Sarcopenia and Associated Outcomes in the Clinical Setting. Nutr Clin Pract, 2016. 31(1): p. 40-8.

94. Covinsky, K.E., R.M. Palmer, R.H. Fortinsky, S.R. Counsell, A.L. Stewart, D. Kresevic, C.J. Burant, and C.S. Landefeld, Loss of independence in activities of daily living in older adults hospitalized with medical illnesses: increased vulnerability with age. J Am Geriatr Soc, 2003. 51(4): p.451-8.

95. Perez-Zepeda, M.U., A. Sgaravatti, and E. Dent, Sarcopenia and post-hospital outcomes in older adults: A longitudinal study. Arch Gerontol Geriatr, 2017. 69: p. 105-109.

96. Trombetti, A., K.F. Reid, M. Hars, F.R. Herrmann, E. Pasha, E.M. Phillips, and R.A. Fielding, Ageassociated declines in muscle mass, strength, power, and physical performance: impact on fear of falling and quality of life. Osteoporos Int, 2016. 27(2): p. 463-71.

97. Sousa, A.S., R.S. Guerra, I. Fonseca, F. Pichel, S. Ferreira, and T.F. Amaral, Financial impact of sarcopenia on hospitalization costs. Eur J Clin Nutr, 2016. 70(9): p. 1046-51.

98. Deutz, N.E., J.M. Bauer, R. Barazzoni, G. Biolo, Y. Boirie, A. Bosy-Westphal, T. Cederholm, A. CruzJentoft, Z. Krznaric, K.S. Nair, P. Singer, D. Teta, K. Tipton, and P.C. Calder, Protein intake and exercise for optimal muscle function with aging: recommendations from the ESPEN Expert Group. Clin Nutr, 2014. 33(6): p. 929-36.

99. Bauer, J., G. Biolo, T. Cederholm, M. Cesari, A.J. Cruz-Jentoft, J.E. Morley, S. Phillips, C. Sieber, P. Stehle, D. Teta, R. Visvanathan, E. Volpi, and Y. Boirie, Evidence-based recommendations for 
optimal dietary protein intake in older people: a position paper from the PROT-AGE Study Group. J Am Med Dir Assoc, 2013. 14(8): p. 542-59.

100. Tieland, M., K.J. Borgonjen-Van den Berg, L.J. van Loon, and L.C. de Groot, Dietary protein intake in community-dwelling, frail, and institutionalized elderly people: scope for improvement. European journal of nutrition, 2012. 51(2): p. 173-9.

101. van Til, A.J., E. Naumann, I.J. Cox-Claessens, S. Kremer, E. Boelsma, and M.A. de van der Schueren, Effects of the daily consumption of protein enriched bread and protein enriched drinking yoghurt on the total protein intake in older adults in a rehabilitation centre: a single blind randomised controlled trial. J Nutr Health Aging, 2015. 19(5): p. 525-30.

102. Beelen, J., E. Vasse, N. Janssen, A. Janse, N.M. de Roos, and L. de Groot, Protein-enriched familiar foods and drinks improve protein intake of hospitalized older patients: A randomized controlled trial. Clin Nutr, 2017.

103. Stelten, S., I.M. Dekker, E.M. Ronday, A. Thijs, E. Boelsma, H.W. Peppelenbos, and M.A. de van der Schueren, Protein-enriched 'regular products' and their effect on protein intake in acute hospitalized older adults; a randomized controlled trial. Clin Nutr, 2015. 34(3): p. 409-14.

104. Dijxhoorn, D.N., M.G.A. van den Berg, W. Kievit, J. Korzilius, J.P.H. Drenth, and G.J.A. Wanten, A novel in-hospital meal service improves protein and energy intake. Clin Nutr, 2017.

105. Ziylan, C., A. Haveman-Nies, S. Kremer, and L.C. de Groot, Protein-Enriched Bread and Readymade Meals Increase Community-Dwelling Older Adults' Protein Intake in a Double-Blind Randomized Controlled Trial. J Am Med Dir Assoc, 2017. 18(2): p. 145-151.

106. Bauer, J.M., S. Verlaan, I. Bautmans, K. Brandt, L.M. Donini, M. Maggio, M.E. McMurdo, T. Mets, C. Seal, S.L. Wijers, G.P. Ceda, G. De Vito, G. Donders, M. Drey, C. Greig, U. Holmback, M. Narici, J. McPhee, E. Poggiogalle, D. Power, A. Scafoglieri, R. Schultz, C.C. Sieber, and T. Cederholm, Effects of a vitamin $D$ and leucine-enriched whey protein nutritional supplement on measures of sarcopenia in older adults, the PROVIDE study: a randomized, double-blind, placebo-controlled trial. J Am Med Dir Assoc, 2015. 16(9): p. 740-7.

107. Tieland, M., M.L. Dirks, N. van der Zwaluw, L.B. Verdijk, O. van de Rest, L.C. de Groot, and L.J. van Loon, Protein supplementation increases muscle mass gain during prolonged resistance-type exercise training in frail elderly people: a randomized, double-blind, placebo-controlled trial. J Am Med Dir Assoc, 2012. 13(8): p. 713-9.

108. Neelemaat, F., P. Lips, J.E. Bosmans, A. Thijs, J.C. Seidell, and M.A. van Bokhorst-de van der Schueren, Short-term oral nutritional intervention with protein and vitamin $D$ decreases falls in malnourished older adults. J Am Geriatr Soc, 2012. 60(4): p. 691-9.

109. Breen, L. and S.M. Phillips, Skeletal muscle protein metabolism in the elderly: Interventions to counteract the 'anabolic resistance' of ageing. Nutr Metab (Lond), 2011. 8: p. 68.

110. Wall, B.T. and L.J. van Loon, Nutritional strategies to attenuate muscle disuse atrophy. Nutrition Reviews, 2012.

111. Rolland, Y., G. Onder, J.E. Morley, S. Gillette-Guyonet, G. Abellan van Kan, and B. Vellas, Current and future pharmacologic treatment of sarcopenia. Clin Geriatr Med, 2011. 27(3): p. 423-47.

112. Hulzebos, E.H. and N.L. van Meeteren, Making the elderly fit for surgery. Br J Surg, 2016. 103(2): p. e12-5.

113. Hoogeboom, T.J., J.J. Dronkers, E.H. Hulzebos, and N.L. van Meeteren, Merits of exercise therapy before and after major surgery. Curr Opin Anaesthesiol, 2014. 27(2): p. 161-6.

114. Wall, B.T., J.P. Morton, and L.J. van Loon, Strategies to maintain skeletal muscle mass in the injured athlete: nutritional considerations and exercise mimetics. Eur J Sport Sci, 2015. 15(1): p. 53-62.

115. Dirks, M.L., B.T. Wall, and L.J.C. van Loon, Interventional strategies to combat muscle disuse atrophy in humans: focus on neuromuscular electrical stimulation and dietary protein. J Appl Physiol (1985), 2017: p. jap009852016. 
General Introduction 


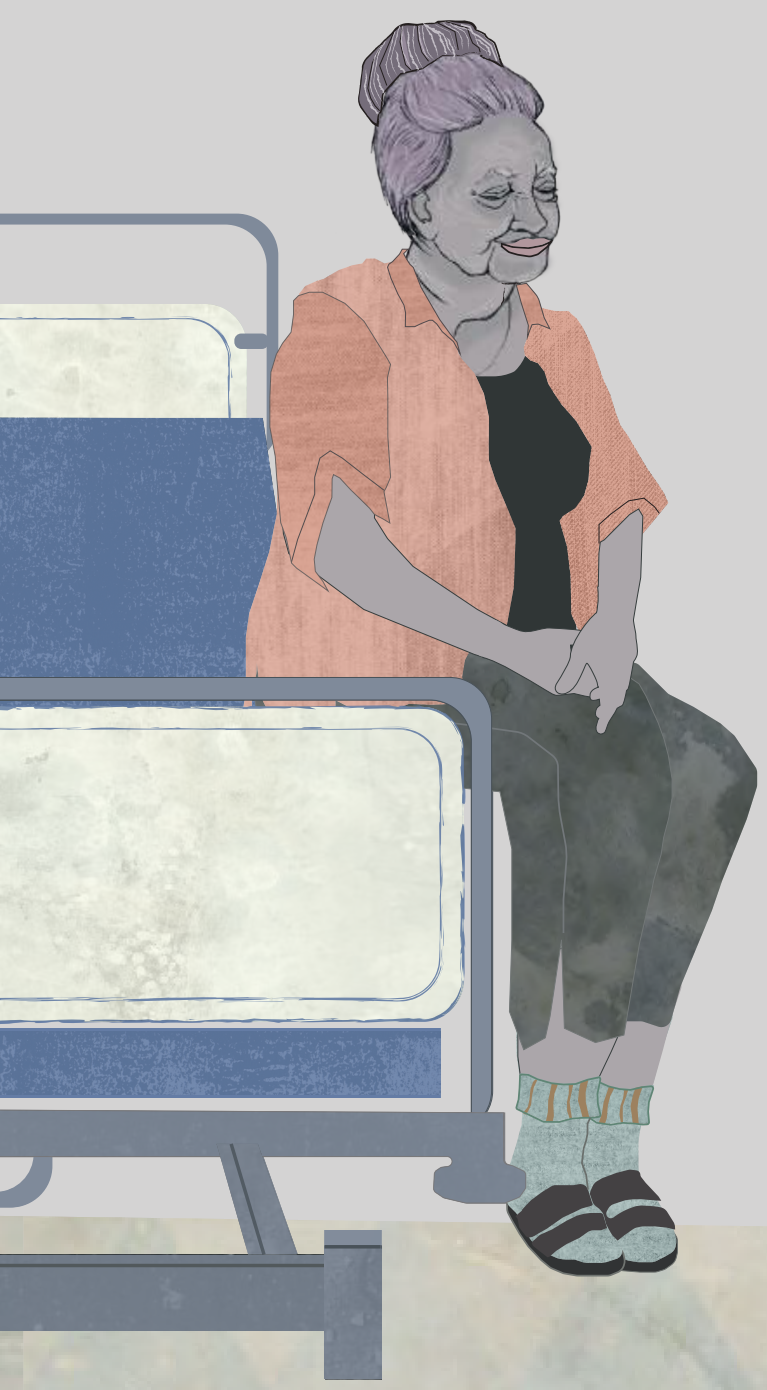




\section{CHAPTER TWO}

\section{One WeEk of hospitalization following ELECTIVE HIP SURGERY INDUCES SUBSTANTIAL MUSCLE ATROPHY IN OLDER PATIENTS}

Imre W.K. Kouw, Bart B.L Groen, Joey S.J. Smeets, Irene Fleur Kramer, Janneau van Kranenburg, Rachel Nilwik, Jan A. Geurts, René H.M. ten Broeke, Martijn Poeze, Luc J.C. van Loon, and Lex B. Verdijk 


\section{ABSTRACT}

Objectives: Short successive periods of skeletal muscle disuse have been suggested to substantially contribute to the observed loss of skeletal muscle mass over the life span. Hospitalization of older individuals due to acute illness, injury, or major surgery generally results in a mean hospital stay of 5 to 7 days, during which the level of physical activity is strongly reduced. We hypothesized that hospitalization following elective total hip arthroplasty is accompanied by substantial leg muscle atrophy in older men and women.

\section{Design and participants:}

Twenty-six older patients $(75 \pm 1$ y) undergoing elective total hip arthroplasty participated in this observational study.

Measurements: On hospital admission and on the day of discharge, computed tomographic (CT) scans were performed to assess muscle cross-sectional area (CSA) of both legs. During surgery and on the day of hospital discharge, a skeletal muscle biopsy was taken from the $\mathrm{m}$. vastus lateralis of the operated leg to assess muscle fiber type-specific CSA.

Results: $\quad$ An average of $5.6 \pm 0.3$ days of hospitalization resulted in a significant decline in quadriceps $(-3.4 \pm 1.0 \%)$ and thigh muscle CSA $(-4.2 \pm 1.1 \%)$ in the nonoperated leg $(P<0.05)$. Edema resulted in a $10.3 \pm 1.7 \%$ increase in leg CSA in the operated leg $(P<0.05)$. At hospital admission, muscle fiber CSA was smaller in the type II vs type I fibers $\left(3326 \pm 253\right.$ vs $4075 \pm 279 \mu \mathrm{m}^{2}$, respectively; $P<0.05)$. During hospitalization, type I and II muscle fiber CSA tended to increase, likely due to edema in the operated leg $(P=0.10)$.

Conclusions: Six days of hospitalization following elective total hip arthroplasty leads to substantial leg muscle atrophy in older patients. Effective intervention strategies are warranted to prevent the loss of muscle mass induced by short periods of muscle disuse during hospitalization. 


\section{INTRODUCTION}

Aging is associated with the progressive loss of skeletal muscle mass and function, termed sarcopenia, which is accompanied by a decline in muscle strength and physical capacity, and an increased risk of developing chronic metabolic diseases [1, 2]. Various situations such as hospitalization or recovery from illness or injury often necessitate a period of physical inactivity that is accompanied by the accelerated loss of muscle mass and muscle strength [3-5]. Such disuse-induced muscle loss contributes to negative health outcomes, including a reduction in the ability to perform activities of daily living, increased incidence of complications and subsequent need for readmission, decreased quality of life, and an increased risk for permanent institutionalization [6-8]. This is likely associated with the fact that older individuals generally do not regain all muscle tissue that was lost during a period of disuse [9-11]. As such, accumulation of (short) periods of muscle disuse that occur throughout the life span may contribute substantially to the etiology of sarcopenia $[3,4,12]$.

Muscle disuse has been studied in healthy young and older subjects using different lab-based models such as limb immobilization or bed rest. Studies investigating muscle disuse atrophy models in humans generally apply a relatively prolonged period of limb immobilization or bed rest (>10 days) to ensure measurable muscle loss in a research setting [13-16]. Recently, we [17-19] as well as others [20-22] showed that even a few days of disuse already leads to significant losses in muscle mass and strength in both young and older individuals. At present, hospitalization in older patients ranges between 5 and 13 days, $[23,24]$ during which the level of physical activity is strongly reduced $[25,26]$. As such, short-term hospitalization might be accompanied by a significant loss in skeletal muscle mass and strength in older patients, posing a major threat to fully regaining physical function after discharge. Muscle disuse models are often used to predict changes in muscle mass during hospitalization. However, the impact of surgery, associated physical and mental stress, and reduced food intake during hospitalization are likely to further aggravate skeletal muscle loss in clinical practice. Although hospital-based deconditioning is well recognized as a negative consequence of hospitalization, there is a paucity of data on the actual loss of muscle tissue during the hospitalized period [27-29]. Moreover, studies so far have largely focused on rather severe conditions, such as cancer cachexia and critical illness [29-35], leaving a gap in knowledge on the negative impact of (planned) short-term hospitalization in relatively healthy older patients.

Elective total hip arthroplasty (THA), a surgical procedure for end-stage osteoarthritis, has evolved into a reliable and suitable surgical procedure to gain pain relief and improve quality of life and function of patients within 3 months up to 2 years after surgery $[36,37]$. Despite the success in treating the osteoarthritic joint, THA patients suffer from muscle atrophy [38$40]$, reduced muscle strength [40-42], and mobility impairment $[40,42,43]$ in the longer term. This places a huge burden on the health care system, which will take on dramatic proportions given the expected doubling of the number of joint arthroplasties over the coming years [37, 
44]. To what extent muscle disuse atrophy occurs during short-term hospitalization following elective total hip replacement surgery is currently unknown.

The specific aim of the present study was to quantitatively assess the extent of muscle atrophy in older hospitalized patients during the first (hospital-based) days of recovery from THA, representing a relatively healthy group of older patients entering the hospital for planned surgery. Therefore, in the present study, we selected 26 male and female patients who were scheduled for THA and assessed skeletal muscle mass and muscle fiber characteristics at admission and on subsequent discharge from the hospital. 


\section{METHODS}

\section{Subjects}

Twenty-six older patients ( $n=7$ males, $n=19$ females, aged $\geq 65$ years) participated in this observational study during an average length of hospital stay of $5.6 \pm 0.3$ days. On hospital admission and on the day of discharge, computed tomographic (CT) scans were obtained to assess muscle mass (primary outcome measure); no CT scans were taken in $n=6$ patients because of conflicting medical appointments, inability to mobilize, or pain. During surgery and on the day of hospital discharge, a skeletal muscle biopsy was taken from the $\mathrm{m}$. vastus lateralis of the (to be) operated leg to assess muscle fiber characteristics (secondary outcome measure). In all 26 patients, skeletal muscle biopsies were taken during surgery; however, no muscle biopsies were taken at hospital discharge in 8 patients because of excessive edema or at the patient's request. A flowchart of patients' enrolment is shown in Figure 1.

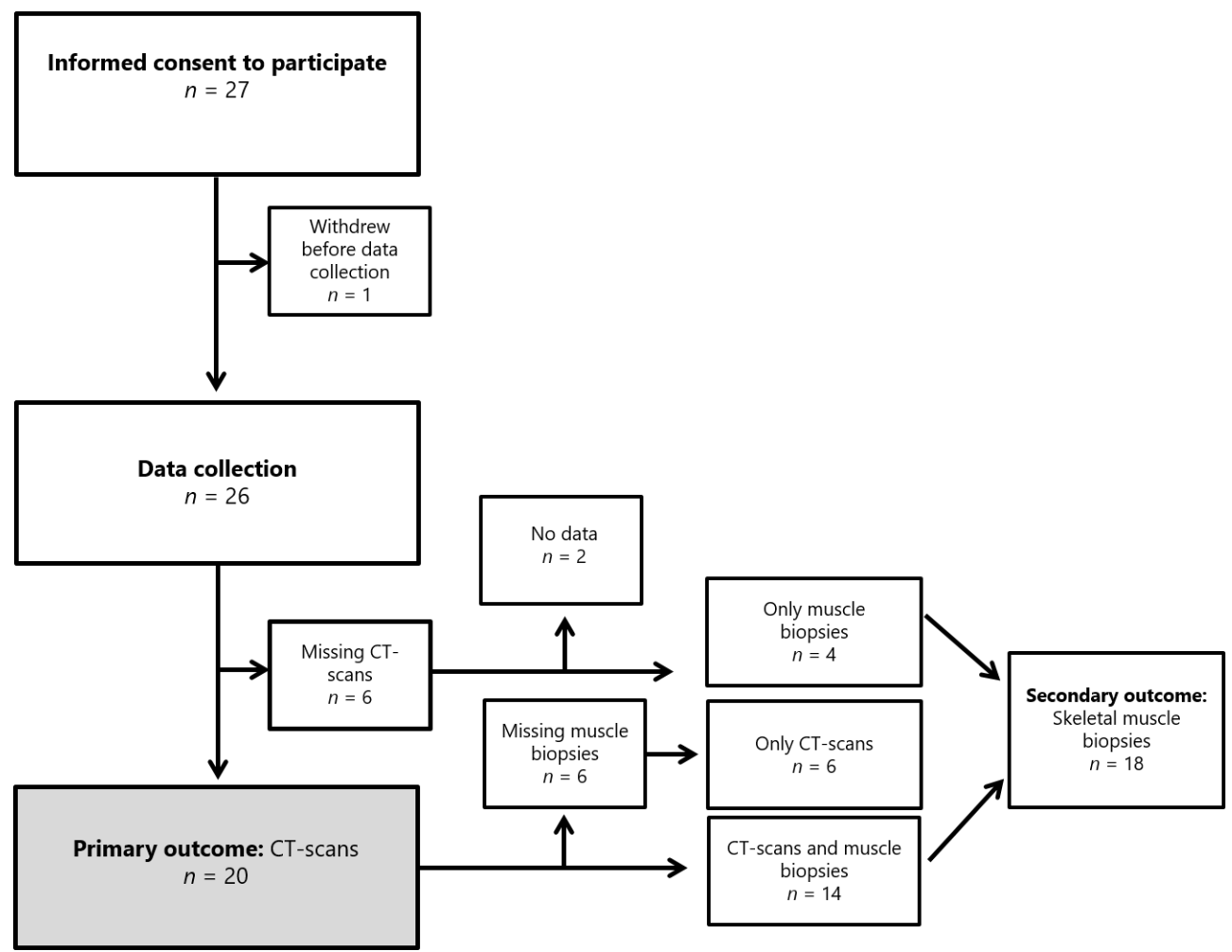

Figure 1 | Flow diagram of patients' enrolment procedure. 
All participants were recruited via the outpatient clinic of the Department of Orthopedic Surgery after scheduling an elective THA. Subjects were informed about the nature and risks of the experimental procedures before written consent was obtained. The study was part of a larger project on the impact of immobility and nutrition on skeletal muscle adaptation during hospitalization and approved by the Medical Ethical Committee of the Maastricht University Medical Centre+, the Netherlands (registered as NTR3773 at www.trialregister.nl), conformed to the standards for the use of human subjects in research as outlined in the latest version of the Declaration of Helsinki.

\section{Protocol}

All eligible subjects were pretested on the day before surgery directly after arrival at the hospital ward. Exclusion criteria included age $\leq 65$ years, all comorbidities and use of medication interacting with muscle metabolism and mobility of the limbs, such as chronic obstructive pulmonary disease, peripheral arterial disease, severe cardiovascular impairment, neurological disorders, coagulation diseases, and malignant disease. Height and weight were measured and body composition was assessed using dual-energy $\mathrm{x}$-ray absorptiometry (Discovery A; Hologic, Bedford, MA). Thereafter, a single-slice CT scan (Brilliance 64, Philips Medical Systems, Best, the Netherlands) was performed to assess upper leg muscle crosssectional area (CSA). The scanning characteristics were as follows: $120 \mathrm{kV}, 300 \mathrm{~mA}$, rotation time of 0.75 seconds, and a field of view of $500 \mathrm{~mm}$. With subjects lying supine with their legs extended, a 3-mm-thick axial image was taken $15 \mathrm{~cm}$ proximal to the top of the patella for both legs. The exact scanning position was measured and marked for replication at the time of discharge from the hospital. Intramuscular adipose tissue was defined using radiation attenuation ranges from -190 to -30 Hounsfield units (HUs), and muscle area of the legs was selected between -29 and $+150 \mathrm{HU}$ [45], after which the quadriceps muscle was selected by manual tracing using ImageJ software (version $1.45 \mathrm{~d}$; National Institute of Health, Bethesda, $\mathrm{MD})[46,47]$. Leg volume measurements were performed using anthropometric measurements on both legs [48].

Information regarding quality of life, habitual physical activity, and nutritional status were evaluated using several questionnaires: Short Form-36 [49], Physical Activity Scale for the Elderly [50, 51], Mini Nutritional Assessment (MNA) [52], Malnutrition Universal Screening Tool [53], and Mini-Mental State Examination [54]. Maximal handgrip strength was measured using a JAMAR handheld dynamometer (model BK-7498, Fred Sammons Inc., Burr Ridge, IL). Grip strength was measured 3 times (with a 10-second interval) with each hand, and the highest value for both hands was reported. Measurements of handgrip strength were taken with the patient sitting on a chair with the elbow in $90^{\circ}$ flexion and the forearm in the neutral position. On the day of surgery, a first muscle biopsy was collected from the $\mathrm{m}$. vastus lateralis of the operated leg during the surgical procedure. A second muscle biopsy was taken from the same leg on the day of hospital discharge. In addition, on the day of hospital discharge, a second CT scan was performed, and maximal handgrip strength and leg volume were assessed. 


\section{Muscle biopsy}

Skeletal muscle biopsy samples were obtained from the operated leg from the middle region of the $\mathrm{m}$. vastus lateralis $15 \mathrm{~cm}$ above the patella and approximately $2 \mathrm{~cm}$ away from the fascia by means of the percutaneous needle biopsy technique described by Bergström et al. [55]. Biopsies were spaced by 1 to $2 \mathrm{~cm}$, and the order of distal and proximal incision was randomized to minimize any potential systematic effect of the previous biopsy. Muscle biopsies were carefully freed from any visible fat and blood, embedded in Tissue-Tek (Sakura Finetek Europe B.V., Zoeterwoude, the Netherlands), and rapidly frozen in liquid nitrogen cooled isopentane and stored at $-80^{\circ} \mathrm{C}$ for subsequent histochemical analysis.

\section{Diet and physical activity}

Nutritional intake was ad libitum during hospitalization, except from the perioperative period since all patients were operated in a fasted state. Nutritional intake was monitored during hospitalization on a thrice-daily basis. Hospital meals were provided at 3 strict timeslots every day-breakfast, lunch, and dinner. In between the meals, patients were provided with hot and/or cold drinks 3 times a day. On the serving tray, patients received a description of their ordered menu, which was collected for the study. Products that were not consumed were recorded. Total energy [mega joules (MJ)] and protein [grams and energy \% (En\%)] contents were calculated for all consumed food based on product specifications provided by the food suppliers and the Dutch Food Consumption Database 2016 (NEVO; RIVM, Bilthoven, the Netherlands). Food intake data were available for 23 patients. Dietary intake was only reported when complete data for all 3 main meals was available; separate data were calculated for the day of surgery $(n=13)$ and combined for the hospitalization days following surgery $(n=23)$. During hospital stay, patients were encouraged to mobilize as soon as possible and received physiotherapy training twice daily for 20 minutes from the first day after surgery onward. Patients were allowed to also mobilize without supervision from nursing staff or physical therapists from day 1 onward; however, from observations made while being on the nursing ward, patients mainly performed sedentary behavior outside of the therapy sessions (i.e., sitting in and around their hospital bed, except for toilet visits and bedside transfers).

\section{Immunohistochemistry}

Frozen muscle biopsies were cut into 5-mm-thick cryosections using a cryostat at_20_C, and thaw mounted on uncoated precleaned glass slides. Samples from pre- and post surgery were mounted together on the same glass slide. Care was taken to properly align the samples for cross-sectional fiber analyses. Muscle biopsies were stained for muscle fiber type determination, that is, type I and type II muscle fibers. Details of the analytical procedures have been described previously [56]. First, antibodies were directed against laminin (polyclonal rabbit anti-laminin, dilution 1:50; Sigma, Zwijndrecht, the Netherlands) and myosin heavy chain-I (A4.840, dilution 1:25; Developmental Studies Hybridoma Bank, lowa City, IA). Images were visualized and automatically captured at $\times 10$ magnification with a fluorescent 
microscope equipped with an automatic stage (IX81 motorized inverted microscope; Olympus, Hamburg, Germany). Quantitative analyses were performed using ImageJ version $1.46 \mathrm{~d}$ software package (version 1.45d, National Institute of Health [47]). All image recordings and analyses were performed by an investigator blinded to subject coding. Muscle fiber type (fiber $\%$ ) and fiber CSA were measured for each separate muscle fiber. As such, mean muscle fiber size was calculated for the type I and type II muscle fibers separately. Mean numbers of $476 \pm 72$ and $504 \pm 70$ muscle fibers were analyzed in the biopsy samples collected during surgery and (on average) 5 days following surgery, respectively.

\section{Statistics}

All data are expressed as mean \pm standard error of the mean. A sample size of $n=16$ was calculated assuming a decline of $2 \%$ (standard deviation 2\%) in muscle CSA based on CT scans, using an $\alpha$-level of 0.05 and $95 \%$ power, based upon previous disuse studies $[17,19,22]$. To err on the side of caution, we aimed to include 20 patients for our primary outcome; 26 patients were finally needed to obtain full data sets (pre and post) for CT scans (Figure 1). Data were analyzed using paired samples $t$-tests to assess changes from pre- (hospital admission) to post-hospitalization (discharge). Muscle CSA and muscle fiber characteristics were analyzed using repeated measures analysis of variance with time (pre vs post) and leg (nonoperated or operated) or fiber type (type I vs II) as within-subject factors. Because of significant 'time $\mathrm{x}$ leg' interaction, paired samples $t$-tests were used to assess changes for each leg separately. Statistical significance was set at $P<0.05$. All calculations were performed using SPSS Statistics (version 24.0, IBM Corp., Armonk, NY). 


\section{RESULTS}

\section{Patients' characteristics and body composition}

Patients' characteristics and body composition data are shown in Table 1. Total lean body mass (presented in absolute and relative numbers) averaged $47.6 \pm 1.9 \mathrm{~kg}(63.0 \pm 1.1 \%)$, appendicular lean mass: $19.9 \pm 1.0 \mathrm{~kg}(26.2 \pm 0.7 \%)$, and fat mass: $25.5 \pm 1.1 \mathrm{~kg}(34.0 \pm 1.2 \%)$. Skeletal muscle mass index (SMMI) was calculated for women $(n=19)$ and men $(n=7)$ separately and averaged $7.0 \pm 0.2$ in women and $9.2 \pm 0.4 \mathrm{~kg} \cdot \mathrm{m}^{-2}$ in men. None of the patients were classified as malnourished based on the MNA (average score $26.2 \pm 0.4$ ). However, 4 of the patients were classified as 'high risk for malnutrition' (a Malnutrition Universal Screening Tool score 2 based on recent weight loss) on hospital admission. Scores for the Short Form36, Physical Activity Scale for the Elderly, and Mine-Mental State Examination are depicted in Table 1. Based on the MMSE, none of the patients presented cognitive impairments at hospital admission. Handgrip strength before surgery averaged $26.4 \pm 1.8 \mathrm{~kg}$ and $25.0 \pm 1.6 \mathrm{~kg}$ in the right and left hand, respectively, and did not change during hospitalization (both $P>0.05$ ).

Table 1 | Patients' baseline characteristics.

\begin{tabular}{|c|c|}
\hline & Patients $(n=26)$ \\
\hline Age (y) & $74.7 \pm 0.8$ \\
\hline Gender: male / female (n) & $7 / 19$ \\
\hline Hospitalization duration (d) & $5.6 \pm 0.3$ \\
\hline Weight (kg) & $73.9 \pm 2.3$ \\
\hline BMI $\left(\mathbf{k g} \cdot \mathbf{m}^{-2}\right)$ & $28.0 \pm 0.8$ \\
\hline Lean body mass (kg and \%) & $47.6 \pm 1.9(63.0 \pm 1.1 \%)$ \\
\hline Fat mass (\%) & $34.0 \pm 1.2$ \\
\hline SMMI (kg·m $\left.{ }^{-2}\right)$ & $7.6 \pm 0.3$ \\
\hline Anesthesia: epidural / general anesthesia (n) & $12 / 14$ \\
\hline MNA score & $26.2 \pm 0.4$ \\
\hline SF-36 score: physical component summary & $45.8 \pm 3.4$ \\
\hline mental component summary & $54.8 \pm 4.3$ \\
\hline MMSE score & $28.4 \pm 0.4$ \\
\hline PASE & $101.7 \pm 14.9$ \\
\hline
\end{tabular}

BMI: body mass index; MMSE: Mini Mental State Examination; MNA: Mini Nutritional Assessment, PASE: Physical Activity Scale for the Elderly; SF-36: Short Form-36; SMMI: skeletal muscle mass index. Values are expressed as mean \pm standard error of the mean. 


\section{Leg muscle mass}

In the nonoperated leg, CSA of the thigh muscles declined by $4.2 \pm 1.1 \%$ (from $11,071 \pm 577$ to $\left.10,565 \pm 528 \mathrm{~mm}^{2}\right)$ during hospitalization ( $P=0.001$; Figure 2). In accordance, quadriceps femoris CSA in the nonoperated leg declined by $3.4 \pm 1.0 \%$ from hospital admission to hospital discharge (from $5285 \pm 320$ to $5095 \pm 303 \mathrm{~mm}^{2}$, respectively, $P=0.004$; Figure 2). Total thigh volume assessed by $C T$ scans decreased by $2.8 \pm 1.2 \%$ during hospitalization in the nonoperated leg (from 20,477 \pm 909 to $19,841 \pm 876 \mathrm{~mm}^{2}$, respectively, $P=0.03$ ). Anthropometric whole leg volume in the nonoperated leg did not change from hospital admission to hospital discharge $\left(7436 \pm 386\right.$ and $7646 \pm 335 \mathrm{~cm}^{3}$, respectively, $\left.P=0.54\right)$. Average muscle radiation attenuation values in the nonoperated leg decreased by $6.4 \pm 1.0 \%$ in the thigh muscles and $6.4 \pm 1.1 \%$ in the quadriceps femoris (from $39.5 \pm 1.4$ to $37.0 \pm 1.5 \mathrm{HU}$ and from $45.0 \pm 1.2$ to $42.2 \pm 1.4 \mathrm{HU}$, respectively, both $P<0.001$ ).

At hospital admission, both thigh and quadriceps muscles CSA were lower in the operated leg $\left(10,359 \pm 599\right.$ and $\left.4740 \pm 332 \mathrm{~mm}^{2}\right)$ when compared with the nonoperated leg $(11,071 \pm 577$ and $5285 \pm 320 \mathrm{~mm}^{2}$; both $P<0.05$ ). In the operated leg, thigh muscle CSA increased by $8.0 \pm 1.7 \%$ during hospitalization (from $10,359 \pm 599$ to $11,095 \pm 584 \mathrm{~mm}^{2}, P<0.001$ ) and quadriceps CSA increased by $12.2 \pm 2.9 \%$ when compared with baseline values (from $4740 \pm 332$ to $5209 \pm 308$ $\left.\mathrm{mm}^{2}, P<0.001\right)$. In accordance, total thigh CSA of the operated leg assessed by CT scans increased during hospital stay with $10.3 \pm 1.7 \%$ (from $20,185 \pm 867 \mathrm{~mm}^{2}$ at hospital admission to $22,154 \pm 897 \mathrm{~mm}^{2}$ at hospital discharge, respectively, $P<0.001$ ). Anthropometric whole leg volume increased by $16.2 \pm 4.6 \%$ during hospitalization (from $7606 \pm 387$ to $8715 \pm 420 \mathrm{~cm}^{3}$, respectively, $P<0.001)$. Average muscle radiation attenuation in the operated leg decreased by $14.1 \pm 1.7 \%$ in the thigh muscles and $14.5 \pm 1.8 \%$ in quadriceps femoris CSA (from $37.4 \pm 1.5$ to $32.3 \pm 1.6 \mathrm{HU}$ and from $42.9 \pm 1.4$ to $37.0 \pm 1.7 \mathrm{HU}$, respectively; both $P<0.001$ ).

Total thigh CSA and anthropometric whole leg volume did not differ between legs at hospital admission (both $P>0.05$ ), but were significantly lower in the nonoperated leg when compared with the operated leg at hospital discharge (both $P<0.001$ ). Moreover, the change in leg volume (both $\mathrm{CT}$ and anthropometric measurements) differed between legs (time $\mathrm{x}$ leg interaction effect, $P<0.001$ ). This was likely due to swelling of the operated leg following the surgery; therefore, muscle mass changes were only presented graphically for the nonoperated leg (Figure 2). Moreover, a significant time $\mathrm{x}$ leg interaction effect was observed for muscle radiation attenuation in thigh muscles and quadriceps CSA (both $P<0.05$ ). HU values in thigh muscles and quadriceps femoris were lower in the operated leg when compared with the nonoperated leg both at hospital admission and hospital discharge (both $P<0.05$ ). 
A

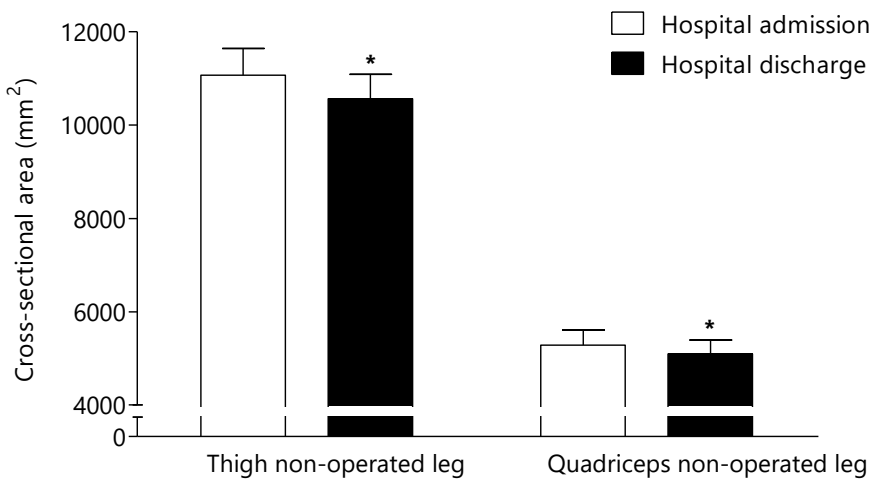

B

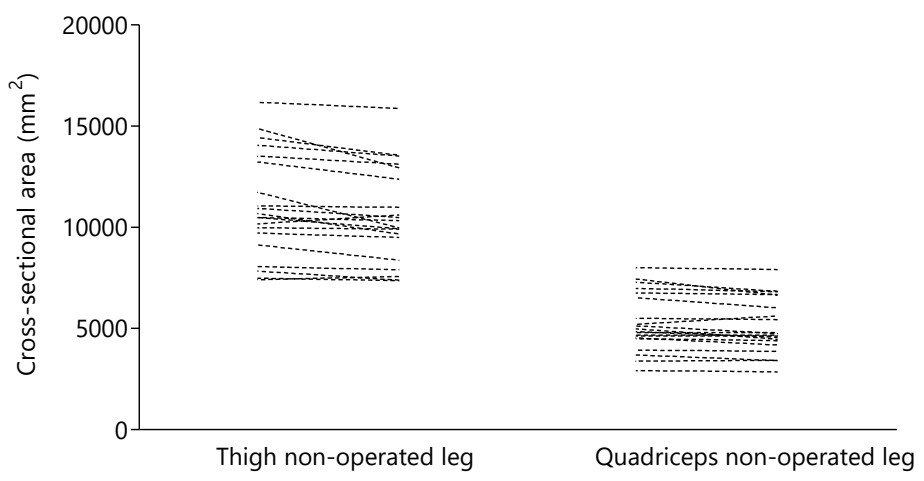

C

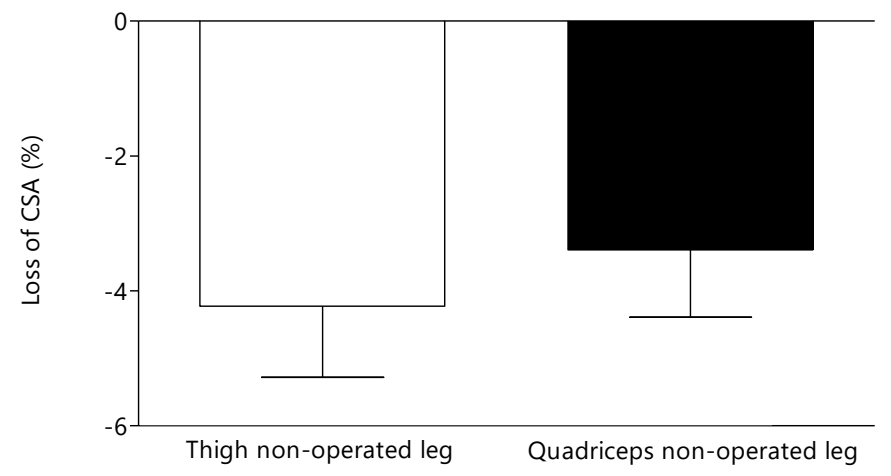

Figure 2 | Muscle cross-sectional area (CSA in millimeters squared) of the quadriceps and thigh muscles of the nonoperated leg in older patients $(n=20)$ undergoing elective total hip arthroplasty, assessed by single-slice CT scans taken on the day of hospital admission and on the day of discharge. (A) mean standard error of the mean; (B) individual data; (C) mean standard error of the mean of relative decline CSA (in percentage). *Significantly different from hospital admission. 


\section{Muscle fiber characteristics}

Muscle fiber characteristics of skeletal muscle biopsies collected from the operated leg during surgery and on the day of hospital discharge are displayed in Table 2. At hospital admission and discharge, type II muscle fibers were smaller when compared with type I muscle fibers (3325 \pm 253 vs $4075 \pm 279 \mu \mathrm{m}^{2}$, respectively, $P=0.001$ ). No significant time $x$ fiber type interaction was observed for muscle fiber size $(P=0.37)$. Six days of hospitalization tended to increase both type I and II muscle fiber size by $21.9 \pm 11.0 \%$ and $17.8 \pm 9.2 \%$, respectively (main time effect, $P=0.10$ ). Subtle changes in fiber type distribution were observed during hospitalization (Table 2).

Table 2 | Muscle fiber characteristics.

\begin{tabular}{lcccc}
\hline & \multicolumn{2}{c}{ Hospital admission } & \multicolumn{2}{c}{ Hospital discharge } \\
& Type I & Type II & Type I & Type II \\
\hline No. of fibers & $198 \pm 32$ & $278 \pm 45$ & $175 \pm 28$ & $329 \pm 48$ \\
Muscle fiber CSA $\left(\boldsymbol{\mu m}^{2}\right)$ & $4075 \pm 279$ & $3326 \pm 253^{*}$ & $4881 \pm 548$ & $3953 \pm 471^{*}$ \\
\% fiber & $42.3 \pm 3.4$ & $57.7 \pm 3.4$ & $34.7 \pm 2.5^{+}$ & $65.3 \pm 2.5$ \\
\% fiber area & $47.2 \pm 4.1$ & $52.8 \pm 4.1$ & $40.1 \pm 3.1^{+}$ & $59.9 \pm 3.1$ \\
\hline
\end{tabular}

Values are expressed as mean standard error of the mean. No time x fiber type interaction was observed for any of the outcomes $(P>0.05)$. * Main fiber type effect: significantly different from type $1,+$ Main time effect: significantly different from hospital admission, $P=0.01$.

\section{Nutritional intake}

On the day of surgery, energy intake averaged $1.32 \pm 0.62 \mathrm{MJ}$, whereas energy intake increased to $4.21 \pm 0.38 \mathrm{MJ}(P<0.001)$ on the hospitalization days following surgery. Protein intake averaged $0.08 \pm 0.03 \mathrm{~g} / \mathrm{kg}$ bodyweight/day on the day of surgery, after which protein intake increased to $0.58 \pm 0.04 \mathrm{~g} / \mathrm{kg}$ bodyweight/day during the following days of hospitalization $(P<0.001)$. 


\section{DISCUSSION}

Six days of hospitalization leads to a substantial decrease in thigh and quadriceps femoris muscle CSA in the nonoperated leg following elective hip arthroplasty. This reduction in muscle CSA is not observed in the operated leg, showing a 10\% increase in thigh CSA and $\sim 16 \%$ increase in whole leg volume due to postsurgery edema.

Muscle disuse is associated with a decline in skeletal muscle mass and strength [4]. Experimental models studying muscle disuse have shown a $\sim 2$ to $6 \%$ decrease in leg muscle mass and an $\sim 8$ to $22 \%$ decrease in leg strength following as little as 4 to 7 days of limb immobilization in both young $[17,19,57]$ and older $[18,20]$ subjects. Moreover, up to 14 days of bed rest typically results in a similar decline in whole-body and appendicular lean body mass in young and older individuals [11, 21, 58-62]. As the average hospital length of stay in older patients is 5 to 13 days [23, 24], a short period of hospitalization may already induce a substantial decline in skeletal muscle mass and strength. Studies applying muscle disuse models are often used to predict changes in muscle mass during hospitalization; however, only few data are available on actual muscle loss in a clinical setting. Such a period of hospitalization is generally accompanied by general anesthesia, surgery, associated physical and mental stress, a reduced level of physical activity, enforced bedrest, and/or changes in habitual food intake. Therefore, we hypothesized that even a short period of hospitalization is associated with substantial muscle loss.

With the increasing aging population, elective joint replacement surgeries such as THA have increased exponentially over the last decades with more than $60 \%$ of the patients being 65 years and older $[37,44,63]$. Elective hip replacement surgeries are effective for pain relief and improving quality of life and function in patients with end stage osteoarthritis [36, 37]; however, elective THA in older patients is typically followed by a short hospitalization period of 3 to 4 days [63]. In the present study, we assessed the impact of such a short-term hospitalization period on skeletal muscle mass following elective THA. We performed singleslice CT scans of the upper leg on the day of hospital admission and on the day of discharge to assess muscle CSA of both legs. We show for the first time that 5 days of hospitalization following elective THA is accompanied by a substantial loss of muscle CSA. Thigh muscle CSA significantly declined by $4.2 \pm 1.1 \%$ and quadriceps femoris CSA by $3.4 \pm 1.0 \%$ during hospitalization in the nonoperated leg when compared with baseline values (both $P<0.001$ ). In contrast, in the operated leg, we observed a $~ 10 \%$ increase in total thigh CSA and a $\sim 16 \%$ increase in anthropometrically determined leg volume, probably because of swelling following surgery. In support, muscle radiation attenuation values in the thigh and quadriceps femoris muscle area were substantially decreased in the operated leg when compared with the nonoperated leg $(P<0.001)$. The pronounced decrease in muscle attenuation in the operated leg may be attributed to edema, fluid retention in the interstitial spaces, and/or fat deposition [45]. For example, reduced muscle attenuation values have been associated with conditions such as obesity, diabetes, physical inactivity, and muscle deconditioning $[38,45,64]$. Because 
of the observed swelling and extensive increase in leg volume in the operated leg, we were not able to reliably assess changes in muscle mass in the operated leg. However, the substantial declines in leg muscle mass observed in the nonoperated leg within as little as 5 days of hospital stay clearly indicate the detrimental impact of hospitalization on muscle mass maintenance in older patients. In a recent meta-analysis, it was reported that muscle mass is lost in electively admitted older patients (in line with our findings), whereas generally no decline was observed when patients were admitted acutely [29]. Importantly though, changes in hydration status may strongly influence the assessment of muscle mass, and the methodology used to determine muscle loss likely explains part of the inconsistent findings in literature $[29,35]$. As such, the CT scans performed on the nonoperated leg in the present study provide a very accurate and sensitive measure, clearly showing substantial reductions in muscle mass during hospitalization.

In addition to performing CT scans, we obtained skeletal muscle biopsies from the vastus lateralis muscle of the operated leg during the surgical procedure and on the day of hospital discharge to assess muscle atrophy-related changes in muscle fiber characteristics. At baseline, type II muscle fibers were smaller than type I muscle fibers $(P<0.05)$, which is in line with previous research showing substantial type II muscle fiber atrophy with aging $[65,66]$, type 2 diabetes [67], and hip fracture patients [68]. Six days of hospitalization tended to increase both type I and II muscle fiber size by $\sim 20 \%(P=0.10)$. The observed swelling and substantial increase in leg volume observed in the operated as opposed to the nonoperated leg was likely not only associated with extracellular edema, but also caused a fluid shift into the muscle cells and, as such, intracellular edema, thereby increasing muscle fiber CSA. Therefore, we were unable to adequately assess muscle fiber size and characteristics following surgery in these hospitalized patients. We hypothesized that short-term hospitalization would be characterized by a decline in muscle fiber size in the operated leg, which could explain the observed muscle atrophy in such a clinical setting. For example, substantial decreases in muscle fiber size have been observed during critical illness [69] and bed rest [62]. However, because of the presence of postoperative (intracellular) edema, we could not reliably assess muscle fiber changes in the operated leg. Therefore, future studies should be aware that muscle fiber size loss during hospitalization after orthopedic surgery should not be assessed in the limb in which surgery has been performed.

Short, successive 'catabolic crises' have been proposed to contribute to the persistent agerelated loss of skeletal muscle mass and strength [3,12]. Assuming the usual age-related decline in muscle mass of 1 to $2 \%$ per year above the age of $65[1,3]$, the 3 to $4 \%$ muscle loss observed during only a few days of hospitalization likely has a dramatic impact on the development of sarcopenia. Moreover, older individuals generally do not regain all muscle tissue that was lost during a period of disuse [9-11]. Therefore, cumulative periods of disuse episodes do not only impact muscle loss during hospitalization but likely also contribute to impaired recovery and physical functioning after hospital discharge. Indeed, it has been well established that hospital-associated deconditioning in the older population contributes to an overall functional decline during and following a period of hospitalization, impacting long- 
term clinical outcomes after hospitalization [12, 27, 28]. Although such deconditioning is known to occur in various clinical situations, the actual loss of muscle mass during hospitalization is rarely assessed. Moreover, much of this work so far has focused on severe medical conditions (e.g., ICU-acquired weakness, organ failure, and cancer cachexia [29-35], which may be different from the large group of relatively healthy individuals entering the hospital for planned surgery. In the present study, we quantitatively assessed the extent of skeletal muscle atrophy during short-term hospitalization in older patients who were electively admitted for THA. We observed substantial muscle loss during only several days of hospitalization, although patients were encouraged to mobilize as soon as possible and were provided with daily physical therapy and standard nutritional care. This loss in skeletal muscle mass seems greater when compared to muscle disuse observed in experimental models, which generally report $\sim 0.5 \%$ loss of appendicular muscle mass per day during limb immobilization or bedrest $[4,5]$. In line with the literature on deconditioning, probably the combination of multiple factors such as the impact of surgery, the associated physical and mental stress, reduced food intake during hospitalization, inflammation, medication, type of anesthesia, and medical history could further impact skeletal muscle loss in clinical practice $[27,28]$. With the relative low number of patients included here $(n=26)$ we are unable to further study the relative contribution of these factors to the observed muscle loss. Furthermore, although we would expect the substantial loss of muscle mass during hospitalization to also occur in other older patient populations, it is clear that the reason for admission (i.e., underlying pathology) and the type of admission (i.e., acute vs elective [29]) can affect the extent of muscle loss. Thus, future work is needed to further establish the various factors that affect the extent of muscle atrophy in clinical conditions, and to what extent hospital-associated muscle loss differs between various patient populations.

Apart from the above-mentioned patient-related factors that may affect muscle maintenance, the 2 key anabolic stimuli for skeletal muscle tissue are muscle contraction and food intake [2]. In the present study, daily protein intake was very low on the day of surgery (only $\sim 6 \mathrm{~g}$ in total), as well as on the following days of hospitalization $(\sim 0.6 \mathrm{~g} / \mathrm{kg}$ bodyweight/day). As such, daily protein intake remained well below the recommended protein intake guidelines of 1.2 to $1.5 \mathrm{~g} / \mathrm{kg}$ bodyweight/day for older adults [70]. A protein intake of less than $1.2 \mathrm{~g} / \mathrm{kg}$ bodyweight/day will likely be insufficient to maintain or regain skeletal muscle mass during postsurgery hospitalization in these patients. Increasing protein intake has been proposed as a nutritional strategy to attenuate the loss of muscle mass during hospitalization. Protein supplementation has been shown to increase muscle mass and function in older adults [71, 72]. Moreover, amino acid supplementation (i.e., leucine and $\beta$-hydroxy $\beta$-methylbutyric acid) have been shown to attenuate the loss of muscle mass during a period of bed rest $[14,60,61]$. However, additional protein supplementation during limb immobilization does not seem to preserve the loss of skeletal muscle mass in healthy older subjects $[18,73]$. Though it has not been proven whether increasing habitual protein intake during short-term hospitalization can attenuate muscle loss, it has been well established that a decline in protein intake below habitual intake levels aggravates muscle loss during a period of bedrest or immobilization [3, 
$14,74,75]$. Therefore, nutritional interventions should focus on maintaining habitual protein intake levels in both the perioperative phase as well as during hospital stay.

Hospitalization is typically a period during which physical activity levels are reduced, and it has been shown that older patients spend $>80 \%$ of their hospital stay in bed $[25,26]$. Because muscle contraction directly stimulates muscle protein synthesis [2], increasing physical activity and/or introducing physical activity mimetics during hospitalization forms an important strategy to reduce muscle loss. In addition, as protein ingestion and exercise have a synergistic effect [2], physical activity (mimetics) should be combined with nutritional support in clinical practice to minimize muscle and strength loss in older and more clinically compromised patient groups.

\section{Conclusion}

We conclude that short-term hospitalization following elective THA leads to substantial muscle loss in older patients. Effective intervention strategies are warranted to prevent the loss of muscle mass induced by short periods of muscle disuse during hospitalization. 


\section{REFERENCES}

1. Abellan van Kan, G., Epidemiology and consequences of sarcopenia. J Nutr Health Aging, 2009. 13(8): p. 708-12.

2. Koopman, R. and L.J. van Loon, Aging, exercise, and muscle protein metabolism. Journal of applied physiology, 2009. 106(6): p. 2040-8.

3. English, K.L. and D. Paddon-Jones, Protecting muscle mass and function in older adults during bed rest. Curr Opin Clin Nutr Metab Care, 2010. 13(1): p. 34-9.

4. Wall, B.T., M.L. Dirks, and L.J. van Loon, Skeletal muscle atrophy during short-term disuse: implications for age-related sarcopenia. Ageing Res Rev, 2013. 12(4): p. 898-906.

5. Phillips, S.M., E.I. Glover, and M.J. Rennie, Alterations of protein turnover underlying disuse atrophy in human skeletal muscle. Journal of applied physiology, 2009. 107(3): p. 645-54.

6. Covinsky, K.E., R.M. Palmer, R.H. Fortinsky, S.R. Counsell, A.L. Stewart, D. Kresevic, C.J. Burant, and C.S. Landefeld, Loss of independence in activities of DAILY living in older adults hospitalized with medical illnesses: increased vulnerability with age. J Am Geriatr Soc, 2003. 51(4): p. 451-8.

7. Trombetti, A., K.F. Reid, M. Hars, F.R. Herrmann, E. Pasha, E.M. Phillips, and R.A. Fielding, Ageassociated declines in muscle mass, strength, power, and physical performance: impact on fear of falling and quality of life. Osteoporos Int, 2016. 27(2): p. 463-71.

8. Perez-Zepeda, M.U., A. Sgaravatti, and E. Dent, Sarcopenia and post-hospital outcomes in older adults: A longitudinal study. Arch Gerontol Geriatr, 2017. 69: p. 105-109.

9. Suetta, C., U. Frandsen, A.L. Mackey, L. Jensen, L.G. Hvid, M.L. Bayer, S.J. Petersson, H.D. Schroder, J.L. Andersen, P. Aagaard, P. Schjerling, and M. Kjaer, Ageing is associated with diminished muscle re-growth and myogenic precursor cell expansion early after immobility-induced atrophy in human skeletal muscle. J Physiol, 2013. 591(15): p. 3789-804.

10. Hvid, L., P. Aagaard, L. Justesen, M.L. Bayer, J.L. Andersen, N. Ortenblad, M. Kjaer, and C. Suetta, Effects of aging on muscle mechanical function and muscle fiber morphology during short-term immobilization and subsequent retraining. J Appl Physiol (1985), 2010. 109(6): p. 1628-34.

11. Pisot, R., U. Marusic, G. Biolo, S. Mazzucco, S. Lazzer, B. Grassi, C. Reggiani, L. Toniolo, P.E. di Prampero, A. Passaro, M. Narici, S. Mohammed, J. Rittweger, M. Gasparini, M. Gabrijelcic Blenkus, and B. Simunic, Greater loss in muscle mass and function but smaller metabolic alterations in older compared with younger men following 2 wk of bed rest and recovery. J Appl Physiol (1985), 2016. 120(8): p. 922-9.

12. Alley, D.E., A. Koster, D. Mackey, P. Cawthon, L. Ferrucci, E.M. Simonsick, B. Yu, S. Hardy, B. Goodpaster, C. Sarkisian, D.K. Houston, S.B. Kritchevsky, S. Cummings, J.S. Lee, F.A. Tylavsky, A. Newman, T. Harris, A. Health, and S. Body Composition, Hospitalization and change in body composition and strength in a population-based cohort of older persons. J Am Geriatr Soc, 2010. 58(11): p. 2085-91.

13. Gibson, J.N., D. Halliday, W.L. Morrison, P.J. Stoward, G.A. Hornsby, P.W. Watt, G. Murdoch, and M.J. Rennie, Decrease in human quadriceps muscle protein turnover consequent upon leg immobilization. Clin Sci (Lond), 1987. 72(4): p. 503-9.

14. Paddon-Jones, D., M. Sheffield-Moore, R.J. Urban, A.P. Sanford, A. Aarsland, R.R. Wolfe, and A.A. Ferrando, Essential amino acid and carbohydrate supplementation ameliorates muscle protein loss in humans during 28 days bedrest. J Clin Endocrinol Metab, 2004. 89(9): p. 4351-8.

15. Jones, S.W., R.J. Hill, P.A. Krasney, B. O'Conner, N. Peirce, and P.L. Greenhaff, Disuse atrophy and exercise rehabilitation in humans profoundly affects the expression of genes associated with the regulation of skeletal muscle mass. FASEB J, 2004. 18(9): p. 1025-7.

16. Ferrando, A.A., H.W. Lane, C.A. Stuart, J. Davis-Street, and R.R. Wolfe, Prolonged bed rest decreases skeletal muscle and whole body protein synthesis. Am J Physiol, 1996. 270(4 Pt 1): p. E627-33.

17. Wall, B.T., M.L. Dirks, T. Snijders, J.M. Senden, J. Dolmans, and L.J. van Loon, Substantial skeletal muscle loss occurs during only 5 days of disuse. Acta Physiol (Oxf), 2014. 210(3): p. 600-11. 
18. Dirks, M.L., B.T. Wall, R. Nilwik, D.H. Weerts, L.B. Verdijk, and L.J. van Loon, Skeletal muscle disuse atrophy is not attenuated by dietary protein supplementation in healthy older men. J Nutr, 2014. 144(8): p. 1196-203.

19. Dirks, M.L., B.T. Wall, T. Snijders, C.L. Ottenbros, L.B. Verdijk, and L.J. van Loon, Neuromuscular electrical stimulation prevents muscle disuse atrophy during leg immobilization in humans. Acta Physiol (Oxf), 2014. 210(3): p. 628-41.

20. Suetta, C., U. Frandsen, L. Jensen, M.M. Jensen, J.G. Jespersen, L.G. Hvid, M. Bayer, S.J. Petersson, H.D. Schroder, J.L. Andersen, K.M. Heinemeier, P. Aagaard, P. Schjerling, and M. Kjaer, Aging affects the transcriptional regulation of human skeletal muscle disuse atrophy. PLoS One, 2012. 7(12): p. e51238.

21. Tanner, R.E., L.B. Brunker, J. Agergaard, K.M. Barrows, R.A. Briggs, O.S. Kwon, L.M. Young, P.N. Hopkins, E. Volpi, R.L. Marcus, P.C. LaStayo, and M.J. Drummond, Age-related differences in lean mass, protein synthesis and skeletal muscle markers of proteolysis after bed rest and exercise rehabilitation. J Physiol, 2015. 593(18): p. 4259-73.

22. Hvid, L.G., C. Suetta, P. Aagaard, M. Kjaer, U. Frandsen, and N. Ortenblad, Four days of muscle disuse impairs single fiber contractile function in young and old healthy men. Exp Gerontol, 2013. 48(2): p. 154-61.

23. Agency for Healthcare Research and Quality, Healthcare Cost and Utilization Project (HCUP): Hospital Inpatient National Statistics, in Database. 2013. Available from: https://hcupnet.ahrq.gov/

24. European Union, Hospital discharges and length of stay statistics. 2016. Available from: http://ec.europa.eu/eurostat/statisticsexplained/index.php/Hospital_discharges_and_length_of_st ay_statistics\#Further_Eurostat_information

25. Fisher, S.R., J.S. Goodwin, E.J. Protas, Y.F. Kuo, J.E. Graham, K.J. Ottenbacher, and G.V. Ostir, Ambulatory activity of older adults hospitalized with acute medical illness. J Am Geriatr Soc, 2011. 59(1): p. 91-5.

26. Brown, C.J., D.T. Redden, K.L. Flood, and R.M. Allman, The underrecognized epidemic of low mobility during hospitalization of older adults. J Am Geriatr Soc, 2009. 57(9): p. 1660-5.

27. Welch, C. K.Z. Hassan-Smith, A.C. Greig, M.J. Lord, A.T. Jackson, Acute Sarcopenia Secondary to Hospitalisation - An Emerging Condition Affecting Older Adults. Aging Dis, 2018. 9(1): p. 151-164.

28. Kortebein, P., Rehabilitation for hospital-associated deconditioning. Am J Phys Med Rehabil, 2009. 88(1): p. 66-77.

29. Van Ancum, J.M., K. Scheerman, N.H. Jonkman, H.E. Smeenk, R.C. Kruizinga, C.G.M. Meskers, and A.B. Maier, Change in muscle strength and muscle mass in older hospitalized patients: A systematic review and meta-analysis. Exp Gerontol, 2017. 92: p. 34-41.

30. Puthucheary, Z.A., J. Rawal, M. McPhail, B. Connolly, G. Ratnayake, P. Chan, N.S. Hopkinson, R. Phadke, T. Dew, P.S. Sidhu, C. Velloso, J. Seymour, C.C. Agley, A. Selby, M. Limb, L.M. Edwards, K. Smith, A. Rowlerson, M.J. Rennie, J. Moxham, S.D. Harridge, N. Hart, and H.E. Montgomery, Acute skeletal muscle wasting in critical illness. JAMA, 2013. 310(15): p. 1591-600.

31. Houborg, K.B., M.B. Jensen, I. Hessov, and S. Laurberg, Little effect of physical training on body composition and nutritional intake following colorectal surgery--a randomised placebocontrolled trial. Eur J Clin Nutr, 2005. 59(8): p. 969-77.

32. Huang, D.D., Y.B. Ji, D.L. Zhou, B. Li, S.L. Wang, X.L. Chen, Z. Yu, and C.L. Zhuang, Effect of surgeryinduced acute muscle wasting on postoperative outcomes and quality of life. J Surg Res, 2017. 218: p. 58-66.

33. Chae, M.S., K.U. Moon, J.Y. Jung, H.J. Choi, H.S. Chung, C.S. Park, J. Lee, J.H. Choi, and S.H. Hong, Perioperative loss of psoas muscle is associated with patient survival in living donor liver transplantation. Liver Transpl, 2018. 24(5): p. 623-633.

34. Parry, S.M., D. El-Ansary, M.S. Cartwright, A. Sarwal, S. Berney, R. Koopman, R. Annoni, Z. Puthucheary, I.R. Gordon, P.E. Morris, and L. Denehy, Ultrasonography in the intensive care setting can be used to detect changes in the quality and quantity of muscle and is related to muscle strength and function. J Crit Care, 2015. 30(5): p. 1151 e9-14. 
35. Van Ancum, J.M., K. Scheerman, V.D. Pierik, S.T. Numans, S. Verlaan, H.E. Smeenk, M. Slee-Valentijn, R.C. Kruizinga, C.G.M. Meskers, and A.B. Maier, Muscle Strength and Muscle Mass in Older Patients during Hospitalization: The EMPOWER Study. Gerontology, 2017. 63(6): p. 507-514.

36. Ethgen, O., O. Bruyere, F. Richy, C. Dardennes, and J.Y. Reginster, Health-related quality of life in total hip and total knee arthroplasty. A qualitative and systematic review of the literature. J Bone Joint Surg Am, 2004. 86-A(5): p. 963-74.

37. Learmonth, I.D., C. Young, and C. Rorabeck, The operation of the century: total hip replacement. Lancet, 2007. 370(9597): p. 1508-19.

38. Rasch, A., A.H. Bystrom, N. Dalen, N. Martinez-Carranza, and H.E. Berg, Persisting muscle atrophy two years after replacement of the hip. J Bone Joint Surg Br, 2009. 91(5): p. 583-8.

39. Reardon, K., M. Galea, X. Dennett, P. Choong, and E. Byrne, Quadriceps muscle wasting persists 5 months after total hip arthroplasty for osteoarthritis of the hip: a pilot study. Intern Med J, 2001. 31(1): p. 7-14.

40. Suetta, C., S.P. Magnusson, A. Rosted, P. Aagaard, A.K. Jakobsen, L.H. Larsen, B. Duus, and M. Kjaer, Resistance training in the early postoperative phase reduces hospitalization and leads to muscle hypertrophy in elderly hip surgery patients--a controlled, randomized study. J Am Geriatr Soc, 2004. 52(12): p. 2016-22.

41. Rasch, A., N. Dalen, and H.E. Berg, Muscle strength, gait, and balance in 20 patients with hip osteoarthritis followed for 2 years after THA. Acta Orthop, 2010. 81(2): p. 183-8.

42. Sicard-Rosenbaum, L., K.E. Light, and A.L. Behrman, Gait, lower extremity strength, and selfassessed mobility after hip arthroplasty. J Gerontol A Biol Sci Med Sci, 2002. 57(1): p. M47-51.

43. Dechartres, A., I. Boutron, R. Nizard, S. Poiraudeau, C. Roy, J.F. Ravaud, and P. Ravaud, Evolution of disability in adults with hip arthroplasty: a national longitudinal study. Arthritis Rheum, 2007. 57(3): p. 364-71.

44. Pivec, R., A.J. Johnson, S.C. Mears, and M.A. Mont, Hip arthroplasty. Lancet, 2012. 380(9855): p. 1768-77.

45. Aubrey, J., N. Esfandiari, V.E. Baracos, F.A. Buteau, J. Frenette, C.T. Putman, and V.C. Mazurak, Measurement of skeletal muscle radiation attenuation and basis of its biological variation. Acta Physiol (Oxf), 2014. 210(3): p. 489-97.

46. Goodpaster, B.H., D.E. Kelley, F.L. Thaete, J. He, and R. Ross, Skeletal muscle attenuation determined by computed tomography is associated with skeletal muscle lipid content. J Appl Physiol (1985), 2000. 89(1): p. 104-10.

47. Strandberg, S., M.L. Wretling, T. Wredmark, and A. Shalabi, Reliability of computed tomography measurements in assessment of thigh muscle cross-sectional area and attenuation. BMC Med Imaging, 2010. 10: p. 18.

48. Jones, P.R. and J. Pearson, Anthropometric determination of leg fat and muscle plus bone volumes in young male and female adults. The Journal of physiology, 1969. 204(2): p. 63P-66P.

49. Ware, J.E., Jr. and C.D. Sherbourne, The MOS 36-item short-form health survey (SF-36). I. Conceptual framework and item selection. Med Care, 1992. 30(6): p. 473-83.

50. Svege, I., E. Kolle, and M.A. Risberg, Reliability and validity of the Physical Activity Scale for the Elderly (PASE) in patients with hip osteoarthritis. BMC Musculoskelet Disord, 2012. 13: p. 26.

51. Washburn, R.A., K.W. Smith, A.M. Jette, and C.A. Janney, The Physical Activity Scale for the Elderly (PASE): development and evaluation. J Clin Epidemiol, 1993. 46(2): p. 153-62.

52. Vellas, B., Y. Guigoz, P.J. Garry, F. Nourhashemi, D. Bennahum, S. Lauque, and J.L. Albarede, The Mini Nutritional Assessment (MNA) and its use in grading the nutritional state of elderly patients. Nutrition, 1999. 15(2): p. 116-22.

53. Stratton, R.J., A. Hackston, D. Longmore, R. Dixon, S. Price, M. Stroud, C. King, and M. Elia, Malnutrition in hospital outpatients and inpatients: prevalence, concurrent validity and ease of use of the 'malnutrition universal screening tool' ('MUST') for adults. Br J Nutr, 2004. 92(5): p. 799808. 
54. Folstein, M.F., S.E. Folstein, and P.R. McHugh, "Mini-mental state". A practical method for grading the cognitive state of patients for the clinician. J Psychiatr Res, 1975. 12(3): p. 189-98.

55. Bergstrom, J., Percutaneous needle biopsy of skeletal muscle in physiological and clinical research. Scand J Clin Lab Invest, 1975. 35(7): p. 609-16.

56. Verdijk, L.B., B.G. Gleeson, R.A. Jonkers, K. Meijer, H.H. Savelberg, P. Dendale, and L.J. van Loon, Skeletal muscle hypertrophy following resistance training is accompanied by a fiber type-specific increase in satellite cell content in elderly men. J Gerontol A Biol Sci Med Sci, 2009. 64(3):p.332-9.

57. Wall, B.T., M.L. Dirks, T. Snijders, J.W. van Dijk, M. Fritsch, L.B. Verdijk, and L.J. van Loon, Short-term muscle disuse lowers myofibrillar protein synthesis rates and induces anabolic resistance to protein ingestion. Am J Physiol Endocrinol Metab, 2016. 310(2): p. E137-47.

58. Biolo, G., R. Pisot, S. Mazzucco, F.G. Di Girolamo, R. Situlin, S. Lazzer, B. Grassi, C. Reggiani, A. Passaro, J. Rittweger, M. Gasparini, B. Simunic, and M. Narici, Anabolic resistance assessed by oral stable isotope ingestion following bed rest in young and older adult volunteers: Relationships with changes in muscle mass. Clin Nutr, 2017. 36(5): p. 1420-1426.

59. Kortebein, P., A. Ferrando, J. Lombeida, R. Wolfe, and W.J. Evans, Effect of 10 days of bed rest on skeletal muscle in healthy older adults. JAMA, 2007. 297(16): p. 1772-4.

60. English, K.L., J.A. Mettler, J.B. Ellison, M.M. Mamerow, E. Arentson-Lantz, J.M. Pattarini, R. PloutzSnyder, M. Sheffield-Moore, and D. Paddon-Jones, Leucine partially protects muscle mass and function during bed rest in middle-aged adults. Am J Clin Nutr, 2016. 103(2): p. 465-73.

61. Deutz, N.E., S.L. Pereira, N.P. Hays, J.S. Oliver, N.K. Edens, C.M. Evans, and R.R. Wolfe, Effect of betahydroxy-beta-methylbutyrate (HMB) on lean body mass during 10 days of bed rest in older adults. Clin Nutr, 2013. 32(5): p. 704-12.

62. Dirks, M.L., B.T. Wall, B. van de Valk, T.M. Holloway, G.P. Holloway, A. Chabowski, G.H. Goossens, and L.J. van Loon, One Week of Bed Rest Leads to Substantial Muscle Atrophy and Induces WholeBody Insulin Resistance in the Absence of Skeletal Muscle Lipid Accumulation. Diabetes, 2016. 65(10): p. 2862-75.

63. Healthcare Cost and Utilization Project (HCUP), A.f.H.R.a.Q., Mobility/Orthopedic Procedures 2003-2012 Report 2012-03. 2012.

64. Goodpaster, B.H., D.E. Kelley, F.L. Thaete, J. He, and R. Ross, Skeletal muscle attenuation determined by computed tomography is associated with skeletal muscle lipid content. Journal of applied physiology, 2000. 89(1): p. 104-10.

65. Nilwik, R., T. Snijders, M. Leenders, B.B. Groen, J. van Kranenburg, L.B. Verdijk, and L.J. van Loon, The decline in skeletal muscle mass with aging is mainly attributed to a reduction in type II muscle fiber size. Exp Gerontol, 2013. 48(5): p. 492-8.

66. Verdijk, L.B., T. Snijders, M. Beelen, H.H. Savelberg, K. Meijer, H. Kuipers, and L.J. Van Loon, Characteristics of muscle fiber type are predictive of skeletal muscle mass and strength in elderly men. J Am Geriatr Soc, 2010. 58(11): p. 2069-75.

67. Leenders, M., L.B. Verdijk, L. van der Hoeven, J.J. Adam, J. van Kranenburg, R. Nilwik, and L.J. van Loon, Patients with type 2 diabetes show a greater decline in muscle mass, muscle strength, and functional capacity with aging. J Am Med Dir Assoc, 2013. 14(8): p. 585-92.

68. Kramer, I.F., T. Snijders, J.S.J. Smeets, M. Leenders, J. van Kranenburg, M. den Hoed, L.B. Verdijk, M. Poeze, and L.J.C. van Loon, Extensive Type II Muscle Fiber Atrophy in Elderly Female Hip Fracture Patients. J Gerontol A Biol Sci Med Sci, 2017. 72(10): p. 1369-1375.

69. Dirks, M.L., D. Hansen, A. Van Assche, P. Dendale, and L.J. Van Loon, Neuromuscular electrical stimulation prevents muscle wasting in critically ill comatose patients. Clin Sci (Lond), 2015. 128(6): p. 357-65.

70. Deutz, N.E., J.M. Bauer, R. Barazzoni, G. Biolo, Y. Boirie, A. Bosy-Westphal, T. Cederholm, A. CruzJentoft, Z. Krznaric, K.S. Nair, P. Singer, D. Teta, K. Tipton, and P.C. Calder, Protein intake and exercise for optimal muscle function with aging: recommendations from the ESPEN Expert Group. Clin Nutr, 2014. 33(6): p. 929-36. 
71. Bauer, J.M., S. Verlaan, I. Bautmans, K. Brandt, L.M. Donini, M. Maggio, M.E. McMurdo, T. Mets, C. Seal, S.L. Wijers, G.P. Ceda, G. De Vito, G. Donders, M. Drey, C. Greig, U. Holmback, M. Narici, J. McPhee, E. Poggiogalle, D. Power, A. Scafoglieri, R. Schultz, C.C. Sieber, and T. Cederholm, Effects of a vitamin $D$ and leucine-enriched whey protein nutritional supplement on measures of sarcopenia in older adults, the PROVIDE study: a randomized, double-blind, placebo-controlled trial. J Am Med Dir Assoc, 2015. 16(9): p. 740-7.

72. Norton, C., C. Toomey, W.G. McCormack, P. Francis, J. Saunders, E. Kerin, and P. Jakeman, Protein Supplementation at Breakfast and Lunch for 24 Weeks beyond Habitual Intakes Increases WholeBody Lean Tissue Mass in Healthy Older Adults. J Nutr, 2016. 146(1): p. 65-9.

73. Mitchell, C.J., R.F. D'Souza, S.M. Mitchell, V.C. Figueiredo, B.F. Miller, K.L. Hamilton, F.F. Peelor, 3rd, M. Coronet, C.A. Pileggi, B. Durainayagam, A.C. Fanning, S.D. Poppitt, and D. Cameron-Smith, Impact of dairy protein during limb immobilization and recovery on muscle size and protein synthesis; a randomized controlled trial. J Appl Physiol (1985), 2018. 124(3): p. 717-728.

74. Wall, B.T. and L.J. van Loon, Nutritional strategies to attenuate muscle disuse atrophy. Nutrition Reviews, 2012.

75. Ferrando, A.A., D. Paddon-Jones, N.P. Hays, P. Kortebein, O. Ronsen, R.H. Williams, A. McComb, T.B. Symons, R.R. Wolfe, and W. Evans, EAA supplementation to increase nitrogen intake improves muscle function during bed rest in the elderly. Clin Nutr, 2010. 29(1): p. 18-23. 


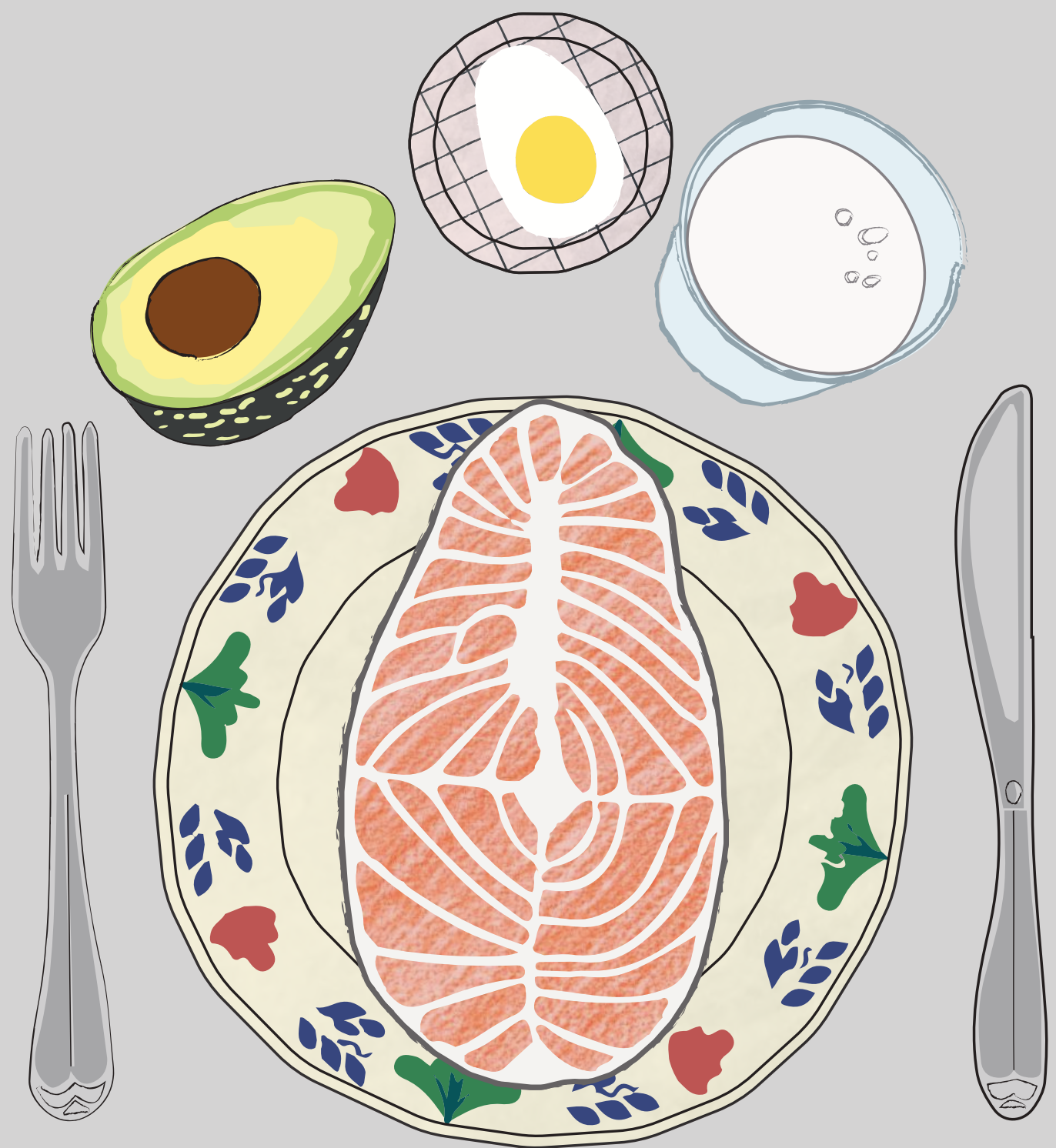




\section{CHAPTER THRE}

\section{PROTEIN INTAKE FALLS BELOW 0.6 G/KG/D IN HEALTHY, OLDER PATIENTS ADMITTED FOR ELECTIVE HIP OR KNEE ARTHROPLASTY}

Imre W.K. Kouw*, Michelle E.G. Weijzen*, Albert A.J. Verschuren, Roger Muyters, Jan A. Geurts, Pieter J. Emans, Phil Geerlings, Lex B. Verdijk, and Luc J.C. van Loon

*Contributed equally to the work 


\section{ABSTRACT}

Background: Hospitalization is generally accompanied by changes in food intake. Patients typically receive hospital meals upon personal preference within the framework of the food administration services of the hospital.

Aim: In the present study, we assessed food provision and actual food and snack consumption in older patients admitted for elective hip or knee arthroplasty.

Methods: In the present study $n=101$ patients (age: $67 \pm 10$ y; hospital stay: $6.1 \pm 1.8 \mathrm{~d}$ ) were monitored during hospitalization following elective hip or knee arthroplasty. Food provided by self-selected hospital meals and snacks, and actual food consumed by patients was weighed and recorded throughout 1-6 days. Nutritional values of food products were calculated using product specifications.

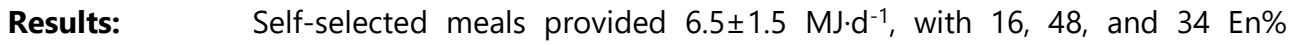
provided as protein, carbohydrate, and fat, respectively. Self-selected hospital meals provided $0.75 \pm 0.16$ and $0.79 \pm 0.21 \mathrm{~g} \cdot \mathrm{kg}^{-1} \cdot \mathrm{d}^{-1}$ protein in males and females, respectively. Actual protein consumption averaged merely $0.59 \pm 0.18$ and $0.50 \pm 0.21 \mathrm{~g} \mathrm{~kg}^{-1} \cdot \mathrm{d}^{-1}$, respectively. Protein consumption at breakfast, lunch, and dinner averaged $16 \pm 8,18 \pm 9$, and $20 \pm 6 \mathrm{~g}$ per meal, respectively.

Conclusions: Though self-selected hospital meals provide patients with $\sim 0.8 \mathrm{~g} \cdot \mathrm{kg}^{-1} \cdot \mathrm{d}^{-1}$ protein during short-term hospitalization, actual protein consumption falls well below $0.6 \mathrm{~g} \cdot \mathrm{kg}^{-1} \cdot \mathrm{d}^{-1}$ with a large proportion ( 32\%) of the provided food being discarded. Alternative strategies are required to ensure maintenance of habitual protein intake in older patients admitted for elective orthopedic surgery. 


\section{INTRODUCTION}

Hospitalization in older adults is accompanied by substantial changes in food intake. At present, the hospitalization duration in older patients is 5 days or longer [1,2]. During such a short period of hospitalization, food intake is generally reduced due to periods of fasting, adverse effects of medication, strict timing of food provision, reduced appetite, and/or pain and discomfort [3-5]. Such a reduced food intake throughout the hospitalization period often results in a negative energy and/or protein balance. Low levels of energy and protein intake, also referred to as protein-energy malnutrition, result in accelerated loss of lean body mass, muscle strength, and impairments in functional capacity [6-8]. Moreover, malnutrition during hospitalization has been shown to increase the length of hospital stay, the risk for infections, the incidence of hospital readmissions, and mortality rates [9-12].

The negative health consequences of malnutrition are at least partly attributed to the concomitant loss of skeletal muscle mass and strength. Several studies from our group, as well as others, have shown significant declines in muscle mass and strength during short periods of immobilization [13-18] and hospitalization [19]. It has been well-established that the loss of muscle tissue is accelerated when energy balance remains negative [20]. Apart from the negative effects of physical inactivity, the loss of muscle mass observed during hospitalization may be particularly attributed to an insufficient protein intake as a direct consequence of the lower energy intake. The current recommended dietary intake for protein has been set at 0.8 $\mathrm{g} \cdot \mathrm{kg}^{-1} \cdot \mathrm{d}^{-1}$ for healthy adults of all ages. In the general population, older community-dwelling individuals consume well above $\left(\sim 1.0 \mathrm{~g} \cdot \mathrm{kg}^{-1} \cdot \mathrm{d}^{-1}\right)$ these recommended protein intake levels [6, 21-23]. Recently updated guidelines suggest a protein intake of $1.2-1.5 \mathrm{~g} \cdot \mathrm{kg}^{-1} \cdot \mathrm{d}^{-1}$ for older individuals suffering from acute or chronic diseases in order to maintain muscle mass during hospitalization [24, 25]. Minimal requirements during hospitalization should be aimed at achieving energy balance and maintaining habitual protein intake. Currently, patients typically receive hospital meals upon personal request within the framework of the food administration services of the hospital. However, it is unknown whether these self-selected hospital meals provide sufficient energy and/or protein.

Whereas several studies have assessed energy and/or protein provision in patients during hospitalization [3, 9, 26-32], only few studies have measured the actual amount of energy and protein consumed by patients [4,33-37]. In addition, snack consumption between meals is generally not reported. Recent studies show that less than $30 \%$ of the older hospitalized patients reach a protein intake of $1.2 \mathrm{~g} \cdot \mathrm{kg}^{-1} \cdot \mathrm{d}^{-1}[35,38]$. Moreover, protein intake has been shown to be well below these increased recommendation levels for at least one day in older patients during hospitalization $[35,37]$. There is no data available on actual energy and protein intake during the entire hospitalization period in older patients. In addition, a clear quantification on the protein consumption pattern in hospitalized patients such as the protein amount per meal, protein distribution, and protein sources has not been reported. We 
hypothesized that older patients during several days of hospitalization consume well below the recommended protein intake level of $1.2-1.5 \mathrm{~g} \cdot \mathrm{kg}^{-1} \cdot \mathrm{d}^{-1}$.

In the present study we assessed food provision as well as actual food and snack consumption in older patients $(n=101)$ during short-term hospitalization following elective total hip or knee arthroplasty. We quantified the amount, distribution, and source of protein in selfselected hospital meals consumed at breakfast, lunch, dinner, and snacks during several days of hospitalization. 


\section{METHODS}

\section{Study design}

This observational study assessed the nutritional content of self-selected hospital meals, and measured actual food and snack consumption in all patients undergoing elective hip or knee arthroplasty between April 2016 and August 2016. Patients were screened for malnutrition using the Malnutrition Universal Screening Tool (MUST) [39] upon arrival on the nursing ward as part of standard admission procedures (all included patients had a MUST $=0$ score upon hospital admission). Information concerning the project was given orally and patients gave consent to collect their food trays after meal consumption. Age, BMI, type of anesthesia used during surgery, and length of stay (LOS) were recorded. There was no extra burden on the patient during hospitalization. There were no exclusion criteria. The study was registered as NTR5942 (www.trialregister.nl).

\section{Provision of hospital meals}

Hospital meals were provided at three strict timeslots every day; at breakfast, lunch, and dinner. In between the main meals, patients were provided with hot and/or cold drinks 3 times a day. There was mealtime assistance during the provision of all meals. Patients selected their meals upon request the day before and could indicate different portion sizes of 0.5 , 1 , or 2 portion(s). During the first day after surgery, when patients were not able to select their meals due to the time spent at the surgery room, they received standard hospital meals.

\section{Consumption of hospital meals}

On the serving tray, patients received a description of their ordered menu, which was collected for the study. When patients were finished eating, the serving tray was taken and all leftovers were weighed using a scale (Exacta Pure, Soehnle) and reported. This was done for breakfast, lunch, and dinner. To assess snack consumption, patients were asked to fill in a daily snack list during hospitalization that was collected daily. If patients were not able to complete the snack list, the researcher recalled their snack consumption in between meals and reported this. During the entire assessment period the researcher was present at the ward. 


\section{Nutritional content of hospital meals}

Total energy (MJ), protein ( $g$ and En\%), carbohydrate ( $g$ and En\%), and fat ( $g$ and En\%) were calculated for all provided and consumed food based upon product specifications provided by the food suppliers and the Dutch Food Consumption Database 2016 (NEVO; RIVM, Bilthoven, the Netherlands) [40]. The contribution of animal- and plant-based sources to dietary protein intake was determined and expressed as a percentage of total protein intake for all meals. In addition, food products were divided in five categories: "meat and fish", "dairy products and eggs", "bread, cereal, and potatoes", "fruits, vegetables, and legumes", and "other plant sources". Food intake was recorded from the day of hospital admission (day 0) until the day of hospital discharge (day 2-6). Data on food intake on the day of hospital admission and discharge was not included, since these days did not include all main meals. The reported intake was calculated in $n=101$ patients from the day of surgery (day 1 ) until day 2, in $n=98$ until day 3, in $n=52$ until day 4 , and in $n=17$ until day 5. To determine patients' nutritional needs, energy requirements were calculated based upon resting energy expenditure using the Harris and Benedict equation [41]. A Physical Activity Level (PAL) of 1.3 for patients "not restricted to bed" and an Injury Factor (IF) of 1.2 for "minor operation" was used, resulting in a correction factor of 1.56 to estimate (minimal) energy requirements [42]. During hospital stay patients were encouraged to mobilize as soon as possible and received physiotherapy training for 30 min daily, from day 2 onwards.

\section{Statistical analysis}

All data was checked for normality and was normal distributed, except for energy and protein consumption on day of surgery (day 1 ). Data are expressed as mean \pm SD (for consistency; both normal and non-normal distributed data). Differences between provided and consumed food intake were analyzed using a paired Students t-test. Energy and protein intake during hospitalization and between main meals were analyzed using repeated measures ANOVA with time as within-group factor (either days or meals) and gender as between-group factor. Analyses for energy and protein intake were performed for patients hospitalized until day 3 (Figure 1 and 2) and analyses for protein intake distribution were performed excluding snack consumption (Figure 3). In case of a significant interaction between time and gender, separate analyses were performed to determine time-effects for males and females (one-factor repeated measures ANOVA) with a Bonferroni post-hoc test to locate these differences and between-group effects for each time-point (Students t-test). Statistical significance was set at $P<0.05$. All calculations were performed using the statistical software program SPSS (version 24.0, IBM Corp., Armonk, USA). 


\section{RESULTS}

\section{Patients' characteristics}

In total, 101 older patients were monitored (males/females: 37/64; age: $67 \pm 10$ y; hospital stay: $6.1 \pm 1.8 \mathrm{~d}$ ) during hospitalization following elective hip or knee arthroplasty. Patients' characteristics are presented in Table 1. Estimated resting metabolic rate averaged $7.15 \pm 0.74$ $\mathrm{MJ} \cdot \mathrm{d}^{-1}$ in males and $5.81 \pm 0.87 \mathrm{MJ} \cdot \mathrm{d}^{-1}$ in females. The estimated (minimal) energy requirements

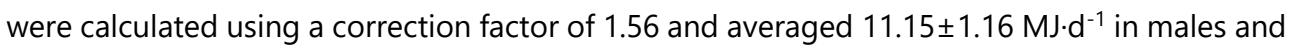
$9.06 \pm 1.35 \mathrm{MJ} \cdot \mathrm{d}^{-1}$ in females.

Table 1 | Patients' characteristics.

\begin{tabular}{lccc}
\hline & $\begin{array}{c}\text { All patients } \\
(n=101)\end{array}$ & $\begin{array}{c}\text { Males } \\
(n=37)\end{array}$ & $\begin{array}{c}\text { Females } \\
(n=64)\end{array}$ \\
\hline Age $(\mathbf{y})$ & $67 \pm 10$ & $66 \pm 8$ & $68 \pm 10$ \\
Body weight $(\mathbf{k g})$ & $81.1 \pm 16.9$ & $86.3 \pm 11.0$ & $78.1 \pm 18.9^{*}$ \\
Height $(\mathbf{m})$ & $1.69 \pm 0.09$ & $1.75 \pm 0.07$ & $1.65 \pm 0.08^{*}$ \\
BMI $\left(\mathbf{k g} \cdot \mathbf{m}^{-\mathbf{2}}\right)$ & $28.4 \pm 5.0$ & $28.3 \pm 3.6$ & $28.5 \pm 5.7$ \\
Length of stay (d) & $6.1 \pm 1.8$ & $6.1 \pm 1.8$ & $6.1 \pm 1.9$ \\
Resting metabolic rate $\left(\mathbf{M J}^{*} \mathbf{d}^{-\mathbf{1}}\right)$ & $6.30 \pm 1.04$ & $7.15 \pm 0.74$ & $5.81 \pm 0.87^{*}$ \\
General anesthesia $(\boldsymbol{n})$ & $68(67 \%)$ & $25(68 \%)$ & $43(67 \%)$ \\
Spinal anesthesia $(\boldsymbol{n})$ & $33(33 \%)$ & $12(32 \%)$ & $21(33 \%)$ \\
THA $(\boldsymbol{n}$ and \%) & $57(56 \%)$ & $19(51 \%)$ & $25(39 \%)$ \\
TKA $(\boldsymbol{n}$ and \%) & $44(44 \%)$ & $18(49 \%)$ & $39(61 \%)$ \\
\hline
\end{tabular}

Values are mean \pm SD. BMI: body mass index, THA: total hip arthroplasty, TKA: total knee arthroplasty. Resting metabolic rate was calculated based upon gender, body weight, height and age, using the adjusted Harris and Benedict equation. Data were analyzed by a Students t-test. * Indicates a significant difference between males and females, $P<0.05$. 


\section{Energy provision and consumption}

Energy provision and consumption $\left(\mathrm{MJ}^{\mathrm{J}} \mathrm{d}^{-1}\right)$ from self-selected hospital meals during hospitalization are presented in Figure 1. Hospital meals provided $6.90 \pm 1.78 \mathrm{MJ} \cdot \mathrm{d}^{-1}$ in males

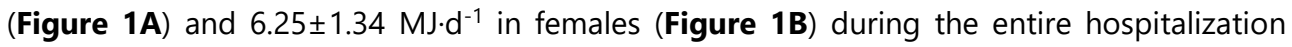
period, while energy consumption averaged $5.29 \pm 1.77$ and $3.96 \pm 1.39 \mathrm{MJ}^{\mathrm{J}} \mathrm{d}^{-1}$, respectively. On average, $32 \pm 17 \%$ of the provided food (i.e. energy content) was not consumed $(P<0.001)$. For energy intake, a significant time $x$ gender interaction was observed $(P<0.001)$. For both males

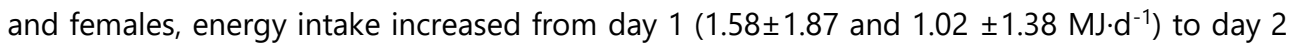
$\left(6.45 \pm 2.66\right.$ and $\left.4.60 \pm 2.00 \mathrm{MJ} \cdot \mathrm{d}^{-1} ; P<0.001\right)$, with a further increase observed to day 3

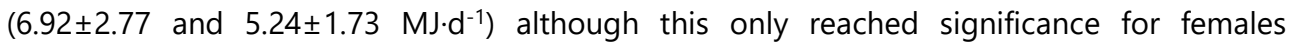
$(P=0.001)$. Energy consumption was lower in females when compared with males on day 2 and 3 of hospitalization (both $P<0.001)$ and tended to be lower in females on day $1(P=0.084)$. Total macronutrient consumption ( $\mathrm{g}$ and En\%) in males and females are presented in Table 2.

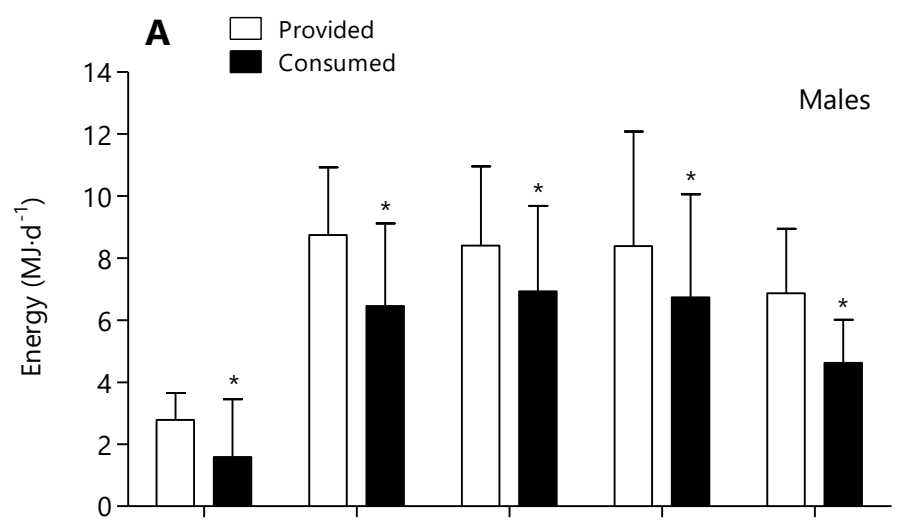

B

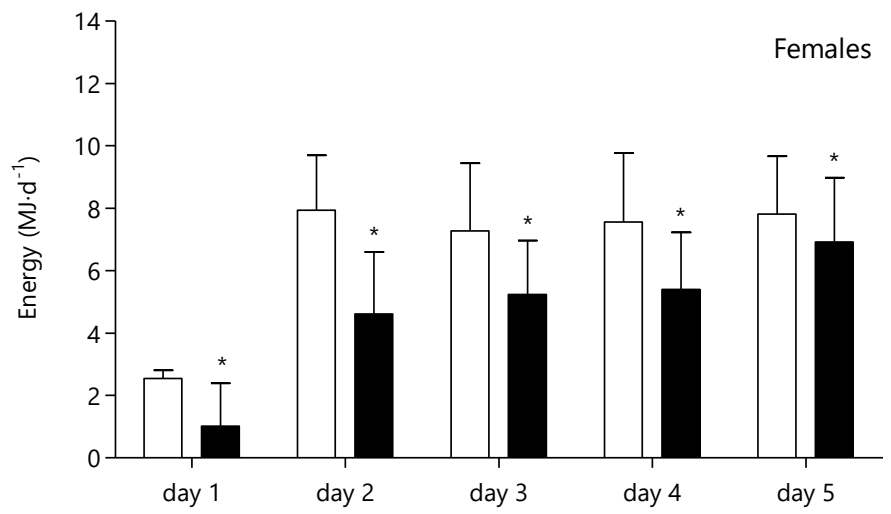

Figure 1 | Mean $( \pm S D)$ energy provision and consumption $\left(\mathrm{MJ}^{\left.-\mathrm{d}^{-1}\right)}\right.$ during short-term hospitalization in older, hospitalized males (A) and females (B). Food intake was calculated in $n=101$ (M/F: 37/64) patients until day 2, in $n=98$ (M/F 36/62) until day 3 , in $n=52$ (M/F: 17/35) until day 4, and in $n=17$ (M/F: 6/11) until day 5 . * Indicates a significant difference when compared with provided food, $P<0.001$. 


\section{Protein provision and consumption}

Protein provision and consumption $\left(\mathrm{g} \cdot \mathrm{kg}^{-1} \cdot \mathrm{d}^{-1}\right)$ from self-selected hospital meals during hospitalization are presented in Figure 2. Self-selected hospital meals provided $0.75 \pm 0.16$ $\mathrm{g} \cdot \mathrm{kg}^{-1} \cdot \mathrm{d}^{-1}$ in males (Figure 2A) and $0.79 \pm 0.21 \mathrm{~g} \cdot \mathrm{kg}^{-1} \cdot \mathrm{d}^{-1}$ in females (Figure 2B) during hospitalization, while actual protein consumption averaged merely $0.59 \pm 0.18$ and $0.50 \pm 0.21$ $\mathrm{g} \cdot \mathrm{kg}^{-1} \cdot \mathrm{d}^{-1}$, respectively. The consumed amount of protein was $32 \pm 19 \%$ lower than the provided amount of protein at all days of hospitalization $(P<0.001)$. Protein intake levels increased during hospitalization to a similar extent in males and females (time $x$ gender interaction effect, $P=0.306$, main time effect, $P<0.001)$, with lower protein intakes on the day of surgery (day 1 ) when compared with day 2 and day $3(P<0.001)$, and on day 2 when compared with day $3(P=0.007)$. Protein intake during hospitalization was overall lower in females when compared with males (main gender effect, $P=0.028$ ).
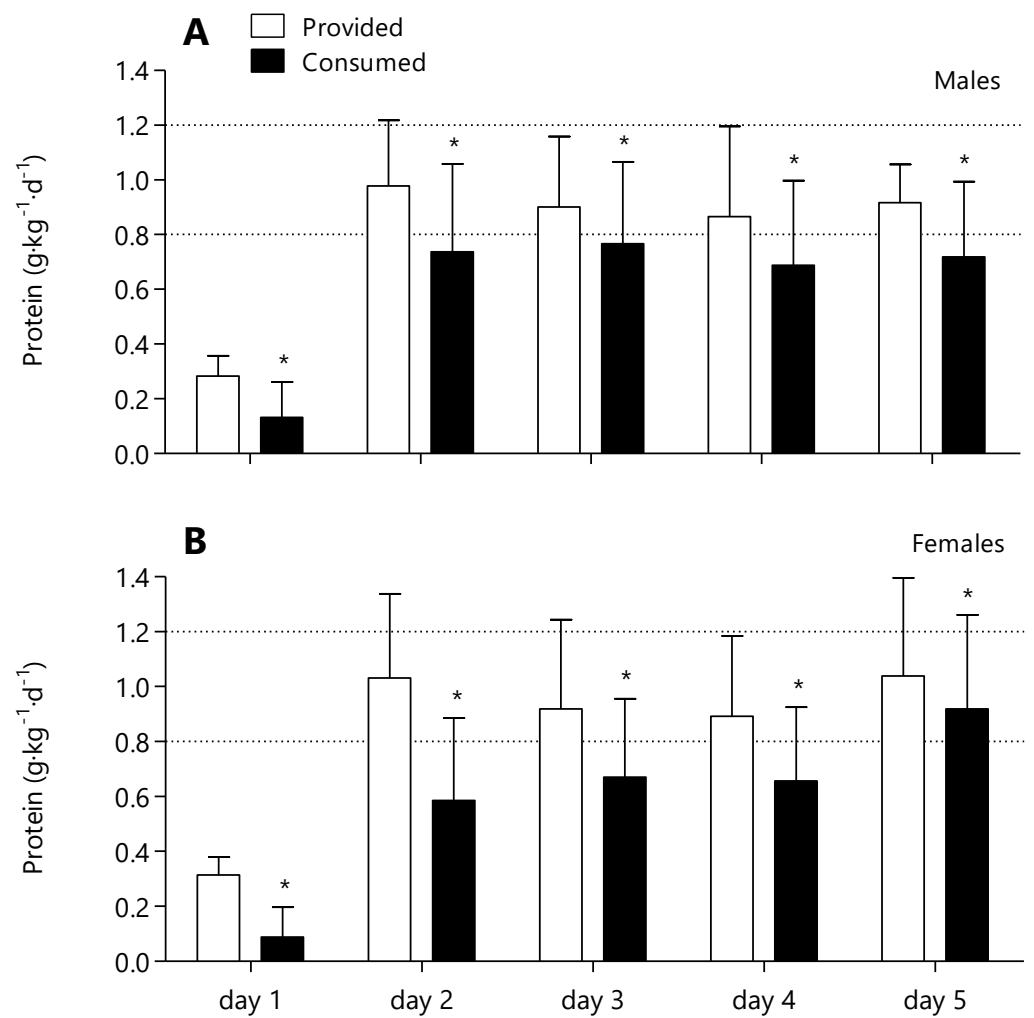

Figure $2 \mid$ Mean $( \pm S D)$ protein provision and consumption $\left(\mathrm{g} \cdot \mathrm{kg}^{-1} \cdot \mathrm{d}^{-1}\right)$ during short-term hospitalization in older, hospitalized males (A) and females (B). Food intake was calculated in $n=101$ (M/F: 37/64) patients until day 2, in $n=98$ (M/F 36/62) until day 3, in $n=52$ (M/F: 17/35) until day 4, and in $n=17$ (M/F: 6/11) until day 5. The dotted lines represent the recommended dietary intake of $0.8 \mathrm{~g} \cdot \mathrm{kg}^{-1} \cdot \mathrm{d}^{-1}$ and the recommended protein intake of $1.2 \mathrm{~g}$. $\mathrm{kg}^{-1} \cdot \mathrm{d}^{-1}$ suggested for older, hospitalized individuals. ${ }^{*}$ Indicates a significant difference when compared with provided food, $P<0.001$. 


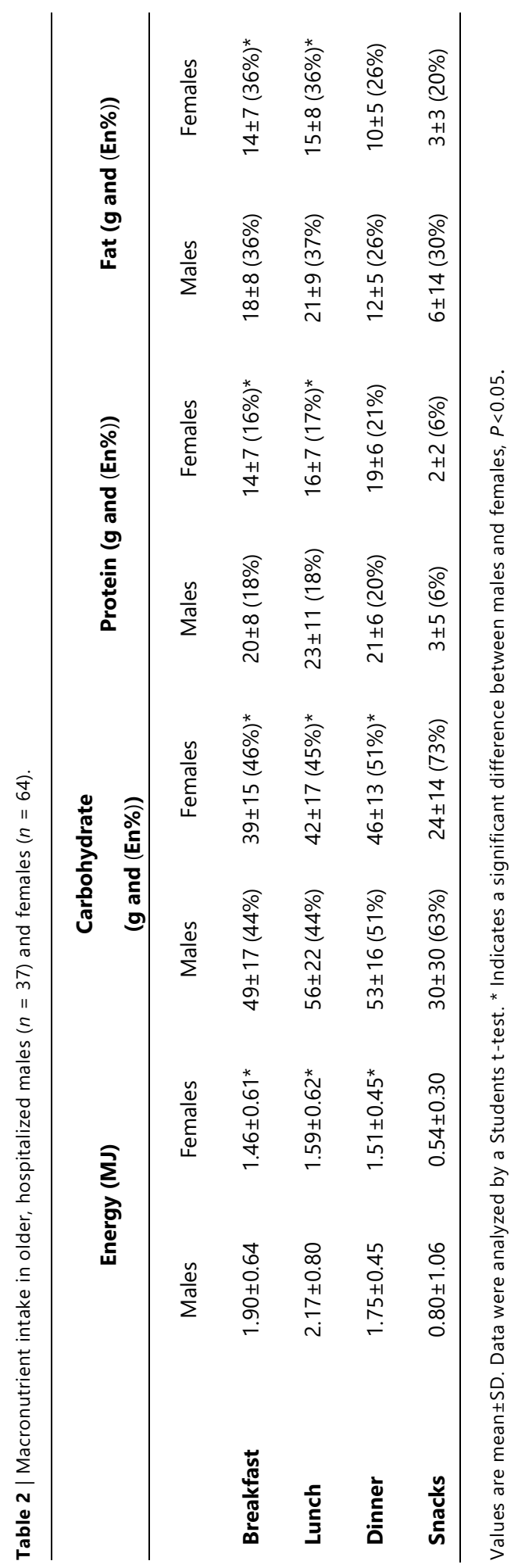




\section{Protein intake per meal}

Distribution of protein provision and consumption $(\mathrm{g})$ across main meals is presented in Figure 3. Absolute protein intake across main meals is shown in Table 2. Self-selected hospital meals provided $26 \pm 8,28 \pm 10$, and $23 \pm 4 \mathrm{~g}$ protein in males, and $23 \pm 7,23 \pm 6$, and $24 \pm 4 \mathrm{~g}$ protein in females at breakfast, lunch, and dinner, respectively. Protein consumption was $32 \pm 23 \%$ lower than protein provision at breakfast $(P<0.001), 27 \pm 23 \%$ at lunch $(P<0.001)$, and $17 \pm 18 \%$ at dinner $(P<0.001)$. A significant time $x$ gender interaction effect was observed for protein intake distribution during hospitalization $(P<0.001)$. Protein intake in males averaged $20 \pm 7,22 \pm 11$, and $21 \pm 6 \mathrm{~g}$ at breakfast, lunch, and dinner, respectively, with no differences between main meals $(P=0.157)$. Protein intake in females differed between main meals and averaged $14 \pm 7,16 \pm 7$, and $19 \pm 6 \mathrm{~g}$, respectively $(P<0.001)$. Post-hoc analyses in females showed that protein consumption was lower at breakfast and lunch when compared with dinner (both $P<0.001)$, and lower at breakfast when compared with lunch $(P=0.042)$. Protein consumption during hospital admission was lower in females when compared with males at breakfast and lunch (both $P<0.001)$, but did not differ at dinner between genders $(P=0.120)$. Snack consumption provided merely $3 \pm 5 \mathrm{~g}$ protein per day in males and $2 \pm 2 \mathrm{~g}$ in females, with no differences between genders (Figure $\mathbf{3 A}$ and $\mathbf{B} ; P=0.141$ ). Protein distribution per main meal as $\%$ of the total consumed amount of protein is presented in Figure 4. Breakfast, lunch, and dinner provided $30 \pm 7,33 \pm 8$, and $33 \pm 7 \%$ protein in males (Figure 4A) and $27 \pm 8$, $30 \pm 7,39 \pm 9 \%$ protein in females (Figure 4B). Snacks contributed for the remaining $4 \pm 5 \%$ protein in males and $4 \pm 3 \%$ in females. 

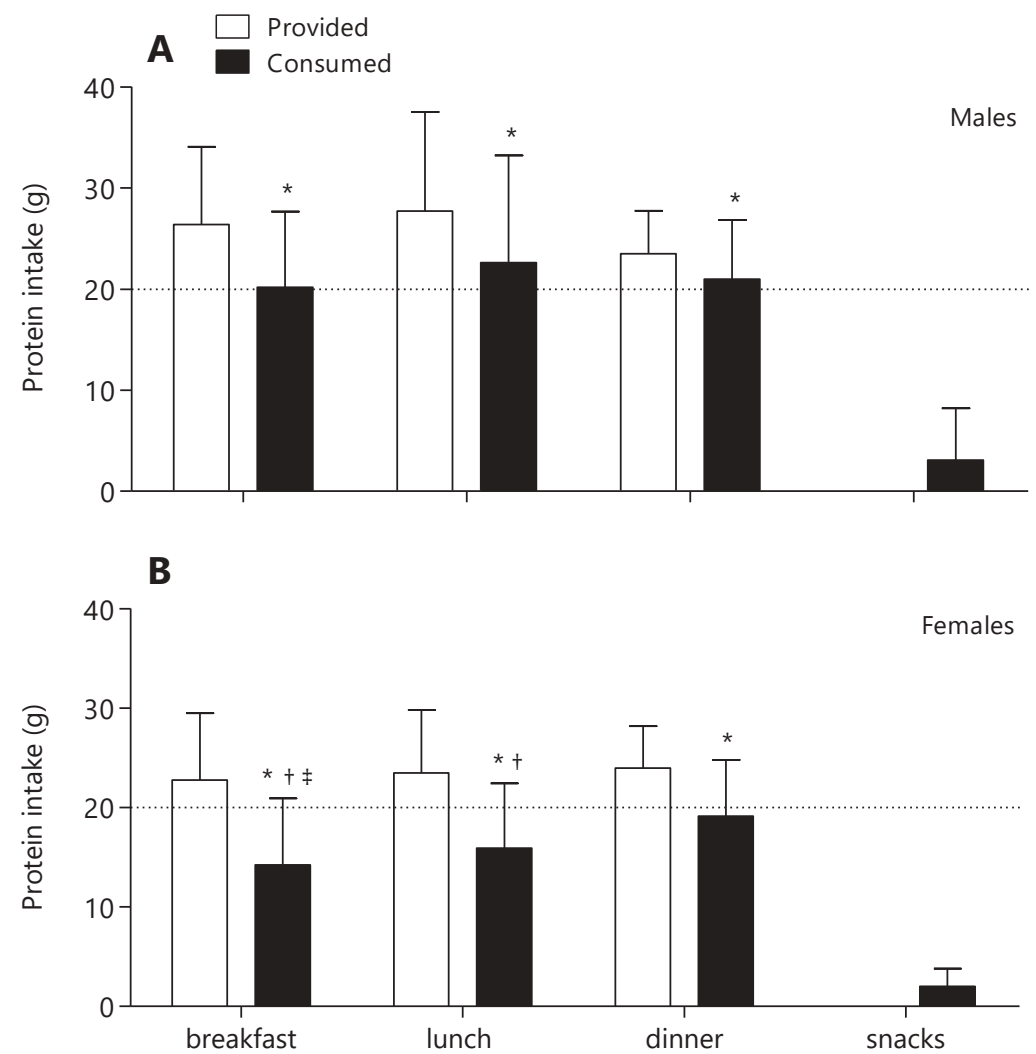

Figure 3 | Mean $( \pm S D)$ dietary protein provision and consumption (g) across main meals in older, hospitalized males $(\mathbf{A} ; n=37)$ and females $(\mathbf{B} ; n=64)$. * Indicates a significant difference when compared with provided, $P<0.001 ;+$ Indicates a significant difference when compared with dinner, $P<0.001 ; \ddagger$ Indicates a significant difference when compared with lunch, $P<0.05$. 


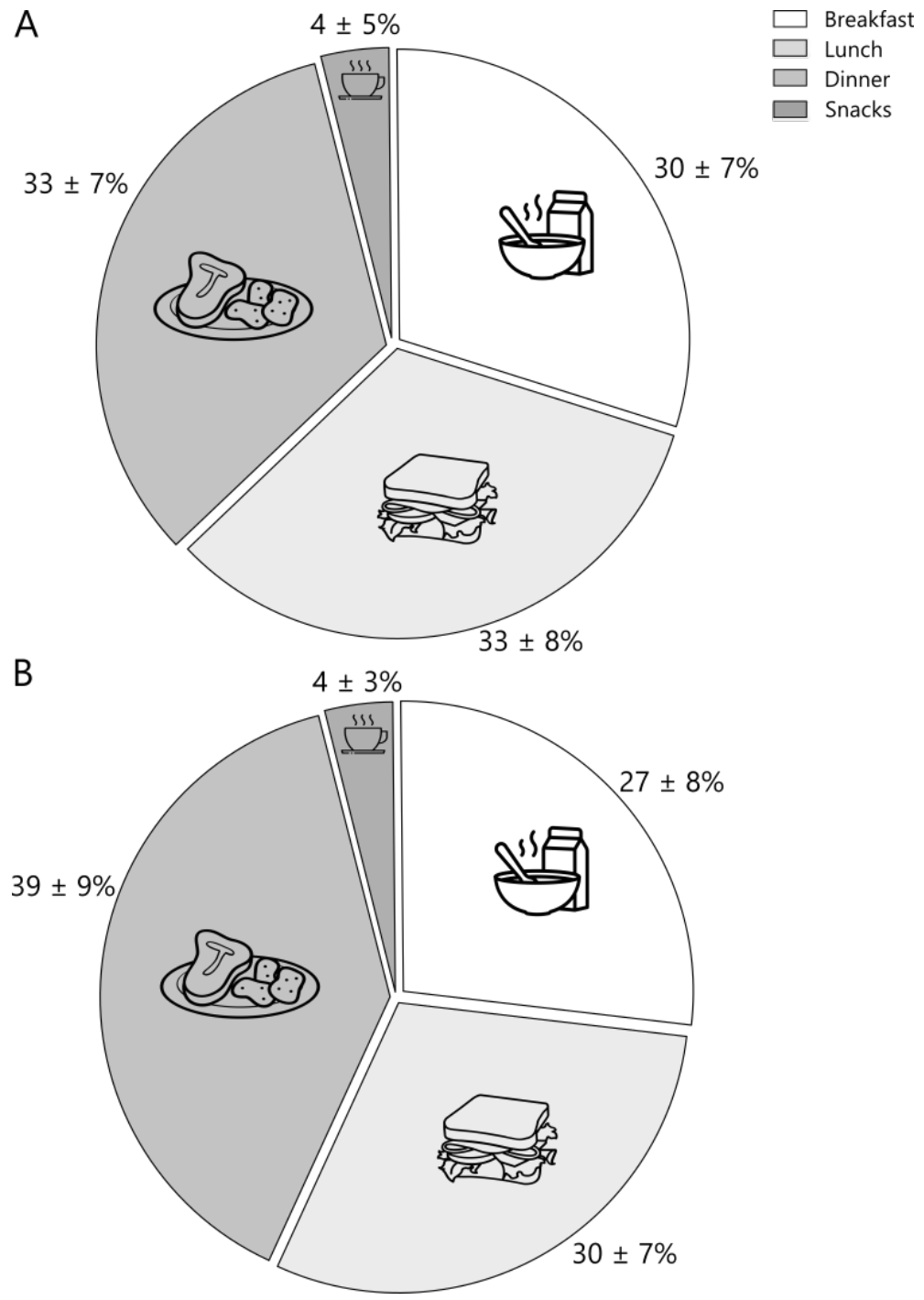

Figure 4 | Distribution of protein intake across main meals and snacks (in \% of the total amount of protein consumed) during short-term hospitalization in older, hospitalized males $(\mathbf{A} ; n=37)$ and females $(\mathbf{B} ; n=64)$. 


\section{Protein sources}

The contribution of animal- and plant-based sources to total protein intake (\%) is shown in Figure 5. In total, protein intake from self-selected hospital meals contained a higher amount animal-based protein sources when compared with plant-based protein sources $(66 \pm 7 \%$ and $34 \pm 7 \%$, respectively, $P<0.001$ ). Dairy products and eggs provided the largest amount of animal-based proteins $(35 \pm 12 \%)$, followed by meat and fish $(30 \pm 11 \%)$. For plant-based protein sources, bread, cereals, and potatoes provided the largest amount of protein (26 $\pm 7 \%$ ). Fruit, vegetables, and legumes provided only $4 \pm 2 \%$ of plant-based protein to the total diet, and $4 \pm 3 \%$ did not fit in any of these categories.

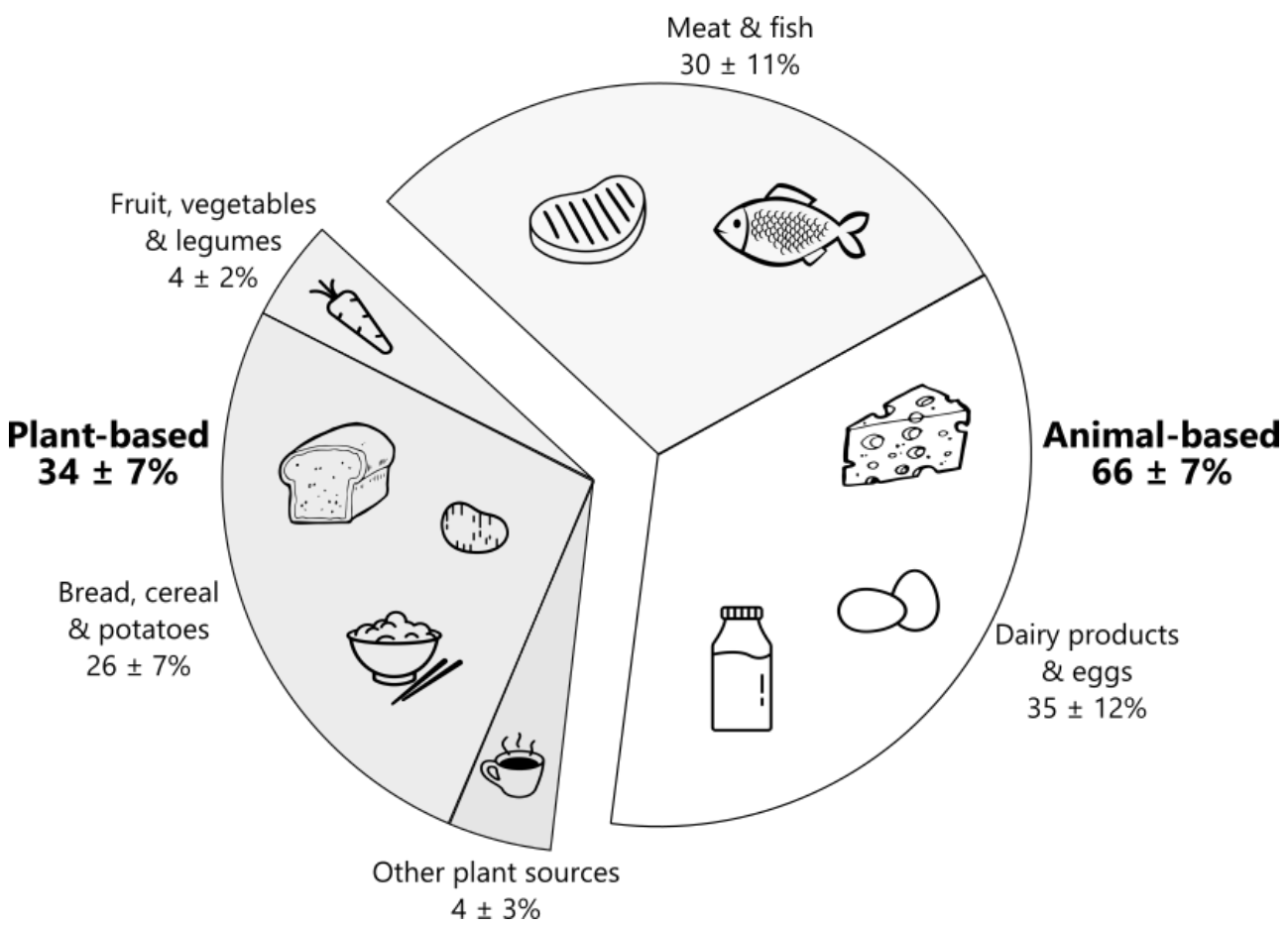

Figure 5 | Contribution of animal- and plant-based sources to total dietary protein intake (expressed as a percentage of total protein intake) in older, hospitalized patients $(n=101)$. 


\section{DISCUSSION}

Self-selected hospital meals provided patients with $\sim 0.8 \mathrm{~g} \cdot \mathrm{kg}^{-1} \cdot \mathrm{d}^{-1}$ protein during short-term hospitalization, while actual protein intake was below $0.6 \mathrm{~g} \cdot \mathrm{kg}^{-1} \cdot \mathrm{d}^{-1}$ with more than $30 \%$ of the provided food being discarded. Absolute protein intake per main meal ranged from 14 to 22 $\mathrm{g}$ in all patients, with protein intake being particularly low at breakfast in females. A total of $34 \%$ of daily protein intake was derived from plant-based protein sources.

In the present study, we assessed actual energy and protein consumption patterns during short-term hospitalization in older patients admitted for elective hip and knee arthroplasty. Daily energy consumption averaged $5.29 \pm 1.77$ and $3.96 \pm 1.39 \mathrm{MJ}^{-1} \mathrm{~d}^{-1}$ in males and females, respectively, which is merely $\sim 50 \%$ of the estimated energy requirements. Consequently, all patients remained in a negative energy balance throughout their hospitalization. At present, up to $30 \%$ of the older patients in Western-European hospitals have been identified as being malnourished during hospitalization [9-11, 43, 44]. Poor nutritional status in older hospitalized patients has been associated with accelerated weight loss, slower wound healing, an increase in length of hospital stay, higher mortality rates, and more frequent hospital readmission [9$11,44,45]$. An energy deficit during hospitalization and bedrest accelerates the loss of skeletal muscle mass [20]. The muscle atrophy typically observed during hospitalization [19, 46] may be largely attributed to the lack of sufficient protein consumed as a result of low(er) energy intake levels. We assessed dietary protein consumption in older patients during short-term hospitalization after total hip or knee arthroplasty. Self-selected hospital meals provided patients with merely $\sim 0.8 \mathrm{~g} \cdot \mathrm{kg}^{-1} \cdot \mathrm{d}^{-1}$ protein, which is well below recommended daily intake levels of $1.2 \mathrm{~g} \cdot \mathrm{kg}^{-1} \cdot \mathrm{d}^{-1}$. Since $30 \%$ of food provided was discarded, actual protein consumption was much lower and averaged $0.6 \mathrm{~g} \cdot \mathrm{kg}^{-1} \cdot \mathrm{d}^{-1}$. Protein intake was particularly low on the day of surgery when compared with subsequent hospitalization days (Figure 2). Though protein consumption increased on the following days of recovery on the orthopedic ward, protein consumption still remained far below recommended daily intake levels $\left(1.2 \mathrm{~g} \cdot \mathrm{kg}^{-1} \cdot \mathrm{d}^{-1}\right)$ throughout the entire hospitalization period. This seems to support previous work showing that protein consumption is insufficient in older patients during short-term hospitalization [35, 38]. Consequently, interventional strategies should be employed to effectively increase energy intake to match energy requirements and, as such, avoid energy malnutrition. Furthermore, protein intake should be maintained at habitual intake levels, which in the light of a reduced daily energy intake, requires the instalment of a more protein-dense diet.

The ingestion of dietary protein, and more specifically the postprandial rise in plasma amino acid concentrations, stimulates muscle protein synthesis and inhibits muscle protein breakdown, thereby stimulating muscle protein accretion [47]. The postprandial increase in muscle protein synthesis rates forms an important factor in muscle mass maintenance. Ingestion of $20 \mathrm{~g}$ of a high quality protein has been shown to increase postprandial muscle protein synthesis rates in young adults $[48,49]$. Due to anabolic resistance with aging, greater amounts of protein ( $>20 \mathrm{~g}$ per meal) are required to significantly stimulate muscle protein 
synthesis in older individuals [50-52]. In the present study, the amount of protein consumed at breakfast, lunch, and dinner varied between 14 and $22 \mathrm{~g}$ in both the male and female patients (Table 2). While protein intake per meal was likely sufficient to induce an anabolic response in the male patients, protein intake remained well below $20 \mathrm{~g}$ for most meals in females. Particularly at breakfast, protein intake averaged only $14 \pm 7 \mathrm{~g}$ in the female patients. This seems to agree with previous findings showing that protein consumption is particularly low at breakfast in older individuals $[21,23,53]$. Given the suboptimal anabolic response with every main meal and the presence of anabolic resistance to protein ingestion in older individuals [52], the protein content of each main meal should be increased to allow ingestion of at least $20 \mathrm{~g}$ protein per main meal.

As animal-based proteins are generally regarded as being more anabolic than plant-based proteins [54,55], we also assessed the contribution of animal- and plant-based protein sources to total dietary protein intake (Figure 5). Self-selected hospital meals contained a relative large amount of animal-based protein sources $(66 \pm 1 \%)$ when compared with plant-based protein sources $(34 \pm 1 \%)$. This is in line with the general Western diet in community-dwelling older adults [56]. As shown in Figure 5, protein intake in older patients was mainly derived from meat, fish, dairy products and eggs, which are the main protein sources consumed in the aging population $[6,57,58]$. The relative contribution of animal versus plant-based protein sources in the hospital diet does not seem to require any modification.

Our data clearly show that even healthy patients admitted for elective hip or knee arthroplasty consume far less energy and protein than the estimated daily requirements. Since more than $30 \%$ of the provided food is not consumed, it is obvious that simply increasing food provision will not be effective to prevent energy and protein malnutrition during hospitalization. As the maintenance of habitual protein intake levels is key to attenuate muscle mass loss, a more protein-dense diet should be consumed as total energy intake is typically reduced during hospitalization. Various strategies can be applied to increase the relative protein intake in the diet, including the consumption of more protein-rich foods, supplementation with oral nutritional supplements (ONS), fortification of meals with protein isolates, and/or the provision of well-timed protein-rich snacks $[35,37,59,60]$. To increase absolute protein intake in the diet, a first target for intervention should be breakfast. As protein consumption is typically low at breakfast (Figure 3), increasing protein intake at breakfast should be of greater benefit. In support, additional protein supplementation at breakfast has been shown to increase skeletal muscle mass and function in older, frail individuals [61, 62]. Another target would be increasing food consumption on the day of surgery. As energy and protein intake were hardly existing on the day of surgery, food provision during the pre- and post-surgery period could be installed within the restraints set by the surgical procedures. The provision of ONS may help to cover the energy and protein deficits during the first 1-2 days following surgery. However, as time progresses food fortification, provision of more protein-dense foods, and/or an adding an extra protein meal will likely be more appropriate. In line, provision of protein-enriched foods (such as bread, yoghurt, cake, fruit juice, and soup) or the use of more protein-dense foods throughout the day have been shown effective in improving protein intake during 
hospitalization $[35,37,59]$. In addition, the timing of protein-rich products serves as alternative strategy to increase protein intake levels during hospitalization. We have recently shown that protein ingestion prior to sleep increases overnight muscle protein synthesis rates in healthy, older men [63,64], and supports muscle mass and strength gains during prolonged exercise training in young adults [65]. However, whether prolonged pre-sleep protein supplementation can attenuate muscle mass and/or strength loss in older patients during hospitalization remains to be assessed. Nutritional intervention strategies need to be assessed for their efficacy to increase energy and protein intake and, as such, to help preserve muscle mass and strength in older patients during hospitalization.

In conclusion, energy and protein intake levels remain well below requirements during hospitalization in older patients admitted for elective hip or knee arthroplasty. While patients are provided with $0.8 \mathrm{~g}$ protein $\cdot \mathrm{kg}^{-1} \cdot \mathrm{d}^{-1}$, actual protein consumption does not even reach 0.6 $\mathrm{g} \cdot \mathrm{kg}^{-1} \cdot \mathrm{d}^{-1}$ with $30 \%$ of the provided food being discarded. Strategic interventions are required to increase energy intake and ensure maintenance of habitual protein intake levels in older patients admitted for elective orthopedic surgery.

\section{ACKNOWLEDGEMENTS}

We thank all medical staff and meal assistants of the Orthopedic nursing ward of the Maastricht University Medical Centre+ for their collaboration and assistance. 


\section{REFERENCES}

1. Agency for Healthcare Research and Quality, Healthcare Cost and Utilization Project (HCUP): Hospital Inpatient National Statistics, in Database. 2013 [cited 25-10-2017]. Available from: https://hcupnet.ahrq.gov/

2. European Union, Hospital discharges and length of stay statistics. 2016 [cited 25-10-2017]. Available from: http://ec.europa.eu/eurostat/statistics-explained/index.php/Hospital_ discharges_and_length_of_stay_statistics\#Further_Eurostat_information

3. Mudge, A.M., L.J. Ross, A.M. Young, E.A. Isenring, and M.D. Banks, Helping understand nutritional gaps in the elderly (HUNGER): a prospective study of patient factors associated with inadequate nutritional intake in older medical inpatients. Clin Nutr, 2011. 30(3): p. 320-5.

4. Hickson, M., A. Connolly, and K. Whelan, Impact of protected mealtimes on ward mealtime environment, patient experience and nutrient intake in hospitalised patients. J Hum Nutr Diet, 2011. 24(4): p. 370-4.

5. Corish, C.A. and N.P. Kennedy, Protein-energy undernutrition in hospital in-patients. Br J Nutr, 2000. 83(6): p. 575-91.

6. Houston, D.K., B.J. Nicklas, J. Ding, T.B. Harris, F.A. Tylavsky, A.B. Newman, J.S. Lee, N.R. Sahyoun, M. Visser, S.B. Kritchevsky, and A.B.C.S. Health, Dietary protein intake is associated with lean mass change in older, community-dwelling adults: the Health, Aging, and Body Composition (Health ABC) Study. Am J Clin Nutr, 2008. 87(1): p. 150-5.

7. Farsijani, S., J.A. Morais, H. Payette, P. Gaudreau, B. Shatenstein, K. Gray-Donald, and S. Chevalier, Relation between mealtime distribution of protein intake and lean mass loss in free-living older adults of the NuAge study. Am J Clin Nutr, 2016.

8. Isanejad, M., J. Mursu, J. Sirola, H. Kroger, T. Rikkonen, M. Tuppurainen, and A.T. Erkkila, Association of protein intake with the change of lean mass among elderly women: The Osteoporosis Risk Factor and Prevention - Fracture Prevention Study (OSTPRE-FPS). J Nutr Sci, 2015. 4: p.41.

9. Hiesmayr, M., K. Schindler, E. Pernicka, C. Schuh, A. Schoeniger-Hekele, P. Bauer, A. Laviano, A.D. Lovell, M. Mouhieddine, T. Schuetz, S.M. Schneider, P. Singer, C. Pichard, P. Howard, C. Jonkers, I. Grecu, O. Ljungqvist, and T. NutritionDay Audit, Decreased food intake is a risk factor for mortality in hospitalised patients: the NutritionDay survey 2006. Clin Nutr, 2009. 28(5): p. 484-91.

10. Kruizenga, H., S. van Keeken, P. Weijs, L. Bastiaanse, S. Beijer, G. Huisman-de Waal, H. JagerWittenaar, C. Jonkers-Schuitema, M. Klos, W. Remijnse-Meester, B. Witteman, and A. Thijs, Undernutrition screening survey in 564,063 patients: patients with a positive undernutrition screening score stay in hospital 1.4 d longer. Am J Clin Nutr, 2016. 103(4): p. 1026-32.

11. Stratton, R.J. and M. Elia, Deprivation linked to malnutrition risk and mortality in hospital. British Journal of Nutrition, 2006. 96(5): p. 870-876.

12. Correia, M.I. and D.L. Waitzberg, The impact of malnutrition on morbidity, mortality, length of hospital stay and costs evaluated through a multivariate model analysis. Clin Nutr, 2003. 22(3): p. 235-9.

13. Wall, B.T., M.L. Dirks, T. Snijders, J.M. Senden, J. Dolmans, and L.J. van Loon, Substantial skeletal muscle loss occurs during only 5 days of disuse. Acta Physiol (Oxf), 2014. 210(3): p. 600-11.

14. Dirks, M.L., B.T. Wall, R. Nilwik, D.H. Weerts, L.B. Verdijk, and L.J. van Loon, Skeletal muscle disuse atrophy is not attenuated by dietary protein supplementation in healthy older men. J Nutr, 2014. 144(8): p. 1196-203.

15. Dirks, M.L., B.T. Wall, T. Snijders, C.L. Ottenbros, L.B. Verdijk, and L.J. van Loon, Neuromuscular electrical stimulation prevents muscle disuse atrophy during leg immobilization in humans. Acta Physiol (Oxf), 2014. 210(3): p. 628-41.

16. Suetta, C., U. Frandsen, L. Jensen, M.M. Jensen, J.G. Jespersen, L.G. Hvid, M. Bayer, S.J. Petersson, H.D. Schroder, J.L. Andersen, K.M. Heinemeier, P. Aagaard, P. Schjerling, and M. Kjaer, Aging affects 
the transcriptional regulation of human skeletal muscle disuse atrophy. PLoS One, 2012. 7(12): p. e51238.

17. Tanner, R.E., L.B. Brunker, J. Agergaard, K.M. Barrows, R.A. Briggs, O.S. Kwon, L.M. Young, P.N. Hopkins, E. Volpi, R.L. Marcus, P.C. LaStayo, and M.J. Drummond, Age-related differences in lean mass, protein synthesis and skeletal muscle markers of proteolysis after bed rest and exercise rehabilitation. J Physiol, 2015. 593(18): p. 4259-73.

18. Hvid, L.G., C. Suetta, P. Aagaard, M. Kjaer, U. Frandsen, and N. Ortenblad, Four days of muscle disuse impairs single fiber contractile function in young and old healthy men. Exp Gerontol, 2013. 48(2): p. 154-61.

19. Alley, D.E., A. Koster, D. Mackey, P. Cawthon, L. Ferrucci, E.M. Simonsick, B. Yu, S. Hardy, B. Goodpaster, C. Sarkisian, D.K. Houston, S.B. Kritchevsky, S. Cummings, J.S. Lee, F.A. Tylavsky, A. Newman, T. Harris, A. Health, and S. Body Composition, Hospitalization and change in body composition and strength in a population-based cohort of older persons. J Am Geriatr Soc, 2010. 58(11): p. 2085-91.

20. Biolo, G., B. Ciocchi, M. Stulle, A. Bosutti, R. Barazzoni, M. Zanetti, R. Antonione, M. Lebenstedt, P. Platen, M. Heer, and G. Guarnieri, Calorie restriction accelerates the catabolism of lean body mass during 2 wk of bed rest. Am J Clin Nutr, 2007. 86(2): p. 366-72.

21. Tieland, M., K.J. Borgonjen-Van den Berg, L.J. van Loon, and L.C. de Groot, Dietary protein intake in community-dwelling, frail, and institutionalized elderly people: scope for improvement. Eur J Nutr, 2012. 51(2): p. 173-9.

22. National Institute for Public Health and the Environment. Diet of communitydwelling older adults: Dutch National Food Consumption Survey Older adults 2010-2012. 2013.

23. Farsijani, S., J.A. Morais, H. Payette, P. Gaudreau, B. Shatenstein, K. Gray-Donald, and S. Chevalier, Relation between mealtime distribution of protein intake and lean mass loss in free-living older adults of the NuAge study. Am J Clin Nutr, 2016. 104(3): p. 694-703.

24. Bauer, J., G. Biolo, T. Cederholm, M. Cesari, A.J. Cruz-Jentoft, J.E. Morley, S. Phillips, C. Sieber, P. Stehle, D. Teta, R. Visvanathan, E. Volpi, and Y. Boirie, Evidence-based recommendations for optimal dietary protein intake in older people: a position paper from the PROT-AGE Study Group. J Am Med Dir Assoc, 2013. 14(8): p. 542-59.

25. Deutz, N.E., J.M. Bauer, R. Barazzoni, G. Biolo, Y. Boirie, A. Bosy-Westphal, T. Cederholm, A. CruzJentoft, Z. Krznaric, K.S. Nair, P. Singer, D. Teta, K. Tipton, and P.C. Calder, Protein intake and exercise for optimal muscle function with aging: recommendations from the ESPEN Expert Group. Clin Nutr, 2014. 33(6): p. 929-36.

26. Kent-Smith, L., C. Eisenbraun, and H. Wile, Hospital Patients Are Not Eating Their Full Meal: Results of the Canadian 2010-2011 nutritionDay Survey. Can J Diet Pract Res, 2016. 77(1): p. 25-9.

27. Reeves, A., H. White, K. Sosnowski, K. Tran, M. Jones, and M. Palmer, Energy and protein intakes of hospitalised patients with acute respiratory failure receiving non-invasive ventilation. Clin Nutr, 2014. 33(6): p. 1068-73.

28. Dupertuis, Y.M., M.P. Kossovsky, U.G. Kyle, C.A. Raguso, L. Genton, and C. Pichard, Food intake in 1707 hospitalised patients: a prospective comprehensive hospital survey. Clin Nutr, 2003. 22(2): p. 115-23.

29. Hankey, C.R. and H.A. Wynne, An audit of meal provision in an elderly care hospital. Int J Qual Health Care, 1996. 8(4): p. 375-82.

30. Agarwal, E., M. Ferguson, M. Banks, M. Batterham, J. Bauer, S. Capra, and E. Isenring, Malnutrition and poor food intake are associated with prolonged hospital stay, frequent readmissions, and greater in-hospital mortality: results from the Nutrition Care Day Survey 2010. Clin Nutr, 2013. 32(5): p. 737-45.

31. Thibault, R., M. Chikhi, A. Clerc, P. Darmon, P. Chopard, L. Genton, M.P. Kossovsky, and C. Pichard, Assessment of food intake in hospitalised patients: a 10-year comparative study of a prospective hospital survey. Clin Nutr, 2011. 30(3): p. 289-96. 
32. Porter, J., T.P. Haines, and H. Truby, The efficacy of Protected Mealtimes in hospitalised patients: a stepped wedge cluster randomised controlled trial. BMC Med, 2017. 15(1): p. 25.

33. van Bokhorst-de van der Schueren, M.A., M.M. Roosemalen, P.J. Weijs, and J.A. Langius, High waste contributes to low food intake in hospitalized patients. Nutr Clin Pract, 2012. 27(2): p. 274-80.

34. Ofei, K.T., M. Holst, H.H. Rasmussen, and B.E. Mikkelsen, Effect of meal portion size choice on plate waste generation among patients with different nutritional status. An investigation using Dietary Intake Monitoring System (DIMS). Appetite, 2015. 91: p. 157-64.

35. Stelten, S., I.M. Dekker, E.M. Ronday, A. Thijs, E. Boelsma, H.W. Peppelenbos, and M.A. de van der Schueren, Protein-enriched 'regular products' and their effect on protein intake in acute hospitalized older adults; a randomized controlled trial. Clin Nutr, 2015. 34(3): p. 409-14.

36. Simzari, K., D. Vahabzadeh, S. Nouri Saeidlou, S. Khoshbin, and Y. Bektas, Food intake, plate waste and its association with malnutrition in hospitalized patients. Nutr Hosp, 2017. 34(5): p. 13761381.

37. Dijxhoorn, D.N., M.G.A. van den Berg, W. Kievit, J. Korzilius, J.P.H. Drenth, and G.J.A. Wanten, A novel in-hospital meal service improves protein and energy intake. Clin Nutr, 2017.

38. Leistra, E., F. Willeboordse, M.A. van Bokhorst-de van der Schueren, M. Visser, P.J. Weijs, A. Haansvan den Oord, J. Oostenbrink, A.M. Evers, and H.M. Kruizenga, Predictors for achieving protein and energy requirements in undernourished hospital patients. Clin Nutr, 2011. 30(4): p. 484-9.

39. Stratton, R.J., A. Hackston, D. Longmore, R. Dixon, S. Price, M. Stroud, C. King, and M. Elia, Malnutrition in hospital outpatients and inpatients: prevalence, concurrent validity and ease of use of the 'malnutrition universal screening tool' ('MUST') for adults. Br J Nutr, 2004. 92(5): p. 799808.

40. National Institute of Public Health, Welfare and Sport, Dutch Food Composition Database. 2016 [cited 25-10-2017]. Available from: https://nevo-online.rivm.nl

41. Roza, A.M. and H.M. Shizgal, The Harris Benedict equation reevaluated: resting energy requirements and the body cell mass. Am J Clin Nutr, 1984. 40(1): p. 168-82.

42. Long, C.L., N. Schaffel, J.W. Geiger, W.R. Schiller, and W.S. Blakemore, Metabolic response to injury and illness: estimation of energy and protein needs from indirect calorimetry and nitrogen balance. JPEN J Parenter Enteral Nutr, 1979. 3(6): p. 452-6.

43. Rasmussen, H.H., M. Holst, and J. Kondrup, Measuring nutritional risk in hospitals. Clin Epidemiol, 2010. 2: p. 209-16.

44. Feinberg, J., E.E. Nielsen, S.K. Korang, K. Halberg Engell, M.S. Nielsen, K. Zhang, M. Didriksen, L. Lund, N. Lindahl, S. Hallum, N. Liang, W. Xiong, X. Yang, P. Brunsgaard, A. Garioud, S. Safi, J. Lindschou, J. Kondrup, C. Gluud, and J.C. Jakobsen, Nutrition support in hospitalised adults at nutritional risk. Cochrane Database Syst Rev, 2017. 5: p. CD011598.

45. Sullivan, D.H., M.M. Bopp, and P.K. Roberson, Protein-energy undernutrition and life-threatening complications among the hospitalized elderly. J Gen Intern Med, 2002. 17(12): p. 923-32.

46. Van Ancum, J.M., K. Scheerman, N.H. Jonkman, H.E. Smeenk, R.C. Kruizinga, C.G.M. Meskers, and A.B. Maier, Change in muscle strength and muscle mass in older hospitalized patients: A systematic review and meta-analysis. Exp Gerontol, 2017. 92: p. 34-41.

47. Koopman, R. and L.J. van Loon, Aging, exercise, and muscle protein metabolism. Journal of applied physiology, 2009. 106(6): p. 2040-8.

48. Moore, D.R., M.J. Robinson, J.L. Fry, J.E. Tang, E.I. Glover, S.B. Wilkinson, T. Prior, M.A. Tarnopolsky, and S.M. Phillips, Ingested protein dose response of muscle and albumin protein synthesis after resistance exercise in young men. Am J Clin Nutr, 2009. 89(1): p. 161-8.

49. Witard, O.C., S.R. Jackman, L. Breen, K. Smith, A. Selby, and K.D. Tipton, Myofibrillar muscle protein synthesis rates subsequent to a meal in response to increasing doses of whey protein at rest and after resistance exercise. Am J Clin Nutr, 2014. 99(1): p. 86-95.

50. Pennings, B., B. Groen, A. de Lange, A.P. Gijsen, A.H. Zorenc, J.M. Senden, and L.J. van Loon, Amino acid absorption and subsequent muscle protein accretion following graded intakes of whey 
protein in elderly men. American journal of physiology. Endocrinology and metabolism, 2012. 302(8): p. E992-9.

51. Moore, D.R., T.A. Churchward-Venne, O. Witard, L. Breen, N.A. Burd, K.D. Tipton, and S.M. Phillips, Protein ingestion to stimulate myofibrillar protein synthesis requires greater relative protein intakes in healthy older versus younger men. J Gerontol A Biol Sci Med Sci, 2015. 70(1): p. 57-62.

52. Wall, B.T., S.H. Gorissen, B. Pennings, R. Koopman, B.B. Groen, L.B. Verdijk, and L.J. van Loon, Aging Is Accompanied by a Blunted Muscle Protein Synthetic Response to Protein Ingestion. PLoS One, 2015. 10(11): p. e0140903.

53. Norton, C., C. Toomey, W.G. McCormack, P. Francis, J. Saunders, E. Kerin, and P. Jakeman, Protein Supplementation at Breakfast and Lunch for 24 Weeks beyond Habitual Intakes Increases WholeBody Lean Tissue Mass in Healthy Older Adults. J Nutr, 2016. 146(1): p.65-9.

54. van Vliet, S., N.A. Burd, and L.J. van Loon, The Skeletal Muscle Anabolic Response to Plant- versus Animal-Based Protein Consumption. J Nutr, 2015. 145(9): p. 1981-91.

55. Gorissen, S.H., A.M. Horstman, R. Franssen, J.J. Crombag, H. Langer, J. Bierau, F. Respondek, and L.J. van Loon, Ingestion of Wheat Protein Increases In Vivo Muscle Protein Synthesis Rates in Healthy Older Men in a Randomized Trial. J Nutr, 2016. 146(9): p. 1651-9.

56. Environment, N.I.f.P.H.a.t., Diet of communitydwelling older adults: Dutch National Food Consumption Survey Older adults 2010-2012. Database, 2013.

57. Tieland, M., K.J. Borgonjen-Van den Berg, L.J. Van Loon, and L.C. de Groot, Dietary Protein Intake in Dutch Elderly People: A Focus on Protein Sources. Nutrients, 2015. 7(12): p. 9697-706.

58. McLean, R.R., K.M. Mangano, M.T. Hannan, D.P. Kiel, and S. Sahni, Dietary Protein Intake Is Protective Against Loss of Grip Strength Among Older Adults in the Framingham Offspring Cohort. J Gerontol A Biol Sci Med Sci, 2016. 71(3): p. 356-61.

59. Beelen, J., E. Vasse, N. Janssen, A. Janse, N.M. de Roos, and L. de Groot, Protein-enriched familiar foods and drinks improve protein intake of hospitalized older patients: A randomized controlled trial. Clin Nutr, 2017.

60. Neelemaat, F., P. Lips, J.E. Bosmans, A. Thijs, J.C. Seidell, and M.A. van Bokhorst-de van der Schueren, Short-term oral nutritional intervention with protein and vitamin $D$ decreases falls in malnourished older adults. J Am Geriatr Soc, 2012. 60(4): p. 691-9.

61. Tieland, M., R. Franssen, C. Dullemeijer, C. van Dronkelaar, H.K. Kim, T. Ispoglou, K. Zhu, R.L. Prince, L.J.C. van Loon, and L.C.P.G.M. de Groot, The impact of dietary protein or amino acid supplementation on muscle mass and strength in elderly people: Individual participant data and meta-analysis of RCT's. The journal of nutrition, health \& aging, 2017.

62. Bauer, J.M., S. Verlaan, I. Bautmans, K. Brandt, L.M. Donini, M. Maggio, M.E. McMurdo, T. Mets, C. Seal, S.L. Wijers, G.P. Ceda, G. De Vito, G. Donders, M. Drey, C. Greig, U. Holmback, M. Narici, J. McPhee, E. Poggiogalle, D. Power, A. Scafoglieri, R. Schultz, C.C. Sieber, and T. Cederholm, Effects of a vitamin $D$ and leucine-enriched whey protein nutritional supplement on measures of sarcopenia in older adults, the PROVIDE study: a randomized, double-blind, placebo-controlled trial. J Am Med Dir Assoc, 2015. 16(9): p. 740-7.

63. Kouw, I.W., A.M. Holwerda, J. Trommelen, I.F. Kramer, J. Bastiaanse, S.L. Halson, W.K. Wodzig, L.B. Verdijk, and L.J. van Loon, Protein Ingestion before Sleep Increases Overnight Muscle Protein Synthesis Rates in Healthy Older Men: A Randomized Controlled Trial. J Nutr, 2017.

64. Groen, B.B., P.T. Res, B. Pennings, E. Hertle, J.M. Senden, W.H. Saris, and L.J. van Loon, Intragastric protein administration stimulates overnight muscle protein synthesis in elderly men. Am J Physiol Endocrinol Metab, 2012. 302(1): p. E52-60.

65. Snijders, T., P.T. Res, J.S. Smeets, S. van Vliet, J. van Kranenburg, K. Maase, A.K. Kies, L.B. Verdijk, and L.J. van Loon, Protein Ingestion before Sleep Increases Muscle Mass and Strength Gains during Prolonged Resistance-Type Exercise Training in Healthy Young Men. J Nutr, 2015. 145(6): p. $1178-84$. 


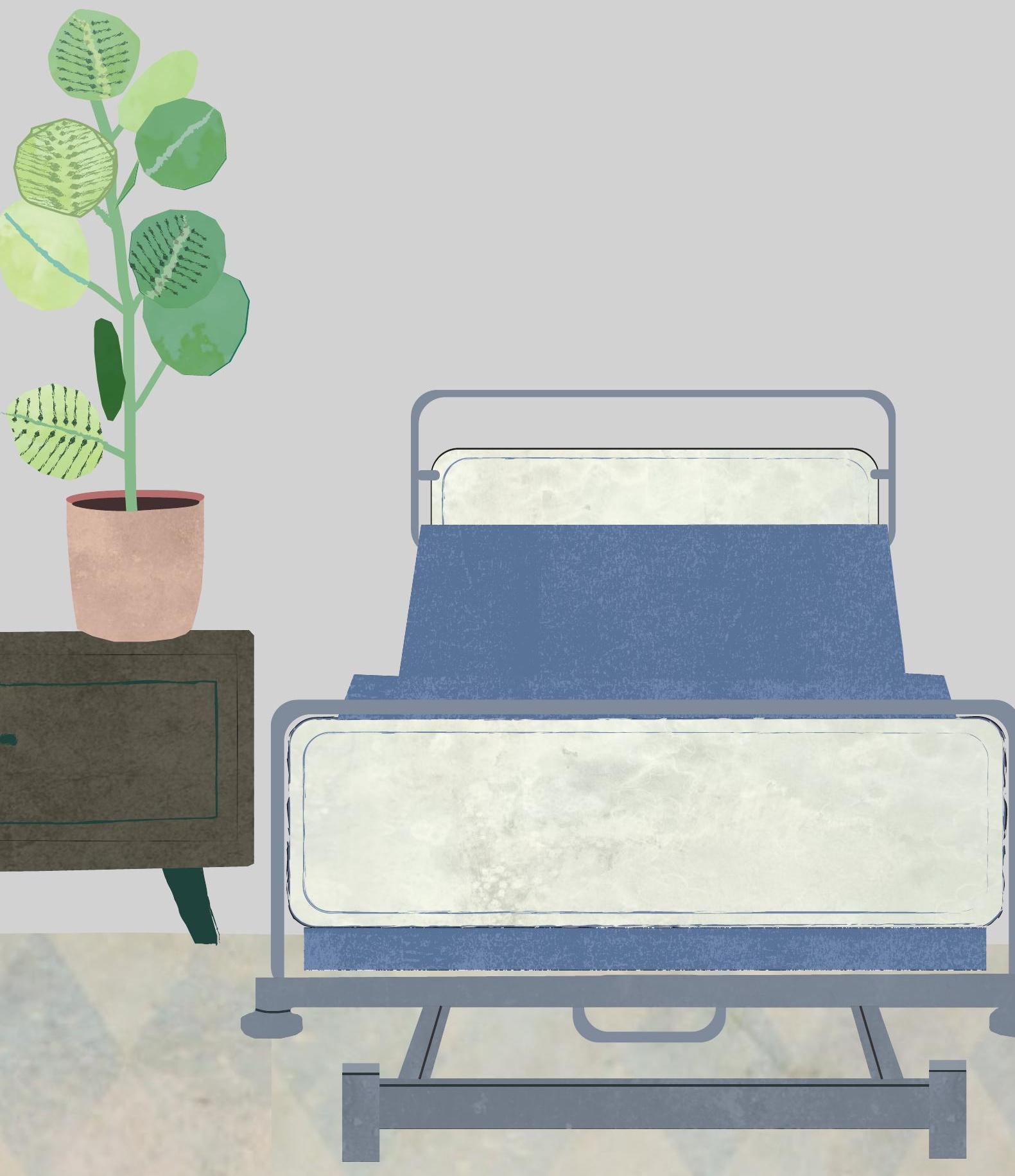




\section{CHAPTER FOUR}

\section{POSTPRANDIAL PROTEIN HANDLING IS NOT IMPAIRED IN TYPE 2 DIABETES PATIENTS WHEN COMPARED WITH NORMOGLYCEMIC CONTROLS}

Imre W.K. Kouw, Stefan H.M. Gorissen, Nicholas A. Burd, Naomi M. Cermak, Annemarie P. Gijsen, Janneau van Kranenburg, and LuC J.C. van Loon J Clin Endocrinol Metab 2015 Aug; 100(8):3103-11 


\section{ABSTRACT}

Context: $\quad$ The progressive loss of muscle mass with aging is accelerated in type 2 diabetes patients. It has been suggested that this is attributed to a blunted muscle protein synthetic response to food intake.

Objective: $\quad$ To test the hypothesis that the muscle protein synthetic response to protein ingestion is impaired in older type 2 diabetes patients when compared with healthy, normoglycemic controls.

Design: We conducted a parallel-group design, clinical intervention study between August 2011 and July 2012.

Setting: The study was conducted at our research unit of Maastricht University, the Netherlands.

Intervention: Eleven older type 2 diabetes males (Diabetes; age: $71 \pm 1$ y, BMI: $26.2 \pm 0.5$ $\mathrm{kg} \cdot \mathrm{m}^{-2}$ ) and twelve age-, and BMI-matched normoglycemic controls (Control; age: $74 \pm 1 \mathrm{y}, \mathrm{BMl}: 24.8 \pm 1.1 \mathrm{~kg} \cdot \mathrm{m}^{-2}$ ) participated in an experiment in which they ingested $20 \mathrm{~g}$ intrinsically $\mathrm{L}-\left[1-{ }^{13} \mathrm{C}\right]$-phenylalanine labelled protein. Continuous intravenous L-[ring- ${ }^{2} \mathrm{H}_{5}$ ]-phenylalanine infusion was applied and blood and muscle samples were obtained to assess amino acid kinetics and muscle protein synthesis rates in the postabsorptive and postprandial state.

Results: Plasma insulin concentrations increased following protein ingestion in both groups, with a greater rise in the Diabetes group. Postabsorptive and postprandial muscle protein synthesis rates did not differ between groups and averaged $0.029 \pm 0.003$ vs $0.029 \pm 0.003 \% \cdot \mathrm{h}^{-1}$ and $0.031 \pm 0.002$ vs $0.033 \pm 0.002 \% \cdot h^{-1}$ in the Diabetes and Control group, respectively. Postprandial L- $\left[1-{ }^{13} \mathrm{C}\right]$-phenylalanine incorporation in muscle protein did not differ between groups $(0.018 \pm 0.001$ vs $0.019 \pm 0.002 \mathrm{MPE}$, respectively).

Conclusions: Postabsorptive muscle protein synthesis and postprandial protein handling is not impaired in older individuals with type 2 diabetes when compared with age-matched, normoglycemic controls. 


\section{INTRODUCTION}

The progressive loss of muscle mass and strength with aging, termed sarcopenia, leads to a decline in functional capacity and an increased risk for developing chronic metabolic diseases, such as obesity and type 2 diabetes. Our laboratory [1,2] as well as others [3, 4] have demonstrated that sarcopenia is more pronounced in older individuals with type 2 diabetes when compared with age-matched, normoglycemic controls. Combined with the fact that skeletal muscle tissue is responsible for most of the glucose taken up from the circulation, it is evident that age-related muscle loss can be regarded both a cause as well as a consequence of type 2 diabetes.

Skeletal muscle mass maintenance is regulated by the dynamic balance between muscle protein synthesis and breakdown. A substantial loss of skeletal muscle mass must be attributed to a chronic increase in muscle protein breakdown rate and/or a decrease in the rate of muscle protein synthesis $[5,6]$. Because basal (postabsorptive) muscle protein synthesis [7-10] and breakdown $[9,10]$ rates do not seem to be affected by age, recent work has been focusing on the anabolic response to food intake. It has been well established that dietary protein ingestion directly stimulates muscle protein synthesis $[6,11-13]$. More recent work shows that older individuals display a reduced responsiveness to the anabolic properties of amino acid or protein administration $[7,9,11,14]$. This anabolic resistance to protein feeding is now believed to represent a key factor responsible for the age-related muscle loss $[5,6,15]$. It has been suggested that skeletal muscle insulin resistance may play a key role in the development of this age-related anabolic resistance $[10,16,17]$. A reduced capacity of the postprandial rise in circulating insulin levels to stimulate muscle perfusion has previously been demonstrated to restrict amino acid delivery to the muscle and, as such, may attenuate the postprandial stimulation of muscle protein synthesis rates $[9,10]$.

We hypothesize that the muscle protein synthetic response to protein ingestion is more impaired in older individuals with type 2 diabetes when compared with age-matched, normoglycemic controls. Few studies have addressed the possible impairments in muscle protein metabolism in the type 2 diabetic state [18-22]. Although several studies have compared basal whole-body [18, 20-27] or muscle protein synthesis rates [19, 21, 22, 28], no studies have been carried out comparing postprandial muscle protein synthesis rates between type 2 diabetes patients and age-matched, normoglycemic controls.

In the present study, we assess both basal muscle protein synthesis rates and muscle protein synthesis rates after the ingestion of a single meal-like bolus $(20 \mathrm{~g})$ of dietary protein in older individuals with and without controlled type 2 diabetes. We combined contemporary stable isotope methodology with the ingestion of intrinsically labeled protein $[29,30]$ which allows us to assess both postabsorptive and postprandial muscle protein synthesis rates as well as the incorporation of dietary-protein derived amino acids into skeletal muscle proteins. 


\section{METHODS}

\section{Subjects}

Eleven older, type 2 diabetes mellitus patients [Diabetes; age: $71 \pm 1$ y, body weight: $80 \pm 2 \mathrm{~kg}$, body mass index: (BMI) $26.2 \pm 0.5 \mathrm{~kg} \cdot \mathrm{m}^{-2}$, lean body mass: $61 \pm 1 \mathrm{~kg}$ ] and 12 age- and BMImatched, normoglycemic controls (Control; age: $74 \pm 1$ y, body weight: $75 \pm 4 \mathrm{~kg}$, BMl: $24.8 \pm 1.1$ $\mathrm{kg} \cdot \mathrm{m}^{-2}$, lean body mass: $57 \pm 3 \mathrm{~kg}$ ) were examined in the current study. Subjects' characteristics are presented in Table 1. Diabetes patients were using oral blood glucose-lowering medication [buguanides $(n=4)$; sulfonylurea derivatives $(n=2)$; buguanides in combination with sulfonylurea derivatives $(n=1)$; buguanides in combination with dipeptidyl peptidase IV inhibitor $(n=1)$; buguanides in combination with sulfonylurea derivatives and dipeptidyl peptidase IV inhibitor $(n=1)$ ] or were undergoing lifestyle intervention $(n=2)$. Habitual medication use was continued prior to and on the day of the experimental trial to be able to maintain their daily living setting of the patients and not disturb their glucose control. Diabetes patients had been diagnosed with type 2 diabetes between 2 and 18 years prior to screening. The subjects were part of two larger projects on muscle protein metabolism in older subjects. The trial was conducted between August 2011 and July 2012 at Maastricht University, The Netherlands. One subject in the diabetes group was unable to complete the trial and was withdrawn from analysis. Subjects were informed of the nature and possible risks of the experimental procedures prior to obtaining written informed consent. This study was approved by the Medical Ethical Committee of the Maastricht University Medical Centre, The Netherlands, conformed to standards for the use of human subjects in research as outlined in the sixth Declaration of Helsinki.

\section{Pretesting}

All subjects participated in a screening session to assess glycated hemoglobin $\left(\mathrm{HbA}_{1 \mathrm{c}}\right)$, glucose tolerance (by a 2-hour oral glucose tolerance test (OGTT) [31], blood pressure, and body composition (by dual-energy X-ray absorptiometry; Discovery A; Hologic). The diabetes patients refrained from consuming their oral blood glucose-lowering medication for 48 hours prior to the screening session. The participants were deemed healthy (except for type 2 diabetes in the diabetes patients) based on their responses to a medical questionnaire and screening results. All participants refrained from strenuous physical activity and maintained their diet as constant as possible for 2 days prior to the experiment. On the evening before the trial, a standardized meal was consumed (570 kcal; $31.7 \pm 1.1 \mathrm{~kJ}^{\mathrm{kg}}{ }^{-1}$ body weight) composed of 16 energy (En)\% protein, 32 En\% carbohydrate, and 49 En\% fat. 
Table 1 | Subjects' characteristics

\begin{tabular}{|c|c|c|}
\hline & Control $(n=12)$ & Diabetes $(n=11)$ \\
\hline Age (y) & $74 \pm 1$ & $71 \pm 1$ \\
\hline Weight (kg) & $75.0 \pm 4.2$ & $80.4 \pm 1.6$ \\
\hline BMI $\left(\mathbf{k g} \cdot \mathbf{m}^{2}\right)$ & $24.8 \pm 1.1$ & $26.2 \pm 0.5$ \\
\hline Fat (\%) & $20.2 \pm 1.3$ & $21.5 \pm 0.8$ \\
\hline Lean body mass (kg) & $57.3 \pm 2.6$ & $60.6 \pm 1.0$ \\
\hline Appendicular lean mass (kg and \%) & $24.5 \pm 1.1(33 \pm 1 \%)$ & $26.1 \pm 0.5(33 \pm 1 \%)$ \\
\hline Skeletal muscle mass index $\left(\mathbf{k g} \cdot \mathbf{m}^{-2}\right)$ & $8.1 \pm 0.3$ & $8.5 \pm 0.1$ \\
\hline Basal plasma leucine $\left(\mu \mathrm{mol} \cdot \mathrm{L}^{-1}\right)$ & $124 \pm 5$ & $144 \pm 5^{\star}$ \\
\hline Basal plasma glucose $\left(\mathrm{mmol}^{\left.-\mathrm{L}^{-1}\right)}\right.$ & $5.7 \pm 0.1$ & $9.6 \pm 0.8^{*}$ \\
\hline Plasma glucose OGTT $t=120 \mathrm{~min}\left(\mathrm{mmol} \cdot \mathrm{L}^{-1}\right)$ & $5.5 \pm 0.4$ & $16.3 \pm 0.9 *$ \\
\hline Basal plasma insulin $\left(\mathrm{mU} \cdot \mathrm{L}^{-1}\right)$ & $5.2 \pm 0.7$ & $16.8 \pm 2.3^{*}$ \\
\hline Plasma insulin OGTT $t=120 \mathrm{~min}\left(\mathrm{mU} \cdot \mathrm{L}^{-1}\right)$ & $30.9 \pm 5.2$ & $45.6 \pm 7.7$ \\
\hline $\mathrm{HbA}_{1} \mathrm{C}\left(\%\right.$ and $\left.\mathrm{mmol} \cdot \mathrm{mol}^{-1}\right)$ & $5.6 \pm 0.1(38.2 \pm 1.2)$ & $7.2 \pm 0.3(54.6 \pm 2.8)^{\star}$ \\
\hline OGIS $\left(\mathrm{mL} \cdot \mathrm{min}^{-1} \cdot \mathrm{m}^{-2}\right)$ & $391 \pm 15$ & $286 \pm 11^{*}$ \\
\hline HOMA-IR & $0.7 \pm 0.1$ & $2.5 \pm 0.3^{*}$ \\
\hline
\end{tabular}

Values are mean \pm SEM. $\mathrm{HbA}_{1 \mathrm{c}}$ : glycated hemoglobin; OGTT: oral glucose tolerance test; OGIS: oral glucose insulin sensitivity, HOMA: homeostasis model assessment. Data were analyzed by unpaired Student's $t$-tests. * Statistically significant difference with $P<0.001$.

\section{Experimental protocol}

At 8:00 AM, after an overnight fast, participants arrived at the laboratory by car or public transport. A Teflon catheter was inserted into an antecubital vein for infusion and a second cannula into the dorsal hand vein of the contralateral arm and was placed in a hot box $\left(60^{\circ} \mathrm{C}\right)$ for arterialized blood sampling [32]. After baseline blood collection ( $t=-210 \mathrm{~min}$ ), the plasma phenylalanine and tyrosine pools were primed with a single iv dose of $\mathrm{L}-\left[\mathrm{ring}_{-}{ }^{2} \mathrm{H}_{5}\right]$ phenylalanine $\left(2 \mu \mathrm{mol} \cdot \mathrm{kg}^{-1}\right)$ and $\mathrm{L}$-[ring-3,5- ${ }^{2} \mathrm{H}_{2}$ ]-tyrosine $\left(0.615 \mu \mathrm{mol} \cdot \mathrm{kg}^{-1}\right)$, after which a continuous 8.5-hour L-[ring- ${ }^{2} \mathrm{H}_{5}$ ]-phenylalanine and L-[ring-3,5- ${ }^{2} \mathrm{H}_{2}$ ]-tyrosine infusion was initiated ( 0.05 and $0.15 \mu \mathrm{mol} \cdot \mathrm{kg}^{-1} \cdot \mathrm{min}^{1}$, respectively). Multiple blood samples were collected during the infusion at $t=-210,-120,-90,-60,-30,0,15,30,45,60,90,120,150,180,210$, 240, 270, and 300 minutes. Blood samples were collected in EDTA-containing tubes and centrifuged at $1000 \times g$ at $4^{\circ} \mathrm{C}$ for 10 minutes. Aliquots of plasma were frozen in liquid nitrogen and stored at $-80^{\circ} \mathrm{C}$. Muscle biopsies were collected for the determination of postabsorptive muscle protein synthesis rates $(t=-120$ and $0 \mathrm{~min}$ ). Immediately after the second biopsy, subjects ingested a single bolus of $20 \mathrm{~g}$ intrinsically L-[1-13 C]-phenylalaninelabeled casein protein dissolved in $350 \mathrm{~mL}$ water, which was flavored with $1.5 \mathrm{~mL}$ vanilla (IMCD 
Benelux N.V.). Additional biopsies were collected at $t=120$ and 300 minutes (from the contralateral leg) for the determination of postprandial muscle protein synthesis rates. Muscle biopsies were collected from the middle region of the vastus lateralis ( $15 \mathrm{~cm}$ above the patella) using the Bergström needle technique [33]. All biopsy samples were freed from any visible adipose tissue and blood, immediately frozen in liquid nitrogen, and stored at $-80^{\circ} \mathrm{C}$ until subsequent analysis.

\section{Production of intrinsically labeled protein}

Intrinsically $\mathrm{L}-\left[1-{ }^{13} \mathrm{C}\right]$-phenylalanine labeled casein was produced by infusing $\mathrm{L}-\left[1-{ }^{13} \mathrm{C}\right]-$ phenylalanine into a lactating Holstein cow, collecting milk, and purifying the casein fraction as described previously [29]. The $\mathrm{L}-\left[1-{ }^{13} \mathrm{C}\right]$-phenylalanine enrichment in casein protein was measured by gas chromatography mass spectrometry (GC-MS; Agilent 7890A GC/5975C; MSD) and averaged 39 mole percent excess (MPE). The dietary protein met all chemical and bacteriologic specifications for human consumption.

\section{Plasma analyses}

Plasma glucose and insulin concentrations were analyzed using commercially available kits (GLUC3; Roche; reference 05168791 190; and Immunologic; Roche; reference 12017547122 , respectively). Plasma amino acid concentrations and enrichments were determined by GC-MS. Specifically, internal standards of $\left[\mathrm{U}^{13} \mathrm{C}_{6}\right]$-leucine, $\left[\mathrm{U}-{ }^{13} \mathrm{C}_{9}{ }^{15} \mathrm{~N}\right]$-phenylalanine, and $\left[\mathrm{U}-{ }^{13} \mathrm{C}_{9}{ }^{15} \mathrm{~N}\right]$ tyrosine were added to the samples. The plasma was deproteinized on ice with 5-sulfosalicylic acid. Free amino acids were purified using cation exchange chromatography (AG 50W-X8 resin, 100-200 $\mu \mathrm{m}$ dry mesh size; Bio-Rad Laboratories, Hercules, CA). The free amino acids were converted to their tert-butyl dimethylsilyl (TBDMS) derivative with MTBSTFA before analysis by GC-MS. The AA concentrations were determined using electron impact ionization by monitoring ions at mass/charge $(\mathrm{m} / \mathrm{z}) 302$ and 308 for unlabeled and $\left[\mathrm{U}-{ }^{13} \mathrm{C}_{6}\right]$-leucine respectively, 336 and 346 for unlabeled and $\left[\mathrm{U}-{ }^{13} \mathrm{C}_{9}{ }^{15} \mathrm{~N}\right]$-phenylalanine respectively, and 466 and 476 for unlabeled and $\left[\mathrm{U}-{ }^{13} \mathrm{C}_{9}{ }^{15} \mathrm{~N}\right]$-tyrosine respectively. The plasma phenylalanine and tyrosine ${ }^{13} \mathrm{C}$ and ${ }^{2} \mathrm{H}$ enrichments were determined using selective ion monitoring at $\mathrm{m} / \mathrm{z} 336$, 337 , and 341 for unlabeled and labeled $\left(1-{ }^{13} \mathrm{C}\right.$ and ring $\left.-{ }^{2} \mathrm{H}_{5}\right)$-phenylalanine respectively, and $\mathrm{m} / \mathrm{z} 466,467,468$, and 470 for unlabeled and labeled $\left(1-{ }^{13} \mathrm{C}\right.$, ring $-3,5-{ }^{2} \mathrm{H}_{2}$, and ring- $\left.{ }^{2} \mathrm{H}_{4}\right)-$ tyrosine respectively. Standard regression curves were applied from a series of known standard enrichment values against the measured values to assess the linearity of the mass spectrometer and to account for any isotope fractionation which may have occurred during the analysis. Phenylalanine and tyrosine enrichments were corrected for the presence of both the ${ }^{13} \mathrm{C}$ and ${ }^{2} \mathrm{H}$ isotopes. 


\section{Muscle analyses}

Muscle-tissue free (intracellular) L-[ring- $\left.{ }^{2} \mathrm{H}_{5}\right]$-phenylalanine and $\mathrm{L}-\left[1-{ }^{13} \mathrm{C}\right]$-phenylalanine enrichments were determined using GC-MS analysis. Mixed muscle protein-bound L-[ring${ }^{2} \mathrm{H}_{5}$ ]-phenylalanine enrichment was determined by GC-MS, and mixed muscle protein-bound $\mathrm{L}-\left[1-{ }^{13} \mathrm{C}\right]$-phenylalanine enrichment were measured by $\mathrm{GC}-\mathrm{C}$-isotope ratio mass (Finnigan MAT 253; Bremen) using an HP Ultra I GC-column (number 19091A-112; Hewlett-Packard).

A piece of wet muscle ( $50 \mathrm{mg}$ ) was freeze-dried, and collagen, blood, and other non-muscle tissue were removed under a dissecting microscope. The freeze-dried muscle was weighed ( $8 \mathrm{mg}$ ) and homogenized in 35 volumes of ice-cold $2 \%$ perchloric acid (PCA). Samples were incubated on ice for $10 \mathrm{~min}$. After centrifugation, the supernatant was collected for determination of $\mathrm{L}-\left[\right.$ ring- $\left.{ }^{2} \mathrm{H}_{5}\right]$-phenylalanine and $\mathrm{L}-\left[1-{ }^{13} \mathrm{C}\right]$-phenylalanine enrichments in the muscle-free AA pool using GC-MS analysis. The mixed muscle protein pellet was washed three times with $1 \mathrm{~mL}$ of ice-cold $2 \%$ PCA and hydrolyzed in $3 \mathrm{~mL}$ of $6 \mathrm{M} \mathrm{HCl}$ overnight at $120{ }^{\circ} \mathrm{C}$. The free $A A$ were then dissolved in $50 \%$ acetic acid solution and passed over cation exchange AG 50W-X8 resin columns (mesh size: 100-200 $\mu \mathrm{m}$, ionic form: hydrogen (Bio-Rad Laboratories, Hercules, $(A)$ ). AA were eluted with $2 \mathrm{M} \mathrm{NH} 4 \mathrm{OH}$ and divided over 2 vials for separate measurements of $\mathrm{L}-\left[1-{ }^{13} \mathrm{C}\right]$-phenylalanine and $\mathrm{L}$-[ring- $\left.{ }^{2} \mathrm{H}_{5}\right]$-phenylalanine enrichments in mixed muscle protein. To determine the $L$-[ring- $\left.{ }^{2} \mathrm{H}_{5}\right]$-phenylalanine enrichment of mixed muscle protein, the purified AA were derivatized into their TBDMS derivatives with MTBSTFA before the ratios of labeled to unlabeled derivatives were determined by GC-MS. To determine the $\mathrm{L}-\left[1-{ }^{13} \mathrm{C}\right]$-phenylalanine enrichment of mixed muscle protein, the purified AA were derivatized into their $\mathrm{N}(\mathrm{O}, \mathrm{S})$-ethoxycarbonyl ethyl ester derivatives with ethyl chloroformate. The derivatives were then measured by GC-C-IRMS (Finnigan MAT 253, Bremen, Germany) using an HP Ultra I GC-column (no. 19091A-112; Hewlett-Packard, Palo Alto, CA) and monitoring of ion masses 44 and 45 . By establishing the relation between the enrichment of a series of $L-\left[1-{ }^{13} \mathrm{C}\right]$-phenylalanine standards of variable enrichments and the enrichments of the $\mathrm{N}(\mathrm{O}, \mathrm{S})$-ethoxycarbonyl ethyl esters of these standards, the mixed muscle protein-bound enrichment of phenylalanine was determined. Standard regression curves were applied to assess the linearity of the mass spectrometer and to control for the loss of tracer.

\section{Calculations}

Whole-body amino acid kinetics (expressed in micromoles of phenylalanine per kilogram body weight $^{-1}$ per hour ${ }^{1}$ ) in nonsteady-state conditions were calculated from the ingestion of L-[1${ }^{13} \mathrm{C}$ ]-phenylalanine-labeled protein, iv infusion of $\mathrm{L}$-[ring- $\left.{ }^{2} \mathrm{H}_{5}\right]$-phenylalanine, and L-[ring-3,5${ }^{2} \mathrm{H}_{2}$ ]-tyrosine and arterialized blood sampling. Total, exogenous, and endogenous phenylalanine rates of appearance $\left(R_{a}\right)$ as well as plasma phenylalanine availability (i.e., the fraction of dietary protein derived phenylalanine that appeared in the systemic circulation) were calculated using modified Steele's equations [34, 35]. 


$$
\text { Total } \mathrm{Ra}=\frac{F_{i v}-\left[p v \cdot C(t) \cdot \frac{d E_{i v}}{d t}\right]}{E_{i v}(t)}
$$

Total phenylalanine Ra was calculated using equation 1, where Fiv is the intravenous tracer infusion rate $\left(\mathrm{mol} \cdot \mathrm{kg}^{-1} \cdot \mathrm{min}^{-1}\right)$ and $\mathrm{pV}$ is the distribution volume for phenylalanine $(0.125$

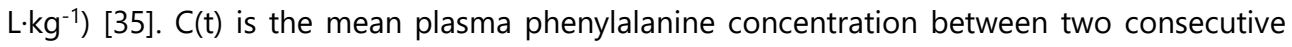
time points, dEiv/dt represents the time-dependent change in plasma phenylalanine enrichment derived from the intravenous tracer, and $\operatorname{Eiv}(\mathrm{t})$ is the mean plasma phenylalanine enrichment from the intravenous tracer between two consecutive time points.

$$
\text { Exogenous } \mathrm{Ra}=\frac{\operatorname{Total~}_{a} \cdot E_{p o}(t)+\left[p V \cdot C(t) \cdot \frac{d E_{p o}}{d t}\right]}{E_{\text {prot }}}
$$

Exogenous phenylalanine rate of appearance (Exo $\mathrm{Ra}$ ) represents the plasma entry rate of dietary protein-derived phenylalanine. $\mathrm{Epo}(\mathrm{t})$ is the mean plasma phenylalanine enrichment of the oral tracer, $\mathrm{dEpo} / \mathrm{dt}$ represents the time-dependent change in plasma phenylalanine enrichment derived from the oral tracer, and Eprot is the enrichment of $\mathrm{L}-\left[1-{ }^{13} \mathrm{C}\right]-$ phenylalanine in the dietary protein.

$$
\text { Endogenous } \mathrm{Ra}=\operatorname{Total} R_{a}-\operatorname{Exo} R_{a}-F_{i v}
$$

Endogenous phenylalanine $\mathrm{Ra}$ (Endo $\mathrm{Ra}$ ) represents the plasma entry rate of phenylalanine derived from whole-body protein breakdown.

$$
\text { Pheplasma }=\left[\frac{A U C_{E x o R a}}{P h e_{\text {prot }}}\right] \cdot \mathrm{BW} \cdot 100 \%
$$

The fraction of dietary protein-derived phenylalanine appearing in the systemic circulation (Pheplasma) was calculated using equation 4. AUCExoRa is the area under the curve (AUC) of Exo Ra; BW is the body weight of the subject in $\mathrm{kg}$; Pheprot is the amount of dietary phenylalanine that is ingested.

Total phenylalanine rate of disappearance $\left(\mathrm{Rd}, \mu \mathrm{mol}\right.$ Phe $\left.\cdot \mathrm{kg}^{-1} \cdot \mathrm{min}^{-1}\right)$ equals the rate of phenylalanine hydroxylation (first step in the conversion of phenylalanine to tyrosine) to the rate of phenylalanine utilization for protein synthesis. These parameters are calculated as follows:

$$
\begin{aligned}
& \text { Total } \mathrm{Rd}=\text { Total } R_{a}-p V \cdot \frac{d C}{d t} \\
& \text { Phe hydroxylation }=\text { Tyr } R_{a} \cdot \frac{E_{t y r}(t)}{E_{p h e}(t)} \cdot \frac{P h e R_{d}}{\left(F_{P h e}+P h e R_{d}\right)} \\
& \text { Protein synthesis }=\text { Total } \mathrm{Rd}-\text { Phe hydroxylation } \\
& \text { Phe net balance = Protein synthesis }- \text { Endo } \mathrm{Ra}
\end{aligned}
$$

TyrRa is the total rate of tyrosine appearance based on the $\mathrm{L}$-[ring-3,5- ${ }^{2} \mathrm{H}_{2}$ ]-tyrosine infusion and plasma enrichment. Etyr(t) and EPhe(t) represent the mean plasma L-[ring- $\left.{ }^{2} \mathrm{H}_{4}\right]$-tyrosine and $\mathrm{L}$-[ring- $\left.{ }^{2} \mathrm{H}_{5}\right]$-phenylalanine enrichment between 2 consecutive time points, respectively. Phe is the intravenous infusion rate of $L-\left[\right.$ ring $\left.^{2} \mathrm{H}_{5}\right]$-phenylalanine $\left(\mu \mathrm{mol} \cdot \mathrm{kg}^{-1} \cdot \mathrm{min}^{-1}\right)$. 
Whole-body net protein balance was calculated by subtracting protein synthesis from endogenous $\mathrm{R}_{\mathrm{a}}$ and presented as the weighted mean over the 5-hour ( $t=0$ and $t=300 \mathrm{~min}$ ) postprandial phase.

Mixed muscle protein fractional synthesis rates (FSR) were calculated using the standard precursor-product equation. For basal muscle protein FSR, muscle biopsies at $t=-120$ and $t=$ 0 min were used, and for postprandial muscle protein FSR biopsies at $t=0,120$, and 300 minutes were used to calculate the early ( $0-2$ hours), late ( $2-5$ hours), and aggregate response (0-5 hours).

$$
F S R=\frac{\Delta E p}{E_{\text {precursor }} \cdot t} \cdot 100 \%
$$

$\triangle E p$ is the increment in mixed muscle protein-bound $L$-[ring- $\left.{ }^{2} \mathrm{H}_{5}\right]$-phenylalanine (MPE) after an incorporation period. Eprecursor is the average plasma $\mathrm{L}$-[ring- $\left.{ }^{2} \mathrm{H}_{5}\right]$-phenylalanine enrichment (MPE) during that incorporation period, and $t$ is the incorporation period $(h)$.

\section{Statistics}

All data are expressed as mean \pm SEM. Differences in baseline values were determined using an unpaired, two-tailed Student's $t$ test. Area under curve (AUC), peak value, and time to peak were calculated for all plasma time curves, and differences were determined using an unpaired, two-tailed Student's $t$ test. A two-way ANOVA with time as within-group factor and condition as between-group factor was used to compare differences over time in plasma glucose, insulin, and amino acid concentrations, plasma L-[1-13 C]-phenylalanine enrichments, and whole-body amino acid kinetics appearance rates. Differences between groups in muscle free and proteinbound $L-\left[1-{ }^{13} \mathrm{C}\right]$-phenylalanine enrichments and mixed-muscle FSR were analyzed with an unpaired, two-tailed Student's $t$ test. For all analyses, statistical significance was set at $P<0.05$. All calculations were performed using IBM SPSS Statistics (version 21). 


\section{RESULTS}

\section{Plasma analyses}

Plasma glucose and insulin concentrations are presented in Figure 1. Fasting plasma glucose concentrations were significantly different between groups $\left(8.2 \pm 0.6\right.$ and $5.6 \pm 0.1 \mathrm{mmol} \cdot \mathrm{L}^{-1}$ in the diabetes and control groups, respectively, $P<0.001$; Figure 1A). Postprandial glucose levels were higher in the diabetes group $(P<0.05)$ and decreased over time, whereas plasma glucose levels remained at baseline values in the controls (group $\times$ time interaction $P<0.001$ ). Basal plasma insulin concentrations were significantly higher in the diabetes group when compared with the control group $\left(9.6 \pm 1.1\right.$ and $5.7 \pm 0.6 \mathrm{mU} \cdot \mathrm{L}^{-1}$, respectively, $P<0.001$; Figure 1B). Plasma insulin concentrations increased after the protein ingestion $(P<0.001)$ to a greater extent in the diabetes group when compared with the controls (group $\times$ time interaction $P<0.05$ ) reaching peak values of $23.3 \pm 2.6$ and $11.9 \pm 2.1 \mathrm{mU} \cdot \mathrm{L}^{-1}$ in the diabetes and control groups $(P<0.01)$, respectively. The AUC of the postprandial period was significantly higher in the diabetes group when compared with the healthy controls $(P<0.001$; Figure 1B, inset).

Plasma amino acid concentrations are presented in Figure 2. Phenylalanine and tyrosine concentrations increased after the protein ingestion $(P<0.001)$, with no differences between groups (Figure $\mathbf{2 A}$ and $\mathbf{B}$ ). Fasting plasma leucine concentrations (Figure 2C) were significantly higher in the diabetes group compared with the controls $(144 \pm 5$ and $124 \pm 6 \mathrm{mU}$. $\mathrm{L}^{-1}$, respectively; $P<0.001$ ). Plasma leucine concentrations increased after the protein ingestion in both groups (time effect $P<0.05$ ) and remained higher in the diabetes group (group effect $P<0.01$; AUC: $P<0.01)$. Peak levels were higher in diabetes patients $(P<0.05 ; 314 \pm 19$ and $254 \pm 13 \mathrm{mU} \cdot \mathrm{L}^{-1}$ in the diabetes and control group, respectively). 

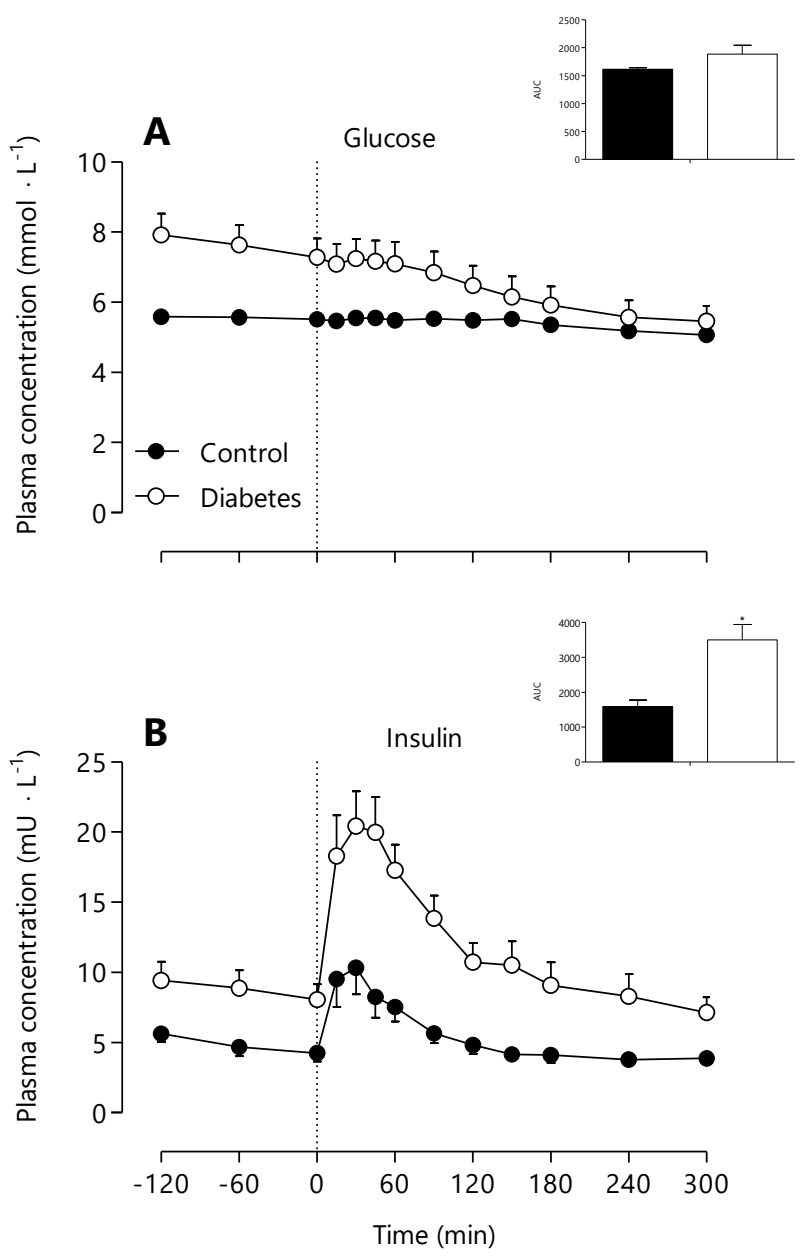

Figure 1 | Mean $\left( \pm\right.$ SEM) plasma glucose $(\mathbf{A})$ and insulin (B) concentrations ( $\mathrm{mmol} \cdot \mathrm{L}^{-1}$ and $\mathrm{mU} \cdot \mathrm{L}^{-1}$, respectively) in healthy $(n=12)$ and type 2 diabetes $(n=11)$ older subjects after the ingestion of $20 \mathrm{~g}$ casein. The dotted line indicates the ingestion of the protein beverage. Data were analyzed by unpaired Student's $t$-test (between groups) and repeated-measures (time $x$ group) ANOVA. * Significantly different from control $(P<0.001)$. Postprandial plasma glucose: time effect $P<0.001$; group effect $P<0.05$, interaction of time $x$ group $P<0.001$; AUC between groups: $P=0.09$. Postprandial plasma insulin: time effect $P<0.001$; group effect $P<0.001$; interaction of time $x$ group, $P<0.05$; AUC between groups: $P<0.001$. 

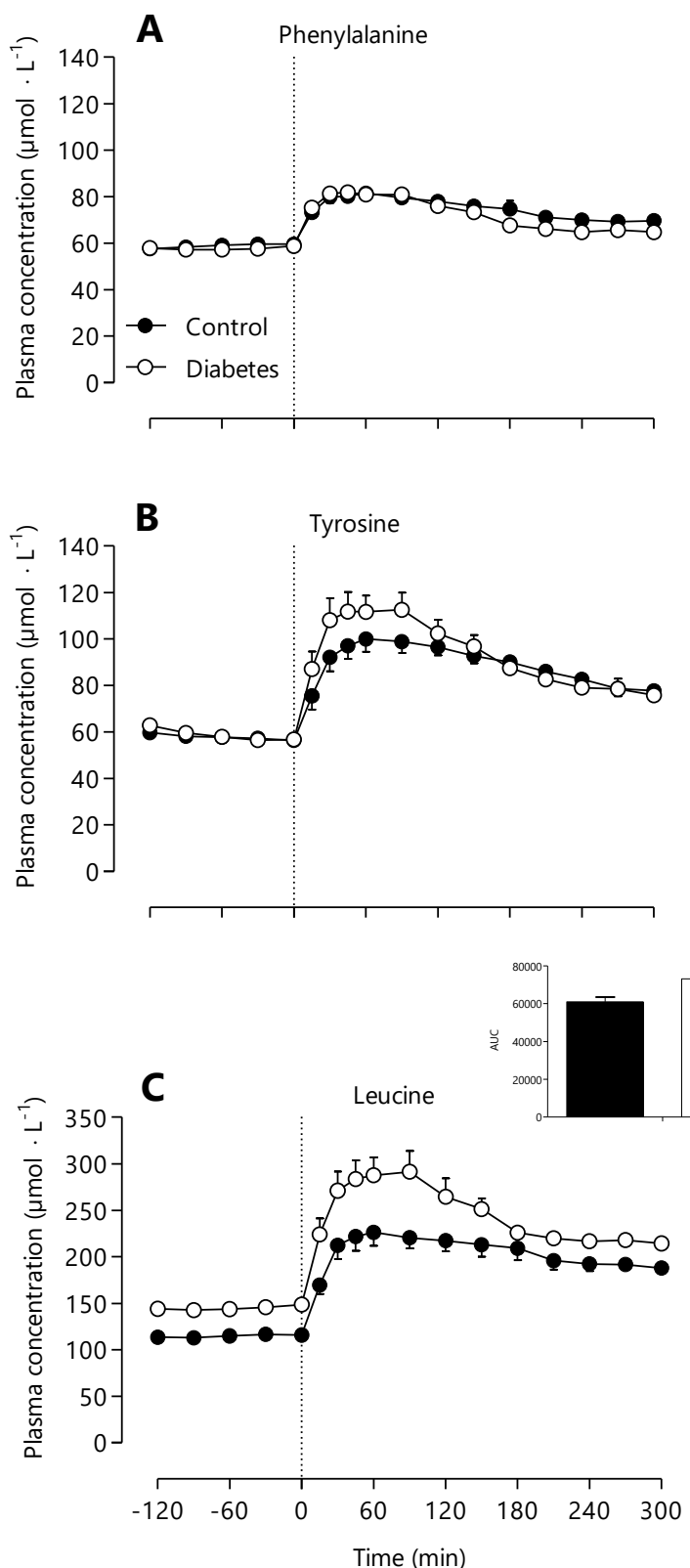

Figure 2 | Mean $\left( \pm\right.$ SEM) plasma phenylalanine $(\mathbf{A})$, tyrosine $(\mathbf{B})$, and leucine $(\mathbf{C})$ concentrations $\left(\mu \mathrm{mol} \cdot \mathrm{L}^{-1}\right)$ in healthy $(n=12)$ and type 2 diabetes $(n=11)$ older subjects after the ingestion of $20 \mathrm{~g}$ casein. Inset shows the AUC calculated over the 5-hour postprandial period. The dotted line indicates the ingestion of the protein beverage. Data were analyzed with repeated-measures (time $\times$ group) ANOVA. * Significantly different from control $(P<0.001)$. Postprandial plasma phenylalanine: time effect $P<0.001$. Postprandial plasma tyrosine: time effect $P<0.001$. Basal plasma leucine: time effect $P<0.01$; group effect $P<0.001$; interaction of time $\mathrm{x}$ group $P<0.01$. Postprandial plasma leucine: time effect $P<0.001$; group effect $P<0.01$; AUC between groups: $P<0.01$. 
Plasma L-[ring- $\left.{ }^{2} \mathrm{H}_{5}\right]$-phenylalanine, $\mathrm{L}$-[ring- $\left.{ }^{2} \mathrm{H}_{4}\right]$-phenylalanine, and $\mathrm{L}-\left[3,5-{ }^{2} \mathrm{H}_{2}\right]$-phenylalanine enrichments (from the infused tracer), and $\mathrm{L}-\left[1-{ }^{13} \mathrm{C}\right]$-phenylalanine and $\mathrm{L}-\left[1-{ }^{13} \mathrm{C}\right]$-tyrosine enrichments (from the ingested tracer) are presented in Figure 3 and $\mathbf{4}$. Plasma L-[ring- $\left.{ }^{2} \mathrm{H}_{5}\right]$ phenylalanine enrichments (Figure 3A) did not differ between groups in the postabsorptive period and transiently declined after the protein ingestion, with no differences between groups. Plasma L- $\left[1-{ }^{13} \mathrm{C}\right]$-phenylalanine enrichments (Figure $3 \mathbf{B}$ ) rapidly increased after ingestion of protein in both groups $(P<0.001)$, reaching peak levels of $12.3 \pm 0.7 \mathrm{MPE}$ at $72 \pm 12$ minutes and $11.5 \pm 0.9 \mathrm{MPE}$ at $76 \pm 16$ minutes in the diabetes and control groups, respectively, with no differences between groups (AUC, peak values, and time to peak).
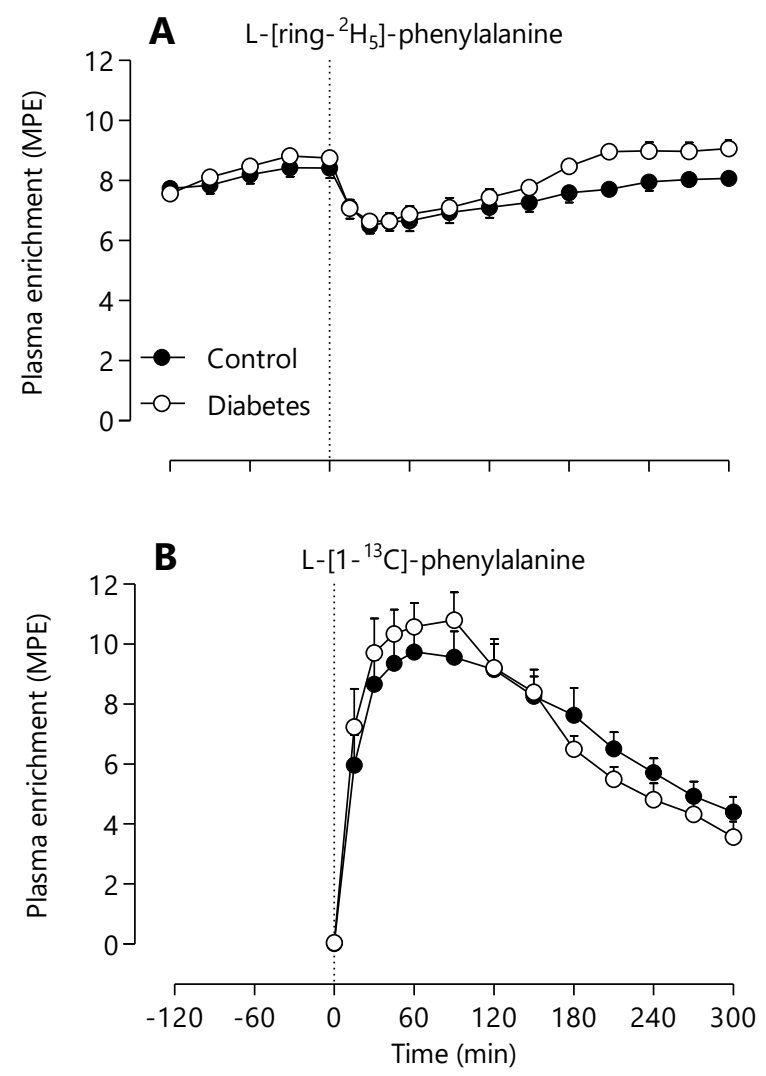

Figure 3 | Mean $\left( \pm\right.$ SEM) plasma L-[ring $\left.-{ }^{2} \mathrm{H}_{5}\right]$-phenylalanine $(\mathbf{A})$ and $L-\left[1-{ }^{13} \mathrm{C}\right]$-phenylalanine (B) enrichments (mole percent excess, MPE) enrichments (MPE) in healthy $(n=12)$ and type 2 diabetes $(n=11)$ older subjects after the ingestion of $20 \mathrm{~g}$ casein. The dotted line indicates the ingestion of the protein beverage. Data were analyzed with repeated-measures (time $\times$ group) ANOVA. Postprandial plasma L-[ring- ${ }^{2} \mathrm{H}_{5}$ ]-phenylalanine enrichments: time effect $P<0.001$. Plasma L- $\left[1-{ }^{13} \mathrm{C}\right]$-phenylalanine enrichments: time effect $P<0.001$. 

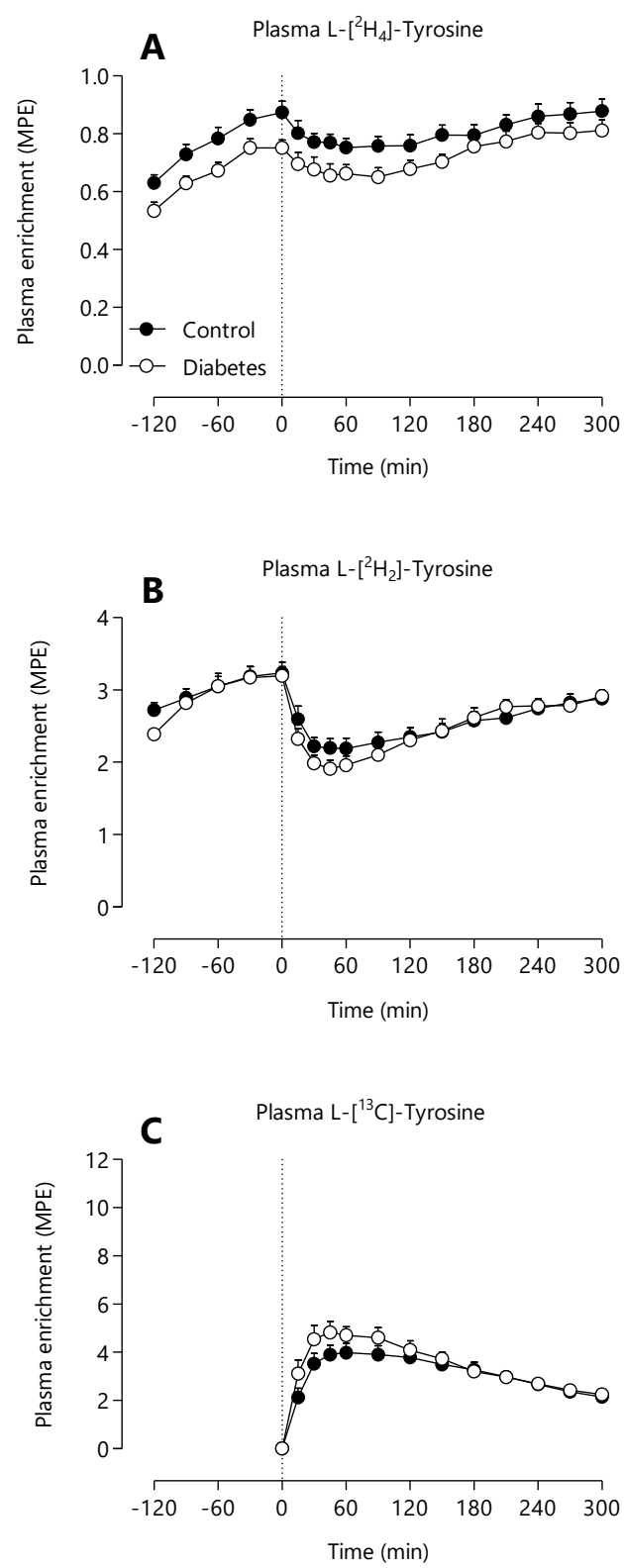

Figure 4 | Mean $( \pm \mathrm{SEM})$ plasma L-[ring- $\left.{ }^{2} \mathrm{H}_{4}\right]$-tyrosine $(\mathbf{A})$, L-[ring-3,5- $\left.{ }^{2} \mathrm{H}_{2}\right]$-tyrosine $(\mathbf{B})$, and L- $\left[1-{ }^{13} \mathrm{C}\right]$-tyrosine $(\mathbf{C})$ enrichments (mole percent excess, MPE) in healthy $(n=12)$ and type 2 diabetes $(n=11)$ older subjects following ingestion of $20 \mathrm{~g}$ casein. The dotted line indicates the ingestion of the protein beverage. Data were analyzed with repeated measures (time $x$ group) ANOVA.Basal L-[ring- ${ }^{2} \mathrm{H}_{4}$ ]-tyrosine enrichments: time $P<0.001$, group $P<0.05$, group $x$ time interaction $P=0.7$, postprandial $L$-[ring- ${ }^{2} \mathrm{H}_{4}$ ]-tyrosine enrichments: time $P<0.001$, group $P=0.1$, group $x$ time interaction $P=0.1$. Basal L-[ring $-3,5-{ }^{2} \mathrm{H}_{2}$ ]-tyrosine enrichments: time $P<0.001$, group $P=0.2$, group $\mathrm{x}$ time interaction $P=0.3$, postprandial $L$ - $\left[\right.$ ring-3, $5-{ }^{2} \mathrm{H}_{2}$ ]-tyrosine enrichments: time $P<0.001$, group $P=0.4$, group $x$ time interaction $P=0.09$. Postprandial $L-\left[1-{ }^{13} \mathrm{C}\right]$-tyrosine enrichments: time $P<0.001$, group $P=0.2$, group $\mathrm{x}$ time interaction $P=0.4$. 


\section{Whole-body amino acid kinetics}

Whole-body phenylalanine kinetics are presented in Figure 5. Exogenous phenylalanine rates of appearance (Figure 5A) (i.e., the rate at which dietary protein derived phenylalanine enters the circulation) increased after the protein ingestion $(P<0.001)$ and did not differ between groups. The fraction of dietary protein-derived phenylalanine that appeared in the plasma over the 5-hour postprandial period was $55 \pm 3 \%$ and $62 \pm 4 \%$ in the diabetes and control groups, respectively $(P=0.2)$. Endogenous phenylalanine rates of appearance (Figure 5B) (i.e., the rate at which phenylalanine derived from whole body protein breakdown enters the circulation) decreased after the protein ingestion $(P<0.001)$, with no significant differences between groups. Total phenylalanine rates of disappearance (Figure $\mathbf{5 C}$ ) increased after the protein ingestion $(P<0.001)$, with no significant differences between groups. 

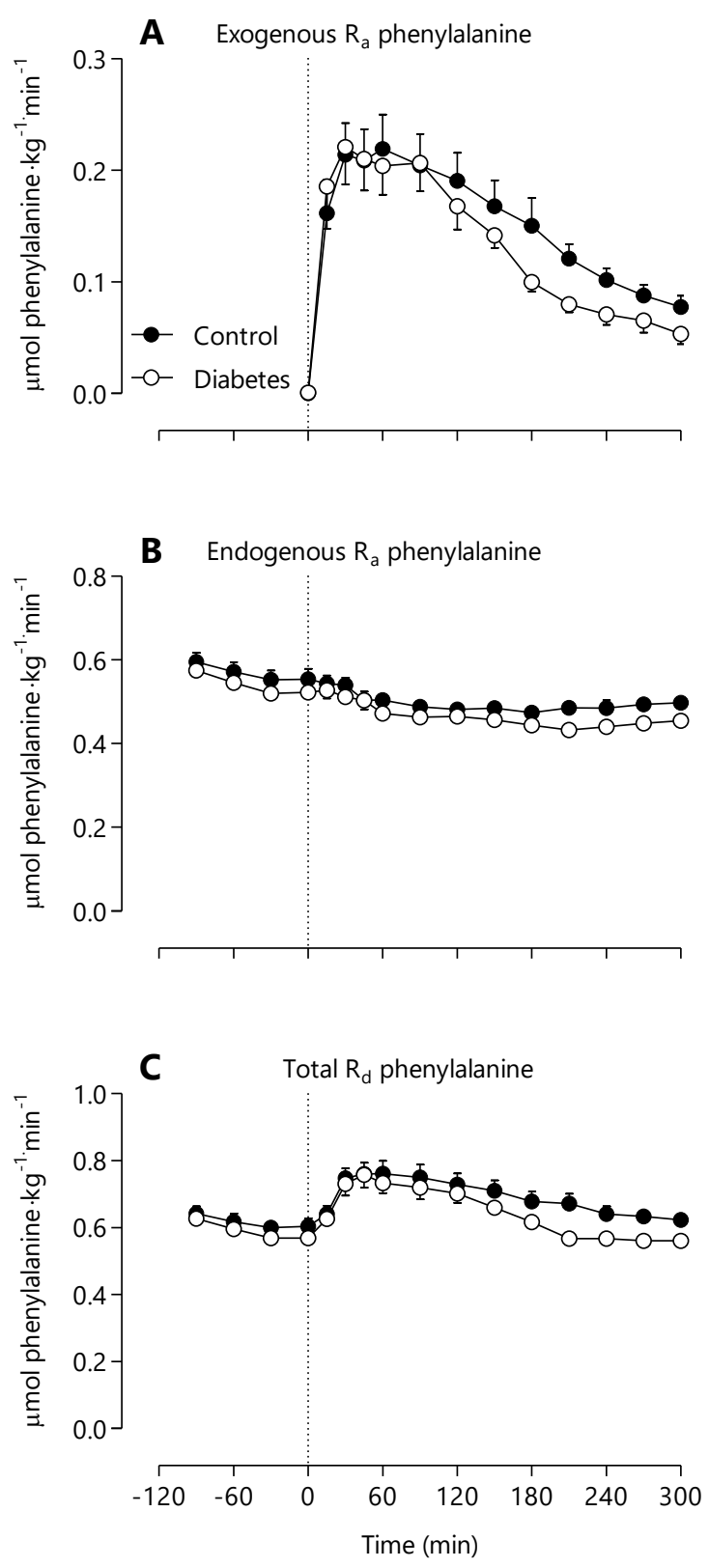

Figure 5 | Whole-body phenylalanine kinetics. Mean $( \pm S E M)$ exogenous rate of appearance (Ra, A), endogenous $\mathrm{Ra}(\mathbf{B})$, and total rate of disappearance $(\mathrm{Rd}, \mathbf{C})\left(\mu \mathrm{mol}\right.$ phenylalanine $\left.\cdot \mathrm{kg}^{-1} \cdot \mathrm{min}^{-1}\right)$ in healthy $(n=12)$ and type 2 diabetes $(n=11)$ elderly subjects following ingestion of $20 \mathrm{~g}$ casein. The dotted line indicates the ingestion of the protein beverage. Data were analysed with repeated measures (time $x$ group) ANOVA. Exogenous phenylalanine rates of appearance: time effect $P<0.001$. Endogenous phenylalanine rates of appearance: time effect $P<0.001$. Total phenylalanine rates of disappearance: time effect $P<0.001$. 
Postabsorptive and postprandial whole-body protein breakdown, synthesis, oxidation, and net balance are presented in Figure 6. No differences were observed in postabsorptive wholebody protein breakdown, synthesis, and oxidation rates between groups. Whole-body net protein balance did not differ between groups and averaged $0.7 \pm 0.1$ vs $0.2 \pm 0.2 \mu \mathrm{mol} \cdot \mathrm{h}^{-1}$. $\mathrm{kg}^{-1}$ phenylalanine in the diabetes and control groups, respectively. During the 5-hour postprandial period, whole-body protein breakdown decreased, and protein synthesis and oxidation rates significantly increased $(P<0.001)$, with no differences being observed between groups. Whole-body net protein balance increased in the postprandial state to $7.1 \pm 0.3$ and $7.8 \pm 0.6 \mu \mathrm{mol} \cdot \mathrm{h}^{-1} \cdot \mathrm{kg}^{-1}$ phenylalanine in the diabetes and control groups, respectively $(P<0.001)$ and did not differ between groups.
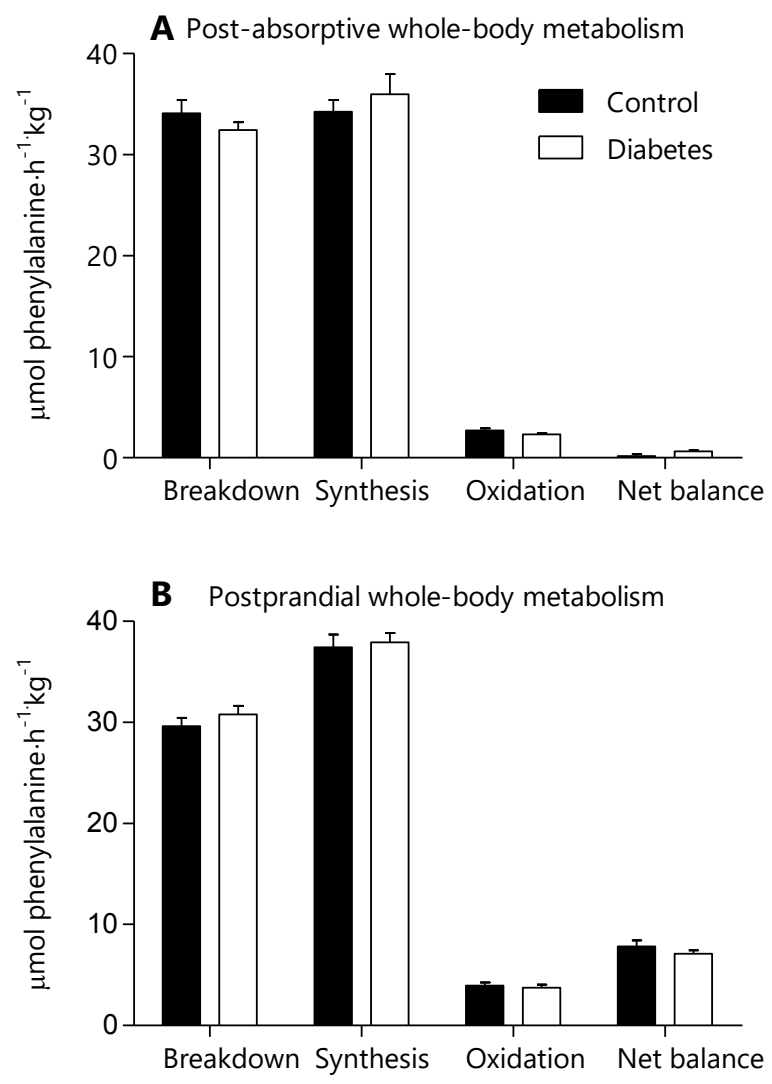

Figure 6 | Whole-body protein metabolism during the postabsorptive (A) and postprandial (B) state in healthy $(n=12)$ and type 2 diabetes $(n=11)$ older subjects following ingestion of $20 \mathrm{~g}$ casein. Values represent mean \pm SEM. Data were analyzed with unpaired Student's t-test (between groups) and repeated measures (time $x$ group) ANOVA. Whole-body protein synthesis rates: time effect $P<0.001$; whole-body protein breakdown rates: time effect $P<0.001$; interaction of time $x$ group $P<0.01$; whole-body protein oxidation rates: time effect $P<0.001$; whole-body protein net balance: time effect $P<0.001$; ${ }^{*}$ Significantly different from control, $P<0.05$. 


\section{Muscle protein synthesis}

Muscle tissue-free $\mathrm{L}-\left[\mathrm{ring}_{-}{ }^{2} \mathrm{H}_{5}\right]$-phenylalanine and $\mathrm{L}-\left[1-{ }^{13} \mathrm{C}\right]$-phenylalanine enrichments are presented in Table 2. Muscle intracellular-free $L$-[ring- $\left.{ }^{2} \mathrm{H}_{5}\right]$-phenylalanine enrichments increased in both the entire postabsorptive and postprandial states $(P<0.001)$ and decreased in the first 2 hours after the protein ingestion when compared with the basal values $(P<0.05)$, with no differences between groups. The muscle-intracellular free $L-\left[1-{ }^{13} C\right.$ phenylalanine enrichments were higher at 2 hours when compared with 5 hours $(P<0.001)$ and did not differ between groups.

Table 2 | Muscle tissue-free enrichments

\begin{tabular}{llcccc}
\hline & & $\mathbf{- 2 h}$ & $\mathbf{0 h}$ & $\mathbf{2 h}$ & $\mathbf{5 h}$ \\
\hline $\begin{array}{l}\left.\text { L-[ring- }{ }^{2} \mathbf{H}_{5}\right]- \\
\text { phenylalanine } \\
(\mathbf{M P E})\end{array}$ & Control $(n=12)$ & $4.08 \pm 0.20$ & $5.57 \pm 0.25$ & $4.88 \pm 0.20$ & $5.85 \pm 0.25$ \\
$\begin{array}{l}\text { L-[1-13} \mathbf{C}]- \\
\begin{array}{l}\text { phenylalanine } \\
\text { (MPE) }\end{array}\end{array}$ & Diabetes $(n=11)$ & $4.37 \pm 0.41$ & $5.50 \pm 0.39$ & $5.00 \pm 0.25$ & $5.91 \pm 0.18$ \\
\hline
\end{tabular}

Values are mean \pm SEM. MPE: mole percent excess. Data were analyzed by repeated measures (time $x$ group) ANOVA. L-[ring $\left.-{ }^{2} \mathrm{H}_{5}\right]$-phenylalanine: time effect $P<0.001$. L- $\left[1-{ }^{13} \mathrm{C}\right]$-phenylalanine: time effect $P<0.001$. There were no differences between groups.

Mixed-muscle protein synthesis rates, expressed as FSR, are presented in Figure 7A. Basal mixed-muscle protein $\mathrm{FSR}$, using the plasma L-[ring- $\left.{ }^{2} \mathrm{H}_{5}\right]$-phenylalanine enrichments as precursor, averaged $0.029 \pm 0.003$ and $0.029 \pm 0.003 \% \cdot \mathrm{h}^{-1}$ in the diabetes and control groups, respectively, with no significant differences between groups. After the protein ingestion, FSR values did not increase during the early stages of the postprandial period and averaged $0.027 \pm 0.005$ and $0.028 \pm 0.004 \% \cdot \mathrm{h}^{-1}$ during the first 2 hours of the postprandial phase $(0-2$ hours) in the diabetes and control groups, respectively $(P=0.7)$. Muscle protein synthesis rates were significantly higher in the later stage of the postprandial period (2-5 hours) when compared with the basal, postabsorptive values $\left(0.036 \pm 0.002\right.$ and $0.037 \pm 0.003 \% \cdot \mathrm{h}^{-1}$, respectively, $P<0.001)$. The postprandial increase in muscle protein synthesis rates was observed in the $2-5$-hour period after protein ingestion in both groups (time effect $P=0.04$, group $\times$ time interaction $P=0.9$ ), with no differences between groups $(P=0.8$, Figure 7A). Over the entire 5-hour postprandial period, FSR tended to be higher when compared with postabsorptive protein synthesis rates $(P=0.12)$, with values averaging $0.031 \pm 0.002$ and $0.033 \pm 0.002 \% \cdot \mathrm{h}^{-1}$ in the diabetes and control groups, respectively. Similar observations were obtained when mixed-muscle protein synthesis rates were calculated based on muscle-free phenylalanine enrichments as precursor pool (data not shown). Muscle protein-bound L-[1${ }^{13} \mathrm{C}$ ]-phenylalanine enrichments (Figure 7B) increased after the protein ingestion $(0.018 \pm 0.001$ and $0.019 \pm 0.002 \mathrm{MPE}$ in the diabetes and control groups, respectively, $P<0.001$ ), with no differences between groups. 

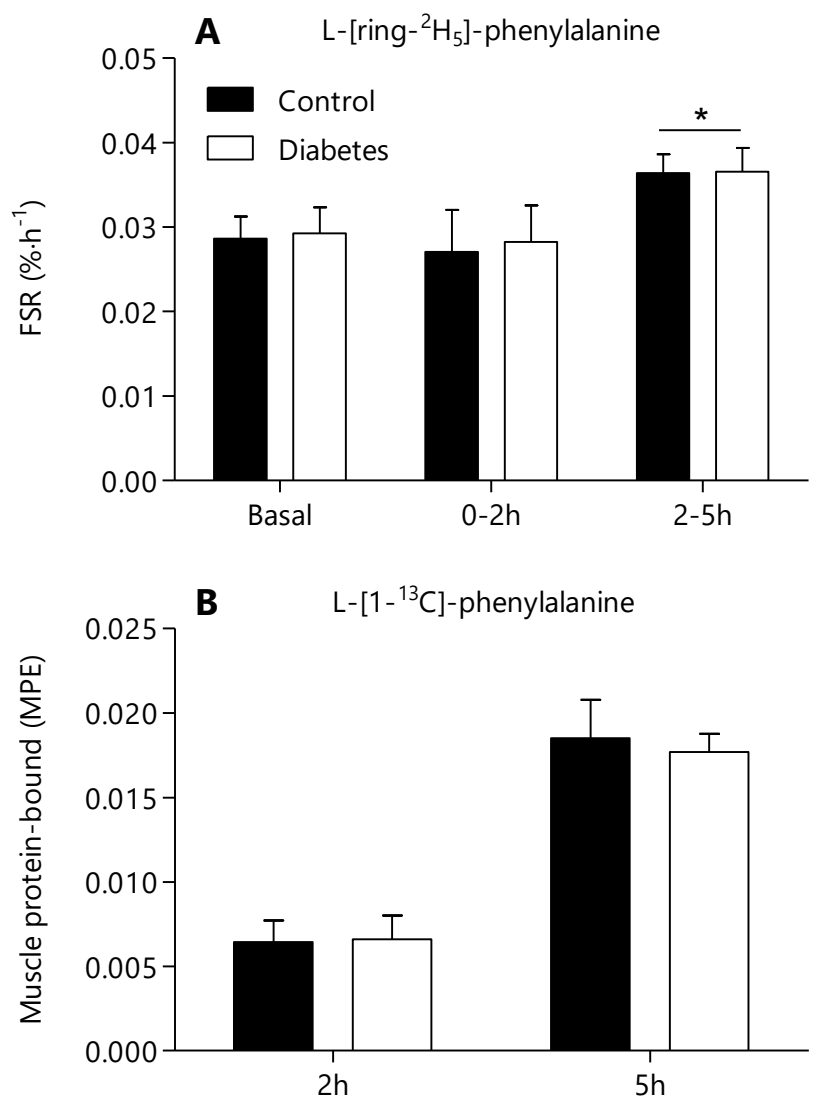

Figure 7 | Mean $\left( \pm\right.$ SEM) mixed-muscle protein FSR using iv L-[ring- $\left.{ }^{2} \mathrm{H}_{5}\right]$-phenylalanine infusion $\left(\mathbf{A} ;\right.$ in $\left(\% \cdot \mathrm{h}^{-1}\right)$ and dietary protein-derived muscle protein-bound L- $\left[1-{ }^{13} \mathrm{C}\right]$-phenylalanine enrichments $(\mathbf{B}$; in MPE) in healthy $(n=12)$ and type 2 diabetes $(n=11)$ older subjects after the ingestion of $20 \mathrm{~g}$ casein. Data were analyzed with an unpaired Student's $t$ test (between groups) and a repeated-measures (time $\times$ group) ANOVA. *, Significantly different from basal values $(P<0.001)$. Mixed-muscle $L$ - $\left[\right.$ ring $\left.-{ }^{2} \mathrm{H}_{5}\right]$-phenylalanine FSR comprised time effect $P=0.04,0-2$ hours compared with basal $P=0.7,2-5$ hours compared with basal $P<0.001$; muscle protein-bound $L-\left[1-{ }^{13} C\right]-$ phenylalanine enrichments comprised time effect $P<0.001$. 


\section{DISCUSSION}

In the present study, we show that basal muscle protein synthesis rates do not differ between older type 2 diabetes patients and age-matched, normoglycemic controls. Protein digestion and absorption kinetics did not differ between type 2 diabetes subjects and healthy controls. The postprandial rise in circulating insulin levels was greater in the type 2 diabetes patients when compared with healthy controls. Postprandial muscle protein synthesis rates and the use of dietary protein-derived amino acids for de novo muscle protein accretion did not differ between type 2 diabetes patients and normoglycemic controls.

We $[1,2]$ as well as others $[3,4]$ have previously shown that muscle mass loss with aging seems to be more pronounced in the type 2 diabetic state. Therefore, we compared basal protein metabolism between older diabetes patients and aged-matched healthy controls. On a wholebody level, we did not observe any significant differences in protein synthesis, breakdown, oxidation rates, and net protein balance between groups. In agreement, on a muscle tissue level, we did not detect differences in basal muscle protein synthesis rates between groups $\left(0.029 \pm 0.003\right.$ and $0.029 \pm 0.003 \% \cdot h^{-1}$ in the diabetes and control groups, respectively. These data extend on previous findings in type 2 diabetes patients [18-21, 23-25, 28] and show that basal muscle protein synthesis rates do not differ between older type 2 diabetes patients and age-matched, normoglycemic controls.

The combined application of iv amino acid tracer infusions with the ingestion of intrinsically labeled protein allows us to assess protein digestion and amino acid absorption kinetics. Upon ingestion of $20 \mathrm{~g}$ casein, we observed a rapid release of protein-derived phenylalanine into the circulation in both groups with $55 \pm 3 \%$ and $62 \pm 4 \%$ of the ingested protein-derived phenylalanine becoming available in the circulation in diabetes and controls, respectively. Consequently, protein ingestion resulted in a rapid rise in circulating plasma amino acid concentrations and a concomitant increase in endogenous insulin release. The postprandial insulin response was greater in the diabetes group compared with the control group (peak values: $23.3 \pm 2.6$ vs $11.9 \pm 2.1 \mathrm{mU} \cdot \mathrm{L}^{-1}$, respectively). This is not surprising because compensatory postprandial hyperinsulinemia is generally apparent in these patients, and amino acid-induced insulin secretion has previously been shown to be uncompromised, even in long-standing type 2 diabetes patients [36, 37].

During the early stages of the postprandial phase (0-2 hours) we did not observe a significant increase in muscle protein synthesis rates above basal, fasting values. However, muscle protein synthesis rates were significantly higher during the later stages of the postprandial phase (25 hours) when compared with the basal, postabsorptive values. A delay in the postprandial rise in muscle protein synthesis has been reported previously in the older population [22]. No differences were observed in the postprandial increase in muscle protein synthesis rates between the type 2 diabetes patients and their age-matched, normoglycemic controls. Because we applied intrinsically $L-\left[1-{ }^{13} C\right]$-phenylalanine-labeled casein $[29,30]$, we were also able to assess the metabolic fate of the dietary protein-derived phenylalanine toward de novo 
skeletal muscle protein accretion. We did not observe differences in L-[1-13C]-phenylalanine incorporation in mixed-muscle protein after the protein ingestion between groups at 2 and 5 hours after protein ingestion. To our knowledge, this is the first study measuring basal as well as postprandial muscle protein synthesis rates after the ingestion of a meal-like amount of protein [38] in older type 2 diabetes patients and age-matched, normoglycemic controls. Here we show that the use of dietary protein-derived amino acids for de novo muscle protein accretion does not differ between type 2 diabetes subjects and healthy controls when a meallike amount of dietary protein is consumed.

We hypothesized that the greater loss of skeletal muscle mass with aging in the type 2 diabetic state [1] is attributed to lower postprandial muscle protein synthesis rates. Previous work did not observe lower basal muscle protein synthesis rates in obese and insulin resistant subjects $[20,25,28,39]$. The present study shows no difference in the postprandial muscle protein synthetic response to the ingestion of a meal-like amount of protein between older type 2 diabetes patients and normoglycemic controls. The level of insulin resistance does not seem to modulate basal protein synthesis rates or postprandial protein handling in older type 2 diabetes patients when compared with age-matched, normoglycemic controls. However, it should be noted that basal and postprandial plasma insulin and leucine concentrations were elevated in the type 2 diabetic state. Therefore, it could be speculated that the prevalence of compensatory postprandial hyperinsulinemia (and/or leucinemia) in the type 2 diabetes patients may have compensated for the level of insulin resistance (and possibly leucine resistance) in the muscle protein synthetic response to feeding.

Based on our findings, we can only conclude that the proposed greater decline in skeletal muscle mass with aging in the type 2 diabetic state is not attributed to a decline in basal, postabsorptive protein synthesis rates, impairments in dietary protein digestion and absorption, or the reduced postprandial muscle protein synthetic response. It could be speculated that higher basal muscle protein breakdown rates and/or reduced postprandial inhibition of proteolysis may be prevalent in an insulin-resistant state. Some studies suggest higher basal muscle or whole-body protein breakdown rates in an insulin resistant state [23, $25,26,28,39-42]$. However, others have failed to confirm these findings [21, 22, 43, 44]. The few studies that assessed postprandial muscle protein breakdown rates in vivo in man $[9,45-$ 47] find little evidence to suggest that the postprandial inhibition of proteolysis is blunted in the type 2 diabetic state $[21,22]$. In the present study, we observed no differences in basal or postprandial whole-body protein breakdown rates between diabetes patients and their normoglycemic controls. However, because whole-body protein breakdown rates do not necessarily reflect skeletal muscle tissue per se, we can only speculate on the contribution of greater postabsorptive muscle protein breakdown rates or a blunted muscle proteolytic response to feeding in the type 2 diabetic state. Moreover, multiple other factors such as medication use, systemic inflammation, neurological deficits associated with type 2 diabetes, and/or differences in lifestyle and daily living activities $[1,2,48]$ may be responsible for the accelerated loss of muscle mass and strength in type 2 diabetes patients. 
In conclusion, postabsorptive and postprandial muscle protein synthesis rates are not reduced in older type 2 diabetes patients when compared with age-matched, normoglycemic controls. The more pronounced loss of skeletal muscle mass and strength in older type 2 diabetes patients does not seem to be attributed to a greater level of anabolic resistance.

\section{ACKNOWLEDGEMENTS}

We gratefully acknowledge Dr. Benjamin T. Wall for his assistance while writing the manuscript, and the enthusiastic support of the subjects who volunteered to participate in these experiments. 


\section{REFERENCES}

1. Leenders, M., L.B. Verdijk, L. van der Hoeven, J.J. Adam, J. van Kranenburg, R. Nilwik, and L.J. van Loon, Patients with type 2 diabetes show a greater decline in muscle mass, muscle strength, and functional capacity with aging. J Am Med Dir Assoc, 2013. 14(8): p. 585-92.

2. Groen, B.B., H.M. Hamer, T. Snijders, J. van Kranenburg, D. Frijns, H. Vink, and L.J. van Loon, Skeletal muscle capillary density and microvascular function are compromised with aging and type 2 diabetes. J Appl Physiol (1985), 2014. 116(8): p. 998-1005.

3. Park, S.W., B.H. Goodpaster, J.S. Lee, L.H. Kuller, R. Boudreau, N. de Rekeneire, T.B. Harris, S. Kritchevsky, F.A. Tylavsky, M. Nevitt, Y.W. Cho, and A.B. Newman, Excessive loss of skeletal muscle mass in older adults with type 2 diabetes. Diabetes Care, 2009. 32(11): p. 1993-7.

4. Kim, T.N., M.S. Park, S.J. Yang, H.J. Yoo, H.J. Kang, W. Song, J.A. Seo, S.G. Kim, N.H. Kim, S.H. Baik, D.S. Choi, and K.M. Choi, Prevalence and determinant factors of sarcopenia in patients with type 2 diabetes: the Korean Sarcopenic Obesity Study (KSOS). Diabetes Care, 2010. 33(7): p. 1497-9.

5. Burd, N.A., S.H. Gorissen, and L.J. van Loon, Anabolic resistance of muscle protein synthesis with aging. Exerc Sport Sci Rev, 2013. 41(3): p. 169-73.

6. Koopman, R. and L.J. van Loon, Aging, exercise, and muscle protein metabolism. Journal of applied physiology, 2009. 106(6): p. 2040-8.

7. Cuthbertson, D., K. Smith, J. Babraj, G. Leese, T. Waddell, P. Atherton, H. Wackerhage, P.M. Taylor, and M.J. Rennie, Anabolic signaling deficits underlie amino acid resistance of wasting, aging muscle. FASEB J, 2005. 19(3): p. 422-4.

8. Katsanos, C.S., H. Kobayashi, M. Sheffield-Moore, A. Aarsland, and R.R. Wolfe, A high proportion of leucine is required for optimal stimulation of the rate of muscle protein synthesis by essential amino acids in the elderly. Am J Physiol Endocrinol Metab, 2006. 291(2): p. E381-7.

9. Volpi, E., B. Mittendorfer, B.B. Rasmussen, and R.R. Wolfe, The response of muscle protein anabolism to combined hyperaminoacidemia and glucose-induced hyperinsulinemia is impaired in the elderly. J Clin Endocrinol Metab, 2000. 85(12): p. 4481-90.

10. Rasmussen, B.B., S. Fujita, R.R. Wolfe, B. Mittendorfer, M. Roy, V.L. Rowe, and E. Volpi, Insulin resistance of muscle protein metabolism in aging. FASEB J, 2006. 20(6): p. 768-9.

11. Katsanos, C.S., H. Kobayashi, M. Sheffield-Moore, A. Aarsland, and R.R. Wolfe, Aging is associated with diminished accretion of muscle proteins after the ingestion of a small bolus of essential amino acids. Am J Clin Nutr, 2005. 82(5): p. 1065-73.

12. Pennings, B., B. Groen, A. de Lange, A.P. Gijsen, A.H. Zorenc, J.M. Senden, and L.J. van Loon, Amino acid absorption and subsequent muscle protein accretion following graded intakes of whey protein in elderly men. American journal of physiology. Endocrinology and metabolism, 2012. 302(8): p. E992-9.

13. Rasmussen, B.B., R.R. Wolfe, and E. Volpi, Oral and intravenously administered amino acids produce similar effects on muscle protein synthesis in the elderly. J Nutr Health Aging, 2002. 6(6): p. 358-62.

14. Guillet, C., M. Prod'homme, M. Balage, P. Gachon, C. Giraudet, L. Morin, J. Grizard, and Y. Boirie, Impaired anabolic response of muscle protein synthesis is associated with S6K1 dysregulation in elderly humans. FASEB J, 2004. 18(13): p. 1586-7.

15. Fry, C.S. and B.B. Rasmussen, Skeletal Muscle Protein Balance and Metabolism in the Elderly. Curr Aging Sci, 2011.

16. Fujita, S., E.L. Glynn, K.L. Timmerman, B.B. Rasmussen, and E. Volpi, Supraphysiological hyperinsulinaemia is necessary to stimulate skeletal muscle protein anabolism in older adults: evidence of a true age-related insulin resistance of muscle protein metabolism. Diabetologia, 2009. 52(9): p. 1889-98.

17. Guillet, C. and Y. Boirie, Insulin resistance: a contributing factor to age-related muscle mass loss? Diabetes Metab, 2005. 31 Spec No 2: p. 5S20-5S26. 
18. Halvatsiotis, P.G., D. Turk, A. Alzaid, S. Dinneen, R.A. Rizza, and K.S. Nair, Insulin effect on leucine kinetics in type 2 diabetes mellitus. Diabetes, nutrition \& metabolism, 2002. 15(3): p. 136-42.

19. Manders, R.J., R. Koopman, M. Beelen, A.P. Gijsen, W.K. Wodzig, W.H. Saris, and L.J. van Loon, The muscle protein synthetic response to carbohydrate and protein ingestion is not impaired in men with longstanding type 2 diabetes. J Nutr, 2008. 138(6): p. 1079-85.

20. Lugli, A.K., F. Donatelli, T. Schricker, L. Wykes, and F. Carli, Preoperative glucose and protein metabolism: the influence of diabetes mellitus type 2 in patients with colorectal tumors. Nutr Cancer, 2011. 63(6): p. 924-9.

21. Bell, J.A., E. Volpi, S. Fujita, J.G. Cadenas, M. Sheffield-Moore, and B.B. Rasmussen, Skeletal muscle protein anabolic response to increased energy and insulin is preserved in poorly controlled type 2 diabetes. J Nutr, 2006. 136(5): p. 1249-55.

22. Short, K.R., B.A. Irving, A. Basu, C.M. Johnson, K.S. Nair, and R. Basu, Effects of type 2 diabetes and insulin on whole-body, splanchnic, and leg protein metabolism. J Clin Endocrinol Metab, 2012. 97(12): p. 4733-41.

23. Gougeon, R., K. Styhler, J.A. Morais, P.J. Jones, and E.B. Marliss, Effects of oral hypoglycemic agents and diet on protein metabolism in type 2 diabetes. Diabetes Care, 2000. 23(1): p. 1-8.

24. Tessari, P., D. Cecchet, A. Cosma, L. Puricelli, R. Millioni, M. Vedovato, and A. Tiengo, Insulin resistance of amino acid and protein metabolism in type 2 diabetes. Clin Nutr, 2011. 30(3): p. 26772.

25. Pereira, S., E.B. Marliss, J.A. Morais, S. Chevalier, and R. Gougeon, Insulin resistance of protein metabolism in type 2 diabetes. Diabetes, 2008. 57(1): p. 56-63.

26. Biolo, G., P. Tessari, S. Inchiostro, D. Bruttomesso, L. Sabadin, C. Fongher, G. Panebianco, M.G. Fratton, and A. Tiengo, Fasting and postmeal phenylalanine metabolism in mild type 2 diabetes. Am J Physiol, 1992. 263(5 Pt 1): p. E877-83.

27. Bassil, M., E.B. Marliss, J.A. Morais, S. Pereira, S. Chevalier, and R. Gougeon, Postprandial hyperaminoacidaemia overcomes insulin resistance of protein anabolism in men with type 2 diabetes. Diabetologia, 2011. 54(3): p. 648-56.

28. Halvatsiotis, P., K.R. Short, M. Bigelow, and K.S. Nair, Synthesis rate of muscle proteins, muscle functions, and amino acid kinetics in type 2 diabetes. Diabetes, 2002. 51(8): p. 2395-404.

29. Pennings, B., W.F. Pellikaan, J.M. Senden, A.M. van Vuuren, J. Sikkema, and L.J. van Loon, The production of intrinsically labeled milk and meat protein is feasible and provides functional tools for human nutrition research. Journal of dairy science, 2011. 94(9): p. 4366-73.

30. van Loon, L.J., Y. Boirie, A.P. Gijsen, J. Fauquant, A.L. de Roos, A.K. Kies, S. Lemosquet, W.H. Saris, and R. Koopman, The production of intrinsically labeled milk protein provides a functional tool for human nutrition research. Journal of dairy science, 2009. 92(10): p.4812-22.

31. Alberti, K.G. and P.Z. Zimmet, Definition, diagnosis and classification of diabetes mellitus and its complications. Part 1: diagnosis and classification of diabetes mellitus provisional report of a WHO consultation. Diabetic medicine : a journal of the British Diabetic Association, 1998. 15(7): p. 53953.

32. Abumrad, N.N., D. Rabin, M.P. Diamond, and W.W. Lacy, Use of a heated superficial hand vein as an alternative site for the measurement of amino acid concentrations and for the study of glucose and alanine kinetics in man. Metabolism: clinical and experimental, 1981. 30(9): p. 936-40.

33. Bergstrom, J., Percutaneous needle biopsy of skeletal muscle in physiological and clinical research. Scand J Clin Lab Invest, 1975. 35(7): p. 609-16.

34. Wolfe, R.R. and D.L. Chinkes, Isotope tracers in metabolic research: Principles and practice of kinetic analysis. 2 ed. 2005, Hoboken, New Jersey: John Wiley and Sons, Inc.

35. Boirie, Y., P. Gachon, S. Corny, J. Fauquant, J.L. Maubois, and B. Beaufrere, Acute postprandial changes in leucine metabolism as assessed with an intrinsically labeled milk protein. Am J Physiol, 1996. 271(6 Pt 1): p. E1083-91. 
36. van Loon, L.J., M. Kruijshoop, P.P. Menheere, A.J. Wagenmakers, W.H. Saris, and H.A. Keizer, Amino acid ingestion strongly enhances insulin secretion in patients with long-term type 2 diabetes. Diabetes Care, 2003. 26(3): p. 625-30.

37. Manders, R.J., A.J. Wagenmakers, R. Koopman, A.H. Zorenc, P.P. Menheere, N.C. Schaper, W.H. Saris, and L.J. van Loon, Co-ingestion of a protein hydrolysate and amino acid mixture with carbohydrate improves plasma glucose disposal in patients with type 2 diabetes. Am J Clin Nutr, 2005. 82(1): p. 76-83.

38. Tieland, M., K.J. Borgonjen-Van den Berg, L.J. van Loon, and L.C. de Groot, Dietary protein intake in community-dwelling, frail, and institutionalized elderly people: scope for improvement. European journal of nutrition, 2012. 51(2): p. 173-9.

39. Luzi, L., A.S. Petrides, and R.A. De Fronzo, Different sensitivity of glucose and amino acid metabolism to insulin in NIDDM. Diabetes, 1993. 42(12): p. 1868-77.

40. Welle, S. and K.S. Nair, Failure of glyburide and insulin treatment to decrease leucine flux in obese type II diabetic patients. Int J Obes, 1990. 14(8): p. 701-10.

41. Barazzoni, R., E. Kiwanuka, M. Zanetti, M. Cristini, M. Vettore, and P. Tessari, Insulin acutely increases fibrinogen production in individuals with type 2 diabetes but not in individuals without diabetes. Diabetes, 2003. 52(7): p. 1851-6.

42. Tessari, P., A. Coracina, E. Kiwanuka, M. Vedovato, M. Vettore, A. Valerio, M. Zaramella, and G. Garibotto, Effects of insulin on methionine and homocysteine kinetics in type 2 diabetes with nephropathy. Diabetes, 2005. 54(10): p. 2968-76.

43. Gougeon, R., P.B. Pencharz, and E.B. Marliss, Effect of NIDDM on the kinetics of whole-body protein metabolism. Diabetes, 1994. 43(2): p. 318-28.

44. Denne, S.C., G. Brechtel, A. Johnson, E.A. Liechty, and A.D. Baron, Skeletal muscle proteolysis is reduced in noninsulin-dependent diabetes mellitus and is unaltered by euglycemic hyperinsulinemia or intensive insulin therapy. J Clin Endocrinol Metab, 1995. 80(8): p. 2371-7.

45. Wilkes, E.A., A.L. Selby, P.J. Atherton, R. Patel, D. Rankin, K. Smith, and M.J. Rennie, Blunting of insulin inhibition of proteolysis in legs of older subjects may contribute to age-related sarcopenia. Am J Clin Nutr, 2009. 90(5): p. 1343-50.

46. Guillet, C., I. Delcourt, M. Rance, C. Giraudet, S. Walrand, M. Bedu, P. Duche, and Y. Boirie, Changes in basal and insulin and amino acid response of whole body and skeletal muscle proteins in obese men. The Journal of clinical endocrinology and metabolism, 2009. 94(8): p. 3044-50.

47. Tessari, P., M. Zanetti, R. Barazzoni, M. Vettore, and F. Michielan, Mechanisms of postprandial protein accretion in human skeletal muscle. Insight from leucine and phenylalanine forearm kinetics. J Clin Invest, 1996. 98(6): p. 1361-72.

48. van Dijk, J.W., M. Venema, W. van Mechelen, C.D. Stehouwer, F. Hartgens, and L.J. van Loon, Effect of moderate-intensity exercise versus activities of daily living on 24-hour blood glucose homeostasis in male patients with type 2 diabetes. Diabetes Care, 2013. 36(11): p. 3448-53. 


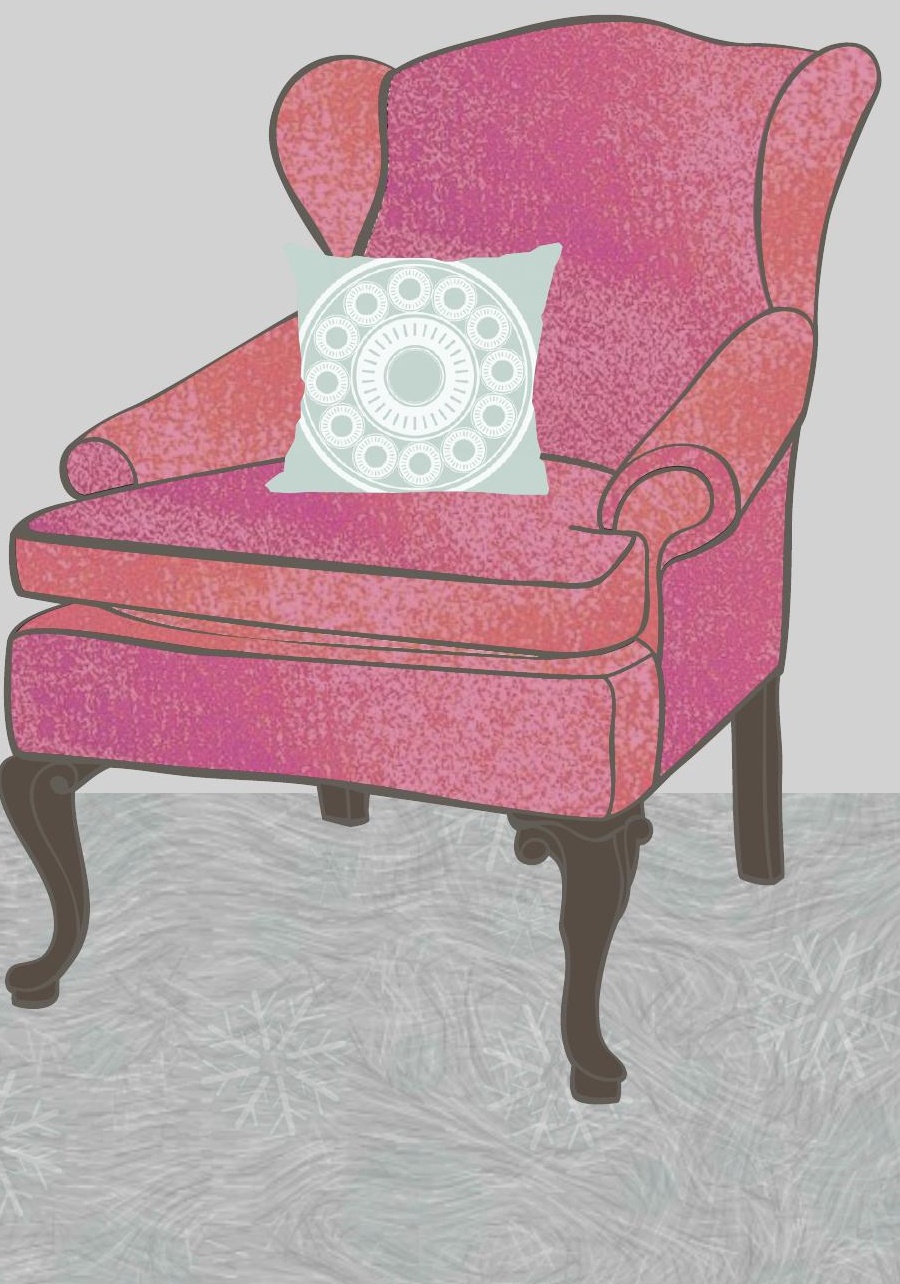




\section{CHAPTER FIVE}

\section{BASAL AND POSTPRANDIAL MYOFIBRILLAR PROTEIN SYNTHESIS RATES DO NOT DIFFER BETWEEN LEAN AND OBESE MALES}

Imre W.K. Kouw, Jan Willem van Dijk, Astrid M.H. Horstman, Irene Fleur Kramer, Joy P.B. Goessens, François M.H. van Dielen, Lex B. Verdijk, and LuC J.C. van Loon 


\section{ABSTRACT}

Introduction: Excess lipid availability has been associated with the development of anabolic resistance. As such, obesity may be accompanied by impairments in muscle protein metabolism. We hypothesized that basal and postprandial muscle protein synthesis rates are lower in obese when compared to lean men.

Methods: $\quad$ Twelve normoglycemic, obese men (age: $48 \pm 2 \mathrm{y}, \mathrm{BMI}: 37.0 \pm 1.5 \mathrm{~kg} \cdot \mathrm{m}^{-2}$, body fat: $32 \pm 2 \%$ ) and twelve age-matched, lean controls (age: $43 \pm 3$ y, BMl: $23.4 \pm 0.4 \mathrm{~kg} \cdot \mathrm{m}^{-2}$, body fat: $21 \pm 1 \%$ received primed continuous L-[ring ${ }^{2} \mathrm{H}_{5}$ ]phenylalanine and L-[ring-3, $\left.-^{2} \mathrm{H}_{2}\right]$-tyrosine infusions, and ingested $25 \mathrm{~g}$ intrinsically $\mathrm{L}-\left[1-{ }^{13} \mathrm{C}\right]$-phenylalanine labeled whey protein. Repeated blood and muscle samples were obtained to assess protein digestion and amino acid absorption kinetics, and basal and postprandial myofibrillar protein synthesis rates.

Results: $\quad$ Exogenous phenylalanine appearance rates increased following protein ingestion in both groups $(P<0.001)$, with a total of $53 \pm 1$ and $53 \pm 2 \%$ of dietary protein-derived phenylalanine appearing in the circulation over the $5 \mathrm{~h}$ postprandial period in lean and obese subjects, respectively $(P=0.82)$. Myofibrillar protein synthesis rates increased from $0.030 \pm 0.002$ and $0.028 \pm 0.003 \% \cdot \mathrm{h}^{-1}$ in the postabsorptive period to $0.034 \pm 0.002$ and $0.035 \pm 0.003 \% \mathrm{~h}^{-1}$ in the $5 \mathrm{~h}$ postprandial period (main time effect, $P=0.03$ ) in lean and obese subjects, respectively, with no differences between groups (time $\mathrm{x}$ group interaction, $P=0.58$ ).

Conclusion: Basal, postabsorptive myofibrillar protein synthesis rates do not differ between lean and obese males. Postprandial protein handling, including protein digestion and amino acid absorption, and the postprandial muscle protein synthetic response following the ingestion of $25 \mathrm{~g}$ whey protein are not impaired in obese men. 


\section{INTRODUCTION}

Skeletal muscle mass maintenance is largely regulated by diurnal rates of muscle protein synthesis and breakdown. It has been well established that the postprandial rise in amino acid concentrations following the ingestion of dietary protein stimulates muscle protein synthesis [1-3]. More recent work shows that aging, inactivity, and/or insulin resistance are associated with a reduced responsiveness to the anabolic properties of amino acid and protein ingestion [4-6]. This anabolic resistance to protein intake is now believed to represent a key factor responsible for accelerated (age-related) muscle loss $[5,7,8]$. Skeletal muscle insulin resistance may play an important role in the development of this age-related anabolic resistance [9-11]. Recently, we showed that the muscle protein synthetic response to amino acid administration is blunted under conditions of lipid oversupply [12]. Lipid accumulation in skeletal muscle occurs in response to prolonged obesity and is associated with metabolic dysfunction including reduced insulin sensitivity $[13,14]$. Consequently, it is hypothesized that obesity is accompanied by impairments in muscle protein metabolism [15-17].

Only few studies have examined basal and/or postprandial muscle protein synthesis rates in obese individuals [17-22], and even fewer have made direct comparisons between overweight or obese participants and lean controls [22-27]. Data obtained from these studies demonstrate that obese individuals experience either impairments $[23,26]$ or no differences $[18,20,22,24$, $25]$ in basal, postabsorptive muscle protein synthesis rates when compared to lean controls. Studies examining the postprandial period following protein administration have shown similar [26] or impaired [24, 26] muscle protein synthesis rates in obese subjects when compared with lean controls. However, previous studies have typically been performed under hyperinsulinemic-hyperaminoacidemic clamp conditions, which do not represent a normal physiological response to the ingestion of a single meal-like amount of dietary protein. Recently, Beals et al. compared the postprandial muscle protein synthetic response following the ingestion of $170 \mathrm{~g}$ pork meat ( $36 \mathrm{~g}$ protein) between young lean, overweight, and obese subjects [25]. In this study, the muscle protein synthetic response to protein ingestion was lower in both overweight and obese young subjects when compared with healthy-weight controls [25]. Smeuninx and colleagues showed that the presence of obesity in older individuals does not further impair the anabolic response to the ingestion of a moderate $15 \mathrm{~g}$ protein dose in obese subjects when compared with lean controls [22]. It remains unclear whether the muscle protein synthetic response is impaired in middle-aged, obese individuals following the ingestion of a meal-like amount of dietary protein and whether this could be attributed to impairments in protein digestion and amino acid absorption kinetics and/or an attenuated rise in postprandial muscle protein synthesis rates when compared with lean controls.

In the present study, we combined contemporary stable isotope amino acid infusions with the ingestion of intrinsically labeled protein $[22,23]$ to compare basal, postabsorptive muscle protein synthesis rates, dietary protein digestion and amino acid absorption kinetics, and 
subsequent postprandial muscle protein synthesis rates following the ingestion of $25 \mathrm{~g}$ whey between middle-aged, normoglycemic, lean and obese men. We hypothesized that basal and postprandial muscle protein synthesis rates would be lower in obese subjects when compared to age-matched, lean controls. 


\section{METHODS}

\section{Subjects}

Healthy, recreationally active, middle-aged (age: 30-55 y) lean (BMI: $19-25 \mathrm{~kg} \cdot \mathrm{m}^{-2}$ ) and obese $\left(B M l>30 \mathrm{~kg} \cdot \mathrm{m}^{-2}\right)$ men were recruited by advertisements in local newspapers to participate in a single experimental stable isotope tracer infusion trial. Subjects were informed of the nature and possible risks of the experimental procedures prior to providing written informed consent. The subjects were deemed healthy based on their responses to a medical questionnaire and screening results. The trial was conducted between October 2013 and June 2015 at Maastricht University Medical Centre+, the Netherlands. The study was part of a larger project on muscle protein metabolism in middle-aged individuals. This study was approved by the Medical Ethical Committee of the Maastricht University Medical Centre+ (registered at www.trialregister.nl as NTR4060) and conformed to the standards for the use of human subjects in research as outlined in the latest version of the Declaration of Helsinki.

\section{Pretesting}

All subjects participated in a screening session to assess their $\mathrm{HbA}_{1 \mathrm{C}}$, glucose tolerance $(2 \mathrm{~h}$ oral glucose tolerance test (OGTT) [28]), blood pressure, weight, height, and body composition. Fat mass, fat free mass (FFM), and bone mineral content were determined by dual-energy x-ray absorptiometry (DXA) scan (Hologic Inc., DXA; Discovery A, QDR series, Marlborough, USA). Whole-body and regional lean mass, percent body fat, and visceral adipose tissue (VAT) were determined using the software package Apex (en-CORE 2005, version 9.15.00 Hologic, Marlborough, USA) and reference values from the NHANES population-based dataset [29]. A single slice CT-scan (Philips Brilliance 64, Philips Medical Systems, Best, the Netherlands) was performed to assess upper leg muscle cross sectional area (CSA). The scanning characteristics were as follows: $120 \mathrm{kV}, 300 \mathrm{~mA}$, rotation time of $0.75 \mathrm{~s}$, and a field of view of $500 \mathrm{~mm}$. With subjects lying supine with their legs extended and feet secured, a $3 \mathrm{~mm}$ thick axial image was taken $15 \mathrm{~cm}$ proximal to the top of the patella. Intermuscular adipose tissue was defined using radiation attenuation ranges from -190 to -30 Hounsfield units $(\mathrm{HU})$, muscle area of the legs was selected between -29 and +150 HU [30], after which the thigh muscles, quadriceps muscle and femoral bone were selected by manual tracing using ImageJ software (version 1.45d, National Institute of Health, Maryland, USA) [31, 32]. All subjects were instructed to refrain from strenuous physical activity and to maintain their diet as constant as possible for $2 \mathrm{~d}$ prior to the experimental infusion. On the evening before the trial, a standardized meal was consumed (2.3 MJ; composed of 19 percent energy (En\%) protein, 40 En\% carbohydrate, and 41 En\% fat). Prior to the experimental test, habitual physical activity was assessed using a validated triaxial accelerometer (Actigraph GTX3, Actigraph Inc., Pensacola, USA) worn in a belt around the waist over a $5 \mathrm{~d}$ period. Habitual physical activity was determined by the sum of accelerometer counts of a $24 \mathrm{~h}$ period. Analysis 
was carried our using software (Actilife, version 6, Actigraph Inc., Pensacola, USA). The collected data was analyzed for total time spent in different activity levels (sedentary, light, moderate, vigorous and, very vigorous activities) and step counts.

\section{Experimental protocol}

At 08:00 AM, following an overnight fast, subjects arrived at the laboratory by car or public transport. A Teflon catheter was inserted into an antecubital vein for infusion and a second cannula into the dorsal hand vein of the contralateral arm for arterialized blood sampling [33]. After baseline blood collection ( $t=-210 \mathrm{~min}$ ), the plasma phenylalanine and tyrosine pools were primed with a single intravenous dose (priming dose) of $\mathrm{L}$-[ring- ${ }^{2} \mathrm{H}_{5}$ ]-phenylalanine (3.6 $\mu \mathrm{mol} \cdot \mathrm{kg}^{-1} \mathrm{FFM}$ ) and $\mathrm{L}$-[ring-3,5-2 $\mathrm{H}_{2}$ ]-tyrosine (1.1 $\left.\mu \mathrm{mol} \cdot \mathrm{kg}^{-1} \mathrm{FFM}\right)$. Subsequently, the continuous infusion was initiated (infusion rate: $0.060 \mu \mathrm{mol} \cdot \mathrm{kg}^{-1} \mathrm{FFM} \cdot \mathrm{min}^{-1} \mathrm{~L}-\left[\mathrm{ring}^{-2} \mathrm{H}_{5}\right]_{-}$ phenylalanine and $0.018 \mu \mathrm{mol} \cdot \mathrm{kg}^{-1} \mathrm{FFM} \cdot \mathrm{min}^{-1} \mathrm{~L}$-[ring- $\left.{ }^{2} \mathrm{H}_{2}\right]$-tyrosine), and maintained for $8.5 \mathrm{~h}$. Multiple blood samples were collected during the infusion at $t=-210,-120,-90,-60,-30,0$, $20,40,60,90,120,150,180,240$, and $300 \mathrm{~min}$ for the analysis of plasma amino acid concentrations and enrichments, glucose and insulin concentrations, and non-esterified fatty acids (NEFA). Basal triacylglycerol (TAG) concentrations and plasma interleukin-6 (IL-6) concentrations were analyzed in $t=-210 \mathrm{~min}$. Blood samples were collected in EDTAcontaining tubes and centrifuged at $1000 \mathrm{~g}$ at $4^{\circ} \mathrm{C}$ for $10 \mathrm{~min}$. Aliquots of plasma were then immediately frozen in liquid nitrogen and stored at $-80^{\circ} \mathrm{C}$. Muscle biopsies were collected at $t$ $=-120$ and 0 min for the determination of postabsorptive muscle protein synthesis rates. Immediately following the second biopsy ( $t=0 \mathrm{~min}$, from the contralateral leg), subjects ingested a single bolus of $25 \mathrm{~g}$ intrinsically $\mathrm{L}-\left[1-{ }^{13} \mathrm{C}\right]$-phenylalanine labeled whey dissolved in $350 \mathrm{~mL}$ water, which was flavored with $1.5 \mathrm{~mL}$ vanilla (IMCD Benelux N.V., Rotterdam, the Netherlands). Additional biopsies were then collected at $t=120$ and $300 \mathrm{~min}$ (alternating between legs) relative to the ingestion of the drink for the measurement of postprandial muscle protein synthesis rates. Muscle biopsies were randomized between legs and collected from the middle region of the vastus lateralis $(15 \mathrm{~cm}$ above the patella) using the Bergström needle technique [34]. All biopsy samples were freed from any visible adipose tissue and blood, immediately frozen in liquid nitrogen, and stored at $-80^{\circ} \mathrm{C}$ until subsequent analysis. 


\section{Production of intrinsically labeled protein}

Intrinsically $L-\left[1-{ }^{13} \mathrm{C}\right]$-phenylalanine labeled whey protein was obtained by infusing a lactating Holstein cow with $\mathrm{L}-\left[1{ }^{13} \mathrm{C}\right]$-phenylalanine $\left(455 \mu \mathrm{mol} \cdot \mathrm{min}^{-1}\right)$, collecting milk, and purifying the whey fraction as described previously [35-37]. The enrichment of $L-\left[1-{ }^{13} \mathrm{C}\right]$-phenylalanine in the whey protein was 7.6 mole percent excess (MPE), respectively. The whey protein met all chemical and bacteriological specifications for human consumption.

\section{Plasma analyses}

Plasma glucose, NEFA, and TAG concentrations were analyzed using enzymatic assays on an automated spectrophotometer (ABX Pentra 400 autoanalyser, Horiba ANX, Montpellier, France). Plasma insulin concentrations were determined with radioimmunoassay (RIA) kits (Human Insulin specific RIA, Millipore Corporation, MA, USA). Plasma IL-6 concentrations were measured using an enzyme-linked immunosorbent assay (ELISA) kit (Human Prolnflammatory IL-6, Thermofischer, Bender MedSystems GmbG, Vienna, Austria). Plasma amino acid concentrations and enrichments were determined by gas chromatography-mass spectrometry analysis (GC-MS; Agilent 7890A GC/5975C; MSD, Little Falls, USA). Specifically, internal standards of $\left[\mathrm{U}-{ }^{13} \mathrm{C}_{6}\right]$-leucine, $\left[\mathrm{U}-{ }^{13} \mathrm{C}_{9}{ }^{15} \mathrm{~N}\right]$-phenylalanine, and $\left[\mathrm{U}-{ }^{13} \mathrm{C}_{9}{ }^{15} \mathrm{~N}\right]$-tyrosine were added to the plasma samples. Plasma samples were deproteinized on ice with dry 5-sulfosalicylic acid. Free amino acids were purified using cation exchange chromatography (AG 50W-X8 resin, 100-200 $\mu \mathrm{m}$ dry mesh size; Bio-Rad Laboratories, Hercules, USA). The free amino acids were converted to their N-tert-butyl dimethylsilyl (MTBSTFA) derivative before analysis by GCMS. The amino acid concentrations were determined using electron impact ionization by monitoring ions at mass/charge $(\mathrm{m} / \mathrm{z}) 336$ and 346 for unlabeled and $\left[\mathrm{U}-{ }^{13} \mathrm{C}_{9}{ }^{15} \mathrm{~N}\right]$ labeledphenylalanine respectively, and 466 and 476 for unlabeled and $\left[\mathrm{U}-{ }^{13} \mathrm{C}_{9}{ }^{15} \mathrm{~N}\right]$-tyrosine, respectively. The plasma phenylalanine and tyrosine ${ }^{13} \mathrm{C}$ and ${ }^{2} \mathrm{H}$ enrichments were determined using selective ion monitoring at $\mathrm{m} / \mathrm{z} 336,337$, and 341 for unlabeled and labeled $\left(1-{ }^{13} \mathrm{C}\right.$ and ring- ${ }^{2} \mathrm{H}_{5}$ )-phenylalanine respectively, and $\mathrm{m} / \mathrm{z} 466,467,468$, and 470 for unlabeled and labeled $\left[1-{ }^{13} \mathrm{C}\right.$, ring-3,5- ${ }^{2} \mathrm{H}_{2}$, and ring- $\left.{ }^{2} \mathrm{H}_{4}\right]$-tyrosine respectively. Standard regression curves were applied from a series of known standard enrichment values against the measured values to assess the linearity of the mass spectrometer and to account for any isotope fractionation which may have occurred during the analysis. Phenylalanine and tyrosine enrichments were corrected for the presence of both the ${ }^{13} \mathrm{C}$ and ${ }^{2} \mathrm{H}$ isotopes.

\section{Muscle analyses}

Myofibrillar protein enriched fractions were extracted from a $\sim 50 \mathrm{mg}$ piece of wet muscle tissue by hand-homogenizing on ice using a pestle (Teflon) in a standard extraction buffer (7 $\mu \mathrm{l} \cdot \mathrm{mg}^{-1}$ ) [38]. The samples were spun at $2500 \mathrm{~g}$ and $4^{\circ} \mathrm{C}$ for $5 \mathrm{~min}$. The pellet was washed with $500 \mu \mathrm{L} \mathrm{ddH} 2 \mathrm{O}$ and centrifuged at $250 \mathrm{~g}$ and $4^{\circ} \mathrm{C}$ for $10 \mathrm{~min}$. The myofibrillar protein was solubilized by adding $1 \mathrm{~mL}$ of $0.3 \mathrm{M} \mathrm{NaOH}$ and heating at $50^{\circ} \mathrm{C}$ for 30 min with vortex mixing every $10 \mathrm{~min}$. Samples were centrifuged at $9500 \mathrm{~g}$ and $4^{\circ} \mathrm{C}$ for $5 \mathrm{~min}$ and the supernatant 
containing the myofibrillar-enriched fraction was collected and the collagen pellet was discarded. Myofibrillar proteins were precipitated by the addition of $1 \mathrm{~mL}$ of $1 \mathrm{M}$ PCA and spinning at $700 \mathrm{~g}$ and $4^{\circ} \mathrm{C}$ for $10 \mathrm{~min}$. The myofibrillar protein was washed twice with $70 \%$ ethanol. Amino acids were liberated by adding $2 \mathrm{~mL}$ of $6 \mathrm{~m} \mathrm{HCL}$ and heating at $110^{\circ} \mathrm{C}$ for 18 $\mathrm{h}$. The free amino acids from the hydrolyzed myofibrillar protein pellet were dried under nitrogen stream while being heated to $120^{\circ} \mathrm{C}$, and, subsequently, dissolved in a $25 \%$ acetic acid solution and purified using cation exchange chromatography (AG 50W-X8 resin, 100-200 $\mu \mathrm{m}$ dry mesh size; Bio-Rad Laboratories, Hercules, USA). The free amino acids were eluted with $2 \mathrm{M} \mathrm{NH}_{4} \mathrm{OH}$ and dried under nitrogen stream. To reduce the signal-to-noise ratio during GCMS analysis at low tracer enrichments, L-[ring- $\left.{ }^{2} \mathrm{H}_{5}\right]$-phenylalanine from the dried free amino acids from myofibrillar protein hydrolysates was enzymatically decarboxlated to phenylethylamine [39] prior to MTBSTFA derivatization [40,41]. Enrichments of the proteinbound samples were determined by selected ion monitoring for phenylalanine mass to charge ratio at $183(m+5)$ to $180(m+2)$ and a single linear standard curve (to avoid slope influences on the measured TTR) from mixtures of known $m+5$ to $m+0$ ratios. To avoid saturation of the MS and eliminate bias due to any potential concentration dependencies, the split ratio was adjusted prior to the injection of each sample so that nearly equal amounts of phenylalanine were injected for all samples and standards. The derivatized amino acids were separated on a $30 \mathrm{~m} \times 0.25 \mathrm{~mm} \times 0.50 \mu \mathrm{m} \mathrm{HP}-5 \mathrm{MS}$ column (temperature program: $80^{\circ} \mathrm{C}$ for 1 $\min ; 30^{\circ} \mathrm{C} \mathrm{min}-1$ ramp to $300^{\circ} \mathrm{C}$; hold for $10 \mathrm{~min}$. Standard regression curves were applied from a series of known standard enrichment values against the measured values to assess the linearity of the mass spectrometer and to account for any isotope fractionation which may have occurred during the analysis.

\section{Calculations}

Whole-body amino acid kinetics in non-steady state conditions were calculated from the ingestion of $\mathrm{L}-\left[1-{ }^{13} \mathrm{C}\right]$-phenylalanine labeled whey, intravenous infusion of $\mathrm{L}-\left[\mathrm{ring}-{ }^{2} \mathrm{H}_{5}\right]-$ phenylalanine and $\mathrm{L}$-[ring-3,5- ${ }^{2} \mathrm{H}_{2}$ ]-tyrosine, and arterialized venous blood sampling. Total, exogenous, and endogenous phenylalanine appearance rates $\left(R_{a}\right.$ in $\left.\mu \mathrm{mol} P h \mathrm{Phg}^{-1} \cdot \mathrm{min}^{-1}\right)$, and plasma phenylalanine availability (i.e., the fraction of dietary protein-derived phenylalanine that appeared in the systemic circulation, Phe plasma) were calculated using modified Steele's equations [42-44]:

$$
\text { Total } R_{a}=\frac{F_{i v}-\left[p V \cdot C(t) \cdot \frac{d E_{i v}}{d t}\right]}{E_{i v}(t)}
$$

Total phenylalanine $R_{a}$ was calculated using equation 1 , where $F_{i v}$ is the intravenous tracer infusion rate (in $\mu \mathrm{mol} \cdot \mathrm{kg}^{-1} \cdot \mathrm{min}^{-1}$ ) and $p V$ is the distribution volume for phenylalanine $(0.125$

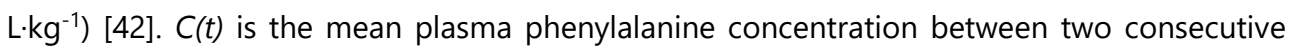
time points, and $d E_{i v} / d t$ represents the time-dependent change in plasma phenylalanine enrichment derived from the intravenous tracer and $E_{i v}(t)$ is the mean plasma phenylalanine enrichment from the intravenous tracer between two consecutive time points. 
Exogenous $R_{a}=\frac{\operatorname{Total} R_{a} \cdot E_{p o}(t)+\left[p V \cdot C(t) \cdot \frac{d E_{p o}}{d t}\right]}{E_{p r o t}}$

Exogenous phenylalanine rate of appearance (Exo $R_{a}$ ) represents the plasma entry rate of dietary protein-derived phenylalanine. $E_{p o}(t)$ is the mean plasma phenylalanine enrichment of the oral tracer, $d E_{p o} / d t$ represents the time-dependent change in plasma phenylalanine enrichment derived from the oral tracer, and $E_{\text {prot }}$ is the enrichment of L- $\left[1-{ }^{13} \mathrm{C}\right]$-phenylalanine in the dietary protein.

Endogenous $R_{a}=\operatorname{Total} R_{a}-\operatorname{Exo} R_{a}-F_{i v}$

Endogenous phenylalanine $R_{a}$ (Endo $R_{a}$ ) represents the plasma entry rate of phenylalanine derived from whole-body protein breakdown.

$$
\text { Phe } e_{\text {plasma }}=\left[\frac{A U C_{E x o R a}}{\text { Phe } e_{\text {prot }}}\right] \cdot \mathrm{BW} \cdot 100 \%
$$

The fraction of dietary protein-derived phenylalanine appearing in the systemic circulation

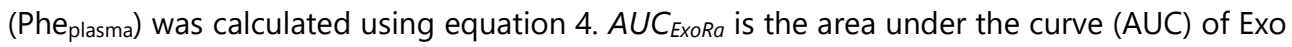
$\mathrm{R}_{\mathrm{a}} ; B W$ is the body weight of the subject in $\mathrm{kg} ;$ Phe $e_{\text {prot }}$ is the amount of dietary phenylalanine that is ingested.

Total phenylalanine rate of disappearance $\left(R_{d}\right.$ in $\left.\mu \mathrm{mol} P h e \cdot \mathrm{kg}^{-1} \cdot \mathrm{min}^{-1}\right)$ equals the rate of phenylalanine hydroxylation (first step in phenylalanine oxidation) and utilization for protein synthesis. These parameters are calculated as follows:

$$
\begin{aligned}
& \text { Total } R_{d}=\text { Total } R_{a}-p V \cdot \frac{d C}{d t} \\
& \text { Phe hydroxylation }=\text { Tyr } R_{a} \cdot \frac{E_{t y r}(t)}{E_{p h e}(t)} \cdot \frac{P h e R_{d}}{\left(F_{P h e}+P h e R_{d}\right)} \\
& \text { Protein synthesis }=\text { Total } R_{d}-\text { Phe hydroxylation } \\
& \text { Phe net balance = Protein synthesis }- \text { Endo } R_{a}
\end{aligned}
$$

TyrR $R_{a}$ is the total rate of tyrosine appearance based on the $\mathrm{L}$-[ring-3,5- ${ }^{2} \mathrm{H}_{2}$ ]-tyrosine infusion and plasma enrichment. $E_{\text {tyr }}(t)$ and $E_{P h e}(t)$ represent the mean plasma L-[ring- $\left.{ }^{2} \mathrm{H}_{4}\right]$-tyrosine and $\mathrm{L}$-[ring- ${ }^{2} \mathrm{H}_{5}$ ]-phenylalanine enrichment between 2 consecutive time points, respectively. $F_{P h e}$ is the intravenous infusion rate of $\mathrm{L}-\left[\right.$ ring $\left.{ }^{2} \mathrm{H}_{5}\right]$-phenylalanine $\left(\mu \mathrm{mol} \cdot \mathrm{kg}^{-1} \cdot \mathrm{min}^{-1}\right)$.

Myofibrillar protein fractional synthesis rates (FSR) were calculated using the standard precursor-product equation:

$$
F S R=\frac{\Delta E p}{E_{\text {precursor }} \cdot t} \cdot 100 \%
$$

where $\triangle E p$ is the increment in myofibrillar protein-bound L-[ring- $\left.{ }^{2} \mathrm{H}_{5}\right]$-phenylalanine after an incorporation period (in MPE). E $E_{\text {precursor }}$ is the weighted average plasma L-[ring- $\left.{ }^{2} \mathrm{H}_{5}\right]$ phenylalanine enrichment during the tracer incorporation period (MPE) and $t$ is the incorporation period (h). For basal FSR, muscle biopsies at $t=-120$ and $t=0$ min were used, 
and for postprandial FSR, biopsies at $t=0,120$, and 300 min were used to calculate the early $(0-2 \mathrm{~h})$ and late $(2-5 \mathrm{~h})$ postprandial muscle protein synthetic response.

\section{Statistics}

All data are expressed as mean \pm SEM. Differences in baseline values, body composition, nutritional intake and physical activity levels were determined using unpaired, two-tailed Student's $t$-tests. Peak values and time to peak were calculated for plasma time curves and differences were determined using an unpaired, two-tailed Student's $t$-test. Two-way ANOVA with time as within-group factor and condition as between-group factor was used to compare differences over time in plasma glucose, insulin, NEFA, amino acid concentrations and enrichments, whole-body phenylalanine appearance rates, and FSR. In case of significant time $x$ group interactions, separate analyses were performed to determine time-effects for each group (one-factor repeated measures ANOVA) and between-group effects for each time-point (two-tailed Student's $t$-test). For all analyses, statistical significance was set at $P<0.05$. All calculations were performed using SPSS (IBM Statistics, version 24.0, IBM Corp., Armonk, USA). 


\section{RESULTS}

\section{Subjects' characteristics and body composition}

Subjects' characteristics are presented in Table 1 and body composition data are presented in Table 2. Whole-body $(76.8 \pm 2.7$ and $57.7 \pm 1.6 \mathrm{~kg})$ and appendicular ( $34.5 \pm 1.4$ and $26.1 \pm 0.9$ $\mathrm{kg}$ ) lean body mass were greater in obese subjects when compared with lean, respectively $(P<0.05)$. Body fat \% $(32 \pm 2$ and $21 \pm 1 \%)$ was higher in obese when compared with lean controls, respectively $(P<0.05)$. Fat mass distribution was predominantly around the upperbody and higher in obese when compared with lean subjects (VAT: $917 \pm 59$ and $363 \pm 28 \mathrm{~g}$, and android/gynoid ratio: $1.4 \pm 0.04$ and $1.1 \pm 0.1$ in obese and lean subjects, respectively, both $P<0.001)$. Upper leg muscle and quadriceps CSA were greater in obese subjects when compared with lean controls (both $P<0.05$ ).

Table 1 | Subjects' characteristics

\begin{tabular}{|c|c|c|}
\hline & Lean $(n=12)$ & Obese $(n=12)$ \\
\hline Age (y) & $43 \pm 3$ & $48 \pm 2$ \\
\hline Weight (kg) & $76.5 \pm 1.6$ & $117.9 \pm 6.5^{\star}$ \\
\hline BMI $\left(\mathbf{k g} \cdot \mathbf{m}^{-2}\right)$ & $23.4 \pm 0.4$ & $37.0 \pm 1.5^{\star}$ \\
\hline Basal plasma glucose $\left(\mathrm{mmol} \cdot \mathrm{L}^{-1}\right)$ & $5.2 \pm 0.1$ & $6.1 \pm 0.2^{*}$ \\
\hline Plasma glucose OGTT $t=120 \mathrm{~min}\left(\mathrm{mmol} \cdot \mathrm{L}^{-1}\right)$ & $4.4 \pm 0.3$ & $6.8 \pm 0.7^{*}$ \\
\hline Basal plasma insulin $\left(\mathrm{pmol} \cdot \mathrm{L}^{-1}\right)$ & $61 \pm 6$ & $215 \pm 19^{*}$ \\
\hline Plasma insulin OGTT $t=120 \min \left(p m o l \cdot \mathrm{L}^{-1}\right)$ & $121 \pm 17$ & $756 \pm 171^{*}$ \\
\hline $\mathrm{HbA}_{1 \mathrm{c}}\left(\mathrm{mmol} \cdot \mathrm{mol}^{-1}\right)$ & $33.7 \pm 1.0$ & $36.8 \pm 1.0^{\#}$ \\
\hline OGIS $\left(\mathrm{mL} \cdot \mathrm{min}^{-1} \cdot \mathrm{m}^{-2}\right)$ & $451 \pm 12$ & $277 \pm 19^{*}$ \\
\hline HOMA-IR & $1.14 \pm 0.12$ & $4.03 \pm 0.34^{*}$ \\
\hline Basal plasma IL-6 $\left(\mathrm{pg} \cdot \mathrm{mL}^{-1}\right)$ & $0.68 \pm 0.12$ & $1.19 \pm 0.20^{\#}$ \\
\hline Basal plasma NEFA $\left(\mu \mathrm{mol} \cdot \mathrm{L}^{-1}\right)$ & $390 \pm 39$ & $451 \pm 45$ \\
\hline Basal plasma TAG $\left(\mathrm{mmol}^{\left.-\mathrm{L}^{-1}\right)}\right.$ & $0.98 \pm 0.16$ & $1.81 \pm 0.29^{*}$ \\
\hline
\end{tabular}

Values are mean \pm SEM. $\mathrm{HbA}_{1}$ : glycated hemoglobin; OGTT: oral glucose tolerance test; OGIS: oral glucose insulin sensitivity, HOMA-IR: homeostasis model assessment of insulin resistance; NEFA: non-esterified fatty acid; TAG: triacylglycerol. Basal plasma IL-6, NEFA, and TAG were analyzed during the experimental trial at $t=-210 \mathrm{~min}$. Data were analyzed by unpaired Student's $t$-test, * Significant difference between conditions, $P<0.05$ and $\# P<0.1$. 
Table 2 | Body composition

\begin{tabular}{|c|c|c|}
\hline & Lean $(n=12)$ & Obese $(n=12)$ \\
\hline Lean body mass (kg and \%) & $57.7 \pm 1.6(75 \pm 1)$ & $76.8 \pm 2.7(66 \pm 2)^{\star}$ \\
\hline Appendicular lean mass (kg and \%) & $26.1 \pm 0.9(34 \pm 1)$ & $34.5 \pm 1.4(30 \pm 1)^{\star}$ \\
\hline Fat mass (kg and \%) & $16.4 \pm 0.7(21 \pm 1)$ & $38.8 \pm 3.8(32 \pm 2)^{\star}$ \\
\hline Trunk / limb fat mass ratio & $1.1 \pm 0.1$ & $1.5 \pm 0.1^{*}$ \\
\hline Android fat mass ( $k g$ and \%) & $1.4 \pm 0.1(25 \pm 2)$ & $4.6 \pm 0.5(40 \pm 2)^{*}$ \\
\hline Gynoid fat mass (kg and \%) & $2.7 \pm 0.1(23 \pm 1)$ & $5.5 \pm 0.7(30 \pm 2)^{*}$ \\
\hline Android / gynoid fat ratio & $1.1 \pm 0.1$ & $1.4 \pm 0.04^{*}$ \\
\hline VAT (g) & $363 \pm 28$ & $917 \pm 59^{*}$ \\
\hline Left leg thigh CSA $\left(\mathrm{mm}^{2}\right)$ & $14,444 \pm 396$ & $17,825 \pm 462^{*}$ \\
\hline Right leg thigh CSA $\left(\mathrm{mm}^{2}\right)$ & $14,637 \pm 454$ & $18,123 \pm 515^{\star}$ \\
\hline Left quadriceps CSA $\left(\mathrm{mm}^{2}\right)$ & $7,659 \pm 242$ & $8,818 \pm 298^{*}$ \\
\hline Right quadriceps CSA $\left(\mathrm{mm}^{2}\right)$ & $7,912 \pm 301$ & $9,095 \pm 331^{\#}$ \\
\hline Left fat CSA $\left(\mathrm{mm}^{2}\right)$ & $3,751 \pm 358$ & $9,473 \pm 1385^{\star}$ \\
\hline Right fat CSA (mm²) & $3,758 \pm 399$ & $9,542 \pm 1420^{*}$ \\
\hline Left leg thigh HU & $51.2 \pm 0.6$ & $45.4 \pm 1.1^{\star}$ \\
\hline Right leg thigh HU & $51.5 \pm 0.7$ & $45.6 \pm 1.2^{*}$ \\
\hline Left leg quadriceps HU & $55.3 \pm 0.7$ & $50.5 \pm 1.0^{*}$ \\
\hline Right leg quadriceps HU & $55.1 \pm 0.7$ & $50.7 \pm 1.1^{*}$ \\
\hline
\end{tabular}

Values are mean \pm SEM. CSA: cross sectional area, HU: Hounsfield Units. Data were analyzed by unpaired Student's $t$-test, * Significant difference between conditions, $P<0.05$ and $\# P<0.1$. 


\section{Dietary intake and physical activity}

Dietary intake and physical activity data are presented in Table 3. Dietary intake did not differ between groups and averaged $10.8 \pm 0.8$ and $9.3 \pm 0.6 \mathrm{MJ} \cdot \mathrm{d}^{-1}$ in lean and obese subjects, respectively $(P=0.15)$. Absolute habitual dietary protein intake did not differ between lean and obese subjects $(92 \pm 8$ and $102 \pm 6$ g, respectively, $P=0.33)$, while habitual protein intake expressed per $\mathrm{kg}$ bodyweight was lower in obese subjects $\left(0.9 \pm 0.1 \mathrm{~g} \cdot \mathrm{kg}^{-1} \cdot \mathrm{d}^{-1}\right)$ when compared with lean controls $\left(1.2 \pm 0.1 \mathrm{~g} \cdot \mathrm{kg}^{-1} \cdot \mathrm{d}^{-1}, P=0.02\right)$. Daily step counts were lower in obese $\left(7436 \pm 1178\right.$ steps $\left.\cdot d^{-1}\right)$ when compared with lean subjects $\left(12,574 \pm 1783\right.$ steps $\left.\cdot d^{-1}, P=0.03\right)$. The time spent in sedentary and light intensity activities per day did not differ between lean and obese subjects (both $P>0.05$ ), while the amount of time spend in moderate-to-vigorous activities (MVPA) per day was lower in obese $(24 \pm 6 \mathrm{~min}$ ) when compared with lean controls (58 \pm 9 min; $P=0.005)$.

Table 3 | Dietary intake and physical activity

\begin{tabular}{|c|c|c|}
\hline & Lean $(n=12)$ & Obese $(n=12)$ \\
\hline Habitual energy intake $\left(\mathrm{MJ} \cdot \mathrm{d}^{-1}\right)$ & $10.8 \pm 0.8$ & $9.3 \pm 0.6$ \\
\hline \multicolumn{3}{|l|}{ Macronutrient intake (En\%) } \\
\hline Carbohydrate/Protein/Fat & $47 / 15 / 33$ & $45 / 19 / 32$ \\
\hline Habitual protein intake $\left(\mathbf{g} \cdot \mathrm{kg}^{-1} \cdot \mathrm{d}^{-1}\right)$ & $1.2 \pm 0.1$ & $0.9 \pm 0.1^{*}$ \\
\hline Time accelerometer worn $\cdot \mathrm{d}^{-1}(\mathrm{~min})$ & $890 \pm 21$ & $845 \pm 30$ \\
\hline Total steps $\cdot \mathbf{d}^{-1}$ & $12,574 \pm 1,783$ & $7,436 \pm 1,178^{*}$ \\
\hline Sedentary time $\cdot d^{-1}$ (min) & $544 \pm 28$ & $554 \pm 37$ \\
\hline Sedentary time $\cdot d^{-1}(\%)$ & $61 \pm 3$ & $65 \pm 3$ \\
\hline Light intensity activity time $\cdot \mathrm{d}^{-1}(\mathrm{~min})$ & $288 \pm 23$ & $267 \pm 19$ \\
\hline Light intensity activity time $\cdot \mathrm{d}^{-1}$ (\%) & $32 \pm 2$ & $32 \pm 2$ \\
\hline MVPA time $\cdot \mathbf{d}^{-1}(\mathrm{~min})$ & $58 \pm 9$ & $24 \pm 6^{\star}$ \\
\hline MVPA time $\cdot \mathrm{d}^{-1}$ (\%) & $7 \pm 1$ & $3 \pm 1^{*}$ \\
\hline
\end{tabular}

Values are mean \pm SEM. En\%: energy\%, MVPA: moderate-to-vigorous physical activity. Data were analyzed by unpaired Student's $t$-test, * Significant difference between conditions, $P<0.05$. 


\section{Plasma glucose, insulin, and free fatty acids}

Plasma glucose, insulin, and NEFA concentrations are presented in Figure 1. Basal plasma glucose concentrations at the start of the experimental trial were higher in obese subjects when compared with lean controls $\left(6.1 \pm 0.2\right.$ and $5.1 \pm 0.1 \mathrm{mmol} \cdot \mathrm{L}^{-1}$ in obese and lean subjects, respectively, $P<0.001$; Figure 1A). Plasma glucose concentrations in the postprandial period decreased over time in both groups (time effect, both $P<0.001$ ), with higher concentrations in obese when compared with lean (during $t=0-180 \mathrm{~min}, P<0.05$ ). Basal plasma insulin concentrations at $t=-210 \mathrm{~min}$ were higher in obese subjects when compared with lean subjects ( $187 \pm 75$ and $57 \pm 29 \mathrm{pmol} \cdot \mathrm{L}^{-1}$, respectively, $P<0.001$; Figure 1B). Following protein ingestion, plasma insulin concentrations increased in both groups (time effect, both $P<0.001$ ), although the postprandial increment was substantially greater in the obese reaching higher peak values $\left(636 \pm 78 \mathrm{pmol} \cdot \mathrm{L}^{-1}\right)$ in obese when compared with lean subjects $\left(155 \pm 18 \mathrm{pmol} \cdot \mathrm{L}^{-1}\right.$; $P<0.001$ ), and remained higher throughout the postprandial period in obese subjects (during $t=0-300 \mathrm{~min}, P<0.001$ ). Basal plasma TAG concentrations (Table 1) were higher in obese subjects $\left(1.81 \pm 0.29 \mathrm{mmol} \cdot \mathrm{L}^{-1}\right)$ when compared with lean subjects $\left(0.98 \pm 0.16 \mathrm{mmol} \cdot \mathrm{L}^{-1}, P=0.02\right)$. Basal NEFA concentrations at $t=-210 \mathrm{~min}$ did not differ between groups $(P=0.35$; Table 1) and decreased during the postabsorptive period to a similar extent in both groups (time $\mathrm{x}$ group interaction, $P=0.41$, main time effect, $P<0.05$ ). NEFAs in the postabsorptive period tended to be higher in the obese subjects when compared with lean (main group effect, $P=0.06$ ). Following protein ingestion, NEFA concentrations decreased (time $\mathrm{x}$ group interaction, $P<0.001$ ) and were higher for $t=20 \mathrm{~min}$ to $t=90 \mathrm{~min}$ in the obese subjects when compared with lean controls (all $P<0.05$ ).

\section{Plasma amino acid concentrations}

Plasma amino acid concentrations are presented in Figure 2. Postabsorptive phenylalanine (Figure 2A), leucine (Figure 2B), and tyrosine (Figure 2C) concentrations were higher in obese subjects when compared with lean controls (group effect, all $P<0.05$ ). The increments in plasma amino acid concentrations after protein ingestion were comparable between lean and obese subjects (for all amino acids main time effect, $P<0.001$, time $x$ group interaction, all $P>0.05$ ). Postprandial phenylalanine concentrations were higher in obese subjects when compared with lean controls (main group effect, $P=0.03$ ). 

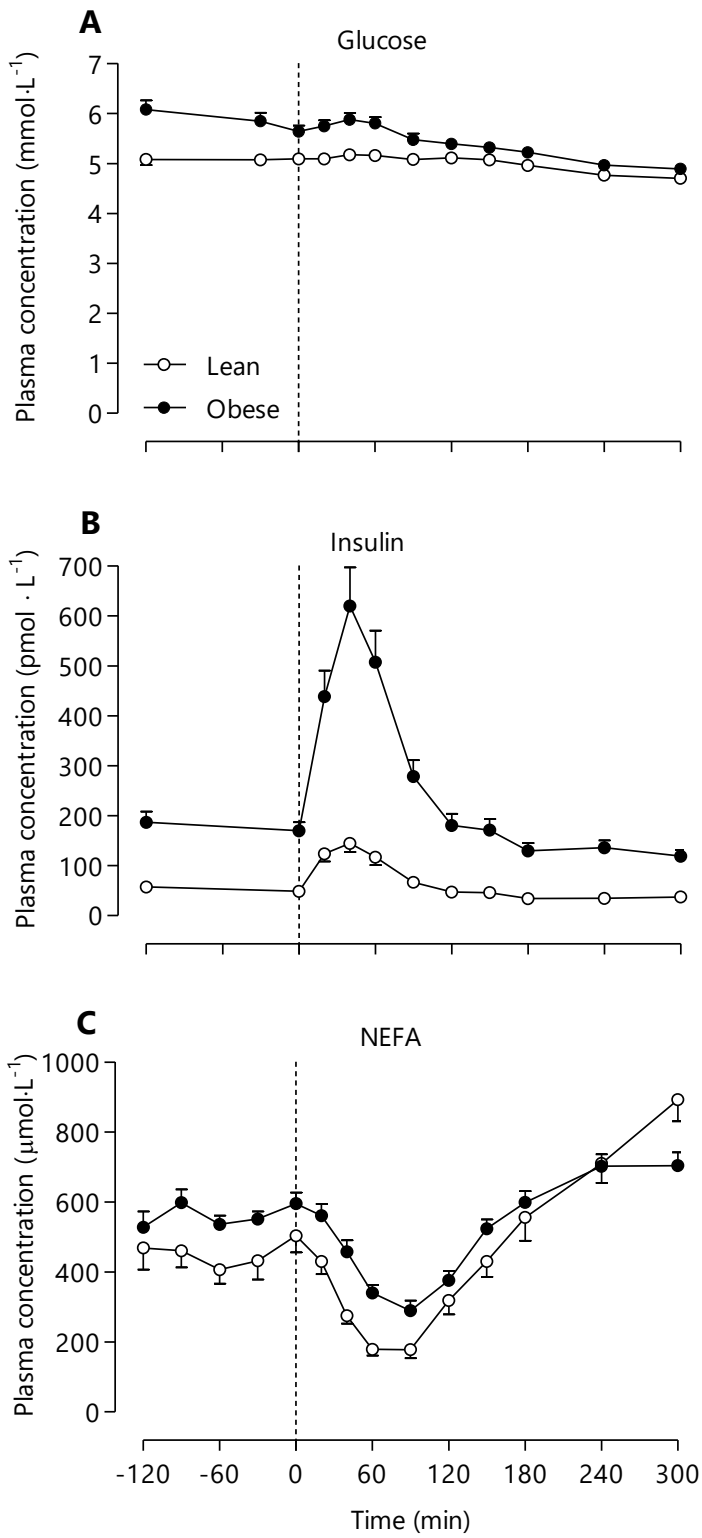

Figure 1 Mean $( \pm$ SEM) plasma glucose $(\mathbf{A})$, insulin (B), and non-esterified fatty acid (NEFA) (C) concentrations (mmol. $\mathrm{L}^{-1}, \mathrm{pmol} \cdot \mathrm{L}^{-1}$, and $\mu \mathrm{mol} \cdot \mathrm{L}^{-1}$, respectively) in lean $(n=12)$ and obese $(n=12)$ middle-aged males at postabsorptive conditions and following the ingestion of $25 \mathrm{~g}$ whey protein. The dotted line indicates the ingestion of the protein beverage. Data were analyzed by repeated measures (time $x$ group) ANOVA. Bonferroni post-hoc test was used to locate differences over time. A: postabsorptive period: main group effect, $P<0.001$; postprandial period: time $\mathrm{x}$ group interaction, $P<0.001$. B: postabsorptive period: main group effect, $P<0.001$; postprandial period: time $x$ group interaction, $P<0.001$. C: postabsorptive period: main time effect, $P<0.05$; main group effect, $P=0.06$; postprandial period: time $x$ group interaction, $P<0.001$. 

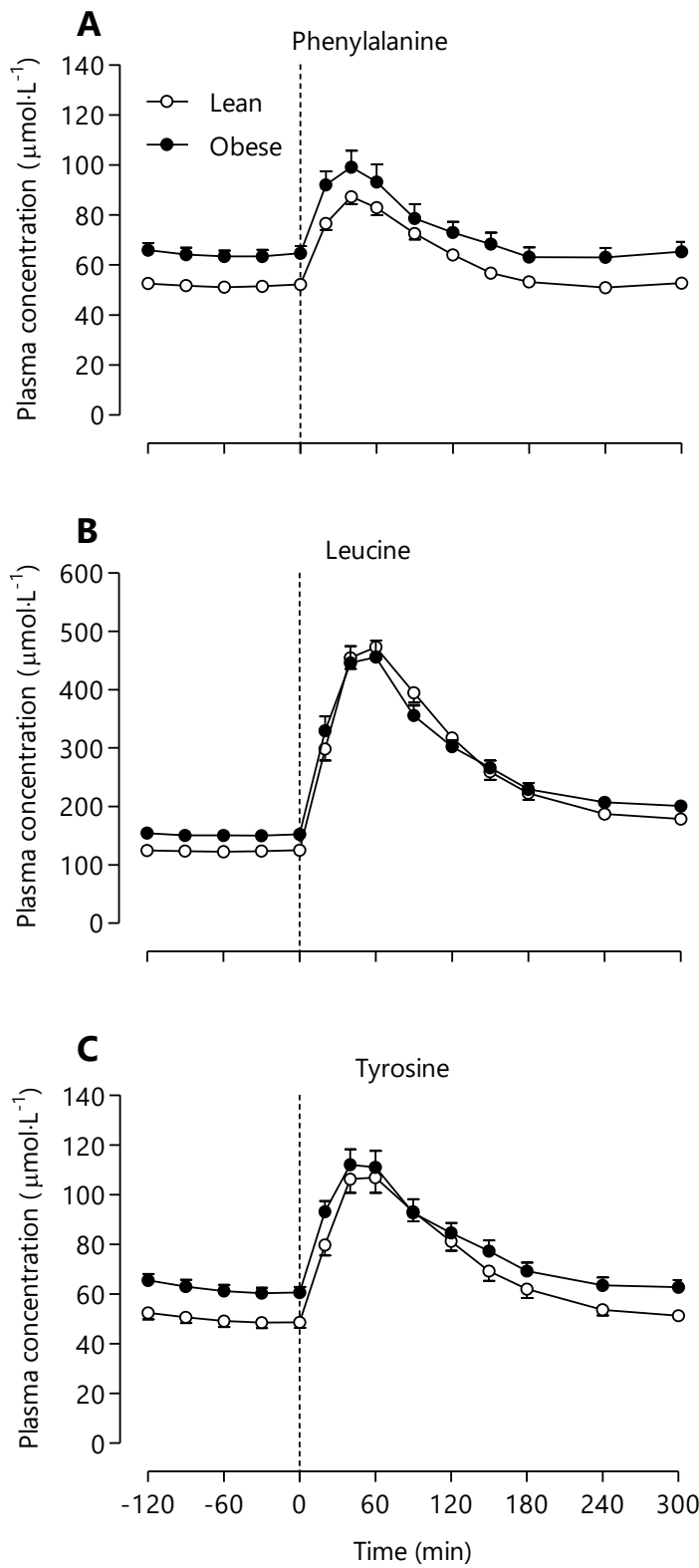

Figure 2 | Mean $\left( \pm\right.$ SEM) plasma phenylalanine $(\mathbf{A})$, leucine $(\mathbf{B})$, and tyrosine $(\mathbf{C})$ concentrations $\left(\mu \mathrm{mol} \cdot \mathrm{L}^{-1}\right)$ in lean $(n=12)$ and obese $(n=12)$ middle-aged males at postabsorptive conditions and following the ingestion of $25 \mathrm{~g}$ whey protein. The dotted line represents the ingestion of the protein beverage. Data were analyzed with repea ted measures (time $x$ group) ANOVA. Bonferroni post-hoc test was used to locate differences over time. A: postabsorptive period: main time effect, $P<0.001$, main group effect, $P<0.001$; postprandial period: main time effect, $P<0.001$, main group effect, $P<0.05$. B: postabsorptive period: main time effect, $P=0.11$, main group effect, $P<0.001$; postprandial period: main time effect, $P<0.001$, main group effect, $P=0.77$. C: postabsorptive period: main time effect, $P<0.001$, main group effect, $P<0.01$; postprandial period: main time effect, $P<0.001$, main group effect, $P=0.14$. 


\section{Plasma amino acid enrichments}

Plasma L-[ring- $\left.{ }^{2} \mathrm{H}_{5}\right]$-phenylalanine (from the infused tracer) and L- $\left[1-{ }^{13} \mathrm{C}\right]$-phenylalanine enrichments (from the ingested tracer) are presented in Figure 3. Postabsorptive plasma L[ring ${ }^{2} \mathrm{H}_{5}$ ]-phenylalanine enrichments were higher in lean subjects when compared with obese (main group effect, $P=0.04$ ). Plasma $\mathrm{L}-\left[\right.$ ring ${ }^{2} \mathrm{H}_{5}$ ]-phenylalanine enrichments decreased after protein ingestion in both groups (time effect, both $P<0.001$ ). Despite a time $\mathrm{x}$ group interaction $(P=0.02)$, no differences were observed between individual time points in the postprandial period (all $P>0.05$; Figure $3 \mathrm{~A}$ ). Following protein ingestion, plasma $\mathrm{L}-\left[1-{ }^{13} \mathrm{C}\right]$ phenylalanine enrichments increased to a greater extent in lean as opposed to obese subjects (time $x$ group interaction, $P=0.03)$, reaching higher peak values in lean ( $3.1 \pm 0.1 \mathrm{MPE}$ at $t=40$ ) when compared with obese subjects (2.6 $\pm 0.1 \mathrm{MPE}$ at $t=40 \mathrm{~min} ; P<0.001$, Figure 3B). Higher postprandial plasma $\mathrm{L}-\left[1-{ }^{13} \mathrm{C}\right]$-phenylalanine enrichments in lean as opposed to obese subjects were also observed for $t=40$ to $t=120 \mathrm{~min}$, and for $t=240$ to $t=300 \mathrm{~min}$ (posthoc analyses for all time points, all $P<0.05)$.
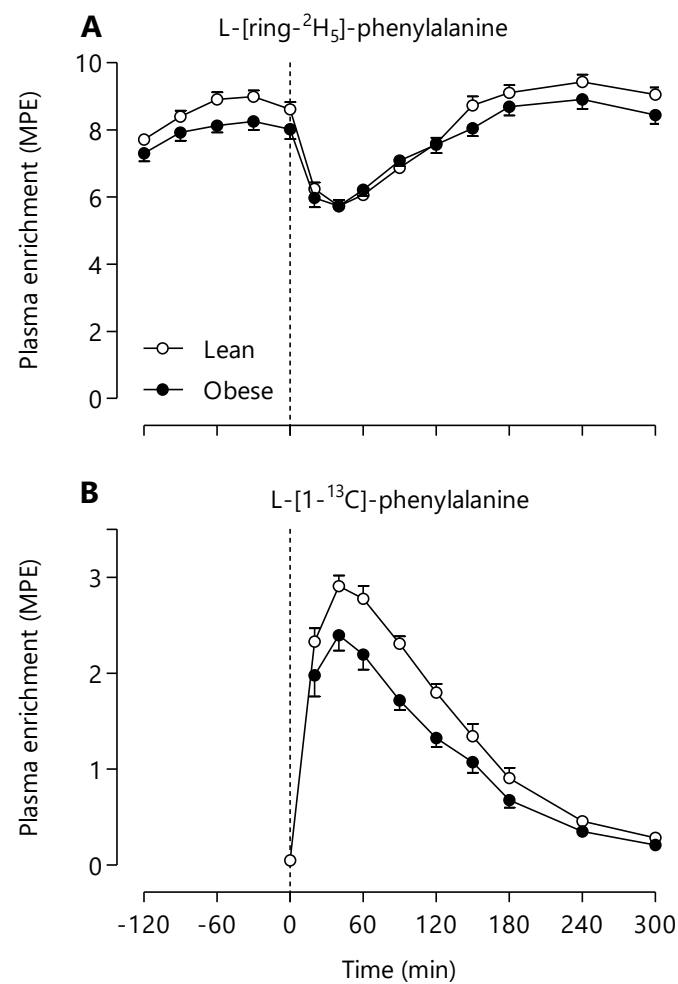

Figure 3 | Mean $\left( \pm\right.$ SEM) plasma L-[ring $\left.-{ }^{2} \mathrm{H}_{5}\right]$-phenylalanine $(\mathbf{A})$ and $\mathrm{L}-\left[1-{ }^{13} \mathrm{C}\right]$-phenylalanine enrichments $(\mathbf{B}$; mole percent excess, MPE) in lean $(n=12)$ and obese $(n=12)$ middle-aged males at postabsorptive conditions and following the ingestion of $25 \mathrm{~g}$ whey protein. The dotted line represents the ingestion of the protein beverage. Data were analyzed with repeated measures (time $x$ group) ANOVA. Bonferroni post-hoc test was used to locate differences over time. A: postabsorptive period: main time effect, $P<0.001$, main group effect, $P<0.05$; postprandial period: time $\mathrm{x}$ group interaction, $P<0.05$. B: time $\mathrm{x}$ group interaction, $P<0.05$. 


\section{Whole-body protein kinetics}

Whole-body phenylalanine kinetics are presented in Figure 4. Exogenous phenylalanine rates of appearance (Figure 4A) (i.e., the rate at which dietary protein-derived phenylalanine enters the circulation) increased to a higher extent in lean compared with obese subjects (time $x$ group interaction, $P<0.001$ ), with higher values observed at $t=40$ to $t=300 \mathrm{~min}$ in lean as opposed to obese (post-hoc analyses for all time points, all $P<0.05$ ). The fraction of dietary protein-derived phenylalanine that appeared in the plasma over the $5 \mathrm{~h}$ postprandial period did not differ between groups averaging $53 \pm 1$ and $53 \pm 2 \%$ in lean and obese subjects $(P=0.82)$, respectively. Endogenous phenylalanine rates of appearance (Figure 4B) (i.e., the rate at which phenylalanine derived from whole-body protein breakdown enters the circulation) decreased following protein ingestion in both groups (main time effect, $P<0.001$ ), with absolute rates being higher in lean when compared with obese subjects (main group effect, $P=0.02$ ). In addition, total phenylalanine rates of appearance and disappearance (Figure 4C and 4D, respectively) increased in both groups following protein ingestion, with rates being higher in lean compared with obese subjects (time $x$ group interaction, $P<0.001$, post-hoc analyses for time points $t=40-300 \mathrm{~min}$, all $P<0.001)$. 

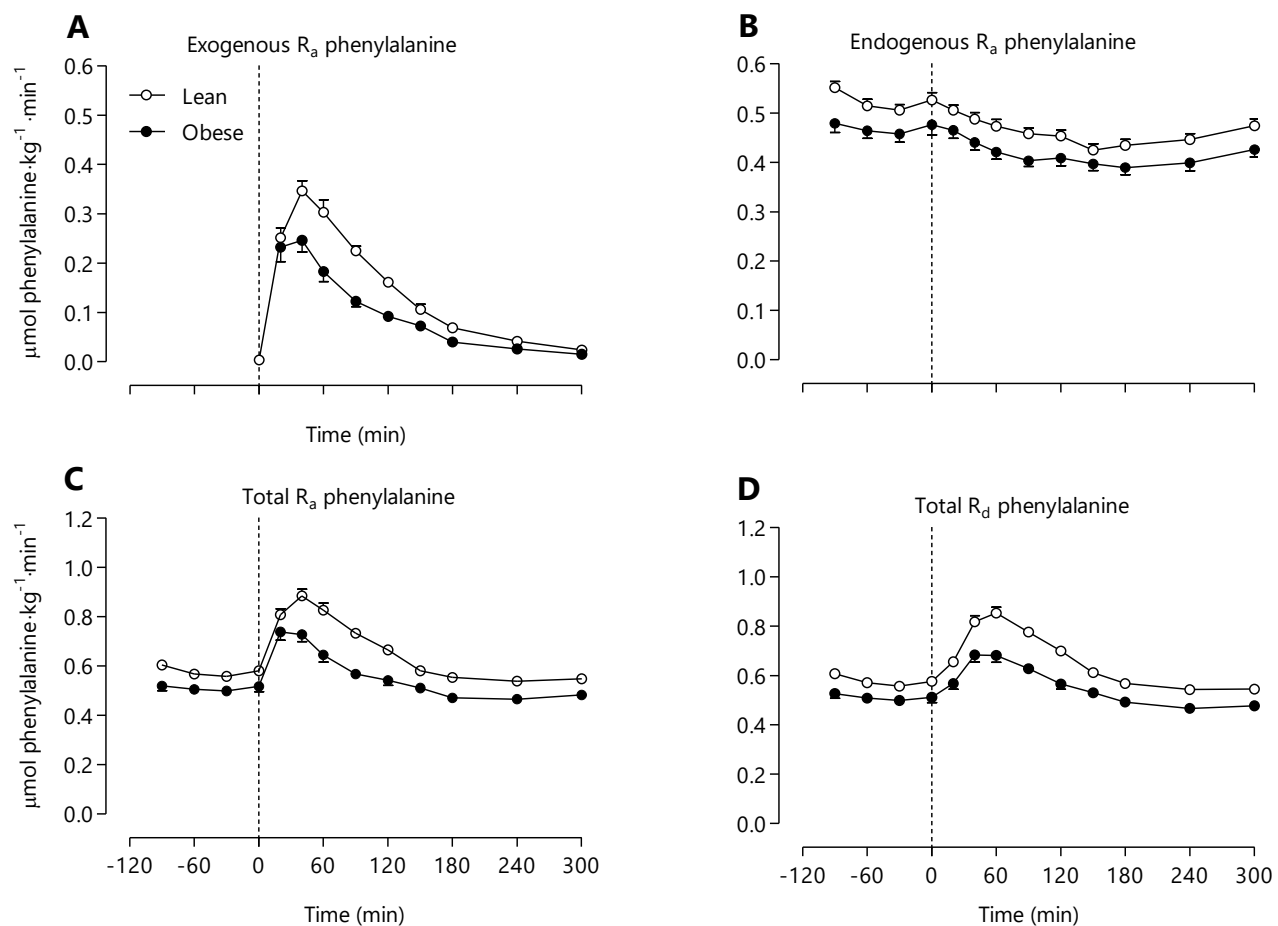

Figure 4 | Mean $\left( \pm\right.$ SEM) exogenous rate of appearance $\left(R_{a} ; \mathbf{A}\right)$, endogenous $R_{a}(\mathbf{B})$, total $R_{a}(\mathbf{C})$, and total rate of disappearance $\left(R_{d} ; \mathbf{D}\right)\left(\mu \mathrm{mol}\right.$ phenylalanine $\left.\cdot \mathrm{kg}^{-1} \cdot \mathrm{min}^{-1}\right)$ in lean $(n=12)$ and obese $(n=12)$ middle-aged males at postabsorptive conditions and following the ingestion of $25 \mathrm{~g}$ whey protein. The dotted line represents the ingestion of the protein beverage. Data were analyzed with repeated measures (time $x$ group) ANOVA. Bonferroni post-hoc test was used to locate differences over time. A: time $\mathrm{x}$ group interaction, $P<0.001$. B: postabsorptive; time $\times$ group interaction, $P<0.001$; postprandial period: main time effect, $P<0.001$, main group effect, $P<0.05 ; \mathbf{C}$ : postabsorptive period: time $\mathrm{x}$ group interaction, $P<0.001$; postprandial period: time $\mathrm{x}$ group interaction, $P<0.001$; D: postabsorptive period: time $\mathrm{x}$ group interaction, $P<0.001$; postprandial period: time $\mathrm{x}$ group interaction, $P<0.001$. 
Whole-body protein turnover rates are presented in Figure 5. Postabsorptive whole-body protein breakdown, synthesis, and oxidation rates were lower in obese subjects when compared with lean controls (all $P<0.05$ ). Postabsorptive whole-body protein net balance did not differ between groups $\left(0.1 \pm 0.2\right.$ vs $0.3 \pm 0.1 \mu \mathrm{mol}$ phenylalanine $\cdot \mathrm{h}^{-1} \cdot \mathrm{kg}^{-1}$, in obese vs lean subjects, respectively; $P=0.36$ ). During the $5 \mathrm{~h}$ postprandial period, whole-body protein breakdown rates decreased to a similar extent in both groups (time $\mathrm{x}$ group interaction, $P=0.15$ ), while protein synthesis and oxidation rates increased to a greater extent in lean subjects as opposed to obese (time $x$ group interaction, $P<0.05$ ). Postprandial whole-body protein breakdown, synthesis, and oxidation rates were lower in obese subjects when compared with lean subjects (all $P<0.05$ ). Whole-body protein net balance increased to a greater extent in lean subjects as opposed to obese in the postprandial state $(4.6 \pm 0.4$ and $7.1 \pm 0.2 \mu \mathrm{mol}$ phenylalanine $\cdot \mathrm{h}^{-1} \cdot \mathrm{kg}^{-1}$ in obese and lean subjects, respectively, time $\mathrm{x}$ group interaction, $P<0.001)$, but were lower in obese when compared with lean controls $(P<0.001)$.

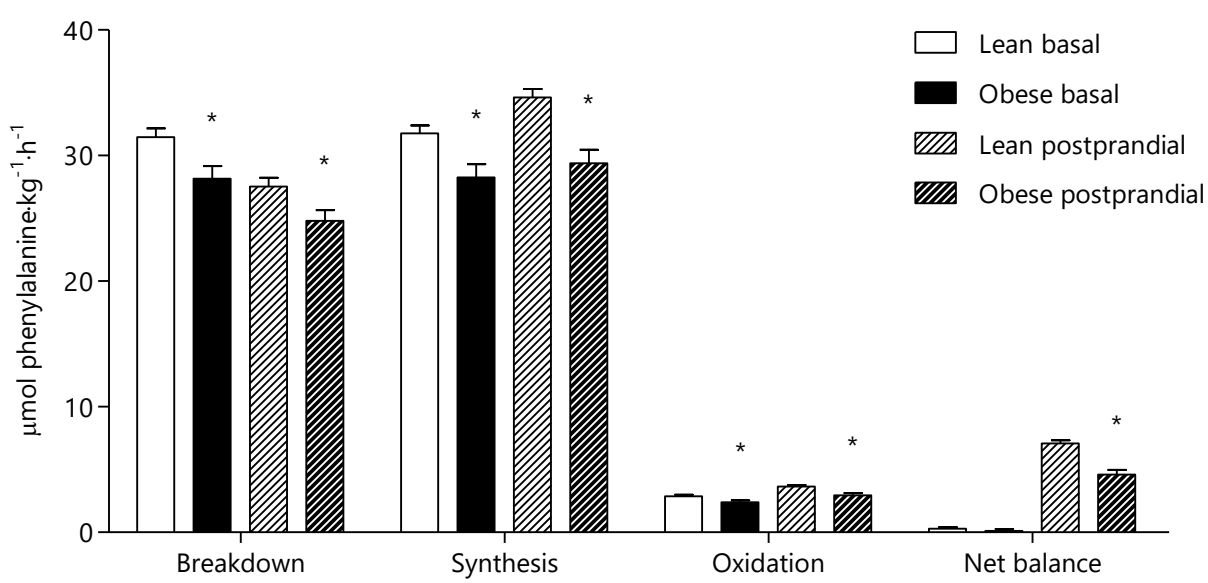

Figure 5 | Rates of whole-body protein synthesis, breakdown, oxidation, and net protein balance in lean ( $n=12)$ and obese $(n=12)$ middle-aged males during basal conditions and following the ingestion of $25 \mathrm{~g}$ whey protein. Data were analyzed with unpaired Student's t-test (between groups) and repeated measures (time $x$ group) ANOVA. Breakdown: main time effect, $P<0.001$; main group effect, $P<0.05$. Synthesis: time $x$ group interaction, $P<0.05$. Oxidation: time $\times$ group interaction, $P<0.05$. Net balance: time $x$ group interaction, $P<0.001$. ${ }^{*}$ Significant difference between groups, $P<0.05$. 


\section{Muscle protein synthesis}

Myofibrillar protein synthesis rates, expressed as FSR, are presented in Figure 6. Postabsorptive myofibrillar protein synthesis rates did not differ between lean and obese subjects $\left(0.030 \pm 0.002\right.$ vs $0.028 \pm 0.003 \% \cdot h^{-1}$, respectively; $\left.P=0.60\right)$. Following the ingestion of $25 \mathrm{~g}$ whey protein, myofibrillar FSR increased to $0.031 \pm 0.002$ vs $0.033 \pm 0.005 \% \cdot \mathrm{h}^{-1}$ during the 'early' $0-2 \mathrm{~h}$ period, and $0.036 \pm 0.002$ vs $0.036 \pm 0.003 \% \cdot \mathrm{h}^{-1}$ during the 'late' $2-5 \mathrm{~h}$ period in lean vs obese subjects, respectively, with no differences between groups (time $\mathrm{x}$ group interaction, $P=0.84$, main time effect, $P=0.05$, Figure $6 \mathrm{~A}$ ). Myofibrillar protein synthesis rates assessed over the entire $5 \mathrm{~h}$ postprandial period $\left(0.034 \pm 0.002\right.$ and $0.035 \pm 0.003 \% \cdot \mathrm{h}^{-1}$ in lean and obese subjects, respectively) were significantly higher when compared to postabsorptive myofibrillar FSR (main time effect, $P=0.03$ ) but no differences were observed between groups (time $\mathrm{x}$ group interaction, $P=0.58$, Figure 6B).
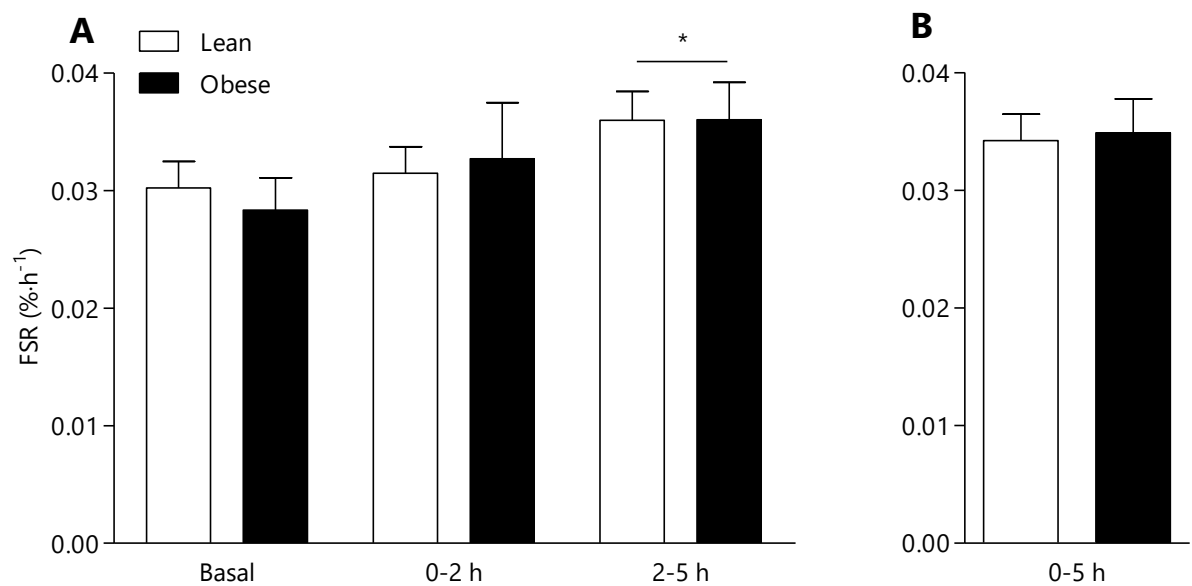

Figure 6 | Mean $\left( \pm\right.$ SEM) myofibrillar protein fractional synthetic rates (FSR in $\% \cdot \mathrm{h}^{-1}$ ) during the postabsorptive, early $(0-2 \mathrm{~h})$, and late $(2-5 \mathrm{~h})(\mathbf{A})$ and $0-5 \mathrm{~h}(\mathbf{B})$ postprandial period, using intravenous L-[ring- $\left.{ }^{2} \mathrm{H}_{5}\right]$-phenylalanine infusions in lean $(n=12)$ and obese $(n=12)$ middle-aged males. Data were analyzed with unpaired Student's ttest (between groups) and repeated measures (time x group) ANOVA. A: Postabsorptive between groups, $P=0.60$; main time effect, $P=0.05$, main group effect, $P=0.95$. B: Main time effect, $P=0.03$; main group effect, $P=0.83$. *Indicates a significant time effect, $P<0.05 .{ }^{*}$ Indicates a significant time effect, $P<0.05$. 


\section{DISCUSSION}

The present study assessed basal, postabsorptive and postprandial muscle protein synthesis rates following the ingestion of $25 \mathrm{~g}$ whey protein in obese, normoglycemic males and agematched lean controls. Both postabsorptive myofibrillar protein synthesis rates as well as postprandial protein handling, including protein digestion and amino acid absorption, and the postprandial muscle protein synthetic response to protein ingestion were not impaired in obese men when compared with age-matched, lean controls.

Obesity has been suggested to be accompanied by impairments in protein metabolism in skeletal muscle tissue. Basal, postabsorptive muscle protein synthesis rates have been reported to be either lower $[23,26]$ or similar $[18,20,22,24,25]$ in obese when compared with lean individuals. In the present study, we selected 12 obese middle-aged and 12 age-matched, lean controls. The obese volunteers were morbidly obese (class II obesity based upon WHO classification [45]) with a BMI of $37.0 \pm 1.5 \mathrm{~kg} \cdot \mathrm{m}^{-2}$, and a body fat percentage of $32 \pm 2 \%$, with most fat deposited in the visceral area (Tables 1-2). In contrast, the lean controls had a BMI of $23.4 \pm 0.4 \mathrm{~kg} \cdot \mathrm{m}^{-2}$ with a body fat percentage of $21 \pm 1 \%(P<0.001)$. In line, the obese volunteers presented reduced insulin sensitivity, higher basal plasma IL- 6 levels, and higher postabsorptive plasma NEFA and TAG concentrations when compared with lean controls (Table 1 and Figure 1). Despite clear phenotypical and metabolic distinction between groups, postabsorptive muscle protein synthesis rates $\left(0.030 \pm 0.002\right.$ vs $0.028 \pm 0.003 \% \cdot h^{-1}$, respectively; $P=0.60$ ) did not differ between lean and obese individuals (Figure 6). Our data confirms previous observations $[18,20,22,24,25]$ but certainly not all $[23,26]$ showing that there are no impairments in basal, postabsorptive muscle protein synthesis rates between healthy lean and obese males.

Over the last decade, it has become evident that skeletal muscle maintenance is largely dependent on the muscle protein synthetic response to food intake and physical activity [8]. The muscle protein synthetic response to protein ingestion is regulated by protein digestion and subsequent amino acid absorption, resulting in a rapid postprandial rise in plasma amino acid concentrations $[1-3,8]$. In the present study, we combined contemporary stable isotope methodology with the use of intrinsically $L-\left[1-{ }^{13} \mathrm{C}\right]$-phenylalanine labeled whey protein [37, $46]$ to allow us to compare postprandial protein digestion and amino acid absorption kinetics in vivo between healthy obese and lean middle-aged males. Following the ingestion of $25 \mathrm{~g}$ intrinsically labelled whey, plasma amino acid concentrations increased to the same extent in lean and obese subjects (Figure 2). Plasma L-[1- $\left.{ }^{13} \mathrm{C}\right]$-phenylalanine enrichments increased rapidly in both groups, although values increased to a greater extent in the lean compared with the obese males (Figure 3B). The provided $25 \mathrm{~g}$ protein dose was similar for the lean and obese subjects in absolute terms, but smaller for the obese individuals when expressed per $\mathrm{kg}$ bodyweight. The lower plasma $L-\left[1-{ }^{13} \mathrm{C}\right]$-phenylalanine enrichments observed in the obese subjects can, therefore, be attributed to the greater distribution volume and greater wholebody amino acid flux in the obese compared with the lean males. In total, $53 \pm 1$ and $53 \pm 2 \%$ of 
the dietary protein-derived phenylalanine had appeared in the circulation over the $5 \mathrm{~h}$ postprandial period in the lean and obese subjects, respectively. In previous work, we observed similar postprandial amino acid availability following the ingestion of a comparable dose of whey protein in (lean) young and older adults $[2,47,48]$. Despite the greater visceral organ mass in the obese individuals, which could have increased the first-pass splanchnic extraction of the dietary protein-derived amino acids, we did not detect any impairments in protein digestion and amino acid absorption kinetics in the healthy, obese men when compared with the lean men. Consequently, the present study is the first to show that postprandial protein handling, including protein digestion and subsequent protein-derived amino acid appearance in the circulation are not impaired in obese but otherwise healthy men.

The postprandial rise in circulating (essential) amino acids, and leucine in particular, stimulates muscle protein synthesis with a rapid rise in myofibrillar protein synthesis rates for up to $5 \mathrm{~h}$ after protein ingestion. The muscle protein synthetic response to protein ingestion has been shown to be blunted in the older population, now commonly referred to as anabolic resistance $[5,7]$. Previous work has suggested that anabolic resistance to protein ingestion may also develop as a consequence of obesity, due to overfeeding and/or lipid oversupply [12, 24, 25]. In support, lipid infusion has previously been shown to induce a state of anabolic resistance blunting the amino acid induced increase in muscle protein synthesis rates [12, 17]. Consequently, we hypothesized that obese individuals show a blunted muscle protein synthetic response to protein ingestion when compared with age-matched, lean controls. Upon the ingestion of $25 \mathrm{~g}$ whey protein, whole-body protein synthesis rates increased and whole-body protein breakdown rates decreased, causing net protein balance to become positive in both the lean and obese individuals (Figure 5). However, since whole-body protein turnover rates do not necessarily reflect skeletal muscle tissue, we obtained skeletal muscle biopsies to assess postprandial muscle protein synthesis rates. Myofibrillar protein synthesis rates increased by $\sim 26 \%$ during the $5 \mathrm{~h}$ postprandial period, with no differences between the lean and obese individuals (Figure 6B; $P=0.58$ ). In line, we observed no differences in myofibrillar protein synthesis rates assessed during the early $(0-2 h)$ or late (2-5 h) postprandial period (Figure 6A; both $P>0.05$ ). Obviously, we were unable to detect any differences in the muscle protein synthetic response to protein ingestion between healthy obese and lean individuals, despite the considerably higher circulating plasma NEFA, TAG, IL-6, and the severe insulin resistance in the obese males (Table 1). Consequently, we need to reject our hypothesis and conclude that the muscle protein synthetic response to protein ingestion in not impaired in obese, but otherwise healthy, middle aged males.

Our data seem to agree with some $[22,26]$ but certainly not all $[12,24-26]$ studies that have addressed the proposed impairments in postprandial muscle protein synthesis rates in the obese state. Murton and coworkers recently observed a blunted increase in muscle protein synthesis rates under hyperinsulinemic-hyperaminoacidemic clamp conditions in older, obese compared with age-matched lean men [24]. However, these experimental clamped conditions differ from a normal postprandial response upon the ingestion of a single meal-like amount of protein (Figure 1B). More recently, Beals et al. reported anabolic resistance to the ingestion 
of pork meat ( $36 \mathrm{~g}$ protein) in young overweight and obese subjects as opposed to lean controls [25]. In contrast, Smeuninx et al. observed no differences in postprandial muscle protein synthesis rates following the ingestion of $15 \mathrm{~g}$ protein between older obese vs lean males [22]. There is no clear explanation for the apparent discrepancy on the proposed impact of obesity on postprandial muscle protein synthesis in the literature. As discussed previously, anabolic resistance can be the consequence of a more sedentary lifestyle and is not related to age, whole-body insulin resistance, and/or body fat content per se [49]. Where physical activity increases the anabolic response to protein ingestion $[50,51]$, physical inactivity or disuse rapidly lowers the anabolic response to protein ingestion and, as such, induces anabolic resistance $[6,52,53]$. Therefore, habitual physical activity level may be the key parameter explaining the presence or absence of differences in basal and/or postprandial muscle protein synthesis rates between lean and obese individuals. In agreement, Smeuninx et al. showed that the muscle protein synthetic response to protein ingestion correlated well with daily step count [22]. In the present study, we aimed to include healthy, lean, and obese individuals with a (normal) physical activity pattern as opposed to a more sedentary lifestyle. Though daily step count was lower in the obese when compared with the lean individuals (Table 3, $P=0.03$ ), overall step count was relatively high in both groups (>7000 steps $\cdot \mathrm{d}^{-1}$ ) when compared with previous reports on (morbidly) obese individuals [22, 54]. In the recent work by Beals et al. surprisingly large differences in postprandial muscle protein synthesis rates were observed between young, lean and obese adults [25]. Though physical activity levels were not assessed in that study, it is likely that the obese subjects had adopted a severe sedentary lifestyle. That level of obesity (i.e. a $\mathrm{BMI}>35$ with an unhealthy metabolic phenotype) at such a young age (24-27 y) can only be explained by the combined impact of excess energy intake and a severe sedentary lifestyle. Where anabolic resistance can be induced by skeletal muscle disuse and exogenous lipid administration, we conclude that obesity per se does not impair postprandial muscle protein synthesis rates following the ingestion of a meal-like amount of protein.

In conclusion, postabsorptive muscle protein synthesis rates and postprandial protein handling, including protein digestion and amino acid absorption kinetics and the postprandial muscle protein synthetic response to protein ingestion, are not impaired in the obese state.

\section{ACKNOWLEDGEMENTS}

We thank the administrational staff of the Obesity Centre at Máxima Medical Centre, Eindhoven, the Netherlands for the assistance in the recruitment of volunteers. We greatly appreciate the assistance of Henrike Hamer, Stefan Gorissen, Joey Smeets, and Michelle Weijzen in the execution of the experiments. Technical expertise from Jos Stegen and Wendy Sluismans during the sample analyses was greatly appreciated. 


\section{REFERENCES}

1. Katsanos, C.S., H. Kobayashi, M. Sheffield-Moore, A. Aarsland, and R.R. Wolfe, Aging is associated with diminished accretion of muscle proteins after the ingestion of a small bolus of essential amino acids. Am J Clin Nutr, 2005. 82(5): p. 1065-73.

2. Pennings, B., B. Groen, A. de Lange, A.P. Gijsen, A.H. Zorenc, J.M. Senden, and L.J. van Loon, Amino acid absorption and subsequent muscle protein accretion following graded intakes of whey protein in elderly men. American journal of physiology. Endocrinology and metabolism, 2012. 302(8): p. E992-9.

3. Rasmussen, B.B., R.R. Wolfe, and E. Volpi, Oral and intravenously administered amino acids produce similar effects on muscle protein synthesis in the elderly. J Nutr Health Aging, 2002. 6(6): p. 358-62.

4. Cuthbertson, D., K. Smith, J. Babraj, G. Leese, T. Waddell, P. Atherton, H. Wackerhage, P.M. Taylor, and M.J. Rennie, Anabolic signaling deficits underlie amino acid resistance of wasting, aging muscle. FASEB J, 2005. 19(3): p. 422-4.

5. Wall, B.T., S.H. Gorissen, B. Pennings, R. Koopman, B.B. Groen, L.B. Verdijk, and L.J. van Loon, Aging Is Accompanied by a Blunted Muscle Protein Synthetic Response to Protein Ingestion. PLoS One, 2015. 10(11): p. e0140903.

6. Wall, B.T., M.L. Dirks, T. Snijders, J.W. van Dijk, M. Fritsch, L.B. Verdijk, and L.J. van Loon, Short-term muscle disuse lowers myofibrillar protein synthesis rates and induces anabolic resistance to protein ingestion. Am J Physiol Endocrinol Metab, 2016. 310(2): p. E137-47.

7. Burd, N.A., S.H. Gorissen, and L.J. van Loon, Anabolic resistance of muscle protein synthesis with aging. Exerc Sport Sci Rev, 2013. 41(3): p. 169-73.

8. Koopman, R. and L.J. van Loon, Aging, exercise, and muscle protein metabolism. Journal of applied physiology, 2009. 106(6): p. 2040-8.

9. Fujita, S., E.L. Glynn, K.L. Timmerman, B.B. Rasmussen, and E. Volpi, Supraphysiological hyperinsulinaemia is necessary to stimulate skeletal muscle protein anabolism in older adults: evidence of a true age-related insulin resistance of muscle protein metabolism. Diabetologia, 2009. 52(9): p. 1889-98.

10. Rasmussen, B.B., S. Fujita, R.R. Wolfe, B. Mittendorfer, M. Roy, V.L. Rowe, and E. Volpi, Insulin resistance of muscle protein metabolism in aging. FASEB J, 2006. 20(6): p. 768-9.

11. Guillet, C. and Y. Boirie, Insulin resistance: a contributing factor to age-related muscle mass loss? Diabetes Metab, 2005. 31 Spec No 2: p. 5S20-5S26.

12. Stephens, F.B., C. Chee, B.T. Wall, A.J. Murton, C.E. Shannon, L.J. van Loon, and K. Tsintzas, Lipidinduced insulin resistance is associated with an impaired skeletal muscle protein synthetic response to amino acid ingestion in healthy young men. Diabetes, 2015. 64(5): p. 1615-20.

13. Savage, D.B., K.F. Petersen, and G.I. Shulman, Disordered lipid metabolism and the pathogenesis of insulin resistance. Physiol Rev, 2007. 87(2): p. 507-20.

14. Goodpaster, B.H., F.L. Thaete, J.A. Simoneau, and D.E. Kelley, Subcutaneous abdominal fat and thigh muscle composition predict insulin sensitivity independently of visceral fat. Diabetes, 1997. 46(10): p. 1579-85.

15. Chevalier, S., E.B. Marliss, J.A. Morais, M. Lamarche, and R. Gougeon, Whole-body protein anabolic response is resistant to the action of insulin in obese women. Am J Clin Nutr, 2005. 82(2): p. 35565.

16. Guillet, C., I. Delcourt, M. Rance, C. Giraudet, S. Walrand, M. Bedu, P. Duche, and Y. Boirie, Changes in basal and insulin and amino acid response of whole body and skeletal muscle proteins in obese men. J Clin Endocrinol Metab, 2009. 94(8): p. 3044-50.

17. Liebau, F., M.D. Jensen, K.S. Nair, and O. Rooyackers, Upper-body obese women are resistant to postprandial stimulation of protein synthesis. Clin Nutr, 2014. 33(5): p. 802-7. 
18. Villareal, D.T., G.I. Smith, K. Shah, and B. Mittendorfer, Effect of Weight Loss on the Rate of Muscle Protein Synthesis During Fasted and Fed Conditions in Obese Older Adults. Obesity, 2011.

19. Villareal, D.T., G.I. Smith, D.R. Sinacore, K. Shah, and B. Mittendorfer, Regular multicomponent exercise increases physical fitness and muscle protein anabolism in frail, obese, older adults. Obesity, 2011. 19(2): p. 312-8.

20. Chevalier, S., S.A. Burgos, J.A. Morais, R. Gougeon, M. Bassil, M. Lamarche, and E.B. Marliss, Protein and glucose metabolic responses to hyperinsulinemia, hyperglycemia, and hyperaminoacidemia in obese men. Obesity (Silver Spring), 2015. 23(2): p. 351-8.

21. Glynn, E.L., L.W. Piner, K.M. Huffman, C.A. Slentz, L. Elliot-Penry, H. AbouAssi, P.J. White, J.R. Bain, M.J. Muehlbauer, O.R. Ilkayeva, R.D. Stevens, K.N. Porter Starr, C.W. Bales, E. Volpi, M.J. Brosnan, J.K. Trimmer, T.P. Rolph, C.B. Newgard, and W.E. Kraus, Impact of combined resistance and aerobic exercise training on branched-chain amino acid turnover, glycine metabolism and insulin sensitivity in overweight humans. Diabetologia, 2015. 58(10):p. 2324-35.

22. Smeuninx, B., J. McKendry, D. Wilson, U. Martin, and L. Breen, Age-Related Anabolic Resistance of Myofibrillar Protein Synthesis Is Exacerbated in Obese Inactive Individuals. J Clin Endocrinol Metab, 2017. 102(9): p. 3535-3545.

23. Patterson, B.W., J.F. Horowitz, G. Wu, M. Watford, S.W. Coppack, and S. Klein, Regional muscle and adipose tissue amino acid metabolism in lean and obese women. Am J Physiol Endocrinol Metab, 2002. 282(4): p. E931-6.

24. Murton, A.J., K. Marimuthu, J.E. Mallinson, A.L. Selby, K. Smith, M.J. Rennie, and P.L. Greenhaff, Obesity Appears to Be Associated With Altered Muscle Protein Synthetic and Breakdown Responses to Increased Nutrient Delivery in Older Men, but Not Reduced Muscle Mass or Contractile Function. Diabetes, 2015. 64(9): p. 3160-71.

25. Beals, J.W., R.A. Sukiennik, J. Nallabelli, R.S. Emmons, S. van Vliet, J.R. Young, A.V. Ulanov, Z. Li, S.A. Paluska, M. De Lisio, and N.A. Burd, Anabolic sensitivity of postprandial muscle protein synthesis to the ingestion of a protein-dense food is reduced in overweight and obese young adults. Am J Clin Nutr, 2016. 104(4): p. 1014-1022.

26. Guillet, C., I. Delcourt, M. Rance, C. Giraudet, S. Walrand, M. Bedu, P. Duche, and Y. Boirie, Changes in basal and insulin and amino acid response of whole body and skeletal muscle proteins in obese men. The Journal of clinical endocrinology and metabolism, 2009. 94(8): p. 3044-50.

27. Beals, J.W., R.W.A. Mackenzie, S. van Vliet, S.K. Skinner, B.A. Pagni, G.M. Niemiro, A.V. Ulanov, Z. Li, A.C. Dilger, S.A. Paluska, M. De Lisio, and N.A. Burd, Protein-Rich Food Ingestion Stimulates Mitochondrial Protein Synthesis in Sedentary Young Adults of Different BMls. J Clin Endocrinol Metab, 2017. 102(9): p. 3415-3424.

28. Alberti, K.G. and P.Z. Zimmet, Definition, diagnosis and classification of diabetes mellitus and its complications. Part 1: diagnosis and classification of diabetes mellitus provisional report of a WHO consultation. Diabetic medicine : a journal of the British Diabetic Association, 1998. 15(7): p. 53953.

29. Kelly, T.L., K.E. Wilson, and S.B. Heymsfield, Dual energy X-Ray absorptiometry body composition reference values from NHANES. PLoS One, 2009. 4(9): p. e7038.

30. Aubrey, J., N. Esfandiari, V.E. Baracos, F.A. Buteau, J. Frenette, C.T. Putman, and V.C. Mazurak, Measurement of skeletal muscle radiation attenuation and basis of its biological variation. Acta Physiol (Oxf), 2014. 210(3): p. 489-97.

31. Goodpaster, B.H., D.E. Kelley, F.L. Thaete, J. He, and R. Ross, Skeletal muscle attenuation determined by computed tomography is associated with skeletal muscle lipid content. J Appl Physiol (1985), 2000. 89(1): p. 104-10.

32. Strandberg, S., M.L. Wretling, T. Wredmark, and A. Shalabi, Reliability of computed tomography measurements in assessment of thigh muscle cross-sectional area and attenuation. BMC Med Imaging, 2010. 10: p. 18. 
33. Abumrad, N.N., D. Rabin, M.P. Diamond, and W.W. Lacy, Use of a heated superficial hand vein as an alternative site for the measurement of amino acid concentrations and for the study of glucose and alanine kinetics in man. Metabolism: clinical and experimental, 1981. 30(9): p. 936-40.

34. Bergstrom, J., Percutaneous needle biopsy of skeletal muscle in physiological and clinical research. Scand J Clin Lab Invest, 1975. 35(7): p. 609-16.

35. Pennings, B., W.F. Pellikaan, J.M. Senden, A.M. van Vuuren, J. Sikkema, and L.J. van Loon, The production of intrinsically labeled milk and meat protein is feasible and provides functional tools for human nutrition research. Journal of dairy science, 2011. 94(9): p. 4366-73.

36. van Loon, L.J., Y. Boirie, A.P. Gijsen, J. Fauquant, A.L. de Roos, A.K. Kies, S. Lemosquet, W.H. Saris, and R. Koopman, The production of intrinsically labeled milk protein provides a functional tool for human nutrition research. J Dairy Sci, 2009. 92(10): p. 4812-22.

37. Burd, N.A., N.M. Cermak, I.W. Kouw, S.H. Gorissen, A.P. Gijsen, and L.J. van Loon, The use of doubly labeled milk protein to measure postprandial muscle protein synthesis rates in vivo in humans. J Appl Physiol (1985), 2014. 117(11): p. 1363-70.

38. Koopman, R., A.H. Zorenc, R.J. Gransier, D. Cameron-Smith, and L.J. van Loon, Increase in S6K1 phosphorylation in human skeletal muscle following resistance exercise occurs mainly in type II muscle fibers. Am J Physiol Endocrinol Metab, 2006. 290(6): p. E1245-52.

39. Calder, A.G., S.E. Anderson, I. Grant, M.A. McNurlan, and P.J. Garlick, The determination of low d5phenylalanine enrichment (0.002-0.09 atom percent excess), after conversion to phenylethylamine, in relation to protein turnover studies by gas chromatography/electron ionization mass spectrometry. Rapid Commun Mass Spectrom, 1992. 6(7): p. 421-4.

40. Slater, C., T. Preston, D.C. McMillan, J.S. Falconer, and K.C.H. Fearon, GC/MS analysis of [2H5]phenylalanine at very low enrichment: Measurement of protein synthesis in health and disease. Journal of Mass Spectrometry, 1995. 30(9): p. 1325-1332.

41. Schwenk, W.F., P.J. Berg, B. Beaufrere, J.M. Miles, and M.W. Haymond, Use of tbutyldimethylsilylation in the gas chromatographic/mass spectrometric analysis of physiologic compounds found in plasma using electron-impact ionization.Anal Biochem,1984.141(1):p.101-9.

42. Boirie, Y., P. Gachon, S. Corny, J. Fauquant, J.L. Maubois, and B. Beaufrere, Acute postprandial changes in leucine metabolism as assessed with an intrinsically labeled milk protein. Am J Physiol, 1996. 271(6 Pt 1): p. E1083-91.

43. Wolfe, R.R. and D.L. Chinkes, Isotope tracers in metabolic research: Principles and practice of kinetic analysis. 2 ed. 2005, Hoboken, New Jersey: John Wiley and Sons, Inc.

44. Dangin, M., C. Guillet, C. Garcia-Rodenas, P. Gachon, C. Bouteloup-Demange, K. Reiffers-Magnani, J. Fauquant, O. Ballevre, and B. Beaufrere, The rate of protein digestion affects protein gain differently during aging in humans. J Physiol, 2003. 549(Pt 2): p. 635-44.

45. Obesity: preventing and managing the global epidemic. Report of a WHO consultation. World Health Organ Tech Rep Ser, 2000. 894: p. i-xii, 1-253.

46. van Loon, L.J., Y. Boirie, A.P. Gijsen, J. Fauquant, A.L. de Roos, A.K. Kies, S. Lemosquet, W.H. Saris, and R. Koopman, The production of intrinsically labeled milk protein provides a functional tool for human nutrition research. Journal of dairy science, 2009. 92(10): p.4812-22.

47. Pennings, B., Y. Boirie, J.M. Senden, A.P. Gijsen, W.H. Saris, and L.J. van Loon, Whey protein stimulates postprandial muscle protein accretion more effectively than casein and casein hydrolysate in elderly men. Am J Clin Nutr, 2011. in press.

48. Gorissen, S.H., A.M. Horstman, R. Franssen, I.W. Kouw, B.T. Wall, N.A. Burd, L.C. de Groot, and L.J. van Loon, Habituation to low or high protein intake does not modulate basal or postprandial muscle protein synthesis rates: a randomized trial. Am J Clin Nutr, 2017. 105(2): p. 332-342.

49. Burd, N.A., B.T. Wall, and L.J. van Loon, The curious case of anabolic resistance: old wives' tales or new fables? Journal of applied physiology, 2012. 112(7): p. 1233-5.

50. Pennings, B., R. Koopman, M. Beelen, J.M. Senden, W.H. Saris, and L.J. van Loon, Exercising before protein intake allows for greater use of dietary protein-derived amino acids for de novo muscle 
protein synthesis in both young and elderly men. The American journal of clinical nutrition, 2011. 93(2): p. 322-31.

51. Holwerda, A.M., I.W. Kouw, J. Trommelen, S.L. Halson, W.K. Wodzig, L.B. Verdijk, and L.J. van Loon, Physical Activity Performed in the Evening Increases the Overnight Muscle Protein Synthetic Response to Presleep Protein Ingestion in Older Men. J Nutr,2016.146(7):p.1307-14.

52. Biolo, G., R. Pisot, S. Mazzucco, F.G. Di Girolamo, R. Situlin, S. Lazzer, B. Grassi, C. Reggiani, A. Passaro, J. Rittweger, M. Gasparini, B. Simunic, and M. Narici, Anabolic resistance assessed by oral stable isotope ingestion following bed rest in young and older adult volunteers: Relationships with changes in muscle mass. Clin Nutr, 2017. 36(5): p. 1420-1426.

53. Breen, L., K.A. Stokes, T.A. Churchward-Venne, D.R. Moore, S.K. Baker, K. Smith, P.J. Atherton, and S.M. Phillips, Two weeks of reduced activity decreases leg lean mass and induces "anabolic resistance" of myofibrillar protein synthesis in healthy elderly. J Clin Endocrinol Metab, 2013. 98(6): p. 2604-12.

54. Tudor-Locke, C., M.M. Brashear, W.D. Johnson, and P.T. Katzmarzyk, Accelerometer profiles of physical activity and inactivity in normal weight, overweight, and obese U.S. men and women. Int J Behav Nutr Phys Act, 2010. 7: p. 60. 
Postprandial protein handling in obesity 


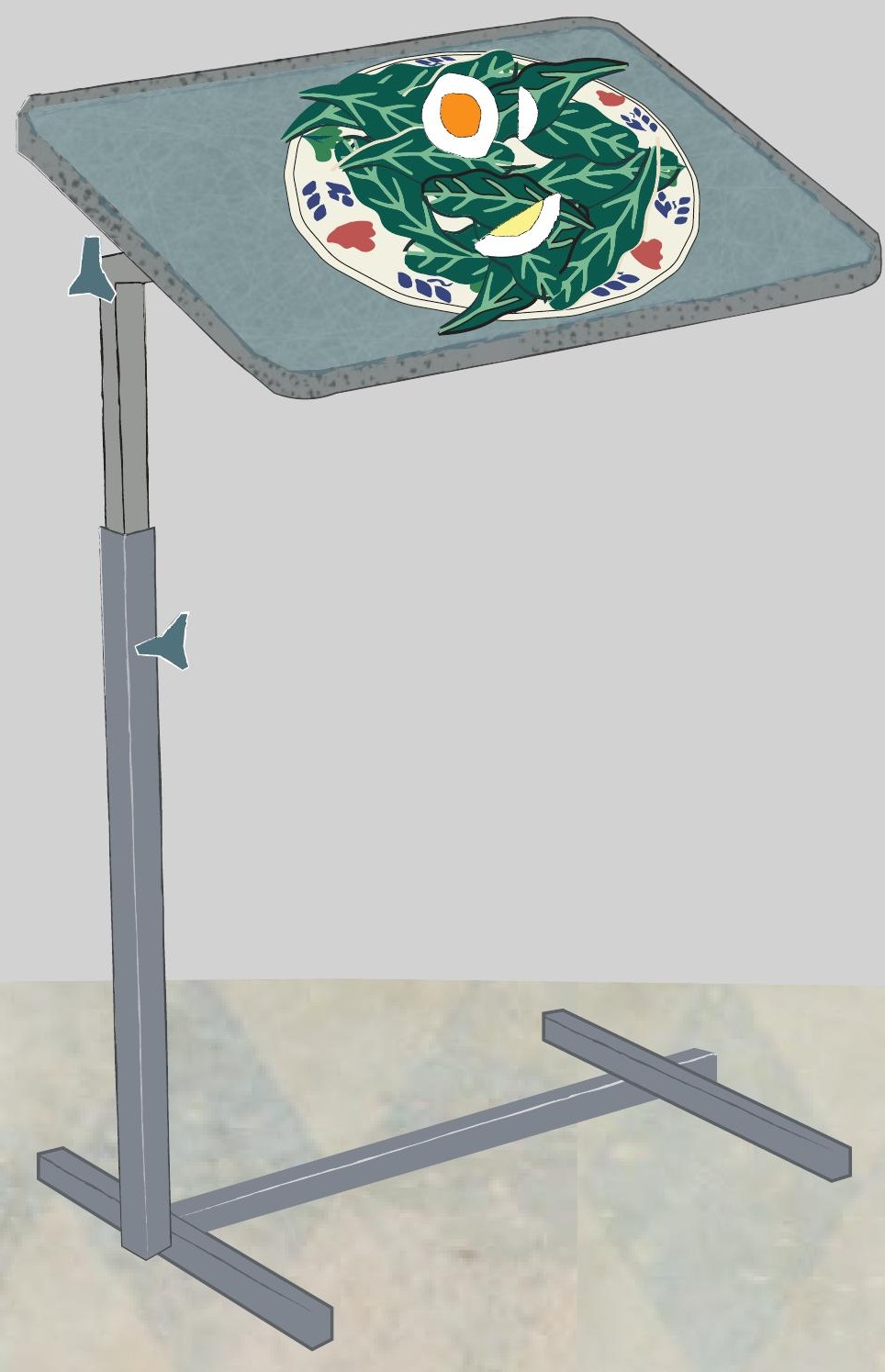




\section{CHAPTER SIX}

SODIUM NITRATE CO-INGESTION WITH PROTEIN DOES NOT AUGMENT POSTPRANDIAL MUSCLE PROTEIN SYNTHESIS RATES IN OLDER, TYPE ? DiABEtES PATIENTS

Imre W.K. Kouw, Naomi M. Cermak, Nicholas A. Burd, Tyler A. Churchward-Venne, Joan M. Senden, Annemarie P. Gijsen, and Luc J.C. van Loon Am J Physiol Endocrinol Metab. 2016 Aug 1;311(2)::325-34 


\section{ABSTRACT}

Introduction: The age-related anabolic resistance to protein ingestion is suggested to be associated with impairments in insulin-mediated capillary recruitment and postprandial muscle tissue perfusion. The present study investigated whether dietary nitrate co-ingestion with protein improves muscle protein synthesis in older, type 2 diabetes patients.

Methods: $\quad$ Twenty-four males with type 2 diabetes $\left(72 \pm 1 \mathrm{y}, 26.7 \pm 1.4 \mathrm{~m} \cdot \mathrm{kg}^{-2}\right.$ body mass index; $7.3 \pm 0.4 \% \mathrm{HbA}_{1 \mathrm{C}}$ ) received a primed continuous infusion of $\mathrm{L}$-[ring$\left.{ }^{2} \mathrm{H}_{5}\right]$-phenylalanine and $\mathrm{L}-\left[1-{ }^{13} \mathrm{C}\right]$-leucine and ingested $20 \mathrm{~g}$ intrinsically $\mathrm{L}$ $\left[1-{ }^{13} \mathrm{C}\right]$-phenylalanine and $\mathrm{L}-\left[1-{ }^{13} \mathrm{C}\right]$-leucine-labeled protein with (PRONO3) or without (PRO) sodium nitrate $\left(\mathrm{NaNO}_{3} ; 0.15 \mathrm{mmol} \cdot \mathrm{kg}^{-1}\right)$. Blood and muscle samples were collected to assess protein digestion and absorption kinetics and postprandial muscle protein synthesis rates.

Results: Upon protein ingestion, exogenous phenylalanine appearance rates increased in both groups $(P<0.001)$ resulting in $55 \pm 2 \%$ and $53 \pm 2 \%$ of dietary protein-derived amino acids becoming available in the circulation over the $5 \mathrm{~h}$ postprandial period in the PRO and PRONO3 group, respectively. Postprandial myofibrillar protein synthesis rates based on L[ring- ${ }^{2} \mathrm{H}_{5}$ ]-phenylalanine did not differ between groups $(0.025 \pm 0.004$ and $0.021 \pm 0.007 \% \cdot h^{-1}$ over $0-2 h$ and $0.032 \pm 0.004$ and $0.030 \pm 0.003 \% \cdot h^{-1}$ over 2$5 \mathrm{~h}$ in PRO and PRONO3, respectively; $P=0.7$ ). No differences in the incorporation of dietary protein-derived $L-\left[1-{ }^{13} \mathrm{C}\right]$-phenylalanine into de novo myofibrillar protein were observed at $5 \mathrm{~h}(0.016 \pm 0.002$ and $0.014 \pm 0.002$ $M P E$, in $P R O$ and $P R O N O 3$, respectively; $P=0.8$ ).

Conclusion: Dietary nitrate co-ingestion with protein does not modulate protein digestion and absorption kinetics, nor does it further increase postprandial muscle protein synthesis rates or the incorporation of dietary proteinderived amino acids into de novo myofibrillar protein in older, type 2 diabetes patients. 


\section{INTRODUCTION}

Aging is associated with loss of skeletal muscle mass and strength, termed sarcopenia, and results in loss of functional capacity, a higher risk for hospitalization, and development of chronic metabolic diseases [1]. Recently we [2, 3], as well as others [4, 5], showed that sarcopenia is more pronounced in older individuals with type 2 diabetes than in age-matched, normoglycemic controls. Since skeletal muscle tissue is a large site of postprandial glucose disposal, it is evident that the age-related loss of skeletal muscle mass is often accompanied by an insulin-resistant state [2-4].

Maintenance of skeletal muscle mass is regulated by muscle protein synthesis and muscle protein breakdown rates. A chronic imbalance between muscle protein synthesis and muscle protein breakdown rates contributes to the accelerated loss of skeletal muscle mass with aging. It has been well established that protein ingestion and the associated increase in postprandial plasma amino acids in the circulation directly increase muscle protein synthesis rates [6-9]. However, the postprandial stimulation of muscle protein synthesis following protein intake is impaired with aging, a phenomenon commonly referred to as anabolic resistance [9]. This anabolic resistance to protein intake is considered to be a key factor in the progressive loss of skeletal muscle mass with aging. Although the factor(s) underpinning anabolic resistance remains unclear, age-related impairments in endothelium-dependent vasodilation and blood flow in response to nutrient [10] and exercise [11] stimuli are suggested to play a key role.

The postprandial muscle protein synthetic response to protein feeding is regulated by numerous factors, such as protein digestion and amino acid absorption, amino acid availability in the circulation, delivery to skeletal muscle tissue, and uptake in the muscle [12]. The postprandial increase in muscle microvascular perfusion facilitates the delivery of amino acids, nutrients, and growth factors to the muscle, thereby allowing muscle protein synthesis rates to increase after protein ingestion [13, 14]. However, aging and insulin resistance are associated with reduced skeletal muscle capillary density, impaired endothelial function, and reduced nitric oxide (NO) availability [3, 10, 15-17]. As such, age-related impairments in vascular function due to an impaired NO-mediated vasodilatory response and decreased muscle tissue perfusion may diminish feeding-mediated increases in muscle protein synthesis and, thus, contribute to the anabolic resistance of aging $[18,19]$.

It has been reported that dietary nitrate $\left(\mathrm{NO}_{3}^{-}\right)$supplementation, via sequential reduction of $\mathrm{NO}_{3}{ }^{-}$to nitrite $\left(\mathrm{NO}_{2}^{-}\right)$and $\mathrm{NO}$, can stimulate $\mathrm{NO}$ synthesis and increase $\mathrm{NO}$ bioavailability [20]. Moreover, it has been suggested that NO has a role in promoting insulin delivery to skeletal muscle tissue and increasing insulin-stimulated muscle perfusion and capillary action $[21,22]$. As such, ingestion of a single dose of dietary $\mathrm{NO}_{3}{ }^{-}$might increase endothelial $\mathrm{NO}$ availability, thereby increasing blood flow and tissue perfusion and the subsequent muscle anabolic response to food intake. Recently, the acute ingestion of $\mathrm{NO}_{3}{ }^{-}$-rich dietary sources has been shown to improve vascular function [23-26] and macro- and microvascular blood 
flow $[24,27]$ in healthy subjects, as well as in overweight individuals and diabetes patients. In support of these findings, pharmacological increases in blood flow and tissue perfusion following administration of a NO-donating vasodilator, sodium nitroprusside, combined with amino acid provision have been shown to increase postprandial muscle protein synthesis rates in older subjects [28]. However, whether dietary $\mathrm{NO}_{3}{ }^{-}$co-ingestion with a protein meal can be used as a nutritional strategy to augment the postprandial muscle protein synthetic response remains to be assessed.

In particular, dietary $\mathrm{NO}_{3}{ }^{-}$may serve as an effective nutritional strategy to counteract the agerelated anabolic resistance of muscle protein synthesis to protein ingestion through NOmediated increases in skeletal muscle microvascular perfusion. In the current investigation, we hypothesized that a single dose of dietary $\mathrm{NO}_{3}{ }^{-}$co-ingested with protein increases amino acid delivery to skeletal muscle tissue and, subsequently, enhances the postprandial muscle protein synthetic response. 


\section{METHODS}

\section{Subjects}

Twenty-four older $\left(72 \pm 1 \mathrm{yr}\right.$ ), type 2 diabetes patients (body mass index $=26.7 \pm 1.4 \mathrm{~m} \cdot \mathrm{kg}^{-2}$, $\mathrm{HbA}_{1 \mathrm{C}}=7.3 \pm 0.4 \%$ ) were randomly assigned to two groups: a group that ingested protein with $\mathrm{NaCl}(\mathrm{PRO})$ or a group that ingested protein with $\mathrm{NaNO}_{3}{ }^{-}$(PRONO3). Subjects' characteristics are presented in Table 1. All subjects were using oral blood glucose-lowering medication and continued their habitual medication. Diabetes patients had been diagnosed with type 2 diabetes 2-18 yr prior to screening. One subject in the PRO group was unable to complete the trial and was, therefore, excluded from analysis. Subjects were informed of the nature and possible risks of the experimental procedures prior to providing written informed consent. The trial, conducted between August 2011 and July 2012 at Maastricht University, was part of a larger project investigating the impact of protein feeding on muscle metabolism in older, type 2 diabetes patients [29]. The study was approved by the Medical Ethical Committee of the Maastricht University Medical Centre and conformed to standards for the use of human subjects in research as outlined in the latest version of the Declaration of Helsinki.

\section{Pretesting}

All subjects participated in a prescreening session to assess their $\mathrm{HbA}_{1 c}$, glucose tolerance (by a 2-h oral glucose tolerance test [30]), blood pressure, weight, height, and body composition [by dual-energy X-ray absorptiometry (Discovery A, Hologic, Bedford, MA)]. The subjects were deemed healthy on the basis of their responses to a medical questionnaire and screening results. All subjects were instructed to refrain from strenuous physical activity and to maintain their diet as constant as possible for 2 days prior to the experimental infusions. On the evening before the trial, the subjects consumed a standardized meal $\left(2.38 \mathrm{MJ}, 31.7 \pm 1.1 \mathrm{~kJ} \cdot \mathrm{kg}^{-1}\right.$ body wt) composed of 15 energy percent (En\%) protein, 55 En\% carbohydrate, and $30 \mathrm{En} \%$ fat. 
Table 1 | Subjects' characteristics

\begin{tabular}{|c|c|c|}
\hline & $\operatorname{PRO}(n=11)$ & PRONO3 $(n=12)$ \\
\hline Age (y) & $71 \pm 1$ & $73 \pm 1$ \\
\hline Weight (kg) & $80.4 \pm 1.6$ & $83.0 \pm 1.8$ \\
\hline BMI $\left(\mathbf{k g} \cdot \mathbf{m}^{-2}\right)$ & $26.2 \pm 0.5$ & $27.3 \pm 0.6$ \\
\hline Lean body mass (kg) & $60.6 \pm 1.0$ & $60.8 \pm 1.4$ \\
\hline Appendicular lean mass (kg) & $25.8 \pm 0.6(32 \%)$ & $25.1 \pm 0.8(30 \%)$ \\
\hline Skeletal mass index $\left(\mathbf{k g} \cdot \mathbf{m}^{-2}\right)$ & $8.4 \pm 0.2$ & $8.3 \pm 0.3$ \\
\hline Fat (\%) & $21.8 \pm 0.8$ & $23.8 \pm 0.8$ \\
\hline Basal plasma glucose $\left(\mathrm{mmol} \cdot \mathrm{L}^{-1}\right)$ & $9.6 \pm 0.9$ & $9.6 \pm 0.6$ \\
\hline Plasma glucose OGTT $t=120 \mathrm{~min}\left(\mathrm{mmol} \cdot \mathrm{L}^{-1}\right)$ & $16.3 \pm 0.9$ & $17.9 \pm 0.9$ \\
\hline Basal plasma insulin $\left(\mathrm{mU} \cdot \mathrm{L}^{-1}\right)$ & $16.8 \pm 2.4$ & $17.4 \pm 1.6$ \\
\hline Plasma insulin OGTT $t=120 \mathrm{~min}\left(\mathrm{mU} \cdot \mathrm{L}^{-1}\right)$ & $45.6 \pm 8.0$ & $42.3 \pm 7.1$ \\
\hline $\mathrm{HbA}_{1} \mathrm{C}(\%)$ & $7.1 \pm 0.3$ & $7.6 \pm 0.2$ \\
\hline OGIS $\left(\mathrm{mL} \cdot \mathrm{min}^{-1} \cdot \mathrm{m}^{-2}\right)$ & $286 \pm 11$ & $260 \pm 9$ \\
\hline HOMA-IR & $2.5 \pm 0.3$ & $2.5 \pm 0.2$ \\
\hline
\end{tabular}

Values are mean \pm SEM. $\mathrm{HbA}_{1 \mathrm{c}}$ : glycosylated hemoglobin; OGTT: oral glucose tolerance test; OGIS: oral glucose insulin sensitivity, HOMA: homeostasis model assessment. Data were analyzed by unpaired Student's $t$-test.

\section{Experimental protocol}

At 0800 , after an overnight fast, subjects arrived at the laboratory by car or public transport. Upon the subjects' arrival at the laboratory, a Teflon catheter was inserted into an antecubital vein for infusion and a second cannula was inserted into the dorsal hand vein of the contralateral arm, which was placed in a hot box $\left(60^{\circ} \mathrm{C}\right)$ for arterialized blood sampling [31]. After baseline blood collection (-210 $\mathrm{min}$ ), the plasma phenylalanine, tyrosine, and leucine pools were primed with a single intravenous (priming) dose of $L$-[ $\left[\right.$ ring- $\left.^{2} \mathrm{H}_{5}\right]$-phenylalanine (2 $\left.\mu \mathrm{mol} \cdot \mathrm{kg}^{-1}\right), \mathrm{L}$-[ring-3,5- $\left.{ }^{2} \mathrm{H}_{2}\right]$-tyrosine $\left(0.615 \mu \mathrm{mol} \cdot \mathrm{kg}^{-1}\right)$, and $\mathrm{L}-\left[1{ }^{13} \mathrm{C}\right]$-leucine $\left(4.0 \mu \mathrm{mol} \cdot \mathrm{kg}^{-1}\right)$. Subsequently, the continuous infusion $\left(0.05 \mu \mathrm{mol} \cdot \mathrm{kg}^{-1} \cdot \mathrm{min}^{-1}\right.$ for $\mathrm{L}-\left[\mathrm{ring}^{-2} \mathrm{H}_{5}\right]$-phenylalanine, $0.015 \mu \mathrm{mol} \cdot \mathrm{kg}^{-1} \cdot \mathrm{min}^{-1}$ for $\mathrm{L}$-[ring- $\left.{ }^{2} \mathrm{H}_{2}\right]$-tyrosine, and $0.100 \mu \mathrm{mol} \cdot \mathrm{kg}^{-1} \cdot \mathrm{min}^{-1}$ for $\mathrm{L}-\left[1-{ }^{13} \mathrm{C}\right]-$ leucine) was initiated and maintained for $8.5 \mathrm{~h}$. At $-120 \mathrm{~min}$, subjects ingested a single bolus of $\mathrm{NaNO}_{3}{ }^{-}$[(0.15 mmol. $\mathrm{kg}^{-1}$ body wt, which provided $\mathrm{NO}_{3}{ }^{-}$at $9.3 \mathrm{mg} \cdot \mathrm{kg}^{-1}$ body wt (PRONO3 group; BASF, Ludwigshafen, Germany)] or an equimolar amount of $\mathrm{NaCl}$ dissolved in $250 \mathrm{~mL}$ of water (PRO group; Glacia British salt, United Kingdom) dissolved in $250 \mathrm{~mL}$ of water. We provided a single dose of dietary $\mathrm{NO}_{3}{ }^{-}$at $2 \mathrm{~h}$ prior to protein ingestion to ensure that the increase in $\mathrm{NO}_{3}{ }^{-} / \mathrm{NO}_{2}{ }^{-}$concentrations would correspond with the postprandial increase in 
plasma amino acid concentrations [32]. Blood samples were collected during the infusion at $-120,-90,-60,-30,0,15,30,45,60,90,120,150,180,210,240,270$, and 300 min relative to the intake of the protein drink. Blood samples were collected into EDTA-containing tubes and centrifuged at $1,000 \mathrm{~g}$ at $4^{\circ} \mathrm{C}$ for $10 \mathrm{~min}$. Aliquots of plasma were frozen in liquid nitrogen and stored at $-80^{\circ} \mathrm{C}$. Muscle biopsies were collected for determination of postabsorptive muscle protein synthesis rates $(-120$ and $0 \mathrm{~min}$ ). Immediately after the second biopsy, subjects ingested a single bolus of $20 \mathrm{~g}$ of intrinsically $\mathrm{L}-\left[1-{ }^{13} \mathrm{C}\right]$-phenylalanine- and $\mathrm{L}-\left[1-{ }^{13} \mathrm{C}\right]$-leucinelabeled casein protein dissolved in water that was flavored with $1.5 \mathrm{~mL}$ of vanilla (IMCD Benelux, Rotterdam, the Netherlands). Additional biopsies (from the contralateral leg) were collected at 120 and 300 min for measurement of postprandial muscle protein synthesis rates. The Bergström needle technique [33] was used to collect muscle biopsies from the middle region of the vastus lateralis ( $15 \mathrm{~cm}$ above the patella). All biopsy samples were freed from visible adipose tissue and blood, immediately frozen in liquid nitrogen, and stored at $-80^{\circ} \mathrm{C}$ until subsequent analysis.

\section{Production of intrinsically labeled protein}

Intrinsically L-[1-13 C]-phenylalanine- and L-[1-13 C]-leucine-labeled casein was obtained by infusion of a lactating Holstein cow with L-[1-13 C]-phenylalanine $\left(455 \mu \mathrm{mol} \cdot \mathrm{min}^{-1}\right)$ and L-[1${ }^{13} \mathrm{C}$ ]-leucine $\left(200 \mu \mathrm{mol} \cdot \mathrm{min}^{-1}\right)$, collection of the milk, and purification of the casein fraction, as described previously [34-36]. Enrichments of $L-\left[1-{ }^{13} \mathrm{C}\right]$-phenylalanine and $L-\left[1-{ }^{13} \mathrm{C}\right]$-leucine in the casein were 38.7 and 9.3 mole percent excess (MPE), respectively. Participants received a beverage containing $20 \mathrm{~g}$ of casein (containing $1.54 \mathrm{~g}$ of leucine) in a total volume of $350 \mathrm{~mL}$. The casein protein met all chemical and bacteriological specifications for human consumption.

\section{Plasma analyses}

Plasma $\mathrm{NO}_{3}{ }^{-}$and $\mathrm{NO}_{2}{ }^{-}$were analyzed by gas-phase chemiluminescence analysis, which has been described previously [37]. Briefly, plasma $\mathrm{NO}_{3}{ }^{-}$and $\mathrm{NO}_{2}{ }^{-}$concentrations are determined by their reduction to NO. The spectral emission of electronically excited nitrogen dioxide, from the NO reaction with ozone, is detected by a thermoelectrically cooled, red-sensitive photomultiplier tube, housed in a gas-phase chemiluminescence NO analyzer (Sievers NOA 280i, Analytix). Plasma glucose and insulin concentrations were analyzed using commercially available kits [GLUC3 (catalog no. 05168791 190, Roche) and Immunologic (catalog no. 12017547 122, Roche), respectively]. Plasma amino acid concentrations and enrichments were determined by gas chromatography-mass spectrometry (GC-MS) analysis (model 7890A/GC/5975C/MSD, Agilent, Little Falls, VA). Specifically, internal standards of $\left[\mathrm{U}-{ }^{13} \mathrm{C}_{6}\right]-$ leucine, $\left[\mathrm{U}-{ }^{13} \mathrm{C}_{9}{ }^{15} \mathrm{~N}\right]$-phenylalanine, and $\left[\mathrm{U}-{ }^{13} \mathrm{C}_{9}{ }^{15} \mathrm{~N}\right]$-tyrosine were added to the samples, which were deproteinized on ice with dry 5-sulfosalicylic acid. Free amino acids were purified using cation-exchange chromatography (AG 50W-X8 resin, 100- to 200- $\mu \mathrm{m}$ dry mesh; Bio-Rad Laboratories, Hercules, CA) and converted to their tert-butyl dimethylsilyl (t-BDMS) derivative before GC-MS analysis. The amino acid concentrations were determined using electron impact ionization by monitoring ions at mass-to-charge ratios $(\mathrm{m} / \mathrm{z})$ of 302 and 308 for unlabeled and 
$\left[\mathrm{U}-{ }^{13} \mathrm{C}_{6}\right]$-labeled leucine, respectively, $\mathrm{m} / \mathrm{z} 336$ and 346 for unlabeled and $\left[\mathrm{U}-{ }^{13} \mathrm{C}_{9}{ }^{15} \mathrm{~N}\right]$-labeled phenylalanine, respectively, and $\mathrm{m} / \mathrm{z} 466$ and 476 for unlabeled and $\left[\mathrm{U}-{ }^{13} \mathrm{C}_{9}{ }^{15} \mathrm{~N}\right]$-labeled tyrosine, respectively. The plasma phenylalanine and tyrosine ${ }^{13} \mathrm{C}$ and ${ }^{2} \mathrm{H}$ enrichments were determined using selective ion monitoring at $\mathrm{m} / \mathrm{z} 336,337$, and 341 for unlabeled and labeled $\left(1-{ }^{13} \mathrm{C}\right.$ and ring- $\left.{ }^{2} \mathrm{H}_{5}\right)$-phenylalanine, respectively, and $\mathrm{m} / \mathrm{z} 466,467,468$, and 470 for unlabeled and labeled $\left(1-{ }^{13} \mathrm{C}\right.$, ring-3,5-2 $\mathrm{H}_{2}$, and ring- $\left.{ }^{2} \mathrm{H}_{4}\right)$-tyrosine, respectively. For $\mathrm{L}-\left[1-{ }^{13} \mathrm{C}\right]-$ leucine, $\mathrm{m} / \mathrm{z} 302(\mathrm{~m}+0)$ and $\mathrm{m} / \mathrm{z} 303(\mathrm{~m}+1)$ were monitored. Standard regression curves were applied from a series of known standard enrichment values against the measured values to assess the linearity of the mass spectrometer and to account for any isotope fractionation that may have occurred during the analysis. Phenylalanine and tyrosine enrichments were corrected for the presence of the ${ }^{13} \mathrm{C}$ and ${ }^{2} \mathrm{H}$ isotopes. Plasma isotopic enrichment of the $\mathrm{t}$ BDMS derivative of $\alpha-\left[{ }^{13} \mathrm{C}\right]$-ketoisocaproate $(\mathrm{KIC})$ was measured by GC-MS analysis for use as a surrogate for leucyl-tRNA labeling [38].

\section{Muscle analyses}

The muscle intracellular free amino acids were extracted from $\sim 50 \mathrm{mg}$ of wet muscle tissue. The muscle was homogenized on ice with a Teflon-coated pestle using ice-cold $2 \%$ perchloric acid $\left(7 \mu \mathrm{l} \times\right.$ wet weight) and then centrifuged at $10,000 \mathrm{~g}$ and $4^{\circ} \mathrm{C}$ for $5 \mathrm{~min}$. The supernatant was collected, and this process was repeated twice. The supernatant was taken as the muscle intracellular free amino acid pool and processed in the same manner as the plasma samples for isotopic enrichment by GC-MS analysis. Myofibrillar protein-enriched fractions were extracted from a separate $\sim 50 \mathrm{mg}$ piece of wet muscle tissue by hand-homogenization on ice using a pestle (Teflon) in a standard extraction buffer $\left(7.5 \mu \mathrm{l} \cdot \mathrm{mg}^{-1}\right)$ [39]. The samples were spun at $1,500 \mathrm{~g}$ and $4^{\circ} \mathrm{C}$ for $10 \mathrm{~min}$. The supernatants containing sarcoplasmic proteins were removed. The remaining myofibrillar and collagen pellets were washed with $500 \mu$ of extraction buffer and spun at $700 \mathrm{~g}$ and $4^{\circ} \mathrm{C}$ for $10 \mathrm{~min}$. The myofibrillar protein was solubilized by addition of $1.5 \mathrm{ml}$ of $0.3 \mathrm{M} \mathrm{NaOH}$ and heating at $50^{\circ} \mathrm{C}$ for $30 \mathrm{~min}$, with vortex mixing every $10 \mathrm{~min}$. Samples were centrifuged at $10,000 \mathrm{~g}$ and $4^{\circ} \mathrm{C}$ for $5 \mathrm{~min}$, and the supernatant containing the myofibrillar-enriched fraction was collected and the collagen pellet was discarded. Myofibrillar proteins were precipitated by addition of $1 \mathrm{ml}$ of $1 \mathrm{M}$ perchloric acid and spinning at $700 \mathrm{~g}$ and $4^{\circ} \mathrm{C}$ for $10 \mathrm{~min}$. The myofibrillar protein was washed twice with $70 \%$ ethanol. Amino acids were liberated by addition of $2 \mathrm{ml}$ of $6 \mathrm{M} \mathrm{HCl}$ and heating at $110^{\circ} \mathrm{C}$ for $24 \mathrm{~h}$. The hydrolyzed myofibrillar protein fraction was dried under a nitrogen stream while being heated to $120^{\circ} \mathrm{C}$ and, subsequently, dissolved in a $25 \%$ acetic acid solution and passed over a Dowex exchange resin (AG 50W-X8, 100- to 200- $\mu \mathrm{m}$ mesh hydrogen form; Bio-Rad Laboratories). The free amino acids were eluted with $2 \mathrm{M} \mathrm{NH}_{4} \mathrm{OH}$ and dried, and the purified amino acids were derivatized into $\mathrm{N}$-tert-butylmethylsilyl-N-methyltrifluoroacetamidephenylethylamines $[40,41]$ for measurement of I-[ring- $\left.{ }^{2} \mathrm{H}_{5}\right]$ phenylalanine labeling using GCMS analysis, as described previously [42]. To reduce the signal-to-noise ratio during GC-MS analysis at low tracer enrichments, the phenylalanine from the myofibrillar protein hydrolysates was enzymatically decarboxylated to phenylethylamine [41] prior to MTBSTFA 
derivatization [40, 43]. Enrichments of the protein-bound samples were determined by selected ion monitoring for phenylalanine m/z $183(m+5)$ to $\mathrm{m} / \mathrm{z} 180(\mathrm{~m}+2)$ and a single linear standard curve (to avoid slope influences on the measured tracer-to-tracee ratio) from mixtures of known $m+5$ to $m+0$ ratios. To avoid saturation of the mass spectrometer and eliminate bias due to any potential concentration dependencies (22), the split ratio was adjusted prior to the injection of each sample, so that nearly equal amounts of phenylalanine were injected for all samples and standards. The derivatized amino acids were separated on a $30 \mathrm{~m} \times 0.25 \mathrm{~mm} \times 0.50 \mu \mathrm{m} \mathrm{HP}-5 \mathrm{MS}$ column (temperature program: $80^{\circ} \mathrm{C}$ for $1 \mathrm{~min}, 30^{\circ} \mathrm{C} \cdot \mathrm{min}^{-}$ ${ }^{1}$ ramp to $300^{\circ} \mathrm{C}$, hold for $10 \mathrm{~min}$ ). Separate aliquots of the purified amino acids were also converted to their $\mathrm{N}(\mathrm{O}, \mathrm{S})$-ethoxycarbonyl ethyl ester derivatives with ethyl chloroformate for determination of the $\mathrm{I}-\left[1-{ }^{13} \mathrm{C}\right]$ phenylalanine and $\mathrm{I}-\left[1-{ }^{13} \mathrm{C}\right]$ leucine labeling of the myofibrillar proteins by gas chromatography combustion-isotope ratio mass spectrometry analysis (GC-IRMS Trace GC Ultra, model MAT 253, Thermo Scientific, Bremen, Germany). Standard regression curves were applied from a series of known standard enrichment values against the measured values to assess the linearity of the mass spectrometer and to account for any isotope fractionation that may have occurred during the analysis.

\section{Calculations}

Whole body amino acid kinetics in non-steady-state conditions were calculated from ingestion of $\mathrm{L}-\left[1-{ }^{13} \mathrm{C}\right]$-phenylalanine-labeled protein, intravenous infusion of $\mathrm{L}$-[ring- $\left.{ }^{2} \mathrm{H}_{5}\right]$-phenylalanine and $\mathrm{L}$-[ring-3,5- ${ }^{2} \mathrm{H}_{2}$ ]-tyrosine, and arterialized venous blood sampling. Total, exogenous, and endogenous phenylalanine appearance rates $\left(R_{a}\right.$ in $\mu \mathrm{mol}$ Phe $\left.\cdot \mathrm{kg}^{-1} \cdot \mathrm{min}^{-1}\right)$ and plasma phenylalanine availability [i.e., the fraction of dietary protein-derived phenylalanine that appeared in the systemic circulation (Phe plasma$\left._{2}\right)$ ] were calculated using modified Steele's equations [44-46].

$$
\text { Total } R_{a}=\frac{F_{i v}-\left[p V \cdot C(t) \cdot \frac{d E_{i v}}{d t}\right]}{E_{i v}(t)}
$$

Total phenylalanine $\mathrm{R}_{\mathrm{a}}$ was calculated using Eq. 1, where $F_{\text {iv }}$ is the intravenous tracer infusion rate (in $\mu \mathrm{mol} \cdot \mathrm{kg}^{-1} \cdot \mathrm{min}^{-1}$ ) and $\mathrm{pV}$ is the distribution volume for phenylalanine $\left(0.125 \mathrm{~L}^{\mathrm{kg}} \mathrm{kg}^{-1}\right.$ ) [44]. $(C(t)$ is the mean plasma phenylalanine concentration between two consecutive time points, and $\mathrm{dE}_{\mathrm{iv}} / \mathrm{d} t$ represents the time-dependent change in plasma phenylalanine enrichment derived from the intravenous tracer and $\mathrm{E}_{\mathrm{iv}}(t)$ is the mean plasma phenylalanine enrichment from the intravenous tracer between 2 consecutive time points.

$$
\text { Exogenous } R_{a}=\frac{\operatorname{Total} R_{a} \cdot E_{p o}(t)+\left[p V \cdot C(t) \cdot \frac{d E_{p o}}{d t}\right]}{E_{p r o t}}
$$

Exogenous phenylalanine $\mathrm{R}_{a}$ (Eq. 2; Exo $\mathrm{R}_{\mathrm{a}}$ ) represents the plasma entry rate of dietary proteinderived phenylalanine. $E_{p o}(t)$ is the mean plasma phenylalanine enrichment of the oral tracer, $\mathrm{dE}_{\mathrm{po}} / \mathrm{d} t$ represents the time-dependent change in plasma phenylalanine enrichment derived from the oral tracer, and $E_{\text {prot }}$ is the enrichment of $L-\left[1-{ }^{13} \mathrm{C}\right]$-phenylalanine in the dietary protein. 
Endogenous phenylalanine $\mathrm{R}_{a}$ (Eq. 3; Endo $\mathrm{R}_{a}$ ) represents the plasma entry rate of phenylalanine derived from whole body protein breakdown.

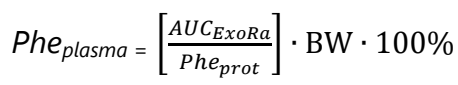

Phe plasma was calculated using Eq. 4. AUC ExoRa is the area under the curve (AUC) of Exo $R_{a}, B W$

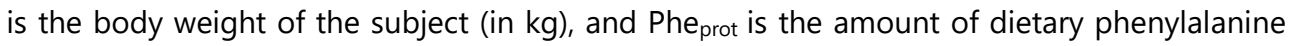
that is ingested.

Total phenylalanine rate of disappearance (Eq. 5; $R_{\mathrm{d}}$ in $\mu \mathrm{mol} P \mathrm{Phe} \cdot \mathrm{kg}^{-1} \cdot \mathrm{min}^{-1}$ ) equals the rate of phenylalanine hydroxylation (the 1st step in phenylalanine oxidation) and utilization for protein synthesis. These parameters are calculated as follows

$$
\begin{aligned}
& \text { Total } R_{d}=\text { Total } R_{a}-p V \cdot \frac{d C}{d t} \\
& \text { Phe hydroxylation }=\text { Tyr } R_{a} \cdot \frac{E_{t y r}(t)}{E_{p h e}(t)} \cdot \frac{P h e R_{d}}{\left(F_{P h e}+P h e R_{d}\right)} \\
& \text { Protein synthesis }=\text { Total } R_{d}-\text { Phe hydroxylation } \\
& \text { Phe net balance = Protein synthesis }- \text { Endo } R_{a}
\end{aligned}
$$

Tyr $\mathrm{R}_{\mathrm{a}}$ is the total rate of tyrosine appearance based on the L-[ring-3,5-2 $\mathrm{H}_{2}$ ]-tyrosine infusion and plasma enrichment. $\mathrm{E}_{\mathrm{Tyr}}(\mathrm{t})$ and $\mathrm{E}_{\mathrm{Phe}}(\mathrm{t})$ represent the mean plasma $\mathrm{L}$-[ring- $\left.{ }^{2} \mathrm{H}_{4}\right]$-tyrosine and $\mathrm{L}$-[ring- $\left.{ }^{2} \mathrm{H}_{5}\right]$-phenylalanine enrichment between two consecutive time points, respectively. $\mathrm{F}_{\mathrm{Phe}}$ is the intravenous infusion rate of $\mathrm{L}$-[ $\left.\mathrm{ring}-{ }^{2} \mathrm{H}_{5}\right]$-phenylalanine (in $\left.\mu \mathrm{mol} \cdot \mathrm{kg}^{-1} \cdot \mathrm{min}^{-1}\right)$.

Myofibrillar protein fractional synthesis rates (FSR) were calculated using the standard precursor-product equation

$$
F S R=\frac{\Delta E p}{E_{\text {precursor }} \cdot t} \cdot 100 \%
$$

where $\Delta \mathrm{Ep}$ is the increment in myofibrillar protein-bound L-[ring- $\left.{ }^{2} \mathrm{H}_{5}\right]$-phenylalanine or $\mathrm{L}$-[1$\left.{ }^{13} \mathrm{C}\right]$-leucine enrichments after an incorporation period (in mole percent excess; MPE). $E_{\text {precursor }}$ is the average plasma L-[ring- $\left.{ }^{2} \mathrm{H}_{5}\right]$-phenylalanine or $\alpha-\left[1-{ }^{13} \mathrm{C}\right]-\mathrm{KIC}$ enrichment during the tracer incorporation period (in MPE), and $t$ is the incorporation period (in hours). For basal FSR, muscle biopsies at -120 and 0 min were used; for postprandial FSR, biopsies at 0,120 , and 300 min were used to calculate the early $(0-2 \mathrm{~h})$ and late $(2-5 \mathrm{~h})$ postprandial muscle protein synthetic response.

\section{Statistics}

Values are means \pm SE. Differences in baseline values were determined using an unpaired, twotailed Student's $t$-test. Incremental AUC (iAUC), peak value, and time to peak were calculated for all plasma time curves, and differences were determined using an unpaired, two-tailed 
Student's $t$-test. Two-way ANOVA with time as the within-group factor and intervention as the between-group factor was used to compare differences over time in plasma glucose, insulin, $\mathrm{NO}_{3}{ }^{-}, \mathrm{NO}_{2}{ }^{-}$, amino acid concentrations and enrichments, whole body phenylalanine $\mathrm{R}_{\mathrm{a}}$, and FSR. In case of significant interaction between time and intervention, Bonferroni's post hoc test was applied. Differences between intervention groups in muscle free and protein-bound amino acid enrichments were analyzed with an unpaired, two-tailed Student's $t$-test. For all analyses, statistical significance was set at $P<0.05$. All calculations were performed using IBM SPSS Statistics (version 21). 


\section{RESULTS}

\section{Plasma analyses}

Plasma $\mathrm{NO}_{3}{ }^{-}$and $\mathrm{NO}_{2}{ }^{-}$concentrations are presented in Figure 1. Plasma $\mathrm{NO}_{3}{ }^{-}$concentrations (Figure 1A) did not differ at baseline (-210 $\mathrm{min}$ ) between intervention groups and increased following $\mathrm{NaNO}_{3}-$ ingestion $(P<0.001)$. Throughout the experiment, $\mathrm{NO}_{3}{ }^{-}$concentrations were significantly higher in the PRONO3 than the PRO group $(P<0.001$, time $\times$ intervention interaction $P<0.001$, iAUC $P<0.001$ ), reaching peak values of $663 \pm 22$ and $39 \pm 2 \mu \mathrm{mol} \cdot \mathrm{L}^{-1}$ in the PRONO3 and PRO groups, respectively $(P<0.001)$. Plasma $\mathrm{NO}_{2}{ }^{-}$concentrations (Figure 1B) increased significantly following $\mathrm{NaNO}_{3}{ }^{-}$ingestion in the PRONO3 group only (time effect $P<0.01$, group effect $P<0.05$, time $\times$ intervention interaction $P<0.01$ ), reaching peak values of $788 \pm 138$ and $389 \pm 55 \mathrm{mmol} \cdot \mathrm{L}^{-1}$ the $\mathrm{PRONO} 3$ and PRO groups, respectively (peak values $P<0.05$, iAUC $P<0.01$ ).
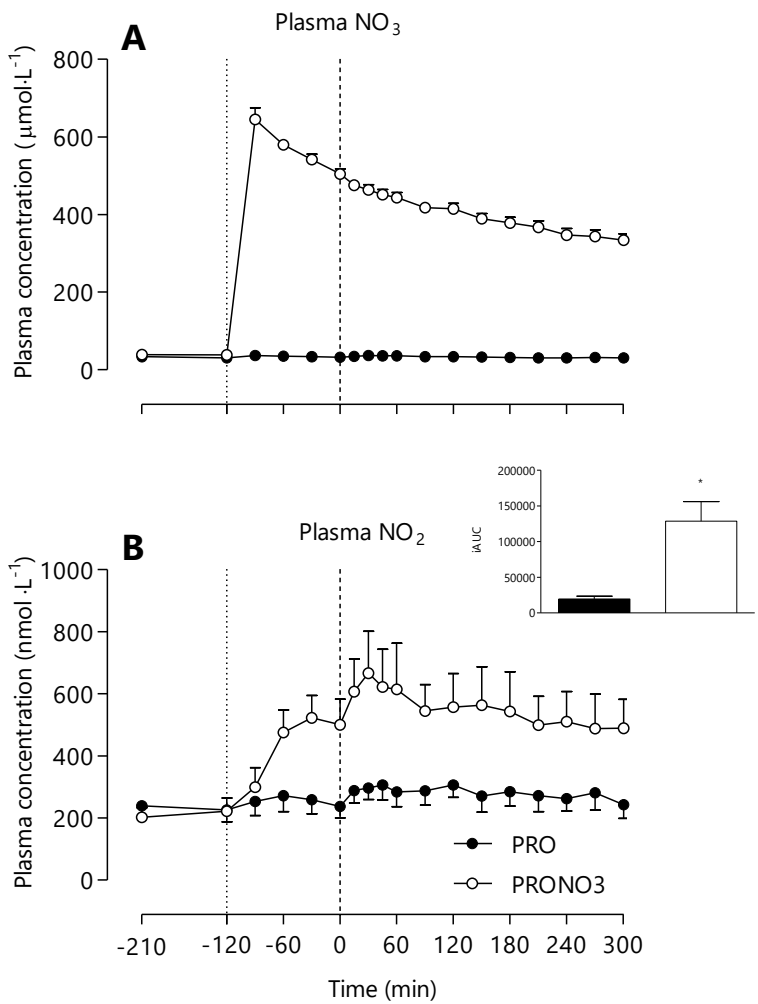

Figure 1 | Plasma nitrate $\left(\mathrm{NO}_{3}{ }^{-}, \mathbf{A}\right)$ and nitrite $\left(\mathrm{NO}_{2}{ }^{-}, \mathbf{B}\right)$ concentrations in older, type 2 diabetes patients following protein ingestion with (PRONO3, $n=12$ ) or without ( $\mathrm{PRO}, n=11$ ) dietary $\mathrm{NO}_{3}^{-}$. Vertical lines indicate ingestion of the drinks: dotted lines, $\mathrm{NaNO}_{3}{ }^{-}$or $\mathrm{NaCl}$; dashed lines, $20 \mathrm{~g}$ protein. Inset: integrated area under the curve (iAUC). Values are means \pm SE. Data were analyzed with repeated-measures (time $\times$ intervention) ANOVA. * Significant difference between groups, $P<0.01$. 
Plasma glucose and insulin concentrations are shown in Figure 2. Plasma glucose concentrations (Figure 2A) did not differ between interventions throughout the experimental trial. Plasma insulin concentrations (Figure 2B) increased following protein ingestion $(P<0.001)$, but to a greater extent in the PRO than the PRONO3 group (time $\times$ intervention interaction $P<0.001$, iAUC $P=0.4$ ).
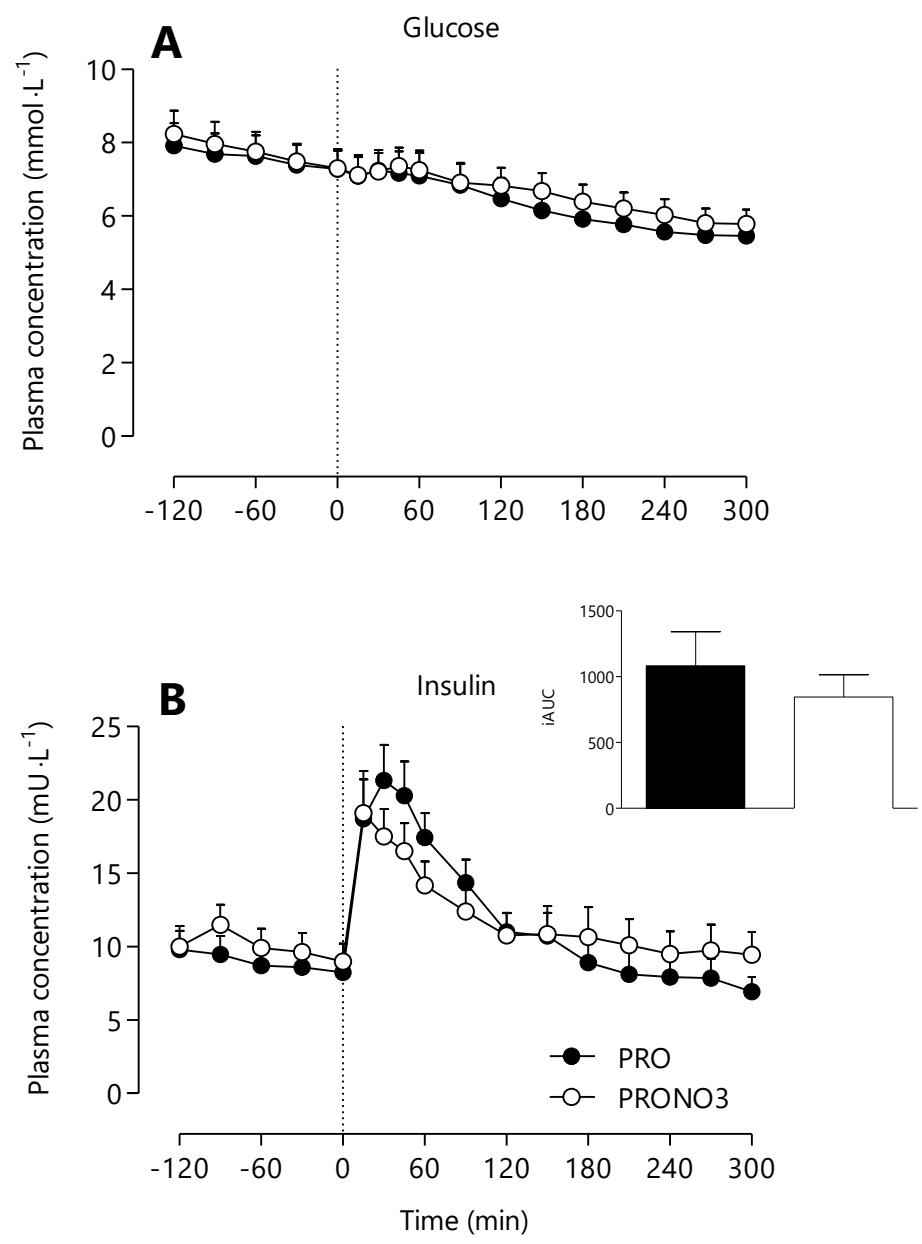

Figure 2 | Plasma glucose (A) and insulin (B) concentrations in older, type 2 diabetes patients following protein ingestion with (PRONO3, $n=12$ ) or without (PRO, $n=11$ ) dietary $\mathrm{NO}_{3}^{-}$. Vertical lines indicate ingestion of the

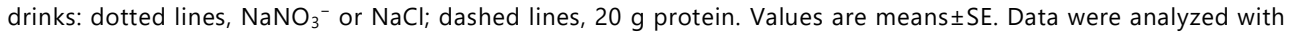
repeated-measures (time $\times$ intervention) ANOVA. 
Plasma amino acid concentrations (Figure 3 ) increased after protein ingestion $(P<0.001)$, with no differences between groups for phenylalanine (Figure $\mathbf{3 A}$ ) and leucine (Figure $\mathbf{3 C}$ ) concentrations. Plasma tyrosine concentrations (Figure 3B) were higher in the PRO group during the postprandial period (intervention effect $P<0.05$, iAUC $P=0.3$ ).

Plasma amino acid enrichments are presented in Figure 4. Plasma L-[ring- $\left.{ }^{2} \mathrm{H}_{5}\right]$-phenylalanine (Figure 4A) and L-[1-13 C]-leucine (Figure 4C) enrichments did not differ between interventions in the basal and postprandial periods. Plasma $L-\left[1-{ }^{13} \mathrm{C}\right]$-phenylalanine enrichments (Figure 4B) increased following protein ingestion in both intervention groups $(P<0.001)$, reaching peak values of $12.3 \pm 0.7 \mathrm{MPE}$ at $72 \pm 12 \mathrm{~min}$ and $11.8 \pm 0.8 \mathrm{MPE}$ at $86 \pm 24$ min in the PRO and PRONO3 groups, respectively, and did not differ between groups (intervention effect $P=0.7$, iAUC $P=0.8$ ). 

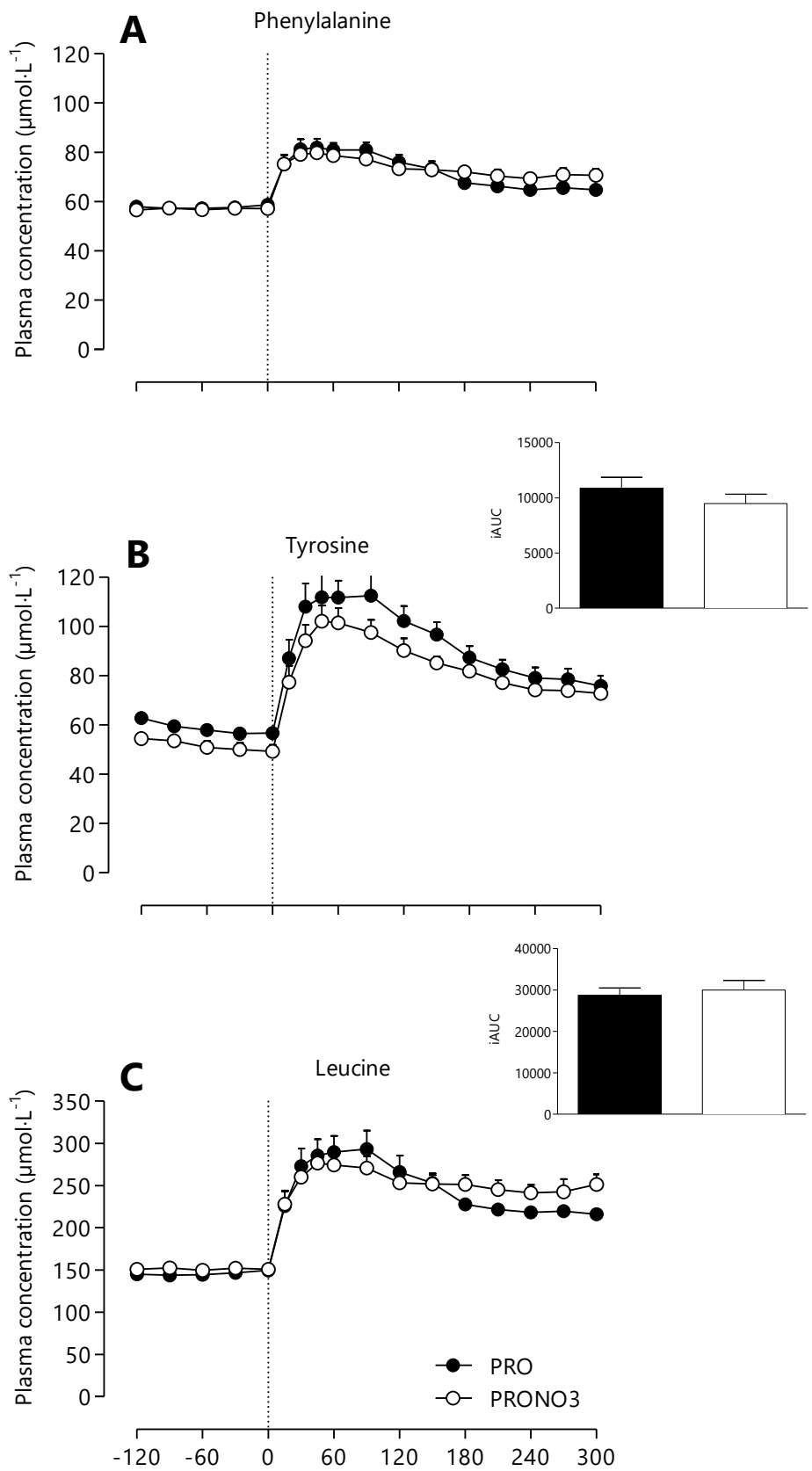

Figure 3 | Plasma phenylalanine (A), tyrosine (B), and leucine $(\mathbf{C})$ concentrations in older, type 2 diabetes patients following protein ingestion with (PRONO3, $n=12$ ) or without (PRO, $n=11$ ) dietary $\mathrm{NO}_{3}{ }^{-}$. Vertical lines indicate

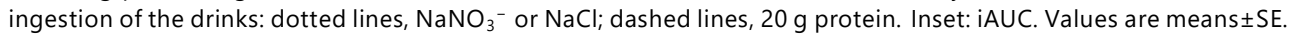
Data were analyzed with repeated-measures (time $\times$ intervention) ANOVA. 

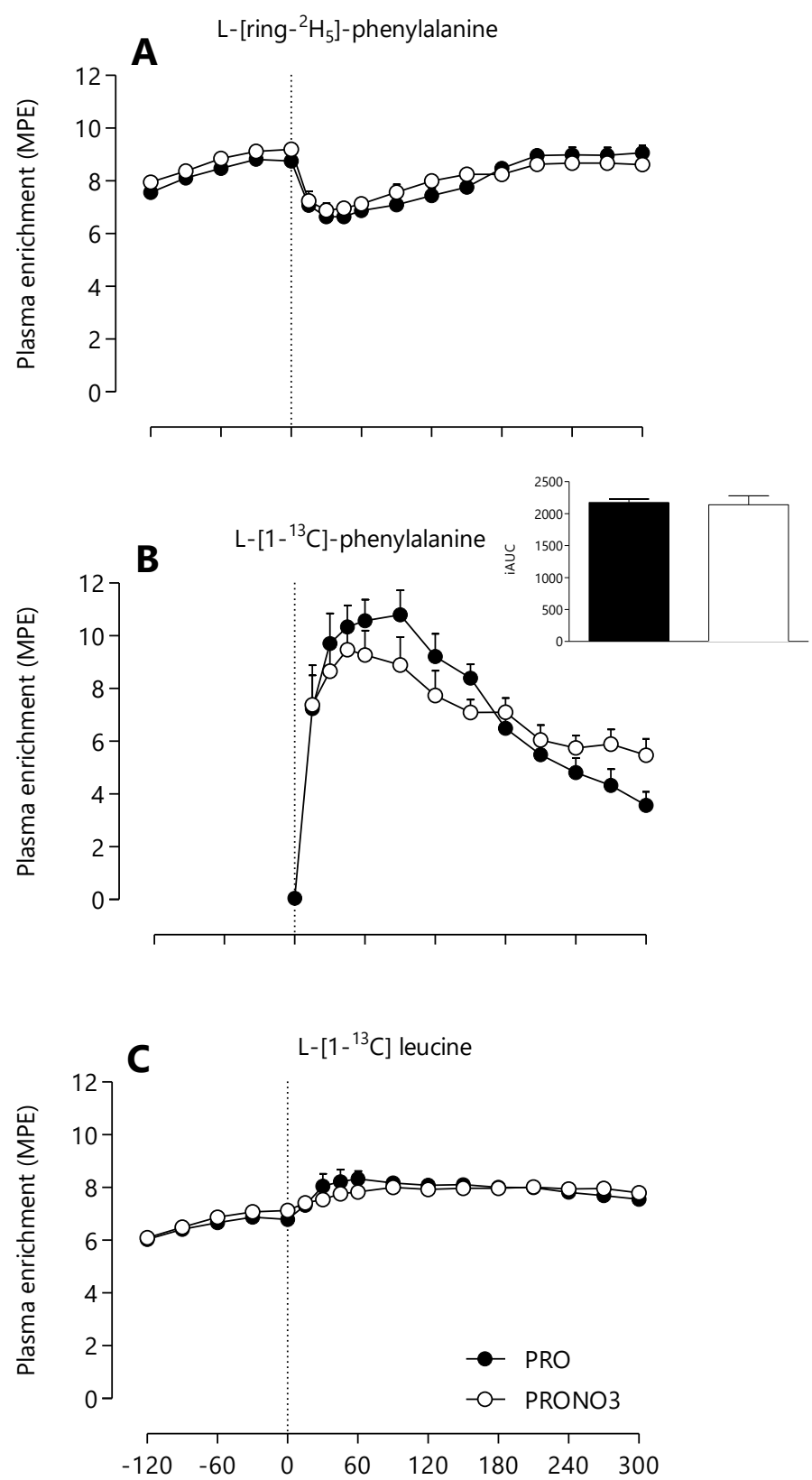

Figure 4 Plasma L-[ring- $\left.{ }^{2} \mathrm{H}_{5}\right]$-phenylalanine (A), L-[1- $\left.{ }^{13} \mathrm{C}\right]$-phenylalanine $(\mathbf{B})$, and L-[1- $\left.{ }^{13} \mathrm{C}\right]-$-leucine $(\mathbf{C})$ enrichments [mole percent excess (MPE)] in older, type 2 diabetes patients following protein ingestion with (PRONO3, $n=12$ ) or without (PRO, $n=11$ ) dietary $\mathrm{NO}_{3}{ }^{-}$. Vertical lines indicate ingestion of the drinks: dotted lines, $\mathrm{NaNO}_{3}{ }^{-}$or $\mathrm{NaCl}_{\text {; }}$ dashed lines, $20 \mathrm{~g}$ protein. Inset: iAUC. Values are means $\pm \mathrm{SE}$. Data were analyzed with repeated-measures (time $\times$ intervention) ANOVA. 


\section{Whole body phenylalanine kinetics}

Whole body phenylalanine Ra values are presented in Figure 5. Exogenous phenylalanine Ra (Figure 5A) increased rapidly following protein ingestion $(P<0.001)$ and did not differ between groups. The fraction of dietary protein-derived phenylalanine that was released in the plasma over the $5 \mathrm{~h}$ postprandial period was $55 \pm 2 \%$ and $53 \pm 2 \%$ in the PRO and PRONO3 groups, respectively. Endogenous phenylalanine Ra (Figure 5B) decreased following protein ingestion and did not differ between intervention groups. No differences were detected between interventions in total plasma phenylalanine Ra (Figure 5C) and Rd (Figure 5D).
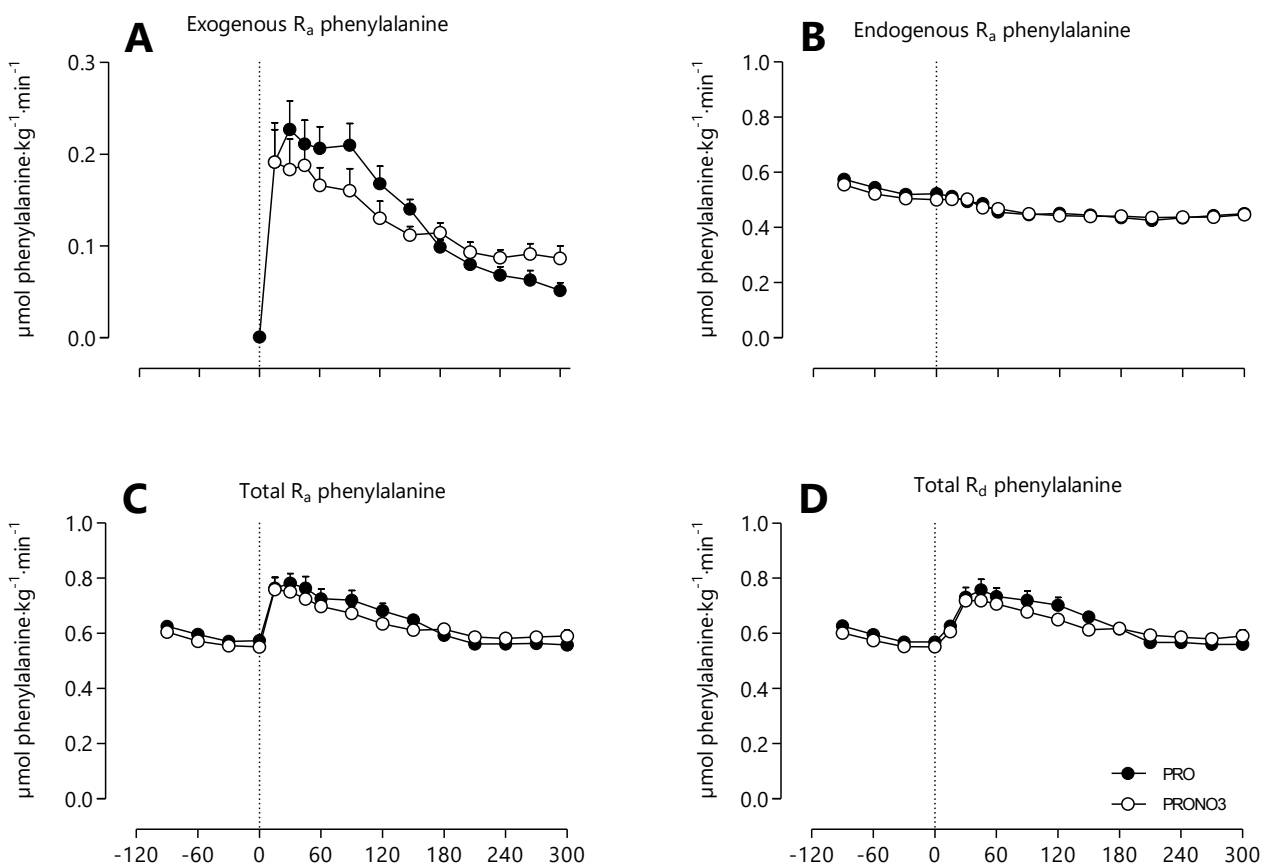

Figure 5 | Exogenous rate of appearance $\left(R_{a}, \mathbf{A}\right)$, endogenous $R_{a}(\mathbf{B})$, total $R_{a}(\mathbf{C})$, and total rate of disappearance $\left(R_{d}, D\right)$ in older, type 2 diabetes patients following protein ingestion with (PRONO3, $\left.n=12\right)$ or without $(P R O, n=$ 11) dietary $\mathrm{NO}_{3}{ }^{-}$. Vertical lines indicate ingestion of the drinks: dotted lines, $\mathrm{NaNO}_{3}{ }^{-}$or $\mathrm{NaCl}$; dashed lines, $20 \mathrm{~g}$ protein. Values are means \pm SE. Data were analyzed with repeated-measures (time $\times$ intervention) ANOVA. 
Postabsorptive and postprandial whole body protein breakdown, synthesis, oxidation, and net balance are presented in Figure 6. Whole body protein breakdown rates decreased following protein ingestion $(P<0.001)$. Whole body protein synthesis rates increased after protein ingestion $(P<0.001)$, with no differences between groups $(P=0.3)$. Whole body protein oxidation rates were significantly higher in the PRO than the PRONO3 group in the basal and postprandial periods $(P<0.05)$. Whole body protein net balance in the postabsorptive phase was significantly higher in the PRONO3 than the PRO group $(0.66 \pm 0.10$ vs. $1.04 \pm 0.12$ $\left.\mu \mathrm{mol} \cdot \mathrm{kg} \cdot \mathrm{h}^{-1}, P<0.05\right)$ and increased in the postprandial phase $(7.71 \pm 0.33$ and $7.80 \pm 0.53$ $\mu \mathrm{mol} \cdot \mathrm{kg} \cdot \mathrm{h}^{-1}$ in PRO and PRONO3, respectively, $\left.P<0.001\right)$, with no differences between groups $(P=0.8)$.

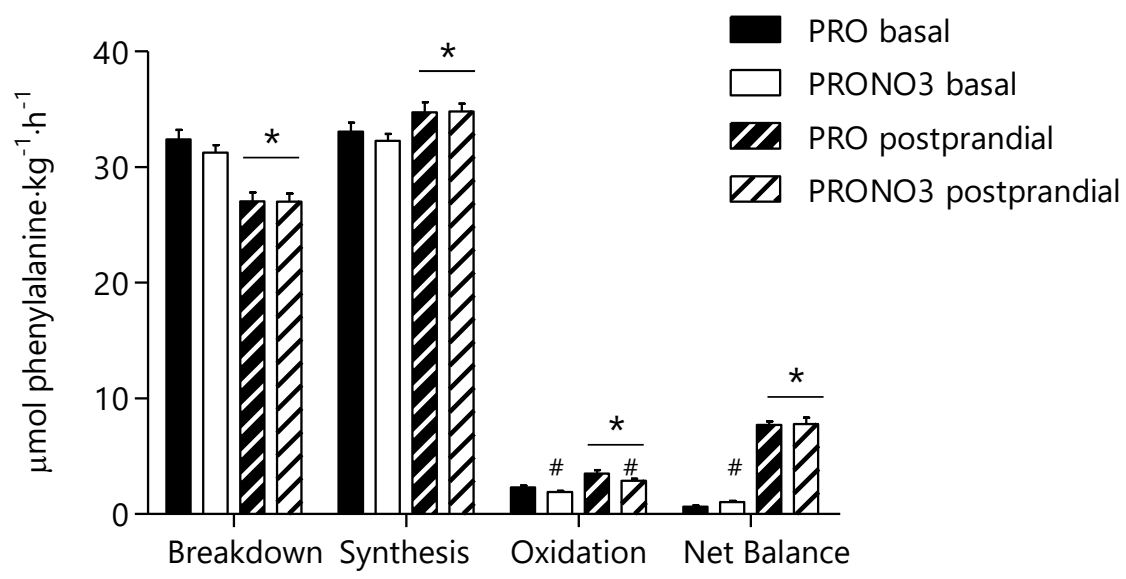

Figure 6 | Whole body protein metabolism during basal and postprandial periods in older, type 2 diabetes patients following $20 \mathrm{~g}$ protein ingestion with (PRONO3, $n=12$ ) or without (PRO, $n=11$ ) dietary $\mathrm{NO}_{3}{ }^{-}$. Values are means \pm SE. Data were analyzed with unpaired Student's $t$-test (between groups) and repeated-measures (time $\times$ intervention) ANOVA. Whole body protein breakdown rates: time effect $P<0.001$; whole body protein synthesis rates: time effect $P<0.001$; whole body protein oxidation rates: time effect $P<0.001$, basal between-groups $P=0.01$, postprandial between-groups $P=0.04$; whole body protein net balance: time effect $P<0.001$, basal betweengroups $P=0.02$. * Significant time effect, $P<0.01$. \#Significant difference between groups, $P<0.05$. 


\section{Muscle protein synthesis}

Myofibrillar protein synthesis rates, expressed as FSR, are presented in Figure 7. Postabsorptive myofibrillar FSR based on the L-[ring- $\left.{ }^{2} \mathrm{H}_{5}\right]$-phenylalanine tracer (Figure 7A), with plasma L-[ring ${ }^{-2} \mathrm{H}_{5}$ ]-phenylalanine enrichments used as precursor pool, did not differ between interventions $(P=0.6)$. After protein ingestion, myofibrillar protein synthesis rates in the PRO and PRONO3 groups averaged $0.025 \pm 0.004$ and $0.021 \pm 0.007 \% \cdot h^{-1}$, respectively, in the early $\left(0-2 \mathrm{~h}\right.$ ) postprandial phase and $0.032 \pm 0.004$ and $0.030 \pm 0.003 \% \cdot \mathrm{h}^{-1}$, respectively, in the late $(2-5 \mathrm{~h})$ postprandial phase, with no differences between groups (time effect $P<0.05$, intervention effect $P=0.7)$. Postabsorptive myofibrillar FSR based on the $L-\left[1-{ }^{13} \mathrm{C}\right]$-leucine tracer (Figure 7B), with plasma $\alpha-\left[1-{ }^{13} \mathrm{C}\right]-\mathrm{KIC}$ enrichments used as precursor pool, did not differ between groups $(P=0.8)$. After protein ingestion, early and late postprandial muscle protein synthesis rates in PRO and PRONO3 groups averaged $0.039 \pm 0.007$ and $0.040 \pm 0.011$ $\% \cdot h^{-1}$ and $0.046 \pm 0.008$ and $0.038 \pm 0.007 \% \cdot h^{-1}$, respectively, with no differences between groups (time effect $P=0.7$, intervention effect $P=0.7$ ).

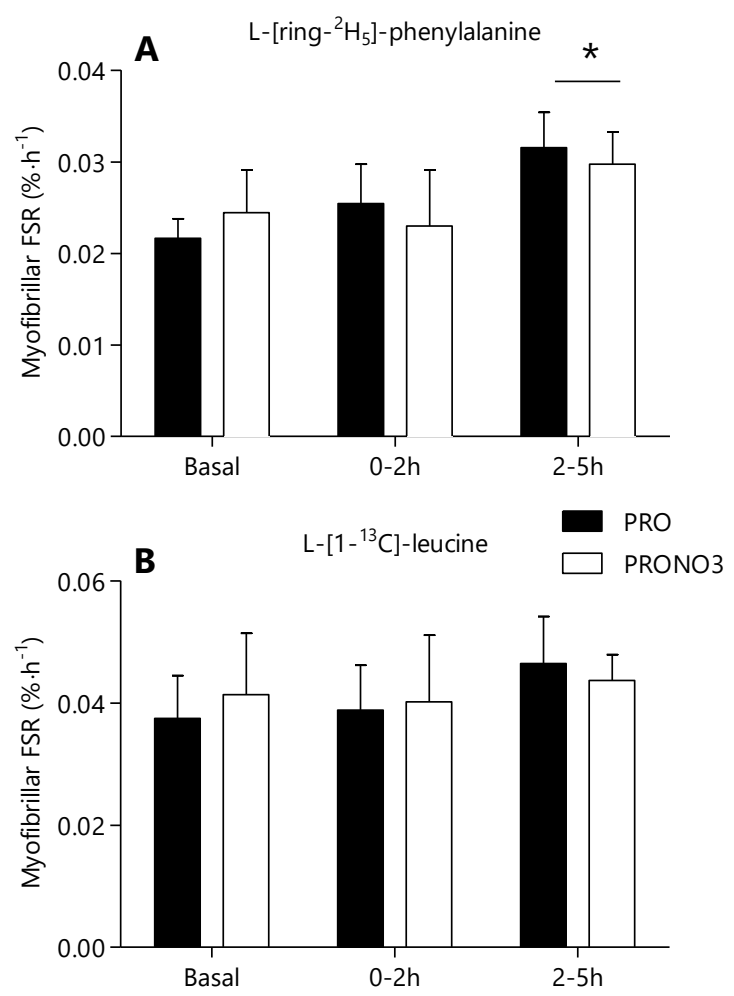

Figure 7 Myofibrillar muscle protein fractional synthesis rates (FSR) in older, type 2 diabetes patients intravenously infused with L-[ring- $\left.{ }^{2} \mathrm{H}_{5}\right]$-phenylalanine (A) and L-[1-13 C]-leucine (B) following $20 \mathrm{~g}$ protein ingestion with (PRONO3, $n=12$ ) or without (PRO, $n=11$ ) dietary $\mathrm{NO}_{3}{ }^{-}$. Values are means $\pm \mathrm{SE}$. Data were analyzed with unpaired Student's $t$-test (between groups) and repeated-measures (time $\times$ intervention) ANOVA. FSR based on L-[ring- ${ }^{2} \mathrm{H}_{5}$ ]-phenylalanine enrichments: time effect $P=0.03$, intervention effect $P=0.7$; FSR based on L-[1- $\left.{ }^{13} \mathrm{C}\right]-$ leucine enrichments: time effect $P=0.7$, intervention effect $P=0.7$. * Significant time effect, $P<0.05$. 
Myofibrillar protein-bound L-[1-13 C]-phenylalanine enrichments in PRO and PRONO3 groups averaged $0.0051 \pm 0.0011$ and $0.0061 \pm 0.0013 \mathrm{MPE}$, respectively, at $2 \mathrm{~h}$ and $0.0155 \pm 0.0020$ and $0.0135 \pm 0.0022 \mathrm{MPE}$, respectively, at $5 \mathrm{~h}$, with no differences between groups (time effect $P<0.001$, intervention effect $P=0.8$ ).

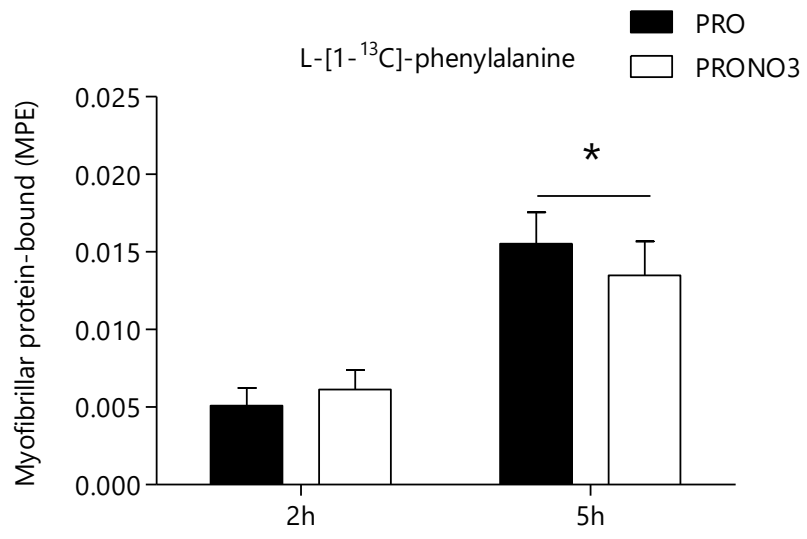

Figure 8 | Myofibrillar protein-bound L- $\left[1-{ }^{13} \mathrm{C}\right]$-phenylalanine enrichments in older, type 2 diabetes patients following $20 \mathrm{~g}$ protein ingestion with (PRONO3, $n=12$ ) or without (PRO, $n=11$ ) dietary $\mathrm{NO}_{3}{ }^{-}$. Values are means \pm SE. Data were analyzed with unpaired Student's $t$-test (between groups) and repeated-measures (time $\times$ intervention) ANOVA. Time effect $P<0.001$, intervention effect $P=0.8$. * Significant time effect, $P<0.001$.

Muscle tissue free $\mathrm{L}-\left[\right.$ ring- $\left.{ }^{2} \mathrm{H}_{5}\right]$-phenylalanine, $\mathrm{L}-\left[1-{ }^{13} \mathrm{C}\right]$-leucine, and $\mathrm{L}-\left[1-{ }^{13} \mathrm{C}\right]$-phenylalanine enrichments did not differ between groups (Table 2). Similar observations were observed when myofibrillar protein synthesis rates were calculated based on use of muscle free phenylalanine enrichments as precursor pool (data not shown).

Table 2 | Muscle tissue-free enrichments

\begin{tabular}{|c|c|c|c|c|c|}
\hline & & $-2 h$ & $\mathbf{O h}$ & $2 \mathrm{~h}$ & $5 \mathrm{~h}$ \\
\hline \multirow{2}{*}{$\begin{array}{l}\left.\text { L-[ring }-{ }^{2} \mathrm{H}_{5}\right]- \\
\text { phenylalanine (MPE) }\end{array}$} & $\operatorname{PRO}(n=11)$ & $4.37 \pm 0.42$ & $5.50 \pm 0.38$ & $5.00 \pm 0.26$ & $5.91 \pm 0.20$ \\
\hline & $\begin{array}{l}\text { PRONO3 }(n \\
=12)\end{array}$ & $4.40 \pm 0.44$ & $5.31 \pm 0.48$ & $5.14 \pm 0.28$ & $5.87 \pm 0.33$ \\
\hline \multirow[b]{2}{*}{ L-[1- $\left.{ }^{13} \mathrm{C}\right]$-leucine (MPE) } & PRO $(n=11)$ & $3.51 \pm 0.28$ & $4.64 \pm 0.20$ & $5.68 \pm 0.26$ & $5.74 \pm 0.17$ \\
\hline & $\begin{array}{l}\text { PRONO3 } \\
(n=12)\end{array}$ & $3.47 \pm 0.23$ & $4.34 \pm 0.28$ & $5.69 \pm 0.29$ & $5.85 \pm 0.21$ \\
\hline \multirow{2}{*}{$\begin{array}{l}\text { L- }\left[1-{ }^{13} \mathrm{C}\right]-\text { phenylalanine } \\
\text { (MPE) }\end{array}$} & PRO $(n=11)$ & N/A & N/A & $5.44 \pm 0.68$ & $3.10 \pm 0.33$ \\
\hline & $\begin{array}{l}\text { PRONO3 } \\
(n=12)\end{array}$ & N/A & N/A & $5.06 \pm 0.77$ & $3.59 \pm 0.23$ \\
\hline
\end{tabular}

Values are means $\pm \mathrm{SE}$. MPE, mole percent excess; NA, not available. Data were analyzed by repeated-measures (time $\times$ intervention) ANOVA. 


\section{DISCUSSION}

This is the first study to assess if a single dose of dietary $\mathrm{NO}_{3}{ }^{-}$ingested with protein increases amino acid delivery to skeletal muscle tissue and, subsequently, augments the postprandial muscle protein synthetic response in older, type 2 diabetes patients. The ingestion of $20 \mathrm{~g}$ of protein increased plasma amino acid availability (Figures 3-5), stimulated whole body protein synthesis (Figure 6), increased myofibrillar protein synthesis rates (Figure 7), and enhanced the use of dietary protein-derived amino acids for de novo muscle protein synthesis (Figure 8). However, co-ingestion of a single dose of dietary $\mathrm{NO}_{3}{ }^{-}$with the same amount of protein did not modulate postprandial protein handling in older men with type 2 diabetes.

Reductions in vascular function in response to aging and/or diabetes may be due in part to reductions in NO synthesis and a reduced NO-mediated vasodilatory response to feedinginduced hyperinsulinemia [19]. Consequently, a reduction in NO-mediated vascular function may attenuate postprandial plasma amino acid delivery to tissues, thereby having a negative impact on normal feeding-mediated increases in postprandial muscle protein synthesis rates. Current evidence suggests that the ingestion of dietary $\mathrm{NO}_{3}{ }^{-}$can substantially increase $\mathrm{NO}$ availability, which may be of particular importance in pathological conditions associated with a disrupted NO synthase (NOS)-NO pathway, as in the case of aging or diabetes [22, 47]. Inorganic $\mathrm{NO}_{3}{ }^{-}$is converted to $\mathrm{NO}_{2}{ }^{-}$by $\mathrm{NO}_{3}{ }^{-}$reductase-expressing bacteria, which naturally reside in the oral cavity. Once salivary $\mathrm{NO}_{2}{ }^{-}$is swallowed, some of it enters the systemic circulation, where it is chemically reduced to NO. A recent study by Wylie and co-workers [32] showed that changes in plasma $\mathrm{NO}_{2}{ }^{-}$occur 2-3 $\mathrm{h}$ after ingestion of beetroot juice (a concentrated source of dietary $\mathrm{NO}_{3}{ }^{-}$). Therefore, we provided a single dose of dietary $\mathrm{NO}_{3}{ }^{-}$at $2 \mathrm{~h}$ prior to protein ingestion, so that increased $\mathrm{NO}_{2}{ }^{-}$concentrations would temporally correspond with increased postprandial plasma amino acid concentrations. The ingestion of $\mathrm{NaNO}_{3}{ }^{-}$increased plasma $\mathrm{NO}_{3}{ }^{-}$concentrations, which remained elevated for up to $7 \mathrm{~h}$ (Figure 1). Moreover, plasma $\mathrm{NO}_{2}{ }^{-}$increased following the ingestion of $\mathrm{NaNO}_{3}^{-}$, reaching peak concentrations of $\sim 800 \mathrm{mmol} \cdot \mathrm{I}^{-1}$ at 30 min after protein ingestion. These findings indicate an intact enterosalivary circuit in older, type 2 diabetes patients.

After protein ingestion, plasma amino acid concentrations increased in both groups (Figure 3). By combining the ingestion of intrinsically $L-\left[1-{ }^{13} \mathrm{C}\right]$-phenylalanine-labeled protein with a primed continuous $L-\left[\right.$ ring- ${ }^{2} \mathrm{H}_{5}$ ]-phenylalanine infusion, we were able to measure proteinderived $L-\left[1-{ }^{13} \mathrm{C}\right]$-phenylalanine enrichments (Figure 4) and quantify the $\mathrm{R}_{\mathrm{a}}$ of dietary proteinderived amino acids into the circulation (Figure 5) $[36,48]$. Plasma L- $\left[1-{ }^{13} \mathrm{C}\right]$-phenylalanine enrichments increased directly following protein ingestion in both groups, reaching peak values of $12.3 \pm 0.7$ and $11.8 \pm 0.8 \mathrm{MPE}$ in the PRO and PRONO3 groups, respectively. In total, $55 \pm 2 \%$ and $53 \pm 2 \%$ of the ingested protein became available in the circulation during the $5-h$ postprandial period in the PRO and PRONO3 groups, respectively. Despite previous reports that dietary strategies augmenting $\mathrm{NO}$ metabolism may alter gut and organ tissue perfusion $[49,50]$, the greater plasma $\mathrm{NO}_{2}{ }^{-}$availability in the PRONO3 group did not modulate dietary 
protein digestion, amino acid absorption, or the amount of protein-derived amino acids that became available within the circulation after the ingestion of $20 \mathrm{~g}$ of protein in these older, type 2 diabetes patients.

Protein ingestion increased postprandial whole body protein synthesis and decreased whole body protein breakdown rates, resulting in a positive postprandial whole body protein net balance. However, ingestion of dietary $\mathrm{NO}_{3}{ }^{-}$did not modulate postprandial whole body protein turnover rates (Figure 6). Our results seem to agree with previous observations by Thibault and colleagues [51], who were unable to detect an effect of citrulline, a substrate for NOS-mediated NO synthesis, on whole body protein turnover. In addition to measuring whole body protein turnover rates, we also measured the impact of dietary $\mathrm{NO}_{3}$ - ingestion on the postprandial myofibrillar protein synthetic response. The ingestion of a meal-like amount of protein increased postprandial myofibrillar protein synthesis rates; however, co-ingestion of dietary $\mathrm{NO}_{3}{ }^{-}$did not further increase postprandial myofibrillar protein synthesis rates (Figure 7). In addition to determining the postprandial myofibrillar protein synthesis rates, we used highly enriched (38.7 MPE), intrinsically L- $\left[1-{ }^{13} \mathrm{C}\right]$-phenylalanine-labeled protein to assess the metabolic fate of the ingested protein by measuring the incorporation of dietary proteinderived $\mathrm{L}-\left[1-{ }^{13} \mathrm{C}\right]$-phenylalanine into de novo muscle tissue (Figure 8). Protein ingestion resulted in a substantial increase in myofibrillar protein-bound L-[1-13C]-phenylalanine enrichments at 2 and $5 \mathrm{~h}$, but no additional effect of dietary $\mathrm{NO}_{3}{ }^{-}$co-ingestion was observed.

Reductions in NO synthesis in older adults may be partly responsible for diminished NOmediated capillary recruitment and the blunted muscle protein synthetic response to the postprandial rise in plasma amino acid concentrations. In support of this notion, pharmacological strategies utilizing NO donors (i.e., sodium nitroprusside or methacholine) have been shown to effectively increase blood flow and microvascular perfusion and augment the muscle protein synthetic response to amino acid administration [52, 53]. However, practical dietary interventions providing precursors for endothelial NOS-mediated NO synthesis, such as citrulline [54] and/or arginine [55] co-ingested with protein, have not been effective in increasing the postprandial rise in muscle protein synthesis rates. In the present study, dietary $\mathrm{NO}_{3}{ }^{-}$was provided as a practical nutritional strategy to increase $\mathrm{NO}$ availability through a separate pathway that does not require endothelial NOS. Supplementation of dietary $\mathrm{NO}_{3}$ - has been shown to have significant effects on endothelial function [25], blood pressure $[26,32,56]$, and $\mathrm{O}_{2}$ consumption during exercise [32] in young and older subjects. However, despite the established effects of $\mathrm{NO}_{3}{ }^{-}$on vascular function, our results demonstrate that coingestion of $\mathrm{NO}_{3}{ }^{-}$with a meal-like amount of protein does not augment postprandial plasma amino acid availability, modulate whole body protein metabolism, increase skeletal muscle protein synthesis rates, or stimulate incorporation of dietary protein-derived amino acids into de novo myofibrillar protein. These data are the first to demonstrate that acute $\mathrm{NO}_{3}{ }^{-}$supplementation does not represent an effective nutritional strategy to enhance postprandial protein handling in vivo in humans. As acute dietary interventions to restore vascular function do not appear to increase postprandial muscle protein synthesis rates [54, $55,57]$, longer-term intervention studies involving chronic supplementation of NO substrates 
may be necessary to enhance vascular function and augment the anabolic response to protein ingestion [58-60]. Furthermore, more clinically compromised subpopulations suffering from macro- and/or microvascular complications may present greater benefits from the use of dietary $\mathrm{NO}_{3}-$ ingestion.

In conclusion, co-ingestion of dietary $\mathrm{NO}_{3}{ }^{-}$with a single meal-like amount of protein increases plasma $\mathrm{NO}_{3}{ }^{-}$and $\mathrm{NO}_{2}{ }^{-}$concentrations but does not modulate protein digestion and amino acid absorption, augment postprandial whole body or skeletal muscle protein synthesis rates, or stimulate incorporation of dietary protein-derived amino acids into de novo muscle protein in older, type 2 diabetes patients. Therefore, acute dietary $\mathrm{NO}_{3}{ }^{-}$supplementation does not represent an effective nutritional strategy to restore or enhance NO metabolism and improve postprandial protein handling in older, type 2 diabetes patients.

\section{ACKNOWLEDGEMENTS}

We gratefully acknowledge the enthusiastic support of the subjects who volunteered to participate in these experiments. 


\section{REFERENCES}

1. Morley, J.E., S.D. Anker, and S. von Haehling, Prevalence, incidence, and clinical impact of sarcopenia: facts, numbers, and epidemiology-update 2014. J Cachexia Sarcopenia Muscle, 2014. 5(4): p. 253-259.

2. Leenders, M., L.B. Verdijk, L. van der Hoeven, J.J. Adam, J. van Kranenburg, R. Nilwik, and L.J. van Loon, Patients with type 2 diabetes show a greater decline in muscle mass, muscle strength, and functional capacity with aging. J Am Med Dir Assoc, 2013. 14(8): p. 585-92.

3. Groen, B.B., H.M. Hamer, T. Snijders, J. van Kranenburg, D. Frijns, H. Vink, and L.J. van Loon, Skeletal muscle capillary density and microvascular function are compromised with aging and type 2 diabetes. J Appl Physiol (1985), 2014. 116(8): p. 998-1005.

4. Park, S.W., B.H. Goodpaster, J.S. Lee, L.H. Kuller, R. Boudreau, N. de Rekeneire, T.B. Harris, S. Kritchevsky, F.A. Tylavsky, M. Nevitt, Y.W. Cho, and A.B. Newman, Excessive loss of skeletal muscle mass in older adults with type 2 diabetes. Diabetes Care, 2009. 32(11): p. 1993-7.

5. Kim, T.N., M.S. Park, S.J. Yang, H.J. Yoo, H.J. Kang, W. Song, J.A. Seo, S.G. Kim, N.H. Kim, S.H. Baik, D.S. Choi, and K.M. Choi, Prevalence and determinant factors of sarcopenia in patients with type 2 diabetes: the Korean Sarcopenic Obesity Study (KSOS). Diabetes Care, 2010. 33(7): p. 1497-9.

6. Koopman, R., S. Walrand, M. Beelen, A.P. Gijsen, A.K. Kies, Y. Boirie, W.H. Saris, and L.J. van Loon, Dietary protein digestion and absorption rates and the subsequent postprandial muscle protein synthetic response do not differ between young and elderly men. The Journal of nutrition, 2009. 139(9): p. 1707-13.

7. Paddon-Jones, D., K.R. Short, W.W. Campbell, E. Volpi, and R.R. Wolfe, Role of dietary protein in the sarcopenia of aging. Am J Clin Nutr, 2008. 87(5): p. 1562S-6S.

8. Volpi, E., A.A. Ferrando, C.W. Yeckel, K.D. Tipton, and R.R. Wolfe, Exogenous amino acids stimulate net muscle protein synthesis in the elderly. J Clin Invest, 1998. 101(9): p. 2000-7.

9. Cuthbertson, D., K. Smith, J. Babraj, G. Leese, T. Waddell, P. Atherton, H. Wackerhage, P.M. Taylor, and M.J. Rennie, Anabolic signaling deficits underlie amino acid resistance of wasting, aging muscle. FASEB J, 2005. 19(3): p. 422-4.

10. Mitchell, W.K., B.E. Phillips, J.P. Williams, D. Rankin, K. Smith, J.N. Lund, and P.J. Atherton, Development of a new Sonovue contrast-enhanced ultrasound approach reveals temporal and age-related features of muscle microvascular responses to feeding. Physiol Rep, 2013. 1(5): p. e00119.

11. Durham, W.J., S.L. Casperson, E.L. Dillon, M.A. Keske, D. Paddon-Jones, A.P. Sanford, R.C. Hickner, J.J. Grady, and M. Sheffield-Moore, Age-related anabolic resistance after endurance-type exercise in healthy humans. FASEB J, 2010. 24(10): p. 4117-27.

12. Burd, N.A., S.H. Gorissen, and L.J. van Loon, Anabolic resistance of muscle protein synthesis with aging. Exerc Sport Sci Rev, 2013. 41(3): p. 169-73.

13. Timmerman, K.L., J.L. Lee, H.C. Dreyer, S. Dhanani, E.L. Glynn, C.S. Fry, M.J. Drummond, M. SheffieldMoore, B.B. Rasmussen, and E. Volpi, Insulin stimulates human skeletal muscle protein synthesis via an indirect mechanism involving endothelial-dependent vasodilation and mammalian target of rapamycin complex 1 signaling. J Clin Endocrinol Metab, 2010. 95(8): p. 3848-57.

14. Vincent, M.A., L.H. Clerk, J.R. Lindner, W.J. Price, L.A. Jahn, H. Leong-Poi, and E.J. Barrett, Mixed meal and light exercise each recruit muscle capillaries in healthy humans. Am J Physiol Endocrinol Metab, 2006. 290(6): p. E1191-7.

15. Solomon, T.P., J.M. Haus, Y. Li, and J.P. Kirwan, Progressive hyperglycemia across the glucose tolerance continuum in older obese adults is related to skeletal muscle capillarization and nitric oxide bioavailability. J Clin Endocrinol Metab, 2011. 96(5): p. 1377-84.

16. Taddei, S., A. Virdis, L. Ghiadoni, G. Salvetti, G. Bernini, A. Magagna, and A. Salvetti, Age-related reduction of $\mathrm{NO}$ availability and oxidative stress in humans. Hypertension,2001.38(2):p.274-9. 
17. Clark, M.G., M.G. Wallis, E.J. Barrett, M.A. Vincent, S.M. Richards, L.H. Clerk, and S. Rattigan, Blood flow and muscle metabolism: a focus on insulin action. Am J Physiol Endocrinol Metab, 2003. 284(2): p. E241-58.

18. Bradley, E.A., S.M. Richards, M.A. Keske, and S. Rattigan, Local NOS inhibition impairs vascular and metabolic actions of insulin in rat hindleg muscle in vivo. Am J Physiol Endocrinol Metab, 2013. 305(6): p. E745-50.

19. Keske, M.A., D. Premilovac, E.A. Bradley, R.M. Dwyer, S.M. Richards, and S. Rattigan, Muscle microvascular blood flow responses in insulin resistance and ageing. J Physiol, 2014.

20. Weitzberg, E. and J.O. Lundberg, Novel aspects of dietary nitrate and human health. Annu Rev Nutr, 2013. 33: p. 129-59.

21. Wang, H., A.X. Wang, K. Aylor, and E.J. Barrett, Nitric oxide directly promotes vascular endothelial insulin transport. Diabetes, 2013. 62(12): p. 4030-42.

22. Kapil, V., E. Weitzberg, J.O. Lundberg, and A. Ahluwalia, Clinical evidence demonstrating the utility of inorganic nitrate in cardiovascular health. Nitric Oxide, 2014. 38: p. 45-57.

23. Kenjale, A.A., K.L. Ham, T. Stabler, J.L. Robbins, J.L. Johnson, M. Vanbruggen, G. Privette, E. Yim, W.E. Kraus, and J.D. Allen, Dietary nitrate supplementation enhances exercise performance in peripheral arterial disease. J Appl Physiol, 2011. 110(6): p. 1582-91.

24. Lara, J., A.W. Ashor, C. Oggioni, A. Ahluwalia, J.C. Mathers, and M. Siervo, Effects of inorganic nitrate and beetroot supplementation on endothelial function: a systematic review and metaanalysis. Eur J Nutr, 2015.

25. Joris, P.J. and R.P. Mensink, Beetroot juice improves in overweight and slightly obese men postprandial endothelial function after consumption of a mixed meal. Atherosclerosis, 2013. 231(1): p. 78-83.

26. Webb, A.J., N. Patel, S. Loukogeorgakis, M. Okorie, Z. Aboud, S. Misra, R. Rashid, P. Miall, J. Deanfield, N. Benjamin, R. MacAllister, A.J. Hobbs, and A. Ahluwalia, Acute blood pressure lowering, vasoprotective, and antiplatelet properties of dietary nitrate via bioconversion to nitrite. Hypertension, 2008. 51(3): p. 784-90.

27. Ashor, A.W., A. Jajja, A. Sutyarjoko, K. Brandt, O. Qadir, J. Lara, and M. Siervo, Effects of beetroot juice supplementation on microvascular blood flow in older overweight and obese subjects: a pilot randomised controlled study.J Hum Hypertens,2015.29(8):p.511-3.

28. Dillon, E.L., S.L. Casperson, W.J. Durham, K.M. Randolph, R.J. Urban, E. Volpi, M. Ahmad, M.P. Kinsky, and M. Sheffield-Moore, Muscle protein metabolism responds similarly to exogenous amino acids in healthy younger and older adults during NO-induced hyperemia. Am J Physiol Regul Integr Comp Physiol, 2011. 301(5): p. R1408-17.

29. Kouw, I.W., S.H. Gorissen, N.A. Burd, N.M. Cermak, A.P. Gijsen, J. van Kranenburg, and L.J. van Loon, Postprandial Protein Handling Is Not Impaired in Type 2 Diabetes Patients When Compared With Normoglycemic Controls. J Clin Endocrinol Metab, 2015. 100(8): p. 3103-11.

30. Alberti, K.G. and P.Z. Zimmet, Definition, diagnosis and classification of diabetes mellitus and its complications. Part 1: diagnosis and classification of diabetes mellitus provisional report of a WHO consultation. Diabetic medicine : a journal of the British Diabetic Association, 1998. 15(7): p. 53953.

31. Abumrad, N.N., D. Rabin, M.P. Diamond, and W.W. Lacy, Use of a heated superficial hand vein as an alternative site for the measurement of amino acid concentrations and for the study of glucose and alanine kinetics in man. Metabolism: clinical and experimental, 1981. 30(9): p. 936-40.

32. Wylie, L.J., J. Kelly, S.J. Bailey, J.R. Blackwell, P.F. Skiba, P.G. Winyard, A.E. Jeukendrup, A. Vanhatalo, and A.M. Jones, Beetroot juice and exercise: pharmacodynamic and dose-response relationships. J Appl Physiol (1985), 2013. 115(3): p. 325-36.

33. Bergstrom, J., Percutaneous needle biopsy of skeletal muscle in physiological and clinical research. Scand J Clin Lab Invest, 1975. 35(7): p. 609-16. 
34. Pennings, B., W.F. Pellikaan, J.M. Senden, A.M. van Vuuren, J. Sikkema, and L.J. van Loon, The production of intrinsically labeled milk and meat protein is feasible and provides functional tools for human nutrition research. Journal of dairy science, 2011. 94(9): p. 4366-73.

35. van Loon, L.J., Y. Boirie, A.P. Gijsen, J. Fauquant, A.L. de Roos, A.K. Kies, S. Lemosquet, W.H. Saris, and R. Koopman, The production of intrinsically labeled milk protein provides a functional tool for human nutrition research. J Dairy Sci, 2009. 92(10): p. 4812-22.

36. Burd, N.A., N.M. Cermak, I.W. Kouw, S.H. Gorissen, A.P. Gijsen, and L.J. van Loon, The use of doubly labeled milk protein to measure postprandial muscle protein synthesis rates in vivo in humans. J Appl Physiol (1985), 2014. 117(11): p. 1363-70.

37. Cermak, N.M., D. Hansen, I.W. Kouw, J.W. van Dijk, J.R. Blackwell, A.M. Jones, M.J. Gibala, and L.J. van Loon, A single dose of sodium nitrate does not improve oral glucose tolerance in patients with type 2 diabetes mellitus. Nutr Res, 2015. 35(8): p. 674-80.

38. Watt, P.W., Y. Lindsay, C.M. Scrimgeour, P.A. Chien, J.N. Gibson, D.J. Taylor, and M.J. Rennie, Isolation of aminoacyl-tRNA and its labeling with stable-isotope tracers: Use in studies of human tissue protein synthesis. Proc Natl Acad Sci U S A, 1991. 88(13): p. 5892-6.

39. Koopman, R., A.H. Zorenc, R.J. Gransier, D. Cameron-Smith, and L.J. van Loon, Increase in S6K1 phosphorylation in human skeletal muscle following resistance exercise occurs mainly in type II muscle fibers. Am J Physiol Endocrinol Metab, 2006. 290(6): p. E1245-52.

40. Schwenk, W.F., P.J. Berg, B. Beaufrere, J.M. Miles, and M.W. Haymond, Use of tbutyldimethylsilylation in the gas chromatographic/mass spectrometric analysis of physiologic compounds found in plasma using electron-impact ionization.Anal Biochem, 1984.141(1):p.101-9.

41. Calder, A.G., S.E. Anderson, I. Grant, M.A. McNurlan, and P.J. Garlick, The determination of low d5phenylalanine enrichment (0.002-0.09 atom percent excess), after conversion to phenylethylamine, in relation to protein turnover studies by gas chromatography/electron ionization mass spectrometry. Rapid Commun Mass Spectrom, 1992. 6(7): p. 421-4.

42. Burd, N.A., B. Pennings, B.B. Groen, A.P. Gijsen, J.M. Senden, and L.J. van Loon, The single biopsy approach is reliable for the measurement of muscle protein synthesis rates in vivo in older men. J Appl Physiol, 2012. 113(6): p. 896-902.

43. Slater, C., T. Preston, D.C. McMillan, J.S. Falconer, and K.C.H. Fearon, GC/MS analysis of [2H5]phenylalanine at very low enrichment: Measurement of protein synthesis in health and disease. Journal of Mass Spectrometry, 1995. 30(9): p. 1325-1332.

44. Boirie, Y., P. Gachon, S. Corny, J. Fauquant, J.L. Maubois, and B. Beaufrere, Acute postprandial changes in leucine metabolism as assessed with an intrinsically labeled milk protein. Am J Physiol, 1996. 271(6 Pt 1): p. E1083-91.

45. Wolfe, R.R. and D.L. Chinkes, Isotope tracers in metabolic research: Principles and practice of kinetic analysis. 2 ed. 2005, Hoboken, New Jersey: John Wiley and Sons, Inc.

46. Dangin, M., C. Guillet, C. Garcia-Rodenas, P. Gachon, C. Bouteloup-Demange, K. Reiffers-Magnani, J. Fauquant, O. Ballevre, and B. Beaufrere, The rate of protein digestion affects protein gain differently during aging in humans. J Physiol, 2003. 549(Pt 2): p. 635-44.

47. Weitzberg, E., M. Hezel, and J.O. Lundberg, Nitrate-nitrite-nitric oxide pathway: implications for anesthesiology and intensive care. Anesthesiology, 2010. 113(6): p. 1460-75.

48. van Loon, L.J., Y. Boirie, A.P. Gijsen, J. Fauquant, A.L. de Roos, A.K. Kies, S. Lemosquet, W.H. Saris, and R. Koopman, The production of intrinsically labeled milk protein provides a functional tool for human nutrition research. Journal of dairy science, 2009. 92(10): p.4812-22.

49. Wijnands, K.A., D.M. Meesters, K.W. van Barneveld, R.G. Visschers, J.J. Briede, B. Vandendriessche, H.M. van Eijk, B.A. Bessems, N. van den Hoven, C.J. von Wintersdorff, P. Brouckaert, N.D. Bouvy, W.H. Lamers, A. Cauwels, and M. Poeze, Citrulline Supplementation Improves Organ Perfusion and Arginine Availability under Conditions with Enhanced Arginase Activity. Nutrients, 2015. 7(7): p. 5217-38. 
50. van Wijck, K., K.A. Wijnands, D.M. Meesters, B. Boonen, L.J. van Loon, W.A. Buurman, C.H. Dejong, $\mathrm{K}$. Lenaerts, and M. Poeze, L-citrulline improves splanchnic perfusion and reduces gut injury during exercise. Med Sci Sports Exerc, 2014. 46(11): p. 2039-46.

51. Thibault, R., L. Flet, F. Vavasseur, M. Lemerle, V. Ferchaud-Roucher, D. Picot, and D. Darmaun, Oral citrulline does not affect whole body protein metabolism in healthy human volunteers: results of a prospective, randomized, double-blind, cross-over study. Clin Nutr, 2011. 30(6): p. 807-11.

52. Timmerman, K.L., J.L. Lee, S. Fujita, S. Dhanani, H.C. Dreyer, C.S. Fry, M.J. Drummond, M. SheffieldMoore, B.B. Rasmussen, and E. Volpi, Pharmacological vasodilation improves insulin-stimulated muscle protein anabolism but not glucose utilization in older adults. Diabetes, 2010. 59(11): p. 2764-71.

53. Dillon, E.L., S.L. Casperson, W.J. Durham, K.M. Randolph, R.J. Urban, E. Volpi, M. Ahmad, M.P. Kinsky, and M. Sheffield-Moore, Muscle protein metabolism responds similarly to exogenous amino acids in healthy younger and older adults during NO-induced hyperemia. American journal of physiology. Regulatory, integrative and comparative physiology, 2011. 301(5): p. R1408-17.

54. Churchward-Venne, T.A., L.M. Cotie, M.J. MacDonald, C.J. Mitchell, T. Prior, S.K. Baker, and S.M. Phillips, Citrulline does not enhance blood flow, microvascular circulation, or myofibrillar protein synthesis in elderly men at rest or following exercise. Am J Physiol Endocrinol Metab, 2014. 307(1): p. E71-83.

55. Tang, J.E., P.J. Lysecki, J.J. Manolakos, M.J. MacDonald, M.A. Tarnopolsky, and S.M. Phillips, Bolus arginine supplementation affects neither muscle blood flow nor muscle protein synthesis in young men at rest or after resistance exercise. J Nutr, 2011. 141(2): p. 195-200.

56. Bahra, M., V. Kapil, V. Pearl, S. Ghosh, and A. Ahluwalia, Inorganic nitrate ingestion improves vascular compliance but does not alter flow-mediated dilatation in healthy volunteers. Nitric Oxide, 2012. 26(4): p. 197-202.

57. Phillips, B.E., P.J. Atherton, K. Varadhan, M.C. Limb, J.P. Williams, and K. Smith, Acute cocoa flavanol supplementation improves muscle macro- and microvascular but not anabolic responses to amino acids in older men. Appl Physiol Nutr Metab, 2016. 41(5): p. 548-556.

58. Wylie, L.J., J. Ortiz de Zevallos, T. Isidore, L. Nyman, A. Vanhatalo, S.J. Bailey, and A.M. Jones, Dosedependent effects of dietary nitrate on the oxygen cost of moderate-intensity exercise: Acute vs. chronic supplementation. Nitric Oxide, 2016.

59. Vanhatalo, A., S.J. Bailey, J.R. Blackwell, F.J. DiMenna, T.G. Pavey, D.P. Wilkerson, N. Benjamin, P.G. Winyard, and A.M. Jones, Acute and chronic effects of dietary nitrate supplementation on blood pressure and the physiological responses to moderate-intensity and incremental exercise. Am J Physiol Regul Integr Comp Physiol, 2010. 299(4): p. R1121-31.

60. Lee, J.S., C.L. Stebbins, E. Jung, H. Nho, J.K. Kim, M.J. Chang, and H.M. Choi, Effects of chronic dietary nitrate supplementation on the hemodynamic response to dynamic exercise. Am J Physiol Regul Integr Comp Physiol, 2015. 309(5): p. R459-66. 


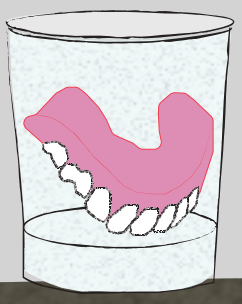

23:16 


\section{CHAPTER SEVEN}

\section{PROTEIN INGESTION BEFORE SLEEP INCREASES OVERNIGHT MUSCLE PROTEIN SYNTHESIS RATES IN HEALTHY OLDER MEN: A RANDOMIZED CONTROLLED TRIAL}

Imre W.K. Kouw, Andrew M. Holwerda, Jorn Trommelen, Irene Fleur Kramer, Jacqueline Bastiaanse, Shona L. Halson, Will K.W.H.Wodzig, Lex B. Verdijk, and Luc J.C. van Loon 


\section{ABSTRACT}

Background: The loss of skeletal muscle mass with aging has been attributed to the blunted anabolic response to protein intake. Presleep protein ingestion has been suggested as an effective strategy to compensate for such anabolic resistance.

Objective: We assessed the efficacy of presleep protein ingestion on dietary protein digestion and absorption kinetics and overnight muscle protein synthesis rates in older men.

Methods: In a randomized, double-blind, parallel design, 48 older men (mean \pm SEM age: $72 \pm 1 \mathrm{y}$ ) ingested $40 \mathrm{~g}$ casein (PRO40), $20 \mathrm{~g}$ casein (PRO20), $20 \mathrm{~g}$ casein plus $1.5 \mathrm{~g}$ leucine (PRO20+LEU), or a placebo before sleep. Ingestion of intrinsically $\mathrm{L}-\left[1-{ }^{13} \mathrm{C}\right]$-phenylalanine and $\mathrm{L}-\left[1-{ }^{13} \mathrm{C}\right]$-leucine-labeled protein was combined with intravenous $\mathrm{L}-\left[\right.$ ring- $\left.{ }^{2} \mathrm{H}_{5}\right]$-phenylalanine and $\mathrm{L}-\left[1-{ }^{13} \mathrm{C}\right]-$ leucine infusions during sleep. Muscle and blood samples were collected throughout overnight sleep.

Results: Exogenous phenylalanine appearance rates increased after protein ingestion, but to a greater extent in PRO40 than in PRO20 and PRO20+LEU $(P<0.05)$. Overnight myofibrillar protein synthesis rates (based on $\mathrm{L}$-[ring${ }^{2} \mathrm{H}_{5}$ ]-phenylalanine) were $0.033 \pm 0.002 \% \cdot \mathrm{h}^{-1}, 0.037 \pm 0.003 \% \cdot \mathrm{h}^{-1}, 0.039 \pm 0.002$ $\% \cdot \mathrm{h}^{-1}$, and $0.044 \pm 0.003 \% \cdot \mathrm{h}^{-1}$ in placebo, PRO20, PRO20+LEU, and PRO40, respectively, and were higher in PRO40 than in placebo $(P=0.02)$. Observations were similar based on $\mathrm{L}-\left[1-{ }^{13} \mathrm{C}\right]$-leucine tracer (placebo: $0.047 \pm 0.004 \% \cdot h^{-1}$ and PRO40: $\left.0.058 \pm 0.003 \% \cdot h^{-1}, P=0.08\right)$. More proteinderived amino acids ( $\mathrm{L}-\left[1-{ }^{13} \mathrm{C}\right]$-phenylalanine) were incorporated into myofibrillar protein in PRO40 than in PRO20 $(0.033 \pm 0.002$ and $0.019 \pm 0.002$ $M P E$, respectively, $P<0.001)$ and tended to be higher than in $P R O 20+L E U$ (0.025 \pm 0.002 MPE, $P=0.06)$.

Conclusions: Protein ingested before sleep is properly digested and absorbed throughout the night, providing precursors for myofibrillar protein synthesis during sleep in healthy older men. Ingestion of $40 \mathrm{~g}$ protein before sleep increases myofibrillar protein synthesis rates during overnight sleep. These findings provide the scientific basis for a novel nutritional strategy to support muscle mass preservation in aging and disease. 


\section{INTRODUCTION}

Age-related changes in skeletal muscle mass are attributed to a disruption in the regulation of muscle protein synthesis and breakdown rates. Protein ingestion stimulates muscle protein synthesis and forms an important factor in maintaining skeletal muscle mass over the lifespan [1]. The ingestion of $20 \mathrm{~g}$ protein increases muscle protein synthesis rates by $\sim 75 \%$ in young individuals [2-4], whereas $\sim 40 \mathrm{~g}$ protein seems to be required to allow a similar postprandial rise in muscle protein synthesis rates in the older population [5-8]. Besides ingesting larger amounts of protein, fortifying lower amounts of protein with free leucine has been shown to increase postprandial muscle protein synthesis rates [9-11]. Instead of increasing the anabolic response to a single meal, we recently proposed the overnight period as a window of opportunity to stimulate muscle protein synthesis. In a first proof-of-concept study, we showed that $40 \mathrm{~g}$ protein administered via a nasogastric tube during sleep is rapidly digested and absorbed, with dietary protein-derived amino acids being used for de novo muscle protein synthesis during overnight sleep [12]. Intragastric feeding during sleep may represent an interesting clinical strategy to preserve skeletal muscle mass in hospitalized patients but does not represent a feasible dietary strategy to support muscle mass maintenance in healthy or less clinically compromised older individuals. We therefore propose presleep protein ingestion as a nutritional strategy to augment muscle protein synthesis rates during the overnight period to support muscle mass preservation in the older population.

The present study (registered at www.trialregister.nl as NTR3885) assessed the effect of varying amounts of protein ingested before sleep on overnight muscle protein synthesis during a 7.5h postprandial period. In contrast to typical postprandial periods of 4-6 h [5-8], such an extended overnight period should allow the ingested protein dose to be fully digested and absorbed throughout the night. We hypothesized that ingesting $40 \mathrm{~g}$ protein before sleep would increase overnight plasma amino acid availability, thereby stimulating overnight muscle protein synthesis in older individuals. Because smaller amounts of protein would be more practical to ingest, we evaluated the effect of ingesting $20 \mathrm{~g}$ protein on overnight muscle protein synthesis rates. We also assessed whether fortifying the lower 20 -g protein dose with $1.5 \mathrm{~g}$ free leucine (providing the same amount of leucine as $40 \mathrm{~g}$ protein) can further augment the overnight muscle protein synthetic response compared with the presleep ingestion of 20 g protein. 


\section{METHODS}

\section{Subjects}

A total of 48 healthy, normoglycemic, older men [mean \pm SEM age: $72 \pm 1 \mathrm{y} ; \mathrm{BMI}$ (in $\mathrm{kg} \cdot \mathrm{m}^{-2}$ ): 25.4 \pm 0.3 ; glycated hemoglobin: $5.5 \pm 0.1 \%$ ] participated in this study. Subjects' characteristics are presented in Table 1. After pretesting, subjects were randomly assigned to 1 of 4 groups: $40 \mathrm{~g}$ casein (PRO40), $20 \mathrm{~g}$ casein (PRO20), $20 \mathrm{~g}$ casein plus $1.5 \mathrm{~g}$ of crystalline leucine (PRO20+LEU), or placebo. Randomization was computer generated, and all procedures and analysis were performed in a double-blind manner. The trial was conducted between April 2013 and October 2013 at Maastricht University Medical Centre+, Maastricht, Netherlands. All participants were informed about the purpose of the study, the experimental procedures, and possible risks before providing written consent. This study is part of a greater project investigating the effect of presleep protein ingestion on overnight muscle protein synthesis. Data from the PRO40 group were published in recent work that assessed the effect of physical activity performed in the evening on overnight muscle protein synthesis [13]. The present study was approved by the Maastricht University Medical Centre+ Medical Ethical Committee, Maastricht, Netherlands, and conformed to the latest version of the Declaration of Helsinki.

Table 1 | Subjects' characteristics

\begin{tabular}{|c|c|c|c|c|}
\hline & PLA & PRO20 & PRO20+LEU & PRO40 \\
\hline Age (y) & $71 \pm 2$ & $72 \pm 1$ & $74 \pm 2$ & $70 \pm 1$ \\
\hline Weight (kg) & $76.5 \pm 2.9$ & $76.9 \pm 2.1$ & $76.5 \pm 1.7$ & $79.4 \pm 2.2$ \\
\hline BMI $\left(\mathbf{k g} \cdot \mathbf{m}^{-2}\right)$ & $24.4 \pm 0.6$ & $25.3 \pm 0.5$ & $26.0 \pm 0.5$ & $25.7 \pm 0.6$ \\
\hline Fat (\%) & $19.7 \pm 0.7$ & $20.9 \pm 0.9$ & $22.6 \pm 1.2$ & $20.8 \pm 0.9$ \\
\hline Lean body mass $(\mathbf{k g})$ & $58.9 \pm 2.1$ & $58.7 \pm 1.8$ & $57.1 \pm 1.1$ & $60.6 \pm 1.4$ \\
\hline Appendicular lean mass $(\mathbf{k g})$ & $25.6 \pm 1.1$ & $25.5 \pm 0.9$ & $24.5 \pm 0.5$ & $26.2 \pm 0.7$ \\
\hline Skeletal muscle mass index $\left(\mathrm{kg} \cdot \mathrm{m}^{-2}\right)$ & $8.2 \pm 0.2$ & $8.4 \pm 0.3$ & $8.3 \pm 0.1$ & $8.5 \pm 0.1$ \\
\hline Basal plasma glucose $\left(\mathrm{mmol} \cdot \mathrm{L}^{-1}\right)$ & $5.4 \pm 0.1$ & $5.8 \pm 0.2$ & $5.7 \pm 0.2$ & $5.8 \pm 0.2$ \\
\hline Plasma glucose 2 h OGTT (mmol. $\left.\mathrm{L}^{-1}\right)$ & $6.3 \pm 0.4$ & $6.8 \pm 0.6$ & $7.0 \pm 0.5$ & $6.5 \pm 0.3$ \\
\hline Glycated hemoglobin (\%) & $5.6 \pm 0.1$ & $5.6 \pm 0.1$ & $5.5 \pm 0.1$ & $5.3 \pm 0.1$ \\
\hline
\end{tabular}

Values are mean \pm SEM. $n=12$ /treatment group. OGTT, oral glucose tolerance test; PLA, placebo; PRO20, $20 \mathrm{~g}$ dietary protein; PRO20+LEU, $20 \mathrm{~g}$ dietary protein plus $1.5 \mathrm{~g}$ crystalline leucine; PRO40, $40 \mathrm{~g}$ dietary protein. 


\section{Pretesting}

After an overnight fast, participants arrived at the laboratory at 08:30 by car or public transport. All participants underwent a medical screening to assess glycated hemoglobin, glucose tolerance, blood pressure, weight, height, and body composition (DXA, Discovery A; Hologic). Plasma glucose and insulin concentrations were measured at baseline and $2 \mathrm{~h}$ after a $75 \mathrm{~g}$ glucose load was ingested to determine oral glucose intolerance or the presence of type 2 diabetes according to 2006 American Diabetes Association guidelines [14]. Inclusion criteria were male sex, age $\geq 65 \mathrm{y}$, and a BMI from 20 to 30 . Subjects were excluded if any comorbidities or use of medication affecting muscle metabolism and mobility of the limbs, interfering with gastrointestinal function, neurologic or renal diseases, diagnosed diabetes mellitus, smoking, and weight loss $>3 \mathrm{~kg}$ in the last $3 \mathrm{mo}$, the use of protein supplements, participation in an exercise program, or coagulation diseases were present. All subjects were deemed healthy before the experimental trial. See Figure 1 for the Consolidated Standards of Reporting Trials flow diagram. The pretesting and experimental trials were separated by a period of $\geq 7 \mathrm{~d}$.

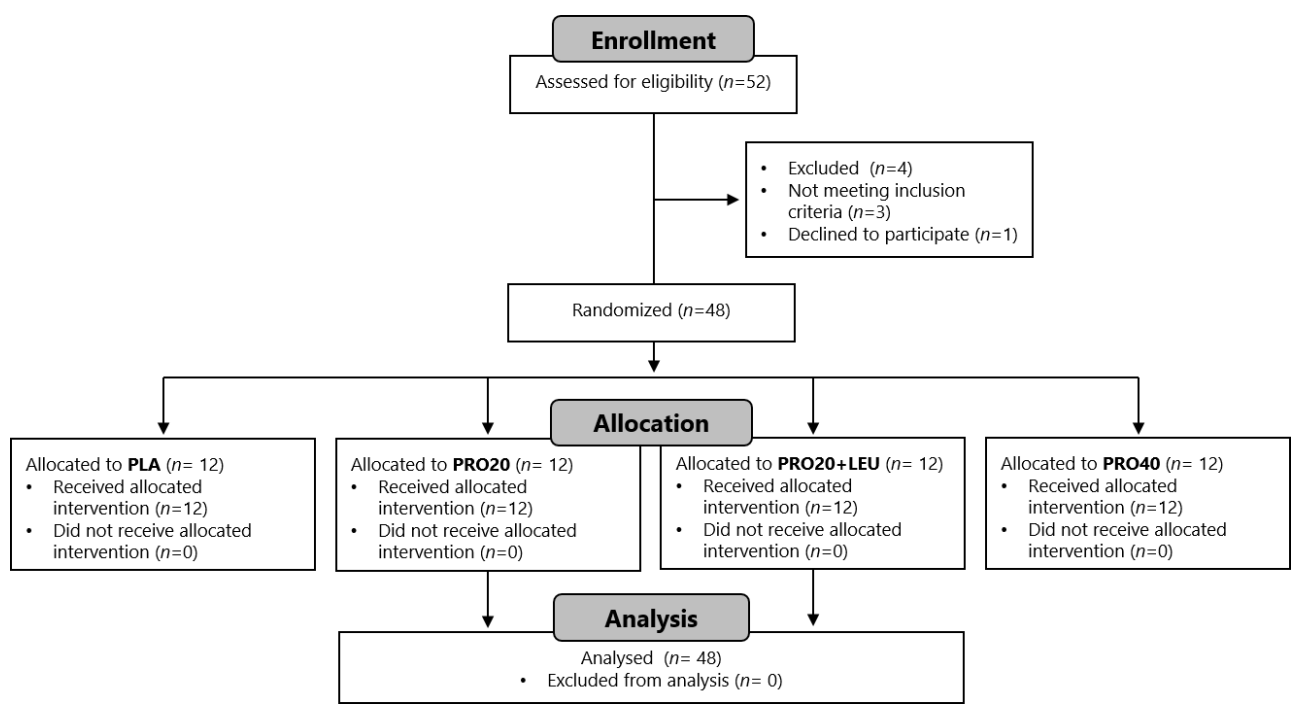

Figure 1 | Flow diagram of participants' enrollment procedure according to the CONSORT (Consolidated Standards of Reporting Trials). PLA: placebo, PRO20: $20 \mathrm{~g}$ dietary protein, PRO20+LEU: $20 \mathrm{~g}$ dietary protein +1.5 $\mathrm{g}$ crystalline leucine, PRO40: $40 \mathrm{~g}$ dietary protein. 


\section{Diet and physical activity control}

All volunteers refrained from any exhaustive physical activity and kept their diet as constant as possible $48 \mathrm{~h}$ before the trial. On the day of the experiment, a standardized diet ( 3 meals and 2 snacks) was consumed that provided 9.3 $\pm 0.6 \mathrm{MJ}$ total energy, $55 \pm 2$ energy\% (En\%) carbohydrate, $27 \pm 2 \mathrm{En} \%$ fat, and $16 \pm 0.2 \mathrm{En} \%$ protein. The energy content of the standardized diet was based on individual energy requirements (Harris-Benedict equation) and adjusted with the use of a physical activity factor of 1.4 to ensure ample energy intake. Dietary protein intake averaged $1.1 \pm 0.01 \mathrm{~g} \cdot \mathrm{kg}^{-1}$ body weight, with $35 \pm 1 \%$ of the protein provided at dinner (i.e., containing $29 \pm 2 \mathrm{~g}$ protein). A visual analog scale (VAS) was used to assess hunger ratings before and in the morning after the intervention [15]. In the morning after the experimental trial, subjects were invited to an ad libitum breakfast where food intake was recorded.

\section{Experimental protocol}

At 17:30, participants reported to the laboratory where 2 catheters were inserted into an antecubital vein of both arms. After basal blood collection at 18:30 ( $t=-300 \mathrm{~min}$ relative to drink ingestion), subjects consumed a standardized dinner under supervision $(2.6 \pm 0.1 \mathrm{MJ}$, providing 62 En\% carbohydrate, 19 En\% protein, and 19 En\% fat). Subjects rested until the initiation of the tracer infusion protocol at 2100. The plasma phenylalanine, tyrosine, and leucine pools were primed with a single intravenous dose of $\mathrm{L}$-[ $\left[\mathrm{ing}-{ }^{2} \mathrm{H}_{5}\right.$ ]-phenylalanine $(2.0$ $\left.\mu \mathrm{mol} \cdot \mathrm{kg}^{-1}\right), \mathrm{L}$-[ring-3,5-2 $\left.\mathrm{H}_{2}\right]$-tyrosine $\left(0.6 \mu \mathrm{mol} \cdot \mathrm{kg}^{-1}\right)$, and $\mathrm{L}-\left[1-{ }^{13} \mathrm{C}\right]$-leucine $\left(4.0 \mu \mathrm{mol} \cdot \mathrm{kg}^{-1}\right)$. Thereafter, a continuous stable isotope infusion was initiated ( $t=-150 \mathrm{~min}$ ) at an infusion rate of $0.050 \mu \mathrm{mol} \cdot \mathrm{kg}^{-1} \cdot \mathrm{min}^{-1}$ for L-[ring- $\left.{ }^{2} \mathrm{H}_{5}\right]$-phenylalanine, $0.015 \mu \mathrm{mol} \cdot \mathrm{kg}^{-1} \cdot \mathrm{min}^{-1}$ for $\mathrm{L}$-[ring$\left.3,5-{ }^{2} \mathrm{H}_{2}\right]$-tyrosine, and $0.100 \mu \mathrm{mol} \cdot \mathrm{kg}^{-1} \cdot \mathrm{min}^{-1}$ for $\mathrm{L}-\left[1-{ }^{13} \mathrm{C}\right]$-leucine. Participants rested supine for 2.5 h. At 23:30 ( $t=0 \mathrm{~min}$ ), a skeletal muscle biopsy was taken. Subjects then ingested the beverage that contained 0,20 , or $40 \mathrm{~g}$ casein intrinsically labeled with $\mathrm{L}-\left[1-{ }^{13} \mathrm{C}\right]$-phenylalanine and L-[1-13 C]-leucine (placebo, PRO20, PRO20+LEU, or PRO40, respectively) within 5 min and went to sleep afterward at $\sim 00: 00$. During the night, blood samples $(10 \mathrm{ml})$ were collected without waking the subjects at $t=30,60,90,150,210,270,330,390$, and 450 min relative to the drink ingestion. A second muscle biopsy was obtained from the contralateral leg $7.5 \mathrm{~h}$ later at 07:00 ( $t=450 \mathrm{~min}$ ). Blood samples were collected in tubes containing EDTA and centrifuged at $1000 \times g$ for $10 \mathrm{~min}$ at $4^{\circ} \mathrm{C}$. Aliquots of plasma were frozen in liquid nitrogen and stored at $-80^{\circ} \mathrm{C}$. The percutaneous needle biopsy technique was used to obtain muscle biopsy samples from the middle region of the vastus lateralis, $15 \mathrm{~cm}$ above the patella and $\sim 4$ $\mathrm{cm}$ below entry through the fascia [16]. Muscle samples were dissected carefully, freed from any visible non-muscle material, and were immediately frozen in liquid nitrogen and stored at $-80^{\circ} \mathrm{C}$ until further analysis. 


\section{Production of intrinsically labeled protein and tracer infusion}

Details on the production and experimental use of intrinsically $\mathrm{L}-\left[1-{ }^{13} \mathrm{C}\right]$-phenylalanine and $\mathrm{L}-$ $\left[1-{ }^{13} \mathrm{C}\right]$-leucine-labeled casein have been reported previously [17-19]. The $\mathrm{L}-\left[1-{ }^{13} \mathrm{C}\right]-$ phenylalanine and $\mathrm{L}-\left[1-{ }^{13} \mathrm{C}\right]$-leucine enrichments in casein averaged 38.7 and 9.3 mole percent excess (MPE), respectively. The micellar casein met all chemical and bacteriologic specifications for human consumption. Micellar casein protein was selected for this study because it represents the more slowly digestible protein source and should thus allow for a more sustained release of amino acids throughout overnight sleep [20] and was the only intrinsically labeled protein available in our laboratory at the time. All test beverages contained $450 \mathrm{~mL}$ water, with 149 or $298 \mathrm{~g}$ micellar casein concentrate containing 20 or $40 \mathrm{~g}$ protein, respectively, and were flavored and matched for taste by adding $1.5 \mathrm{~mL}$ noncaloric vanilla flavor (Dr. Oetker). In the PRO20+LEU treatment, $1.5 \mathrm{~g}$ crystalline leucine (99.95\% L-leucine; Frutarom Ltd.) was added to the beverage, matching the leucine content of the PRO40 treatment. The placebo treatment consisted of $450 \mathrm{~mL}$ water with $1.5 \mathrm{~mL}$ vanilla flavor. The stable isotope tracers $\mathrm{L}$-[ring- $\left.{ }^{2} \mathrm{H}_{5}\right]$-phenylalanine, $\mathrm{L}$-[ring-3,5-2 $\left.\mathrm{H}_{2}\right]$-tyrosine, and $\mathrm{L}-\left[1-{ }^{13} \mathrm{C}\right]$-leucine were purchased from Cambridge Isotopes and dissolved in $0.9 \%$ saline before infusion (Basic Pharma). Continuous intravenous infusions were performed with the use of a calibrated IVAC 598 Volumetric Infusion Pump (Cardinal Health).

\section{Sleep quality assessment}

The Pittsburgh Sleep Quality Index (Sleep Medicine Institute, University of Pittsburgh) was used to assess habitual sleep quality during pretesting, before randomization [21]. Pittsburgh Sleep Quality Index scoring (0-21 points) was used to classify subjects as "very good," "good," "poor," or "very poor" sleepers. Subjects that scored >5 ("poor" or "very poor" sleepers) were excluded from participation. Sleep behavior during the night was monitored with wrist activity monitors and analyzed with Actiware software (Philips Respironics) [22]. Time was scored as awake unless the following conditions were met simultaneously: 1) participant was lying down attempting to sleep and 2) the activity counts from the monitor were sufficiently low to indicate that the participant was immobile. Start and end time of sleep were also recorded throughout the trial. The following variables were derived from sleep records and activity monitors: bedtime (clock time), get-up time (clock time), time in bed (the amount spent in bed attempting to sleep between bedtime and get-up time), sleep onset latency (the period between bedtime and sleep start), sleep duration (in hours), sleep efficiency (percentage of sleep duration expressed as a percentage of time in bed), and total sleep time (in hours: the sum of the sleep obtained at night).

\section{Plasma analyses}

Plasma glucose and insulin concentrations were analyzed with the use of commercially available kits (GLUC3, Ref: 05168791 190, and Immunologic, Ref: 12017547 122, respectively, Roche). Plasma amino acid concentrations and enrichments were determined by GC-MS 
analysis (Agilent 7890A GC/5975C; mass selective detector, Agilent Technologies). Specifically, internal standards of $\left[\mathrm{U}-{ }^{13} \mathrm{C}_{6}\right]$-leucine, $\left[\mathrm{U}-{ }^{13} \mathrm{C}_{9}{ }^{15} \mathrm{~N}\right]$-phenylalanine, and $\left[\mathrm{U}-{ }^{13} \mathrm{C}_{9}{ }^{15} \mathrm{~N}\right]$-tyrosine were added to the plasma samples. Plasma samples were deproteinized with dry 5sulfosalicylic acid. Free amino acids were purified using cation exchange chromatography (AG 50W-X8 resin, mesh size: 100-200 $\mu \mathrm{m}$, ionic form: hydrogen; Bio-Rad Laboratories, Hercules, USA). The purified amino acids were converted into tert-butyldimethylsilyl (tert-BDMS) derivatives with MTBSTFA before analysis by GC-MS. The amino acid concentrations were determined using electron impact ionization by monitoring ions at mass/charge $(\mathrm{m} / \mathrm{z}) 302$ and 308 for unlabeled and [U- ${ }^{13} \mathrm{C}_{6}$ ]-labeled-leucine, 336 and 346 for unlabeled and $\left[\mathrm{U}-{ }^{13} \mathrm{C}_{9}{ }^{15} \mathrm{~N}\right.$ labeled-phenylalanine respectively, and 466 and 476 for unlabeled and $\left[\mathrm{U}-{ }^{13} \mathrm{C}_{9}{ }^{15} \mathrm{~N}\right]$ tyrosine, respectively. The plasma leucine, phenylalanine, and tyrosine ${ }^{13} \mathrm{C}$ and ${ }^{2} \mathrm{H}$ enrichments were determined using selective ion monitoring at $\mathrm{m} / \mathrm{z} 302$ and 303 for unlabeled and labeled L$\left[1-{ }^{13} \mathrm{C}\right]$-leucine, respectively; $\mathrm{m} / \mathrm{z} 336,337$, and 341 for unlabeled and labeled L-[1-13 C]phenylalanine and $\mathrm{L}$-[ring- ${ }^{2} \mathrm{H}_{5}$ ]-phenylalanine, respectively; $\mathrm{m} / \mathrm{z} 466,467,468$, and 470 for unlabeled and labeled $\mathrm{L}-\left[1-{ }^{13} \mathrm{C}\right]$-tyrosine, $\mathrm{L}-\left[\right.$ ring-3,5- $\left.{ }^{2} \mathrm{H}_{2}\right]$-tyrosine and $\mathrm{L}$-[ring- $\left.{ }^{2} \mathrm{H}_{4}\right]$-tyrosine, respectively. Standard regression curves were applied from a series of known standard enrichment values against the measured values to assess the linearity of the mass spectrometer and to account for any isotope fractionation.

\section{Muscle analyses}

Myofibrillar protein-enriched fractions were extracted from $\sim 60 \mathrm{mg}$ wet muscle tissue by hand-homogenizing on ice with a pestle in a standard extraction buffer $\left(7 \mu \mathrm{L} \cdot \mathrm{mg}^{-1}\right)$ [23]. Myofibrillar protein-bound L-[ring- $\left.{ }^{2} \mathrm{H}_{5}\right]$-phenylalanine enrichments were determined by GC$\mathrm{MS}$, and myofibrillar protein-bound $\mathrm{L}-\left[1-{ }^{13} \mathrm{C}\right]$-phenylalanine enrichments were measured by gas chromatography-combustion isotope ratio mass spectrometry (GC-CIRMS) (Trace GC Ultra, IRMS model MAT 253; Thermo Scientific) with the use of a DB-5ms column (no. 1225532; Agilent J+W Scientific GC Column, GC Isolink). The samples were spun at $2500 \mathrm{~g}$ and $4^{\circ} \mathrm{C}$ for $5 \mathrm{~min}$. The pellet was washed with $500 \mu \mathrm{L} \mathrm{ddH} 2 \mathrm{O}$ and centrifuged at $250 \mathrm{~g}$ and $4^{\circ} \mathrm{C}$ for 10 min. The myofibrillar protein was solubilized by adding $1 \mathrm{~mL}$ of $0.3 \mathrm{M} \mathrm{NaOH}$ and heating at $50^{\circ} \mathrm{C}$ for $30 \mathrm{~min}$ with vortex mixing every $10 \mathrm{~min}$. Samples were centrifuged at $9500 \mathrm{~g}$ and $4^{\circ} \mathrm{C}$ for $5 \mathrm{~min}$, the supernatant containing the myofibrillar proteins was collected and the collagen pellet was discarded. Myofibrillar proteins were precipitated by the addition of $1 \mathrm{~mL}$ of $1 \mathrm{M}$ PCA and spinning at $700 \mathrm{~g}$ and $4^{\circ} \mathrm{C}$ for $10 \mathrm{~min}$. The myofibrillar protein pellet was washed twice with $70 \%$ ethanol and hydrolyzed overnight in $2 \mathrm{~mL}$ of $6 \mathrm{M} \mathrm{HCL}$ at $110^{\circ} \mathrm{C}$. The free amino acids from the hydrolyzed myofibrillar protein pellet were dried under nitrogen stream while being heated to $120^{\circ} \mathrm{C}$. The free amino acids were then dissolved in $25 \%$ acetic acid solution, passed over cation exchange AG 50W-X8 resin columns (mesh size: 100-200, ionic form: hydrogen; Bio-Rad Laboratories, Hercules, USA), and eluted with $2 \mathrm{M} \mathrm{NH}_{4} \mathrm{OH}$. The purified amino acids were divided into 2 aliquots to determine the L-[ring $\left.-{ }^{2} \mathrm{H}_{5}\right]$-phenylalanine enrichments by GCMS analysis and the $\mathrm{L}-\left[1-{ }^{13} \mathrm{C}\right]$-phenylalanine and $\mathrm{L}-\left[1-{ }^{13} \mathrm{C}\right]$-leucine enrichments by gas chromatography-combustion-isotope ratio mass spectrometry (GC-C-IRMS) analysis. To 
reduce the signal-to-noise ratio during GC-MS analysis at low tracer enrichments, the phenylalanine from the myofibrillar protein hydrolysates was enzymatically decarboxylated to $\beta$-phenylethylamine prior to derivatization with MTBSTFA. To determine myofibrillar $\mathrm{L}-\left[1-{ }^{13} \mathrm{C}\right]-$ phenylalanine and $\mathrm{L}-\left[1-{ }^{13} \mathrm{C}\right]$-leucine enrichments by GC-C-IRMS analysis, the purified amino acids were converted into $\mathrm{N}$-ethoxycarbonyl ethyl ester derivatives with ethyl chloroformate (ECF). The derivatives were then measured by GC-C-IRMS (Finnigan MAT 253, Bremen, Germany) using a DB5-MS-column (no. 122-5532; Agilent J+W scientific GC Column, GC Isolink), and monitoring of ion masses 44,45 and 46 . Standard regression curves were applied to assess the linearity of the mass spectrometer and to account for isotopic fractionation.

\section{Calculations}

Ingestion of $\mathrm{L}-\left[1-{ }^{13} \mathrm{C}\right]$-phenylalanine-labeled protein, intravenous infusion of $\mathrm{L}-\left[\mathrm{ring}-{ }^{2} \mathrm{H}_{5}\right]$ phenylalanine and $\mathrm{L}$-[ring-3,5- ${ }^{2} \mathrm{H}_{2}$ ]-tyrosine, and venous blood sampling were used to assess whole-body amino acid kinetics in non-steady-state conditions. Modified Steele's equations were used to calculate total, exogenous, and endogenous phenylalanine rates of appearance (expressed as $\mu \mathrm{mol}$ phenylalanine $\cdot \mathrm{kg}^{-1} \cdot \mathrm{min}^{-1}$ ) as well as plasma availability of dietary proteinderived phenylalanine that appeared in the systemic circulation as a fraction of total amount of phenylalanine that was ingested [24-26].

$$
\begin{aligned}
& \text { Total } \mathrm{R}_{\mathrm{a}}=\frac{F_{i v}-\left[p V \cdot C(t) \cdot \frac{d E_{i v}}{d t}\right]}{E_{i v}(t)} \\
& \text { Exogenous } \mathrm{R}_{\mathrm{a}}=\frac{\operatorname{Total} R_{a} \cdot E_{p o(t)}+\left[p V \cdot C_{(t)} \cdot \frac{d E_{p o}}{d t}\right]}{E_{\text {prot }}} \\
& \text { Endogenous } \mathrm{R}_{\mathrm{a}}=\operatorname{TotalR}_{a}-\operatorname{ExoR}_{a}-F_{i v} \\
& \text { Phe }_{\text {plasma }}=\left[\frac{A U C_{E x o R a}}{\text { Phe } e_{\text {prot }}}\right] \cdot \mathrm{BW} \cdot 100 \%
\end{aligned}
$$

$\mathrm{F}_{\mathrm{iv}}$ is the intravenous tracer infusion rate (in $\left.\mu \mathrm{mol} \cdot \mathrm{kg}^{-1} \cdot \mathrm{min}^{-1}\right) ; \mathrm{pV}$ is the distribution volume for phenylalanine $\left(0.125{\left.\mathrm{~L} \cdot \mathrm{kg}^{-1}\right)}^{-1}\right.$ [24]; $\mathrm{C}(\mathrm{t})$ is the mean plasma phenylalanine concentration between two consecutive time points; $\mathrm{dE}_{\mathrm{iv}} / \mathrm{dt}$ represents the time-dependent variations of plasma phenylalanine enrichment derived from the intravenous tracer; and $\mathrm{E}_{\mathrm{iv}}(\mathrm{t})$ is the mean plasma phenylalanine enrichment from the intravenous tracer between two consecutive time points. Exogenous phenylalanine rate of appearance $\left(E_{x o R_{a}}\right)$ represents the plasma entry rate of dietary protein-derived phenylalanine. $\mathrm{E}_{\mathrm{po}}(\mathrm{t})$ is the mean plasma phenylalanine enrichment from the oral tracer between two consecutive time points; $\mathrm{dE}_{\mathrm{po}} / \mathrm{dt}$ represents the timedependent variations of plasma phenylalanine enrichment derived from the oral tracer; and $E_{\text {prot }}$ is the $L-\left[1-{ }^{13} \mathrm{C}\right]$-phenylalanine enrichment in the dietary protein. Endogenous phenylalanine $R_{a}$ (Endo $R_{a}$ ) represents the rate at which phenylalanine derived from wholebody protein breakdown enters the circulation. The fraction of dietary phenylalanine taken up in the systemic circulation was calculated as a fraction of the total amount of phenylalanine that was ingested, Phe plasma. $A \cup C_{\text {ExoRa }}$ is the area under the curve (AUC) of Exo $R_{a}$, which corresponds to the amount of dietary protein-derived phenylalanine that appeared in the 
circulation over the $7.5 \mathrm{~h}$ postprandial period; Phe prot $_{\text {is }}$ the amount of dietary phenylalanine ingested; and BW is the participants' body weight.

Total phenylalanine rate of disappearance $\left(R_{d}\right.$ in $\mu$ mol Phe $\left.\cdot \mathrm{kg}^{-1} \cdot \mathrm{min}^{-1}\right)$ equals the rate of phenylalanine hydroxylation (first step in phenylalanine oxidation) plus the rate of phenylalanine utilization for protein synthesis. Because whole-body $R_{d}$ comprises the rate of phenylalanine disappearance from the free amino acid pool in the blood due to protein synthesis and oxidation, whole-body protein synthesis can be calculated as $R_{d}$ minus oxidation. Whole-body phenylalanine oxidation can be determined from the conversion (hydroxylation) of $\mathrm{L}$-[ring- $\left.{ }^{2} \mathrm{H}_{5}\right]$-phenylalanine to $\mathrm{L}$-[ring- $\left.{ }^{2} \mathrm{H}_{4}\right]$-tyrosine. These parameters are calculated as follows:

Total $R_{d}=$ Total $R_{a}-p V \cdot \frac{d C}{d t}$

Phe hydroxylation $=\operatorname{Tyr} R_{a} \cdot \frac{E_{t y r}(t)}{E_{p h e}(t)} \cdot \frac{P h e R_{d}}{\left(F_{i v}+P h e R_{d}\right)}$

Protein synthesis $=$ Total $R_{d}-$ Phe hydroxylation

Protein net balance $=$ Protein synthesis - Endo $R_{a}$

TyrR $R_{a}$ is the total rate of tyrosine appearance based on the L-[ring-3,5- ${ }^{2} \mathrm{H}_{2}$ ]-tyrosine infusion and plasma enrichments. $E_{t y r}(t)$ and $E_{p h e}(t)$ represent the mean plasma L-[ring- $\left.{ }^{2} \mathrm{H}_{4}\right]$-tyrosine and $\mathrm{L}$-[ring- ${ }^{2} \mathrm{H}_{5}$ ]-phenylalanine enrichment between 2 consecutive time points, respectively; and $F_{i v}$ is the intravenous infusion rate of $\mathrm{L}$-[ring- ${ }^{2} \mathrm{H}_{5}$ ]-phenylalanine. Whole-body protein net balance was calculated as the AUC over the 7.5-h postprandial phase ( $t=0-450 \mathrm{~min}$ ) by using whole-body protein synthesis minus the endogenous rate of appearance.

The fractional synthesis rate (FSR in $\% \cdot h^{-1}$ ) of myofibrillar protein was calculated using the standard precursor-product equation:

$$
F S R=\frac{\Delta E p}{E_{\text {precursor }} \cdot t} \cdot 100 \%
$$

$\triangle E p$ is the increment in myofibrillar protein-bound $\mathrm{L}$-[ring- $\left.{ }^{2} \mathrm{H}_{5}\right]$-phenylalanine or $\mathrm{L}-\left[1-{ }^{13} \mathrm{C}\right]-$ leucine enrichment between two muscle biopsies (in tracer to tracee ratio: TTR); $E_{\text {precursor }}$ is the weighted mean plasma $\mathrm{L}$-[ring- $\left.{ }^{2} \mathrm{H}_{5}\right]$-phenylalanine or plasma $\mathrm{L}-\left[1-{ }^{13} \mathrm{C}\right]$-leucine enrichment during the tracer incorporation period (TTR); and $t(h)$ is the incorporation period between muscle biopsies.

\section{Statistics}

All data are expressed as mean \pm SEM. Baseline characteristics between treatment groups were compared by using 1-factor ANOVA. Plasma metabolite concentrations, plasma amino acid enrichments, and whole-body protein kinetics measured over time were analyzed by 2 -factor repeated-measures ANOVA with time as the within-subjects factor and treatment group as the between-subjects factor. The analysis was done for the period starting at the time of protein ingestion, between $t=0$ and $t=450 \mathrm{~min}$. In case of significant time $\times$ treatment group 
interactions, separate analyses were performed to determine time effects for each treatment group (1-factor repeated-measures ANOVA) and treatment effects for each time point (1factor ANOVA). In addition, 1-factor ANOVA was used to determine differences between treatment groups for peak plasma values as well as the incremental AUC and differences in whole-body protein turnover rates and myofibrillar protein synthesis. In case of significant main effects of treatment group, a Tukey's post hoc test was applied to locate group differences. Results from our previous work [12] were used to calculate a sample size (G*Power 3.1.9.2 software; Heinrich-Heine-University, Dusseldorf, Germany) by using an FSR of $0.029 \pm 0.0052 \% \cdot h^{-1}$ for the placebo group and a clinically relevant difference in FSR of $\sim 30 \%$ $[5,12]$. With a power of $80 \%$, a 2 -sided significance level of 0.01 (to adjust for multiple post hoc testing), and a dropout rate of $10 \%$, the final number of participants to be included after screening was calculated as $n=12$ /group. No dropouts occurred in the 4 treatment groups. Statistical significance was set at $P<0.05$. All calculations were performed with SPSS Statistics 24.0 software (IBM Corp.). 


\section{RESULTS}

Plasma glucose concentrations declined overnight in all treatment groups (main time effect, $P=0.005$ ) and differed between treatment groups (main treatment group effect, $P<0.05$; Figure 2A). Plasma insulin concentrations increased rapidly after protein ingestion but not after placebo (time $\times$ treatment group interaction, $P<0.001$ ) and were higher during the overnight period in PRO20+LEU and PRO40 than in placebo $(P<0.001$, Figure 2B). A main treatment group effect $(P<0.001)$ showed that peak plasma insulin concentrations were higher in all protein groups than in the placebo group (all $P<0.05$ ).
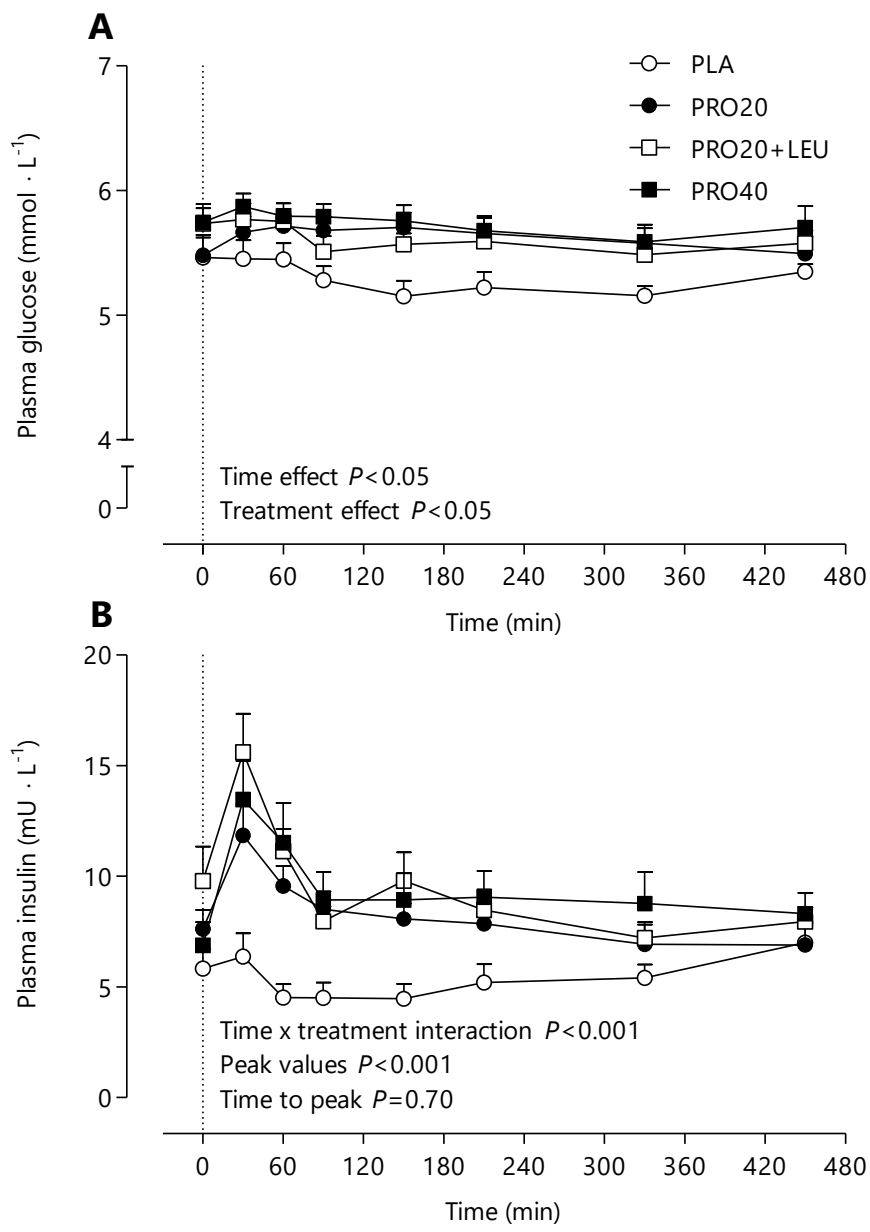

Figure 2 | Plasma glucose (A) and insulin (B) concentrations during overnight sleep in 48 healthy older men who ingested placebo or supplemental protein before sleep. PLA: placebo, PRO20: $20 \mathrm{~g}$ dietary protein, PRO20+LEU: $20 \mathrm{~g}$ dietary protein $+1.5 \mathrm{~g}$ crystalline leucine, PRO40: $40 \mathrm{~g}$ dietary protein. The dotted line represents the ingestion of the treatment. Values are mean $\pm \mathrm{SEM}, n=12$ per treatment group. 
Plasma amino acid concentrations are shown in Figures $\mathbf{3}$ and $\mathbf{4}$. Significant time $\times$ treatment group interactions were observed for all plasma amino acid concentrations (all $P<0.001$ ). Plasma phenylalanine concentrations increased after protein ingestion (main time effects in all protein groups, all $P<0.001)$ and were elevated throughout the night in the protein groups compared with the placebo group $(P<0.001$; Figure 3A). Plasma tyrosine concentrations increased after protein ingestion (main time effects in all protein groups, all $P<0.001$; Figure 3B) and were higher than in the placebo group $(P<0.001)$.
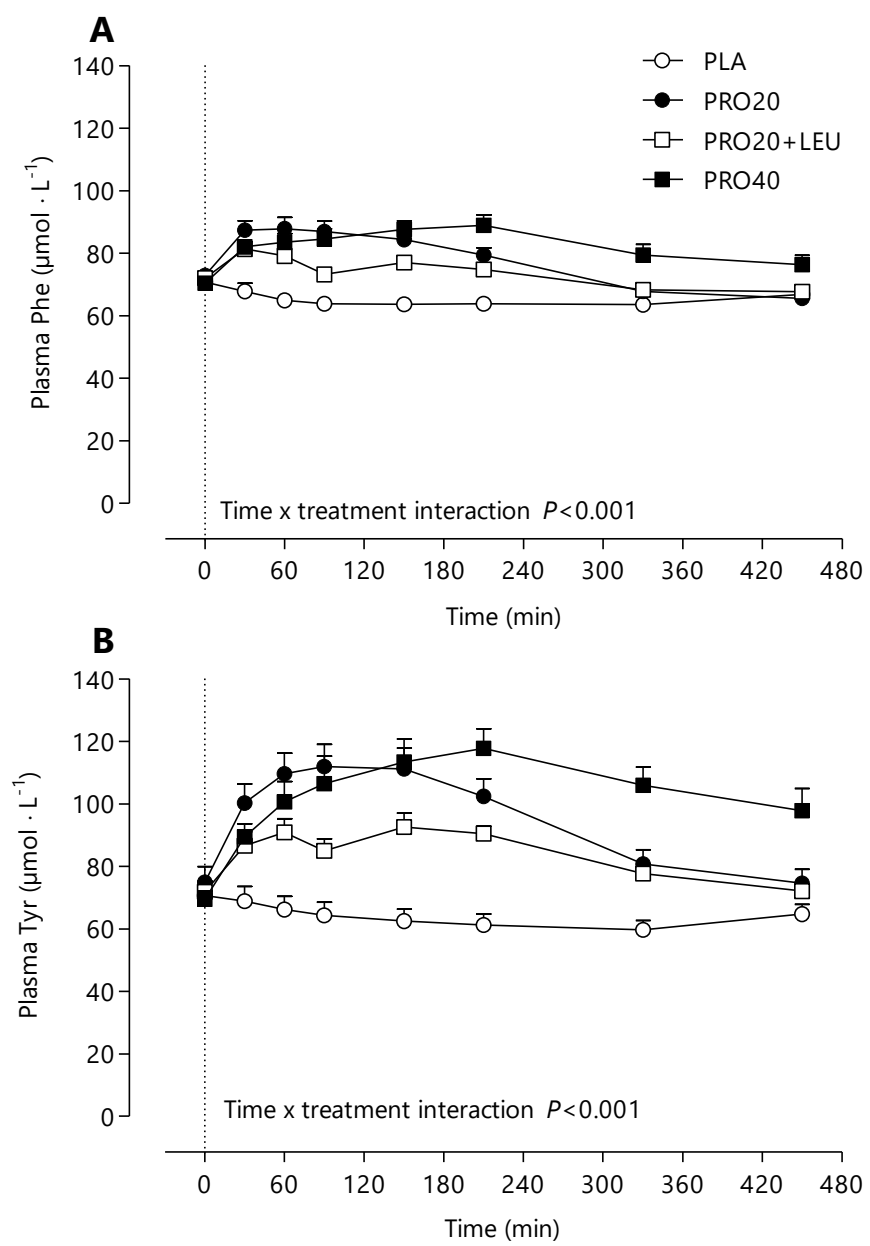

Figure 3 | Plasma phenylalanine (A) and tyrosine (B) concentrations during overnight sleep in 48 healthy older men who ingested PLA or supplemental protein before sleep. The dotted line represents the ingestion of the treatment. Values are mean $\pm \mathrm{SEM}, n=12 /$ treatment group. PLA, placebo; PRO20, $20 \mathrm{~g}$ dietary protein; PRO20+LEU, $20 \mathrm{~g}$ dietary protein plus $1.5 \mathrm{~g}$ crystalline leucine; PRO40, $40 \mathrm{~g}$ dietary protein. 
Plasma leucine concentrations increased rapidly after protein ingestion (main time effects in all protein groups, $P<0.001$; Figure $4 \mathrm{~A}$ ), but to a greater extent in PRO20+LEU (peak values: $\left.396 \pm 20 \mu \mathrm{mol} \cdot \mathrm{L}^{-1}\right)$ than in PRO40 and PRO20 (316 \pm 19 and $269 \pm 10 \mu \mathrm{mol} \cdot \mathrm{L}^{-1}$, respectively, $P<0.001)$. The incremental AUC (Figure 4B) did not differ between PRO20+LEU and PRO40 $(P=0.56)$, but both were higher than in PRO20 and placebo (both $P<0.001)$, and $\mathrm{PRO} 20$ was higher than in placebo $(P<0.001)$.
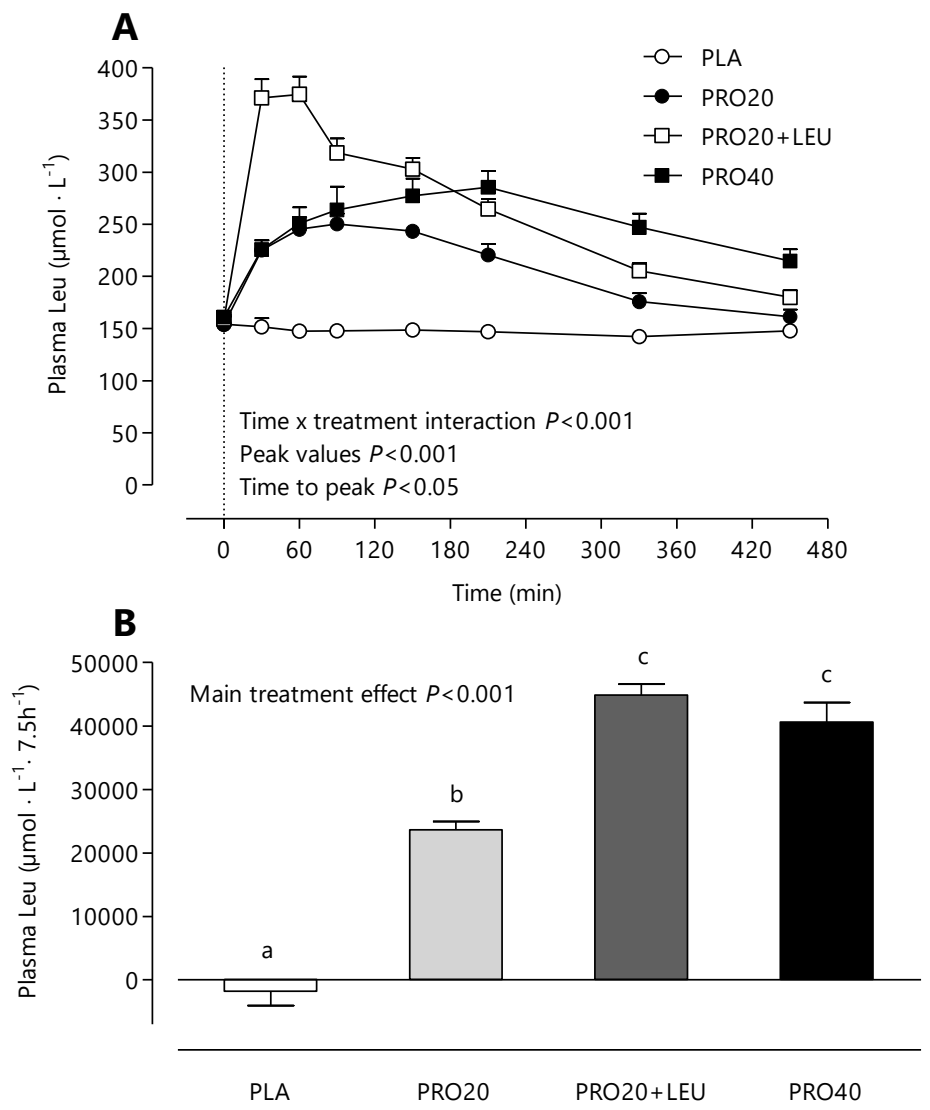

Figure 4 | Plasma leucine concentrations during overnight sleep (A) and expressed as the incremental AUC (B) in 48 healthy older men who ingested PLA or supplemental protein before sleep. The dotted line represents the ingestion of the treatment. Values are mean $\pm \mathrm{SEM}, n=12 /$ treatment group. Labeled bars without a common letter differ, $P<0.001$. PLA, placebo; PRO20, $20 \mathrm{~g}$ dietary protein; PRO20+LEU, $20 \mathrm{~g}$ dietary protein plus $1.5 \mathrm{~g}$ crystall ine leucine; PRO40, $40 \mathrm{~g}$ dietary protein. 


\section{Plasma amino acid enrichments}

Significant time $\times$ treatment group interactions were observed for all plasma amino acid enrichments (all $P<0.05$ ). Plasma L- $\left[1-{ }^{13} \mathrm{C}\right]$-phenylalanine enrichments increased after protein ingestion (main time effects in all protein groups, all $P<0.001$; Figure 5A), and peak values were different between groups (main treatment group effect, $P<0.001$ ), with higher enrichments observed in PRO40 (12.9 $\pm 0.7 \mathrm{MPE})$ than in PRO20 and PRO20+LEU $(10.8 \pm 0.4$ and $10.1 \pm 0.5 \mathrm{MPE}$, respectively, both $P<0.05$ ). Plasma amino acid availability, as a fraction from the ingested amount of protein, differed between treatment groups (main treatment group effect, $P<0.001)$ and was higher in PRO20 and PRO20+LEU $(69 \pm 1 \%$ and $64 \pm 2 \%$, respectively) than in PRO40 $(53 \pm 3 \%$, both $P<0.001)$. The absolute amount of dietary protein derived from the drink that appeared in the circulation during the 7.5 -h overnight postprandial period differed between groups (main treatment group effect, $P<0.001$; Figure 5B) and was higher in PRO40 (21.3 $\pm 1.2 \mathrm{~g})$ than in PRO20 and PRO20+LEU (13.8 \pm 0.3 and $12.8 \pm 0.4 \mathrm{~g}$, respectively, both $P<0.001)$, with no differences between PRO20 and PRO20+LEU $(P=0.70$; Figure 3B).
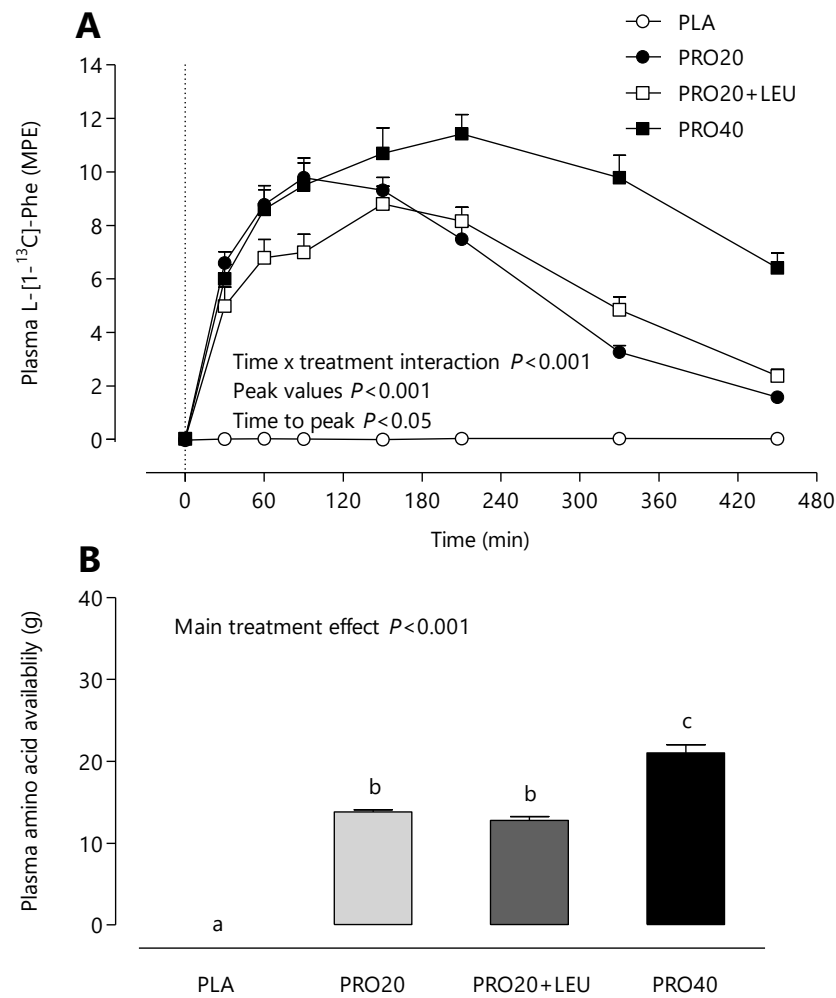

Figure 5 | Plasma L-[1-13 C]-phenylalanine enrichments during overnight sleep (A) and plasma amino acid availability from the ingested protein drink during the 7.5 -h overnight period (B) in 48 healthy older men who ingested PLA or supplemental protein before sleep. The dotted line represents the ingestion of the treatment. Values are mean $\pm \mathrm{SEM}, \mathrm{n}=12$ /treatment group. Labeled bars without a common letter differ, $\mathrm{P}<0.001$. MPE, mole percent excess; PLA, placebo; PRO20, $20 \mathrm{~g}$ dietary protein; PRO20+LEU, $20 \mathrm{~g}$ dietary protein plus $1.5 \mathrm{~g}$ crystalline leucine; PRO40, $40 \mathrm{~g}$ dietary protein. 
Plasma L-[ring- $\left.{ }^{2} \mathrm{H}_{5}\right]$-phenylalanine enrichments were higher in the placebo group than in the PRO groups $\left(P<0.001\right.$; Figure 6 A). Plasma L- $\left[1-{ }^{13} \mathrm{C}\right]$-leucine enrichments were higher in PRO40 than in placebo $(P<0.05$; Figure 6B).
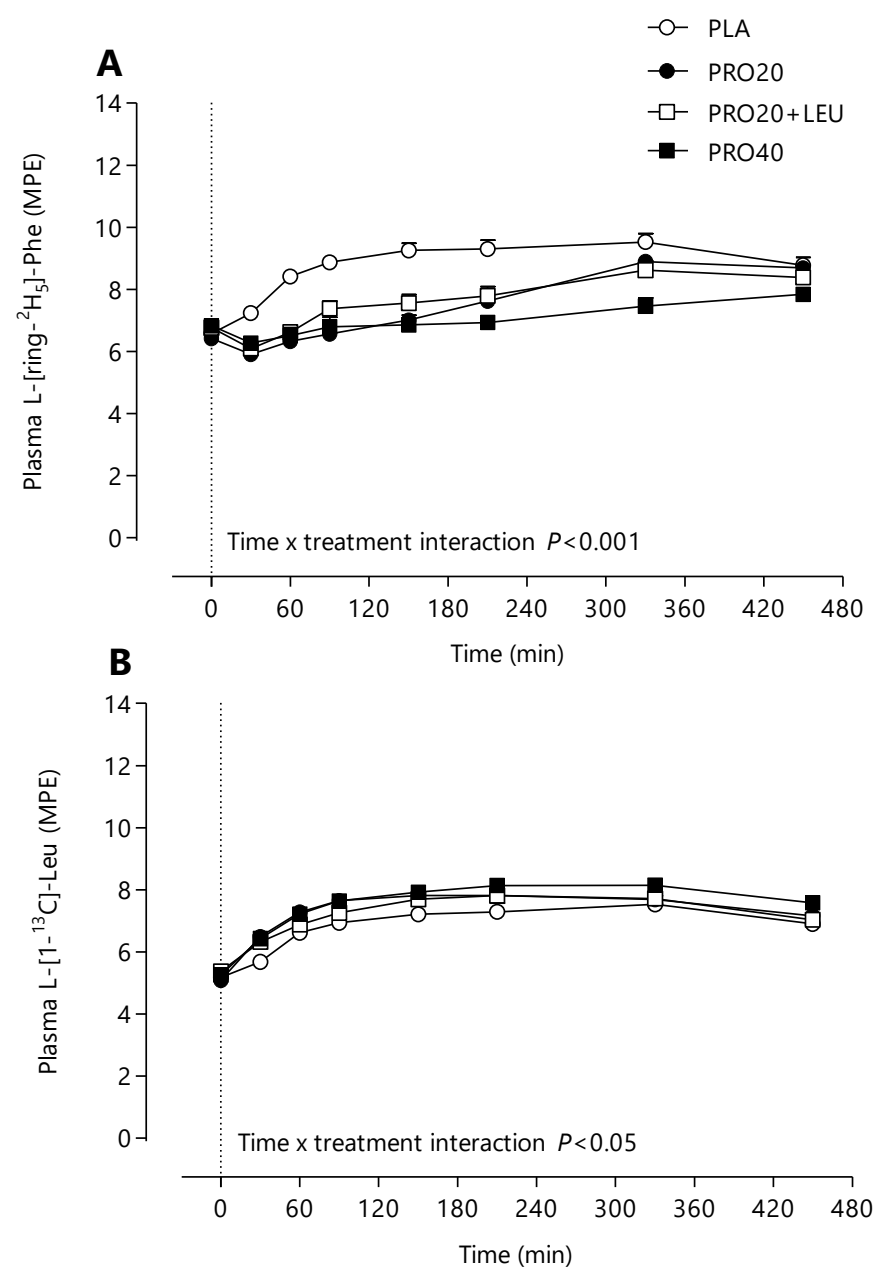

Figure 6 | Plasma L-[ring $\left.{ }^{2} \mathrm{H}_{5}\right]$-phenylalanine $(\mathbf{A})$ and $\mathrm{L}-\left[1-{ }^{13} \mathrm{C}\right]$-leucine $(\mathbf{B})$ enrichments during overnight sleep in 48 healthy older men who ingested placebo or supplemental protein before sleep ( $n=12$ per treatment group). PLA: placebo, PRO20: $20 \mathrm{~g}$ dietary protein, PRO20+LEU: $20 \mathrm{~g}$ dietary protein $+1.5 \mathrm{~g}$ crystalline leucine, PRO40: 40 $\mathrm{g}$ dietary protein. MPE, mole percent excess. The dotted line represents the ingestion of the treatment. Values are mean \pm SEM 


\section{Whole-body amino acids kinetics}

Whole-body protein kinetics are displayed in Figure 7. A significant time $\times$ treatment group interaction $(P<0.001)$ showed an increase in exogenous phenylalanine rates of appearance after protein intake in all groups $(P<0.001)$, which was higher in PRO40 (peak values: $0.26 \pm 0.02$ $\mu \mathrm{mol}$ phenylalanine $\left.\cdot \mathrm{kg}^{-1} \cdot \mathrm{min}^{-1}\right)$ than in PRO20 and PRO20+LEU $(0.22 \pm 0.01$ and $0.18 \pm 0.01$ umol phenylalanine $\cdot \mathrm{kg}^{-1} \cdot \mathrm{min}^{-1}$, respectively, both $P<0.05$; Figure 7A). Endogenous phenylalanine rates of appearance decreased in all groups (main time effect, $P<0.001$ ) with no differences between groups (time $\times$ treatment group interaction, $P=0.30$; Figure 7B). Significant time $\times$ treatment group interactions were observed for total phenylalanine rates of appearance and disappearance (both $P<0.001$ ). Follow-up analyses showed a decrease in all groups in total phenylalanine rates of appearance $(P<0.001)$, and higher values in the protein groups than in the placebo group $(P<0.001$; Figure 7C). Total phenylalanine rates of disappearance were higher in all protein groups than in the placebo group $(P<0.05$; Figure 7D).
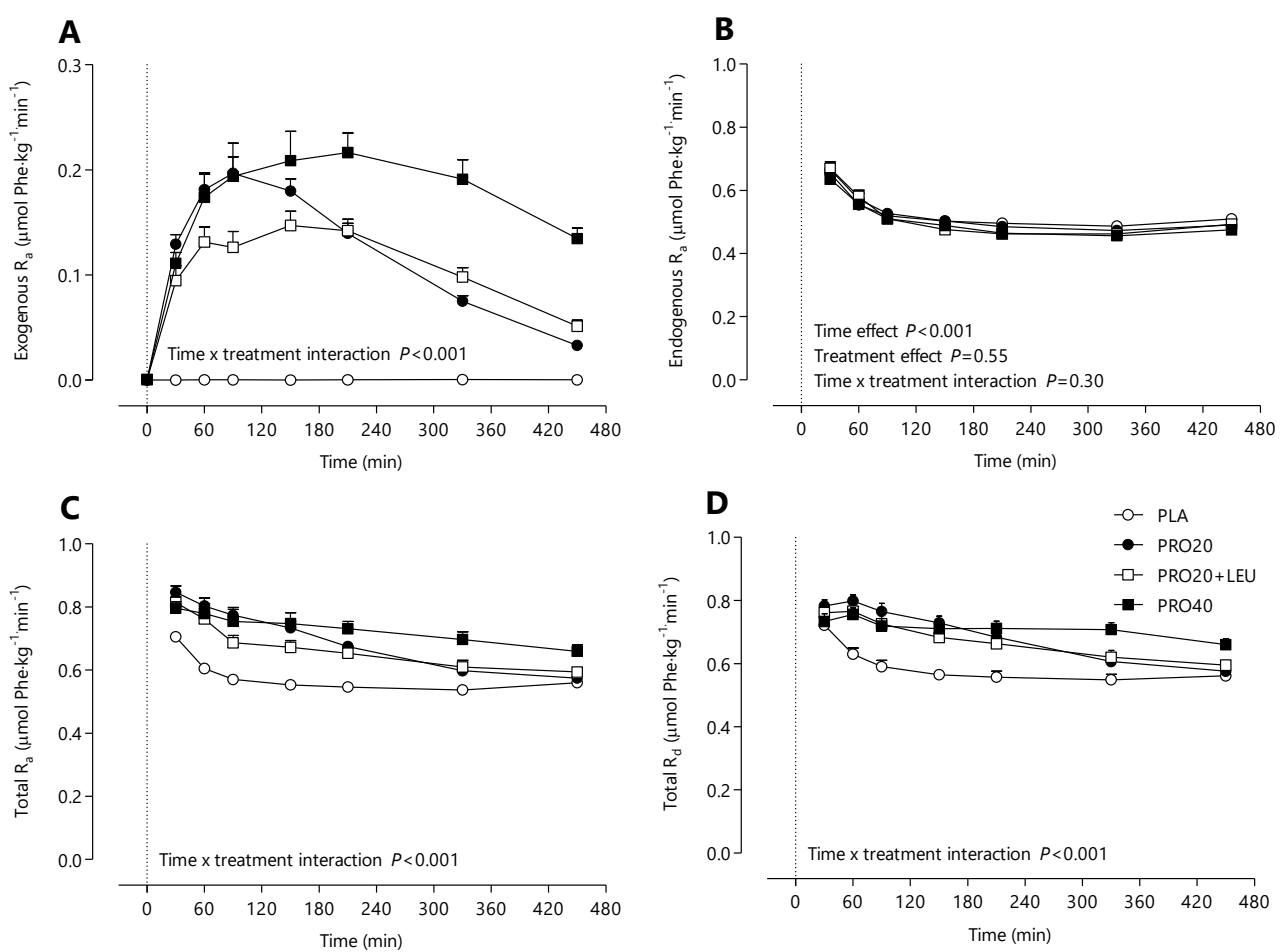

Figure 7 | Exogenous $R_{a}(\mathbf{A})$, endogenous $R_{a}(\mathbf{B})$, total $R_{a}(\mathbf{C})$, and total $R_{d}(\mathbf{D})$ during overnight sleep in 48 healthy older men who ingested PLA or supplemental protein before sleep. The dotted line represents the ingestion of the treatment. Values are mean \pm SEM, $n=12$ /treatment group. PLA, placebo; PRO20, $20 \mathrm{~g}$ dietary protein; PRO20+LEU, $20 \mathrm{~g}$ dietary protein plus $1.5 \mathrm{~g}$ crystalline leucine; PRO $40,40 \mathrm{~g}$ dietary protein; $\mathrm{R}_{\mathrm{a}}$, rate of appearance; $R_{d}$, rate of disappearance. 
Whole-body protein metabolism is shown in Figure 8. Whole-body protein synthesis rates differed between groups (main treatment group effect, $P<0.001$ ), and were higher in PRO20, $\mathrm{PRO} 20+\mathrm{LEU}$, and PRO40 than in placebo (all $P<0.05$ ). Whole-body protein breakdown rates did not differ between treatments $(P=0.26)$. Whole-body protein oxidation rates were different between treatments (main treatment group effect, $P<0.001$ ) and were higher in PRO40 and PRO20 than in placebo (both $P<0.05$ ), and in PRO40 than in PRO20 and PRO20+LEU (both $P<0.05$ ). Whole-body protein net balance differed between treatments (main treatment group effect, $P<0.001)$ and was higher in all PRO groups than in the placebo group (all $P<0.001$ ) and in PRO40 than in PRO20 and PRO20+ LEU (both $P<0.001$ ).

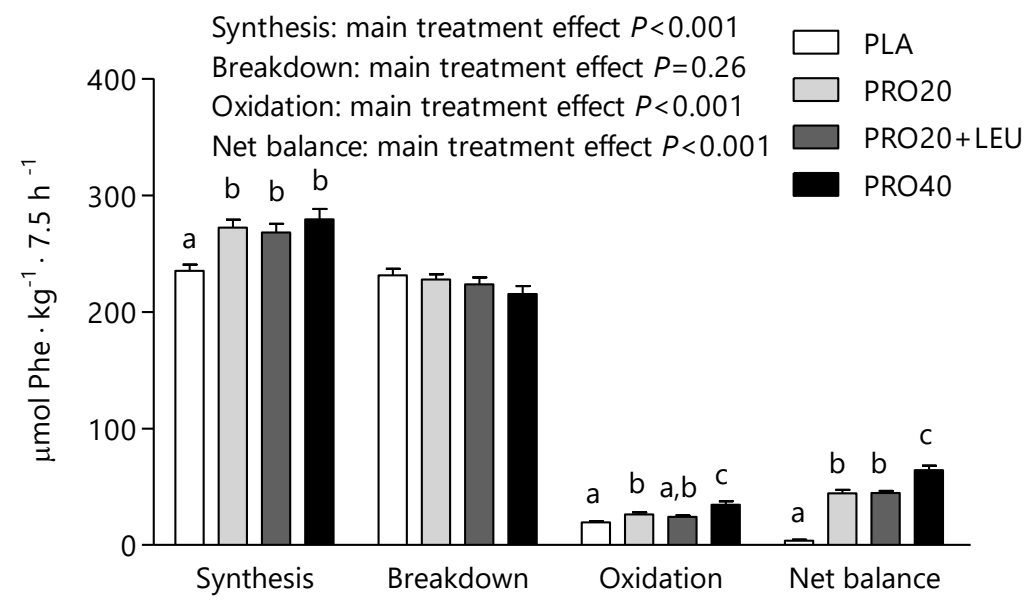

Figure 8 | Rates of whole-body protein synthesis, breakdown, oxidation, and net balance during the 7.5-h overnight period in 48 healthy older men who ingested PLA or supplemental protein before sleep. Values are mean $\pm \mathrm{SEM}, n=12$ /treatment group. Labelled bars without a common letter differ, $P<0.05$. PLA, placebo; PRO20, $20 \mathrm{~g}$ dietary protein; PRO20+LEU, $20 \mathrm{~g}$ dietary protein plus $1.5 \mathrm{~g}$ crystalline leucine; PRO $40,40 \mathrm{~g}$ dietary protein.

\section{Myofibrillar protein synthesis rates and protein-bound enrichments}

Myofibrillar protein FSRs based on L-[ring- $\left.{ }^{2} \mathrm{H}_{5}\right]$-phenylalanine and FSRs based on $\mathrm{L}-\left[1-{ }^{13} \mathrm{C}\right]-$ leucine are displayed in Figure 9. FSR values calculated from $\mathrm{L}$-[ring- $\left.{ }^{2} \mathrm{H}_{5}\right]$-phenylalanine enrichments differed between treatment groups and were a mean of $0.033 \pm 0.002 \% \cdot \mathrm{h}^{-1}$ in placebo, $0.037 \pm 0.003 \% \cdot h^{-1}$ in PRO20, $0.039 \pm 0.002 \% \cdot h^{-1}$ in PRO20 + LEU, and $0.044 \pm 0.003 \%$. $\mathrm{h}^{-1}$ in PRO40 (main treatment group effect, $P=0.03$; Figure 9A). Post hoc analyses showed that myofibrillar FSRs were higher in PRO40 than in placebo $(P=0.02)$. No differences were observed in FSR values for PRO20 $(P=0.73)$ and PRO20+LEU $(P=0.42)$ compared with placebo or between PRO20+LEU and PRO20 ( $P=0.96)$. In accordance, myofibrillar protein synthesis rates based on $\mathrm{L}-\left[1-{ }^{13} \mathrm{C}\right]$-leucine enrichments were different between treatment groups and were a mean of $0.047 \pm 0.004 \% \cdot h^{-1}$ in placebo, $0.046 \pm 0.004 \% \cdot h^{-1}$ in PRO20, $0.056 \pm 0.002 \% \cdot h^{-1}$ in $\mathrm{PRO} 20+\mathrm{LEU}$, and $0.058 \pm 0.003 \% \cdot \mathrm{h}^{-1}$ in $\mathrm{PRO} 40$ (main treatment group effect, $P=0.02$; Figure 9B). 
Post hoc analyses showed that FSRs in PRO40 tended to be higher than in placebo $(P=0.08)$ and PRO20 $(P=0.06)$. PRO20 $(P=0.99)$ and PRO20+LEU $(P=0.19)$ did not differ compared with placebo. No differences were observed in FSR values between PRO20+LEU and PRO20 $(P=0.16)$.
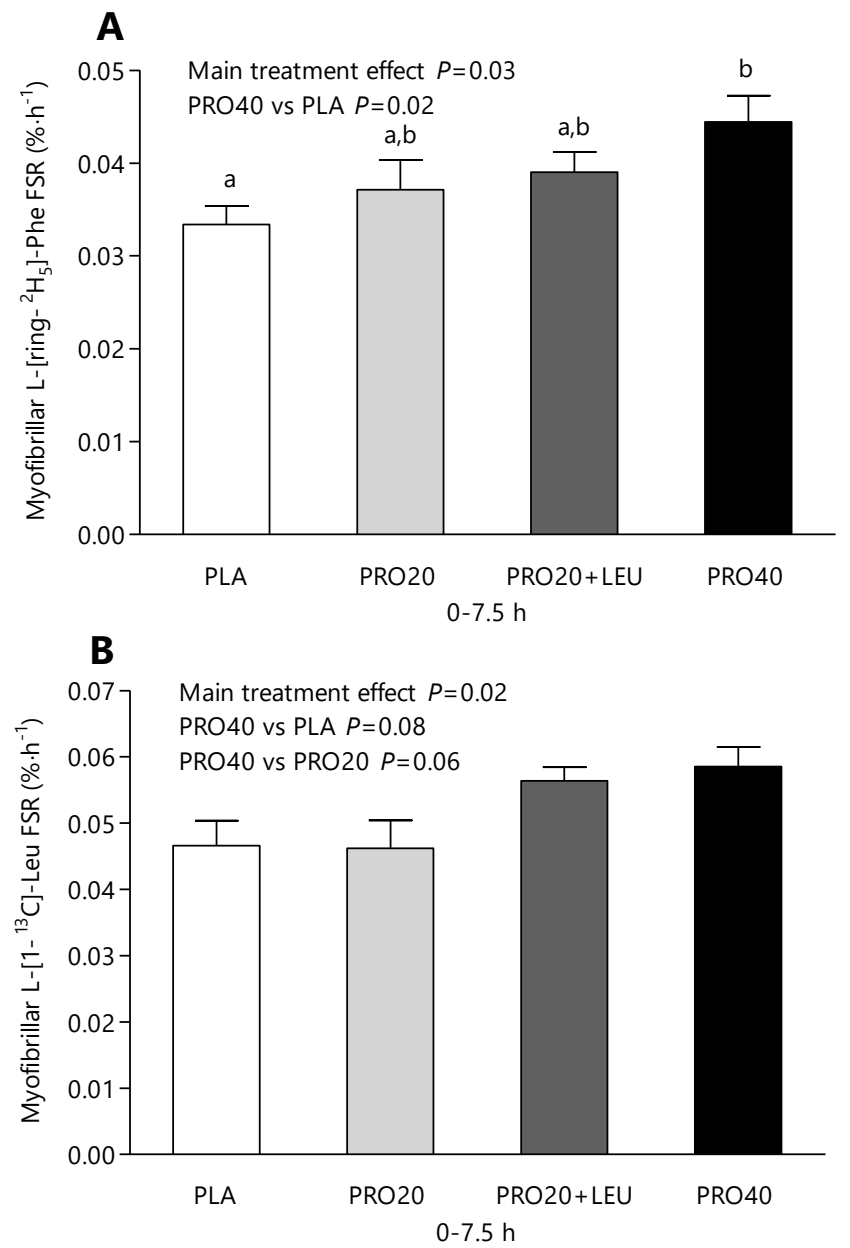

Figure 9 | Myofibrillar protein fractional synthetic rates using intravenous $L$-[ring- $\left.{ }^{2} \mathrm{H}_{5}\right]$-phenylalanine infusion (A) and intravenous and dietary protein-derived muscle protein-bound $\mathrm{L}-\left[1-{ }^{13} \mathrm{C}\right]$-leucine (B) during overnight sleep in 48 healthy older men who ingested PLA or supplemental protein before sleep. Values are mean \pm SEM, $n=12$ / treatment group. Labeled bars without a common letter differ, $P<0.05$. FSR, fractional synthesis rates; PLA, placebo; PRO20, $20 \mathrm{~g}$ dietary protein; PRO20+LEU, $20 \mathrm{~g}$ dietary protein plus $1.5 \mathrm{~g}$ crystalline leucine; PRO40, $40 \mathrm{~g}$ dietary protein. 
The incorporation of dietary protein-derived amino acids $\left(L-\left[1-{ }^{13} \mathrm{C}\right]\right.$-phenylalanine enrichments) into de novo myofibrillar protein was $0.019 \pm 0.002,0.025 \pm 0.002$, and $0.033 \pm 0.002$ MPE in PRO20, PRO20+LEU, and PRO40, respectively, and differed between treatment groups (main treatment group effect, $P<0.001$; Figure 10). Post hoc analyses showed that $\mathrm{L}-\left[1-{ }^{13} \mathrm{C}\right]-$ phenylalanine myofibrillar protein-bound enrichments were higher in PRO40, PRO20+LEU, and $\mathrm{PRO} 20$ than in placebo $(P<0.001)$. Enrichments were also higher in PRO40 than in PRO20 $(P<0.001)$ and tended to be higher than in PRO20+LEU $(P=0.06)$. No differences were observed in MPE values between PRO20+LEU and PRO20 $(P=0.17)$.

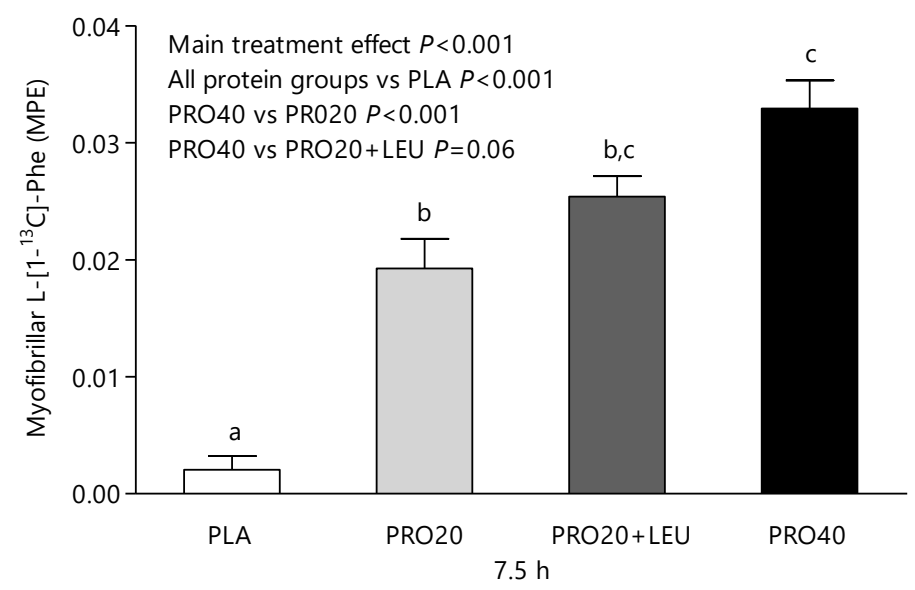

Figure 10 | Diet-derived myofibrillar protein-bound L- $\left[1-{ }^{13} \mathrm{C}\right]$-phenylalanine enrichments after overnight sleep in 48 healthy older men who ingested PLA or supplemental protein before sleep. Values are mean \pm SEM, $n=12$ / treatment group. Labeled bars without a common letter differ, $P<0.05$. MPE, mole percent excess; PLA, placebo; PRO20, $20 \mathrm{~g}$ dietary protein; PRO20+LEU, $20 \mathrm{~g}$ dietary protein plus $1.5 \mathrm{~g}$ crystalline leucine; PRO40, $40 \mathrm{~g}$ dietary protein. 


\section{Sleep quality}

There were no differences in VAS tiredness scores between groups taken before sleep or in the morning (main treatment group effect, both $P>0.05$; data not shown). Sleep analyses data are presented in Table 2. The treatment groups were similar in bedtime, get-up time, sleep onset latency (the time between bedtime and falling asleep), sleep duration (in hours), and sleep efficiency (percentage of sleep duration expressed as a percentage of time in bed) (main treatment group effect, all $P>0.05$ ).

Table 2 | Sleep analyses

\begin{tabular}{lcccccc}
\hline & PLA & PRO20 & PRO20+LEU & PRO40 & mean & SEM \\
\hline Bed time (hh:mm:ss) & $23: 56: 45$ & $23: 47: 00$ & $23: 55: 09$ & $23: 55: 24$ & $23: 53: 34$ & $0: 01: 59$ \\
$\begin{array}{l}\text { Wake time } \\
\text { (hh:mm:ss) }\end{array}$ & $7: 01: 38$ & $7: 01: 50$ & $6: 55: 34$ & $7: 01: 00$ & $7: 00: 00$ & $0: 01: 20$ \\
$\begin{array}{l}\text { Time to fall asleep } \\
\text { (hh:mm:ss) }\end{array}$ & $0: 08: 22$ & $0: 10: 40$ & $0: 09: 43$ & $0: 06: 12$ & $0: 08: 44$ & $0: 00: 52$ \\
$\begin{array}{l}\text { Sleep duration } \\
\text { (hh:mm:ss) }\end{array}$ & $6: 08: 15$ & $6: 21: 40$ & $6: 16: 17$ & $5: 46: 48$ & $6: 08: 15$ & $0: 06: 51$ \\
\begin{tabular}{l} 
Sleep efficiency (\%) \\
\hline
\end{tabular} & 87 & 88 & 89 & 81 & 86 & 2 \\
\hline
\end{tabular}

Sleep analyses in 48 healthy older men who ingested placebo or supplemental protein before sleep. Values are mean, $n=12$ per treatment group. PLA: placebo, PRO20: $20 \mathrm{~g}$ dietary protein, PRO20+LEU: $20 \mathrm{~g}$ dietary protein $+1.5 \mathrm{~g}$ crystalline leucine, PRO40: $40 \mathrm{~g}$ dietary protein. No significant differences between treatment groups were observed $(P<0.05)$.

\section{Hunger and satiety in the morning}

There were no differences between groups in the VAS hunger and satiety scores taken before protein ingestion or after the overnight period before ad libitum breakfast ingestion (main treatment group effect, both $P>0.05$; data not shown). Energy intake at breakfast was $2.53 \pm 0.11 \mathrm{MJ}$ total energy, containing $46 \pm 1 \mathrm{En} \%$ carbohydrate, $38 \pm 1 \mathrm{En} \%$ fat, and $14 \pm 1 \mathrm{En} \%$ protein, with no differences between treatment groups (main treatment group effect, all $P>0.05)$. 


\section{DISCUSSION}

In the present study we show that protein ingested before sleep was properly digested and absorbed throughout the night, thereby increasing overnight plasma amino acid availability and facilitating myofibrillar protein synthesis during sleep in healthy older men. Ingestion of $40 \mathrm{~g}$ protein before sleep increased overnight muscle protein synthesis rates $(0.044 \pm 0.003$ $\left.\% \cdot \mathrm{h}^{-1}\right)$ compared with the placebo treatment $\left(0.033 \pm 0.002 \% \cdot \mathrm{h}^{-1} ; P=0.02\right)$. Ingesting a smaller $(20 \mathrm{~g})$ dose of protein, with or without additional leucine, did not significantly increase overnight muscle protein synthesis rates compared with the placebo intervention.

Because gut motility and gastric acid secretion are affected by circadian oscillations, the $\mathrm{pH}$ of the stomach has been speculated to change during sleep, which may affect digestion and absorption (i.e. clotting of the casein) [27]. By combining the ingestion of intrinsically L-[1${ }^{13} \mathrm{C}$ ]-phenylalanine-labeled protein with primed continuous infusions of $\mathrm{L}$-[ring- $\left.{ }^{2} \mathrm{H}_{5}\right]$ phenylalanine we were able to quantify the rate of appearance of dietary protein-derived amino acids during overnight sleep $[17,18]$. Presleep protein ingestion increased overnight plasma amino acid availability with $53 \pm 3 \%, 69 \pm 1 \%$, and $64 \pm 2 \%$ of protein-derived amino acids being released into the systemic circulation during the 7.5-h overnight period in PRO40, PRO20, and PRO20+LEU treatments, respectively (Figure 5B). As expected, more dietary protein-derived amino acids were released after the ingestion of $40 \mathrm{~g}$ than after $20 \mathrm{~g}$ protein, with greater exogenous amino acid appearance rates in the PRO40 treatment up into the later stages of overnight sleep (Figure 7A). These data tend to be in line with our previous work [12] showing $58 \pm 4 \%$ of the protein-derived amino acids becoming available in the circulation after the administration of $40 \mathrm{~g}$ protein during sleep via a nasogastric tube. The present study extends this prior work by showing that protein ingested before sleep is properly digested and absorbed during subsequent overnight sleep, with postprandial plasma amino acid availability being similar to nasogastric tube feeding during sleep.

The release of dietary protein-derived amino acids into the circulation stimulated whole-body protein synthesis rates during the overnight phase. This resulted in a positive whole-body protein net balance during overnight sleep in all protein groups compared with a zero net balance that was observed in the placebo group (Figure 8). Because plasma amino acid kinetics do not necessarily reflect changes in skeletal muscle protein turnover [28], we also obtained skeletal muscle biopsy samples before and after overnight sleep and measured the $\mathrm{L}-\left[1-{ }^{13} \mathrm{C}\right]$-phenylalanine, $\mathrm{L}$-[ring- $\left.{ }^{2} \mathrm{H}_{5}\right]$-phenylalanine, and $\mathrm{L}-\left[1-{ }^{13} \mathrm{C}\right]$-leucine incorporation into myofibrillar protein. Consequently, this allowed us to quantify the effect of protein ingestion on overnight muscle protein synthesis rates (Figure 9) and assess the direct incorporation of dietary protein-derived amino acids into de novo myofibrillar protein (Figure 10).

The ingestion of $40 \mathrm{~g}$ protein before sleep increased overnight muscle protein synthesis rates by $\sim 33 \%$ above values observed in the placebo group (based on the L-[ring- $\left.{ }^{2} \mathrm{H}_{5}\right]$ phenylalanine tracer, $P=0.02$; Figure 6). Likewise, a $\sim 25 \%$ higher FSR was observed in PRO40 than in placebo based on the $L-\left[1-{ }^{13} \mathrm{C}\right]$-leucine tracer, although this difference did not reach 
statistical significance $(P=0.08)$. These findings are in line with our first proof-of-concept study where we reported a similar increase in overnight muscle protein synthesis rates after the nasogastric administration of $40 \mathrm{~g}$ protein during sleep in older men [12]. We extend this work by showing that ingesting protein before sleep increases overnight amino acid availability, thereby increasing myofibrillar protein synthesis rates during sleep in healthy older men. Ingestion of $20 \mathrm{~g}$ compared with $40 \mathrm{~g}$ protein did not increase overnight muscle protein synthesis rates (Figure 9), confirming our hypothesis that more protein is required to stimulate muscle protein synthesis during the extended postprandial overnight period ( $7.5 \mathrm{~h}$ ) in healthy older men. Because we anticipated a lower muscle protein synthetic response after the ingestion of $20 \mathrm{~g}$ protein compared with $40 \mathrm{~g}$ protein, we assessed whether overnight muscle protein synthesis rates could be further increased by ingesting $20 \mathrm{~g}$ protein fortified with free leucine. Previous work has shown that increasing the leucine content in a dose of protein or amino acids can augment the postprandial muscle protein synthetic response in older individuals [9-11].

Despite the greater plasma leucine availability after leucine co-ingestion (Figure 4), we observed no substantial increase in overnight muscle protein synthesis rates. The absence of a stimulating effect after leucine co-ingestion could be attributed to the absence of a robust insulin response during the overnight period, the lack of sufficient amino acids as precursors for muscle protein synthesis during the relatively long overnight period, or simply that the stimulating properties of leucine are less evident during sleep. We conclude that only increasing the leucine content of a $20 \mathrm{~g}$ g protein dose is not sufficient to drive a similar overnight muscle protein synthetic response to the levels observed after the presleep ingestion of $40 \mathrm{~g}$ protein. These data suggest that the greater plasma amino acid availability after ingestion of $40 \mathrm{~g}$ compared with $20 \mathrm{~g}$ protein during the longer overnight period may be required to allow a measurable increase in muscle protein synthesis rates.

We applied highly enriched ( $239 \mathrm{MPE})$, intrinsically $L-\left[1-{ }^{13} \mathrm{C}\right]$-phenylalanine-labeled casein to allow assessment of the metabolic fate of the ingested protein by measuring the incorporation of dietary protein-derived amino acids into de novo myofibrillar protein. Protein ingested before sleep resulted in a substantial increase in myofibrillar protein-bound $\mathrm{L}-\left[1-{ }^{13} \mathrm{C}\right]-$ phenylalanine enrichments, with more dietary protein-derived amino acids being incorporated after the ingestion of $40 \mathrm{~g}$ compared with $20 \mathrm{~g}$ protein $(P<0.001$; Figure 10). Despite the absence of a measurable increase in overnight muscle protein synthesis rates after ingestion of $20 \mathrm{~g}$ protein, these data clearly show that protein ingested before sleep provides ample precursors that are being used to support overnight muscle protein synthesis. Coingestion of free leucine with $20 \mathrm{~g}$ protein was not effective in further increasing the overnight deposition of dietary protein-derived amino acids into de novo myofibrillar protein $(P=0.17$; Figure 10).

Here, we show that presleep protein ingestion increases overnight muscle protein synthesis rates, even in a setting where substantial amounts $\left(1.1 \pm 0.01 \mathrm{~g} \cdot \mathrm{kg}^{-1} \cdot \mathrm{d}^{-1}\right)$ of protein are already consumed throughout the day, with a normal protein-rich dinner $(29 \pm 2 \mathrm{~g}$ protein) ingested 
5h before sleep. Presleep protein ingestion provides a window of opportunity to stimulate muscle protein synthesis during a period where muscle protein synthesis rates are typically low $[12,29]$. Moreover, we show that protein ingestion before sleep provides amino acids as precursors for de novo overnight muscle protein synthesis. This nutritional strategy may be of relevance for older individuals aiming to maintain skeletal muscle mass and also sarcopenic individuals who have already lost substantial amounts of muscle mass and strength.

Several studies have reported increases in lean body mass after prolonged protein supplementation in various older populations [30-32], whereas others have failed to show measurable increases in muscle mass or strength [33-36]. A proper distribution of protein intake over the main meals has been proposed to increase muscle protein synthesis rates throughout the day [37-39] and is associated with higher lean mass in older adults [40]. However, whether a more balanced protein distribution also increases skeletal muscle mass and strength should be evaluated in long-term intervention studies. We believe that a proper distribution (both timing and quantity) of protein intake is essential to allow protein supplementation to increase muscle mass, strength, and function, which includes presleep protein ingestion. Besides optimizing the protein content with every meal, we recently showed that physical activity performed in the evening can further enhance the overnight muscle protein synthetic response to presleep protein ingestion in older subjects [13]. As such, combining presleep protein ingestion with physical activity may serve as an effective strategy to preserve skeletal muscle mass with aging. Interestingly, we showed that daily presleep protein ingestion increases the gains in muscle mass and strength after 3 mo of resistancetype exercise training in young men who were already consuming ample amounts of protein in their diet $\left(1.3 \mathrm{~g} \cdot \mathrm{kg}^{-1} \cdot \mathrm{d}^{-1}\right)$ [41]. Future work should establish the effect of long-term intervention programs using presleep protein ingestion (combined with physical activity) on lean mass and functional capacity in healthy or clinically compromised older populations. More work is needed on the effect of protein intake distribution and overnight muscle protein synthesis rates in older individuals. Although $\sim 40 \mathrm{~g}$ high-quality protein seems to be required to maximize postprandial muscle protein synthesis rates in older individuals [42], a definite upper threshold remains to be established. Also, previous work has shown greater stimulation of postprandial FSR after whey ingestion than after casein ingestion [20]. Yet, the anabolic response to whey protein ingestion has also been shown to be relatively short lived. Which protein source would be preferred to stimulate muscle protein synthesis throughout overnight sleep clearly remains to be determined. In addition, more work is warranted to assess the effect of reducing the amount of time spent in a fasting state not only on whole-body and tissuespecific protein turnover but also on overall metabolism [43-46]. Finally, we need to evaluate how overnight muscle protein metabolism modulates protein metabolism during the day, and vice versa.

In conclusion, the ingestion of $40 \mathrm{~g}$ casein before sleep is followed by proper protein digestion and amino acid absorption throughout the night, thereby increasing overnight plasma amino acid availability and stimulating overnight muscle protein synthesis in healthy older men. Presleep ingestion of smaller doses of protein $(20 \mathrm{~g})$, with or without additional free leucine, 
do not seem sufficient to increase overnight muscle protein synthesis rates but do provide amino acids as precursors for myofibrillar protein synthesis during overnight sleep in healthy older men. The present study introduces presleep protein ingestion as a practical and effective dietary strategy to stimulate overnight muscle protein accretion and, as such, may help to attenuate or prevent muscle loss in both health and disease. 


\section{REFERENCES}

1. Koopman, R. and L.J. van Loon, Aging, exercise, and muscle protein metabolism. Journal of applied physiology, 2009. 106(6): p. 2040-8.

2. Moore, D.R., M.J. Robinson, J.L. Fry, J.E. Tang, E.I. Glover, S.B. Wilkinson, T. Prior, M.A. Tarnopolsky, and S.M. Phillips, Ingested protein dose response of muscle and albumin protein synthesis after resistance exercise in young men. The American journal of clinical nutrition, 2009. 89(1): p. 161-8.

3. Witard, O.C., S.R. Jackman, L. Breen, K. Smith, A. Selby, and K.D. Tipton, Myofibrillar muscle protein synthesis rates subsequent to a meal in response to increasing doses of whey protein at rest and after resistance exercise. Am J Clin Nutr, 2014. 99(1): p. 86-95.

4. Groen, B.B., A.M. Horstman, H.M. Hamer, M. de Haan, J. van Kranenburg, J. Bierau, M. Poeze, W.K. Wodzig, B.B. Rasmussen, and L.J. van Loon, Post-Prandial Protein Handling: You Are What You Just Ate. PLoS One, 2015. 10(11): p. e0141582.

5. Pennings, B., B. Groen, A. de Lange, A.P. Gijsen, A.H. Zorenc, J.M. Senden, and L.J. van Loon, Amino acid absorption and subsequent muscle protein accretion following graded intakes of whey protein in elderly men. American journal of physiology. Endocrinology and metabolism, 2012. 302(8): p. E992-9.

6. Yang, Y., L. Breen, N.A. Burd, A.J. Hector, T.A. Churchward-Venne, A.R. Josse, M.A. Tarnopolsky, and S.M. Phillips, Resistance exercise enhances myofibrillar protein synthesis with graded intakes of whey protein in older men. The British journal of nutrition, 2012. 108(10): p. 1780-8.

7. Robinson, M.J., N.A. Burd, L. Breen, T. Rerecich, Y. Yang, A.J. Hector, S.K. Baker, and S.M. Phillips, Dose-dependent responses of myofibrillar protein synthesis with beef ingestion are enhanced with resistance exercise in middle-aged men. Appl Physiol Nutr Metab, 2013. 38(2): p. 120-5.

8. Wall, B.T., S.H. Gorissen, B. Pennings, R. Koopman, B.B. Groen, L.B. Verdijk, and L.J. van Loon, Aging Is Accompanied by a Blunted Muscle Protein Synthetic Response to Protein Ingestion. PLoS One, 2015. 10(11): p. e0140903.

9. Wall, B.T., H.M. Hamer, A. de Lange, A. Kiskini, B.B. Groen, J.M. Senden, A.P. Gijsen, L.B. Verdijk, and L.J. van Loon, Leucine co-ingestion improves post-prandial muscle protein accretion in elderly men. Clinical nutrition, 2012.

10. Rieu, I., M. Balage, C. Sornet, C. Giraudet, E. Pujos, J. Grizard, L. Mosoni, and D. Dardevet, Leucine supplementation improves muscle protein synthesis in elderly men independently of hyperaminoacidaemia. J Physiol, 2006. 575(Pt 1): p. 305-15.

11. Katsanos, C.S., H. Kobayashi, M. Sheffield-Moore, A. Aarsland, and R.R. Wolfe, A high proportion of leucine is required for optimal stimulation of the rate of muscle protein synthesis by essential amino acids in the elderly. Am J Physiol Endocrinol Metab, 2006. 291(2): p. E381-7.

12. Groen, B.B., P.T. Res, B. Pennings, E. Hertle, J.M. Senden, W.H. Saris, and L.J. van Loon, Intragastric protein administration stimulates overnight muscle protein synthesis in elderly men. American journal of physiology. Endocrinology and metabolism, 2012. 302(1): p. E52-60.

13. Holwerda, A.M., I.W. Kouw, J. Trommelen, S.L. Halson, W.K. Wodzig, L.B. Verdijk, L.J. van Loon, Physical Activity Performed in the Evening Increases the Overnight Muscle Protein Synthetic Response to Presleep Protein Ingestion in Older Men. J Nutr, 2016. 146(7): p. 1307-14.

14. Alberti, K.G. and P.Z. Zimmet, Definition, diagnosis and classification of diabetes mellitus and its complications. Part 1: diagnosis and classification of diabetes mellitus provisional report of a WHO consultation. Diabetic medicine : a journal of the British Diabetic Association, 1998.15(7):p.539-53.

15. Raben, A., A. Tagliabue, and A. Astrup, The reproducibility of subjective appetite scores. Br J Nutr, 1995. 73(4): p. 517-30.

16. Bergstrom, J., Percutaneous needle biopsy of skeletal muscle in physiological and clinical research. Scand J Clin Lab Invest, 1975. 35(7): p. 609-16. 
17. Burd, N.A., N.M. Cermak, I.W. Kouw, S.H. Gorissen, A.P. Gijsen, and L.J. van Loon, The use of doubly labeled milk protein to measure postprandial muscle protein synthesis rates in vivo in humans. J Appl Physiol (1985), 2014. 117(11): p. 1363-70.

18. van Loon, L.J., Y. Boirie, A.P. Gijsen, J. Fauquant, A.L. de Roos, A.K. Kies, S. Lemosquet, W.H. Saris, and R. Koopman, The production of intrinsically labeled milk protein provides a functional tool for human nutrition research. Journal of dairy science, 2009. 92(10): p. 4812-22.

19. Pennings, B., W.F. Pellikaan, J.M. Senden, A.M. van Vuuren, J. Sikkema, and L.J. van Loon, The production of intrinsically labeled milk and meat protein is feasible and provides functional tools for human nutrition research. Journal of dairy science, 2011. 94(9): p. 4366-73.

20. Pennings, B., Y. Boirie, J.M. Senden, A.P. Gijsen, H. Kuipers, and L.J. van Loon, Whey protein stimulates postprandial muscle protein accretion more effectively than do casein and casein hydrolysate in older men. The American journal of clinical nutrition, 2011. 93(5): p. 997-1005.

21. Buysse, D.J., C.F. Reynolds, 3rd, T.H. Monk, S.R. Berman, and D.J. Kupfer, The Pittsburgh Sleep Quality Index: a new instrument for psychiatric practice and research. Psychiatry Res, 1989. 28(2): p. 193-213.

22. Morgenthaler, T., C. Alessi, L. Friedman, J. Owens, V. Kapur, B. Boehlecke, T. Brown, A. Chesson, Jr., J. Coleman, T. Lee-Chiong, J. Pancer, T.J. Swick, C. Standards of Practice, and M. American Academy of Sleep, Practice parameters for the use of actigraphy in the assessment of sleep and sleep disorders: an update for 2007. Sleep, 2007. 30(4): p. 519-29.

23. Koopman, R., A.H. Zorenc, R.J. Gransier, D. Cameron-Smith, and L.J. van Loon, Increase in S6K1 phosphorylation in human skeletal muscle following resistance exercise occurs mainly in type II muscle fibers. Am J Physiol Endocrinol Metab, 2006. 290(6): p. E1245-52.

24. Boirie, Y., P. Gachon, S. Corny, J. Fauquant, J.L. Maubois, and B. Beaufrere, Acute postprandial changes in leucine metabolism as assessed with an intrinsically labeled milk protein. Am J Physiol, 1996. 271(6 Pt 1): p. E1083-91.

25. Wolfe, R.R. and D.L. Chinkes, Isotope tracers in metabolic research: Principles and practice of kinetic analysis. 2 ed. 2005, Hoboken, New Jersey: John Wiley and Sons, Inc.

26. Dangin, M., C. Guillet, C. Garcia-Rodenas, P. Gachon, C. Bouteloup-Demange, K. Reiffers-Magnani, J. Fauquant, O. Ballevre, and B. Beaufrere, The rate of protein digestion affects protein gain differently during aging in humans. J Physiol, 2003. 549(Pt 2): p. 635-44.

27. Konturek, P.C., T. Brzozowski, and S.J. Konturek, Gut clock: implication of circadian rhythms in the gastrointestinal tract. J Physiol Pharmacol, 2011. 62(2): p. 139-50.

28. Nair, K.S., D. Halliday, and R.C. Griggs, Leucine incorporation into mixed skeletal muscle protein in humans. Am J Physiol, 1988. 254(2 Pt 1): p. E208-13.

29. Beelen, M., M. Tieland, A.P. Gijsen, H. Vandereyt, A.K. Kies, H. Kuipers, W.H. Saris, R. Koopman, and L.J. van Loon, Coingestion of carbohydrate and protein hydrolysate stimulates muscle protein synthesis during exercise in young men, with no further increase during subsequent overnight recovery. J Nutr, 2008. 138(11): p. 2198-204.

30. Bauer, J.M., S. Verlaan, I. Bautmans, K. Brandt, L.M. Donini, M. Maggio, M.E. McMurdo, T. Mets, C. Seal, S.L. Wijers, G.P. Ceda, G. De Vito, G. Donders, M. Drey, C. Greig, U. Holmback, M. Narici, J. McPhee, E. Poggiogalle, D. Power, A. Scafoglieri, R. Schultz, C.C. Sieber, and T. Cederholm, Effects of a vitamin $D$ and leucine-enriched whey protein nutritional supplement on measures of sarcopenia in older adults, the PROVIDE study: a randomized, double-blind, placebo-controlled trial. J Am Med Dir Assoc, 2015. 16(9): p. 740-7.

31. Norton, C., C. Toomey, W.G. McCormack, P. Francis, J. Saunders, E. Kerin, and P. Jakeman, Protein Supplementation at Breakfast and Lunch for 24 Weeks beyond Habitual Intakes Increases WholeBody Lean Tissue Mass in Healthy Older Adults. J Nutr, 2016. 146(1): p. 65-9.

32. Dillon, E.L., M. Sheffield-Moore, D. Paddon-Jones, C. Gilkison, A.P. Sanford, S.L. Casperson, J. Jiang, D.L. Chinkes, and R.J. Urban, Amino acid supplementation increases lean body mass, basal muscle protein synthesis, and insulin-like growth factor-I expression in older women. J Clin Endocrinol Metab, 2009. 94(5): p. 1630-7. 
33. Zhu, K., D.A. Kerr, X. Meng, A. Devine, V. Solah, C.W. Binns, and R.L. Prince, Two-Year Whey Protein Supplementation Did Not Enhance Muscle Mass and Physical Function in Well-Nourished Healthy Older Postmenopausal Women. J Nutr, 2015. 145(11): p. 2520-6.

34. Tieland, M., O. van de Rest, M.L. Dirks, N. van der Zwaluw, M. Mensink, L.J. van Loon, and L.C. de Groot, Protein supplementation improves physical performance in frail elderly people: a randomized, double-blind, placebo-controlled trial. J Am Med Dir Assoc, 2012. 13(8): p. 720-6.

35. Kim, H.K., T. Suzuki, K. Saito, H. Yoshida, H. Kobayashi, H. Kato, and M. Katayama, Effects of exercise and amino acid supplementation on body composition and physical function in communitydwelling elderly Japanese sarcopenic women: a randomized controlled trial. J Am Geriatr Soc, 2012. 60(1): p. 16-23.

36. Leenders, M., L.B. Verdijk, L. Van der Hoeven, J. Van Kranenburg, R. Nilwik, W.K. Wodzig, J.M. Senden, H.A. Keizer, and L.J. Van Loon, Protein supplementation during resistance-type exercise training in the elderly. Med Sci Sports Exerc, 2013. 45(3): p. 542-52.

37. Murphy, C.H., T.A. Churchward-Venne, C.J. Mitchell, N.M. Kolar, A. Kassis, L.G. Karagounis, L.M. Burke, J.A. Hawley, and S.M. Phillips, Hypoenergetic diet-induced reductions in myofibrillar protein synthesis are restored with resistance training and balanced daily protein ingestion in older men. Am J Physiol Endocrinol Metab, 2015. 308(9): p. E734-43.

38. Areta, J.L., L.M. Burke, M.L. Ross, D.M. Camera, D.W. West, E.M. Broad, N.A. Jeacocke, D.R. Moore, T. Stellingwerff, S.M. Phillips, J.A. Hawley, and V.G. Coffey, Timing and distribution of protein ingestion during prolonged recovery from resistance exercise alters myofibrillar protein synthesis. J Physiol, 2013. 591(9): p. 2319-31.

39. Mamerow, M.M., J.A. Mettler, K.L. English, S.L. Casperson, E. Arentson-Lantz, M. Sheffield-Moore, D.K. Layman, and D. Paddon-Jones, Dietary protein distribution positively influences $24-\mathrm{h}$ muscle protein synthesis in healthy adults. J Nutr, 2014. 144(6): p. 876-80.

40. Farsijani, S., J.A. Morais, H. Payette, P. Gaudreau, B. Shatenstein, K. Gray-Donald, and S. Chevalier, Relation between mealtime distribution of protein intake and lean mass loss in free-living older adults of the NuAge study. Am J Clin Nutr, 2016. 104(3): p. 694-703.

41. Snijders, T., P.T. Res, J.S. Smeets, S. van Vliet, J. van Kranenburg, K. Maase, A.K. Kies, L.B. Verdijk, and L.J. van Loon, Protein Ingestion before Sleep Increases Muscle Mass and Strength Gains during Prolonged Resistance-Type Exercise Training in Healthy Young Men. J Nutr, 2015. 145(6): p. 1178-84.

42. Churchward-Venne, T.A., A.M. Holwerda, S.M. Phillips, and L.J. van Loon, What is the Optimal Amount of Protein to Support Post-Exercise Skeletal Muscle Reconditioning in the Older Adult? Sports Med, 2016. 46(9): p. 1205-12.

43. Kinsey, A.W., W.R. Eddy, T.A. Madzima, L.B. Panton, P.J. Arciero, J.S. Kim, and M.J. Ormsbee, Influence of night-time protein and carbohydrate intake on appetite and cardiometabolic risk in sedentary overweight and obese women. Br J Nutr, 2014. 112(3): p. 320-7.

44. Madzima, T.A., L.B. Panton, S.K. Fretti, A.W. Kinsey, and M.J. Ormsbee, Night-time consumption of protein or carbohydrate results in increased morning resting energy expenditure in active collegeaged men. Br J Nutr, 2014. 111(1): p. 71-7.

45. Kinsey, A.W., S.R. Cappadona, L.B. Panton, B.R. Allman, R.J. Contreras, R.C. Hickner, and M.J. Ormsbee, The Effect of Casein Protein Prior to Sleep on Fat Metabolism in Obese Men. Nutrients, 2016. 8(8).

46. Kinsey, A.W. and M.J. Ormsbee, The health impact of nighttime eating: old and new perspectives. Nutrients, 2015. 7(4): p. 2648-62. 
Protein ingestion prior to sleep 


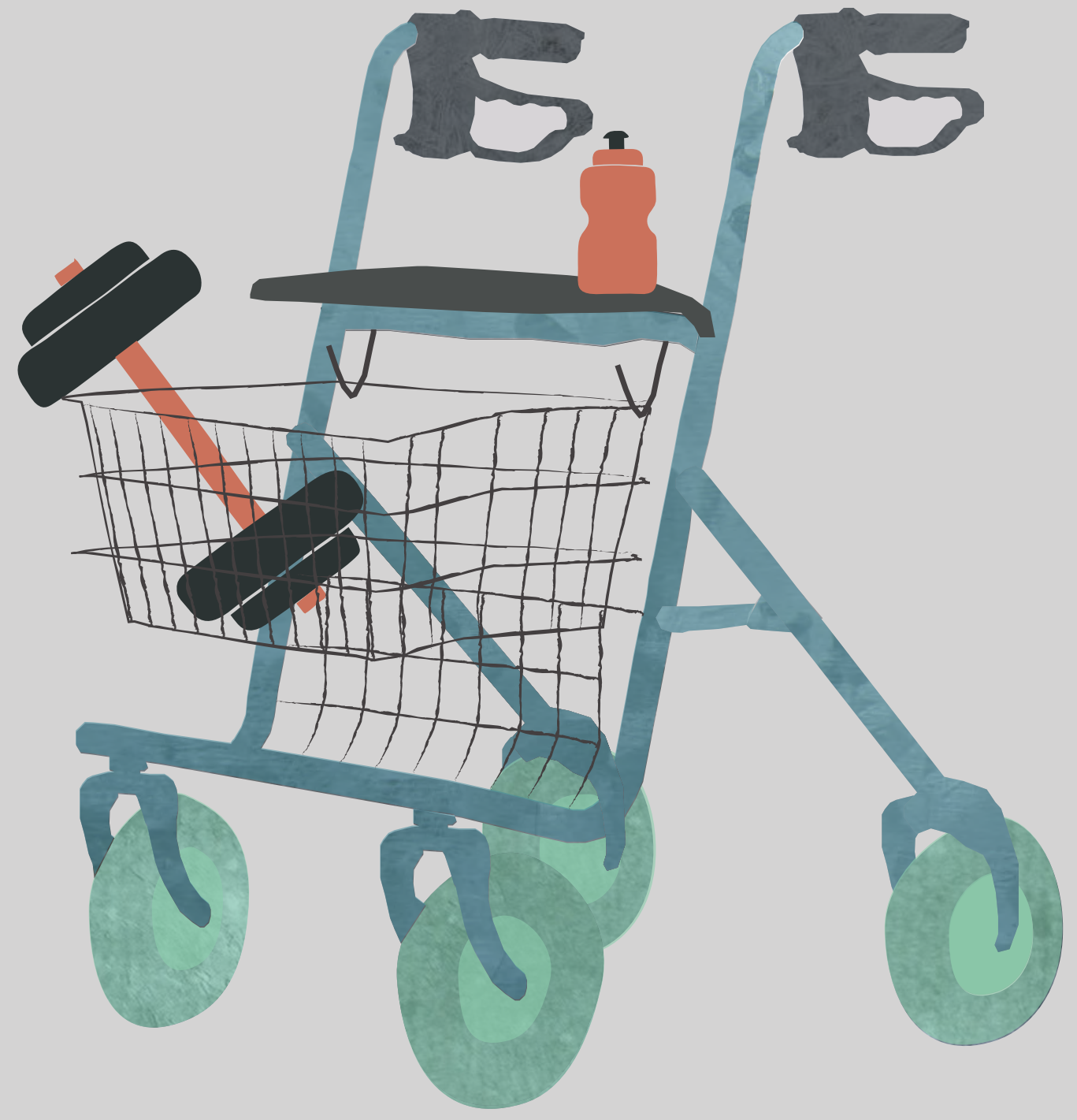




\section{CHAPTER EIGHT}

\section{PHYSICAL ACTIVITY PERFORMED IN THE EVENING INCREASES THE OVERNIGHT MUSCLE PROTEIN SYNTHETIC RESPONSE TO PRE-SLEEP PROTEIN INGESTION IN OLDER MEN}

Andrew M. Holwerda, Imre W.K. Kouw, Jorn Trommelen, Shona L. Halson, Will K.W.H. Wodzig, Lex B. Verdijk, and Luc J.C. van Loon 


\section{ABSTRACT}

Background: The age-related decline in skeletal muscle mass is partly attributed to anabolic resistance to food intake. Dietary protein ingestion before sleep could be used as a nutritional strategy to compensate for anabolic resistance.

Objective: The present study assessed whether physical activity performed in the evening can augment the overnight muscle protein synthetic response to presleep protein ingestion in older men.

Methods: In a parallel group design, 23 healthy older men (mean \pm SEM age: $71 \pm 1 \mathrm{y}$ ) were randomly assigned to ingest $40 \mathrm{~g}$ protein intrinsically labeled with $\mathrm{L}$ $\left[1-{ }^{13} \mathrm{C}\right]$-phenylalanine and $\mathrm{L}-\left[1-{ }^{13} \mathrm{C}\right]$-leucine before going to sleep with $(\mathrm{PRO}+\mathrm{EX})$ or without (PRO) performing physical activity earlier in the evening. Overnight protein digestion and absorption kinetics and myofibrillar protein synthesis rates were assessed by combining primed, continuous infusions of $\mathrm{L}-\left[\mathrm{ring}^{-2} \mathrm{H}_{5}\right]$-phenylalanine, $\mathrm{L}-\left[1-{ }^{13} \mathrm{C}\right]$-leucine, and $\mathrm{L}-$ [ring- $\left.{ }^{2} \mathrm{H}_{2}\right]$-tyrosine with the ingestion of intrinsically labeled casein protein. Muscle and blood samples were collected throughout overnight sleep.

Results: $\quad$ Protein ingested before sleep was normally digested and absorbed, with $54 \pm 2 \%$ of the protein-derived amino acids appearing in the circulation throughout overnight sleep. Overnight myofibrillar protein synthesis rates were $31 \%\left(0.058 \pm 0.002 \% \cdot h^{-1}\right.$ compared with $0.044 \pm 0.003 \% \cdot h^{-1} ; P<0.01$; based on L-[ring- $\left.{ }^{2} \mathrm{H}_{5}\right]$-phenylalanine) and $27 \%\left(0.074 \pm 0.004 \% \cdot \mathrm{h}^{-1}\right.$ compared with $0.058 \pm 0.003 \% \cdot \mathrm{h}^{-1} ; P<0.01$; based on $\mathrm{L}-\left[1{ }^{-13} \mathrm{C}\right]$-leucine) higher in the $\mathrm{PRO}+\mathrm{EX}$ than in the PRO treatment. More dietary protein-derived amino acids were incorporated into de novo myofibrillar protein during overnight sleep in PRO+EX than in PRO treatment $(0.042 \pm 0.002$ compared with $0.033 \pm 0.002 \mathrm{MPE} ; P<0.05)$.

Conclusions: Physical activity performed in the evening augments the overnight muscle protein synthetic response to presleep protein ingestion and allows more of the ingested protein-derived amino acids to be used for de novo muscle protein synthesis during overnight sleep in older men. 


\section{INTRODUCTION}

The age-related decline in muscle mass and strength, termed sarcopenia, is accompanied by impairments in functional capacity and an increased risk of developing chronic metabolic diseases[1, 2]. With no apparent differences in basal, postabsorptive muscle protein synthesis rates between young and older individuals [3, 4], many research groups have started to investigate the muscle protein synthetic response to the main anabolic stimuli, such as food intake and physical activity. This has led to the observation of an attenuated muscle protein synthetic response to food intake in older individuals $[5,6]$, a condition that has been coined anabolic resistance [7].

Effective strategies are needed to augment the muscle protein synthetic response to feeding as a means to compensate for the presence of anabolic resistance. Therefore, our laboratory and many others are investigating nutritional strategies to increase the muscle protein synthetic response to meal ingestion. Such interventions may include modulating the amount [8-10], type [11-13], and timing [14, 15] of protein ingestion, as well as combining protein ingestion with various food compounds $[16,17]$. Besides enhancing the muscle protein synthetic response to the main meals (i.e., breakfast, lunch, and dinner), we have proposed the ingestion of dietary protein before sleep with the aim of providing dietary-derived amino acids to support an increase in overnight muscle protein synthesis [18, 19]. In a proof-of-principle study, Groen et al. [19] found that enteral administration of $40 \mathrm{~g}$ protein during sleep via a nasogastric tube was followed by proper protein digestion and absorption, thereby increasing overnight amino acid availability and stimulating overnight muscle protein synthesis rates in older individuals. Therefore, we proposed dietary protein ingestion before sleep as a practical and effective strategy to improve overnight protein balance and to stimulate overnight muscle protein synthesis.

Physical activity is an important factor responsible for the degree of anabolic resistance [7, 20]. Previous work has established that physical activity or exercise can robustly increase muscle protein synthesis rates [21-24]. Moreover, physical activity augments the postprandial muscle protein synthetic response to protein feeding, thereby compensating for anabolic resistance $[9,10,22]$. Here, we hypothesized that physical activity performed during the evening would augment the overnight muscle protein synthetic response to presleep protein ingestion, allowing more of the ingested protein to be used for de novo myofibrillar protein accretion during sleep. To test our hypothesis that physical activity can augment the impact of presleep protein ingestion on overnight muscle protein synthesis, we selected 23 older men (71 $\pm 1 \mathrm{y})$ who ingested $40 \mathrm{~g}$ casein protein intrinsically labeled with $\mathrm{L}-\left[1-{ }^{13} \mathrm{C}\right]$-phenylalanine and $\mathrm{L}-[1$ ${ }^{13} \mathrm{C}$ ]-leucine before going to sleep with (PRO+EX; $\left.n=11\right)$ or without (PRO; $n=12$ ) a bout of physical activity being performed earlier in the evening. By combining the ingestion of specifically produced casein intrinsically labeled with $L-\left[1-{ }^{13} C\right]$-phenylalanine and $L-\left[1-{ }^{13} C\right]-$ leucine with the administration of primed continuous infusions of $L$ - $\left[\right.$ ring- $\left.{ }^{2} \mathrm{H}_{5}\right]$-phenylalanine, $\mathrm{L}-\left[1-{ }^{13} \mathrm{C}\right]$-leucine, and $\mathrm{L}-\left[\right.$ ring $\left.-{ }^{2} \mathrm{H}_{2}\right]$-tyrosine we were able to assess overnight protein digestion 
and amino acid absorption kinetics, whole-body protein metabolism, muscle protein synthesis rates, and the metabolic fate of the dietary protein-derived amino acids during overnight sleep. 


\section{METHODS}

\section{Subjects}

A total of 24 healthy, normoglycemic, older men $(71 \pm 1 \mathrm{y})$ were selected to participate in the present study. Subject characteristics of the study participants are presented in Table 1. Subjects were randomly assigned to the PRO+EX $(n=11)$ or the PRO $(n=12)$ presleep treatment group. One subject randomly assigned to the PRO+EX group did not complete the physical activity session and was therefore excluded from all analyses. All subjects were informed of the nature and possible risks of the experimental procedures before their written informed consent was obtained. The study was approved by the Medical Ethical Committee of the Maastricht University Medical Centre, Netherlands, and conformed to standards for the use of human subjects in research as outlined in the most recent version of the Helsinki Declaration. The study was registered at Nederlands Trial Register as NTR3885.

Table 1 | Subjects' characteristics of healthy older men who ingested $40 \mathrm{~g}$ protein prior to sleep after either completing a session of resistance exercise or remaining at rest.

\begin{tabular}{|c|c|c|c|}
\hline & PRO & PRO+EX & $P$-value \\
\hline Age, y & $70 \pm 1$ & $71 \pm 1$ & 0.48 \\
\hline Body weight, kg & $79.4 \pm 2.2$ & $79.0 \pm 2.2$ & 0.88 \\
\hline Body mass index, $\mathrm{kg} \cdot \mathrm{m}^{-2}$ & $25.7 \pm 0.6$ & $26.0 \pm 0.7$ & 0.71 \\
\hline Body fat, \% & $20.8 \pm 0.9$ & $20.9 \pm 1.3$ & 0.92 \\
\hline Lean body mass, kg & $60.6 \pm 1.4$ & $60.1 \pm 1.8$ & 0.84 \\
\hline Appendicular lean mass, kg & $26.2 \pm 0.7$ & $25.9 \pm 0.9$ & 0.78 \\
\hline Leg volume, L & $8.4 \pm 0.5$ & $8.1 \pm 0.5$ & 0.70 \\
\hline HbA1c, \% & $5.3 \pm 0.1$ & $5.5 \pm 0.1$ & 0.43 \\
\hline Basal plasma glucose, $\mathrm{mmol} \cdot \mathrm{L}^{-1}$ & $6.4 \pm 0.3$ & $5.8 \pm 0.2$ & 0.08 \\
\hline Basal plasma insulin, $\mathrm{mU} \cdot \mathrm{L}^{-1}$ & $10.6 \pm 1.3$ & $8.5 \pm 1.1$ & 0.24 \\
\hline HOMA-IR & $2.2 \pm 0.3$ & $3.1 \pm 0.4$ & 0.09 \\
\hline 1RM Leg Press, kg & - & $170 \pm 8$ & - \\
\hline 1RM Leg Extension, kg & - & $77 \pm 5$ & - \\
\hline PSQI Score & $2.3 \pm 0.3$ & $2.8 \pm 0.5$ & 0.48 \\
\hline
\end{tabular}

Values are expressed as means \pm SEMs. No differences were observed between treatment groups. HbA1c, glycated hemoglobin; PRO, $40 \mathrm{~g}$ protein in rested state; PRO+EX, $40 \mathrm{~g}$ protein after resistance-type exercise; PSQI, Pittsburg Sleep Quality Index; $1 \mathrm{RM}, 1$ repetition maximum. 


\section{Pretesting}

Participants arrived at the laboratory at $08: 30$ by car or public transport in an overnight fasted state. On arrival, body weight, body composition, and bone mineral content were measured with DXA (Discovery A; Hologic). Thereafter, all participants performed an oral-glucosetolerance test. Plasma glucose and insulin concentrations were measured to determine oral glucose intolerance and/or the presence of type 2 diabetes according to 2006 guidelines from the American Diabetes Association [25]. All subjects were screened on medical issues and were excluded if any gastrointestinal, neurologic, or renal diseases were present.

Subjects randomly assigned to the PRO+EX treatment were cleared to perform physical activity by a cardiologist who examined electrocardiograms measured at rest and during submaximal cycling (performed at $70 \%$ of age-predicted heart rate maximum). The subjects were then familiarized with the exercise equipment and physical activity protocol. Subjects first performed a 10 -min cycling warm-up at $70 \%$ of their age-predicted heart rate maximum before completing an estimation of their 1 repetition maximum (1RM) on the leg press and leg extension exercises with the use of the multiple repetitions testing procedure [26]. For each exercise, subjects performed 10 submaximal, or warm-up, repetitions to become familiarized with the equipment and to have lifting technique critiqued and corrected. Subjects then performed sets at progressively increasing loads until failing to complete a valid repetition, judged by their inability to complete the full range of motion for an exercise. Ideally, subjects failed within 3-6 repetitions during the last and heaviest set. A 2-min resting period between subsequent attempts was allowed. The pretesting and experimental trials were separated by a period of $\geq 7 \mathrm{~d}$.

\section{Diet and physical activity}

All volunteers were instructed to refrain from any exhaustive physical activity and to keep their diet as consistent as possible $48 \mathrm{~h}$ before the trial. On the day of the experiment, a standardized diet ( 3 meals and 2 snacks) was consumed that provided $9.3 \pm 0.6 \mathrm{MJ}$, with $55 \pm 2 \%$ of energy as carbohydrate, $27 \pm 2 \%$ of energy as fat, and $16 \pm 0.2 \%$ of energy as protein. The energy content of the standardized diet was based on individual energy requirements calculated with the Harris-Benedict equation and adjusted with a physical activity factor of 1.4 to ensure ample energy intake. The mean \pm SEM dietary protein intake was $1.1 \pm 0.01 \mathrm{~g} \cdot \mathrm{kg}^{-1}$ bodyweight, with $35 \pm 1 \%$ of the protein consumed at dinner.

\section{Experimental protocol}

At 17:30, participants reported to the laboratory and had Teflon catheters inserted into the antecubital veins of each arm. At 18:30 ( $t=-300 \mathrm{~min}$ ), all subjects consumed the same standardized dinner meal under supervision $(2.5 \pm 0.1 \mathrm{MJ}$, providing $62 \pm 0.2 \%$ of energy as carbohydrate, $19 \pm 0.1 \%$ of energy as fat, and $19 \pm 0.1 \%$ of energy as protein). Subjects in the PRO+EX group performed a single physical activity session between 19:45 and 20:45. After the physical activity session, and at 21:00 ( $t=-150 \mathrm{~min})$, a background blood sample was taken 
before the initiation of the tracer infusion protocol. The plasma and intracellular phenylalanine and leucine pools were primed with a single intravenous dose (priming dose) of L-[ring- $\left.{ }^{2} \mathrm{H}_{5}\right]-$ phenylalanine $\left(2.0 \mu \mathrm{mol} \cdot \mathrm{kg}^{-1}\right), \mathrm{L}$-[ring- $\left.{ }^{2} \mathrm{H}_{2}\right]$-tyrosine $\left(0.615 \mu \mathrm{mol} \cdot \mathrm{kg}^{-1}\right)$, and $\mathrm{L}-\left[1{ }^{-13} \mathrm{C}\right]$-leucine $\left(4.0 \mu \mathrm{mol} \cdot \mathrm{kg}^{-1}\right)$. Once primed, the continuous stable isotope infusion was initiated (infusion rate: $0.05 \mu \mathrm{mol} \cdot \mathrm{kg}^{-1} \cdot \mathrm{min}^{-1} \mathrm{~L}$-[ring- $\left.{ }^{2} \mathrm{H}_{5}\right]$-phenylalanine, $0.015 \mu \mathrm{mol} \cdot \mathrm{kg}^{-1} \cdot \mathrm{min}^{-1} \mathrm{~L}$-[ring- $\left.{ }^{2} \mathrm{H}_{2}\right]-$ tyrosine, and $0.1 \mu \mathrm{mol} \cdot \mathrm{kg}^{-1} \cdot \mathrm{min}^{-1} \mathrm{~L}-\left[1-{ }^{13} \mathrm{C}\right]$-leucine; Cambridge Isotopes Laboratories). Participants rested for $2.5 \mathrm{~h}$ until 23:30 ( $t=0 \mathrm{~min}$ ), when the first muscle biopsy sample was taken. Subsequently, subjects ingested within $5 \mathrm{~min}$ a $450-\mathrm{mL}$ beverage that contained $40 \mathrm{~g}$ casein intrinsically labeled with $\mathrm{L}-\left[1-{ }^{13} \mathrm{C}\right]$-phenylalanine and $\mathrm{L}-\left[1-{ }^{13} \mathrm{C}\right]$-leucine and $1.5 \mathrm{~mL}$ vanilla extract, added to improve palatability (Dr. Oetker, Amersfoort, Netherlands). Subjects went to sleep at 00:00. During the night, blood samples $(10 \mathrm{~mL})$ were taken without waking the subjects at $t=30,60,90,150,210,270,330,390,450 \mathrm{~min}$ relative to the intake of the protein drink. A second muscle biopsy was obtained from the contralateral leg $7.5 \mathrm{~h}$ later at 07:00 ( $t=450 \mathrm{~min})$.

Blood samples were collected in EDTA-containing tubes and were centrifuged at $1000 \mathrm{~g}$ for $10 \mathrm{~min}$ at $4^{\circ} \mathrm{C}$. Aliquots of plasma were frozen in liquid nitrogen and stored at $-80^{\circ} \mathrm{C}$. Muscle biopsies were obtained from the middle region of the $M$. vastus lateralis, $15 \mathrm{~cm}$ above the patella and $\sim 4 \mathrm{~cm}$ below entry through the fascia, using the percutaneous needle biopsy technique [27]. Muscle samples were dissected carefully and freed from any visible non-muscle material. The muscle samples were immediately frozen in liquid nitrogen and stored at $-80^{\circ} \mathrm{C}$ until further analysis. A graphical representation of the experimental protocol is shown in Figure 1.

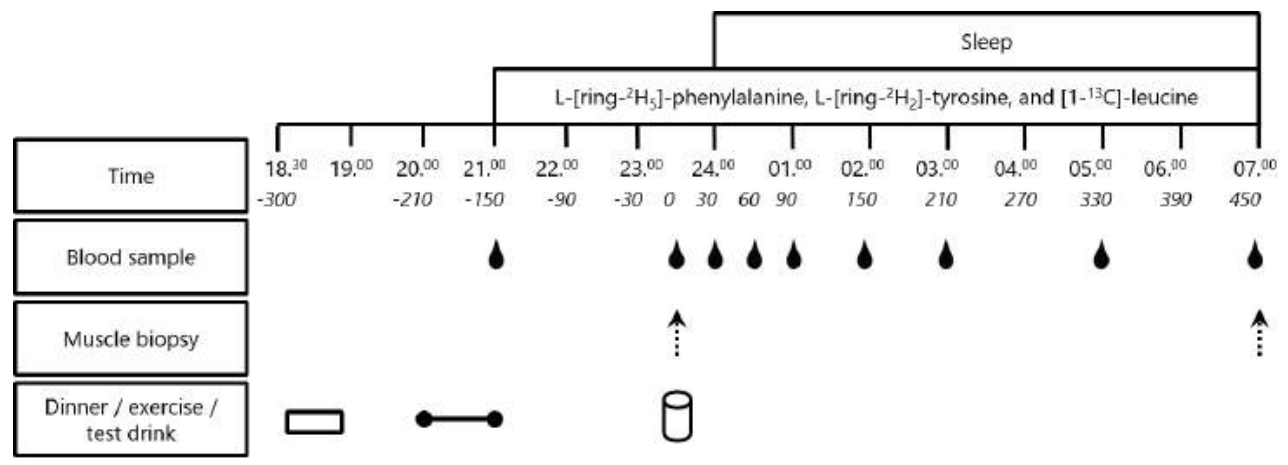

Figure 1 | Graphical representation of the experimental protocol.

\section{Physical activity protocol}

The physical activity protocol consisted of 60 min of moderate-intensity, lower-body, resistance-type exercise. After 15 min of self-paced cycling at $100 \mathrm{~W}$ with a cadence of $60-80$ rpm, subjects performed 6 sets of 10 repetitions on the horizontal leg press machine (Technogym BV) and 6 sets of 10 repetitions on the leg extension machine (Technogym BV). 
The first 2 sets of both exercises were performed at 55\% and 65\% 1RM, respectively, and sets 3-6 were performed at 75\% 1RM. Subjects were allowed to rest for 2 min between all sets.

\section{Sleep quality assessment}

The Pittsburg Sleep Quality Index (Sleep Medicine Institute, University of Pittsburgh) was used to assess habitual sleep quality during pretesting [28]. Pittsburg Sleep Quality Index scoring (global scores 0-21 points) was used to classify all subjects to very good, good, poor, or very poor sleepers. Subjects that scored $>5$ (poor sleepers) were not included in the trial. Sleep behavior during the test night was monitored with wrist activity monitors and analyzed with Actiware software (Philips Respironics). Time was scored as awake unless the following 2 conditions were met simultaneously: participant was lying down attempting to sleep and the activity counts from the monitor were sufficiently low to indicate that the participant was immobile. In addition, the start and end times of sleep were recorded throughout the trial. The following variables were derived from sleep records and activity monitors: bed time (clock time), get up time (clock time), sleep onset latency (the period of time between bedtime and sleep start), sleep duration (h), time awake/light sleep (h), sleep efficiency (sleep duration expressed as a percentage of time in bed), and wake bouts

\section{Preparation of tracer and production of intrinsically labeled protein}

The stable isotope tracers $\mathrm{L}-\left[\right.$ ring- $\left.{ }^{2} \mathrm{H}_{5}\right]$-phenylalanine, $\mathrm{L}-\left[1-{ }^{13} \mathrm{C}\right]$-leucine, and $\mathrm{L}-\left[\mathrm{ring}-{ }^{2} \mathrm{H}_{2}\right]-$ tyrosine were purchased from Cambridge Isotopes and were dissolved in $0.9 \%$ saline before infusion (Basic Pharma). Continuous intravenous infusions were performed with a calibrated IVAC 598 pump. Casein protein intrinsically labeled with $\mathrm{L}-\left[1-{ }^{13} \mathrm{C}\right]$-phenylalanine and $\mathrm{L}-\left[1-{ }^{13} \mathrm{C}\right]-$ leucine was extracted from whole milk obtained during the constant infusion of $\mathrm{L}-\left[1-{ }^{13} \mathrm{C}\right]-$ phenylalanine $\left(455 \mu \mathrm{mol} \cdot \mathrm{min}^{-1}\right)$ and $\mathrm{L}-\left[1-{ }^{13} \mathrm{C}\right]$-leucine $\left(200 \mu \mathrm{mol} \cdot \mathrm{min}^{-1}\right)$ for $96 \mathrm{~h}$ in a lactating dairy cow. The milk was collected, processed, and fractionated into the casein protein concentrate as previously described $[16,18,29]$. The $\mathrm{L}-\left[1-{ }^{13} \mathrm{C}\right]$-phenylalanine and $\mathrm{L}-\left[1-{ }^{13} \mathrm{C}\right]-$ leucine enrichments in casein protein were measured by gas chromatography-combustion isotope ratio mass spectrometry (MAT 252; Finnigan) and averaged 38.7 mole percent excess (MPE) and 9.3 MPE, respectively. The proteins met all chemical and bacteriologic specifications for human consumption

\section{Plasma analysis}

Plasma glucose and insulin concentrations were analyzed using commercially available kits (GLUC3, Roche, Ref: 05168791 190, and Immunologic, Roche, Ref: 12017547 122, respectively). Plasma amino acid concentrations and enrichments were determined by gas chromatographymass spectrometry analysis (GC-MS; Agilent 7890A GC/5975C; MSD, Wilmington, Delaware, USA). Specifically, internal standards of $\left[\mathrm{U}-{ }^{13} \mathrm{C}_{6}\right]$-leucine, $\left[\mathrm{U}-{ }^{13} \mathrm{C}_{9}{ }^{15} \mathrm{~N}\right]$-phenylalanine, and [U${ }^{13} \mathrm{C}_{9}{ }^{15} \mathrm{~N}$ ]-tyrosine were added to the plasma samples. Plasma samples were deproteinized with dry 5-sulfosalicylic acid. Free amino acids were purified using cation exchange 
chromatography (AG 50W-X8 resin, mesh size: 100-200 $\mu \mathrm{m}$, ionic form: hydrogen; Bio-Rad Laboratories, Hercules, CA). The purified amino acids were converted into tertbutyldimethylsilyl (tert-BDMS) derivatives with MTBSTFA before analysis by GC-MS. The amino acid concentrations were determined using electron impact ionization by monitoring ions at mass/charge $(\mathrm{m} / \mathrm{z}) 302$ and 308 for unlabeled and $\left[\mathrm{U}-{ }^{13} \mathrm{C}_{6}\right]$-labeled-leucine, 336 and 346 for unlabeled and $\left[\mathrm{U}-{ }^{13} \mathrm{C}_{9}{ }^{15} \mathrm{~N}\right]$ labelled phenylalanine respectively, and 466 and 476 for unlabeled and $\left[\mathrm{U}-{ }^{13} \mathrm{C}_{9}{ }^{15} \mathrm{~N}\right]$-labeled tyrosine, respectively. The plasma leucine, phenylalanine, and tyrosine ${ }^{13} \mathrm{C}$ and ${ }^{2} \mathrm{H}$ enrichments were determined using selective ion monitoring at $\mathrm{m} / \mathrm{z} 302$ and 303 for unlabeled and labeled $\left(1-{ }^{13} \mathrm{C}\right)$-leucine, respectively; $\mathrm{m} / \mathrm{z} 336,337$, and 341 for unlabeled and labeled $\left(1-{ }^{13} \mathrm{C}\right.$ and ring $\left.-{ }^{2} \mathrm{H}_{5}\right)$-phenylalanine, respectively; $\mathrm{m} / \mathrm{z} 466,467,468$, and 470 for unlabeled and labeled $\left(1-{ }^{13} \mathrm{C}\right.$, ring $-3,5-{ }^{2} \mathrm{H}_{2}$, and ring- $\left.{ }^{2} \mathrm{H}_{4}\right)$-tyrosine, respectively. Standard regression curves were applied from a series of known standard enrichment values against the measured values to assess the linearity of the mass spectrometer and to account for any isotope fractionation.

\section{Muscle analyses}

Myofibrillar protein-bound L-[ring- $\left.{ }^{2} \mathrm{H}_{5}\right]$-phenylalanine enrichments were determined by gas chromatography-mass spectrometry analysis, whereas the $\mathrm{L}-\left[1-{ }^{13} \mathrm{C}\right]$-phenylalanine and $\mathrm{L}-[1$ ${ }^{13} \mathrm{C}$-leucine enrichments were determined by gas chromatography-combustion isotope ratio mass spectrometry analysis (Trace GC Ultra, IRMS model MAT 253; Thermo Scientific). Myofibrillar protein-enriched fractions were extracted from $\sim 60 \mathrm{mg}$ of wet muscle tissue by hand-homogenizing on ice using a pestle in a standard extraction buffer $\left(7 \mu \mathrm{L} \cdot \mathrm{mg}^{-1}\right)$ [19]. The

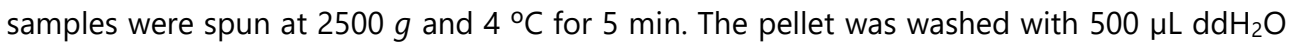
and centrifuged at $250 \mathrm{~g}$ and $4^{\circ} \mathrm{C}$ for $10 \mathrm{~min}$. The myofibrillar protein was solubilized by adding $1 \mathrm{~mL}$ of $0.3 \mathrm{M} \mathrm{NaOH}$ and heating at $50^{\circ} \mathrm{C}$ for 30 min with vortex mixing every $10 \mathrm{~min}$. Samples were centrifuged at $9500 \mathrm{~g}$ and $4^{\circ} \mathrm{C}$ for $5 \mathrm{~min}$, the supernatant containing the myofibrillar proteins was collected and the collagen pellet was discarded. Myofibrillar proteins were precipitated by the addition of $1 \mathrm{~mL}$ of $1 \mathrm{M} \mathrm{PCA}$ and spinning at $700 \mathrm{~g}$ and $4{ }^{\circ} \mathrm{C}$ for 10 min. The myofibrillar protein was washed twice with $70 \%$ ethanol and hydrolyzed overnight in $2 \mathrm{~mL}$ of $6 \mathrm{M} \mathrm{HCL}$ at $110^{\circ} \mathrm{C}$. The free amino acids from the hydrolyzed myofibrillar protein pellet were dried under a nitrogen stream while being heated to $120^{\circ} \mathrm{C}$. The free amino acids were then dissolved in $25 \%$ acetic acid solution, passed over cation exchange AG 50W-X8 resin columns (mesh size: 100-200, ionic form: hydrogen; Bio-Rad Laboratories, Hercules, CA), and eluted with $2 \mathrm{M} \mathrm{NH}_{4} \mathrm{OH}$. The purified amino acids were divided into 2 aliquots to determine the $\mathrm{L}$-[ring- $\left.{ }^{2} \mathrm{H}_{5}\right]$-phenylalanine enrichments by $\mathrm{GC}-\mathrm{MS}$ analysis and the $\mathrm{L}-\left[1-{ }^{13} \mathrm{C}\right]-$ phenylalanine and $\mathrm{L}-\left[1-{ }^{13} \mathrm{C}\right]$-leucine enrichments by gas chromatography-combustionisotope ratio mass spectrometry (GC-C-IRMS) analysis. To reduce the signal-to-noise ratio during GC-MS analysis at low tracer enrichments, the phenylalanine from the myofibrillar protein hydrolysates was enzymatically decarboxylated to $\beta$-phenylethylamine prior to derivatization with MTBSTFA. To determine myofibrillar protein $\mathrm{L}-\left[1-{ }^{13} \mathrm{C}\right]$-phenylalanine and $\mathrm{L}-$ $\left[1-{ }^{13} \mathrm{C}\right]$-leucine enrichments by GC-C-IRMS analysis, the purified amino acids were converted 
into $\mathrm{N}$-ethoxycarbonyl ethyl ester derivatives with ethyl chloroformate (ECF). The derivatives were then measured by GC-C-IRMS (Finnigan MAT 253, Bremen, Germany) using a DB5-MScolumn (no. 122-5532; Agilent J+W scientific GC Column, GC Isolink) and monitoring of ion masses 44, 45 and 46. Standard regression curves were applied to assess the linearity of the mass spectrometer and to account for isotopic fractionation.

\section{Calculations}

Ingestion of L-[1-13 C]-phenylalanine-labeled protein, intravenous infusion of L-[ring- $\left.{ }^{2} \mathrm{H}_{5}\right]-$ phenylalanine, and blood sample enrichment values were used to assess whole-body amino acid kinetics in non-steady state conditions. Total, exogenous, and endogenous phenylalanine rate of appearance $\left(R_{a}\right)$ and rate of plasma availability of dietary protein-derived phenylalanine that appeared in the systemic circulation as a fraction of total amount of phenylalanine that was ingested were calculated with modified Steele's equations [30-32].

These parameters were calculated as follows:

$$
\begin{aligned}
& \text { Total } R_{a}=\frac{F_{i v}-\left[p V \cdot C(t) \cdot \frac{d E_{i v}}{d t}\right]}{E_{i v}(t)} \\
& \operatorname{Exo} R_{a}=\frac{\operatorname{Total} R_{a} \cdot E_{p o}(t)+\left[p V \cdot C(t) \cdot \frac{d E_{p o}}{d t}\right]}{E_{p r o t}} \\
& \text { Endo } R_{a}=\operatorname{Total} R_{a}-\operatorname{Exo} R_{a}-F_{i v} \\
& \text { Pheplasma }=\left(\frac{\mathrm{AUC}_{\text {ExoRa }}}{\text { Phe }_{\text {prot }}}\right) \cdot 100
\end{aligned}
$$

where $F_{i v}$ is the intravenous tracer infusion rate $\left(\mu \mathrm{mol} \cdot \mathrm{kg}^{-1} \cdot \mathrm{min}^{-1}\right), p V\left(0.125 \mathrm{~L} \cdot \mathrm{kg}^{-1}\right)$ is the distribution volume for phenylalanine (3). $C(t)$ is the mean plasma phenylalanine concentration between 2 consecutive time points. $d E_{i v} / d t$ represents the time-dependent variations of plasma phenylalanine enrichment derived from the intravenous tracer and $E_{i v}(t)$ is the mean plasma phenylalanine enrichment from the intravenous tracer between 2 consecutive time points. $E x o R_{a}$ represents the plasma entry rate of dietary phenylalanine, $E_{p o}(t)$ is the mean plasma phenylalanine enrichment for the ingested tracer, $d E_{p o} / d t$ represents the time-dependent variations of plasma phenylalanine enrichment derived from the oral tracer and $E_{\text {prot }}$ is the L$\left[1-{ }^{13} \mathrm{C}\right]$-phenylalanine enrichment in the dietary protein. Phe plasma $_{\text {is }}$ the percentage of ingested dietary phenylalanine that becomes available in the plasma and is calculated using Phe Prot $_{\text {and }}$ $A U C_{\text {ExoRa. }}$. Phe $e_{\text {Prot }}$ is the amount of dietary phenylalanine ingested and $A U C_{\text {ExoRa }}$ represents the area under the curve (AUC) of ExoR $\mathrm{a}_{\mathrm{a}}$ which corresponds to the amount of dietary phenylalanine that appeared in the blood over a $7.5 \mathrm{~h}$ period following ingestion.

Total rate of disappearance of phenylalanine (Total $R_{d}$ ) equals the rate of phenylalanine hydroxylation (first step in phenylalanine oxidation) and utilization for protein synthesis. This parameter is calculated as follows:

$$
\mathrm{R}_{\mathrm{d}}=\operatorname{TotalR}_{\mathrm{a}}-\mathrm{pV} \cdot \frac{\mathrm{dC}}{\mathrm{dt}}
$$


Whole body phenylalanine oxidation can be determined from the conversion (hydroxylation) of $\mathrm{L}$-[ring- $\left.{ }^{2} \mathrm{H}_{5}\right]$-phenylalanine to $\mathrm{L}$ - $\left[\mathrm{ring}^{-}{ }^{2} \mathrm{H}_{4}\right]$-tyrosine. The rate of phenylalanine hydroxylation was calculated by using the following formula:

$$
\mathrm{Phe}_{\text {hydroxylation }}=\operatorname{Tyr} R_{a} \cdot \frac{\mathrm{E}_{\mathrm{t}}(\mathrm{t})}{\mathrm{E}_{\mathrm{p}}(\mathrm{t})} \cdot \frac{\mathrm{PheR}_{d}}{\left(\mathrm{~F}_{\mathrm{iv}}+\mathrm{PheR}_{d}\right)}
$$

Because whole body $R_{d}$ comprises the rate of phenylalanine disappearance from the free amino acid pool in the blood due to protein synthesis (S) and oxidation, whole body protein synthesis can be calculated as Rd minus Phe hydroxylation (oxidation). TyrR $\mathrm{R}_{a}$ represents the rate of appearance of $\mathrm{L}$-[ring- ${ }^{2} \mathrm{H}_{4}$ ]-tyrosine; $\mathrm{Et}(\mathrm{t})$ and $\mathrm{Ep}(\mathrm{t})$ are the $\mathrm{L}$-[ring- ${ }^{2} \mathrm{H}_{4}$ ]-tyrosine and $\mathrm{L}$-[ring${ }^{2} \mathrm{H}_{5}$ ]-phenylalanine enrichments in plasma between 2 consecutive time points, respectively and $F_{i v}$ is the infusion rate of phenylalanine. Whole body protein synthesis was calculated using:

$$
S=R_{d}-\text { Phe }_{\text {hydroxylation }}
$$

Whole body protein net balance was calculated as AUC over the $7.5 \mathrm{~h}$ post-prandial phase using whole body protein synthesis minus endogenous Ra.

$$
\text { Phe } e_{\text {net balance }}=S-\text { Endo }_{R} a
$$

Myofibrillar protein fractional synthetic rate (FSR) was calculated with the standard precursorproduct method. The FSR of myofibrillar protein was calculated by dividing the increment in enrichment in the product, i.e. protein-bound $\mathrm{L}-\left[1-{ }^{13} \mathrm{C}\right]$-leucine or $\mathrm{L}-\left[\mathrm{rin}^{-}{ }^{2} \mathrm{H}_{5}\right]$-phenylalanine, by the enrichment of the respective precursor amino acid enrichments (i.e., plasma free amino acids). Weighted mean plasma L-[ring- $\left.{ }^{2} \mathrm{H}_{5}\right]$-phenylalanine and $\mathrm{L}-\left[1-{ }^{13} \mathrm{C}\right]$-leucine enrichments were used as the preferred precursor pools to estimate myofibrillar protein fractional synthesis rates from the continuously infused $\mathrm{L}$-[ring- $\left.{ }^{2} \mathrm{H}_{5}\right]$-phenylalanine, and $\mathrm{L}-\left[1-{ }^{13} \mathrm{C}\right]$-leucine tracers. Consequently, myofibrillar FSR was calculated as follows (4):

$$
F S R=\frac{\mathrm{E}_{B}(t)-\mathrm{E}_{B}(0)}{\int_{t_{0}}^{t_{1}} \mathrm{E}_{F}(t) \cdot \Delta t} \cdot 100
$$

where $E_{B(t)}-E_{B(0)}$ represents muscle protein bound L-[ring- $\left.{ }^{2} H_{5}\right]$-phenylalanine or $L-\left[1-{ }^{13} C\right]$ leucine. $E_{F}$ represent the average plasma $L$-[ring- $\left.{ }^{2} \mathrm{H}_{5}\right]$-phenylalanine or $L-\left[1-{ }^{13} \mathrm{C}\right]$-leucine enrichment during the tracer incorporation period. $\Delta t$ indicates the time interval $(\mathrm{h})$ between biopsies.

\section{Statistics}

All data are expressed as means \pm SEMs. Baseline characteristics between groups were compared with a Student's unpaired $t$ test. A 2-factor repeated-measures ANOVA (time $\times$ treatment) with time as within-subjects factor and treatment group as between-subjects factor was performed for the analysis of plasma amino acid concentrations, plasma tracer enrichments, whole-body protein kinetics, and glucose and insulin concentrations. The analysis was performed for the period that started at the time of protein administration, between $t=0$ and $450 \mathrm{~min}$. On identification of a statistically significant time $\times$ treatment 
interaction, Bonferroni post hoc testing was used to identify time points in which the treatments differed. Non-time-dependent variables (i.e., whole-body protein metabolism, FSR values, $\mathrm{L}-\left[1-{ }^{13} \mathrm{C}\right]$-phenylalanine myofibrillar enrichments) were compared between treatment groups with the use of Student's unpaired $t$ test. Statistical significance was set at $P<0.05$. All calculations were performed with SPSS 21.0 (SPSS Inc.) 


\section{RESULTS}

\section{Plasma analysis}

Overnight plasma glucose (Figure 2A) and insulin (Figure 2B) concentrations after presleep protein ingestion did not differ between the PRO and $\mathrm{PRO}+\mathrm{EX}$ groups $(P \geq 0.05)$. Plasma insulin concentrations increased after protein ingestion in both treatments, reaching peak concentrations after $30 \mathrm{~min}$.

Plasma concentrations of phenylalanine (Figure 3A), leucine (Figure 3B), and tyrosine (Figure 3C) increased over time, with peak concentrations being reached 210 min after protein ingestion, which did not differ between treatments $(P \geq 0.05)$.
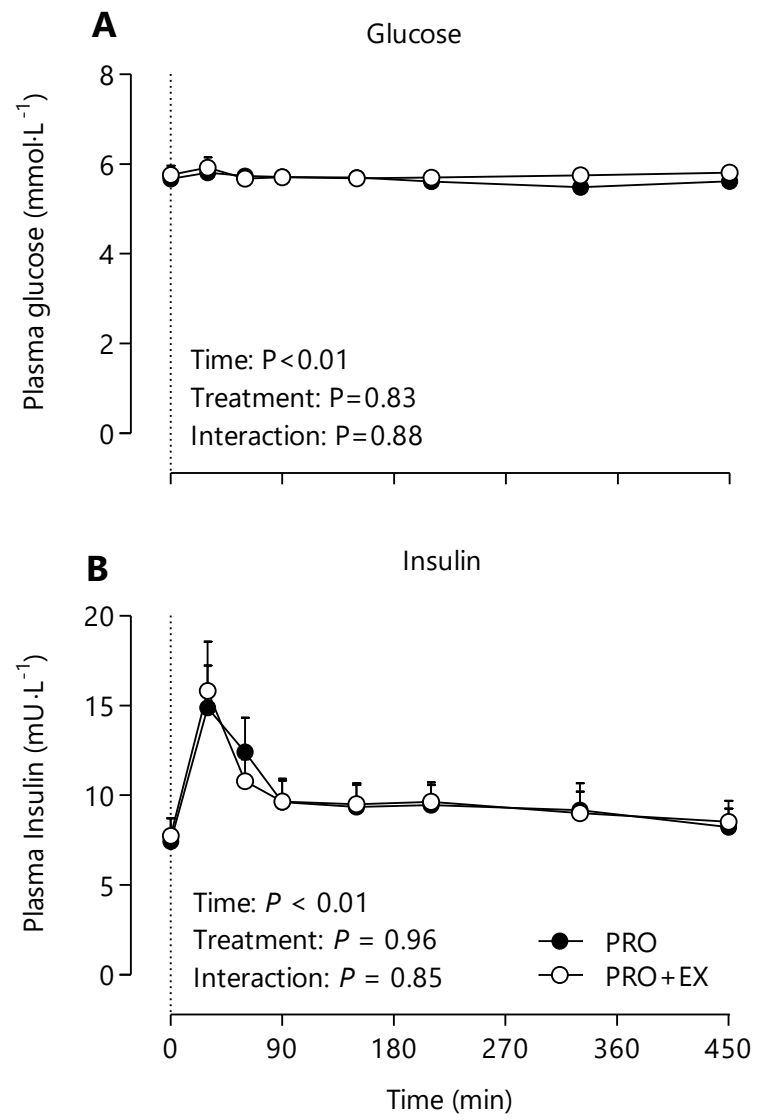

Figure 2 | Overnight plasma glucose $\left(\mathbf{A}, \mathrm{mmol} \cdot \mathrm{L}^{-1}\right)$ and insulin concentrations $\left(\mathbf{B}, \mathrm{mU} \cdot \mathrm{L}^{-1}\right)$ following pre-sleep protein ingestion with (PRO $+\mathrm{EX} ; n=11$ ) and without (PRO; $n=12$ ) prior exercise in older men. The data were analyzed with a two-way repeated-measures (treatment $x$ time) ANOVA. 

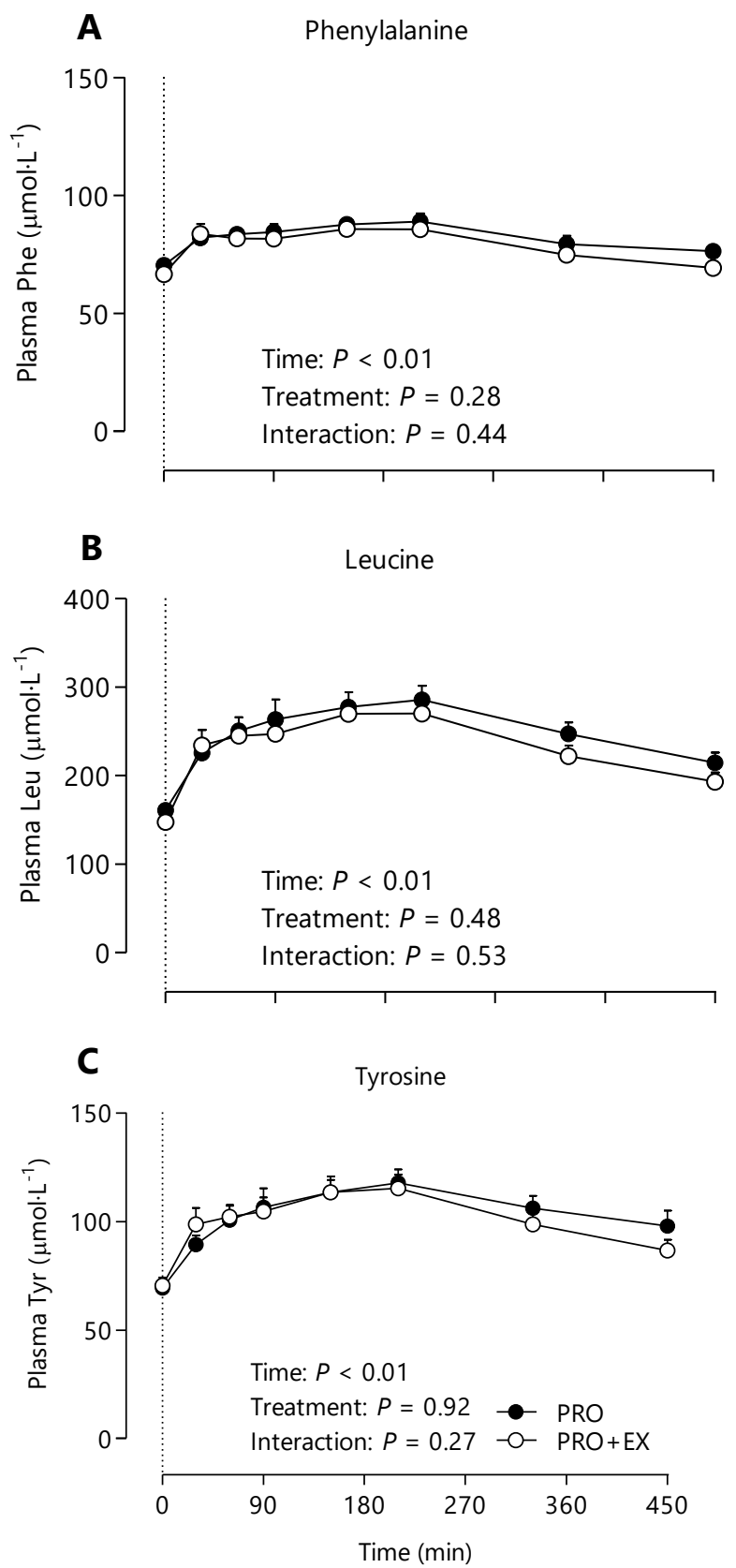

Figure 3 | Overnight plasma concentrations of phenylalanine $(\mathbf{A})$, leucine $(\mathbf{B})$, and tyrosine $(\mathbf{C})$ after PRO+EX $(n=$ $11)$ or PRO $(n=12)$ presleep treatment in older men. The dotted line represents the ingestion of the beverage. Values are means \pm SEMs. Data were analyzed with a 2 -factor repeated-measures (treatment $\times$ time) ANOVA. PRO, $40 \mathrm{~g}$ protein in rested state; $\mathrm{PRO}+\mathrm{EX}, 40 \mathrm{~g}$ protein after resistance-type exercise. 
Plasma enrichments from infused L-[ring- $\left.{ }^{2} \mathrm{H}_{5}\right]$-phenylalanine (Figure $4 \mathrm{~A}$ ), infused and ingested $\mathrm{L}-\left[1-{ }^{13} \mathrm{C}\right]$-leucine (Figure 2B), and ingested $\mathrm{L}-\left[1-{ }^{13} \mathrm{C}\right]$-phenylalanine (Figure $4 \mathrm{C}$ ) did not differ between treatments before ingesting the protein $(t=0 \mathrm{~min} ; P \geq 0.05)$. Plasma $\mathrm{L}$-[ring$\left.{ }^{2} \mathrm{H}_{5}\right]$-phenylalanine enrichments declined after protein ingestion; plasma $\mathrm{L}-\left[1-{ }^{13} \mathrm{C}\right]$-leucine enrichment increased before reaching a steady state for the duration of the trial. After protein ingestion, plasma $\mathrm{L}-\left[1-{ }^{13} \mathrm{C}\right]$-phenylalanine enrichments, originating from the ingested protein, increased in both groups, reaching maximal values at $t=210 \mathrm{~min}$ in the PRO group and $t=$ 150 min in the PRO+EX group and remained elevated for the duration of the night. A main effect for time was detected across groups $(P<0.05)$, but no significant interaction effects were found for treatment $\times$ time. 


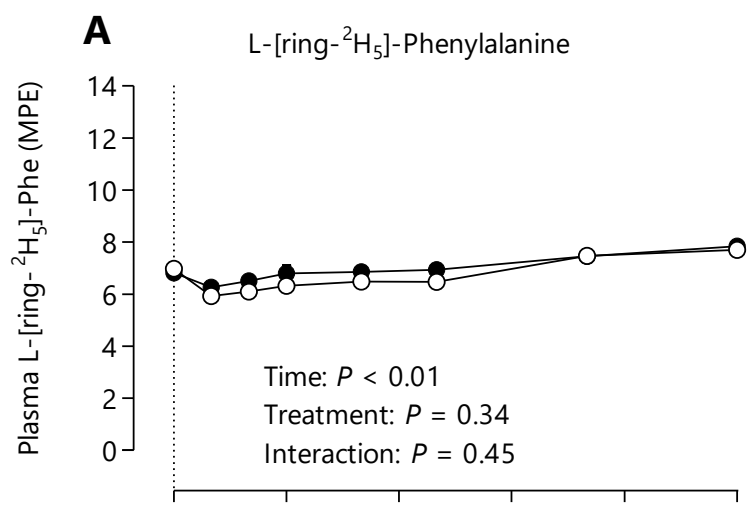

B

$$
\mathrm{L}-\left[1-{ }^{13} \mathrm{C}\right] \text {-leucine }
$$

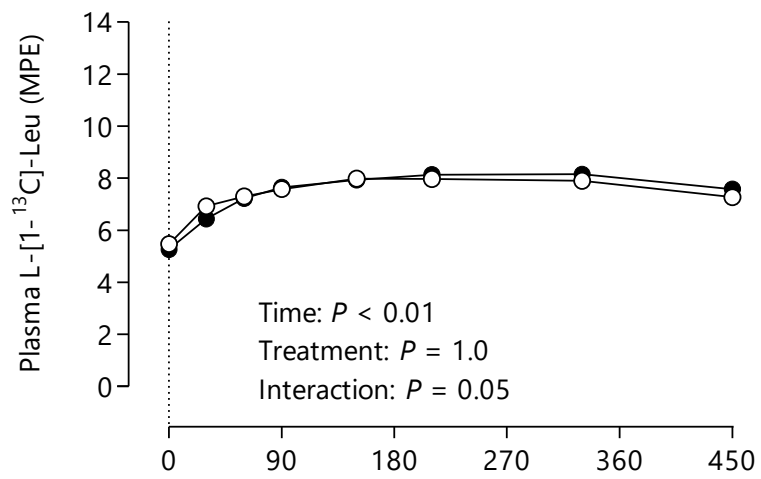

\section{C $\left[1-{ }^{13} \mathrm{C}\right]-$ Phenylalanine}

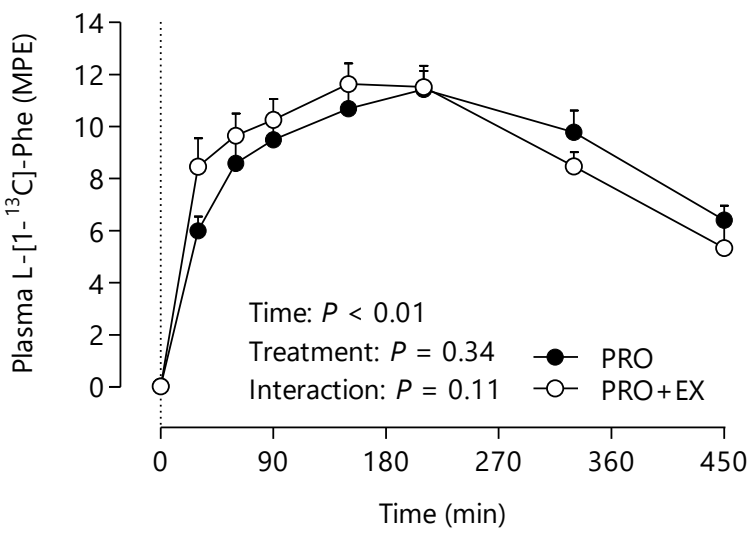

Figure 4 | Overnight plasma L-[ring $\left.-{ }^{2} \mathrm{H}_{5}\right]$-phenylalanine $(\mathbf{A}), \mathrm{L}-\left[1-{ }^{13} \mathrm{C}\right]$-leucine $(\mathbf{B})$, and L- $\left[1-{ }^{13} \mathrm{C}\right]$-phenylalanine (C) enrichments after PRO+EX $(n=11)$ or PRO $(n=12)$ presleep treatment in older men. The dotted line represents the ingestion of the beverage. Values are means \pm SEMs. Data were analyzed with 2 -factor repeated-measures (treatment $\times$ time) ANOVA. MPE, mole percent excess; PRO, $40 \mathrm{~g}$ protein in rested state; $P R O+E X, 40 \mathrm{~g}$ protein after resistance-type exercise. 


\section{Whole-body amino acid kinetics}

Exogenous phenylalanine Ra (Figure 5A) increased after protein ingestion with peak rates being reached at $t=150 \mathrm{~min}$ in the $\mathrm{PRO}$ and $\mathrm{PRO}+\mathrm{EX}$ treatment groups $(P \geq 0.05)$. As a result of increased exogenous $\mathrm{Ra}$, endogenous phenylalanine Ra (Figure 5B) declined after protein ingestion in both groups, with no differences detected $(P \geq 0.05)$. The ingested dietary proteinbound phenylalanine that appeared in the circulation over the entire $7.5-\mathrm{h}$ postprandial period did not differ between groups $(P \geq 0.05)$ and was $54 \pm 2 \%$ overall.
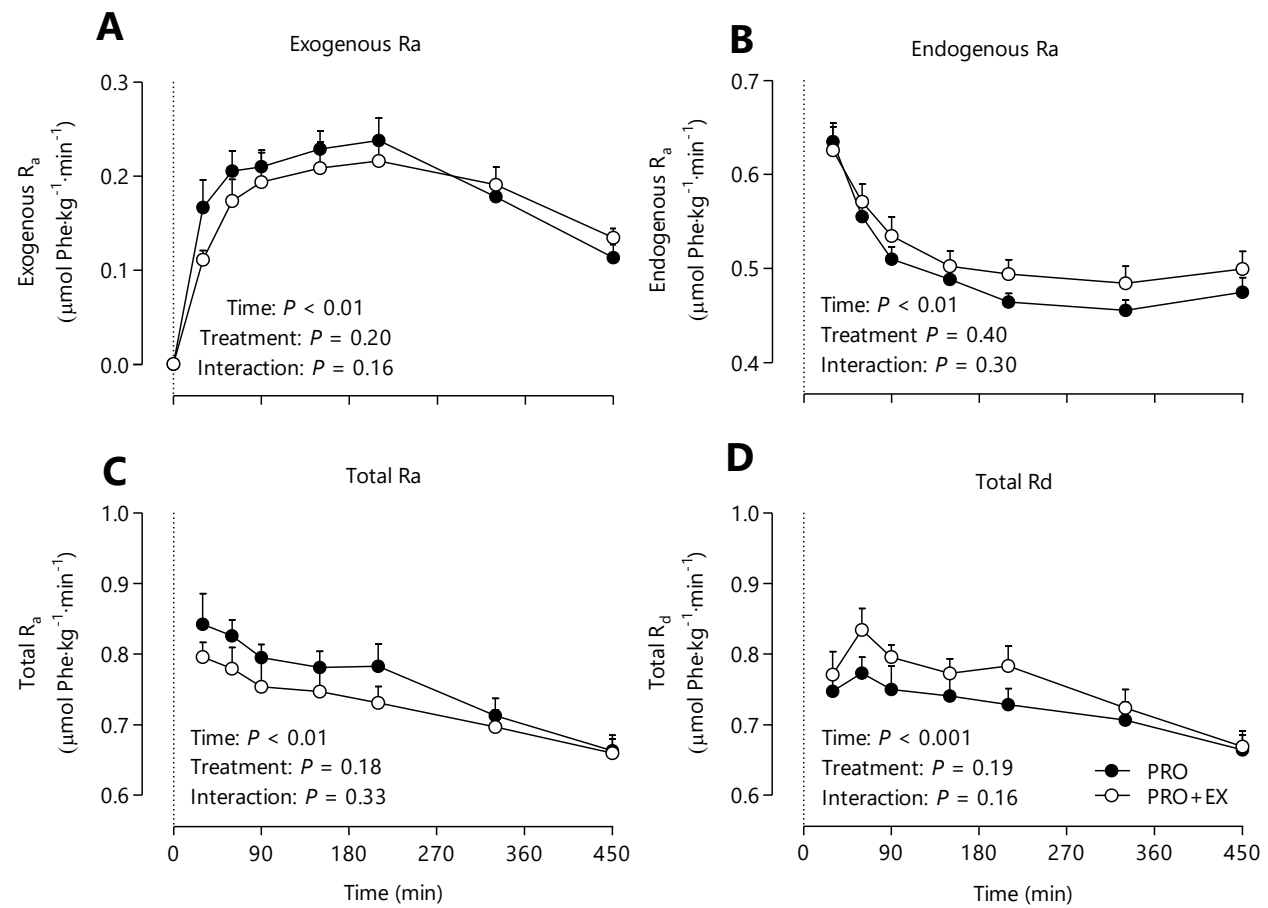

Figure 5 | Exogenous phenylalanine $R_{a}(\mathbf{A})$, endogenous phenylalanine $R_{a}(\mathbf{B})$, total phenylalanine $R_{a}(\mathbf{C})$, and total phenylalanine $\mathrm{R}_{d}(\mathbf{D})$ after PRO+EX $(n=11)$ or PRO $(n=12)$ presleep treatment in older men. Values are means \pm SEMs. Data were analyzed with 2 -factor repeated-measures (treatment $\times$ time) ANOVA. PRO, $40 \mathrm{~g}$ protein in rested state; $P R O+E X, 40 \mathrm{~g}$ protein after resistance-type exercise; $R_{a}$, rate of appearance; $R_{d}$, rate of disappearance. 
Protein ingestion before sleep resulted in positive overnight whole-body protein net balance (Figure 6), with no differences observed between treatment groups ( $P \geq 0.05)$. Furthermore, physical activity did not appear to further influence any other variables of whole-body protein metabolism: synthesis rates $(P \geq 0.05)$, breakdown rates $(P \geq 0.05)$, oxidation rates $(P \geq 0.05)$.

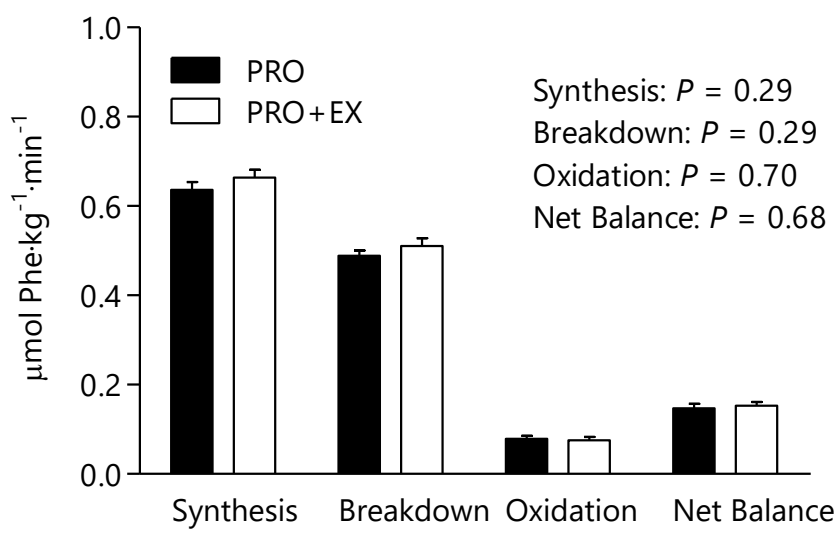

Figure 6 | Calculated rates of whole-body protein synthesis, breakdown, oxidation, and net protein balance after $\mathrm{PRO}+\mathrm{EX}(n=11)$ or PRO $(n=12)$ presleep treatment in older men. Values are means \pm SEMs. Data were analyzed with an unpaired Student's $t$ test. No significant differences were detected. PRO, $40 \mathrm{~g}$ protein in rested state; $\mathrm{PRO}+\mathrm{EX}, 40 \mathrm{~g}$ protein after resistance-type exercise.

\section{Myofibrillar fractional synthesis rates and protein-bound enrichments}

Myofibrillar L-[ring- $\left.{ }^{2} \mathrm{H}_{5}\right]$-phenylalanine and $\mathrm{L}-\left[1-{ }^{13} \mathrm{C}\right]$-leucine enrichments were measured in muscle samples collected immediately before protein ingestion and immediately after waking. The mean postprandial increase in myofibrillar protein-bound $\mathrm{L}$-[ring- ${ }^{2} \mathrm{H}_{5}$ ]-phenylalanine and $\mathrm{L}-\left[1-{ }^{13} \mathrm{C}\right]$-leucine enrichments was $0.0230 \pm 0.0015$ compared with $0.0294 \pm 0.0010 \mathrm{MPE}$ and $0.0334 \pm 0.0020$ compared with $0.0417 \pm 0.0018$ MPE in PRO compared with PRO +EX, respectively $(P<0.05)$. Myofibrillar protein FSR (in $\% \cdot \mathrm{h}^{-1}$ ) was calculated with $\mathrm{L}$-[ring- $\left.{ }^{2} \mathrm{H}_{5}\right]$ phenylalanine plasma (Figure 7A) and muscle protein-bound enrichments and with $\mathrm{L}-\left[1-{ }^{13} \mathrm{C}\right]-$ leucine (Figure 7B) plasma and muscle protein-bound enrichments. PRO+EX resulted in greater stimulation of overnight myofibrillar FSR than PRO, calculated from L-[ring- $\left.{ }^{2} \mathrm{H}_{5}\right]$ phenylalanine $(P<0.05)$ and $\mathrm{L}-\left[1-{ }^{13} \mathrm{C}\right]$-leucine $(P<0.05)$. Overnight FSR was $31 \%$ and $27 \%$ higher in the $\mathrm{PRO}+\mathrm{EX}$ treatment group than in the PRO treatment group, based on L-[ring- $\left.{ }^{2} \mathrm{H}_{5}\right]-$ phenylalanine and L-[1-13 C]-leucine infusion, respectively. Myofibrillar L-[1-13 C]-phenylalanine (Figure 8) protein-bound enrichment (MPE) was 28\% higher after the ingestion of protein intrinsically labeled with $L-\left[1-{ }^{13} \mathrm{C}\right]$-phenylalanine in the $\mathrm{PRO}+\mathrm{EX}$ treatment group than in the PRO treatment group $(P<0.05)$ 


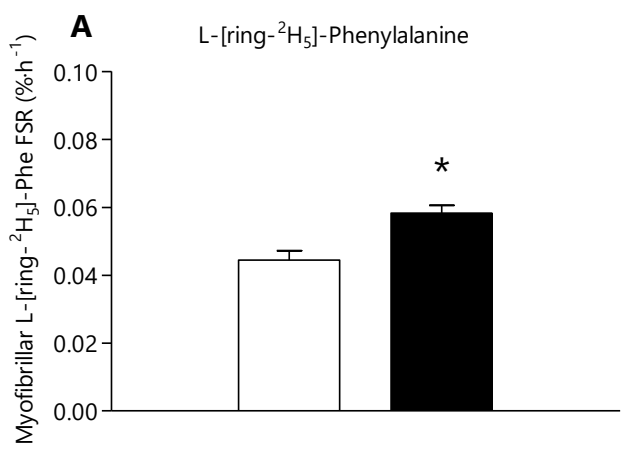

$0-7.5 \mathrm{~h}$

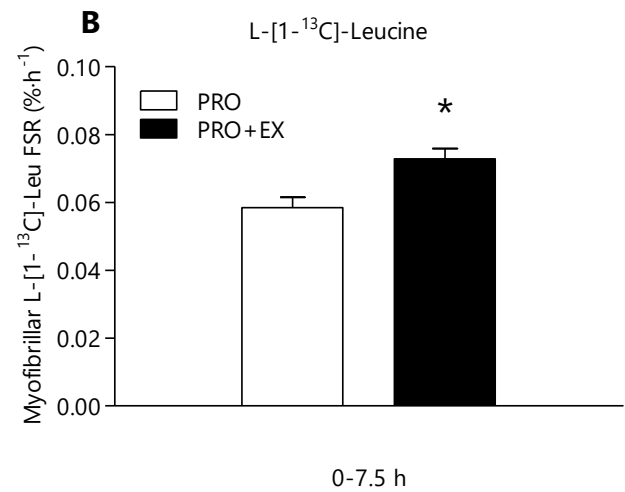

0-7.5 h

Figure 7 | Overnight myofibrillar protein FSRs after PRO+EX $(n=11)$ or PRO $(n=12)$ presleep treatment in older men as calculated with $\mathrm{L}-\left[\right.$ ring $\left.-{ }^{2} \mathrm{H}_{5}\right]$-phenylalanine $(\mathbf{A})$ or $\mathrm{L}-\left[1-{ }^{13} \mathrm{C}\right]$-leucine $(\mathbf{B})$ as tracer. Values are means $\pm \mathrm{SEMs}$. Data were analyzed with an unpaired Student's $t$ test. * Different from $P R O, P<0.01$. FSR, fractional synthetic rate; $\mathrm{PRO}, 40 \mathrm{~g}$ protein in rested state; PRO+EX, $40 \mathrm{~g}$ protein after resistance-type exercise.

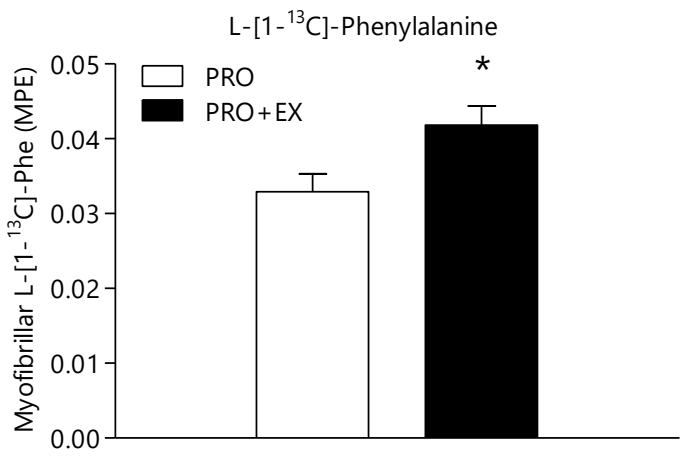

$7.5 \mathrm{~h}$

Figure 8 | Overnight L- $\left[1-{ }^{13} \mathrm{C}\right]$-phenylalanine incorporation into myofibrillar protein after PRO $+\mathrm{EX}(n=11)$ or PRO $(n=12)$ presleep treatment with intrinsically labeled $\mathrm{L}-\left[1-{ }^{13} \mathrm{C}\right]$-phenylalanine in older men. Values are means \pm SEMs. Data were analyzed with an unpaired Student's $t$ test. * Different from $P R O, P<0.01$. MPE, mole percent excess; PRO, $40 \mathrm{~g}$ protein in rested state; $\mathrm{PRO}+\mathrm{EX}, 40 \mathrm{~g}$ protein after resistance-type exercise. 


\section{Sleep data}

Sleep onset latency and sleep efficiency data collected during the overnight sleep test are displayed in Table 2. Sleep onset latency, a measure of the time taken to fall asleep, was $6 \min 12 \mathrm{~s} \pm 2 \mathrm{~min} 4 \mathrm{~s}$ compared with $7 \mathrm{~min} \pm 2 \min 9 \mathrm{~s}$ in the PRO compared with the PRO $+\mathrm{EX}$ treatment groups, respectively $(P \geq 0.05)$. The amount of time that subjects spent awake or in light sleep throughout the sleeping period was $1 \mathrm{~h} 12 \mathrm{~s} \pm 11 \mathrm{~min} 28 \mathrm{~s}$ compared with $38 \min 15 s \pm 6$ min45 $s$ in the PRO and PRO+EX treatment groups, respectively $(P \geq 0.05)$. Sleep efficiency, a measure of sleep quality throughout the night, also did not differ between treatment groups $(81.4 \pm 3.1 \%$ compared with $82.3 \pm 8.7 \%$ in the PRO and PRO+EX groups, respectively; $P \geq 0.05)$.

Table 2 | Sleep quality data collected with wrist activity monitors worn during sleep

\begin{tabular}{lccc}
\hline & PRO & PRO+EX & $P$-value \\
\hline Bed Time, hh:mm & $23: 55$ & $23: 55$ & 0.99 \\
Get up Time, hh:mm & $7: 01$ & $7: 04$ & 0.64 \\
Sleep onset latency, mm:ss & $06: 12 \pm 02: 04$ & $07: 00 \pm 02: 09$ & 0.81 \\
Sleep Duration, hh:mm & $05: 46 \pm 00: 14$ & $05: 53 \pm 00: 37$ & 0.75 \\
Time Awake/Light Sleep, hh:mm & $01: 00 \pm 00: 11$ & $00: 38 \pm 00: 06$ & 0.13 \\
Sleep Efficiency, \% & $81.4 \pm 3.1$ & $82.3 \pm 8.7$ & 0.83 \\
Wake Bouts & $17 \pm 2$ & $12 \pm 2$ & 0.09 \\
\hline
\end{tabular}

Values are expressed as means \pm SEM. PRO treatment, $n=10 ; \mathrm{PRO}+\mathrm{EX}$ treatment, $n=8$. No significant differences were observed between treatment groups. 


\section{DISCUSSION}

In the present study, we assessed whether physical activity performed in the evening after a full day of standardized dietary intake and physical activity could augment the overnight muscle protein synthetic response to presleep protein ingestion in older men. We observed that protein ingested before sleep was normally digested and absorbed, with $54 \pm 2 \%$ of the ingested protein-derived amino acids appearing in the circulation throughout overnight sleep. Myofibrillar protein synthesis rates during overnight sleep were substantially higher when physical activity was performed earlier that evening, with $28 \%$ more of the presleep dietary protein-derived amino acids being directed toward de novo overnight muscle protein synthesis.

We administered a primed, continuous intravenous infusion of $\mathrm{L}$-[ring- ${ }^{2} \mathrm{H}_{5}$ - phenylalanine and $\mathrm{L}-\left[1-{ }^{13} \mathrm{C}\right]$-leucine throughout the night and provided all participants with $40 \mathrm{~g}$ casein protein intrinsically labeled with $\mathrm{L}-\left[1-{ }^{13} \mathrm{C}\right]$-phenylalanine before sleep. With this experimental protocol, we were able to assess overnight protein digestion and amino acid absorption kinetics, wholebody protein metabolism, myofibrillar protein synthesis, and the specific utilization of dietary protein-derived amino acids for de novo muscle protein synthesis [16, 33]. On protein ingestion, we observed a rapid rise in circulating plasma amino acids (Figure 3 ) and L-[1- $\left.{ }^{13} \mathrm{C}\right]-$ phenylalanine enrichments (Figure 4C), indicating proper protein digestion and subsequent amino acid absorption during sleep. Exogenous dietary protein-derived phenylalanine $\mathrm{R}_{\mathrm{a}}$ remained elevated throughout overnight sleep (Figure 5A). Over the entire 7.5-h overnight period, $53 \pm 2 \%$ of the ingested protein-derived amino acids appeared in the circulation, with the other $47 \pm 2 \%$ of the protein-derived amino acids being retained in the gut to support turnover of splanchnic tissues. These data are in line with previous work that quantified firstpass amino acid extraction conducted during the day time $[8,22,34]$ and extend on these findings with the observation that physical activity performed earlier during the evening does not modulate overnight protein digestion and amino acid absorption after presleep protein ingestion.

Protein ingestion before sleep has previously been shown to improve whole-body protein synthesis and to reduce whole-body protein breakdown, allowing for a positive net protein balance during overnight sleep $(18,19)$. In the present study, we confirmed our previous findings by showing that presleep protein ingestion resulted in a (more) positive overnight whole-body protein balance (Figure 6). Physical activity performed earlier that day did not seem to have a substantial impact on overnight whole-body protein synthesis, breakdown, amino acid oxidation, or net balance (Figure 6). However, note that whole-body protein metabolism does not necessarily reflect skeletal muscle protein turnover. Because we aimed to assess the impact of physical activity on the overnight muscle protein synthetic response, we collected muscle biopsies immediately before and after overnight sleep.

With the present amino acid tracer method, we were able to assess rates of muscle protein synthesis under steady state $\left(\mathrm{L}-\left[1-{ }^{13} \mathrm{C}\right]\right.$-leucine) and non-steady state (L-[ring- $\left.{ }^{2} \mathrm{H}_{5}\right]-$ 
phenylalanine) precursor conditions [33]. As hypothesized, myofibrillar protein synthesis rates were $31 \%\left(\mathrm{~L}-\left[\right.\right.$ ring $\left.^{2} \mathrm{H}_{5}\right]$-phenylalanine; Figure $\left.\mathbf{7 A}\right)$ and $27 \%\left(\mathrm{~L}-\left[1-{ }^{13} \mathrm{C}\right]\right.$-leucine; Figure 7B) higher with the $\mathrm{PRO}+\mathrm{EX}$ treatment than with the PRO treatment. These findings extend on our previous work showing that administration of $40 \mathrm{~g}$ protein before sleep increases overnight muscle protein synthesis rates compared with a placebo [19]. Furthermore, these findings are in line with previous work that investigated the impact of physical activity or exercise on the postprandial muscle protein synthetic response to protein or meal feeding after an overnight fast, showing that physical activity further augments the postprandial rise in muscle protein synthesis rate by $\sim 25 \%[22,35]$. This supports the concept that physical activity increases the sensitivity of skeletal muscle tissue to the anabolic properties of protein ingestion and that this response may extend into overnight sleep. In the present study, we combined continuous infusions of $\mathrm{L}$-[ring $\left.{ }^{2} \mathrm{H}_{5}\right]$-phenylalanine and $\mathrm{L}-\left[1-{ }^{13} \mathrm{C}\right]$-leucine with the ingestion of protein intrinsically labeled with $L-\left[1-{ }^{13} \mathrm{C}\right]-$ phenylalanine $[29,33]$. Because this specifically produced protein is highly enriched ( $>35 \mathrm{MPE}$ ), we are able to directly assess the metabolic fate of the dietary protein-derived amino acids. Here, we demonstrate that the ingested protein was used for de novo skeletal muscle protein synthesis throughout overnight sleep (Figure 8). Substantially more (28\%) of the dietary protein-derived phenylalanine was incorporated into skeletal muscle protein when physical activity was performed earlier in the day. Therefore, physical activity throughout the day increases the efficiency by which protein-derived amino acids provided before sleep are directed toward overnight de novo muscle protein synthesis. Consequently, the combination of physical activity or exercise with presleep protein ingestion can augment the overnight muscle protein synthetic response and increase the efficacy by which presleep protein supplementation may help to preserve muscle mass and strength in the older population. In support, we recently reported greater gains in skeletal muscle mass and strength after 3 mo of evening resistance-type exercise training in young men when subjects were provided with additional protein before sleep [36].

It is well established that the anabolic response to protein ingestion is impaired in older $[5,7$, 37] and/or more clinically compromised [20, 37-39] populations. Previous work from our group [8] and from others $[9,10]$ has shown that increasing protein intake can compensate for anabolic resistance. However, ingesting larger protein doses may not be feasible or practical in all older and/or clinically compromised populations. Protein ingestion before sleep may represent an effective nutritional strategy to preserve muscle mass by stimulating and supporting muscle protein accretion during overnight sleep. The current data extend on previous observations and are the first, to our knowledge, to show that physical activity performed throughout the day increases the efficiency by which dietary protein ingested before sleep is directed toward de novo muscle protein synthesis in older individuals. Therefore, older individuals who are unable to ingest large amounts of protein can still benefit from ingesting smaller amounts of protein $(<40 \mathrm{~g})$ before sleep by performing physical activity beforehand. As such, a physical activity program should be implemented in combination with presleep protein ingestion to benefit from the synergy between physical activity and protein to increase overnight muscle protein accretion to support healthy aging. 
In conclusion, physical activity performed in the evening augments the overnight muscle protein synthetic response to presleep protein ingestion and allows more of the ingested protein-derived amino acids to be used for de novo muscle protein synthesis during overnight sleep in older men. Combining presleep protein ingestion with physical activity may aid in preserving skeletal muscle mass and, as such, support healthy aging. 


\section{REFERENCES}

1. Baumgartner, R.N., D.L. Waters, D. Gallagher, J.E. Morley, and P.J. Garry, Predictors of skeletal muscle mass in elderly men and women. Mech Ageing Dev, 1999. 107(2): p. 123-36.

2. Mitchell, W.K., J. Williams, P. Atherton, M. Larvin, J. Lund, and M. Narici, Sarcopenia, dynapenia, and the impact of advancing age on human skeletal muscle size and strength; a quantitative review. Front Physiol, 2012. 3: p. 260.

3. Katsanos, C.S., H. Kobayashi, M. Sheffield-Moore, A. Aarsland, and R.R. Wolfe, A high proportion of leucine is required for optimal stimulation of the rate of muscle protein synthesis by essential amino acids in the elderly. Am J Physiol Endocrinol Metab, 2006. 291(2): p. E381-7.

4. Paddon-Jones, D., M. Sheffield-Moore, X.J. Zhang, E. Volpi, S.E. Wolf, A. Aarsland, A.A. Ferrando, and R.R. Wolfe, Amino acid ingestion improves muscle protein synthesis in the young and elderly. Am J Physiol Endocrinol Metab, 2004. 286(3): p. E321-8.

5. Cuthbertson, D., K. Smith, J. Babraj, G. Leese, T. Waddell, P. Atherton, H. Wackerhage, P.M. Taylor, and M.J. Rennie, Anabolic signaling deficits underlie amino acid resistance of wasting, aging muscle. FASEB J, 2005. 19(3): p. 422-4.

6. Katsanos, C.S., H. Kobayashi, M. Sheffield-Moore, A. Aarsland, and R.R. Wolfe, Aging is associated with diminished accretion of muscle proteins after the ingestion of a small bolus of essential amino acids. Am J Clin Nutr, 2005. 82(5): p. 1065-73.

7. Burd, N.A., S.H. Gorissen, and L.J. van Loon, Anabolic resistance of muscle protein synthesis with aging. Exerc Sport Sci Rev, 2013. 41(3): p. 169-73.

8. Pennings, B., B. Groen, A. de Lange, A.P. Gijsen, A.H. Zorenc, J.M. Senden, and L.J. van Loon, Amino acid absorption and subsequent muscle protein accretion following graded intakes of whey protein in elderly men. American journal of physiology. Endocrinology and metabolism, 2012. 302(8): p. E992-9.

9. Yang, Y., T.A. Churchward-Venne, N.A. Burd, L. Breen, M.A. Tarnopolsky, and S.M. Phillips, Myofibrillar protein synthesis following ingestion of soy protein isolate at rest and after resistance exercise in elderly men. Nutrition \& metabolism, 2012. 9(1): p. 57.

10. Yang, Y., L. Breen, N.A. Burd, A.J. Hector, T.A. Churchward-Venne, A.R. Josse, M.A. Tarnopolsky, and S.M. Phillips, Resistance exercise enhances myofibrillar protein synthesis with graded intakes of whey protein in older men. The British journal of nutrition, 2012. 108(10): p.1780-8.

11. Koopman, R., N. Crombach, A.P. Gijsen, S. Walrand, J. Fauquant, A.K. Kies, S. Lemosquet, W.H. Saris, Y. Boirie, and L.J. van Loon, Ingestion of a protein hydrolysate is accompanied by an accelerated in vivo digestion and absorption rate when compared with its intact protein. The American journal of clinical nutrition, 2009. 90(1): p. 106-15.

12. Pennings, B., Y. Boirie, J.M. Senden, A.P. Gijsen, H. Kuipers, and L.J. van Loon, Whey protein stimulates postprandial muscle protein accretion more effectively than do casein and casein hydrolysate in older men. The American journal of clinical nutrition, 2011. 93(5): p. 997-1005.

13. Paddon-Jones, D., M. Sheffield-Moore, C.S. Katsanos, X.J. Zhang, and R.R. Wolfe, Differential stimulation of muscle protein synthesis in elderly humans following isocaloric ingestion of amino acids or whey protein. Exp Gerontol, 2006. 41(2): p. 215-9.

14. Mamerow, M.M., J.A. Mettler, K.L. English, S.L. Casperson, E. Arentson-Lantz, M. Sheffield-Moore, D.K. Layman, and D. Paddon-Jones, Dietary protein distribution positively influences $24-\mathrm{h}$ muscle protein synthesis in healthy adults. J Nutr, 2014. 144(6): p. 876-80.

15. Murphy, C.H., T.A. Churchward-Venne, C.J. Mitchell, N.M. Kolar, A. Kassis, L.G. Karagounis, L.M. Burke, J.A. Hawley, and S.M. Phillips, Hypoenergetic diet-induced reductions in myofibrillar protein synthesis are restored with resistance training and balanced daily protein ingestion in older men. Am J Physiol Endocrinol Metab, 2015. 308(9): p. E734-43. 
16. Gorissen, S.H., N.A. Burd, H.M. Hamer, A.P. Gijsen, B.B. Groen, and L.J. van Loon, Carbohydrate coingestion delays dietary protein digestion and absorption but does not modulate postprandial muscle protein accretion. J Clin Endocrinol Metab, 2014. 99(6): p. 2250-8.

17. Staples, A.W., N.A. Burd, D.W. West, K.D. Currie, P.J. Atherton, D.R. Moore, M.J. Rennie, M.J. Macdonald, S.K. Baker, and S.M. Phillips, Carbohydrate does not augment exercise-induced protein accretion versus protein alone. Medicine and science in sports and exercise, 2011. 43(7): p. 1154-61.

18. Res, P., B. Groen, B. Pennings, M. Beelen, G.A. Wallis, A.P. Gijsen, J.M.G. Senden, and L.J.C. Van Loon, Protein Ingestion before Sleep Improves Postexercise Overnight Recovery. 2012(1530-0315 (Electronic)).

19. Groen, B.B., P.T. Res, B. Pennings, E. Hertle, J.M. Senden, W.H. Saris, and L.J. van Loon, Intragastric protein administration stimulates overnight muscle protein synthesis in elderly men. American journal of physiology. Endocrinology and metabolism, 2012. 302(1): p. E52-60.

20. Wall, B., M. Dirks, and L. van Loon, Skeletal muscle atrophy during short-term disuse: Implications for age-related sarcopenia. Ageing research reviews, 2013. 12(4): p. 898-906.

21. Moore, D.R., J.E. Tang, N.A. Burd, T. Rerecich, M.A. Tarnopolsky, and S.M. Phillips, Differential stimulation of myofibrillar and sarcoplasmic protein synthesis with protein ingestion at rest and after resistance exercise. J Physiol, 2009. 587(Pt 4): p. 897-904.

22. Pennings, B., R. Koopman, M. Beelen, J.M. Senden, W.H. Saris, and L.J. van Loon, Exercising before protein intake allows for greater use of dietary protein-derived amino acids for de novo muscle protein synthesis in both young and elderly men. The American journal of clinical nutrition, 2011. 93(2): p. 322-31.

23. Phillips, S.M., K.D. Tipton, A. Aarsland, S.E. Wolf, and R.R. Wolfe, Mixed muscle protein synthesis and breakdown after resistance exercise in humans. Am J Physiol, 1997. 273(1 Pt 1): p. E99-107.

24. Biolo, G., S.P. Maggi, B.D. Williams, K.D. Tipton, and R.R. Wolfe, Increased rates of muscle protein turnover and amino acid transport after resistance exercise in humans. Am J Physiol, 1995. 268(3 Pt 1): p. E514-20.

25. Genuth, S., K.G. Alberti, P. Bennett, J. Buse, R. Defronzo, R. Kahn, J. Kitzmiller, W.C. Knowler, H. Lebovitz, A. Lernmark, D. Nathan, J. Palmer, R. Rizza, C. Saudek, J. Shaw, M. Steffes, M. Stern, J. Tuomilehto, P. Zimmet, D. Expert Committee on the, and M. Classification of Diabetes, Follow-up report on the diagnosis of diabetes mellitus. Diabetes Care, 2003. 26(11):p.3160-7.

26. Mayhew, J.L., J.L. Prinster, J.S. Ware, D.L. Zimmer, J.R. Arabas, and M.G. Bemben, Muscular endurance repetitions to predict bench press strength in men of different training levels. J Sports Med Phys Fitness, 1995. 35(2): p. 108-13.

27. Bergstrom, J., Percutaneous needle biopsy of skeletal muscle in physiological and clinical research. Scand J Clin Lab Invest, 1975. 35(7): p. 609-16.

28. Buysse, D.J., C.F. Reynolds, 3rd, T.H. Monk, S.R. Berman, and D.J. Kupfer, The Pittsburgh Sleep Quality Index: a new instrument for psychiatric practice and research. Psychiatry Res, 1989. 28(2): p. 193-213.

29. van Loon, L.J., Y. Boirie, A.P. Gijsen, J. Fauquant, A.L. de Roos, A.K. Kies, S. Lemosquet, W.H. Saris, and R. Koopman, The production of intrinsically labeled milk protein provides a functional tool for human nutrition research. Journal of dairy science, 2009. 92(10): p.4812-22.

30. Dangin, M., C. Guillet, C. Garcia-Rodenas, P. Gachon, C. Bouteloup-Demange, K. Reiffers-Magnani, J. Fauquant, $O$. Ballevre, and B. Beaufrere, The rate of protein digestion affects protein gain differently during aging in humans. J Physiol, 2003. 549(Pt 2): p. 635-44.

31. Boirie, Y., P. Gachon, S. Corny, J. Fauquant, J.L. Maubois, and B. Beaufrere, Acute postprandial changes in leucine metabolism as assessed with an intrinsically labeled milk protein. Am J Physiol, 1996. 271(6 Pt 1): p. E1083-91.

32. Wolfe, R.R. and D.L. Chinkes, Isotope tracers in metabolic research: Principles and practice of kinetic analysis. 2 ed. 2005, Hoboken, New Jersey: John Wiley and Sons, Inc. 
33. Burd, N.A., N.M. Cermak, I.W. Kouw, S.H. Gorissen, A.P. Gijsen, and L.J. van Loon, The use of doubly labeled milk protein to measure postprandial muscle protein synthesis rates in vivo in humans. J Appl Physiol (1985), 2014. 117(11): p. 1363-70.

34. Pennings, B., B.B. Groen, J.W. van Dijk, A. de Lange, A. Kiskini, M. Kuklinski, J.M. Senden, and L.J. van Loon, Minced beef is more rapidly digested and absorbed than beef steak, resulting in greater postprandial protein retention in older men. Am J Clin Nutr, 2013. 98(1): p. 121-8.

35. Witard, O.C., M. Tieland, M. Beelen, K.D. Tipton, L.J. van Loon, and R. Koopman, Resistance exercise increases postprandial muscle protein synthesis in humans. Med Sci Sports Exerc, 2009. 41(1): p. 144-54.

36. Snijders, T., P.T. Res, J.S. Smeets, S. van Vliet, J. van Kranenburg, K. Maase, A.K. Kies, L.B. Verdijk, and L.J. van Loon, Protein Ingestion before Sleep Increases Muscle Mass and Strength Gains during Prolonged Resistance-Type Exercise Training in Healthy Young Men. J Nutr, 2015. 145(6): p. 1178-84.

37. Wall, B.T., S.H. Gorissen, B. Pennings, R. Koopman, B.B. Groen, L.B. Verdijk, and L.J. van Loon, Aging Is Accompanied by a Blunted Muscle Protein Synthetic Response to Protein Ingestion. PLoS One, 2015. 10(11): p. e0140903.

38. Williams, J.P., B.E. Phillips, K. Smith, P.J. Atherton, D. Rankin, A.L. Selby, S. Liptrot, J. Lund, M. Larvin, and M.J. Rennie, Effect of tumor burden and subsequent surgical resection on skeletal muscle mass and protein turnover in colorectal cancer patients. Am J Clin Nutr, 2012. 96(5): p. 1064-70.

39. Murton, A.J., K. Marimuthu, J.E. Mallinson, A.L. Selby, K. Smith, M.J. Rennie, and P.L. Greenhaff, Obesity Appears to Be Associated With Altered Muscle Protein Synthetic and Breakdown Responses to Increased Nutrient Delivery in Older Men, but Not Reduced Muscle Mass or Contractile Function. Diabetes, 2015. 64(9): p. 3160-71. 
Physical activity and protein ingestion prior to sleep 


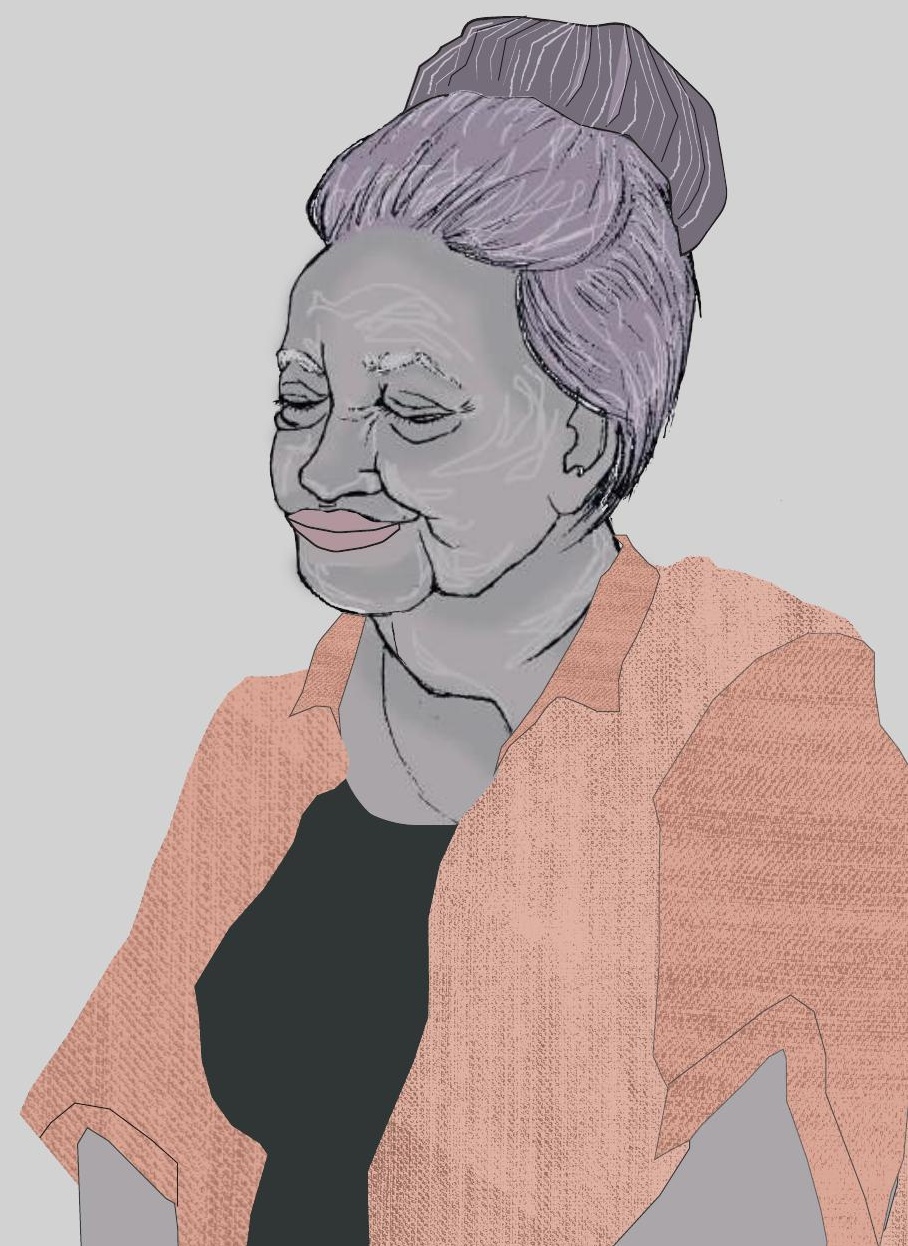




\section{CHAPTER NINE}

general discussion 


\section{GENERAL DISCUSSION}

In view of the ever-increasing number of elderly individuals in our society, the age-related loss of skeletal muscle mass and function has received increased attention over the past years. A blunted response to the main anabolic stimuli of muscle mass regulation, i.e., dietary protein ingestion and physical activity, has been postulated to represent one of the driving factors explaining this generalized age-related muscle loss. More specifically, this "anabolic resistance" may play a key role in the accelerated loss of muscle mass observed in various (clinical) conditions. Anabolic resistance may reside on various levels, from protein digestion and amino acid absorption, to amino acid uptake in muscle tissue, and subsequent stimulation of muscle protein synthesis. Various factors have been identified to contribute to anabolic resistance, including physical inactivity, obesity, insulin resistance, medication use, and inflammation. Particularly in older, compromised clinical populations, acute changes in habitual physical activity level and food intake - often resulting from the development of various health issues - are likely the main cause of the development of anabolic resistance, inducing accelerated loss of muscle mass. Importantly, muscle loss during short periods of inactivity or hospitalization due to sickness, injury, and/or (elective) surgery is now believed to be a key contributor to the progressive age-related decline in muscle mass and strength, as older patients are generally unable to regain muscle tissue lost during successive periods of such muscle disuse.

In the present thesis, we aimed to gain further insight in the different factors that regulate muscle mass maintenance in older individuals, with a focus on nutritional aspects and clinical populations. In the first study, we show that even a short period of hospitalization can result in a substantial loss of skeletal muscle mass in older patients (chapter 2) which is likely associated with the concomitant decrease in physical activity level and habitual food intake. In accordance, in chapter $\mathbf{3}$, we show that actual energy and protein consumption are largely insufficient in older hospitalized patients with $40 \%$ of the provided food not being consumed. Using stable isotope tracer methodology, we assessed post-absorptive and postprandial muscle protein synthesis rates to determine potential alterations herein in older and compromised clinical populations (chapter $\mathbf{4}$ and 5). Finally, we investigated several interventional strategies to increase the muscle protein synthetic response to protein intake in older individuals (chapter 6, 7, and $\mathbf{8}$ ). In this discussion section, we address the findings of the previous chapters, while focusing on different nutritional and physical activity intervention strategies to attenuate muscle mass and strength loss in older and more clinically compromised populations. We propose potential strategies to preserve skeletal muscle mass and strength to be implemented before, during, and after hospitalization.

\section{Before hospitalization}

Having a low muscle mass at an older age increases the risk for hospitalization [1-3]. Moreover, patients with low muscle mass at the time of hospital admission have an increased risk of 
functional decline [3, 4], experience longer length of hospital stay [5-8], show a worsened prognosis of disease $[5,7,8]$, and have higher mortality rates during hospitalization $[1,5-7,9-$ 11]. On average, $5-40 \%$ of the older patients report at the hospital with existing sarcopenia [1, $5,7]$. Importantly though, even a few days of hospitalization, immobilization, or bed rest leads to a significant loss of muscle mass, strength, and function [12-20], further compromising muscle mass in both sarcopenic and non-sarcopenic patients [21]. Experimental models investigating muscle disuse generally report $\sim 0.5 \%$ loss of appendicular muscle mass per day during limb immobilization or bed rest $[12,18,22,23]$. We observed that only 5 days of hospitalization can lead to as much as $3-4 \%$ loss of muscle mass in older patients, even when physical therapy and nutritional support are provided throughout hospital stay (chapter 2). Likely, the impact of surgery, associated physical and mental stress, and reduced food intake during hospitalization further augment disuse-induced loss of skeletal muscle mass and function in clinical practice. Improving pre-hospital nutritional and functional status may be effective to attenuate the impact of hospitalization on overall muscle mass and function and, as such, improve clinical outcome.

Already before hospital admission, up to $50 \%$ of the older patients experience a loss of physical functioning [24] which is a result of, among other things, a decrease in habitual physical activity level $[24,25]$. Exercise therapy prior to hospital admission has been shown to be an effective strategy to improve pre-operative muscle strength and physical function in various patient populations [26-32]. As such, the waiting period prior to surgery represents a particularly suitable opportunity to optimize pre-operative functional capacity and muscle mass in older patients, which seems especially applicable in case of elective hospital admission. Indeed, preoperative exercise training 2-3 months prior to surgery has been shown to improve physical function up to $30 \%$ (e.g. improvements in Short Physical Performance Battery (SPPB) and 6min walk test) in patients waiting for elective cardiac [28, 33, 34], major abdominal and thoracic $[26,27,31,35,36]$, and knee and hip replacement surgery [37, 38]. In addition, short-term preoperative high-intensity interval training (HIIT) has been proposed as an effective strategy to rapidly improve aerobic capacity in patients waiting for surgery $[39,40]$ and combined with resistance type exercise to increase muscle strength during chemotherapy [41]. As such, any (combined) form of resistance, endurance, HIIT, and/or concurrent exercise training could be applied to improve physical function and muscle mass in the pre-operative period. Despite the fact that the actual period of hospitalization still induces a reduction in muscle mass and function, the level of functioning will be better when compared to a situation where no preoperative training was implemented. In addition, such 'pre-conditioning' has been shown to improve post-operative clinical outcomes [42-44].

Considering that pre-operative exercise training is cheap, well tolerated, and clinically relevant in various patient groups, there is a high potential for the implementation in health care. In the Netherlands, clinical home-based concepts like 'Better In, Better Out', 'Strong for Surgery', and 'Fit4surgery' have been developed and are now being implemented in several hospitals. Studies so far have mostly tested generalized, low-to-moderate intensity exercise programs and their clinical effectiveness on changes in muscle mass and strength have not been 
assessed. As these programs were not designed towards specific patient cohorts, more targeted exercise programs have to be developed and evaluated in different patient populations in the pre-hospitalization phase. To better tailor pre-habilitation programs to the patient, studies specifically investigating the exercise type, frequency, intensity, and duration of pre-habilitation programs in various patient populations should be conducted. In addition, detailed information on 'baseline' physical and functional status of the patient should be collected in the pre-hospitalization phase, by implementing more functional measures such as body composition (e.g. DXA or BIA), aerobic capacity, and muscle strength in the physical screening prior to hospitalization and assess the improvement of these clinical outcomes during pre-conditioning. As such, pre-habilitation programs can be better designed for the individual patient and specifically target clinical improvements.

Apart from physical activity, food intake (mainly protein intake) represents another important factor for maintenance of skeletal muscle mass and function. Longitudinal studies show associations between a low protein intake over several years and lower muscle mass and strength, as well as greater declines in muscle mass over time [45-49]. In addition, not only protein quantity, but also protein source and quality $[45,50]$, and protein intake distribution pattern $[49,51]$ have been shown to affect muscle mass and strength. Since nutritional status has been shown to affect clinical outcome during hospitalization, screening for energy and protein malnutrition has become part of usual health care to identify patients at nutritional risk [52]. At present, up to $30 \%$ of the older patients in Western-European hospitals are malnourished upon hospital admission [52-56]. The supplementation of energy and/or protein can improve nutritional status in the pre-hospitalization phase and improve post-operative outcomes [57-61]. However, these studies have focused on patients with a high nutritional risk such as (elective) major abdominal surgery and (head- and neck) cancer patients, as these patients are often malnourished in the pre-hospitalization period [57-59, 62]. Besides the benefits of pre-operative oral nutritional supplements (ONS) or enteral nutrition in patients undergoing major surgery requiring hospitalization, a large body of data demonstrates that the provision of high-protein ONS prior to- and during hospitalization reduces mortality rates, complications, hospital readmissions, length of stay, and hospital costs [63-66]. However, to what extent nutritional interventions implemented in the pre-hospitalization period can improve clinical outcome parameters such as muscle mass, strength, and function in other patient groups (not necessarily at risk for malnutrition) remains to be established. In line with the support of pre-hospitalization exercise training, pre-hospitalization nutritional interventions would benefit from including standardized measurements of these clinical parameters prior to- and throughout subsequent hospitalization. Besides assessing the impact of these nutritional interventions on clinically relevant outcomes in standardized clinical care, the physiological relevance of nutritional supplementation in the pre-hospitalization phase needs to be further investigated. The assessment of muscle mass (by CT-scans or muscle biopsies for research purposes) seems particularly applicable in the pre-operative period, since the surgery itself can serve as an easy way to collect muscle tissue and combine clinical care (i.e. scans for medical purposes) with the assessment of more physiologically relevant outcome 
measurements. Additionally, the application of deuterated water is a feasible tool to measure muscle protein synthesis rates over consecutive days or weeks and, as such, can provide more in depth information on the capacity of nutritional and/or exercise training interventions to modulate muscle protein synthesis during pre-habilitation. In conclusion, nutritional intervention studies that translate research findings from bench to bedside are warranted to further understand the effect of nutrition during pre-habilitation and support the implementation in health care.

As discussed above, pre-habilitation exercise training seems to be effective to improve prehospital functional status and physical capacity. Nutritional support has been shown to further increase the gains in muscle mass and strength during exercise training in older frail as well as in diseased populations $[36,67]$. Therefore, the combination of pre-operative exercise training and nutritional support are key to further support increases in skeletal muscle mass and strength prior to hospitalization. So far, only a handful of studies have assessed the effect of multimodal exercise and nutrition pre-habilitation programs, showing improvements in functional capacity and lean body mass in the pre-operative phase when individualized nutritional counselling, protein supplementation, and exercise therapy were combined [36, 6870]. To be successful, combined pre-habilitation exercise and nutritional interventions require a timeline that needs to start early in the pre-hospitalization phase to ensure patient engagement and should extend into the peri- and post-hospitalization periods. As such, the mind-set of both patients as well as medical staff needs to shift to pre-emptive rather than reactive exercise and nutritional therapies. Therefore, a drastic change towards a more multimodal approach in integrated care is needed to establish the successful execution of prehabilitation programs in older and clinically compromised populations.

\section{Strategies to prevent muscle loss during hospitalization}

Although the benefits of physical activity as well as the detrimental effects of physical inactivity have been well-established during hospitalization, even hospitalized patients who are not bed-ridden spend $\sim 80 \%$ of their day in bed [71, 72]. During hospitalization, bed rest should be minimalized whenever possible $[23,73]$. By simply looking at a typical hospital room, small adjustments such as changing the place of the television from above the bed to a common living room, and serving the food not in bed but at a table in a communal dining room, may already increase physical activity levels. On a broader level, creating an attractive environment with walking routes and gardens will encourage patients to perform physical activity during hospitalization. Besides these factors that are important to increase overall physical activity levels during hospitalization, resistance type exercise training in the pre- and posthospitalization phase is likely a more robust stimulus to suffice in muscle mass and strength (re)gain. Implementation of (functional) resistance type exercise training is often compromised in most hospitalized settings. In addition, since overall food intake reduces dramatically upon hospitalization, this forms another major aspect to improve. 
Food intake during a period of hospitalization generally decreases due to periods of fasting, adverse effects of medication, strict timing of food provision, reduced appetite, and/or pain and discomfort [74-76]. Such reduced food intake often results in a negative energy and/or protein balance, leading to a greater loss of lean body mass, muscle strength, and impairments in functional capacity [77-79]. In the present thesis we show that dietary protein intake during hospitalization is dramatically low (merely $\sim 0.6 \mathrm{~g} \cdot \mathrm{kg}^{-1} \cdot \mathrm{d}^{-1}$ ) in relatively healthy older patients admitted for elective orthopedic surgery (chapter 3). In fact, $35-40 \%$ of the provided hospital food is not consumed, resulting in extremely low energy and protein intake levels during hospital stay (chapter 3 and [80-83]). Recently updated guidelines suggest that a protein intake of $1.2-1.5 \mathrm{~g} \cdot \mathrm{kg}^{-1} \cdot \mathrm{d}^{-1}$ is needed for older individuals suffering from acute or chronic diseases in order to maintain muscle mass during hospitalization [84, 85]. Strikingly though, only one out of four older hospitalized patients meets these increased protein intake recommendation levels $[80,81]$. Habitual protein intake levels in the older communitydwelling population have been reported to range between 0.9 and $1.1 \mathrm{~g}^{\circ} \mathrm{kg}^{-1} \cdot \mathrm{d}^{-1}[45,49,86$, 87], which is fairly consistent with nutritional recommendations for healthy older individuals $[84,88]$. Given the increased protein recommendations for older individuals during hospitalization, the drastic decline in energy and protein consumption levels during (short) periods of hospitalization, disease, or bed rest likely contributes substantially to the concomitant accelerated muscle loss (chapter 2-3 and [77-79]). Therefore, increasing protein intake while simultaneously achieving energy balance during hospitalization are proposed to attenuate muscle loss during hospitalization $[84,89]$. So far, most studies have been unable to establish a benefit of protein supplementation to attenuate muscle disuse atrophy in older individuals when habitual protein intake exceeds $1.0 \mathrm{~g} \cdot \mathrm{kg}^{-1} \cdot \mathrm{d}^{-1}[13,90]$. However, these studies have been conducted in healthy older individuals during experimentally-induced immobilization. This obviously represents a different situation compared with the energy and protein deficiency observed in a clinical setting.

When aiming to maintain habitual protein intake levels, the often used supplementation of energy-dense ONS may not represent the best strategy. In Figure 1, food consumption from hospital meals, protein-rich snacks, and provided ONS in $n=102$ older, hospitalized patients at nutritional risk is presented (unpublished data). Self-selected hospital meals provided patients with $\sim 1.0 \mathrm{~g}$ protein $\cdot \mathrm{kg}^{-1} \cdot \mathrm{d}^{-1}$, while actual protein consumption averaged $\sim 0.7 \mathrm{~g} \cdot \mathrm{kg}^{-1}$. $\mathrm{d}^{-1}$. The provision of ONS was ineffective in increasing protein intake during hospitalization, as $40 \%$ of the provided ONS was not consumed. In addition, since ONS is energy-dense and contains all macronutrients this is likely not an effective strategy to increase absolute protein intake. As an alternative strategy, we suggest to specifically increase the protein density of the diet to allow maintenance of habitual (absolute) protein intake levels during a period of hospitalization. As depicted in Figure 1, providing a more protein-dense diet will increase protein intake levels without necessarily increasing absolute energy intake, shown by the dotted line. Given the reduced appetite in older, hospitalized patients, this may represent a much more feasible strategy to reach increased protein recommendation levels [84, 89]. In terms of hospital meal provision, simply increasing the amount of food provided will not be 
an effective strategy since $\sim 30 \%$ of the hospital food is not consumed $[75,80,82,83]$. Providing a more protein-dense diet should translate into regular consumption of $\sim 25 \mathrm{~g}$ protein per meal, thereby optimizing the anabolic response to each meal (chapter 5-7). Of course, in certain situations in which total energy intake is so low, the energy deficiency will need to be resolved as well. Definitely, the effect of providing a more protein-dense diet on muscle mass maintenance in older patients during hospitalization remains to be established.

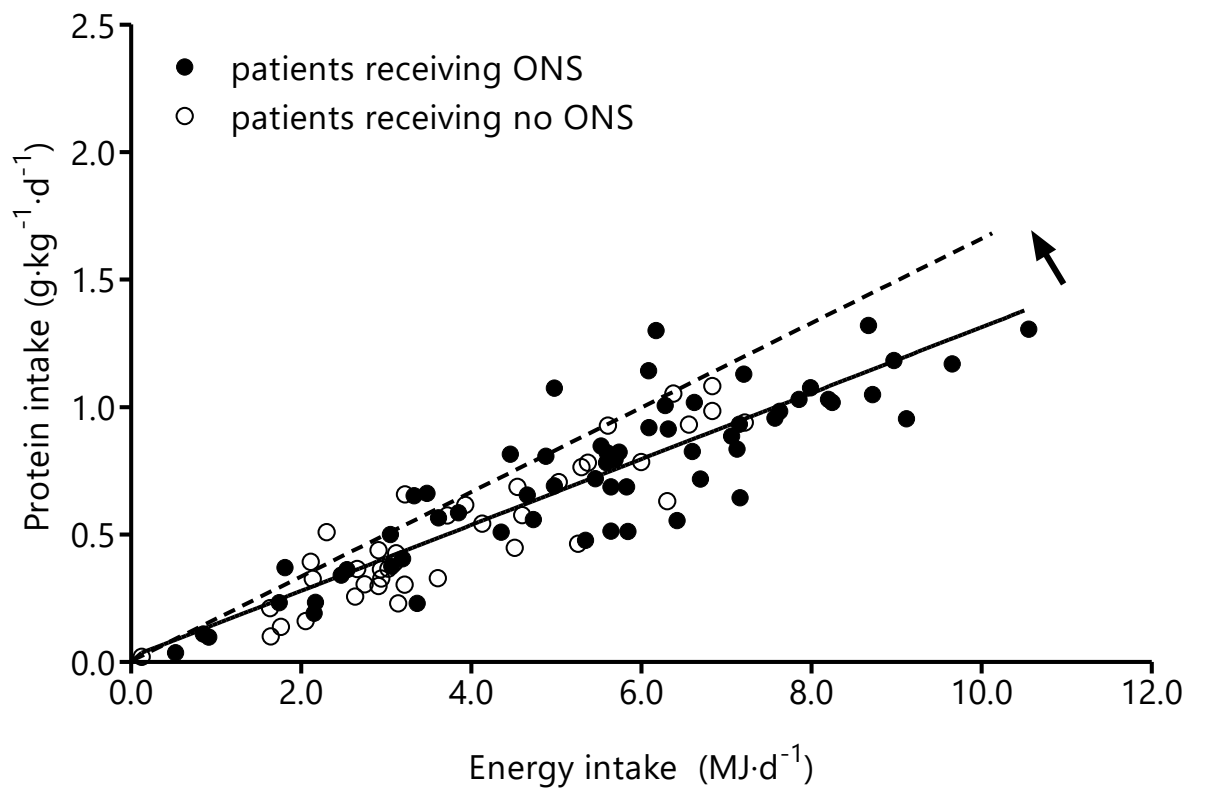

Figure 1 The association between energy and protein intake levels measured in $n=102$ older, hospitalized patients at nutritional risk (unpublished data). Providing a more protein-dense diet will shift the association line between energy and protein intake upwards (dotted line). In this study, the provision of ONS was ineffective at increasing protein intake. Consumption of more protein-dense meals may be more effective to increase daily protein intake in older hospitalized patients.

Various nutritional strategies in the hospital setting have been proposed to increase protein intake levels such as providing protein-rich foods in the diet, food fortification, supplementing with ONS, and/or adjusting the timing of protein-rich snacks [80, 82, 91, 92]. Factors such as medication, dysphagia, cognitive impairment, nausea, loss of appetite, (obligated) periods of fasting, change of social environment, inactivity, social aspects of eating, dislike of the food available, the food presentation, and/or a lack of feeding assistance can strongly impact food intake during hospitalization. To improve the attractiveness of food and increase overall food intake in hospitals, several meal-service concepts have been implemented such as room service, buffet-style meals, order meals upon request, mealtime assistance, and providing restaurant-style meals [82, 93-95]. For example, room service dining has been shown to increase food intake, improve patient satisfaction, and reduce food waste $[82,93,95,96]$. While these strategies provide interesting opportunities to decrease waste, more specific strategies 
to increase the protein content, source, taste, appearance, and timing of the meals are essential to increase the protein-density of the diet.

We propose to apply more specific nutritional strategies throughout different phases of hospitalization to improve overall food intake, as presented in Figure 2. For instance, it can be argued that achieving energy balance and diminishing the protein deficit by the use of highprotein ONS, protein-rich snacks, or peri-operative nutrition is especially relevant on the day of surgery, since food intake on that day is extremely low (chapter $\mathbf{2}$ and $\mathbf{3}$ ) and periods of fasting have been associated with insulin resistance, slower wound healing, and impaired response to treatments $[61,62]$. Subsequently, nutritional strategies such as food fortification, provision of protein-dense meals, and/or an adding an extra meal are likely more effective throughout the later days of hospitalization to specifically increase and evenly distribute protein intake. In chapter 7, we assessed the impact of pre-sleep protein ingestion on overnight muscle protein synthesis rates. We show that the ingestion of $40 \mathrm{~g}$ protein prior to sleep increases overnight plasma amino acid availability and stimulates overnight muscle protein synthesis throughout overnight sleep (chapter 7 and [97]). Based on these findings, we propose that the ingestion of an additional protein meal prior to sleep may be an effective strategy to improve protein intake throughout hospitalization. In addition, pre-sleep protein ingestion the evening before elective surgery may be especially relevant to reduce the period of fasting and stimulate muscle protein synthesis up into the peri-operative period (Figure 2).

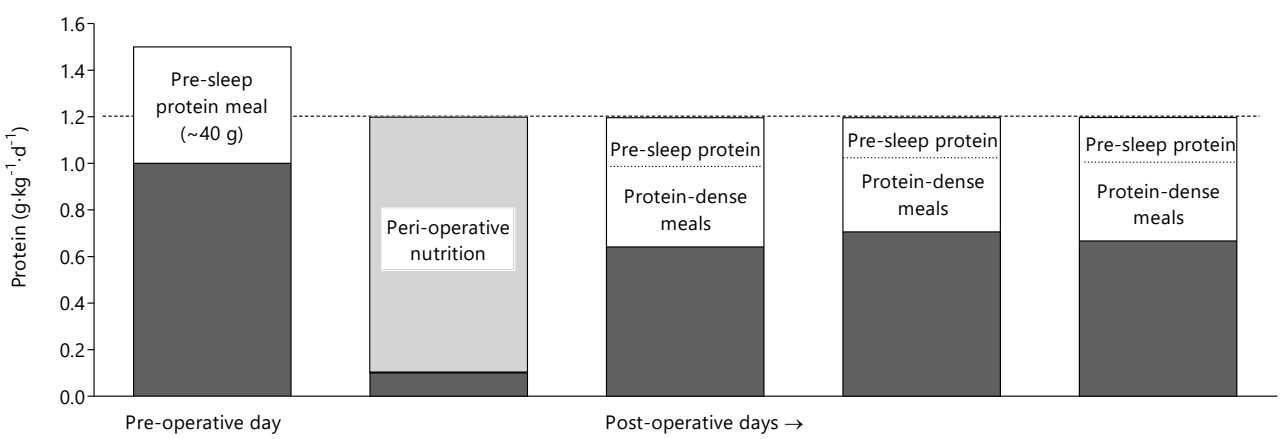

Figure 2 | Conceptual nutritional strategy to improve protein intake during hospitalization in elective surgery patients by; specifically improving nutritional intake with peri-operative nutrition on the day of surgery (e.g., ONS), the provision of protein-dense meals during the following days of hospitalization, and the ingestion of pre-sleep protein on the day prior to surgery and on hospitalization days to improve overall protein intake. The dark grey bars represent protein intake data assessed in chapter 3.

Previous studies providing protein fortified foods (such as bread, yogurt, cake, fruit juice, and soup) or using more protein-dense foods have been effective in improving absolute protein intake during hospitalization [80, 82, 91]. In Dutch hospitals, concepts like "At Your Request" and "FoodforCare" have been developed that provide a restaurant-style menu with room service and advice from a nutritional assistant $[82,93]$. Dijxhoorn et al. showed that the provision of 6-protein-rich meals per day, directly at the bedside and combined with proactive advice from a nutritional assistant, resulted in a $20 \%$ higher protein intake during 
hospitalization when compared with the traditional meal service [82]. In addition, Munck et al. provided a protein-supplemented meal service in older hospitalized patients and showed increased energy and protein intakes when compared with standard meal service during 2 weeks of hospitalization [95]. These studies provide interesting evidence that establishing a more attractive protein-rich meal service is definitely possible within the framework of the hospital. However, current interventional studies are not designed to investigate the effect of meal services on more functional outcomes such as skeletal muscle mass, strength, and/or physical performance during hospitalization. Therefore, more work is needed that assesses clinically relevant physiological and/or functional outcome measures in various patient populations when protein-dense meal services are implemented. In addition, a proper baseline assessment of absolute protein intake levels and consumption patterns throughout hospitalization needs to be included in order to apply more specific nutritional strategies. Lastly, issues including the logistics, training of personnel, education towards patients, and economical evaluations of specific meal service programs all need to be taken into account when aiming to implement more effective strategies in the clinical (hospital) setting.

Notably, physical activity in combination with protein intake has a synergistic anabolic effect (chapter 8). In accordance, specific nutritional interventions such as whey protein, (essential) amino acids (EAA), HMB, vitamin $D$, and/or $n-3$ fatty acids in combination with resistance type exercise training have been shown to improve muscle mass, strength, and/or function in healthy and clinically compromised older individuals [67, 98-102]. During hospitalization, whey protein or EAA supplementation combined with daily in-hospital resistance type and functional exercises has been shown to attenuate the loss of skeletal muscle mass and strength in patients following elective knee arthroplasty [103], admitted for geriatric rehabilitative care [104], and during chemotherapy for chronic liver disease [105]. While there are only a few studies that have assessed the effect of a combined protein supplementation with resistance type exercise training program on skeletal muscle mass and strength in older hospitalized patients [104, 106], more studies in hospital settings are currently ongoing $[107,108]$. Though a certain amount of exercise can be applied in nearly all patients, some conditions do not allow exercise interventions. In a setting of limb immobilization, hemiplegia, or coma, exercise mimetics may be applied effectively during hospitalization. Neuromuscular electrical stimulation (NMES) has been shown to further enhance the muscle protein synthetic response to food intake $[109,110]$. As such, the combination of exercise mimetics combined with adequate nutritional support are likely an effective strategy to reduce muscle atrophy during hospitalization [109, 111, 112]. Overall, during hospitalization, focus should be placed on effectively combining physical activity and nutritional support. Apart from implementing specific exercise programs, this can already be partly accomplished by, for example, providing protein-dense snacks after physical therapy, and stimulating to perform physical activity around the meal times. 


\section{Rehabilitation in the post-hospitalization period}

As described above, there is growing evidence of the beneficial effects of (combined) exercise and nutritional programs both before and during hospitalization in older patients. Yet, such programs are certainly not common practice yet and the long-term functional benefits remain to be elucidated. In contrast, after a period of hospitalization, various rehabilitation training programs including conditioning, ambulatory training, transfer and balance training, and inpatient multidisciplinary programs are already applied in the older population to facilitate recovery and further improve functional status. Once immediate recovery from surgery is established and patients can safely be discharged, it also becomes more feasible to progressively increase training intensities. In general, resistance type exercise training represents the most effective method to induce skeletal muscle hypertrophy and increase muscle strength and functional performance in the older population $[98,102,113]$. In support, Suetta and co-workers showed that resistance type exercise in a clinical setting is more effective to regain muscle mass, strength, muscle fiber size, and functional performance when compared with standard rehabilitation therapy (i.e. functional exercises) or NMES in older patients following total hip replacement surgery $[114,115]$. Nevertheless, studies have showed that though exercise mimetics can be applied effectively to attenuate muscle mass loss during immobilization, they do not preserve muscle strength $[14,114,115]$. Thus, although NMES can support the recovery of mobility in older and clinically compromised patients $[115,116]$ and, as such, serve as an adjuvant training modality when exercise training is not feasible, the implementation of prolonged resistance type exercise programs in the post-hospitalization period should still form a cornerstone in the functional recovery of older patients.

In terms of nutrition, most rehabilitative exercise training programs do not implement concomitant nutritional support. As in professional sports, a proper exercise training program should be combined with a diet that provides all the required nutrients to support muscle mass and strength conditioning. Increasing protein intake during 24 weeks of intense resistance type exercise training in frail older individuals has been shown to further increase muscle mass and strength [98]. So far, several studies have assessed the surplus value of targeted nutritional supplementation during rehabilitative exercise training to increase muscle mass, strength, and/or functional capacity [103, 117-123]. In a rehabilitative setting, some studies applying ambulatory recovery with dietary protein supplementation seem ineffective in increasing muscle mass and strength [103, 122], while other studies applying more progressive resistance type exercise training programs show greater increases in muscle mass, muscle strength, and/or greater functional recovery when nutritional support is provided during rehabilitative exercise training $[107,117,118,121,123]$. Since muscle atrophy following a period of hospitalization and bed rest cannot be fully restored in the older population [21, 23, 124], long-term rehabilitation is of importance to regain (most of) the functional status when compared to pre-hospitalization levels. Interestingly, nutritional strategies that are applied to improve protein intake during hospitalization may also be suitable to extend to the (home-based) post-hospitalization phase. For example, Beelen et al. recently showed that the provision of protein-enriched foods and drinks during 3 months after hospital release 
improved habitual protein intake above adequate intake levels in older geriatric patients [125]. As such, the provision of protein-enriched meals and/or the use of protein supplementation can serve as an effective strategy to increase protein intake levels both at home, as well as in rehabilitation care [125-127].

Though it is clear that combined exercise and nutrition rehabilitation programs are likely more effective in regaining muscle mass and strength, little research has been done. Future studies should include proper evidence-based nutritional strategies applying an adequate protein dose, source, and timing in long-term rehabilitation programs and assess the effect on muscle mass maintenance using physiological and clinical relevant outcomes, during consecutive time points, in older and more clinical compromised patients. In addition, knowledge in sports nutrition should be more readily applied to the healthcare setting where a proper diet and specific applied supplementation can further augment the benefits of intense rehabilitation exercise training. Moreover, it is essential to combine nutritional support, education, physiotherapy, and implementation in the social situation in patients to improve activities of daily living and lifestyle at home. The multimodal approach is key to create a nutritional support team including medical doctors, nurses, dietitians, nutritional assistants, pharmacists, physical therapists, occupational therapists, and speech-language pathologists.

\section{Future research and proposed interventions}

In this last paragraph, we suggest future directions for interventional studies aimed at supporting muscle mass maintenance in older and more clinically compromised populations. There is still little evidence for pre-habilitation training to improve clinical outcome following hospitalization. Yet, the waiting period prior to surgery or hospitalization provides a windowof-opportunity to improve both nutritional as well as physical status. Therefore, intervention studies should focus on the combination of pre-habilitation training combined with nutritional support to augment muscle mass and strength prior to hospitalization. Since malnutrition during hospitalization is still present for $>40 \%$ of the patients, strategies need to be developed to improve nutritional status and, thereby, attenuate muscle loss during hospitalization. The provision of high-protein ONS may compensate for the energy and protein intake deficit during the acute pre- and peri-operative surgery period, whilst the provision of more proteindense meals and pre-sleep protein ingestion may represent feasible nutritional strategies on the subsequent days of recovery from surgery. Pre-sleep protein ingestion the evening before surgery may also represent an effective strategy to increase overnight muscle protein synthesis rates up until actual surgery, and, as such, cover the nutritional deficit in the peri-operative state. In order to obtain clinical evidence for the efficacy of such nutritional interventions, research studies need to assess more clinical and physiologically relevant outcome measurements. The measurement of tissue protein synthesis rates over several days before or after surgery may be helpful to elucidate the impact of the afore-mentioned interventions on a tissue level. The use of deuterated water is a novel and applicable strategy to assess muscle tissue protein synthesis rates on consecutive days or even weeks. Particularly in a clinical setting, this provides a valuable tool to measure muscle protein synthesis rates during 
hospitalization, illness, and in response to nutritional and/or physical activity interventions. In the pre-, post, and hospitalization phase, we need to assess skeletal muscle mass, using available techniques such as DEXA, MRI, or CT, to quantitatively assess net changes in muscle mass during hospitalization or in response to pre- and post-hospitalization interventions [128]. In the post-hospitalization period, we need to consider how to implement rehabilitation strategies on the longer term, as well as build the evidence-base for the overall benefits of (combined) nutritional and exercise interventions to maintain muscle mass and function, increase independence, and improve quality of life in older patients. In the end, changes in lifestyle regarding proper nutrition and physical activity need to be implemented in integrated care and sustained to support active aging and prevent the loss of muscle mass and strength.

To develop more effective interventional strategies to preserve muscle mass and strength in older and clinically compromised populations several questions need to be resolved:

- What is the impact of the protein dose, source, and/or specific (E)AA on the muscle protein synthetic response in hospitalized (older) patients;

- What is the muscle protein synthetic response to the consumption of a full meal when compared to its protein equivalent;

- What is the impact of the food intake distribution on daily muscle protein balance;

- What is the effect of meal preparation and mastication on postprandial protein handling and the subsequent muscle protein synthetic response;

- What is the impact of pre-operative protein ingestion on muscle (and other) tissue protein turnover rates;

- Is pre-sleep protein ingestion during hospitalization a valid means to attenuate muscle loss during hospitalization;

- Does the ingestion of more protein-dense meals increase protein intake in hospitalized patients and attenuate the loss of skeletal muscle mass and strength;

- What is the minimal amount of physical activity that is required to preserve muscle mass during hospitalization;

- What is the effect of combined resistance type exercise and protein supplementation in various older patient populations during the pre- or post- hospitalization period on skeletal muscle mass, strength, and functional outcomes;

- Do the acute changes of combined training and nutrition interventions in the pre-, post-, and hospitalization phase translate to benefits in clinical outcomes on the longer term;

- How can multimodal training and nutrition (p)rehabilitation programs be implemented in integrated health care? 
In conclusion, to attenuate skeletal muscle mass and strength loss before, during, and after hospitalization, nutritional and physical activity intervention strategies are essential in older and clinically compromised populations. Apart from future work that should further determine the effects of nutrition and exercise in the pre-, post-, and hospitalization phase, there is currently enough insight to innovate current health care and apply a more pro-active approach with the pre- and post-hospitalization reconditioning of older patients. 


\section{REFERENCES}

1. Peterson, S.J. and C.A. Braunschweig, Prevalence of Sarcopenia and Associated Outcomes in the Clinical Setting. Nutr Clin Pract, 2016. 31(1): p. 40-8.

2. Fragala, M.S., T.T. Dam, V. Barber, J.O. Judge, S.A. Studenski, P.M. Cawthon, R.R. McLean, T.B. Harris, L. Ferrucci, J.M. Guralnik, D.P. Kiel, S.B. Kritchevsky, M.D. Shardell, M.T. Vassileva, and A.M. Kenny, Strength and function response to clinical interventions of older women categorized by weakness and low lean mass using classifications from the Foundation for the National Institute of Health sarcopenia project. J Gerontol A Biol Sci Med Sci, 2015. 70(2): p. 202-9.

3. Welch, C. K.Z. Hassan-Smith, A.C. Greig, M.J. Lord, A.T. Jackson, Acute Sarcopenia Secondary to Hospitalisation - An Emerging Condition Affecting Older Adults. Aging Dis, 2018. 9(1): p. 151-164.

4. Visser, M., S.B. Kritchevsky, B.H. Goodpaster, A.B. Newman, M. Nevitt, E. Stamm, and T.B. Harris, Leg muscle mass and composition in relation to lower extremity performance in men and women aged 70 to 79: the health, aging and body composition study. J Am Geriatr Soc, 2002. 50(5): p. 897-904.

5. Gariballa, S. and A. Alessa, Sarcopenia: prevalence and prognostic significance in hospitalized patients. Clin Nutr, 2013. 32(5): p. 772-6.

6. Sousa, A.S., R.S. Guerra, I. Fonseca, F. Pichel, and T.F. Amaral, Sarcopenia and length of hospital stay. Eur J Clin Nutr, 2016. 70(5): p. 595-601.

7. Joglekar, S., P.N. Nau, and J.J. Mezhir, The impact of sarcopenia on survival and complications in surgical oncology: A review of the current literature. J Surg Oncol, 2015. 112(5): p. 503-9.

8. Reisinger, K.W., J.L. van Vugt, J.J. Tegels, C. Snijders, K.W. Hulsewe, A.G. Hoofwijk, J.H. Stoot, M.F. Von Meyenfeldt, G.L. Beets, J.P. Derikx, and M. Poeze, Functional compromise reflected by sarcopenia, frailty, and nutritional depletion predicts adverse postoperative outcome after colorectal cancer surgery. Ann Surg, 2015. 261(2): p. 345-52.

9. Morley, J.E., S.D. Anker, and S. von Haehling, Prevalence, incidence, and clinical impact of sarcopenia: facts, numbers, and epidemiology-update 2014. J Cachexia Sarcopenia Muscle, 2014. 5(4): p. 253-259.

10. Valero, V., 3rd, N. Amini, G. Spolverato, M.J. Weiss, K. Hirose, N.N. Dagher, C.L. Wolfgang, A.A. Cameron, B. Philosophe, I.R. Kamel, and T.M. Pawlik, Sarcopenia adversely impacts postoperative complications following resection or transplantation in patients with primary liver tumors. J Gastrointest Surg, 2015. 19(2): p. 272-81.

11. de Hoogt, P.A., K.W. Reisinger, J.J.W. Tegels, J. Bosmans, F. Tijssen, and J. Stoot, Functional Compromise Cohort Study (FCCS): Sarcopenia is a Strong Predictor of Mortality in the Intensive Care Unit. World J Surg, 2017.

12. Wall, B.T., M.L. Dirks, T. Snijders, J.M. Senden, J. Dolmans, and L.J. van Loon, Substantial skeletal muscle loss occurs during only 5 days of disuse. Acta Physiol (Oxf), 2014. 210(3): p. 600-11.

13. Dirks, M.L., B.T. Wall, R. Nilwik, D.H. Weerts, L.B. Verdijk, and L.J. van Loon, Skeletal muscle disuse atrophy is not attenuated by dietary protein supplementation in healthy older men. J Nutr, 2014. 144(8): p. 1196-203.

14. Dirks, M.L., B.T. Wall, T. Snijders, C.L. Ottenbros, L.B. Verdijk, and L.J. van Loon, Neuromuscular electrical stimulation prevents muscle disuse atrophy during leg immobilization in humans. Acta Physiol (Oxf), 2014. 210(3): p. 628-41.

15. Suetta, C., U. Frandsen, L. Jensen, M.M. Jensen, J.G. Jespersen, L.G. Hvid, M. Bayer, S.J. Petersson, H.D. Schroder, J.L. Andersen, K.M. Heinemeier, P. Aagaard, P. Schjerling, and M. Kjaer, Aging affects the transcriptional regulation of human skeletal muscle disuse atrophy. PLoS One, 2012. 7(12): p. e51238.

16. Tanner, R.E., L.B. Brunker, J. Agergaard, K.M. Barrows, R.A. Briggs, O.S. Kwon, L.M. Young, P.N. Hopkins, E. Volpi, R.L. Marcus, P.C. LaStayo, and M.J. Drummond, Age-related differences in lean 
mass, protein synthesis and skeletal muscle markers of proteolysis after bed rest and exercise rehabilitation. J Physiol, 2015. 593(18): p. 4259-73.

17. Hvid, L.G., C. Suetta, P. Aagaard, M. Kjaer, U. Frandsen, and N. Ortenblad, Four days of muscle disuse impairs single fiber contractile function in young and old healthy men. Exp Gerontol, 2013. 48(2): p. 154-61.

18. Dirks, M.L., B.T. Wall, B. van de Valk, T.M. Holloway, G.P. Holloway, A. Chabowski, G.H. Goossens, and L.J. van Loon, One Week of Bed Rest Leads to Substantial Muscle Atrophy and Induces WholeBody Insulin Resistance in the Absence of Skeletal Muscle Lipid Accumulation. Diabetes, 2016. 65(10): p. 2862-75.

19. Van Ancum, J.M., K. Scheerman, N.H. Jonkman, H.E. Smeenk, R.C. Kruizinga, C.G.M. Meskers, and A.B. Maier, Change in muscle strength and muscle mass in older hospitalized patients: A systematic review and meta-analysis. Exp Gerontol, 2017. 92: p. 34-41.

20. Suesada, M.M., M.A. Martins, and C.R. Carvalho, Effect of short-term hospitalization on functional capacity in patients not restricted to bed. Am J Phys Med Rehabil, 2007. 86(6): p. 455-62.

21. Alley, D.E., A. Koster, D. Mackey, P. Cawthon, L. Ferrucci, E.M. Simonsick, B. Yu, S. Hardy, B. Goodpaster, C. Sarkisian, D.K. Houston, S.B. Kritchevsky, S. Cummings, J.S. Lee, F.A. Tylavsky, A. Newman, T. Harris, A. Health, and S. Body Composition, Hospitalization and change in body composition and strength in a population-based cohort of older persons. J Am Geriatr Soc, 2010. 58(11): p. 2085-91.

22. Phillips, S.M., E.I. Glover, and M.J. Rennie, Alterations of protein turnover underlying disuse atrophy in human skeletal muscle. Journal of applied physiology, 2009. 107(3): p. 645-54.

23. English, K.L. and D. Paddon-Jones, Protecting muscle mass and function in older adults during bed rest. Curr Opin Clin Nutr Metab Care, 2010. 13(1): p. 34-9.

24. Palleschi, L., F.L. Fimognari, A. Pierantozzi, B. Salani, A. Marsilii, S.M. Zuccaro, L. Di Cioccio, and W. De Alfieri, Acute functional decline before hospitalization in older patients. Geriatr Gerontol Int, 2014. 14(4): p. 769-77.

25. Gill, T.M., E.A. Gahbauer, T.E. Murphy, L. Han, and H.G. Allore, Risk factors and precipitants of longterm disability in community mobility: a cohort study of older persons. Ann Intern Med, 2012. 156(2): p. 131-40.

26. Pouwels, S., J. Fiddelaers, J.A. Teijink, J.F. Woorst, J. Siebenga, and F.W. Smeenk, Preoperative exercise therapy in lung surgery patients: A systematic review. Respir Med, 2015. 109(12): p. 1495504.

27. Pouwels, S., R.A. Stokmans, E.M. Willigendael, S.W. Nienhuijs, C. Rosman, B. van Ramshorst, and J.A. Teijink, Preoperative exercise therapy for elective major abdominal surgery: a systematic review. Int J Surg, 2014. 12(2): p. 134-40.

28. Pouwels, S., E.M. Willigendael, M.R. van Sambeek, S.W. Nienhuijs, P.W. Cuypers, and J.A. Teijink, Beneficial Effects of Pre-operative Exercise Therapy in Patients with an Abdominal Aortic Aneurysm: A Systematic Review. Eur J Vasc Endovasc Surg, 2015. 49(1): p. 66-76.

29. Hoogeboom, T.J., J.J. Dronkers, E.H. Hulzebos, and N.L. van Meeteren, Merits of exercise therapy before and after major surgery. Curr Opin Anaesthesiol, 2014. 27(2): p. 161-6.

30. Bruns, E.R., B. van den Heuvel, C.J. Buskens, P. van Duijvendijk, S. Festen, E.B. Wassenaar, E.S. van der Zaag, W.A. Bemelman, and B.C. van Munster, The effects of physical prehabilitation in elderly patients undergoing colorectal surgery: a systematic review. Colorectal Dis, 2016.18(8):p.O267-77.

31. O'Doherty, A.F., M. West, S. Jack, and M.P. Grocott, Preoperative aerobic exercise training in elective intra-cavity surgery: a systematic review. Br J Anaesth, 2013. 110(5): p. 679-89.

32. Singh, F., R.U. Newton, D.A. Galvao, N. Spry, and M.K. Baker, A systematic review of pre-surgical exercise intervention studies with cancer patients. Surg Oncol, 2013. 22(2): p. 92-104.

33. Waite, I., R. Deshpande, M. Baghai, T. Massey, O. Wendler, and S. Greenwood, Home-based preoperative rehabilitation (prehab) to improve physical function and reduce hospital length of stay for frail patients undergoing coronary artery bypass graft and valve surgery. J Cardiothorac Surg, 2017. 12(1): p. 91. 
34. Sawatzky, J.A., D.S. Kehler, A.E. Ready, N. Lerner, S. Boreskie, D. Lamont, D. Luchik, R.C. Arora, and T.A. Duhamel, Prehabilitation program for elective coronary artery bypass graft surgery patients: a pilot randomized controlled study. Clin Rehabil, 2014. 28(7): p. 648-57.

35. Sebio Garcia, R., M.I. Yanez Brage, E. Gimenez Moolhuyzen, C.L. Granger, and L. Denehy, Functional and postoperative outcomes after preoperative exercise training in patients with lung cancer: a systematic review and meta-analysis. Interact Cardiovasc Thorac Surg, 2016. 23(3): p. 486-97.

36. Minnella, E.M., G. Bousquet-Dion, R. Awasthi, C. Scheede-Bergdahl, and F. Carli, Multimodal prehabilitation improves functional capacity before and after colorectal surgery for cancer: a fiveyear research experience. Acta Oncol, 2017. 56(2): p. 295-300.

37. Hoogeboom, T.J., E. Oosting, J.E. Vriezekolk, C. Veenhof, P.C. Siemonsma, R.A. de Bie, C.H. van den Ende, and N.L. van Meeteren, Therapeutic validity and effectiveness of preoperative exercise on functional recovery after joint replacement: a systematic review and meta-analysis. PLoS One, 2012. 7(5): p. e38031.

38. Gill, S.D. and H. McBurney, Does exercise reduce pain and improve physical function before hip or knee replacement surgery? A systematic review and meta-analysis of randomized controlled trials. Arch Phys Med Rehabil, 2013. 94(1): p. 164-76.

39. Licker, M., W. Karenovics, J. Diaper, I. Fresard, F. Triponez, C. Ellenberger, R. Schorer, B. Kayser, and P.O. Bridevaux, Short-Term Preoperative High-Intensity Interval Training in Patients Awaiting Lung Cancer Surgery: A Randomized Controlled Trial. J Thorac Oncol, 2017. 12(2): p. 323-333.

40. Dunne, D.F., S. Jack, R.P. Jones, L. Jones, D.T. Lythgoe, H.Z. Malik, G.J. Poston, D.H. Palmer, and S.W. Fenwick, Randomized clinical trial of prehabilitation before planned liver resection. Br J Surg, 2016. 103(5): p. 504-12.

41. Mijwel, S., M. Backman, K.A. Bolam, E. Olofsson, J. Norrbom, J. Bergh, C.J. Sundberg, Y. Wengstrom, and $\mathrm{H}$. Rundqvist, Highly favorable physiological responses to concurrent resistance and highintensity interval training during chemotherapy: the OptiTrain breast cancer trial. Breast Cancer Res Treat, 2018.

42. Moran, J., E. Guinan, P. McCormick, J. Larkin, D. Mockler, J. Hussey, J. Moriarty, and F. Wilson, The ability of prehabilitation to influence postoperative outcome after intra-abdominal operation: A systematic review and meta-analysis. Surgery, 2016. 160(5): p. 1189-1201.

43. Barberan-Garcia, A., M. Ubre, J. Roca, A.M. Lacy, F. Burgos, R. Risco, D. Momblan, J. Balust, I. Blanco, and G. Martinez-Palli, Personalised Prehabilitation in High-risk Patients Undergoing Elective Major Abdominal Surgery: A Randomized Blinded Controlled Trial. Ann Surg, 2018. 267(1): p. 50-56.

44. Valkenet, K., I.G. van de Port, J.J. Dronkers, W.R. de Vries, E. Lindeman, and F.J. Backx, The effects of preoperative exercise therapy on postoperative outcome: a systematic review. Clin Rehabil, 2011. 25(2): p. 99-111.

45. Houston, D.K., B.J. Nicklas, J. Ding, T.B. Harris, F.A. Tylavsky, A.B. Newman, J.S. Lee, N.R. Sahyoun, M. Visser, and S.B. Kritchevsky, Dietary protein intake is associated with lean mass change in older, community-dwelling adults: the Health, Aging, and Body Composition (Health ABC) Study. Am J Clin Nutr, 2008. 87(1): p. 150-5.

46. Scott, D., L. Blizzard, J. Fell, G. Giles, and G. Jones, Associations between dietary nutrient intake and muscle mass and strength in community-dwelling older adults: the Tasmanian Older Adult Cohort Study. J Am Geriatr Soc, 2010. 58(11): p. 2129-34.

47. Stookey, J.D., L. Adair, J. Stevens, and B.M. Popkin, Patterns of long-term change in body composition are associated with diet, activity, income and urban residence among older adults in China. J Nutr, 2001. 131(9): p. 2433S-40S.

48. Meng, X., K. Zhu, A. Devine, D.A. Kerr, C.W. Binns, and R.L. Prince, A 5-year cohort study of the effects of high protein intake on lean mass and BMC in elderly postmenopausal women. J Bone Miner Res, 2009. 24(11): p. 1827-34.

49. Farsijani, S., J.A. Morais, H. Payette, P. Gaudreau, B. Shatenstein, K. Gray-Donald, and S. Chevalier, Relation between mealtime distribution of protein intake and lean mass loss in free-living older adults of the NuAge study. Am J Clin Nutr, 2016. 104(3): p. 694-703. 
50. Lord, C., J.P. Chaput, M. Aubertin-Leheudre, M. Labonte, and I.J. Dionne, Dietary animal protein intake: association with muscle mass index in older women. J Nutr Health Aging, 2007. 11(5): p. 383-7.

51. Farsijani, S., H. Payette, J.A. Morais, B. Shatenstein, P. Gaudreau, and S. Chevalier, Even mealtime distribution of protein intake is associated with greater muscle strength, but not with 3-y physical function decline, in free-living older adults: the Quebec longitudinal study on Nutrition as a Determinant of Successful Aging (NuAge study). Am J Clin Nutr, 2017. 106(1): p. 113-124.

52. Kruizenga, H., S. van Keeken, P. Weijs, L. Bastiaanse, S. Beijer, G. Huisman-de Waal, H. JagerWittenaar, C. Jonkers-Schuitema, M. Klos, W. Remijnse-Meester, B. Witteman, and A. Thijs, Undernutrition screening survey in 564,063 patients: patients with a positive undernutrition screening score stay in hospital 1.4 d longer. Am J Clin Nutr, 2016. 103(4): p. 1026-32.

53. Rasmussen, H.H., M. Holst, and J. Kondrup, Measuring nutritional risk in hospitals. Clin Epidemiol, 2010. 2: p. 209-16.

54. Stratton, R.J. and M. Elia, Deprivation linked to malnutrition risk and mortality in hospital. British Journal of Nutrition, 2006. 96(5): p. 870-876.

55. Feinberg, J., E.E. Nielsen, S.K. Korang, K. Halberg Engell, M.S. Nielsen, K. Zhang, M. Didriksen, L. Lund, N. Lindahl, S. Hallum, N. Liang, W. Xiong, X. Yang, P. Brunsgaard, A. Garioud, S. Safi, J. Lindschou, J. Kondrup, C. Gluud, and J.C. Jakobsen, Nutrition support in hospitalised adults at nutritional risk. Cochrane Database Syst Rev, 2017. 5: p. CD011598.

56. Hiesmayr, M., K. Schindler, E. Pernicka, C. Schuh, A. Schoeniger-Hekele, P. Bauer, A. Laviano, A.D. Lovell, M. Mouhieddine, T. Schuetz, S.M. Schneider, P. Singer, C. Pichard, P. Howard, C. Jonkers, I. Grecu, O. Ljungqvist, and T. NutritionDay Audit, Decreased food intake is a risk factor for mortality in hospitalised patients: the NutritionDay survey 2006. Clin Nutr, 2009. 28(5): p. 484-91.

57. Burden, S., C. Todd, J. Hill, and S. Lal, Pre-operative nutrition support in patients undergoing gastrointestinal surgery. Cochrane Database Syst Rev, 2012. 11: p. CD008879.

58. Fukuda, Y., K. Yamamoto, M. Hirao, K. Nishikawa, S. Maeda, N. Haraguchi, M. Miyake, N. Hama, A. Miyamoto, M. Ikeda, S. Nakamori, M. Sekimoto, K. Fujitani, and T. Tsujinaka, Prevalence of Malnutrition Among Gastric Cancer Patients Undergoing Gastrectomy and Optimal Preoperative Nutritional Support for Preventing Surgical Site Infections. Ann Surg Oncol, 2015. 22 Suppl 3: p. S778-85.

59. Van Bokhorst-de Van der Schuer, M.A., S.I. Langendoen, H. Vondeling, D.J. Kuik, J.J. Quak, and P.A. $V$ an Leeuwen, Perioperative enteral nutrition and quality of life of severely malnourished head and neck cancer patients: a randomized clinical trial. Clin Nutr, 2000. 19(6): p. 437-44.

60. Turnock, A., P.C. Calder, A.L. West, M. Izzard, R.P. Morton, and L.D. Plank, Perioperative immunonutrition in well-nourished patients undergoing surgery for head and neck cancer: evaluation of inflammatory and immunologic outcomes. Nutrients, 2013. 5(4): p. 1186-99.

61. Weimann, A., M. Braga, F. Carli, T. Higashiguchi, M. Hubner, S. Klek, A. Laviano, O. Ljungqvist, D.N. Lobo, R. Martindale, D.L. Waitzberg, S.C. Bischoff, and P. Singer, ESPEN guideline: Clinical nutrition in surgery. Clin Nutr, 2017. 36(3): p. 623-650.

62. Dort, J.C., D.G. Farwell, M. Findlay, G.F. Huber, P. Kerr, M.A. Shea-Budgell, C. Simon, J. Uppington, D. Zygun, O. Ljungqvist, and J. Harris, Optimal Perioperative Care in Major Head and Neck Cancer Surgery With Free Flap Reconstruction: A Consensus Review and Recommendations From the Enhanced Recovery After Surgery Society. JAMA Otolaryngol Head Neck Surg, 2017. 143(3): p. 292-303.

63. Cawood, A.L., M. Elia, and R.J. Stratton, Systematic review and meta-analysis of the effects of high protein oral nutritional supplements. Ageing Res Rev, 2012. 11(2): p. 278-96.

64. Elia, M., C. Normand, K. Norman, and A. Laviano, A systematic review of the cost and cost effectiveness of using standard oral nutritional supplements in the hospital setting. Clin Nutr, 2016. 35(2): p. 370-380.

65. Stratton, R.J., X. Hebuterne, and M. Elia, A systematic review and meta-analysis of the impact of oral nutritional supplements on hospital readmissions.Ageing Res Rev,2013.12(4):p.884-97. 
66. Philipson, T.J., J.T. Snider, D.N. Lakdawalla, B. Stryckman, and D.P. Goldman, Impact of oral nutritional supplementation on hospital outcomes. Am J Manag Care, 2013. 19(2): p. 121-8.

67. Cermak, N.M., P.T. Res, L.C. de Groot, W.H. Saris, and L.J. van Loon, Protein supplementation augments the adaptive response of skeletal muscle to resistance-type exercise training: a metaanalysis. Am J Clin Nutr, 2012. 96(6): p. 1454-64.

68. Gillis, C., S.E. Loiselle, J.F. Fiore, Jr., R. Awasthi, L. Wykes, A.S. Liberman, B. Stein, P. Charlebois, and F. Carli, Prehabilitation with Whey Protein Supplementation on Perioperative Functional Exercise Capacity in Patients Undergoing Colorectal Resection for Cancer: A Pilot Double-Blinded Randomized Placebo-Controlled Trial. J Acad Nutr Diet, 2016. 116(5): p. 802-12.

69. Gillis, C., T.R. Fenton, T.T. Sajobi, E.M. Minnella, R. Awasthi, S.E. Loiselle, A.S. Liberman, B. Stein, P. Charlebois, and F. Carli, Trimodal prehabilitation for colorectal surgery attenuates post-surgical losses in lean body mass: A pooled analysis of randomized controlled trials. Clin Nutr, 2018.

70. Li, C., F. Carli, L. Lee, P. Charlebois, B. Stein, A.S. Liberman, P. Kaneva, B. Augustin, M. Wongyingsinn, A. Gamsa, D.J. Kim, M.C. Vassiliou, and L.S. Feldman, Impact of a trimodal prehabilitation program on functional recovery after colorectal cancer surgery: a pilot study. Surg Endosc, 2013. 27(4): p. 1072-82.

71. Brown, C.J., R.J. Friedkin, and S.K. Inouye, Prevalence and outcomes of low mobility in hospitalized older patients. J Am Geriatr Soc, 2004. 52(8): p. 1263-70.

72. Brown, C.J., D.T. Redden, K.L. Flood, and R.M. Allman, The underrecognized epidemic of low mobility during hospitalization of older adults. J Am Geriatr Soc, 2009. 57(9): p. 1660-5.

73. Wall, B., M. Dirks, and L. van Loon, Skeletal muscle atrophy during short-term disuse: Implications for age-related sarcopenia. Ageing research reviews, 2013. 12(4): p. 898-906.

74. Mudge, A.M., L.J. Ross, A.M. Young, E.A. Isenring, and M.D. Banks, Helping understand nutritional gaps in the elderly (HUNGER): a prospective study of patient factors associated with inadequate nutritional intake in older medical inpatients. Clin Nutr, 2011. 30(3): p. 320-5.

75. Hickson, M., A. Connolly, and K. Whelan, Impact of protected mealtimes on ward mealtime environment, patient experience and nutrient intake in hospitalised patients. J Hum Nutr Diet, 2011. 24(4): p. 370-4.

76. Corish, C.A. and N.P. Kennedy, Protein-energy undernutrition in hospital in-patients. Br J Nutr, 2000. 83(6): p. 575-91.

77. Biolo, G., B. Ciocchi, M. Stulle, A. Bosutti, R. Barazzoni, M. Zanetti, R. Antonione, M. Lebenstedt, P. Platen, M. Heer, and G. Guarnieri, Calorie restriction accelerates the catabolism of lean body mass during 2 wk of bed rest. Am J Clin Nutr, 2007. 86(2): p. 366-72.

78. Fetterplace, K., A.M. Deane, A. Tierney, L.J. Beach, L.D. Knight, J. Presneill, T. Rechnitzer, A. Forsyth, B.M.T. Gill, M. Mourtzakis, and C. Maclsaac, Targeted Full Energy and Protein Delivery in Critically III Patients: A Pilot Randomized Controlled Trial (FEED Trial). JPEN J Parenter Enteral Nutr, 2018.

79. Pasiakos, S.M., J.J. Cao, L.M. Margolis, E.R. Sauter, L.D. Whigham, J.P. McClung, J.C. Rood, J.W. Carbone, G.F. Combs, Jr., and A.J. Young, Effects of high-protein diets on fat-free mass and muscle protein synthesis following weight loss: a randomized controlled trial. FASEB J, 2013. 27(9): p. 3837-47.

80. Stelten, S., I.M. Dekker, E.M. Ronday, A. Thijs, E. Boelsma, H.W. Peppelenbos, and M.A. de van der Schueren, Protein-enriched 'regular products' and their effect on protein intake in acute hospitalized older adults; a randomized controlled trial. Clin Nutr, 2015. 34(3): p. 409-14.

81. Leistra, E., F. Willeboordse, M.A. van Bokhorst-de van der Schueren, M. Visser, P.J. Weijs, A. Haansvan den Oord, J. Oostenbrink, A.M. Evers, and H.M. Kruizenga, Predictors for achieving protein and energy requirements in undernourished hospital patients. Clin Nutr, 2011. 30(4): p. 484-9.

82. Dijxhoorn, D.N., M.G.A. van den Berg, W. Kievit, J. Korzilius, J.P.H. Drenth, and G.J.A. Wanten, A novel in-hospital meal service improves protein and energy intake. Clin Nutr, 2017.

83. van Bokhorst-de van der Schueren, M.A., M.M. Roosemalen, P.J. Weijs, and J.A. Langius, High waste contributes to low food intake in hospitalized patients. Nutr Clin Pract, 2012. 27(2): p. 274-80. 
84. Deutz, N.E., J.M. Bauer, R. Barazzoni, G. Biolo, Y. Boirie, A. Bosy-Westphal, T. Cederholm, A. CruzJentoft, Z. Krznaric, K.S. Nair, P. Singer, D. Teta, K. Tipton, and P.C. Calder, Protein intake and exercise for optimal muscle function with aging: recommendations from the ESPEN Expert Group. Clin Nutr, 2014. 33(6): p. 929-36.

85. Bauer, J., G. Biolo, T. Cederholm, M. Cesari, A.J. Cruz-Jentoft, J.E. Morley, S. Phillips, C. Sieber, P. Stehle, D. Teta, R. Visvanathan, E. Volpi, and Y. Boirie, Evidence-based recommendations for optimal dietary protein intake in older people: a position paper from the PROT-AGE Study Group. J Am Med Dir Assoc, 2013. 14(8): p. 542-59.

86. Tieland, M., K.J. Borgonjen-Van den Berg, L.J. van Loon, and L.C. de Groot, Dietary protein intake in community-dwelling, frail, and institutionalized elderly people: scope for improvement. Eur J Nutr, 2012. 51(2): p. 173-9.

87. (RIVM), N.I...P.H.a.t.E., Diet of communitydwelling older adults: Dutch National Food Consumption Survey Older adults 2010-2012. Database, 2013.

88. Morley, J.E., J.M. Argiles, W.J. Evans, S. Bhasin, D. Cella, N.E. Deutz, W. Doehner, K.C. Fearon, L. Ferrucci, M.K. Hellerstein, K. Kalantar-Zadeh, H. Lochs, N. MacDonald, K. Mulligan, M. Muscaritoli, P. Ponikowski, M.E. Posthauer, F. Rossi Fanelli, M. Schambelan, A.M. Schols, M.W. Schuster, S.D. Anker, C. Society for Sarcopenia, and D. Wasting, Nutritional recommendations for the management of sarcopenia. J Am Med Dir Assoc, 2010. 11(6): p. 391-6.

89. Pasiakos, S.M., L.M. Margolis, and J.S. Orr, Optimized dietary strategies to protect skeletal muscle mass during periods of unavoidable energy deficit. FASEB J, 2015. 29(4): p. 1136-42.

90. Mitchell, C.J., R.F. D'Souza, S.M. Mitchell, V.C. Figueiredo, B.F. Miller, K.L. Hamilton, F.F. Peelor, 3rd, M. Coronet, C.A. Pileggi, B. Durainayagam, A.C. Fanning, S.D. Poppitt, and D. Cameron-Smith, Impact of dairy protein during limb immobilization and recovery on muscle size and protein synthesis; a randomized controlled trial. J Appl Physiol (1985), 2018. 124(3): p. 717-728.

91. Beelen, J., E. Vasse, N. Janssen, A. Janse, N.M. de Roos, and L. de Groot, Protein-enriched familiar foods and drinks improve protein intake of hospitalized older patients: A randomized controlled trial. Clin Nutr, 2017.

92. Neelemaat, F., P. Lips, J.E. Bosmans, A. Thijs, J.C. Seidell, and M.A. van Bokhorst-de van der Schueren, Short-term oral nutritional intervention with protein and vitamin $D$ decreases falls in malnourished older adults. J Am Geriatr Soc, 2012. 60(4): p. 691-9.

93. Doorduijn, A.S., Y. van Gameren, E. Vasse, and N.M. de Roos, At Your Request((R)) room service dining improves patient satisfaction, maintains nutritional status, and offers opportunities to improve intake. Clin Nutr, 2016. 35(5): p. 1174-80.

94. Manning, F., K. Harris, R. Duncan, K. Walton, J. Bracks, L. Larby, L. Vari, K. Jukkola, J. Bell, M. Chan, and $\mathrm{M}$. Batterham, Additional feeding assistance improves the energy and protein intakes of hospitalised elderly patients. A health services evaluation. Appetite, 2012. 59(2): p. 471-7.

95. Munk, T., A.M. Beck, M. Holst, E. Rosenbom, H.H. Rasmussen, M.A. Nielsen, and T. Thomsen, Positive effect of protein-supplemented hospital food on protein intake in patients at nutritional risk: a randomised controlled trial. J Hum Nutr Diet, 2014. 27(2): p. 122-32.

96. McCray, S., K. Maunder, R. Krikowa, and K. MacKenzie-Shalders, Room Service Improves Nutritional Intake and Increases Patient Satisfaction While Decreasing Food Waste and Cost. J Acad Nutr Diet, 2018. 118(2): p. 284-293.

97. Groen, B.B., P.T. Res, B. Pennings, E. Hertle, J.M. Senden, W.H. Saris, and L.J. van Loon, Intragastric protein administration stimulates overnight muscle protein synthesis in elderly men. American journal of physiology. Endocrinology and metabolism, 2012. 302(1): p. E52-60.

98. Tieland, M., M.L. Dirks, N. van der Zwaluw, L.B. Verdijk, O. van de Rest, L.C. de Groot, and L.J. van Loon, Protein supplementation increases muscle mass gain during prolonged resistance-type exercise training in frail elderly people: a randomized, double-blind, placebo-controlled trial. J Am Med Dir Assoc, 2012. 13(8): p. 713-9. 
99. Smith, G.I., S. Julliand, D.N. Reeds, D.R. Sinacore, S. Klein, and B. Mittendorfer, Fish oil-derived n-3 PUFA therapy increases muscle mass and function in healthy older adults. Am J Clin Nutr, 2015. 102(1): p. 115-22.

100. Bell, K.E., T. Snijders, M. Zulyniak, D. Kumbhare, G. Parise, A. Chabowski, and S.M. Phillips, A whey protein-based multi-ingredient nutritional supplement stimulates gains in lean body mass and strength in healthy older men: A randomized controlled trial. PLoS One, 2017. 12(7): p. e0181387.

101. Rondanelli, M., C. Klersy, G. Terracol, J. Talluri, R. Maugeri, D. Guido, M.A. Faliva, B.S. Solerte, M. Fioravanti, H. Lukaski, and S. Perna, Whey protein, amino acids, and vitamin D supplementation with physical activity increases fat-free mass and strength, functionality, and quality of life and decreases inflammation in sarcopenic elderly. Am J Clin Nutr, 2016. 103(3): p. 830-40.

102. Fiatarone, M.A., E.F. O'Neill, N.D. Ryan, K.M. Clements, G.R. Solares, M.E. Nelson, S.B. Roberts, J.J. Kehayias, L.A. Lipsitz, and W.J. Evans, Exercise training and nutritional supplementation for physical frailty in very elderly people. N Engl J Med, 1994. 330(25): p. 1769-75.

103. Dreyer, H.C., L.A. Strycker, H.A. Senesac, A.D. Hocker, K. Smolkowski, S.N. Shah, and B.A. Jewett, Essential amino acid supplementation in patients following total knee arthroplasty. J Clin Invest, 2013. 123(11): p. 4654-66.

104. Niccoli, S., A. Kolobov, T. Bon, S. Rafilovich, H. Munro, K. Tanner, T. Pearson, and S.J. Lees, Whey Protein Supplementation Improves Rehabilitation Outcomes in Hospitalized Geriatric Patients: A Double Blinded, Randomized Controlled Trial. J Nutr Gerontol Geriatr, 2017.36(4):p.149-165.

105. Koya, S., T. Kawaguchi, R. Hashida, E. Goto, H. Matsuse, H. Saito, K. Hirota, R. Taira, Y. Matsushita, M. Imanaga, A. Nagamatsu, T. Shirono, S. Shimose, H. Iwamoto, T. Niizeki, R. Kuromatsu, H. Miura, N. Shiba, and T. Torimura, Effects of in-hospital exercise on liver function, physical ability, and muscle mass during treatment of hepatoma in patients with chronic liver disease. Hepatol Res, 2017. 47(3): p. E22-E34.

106. Buhl, S.F., A.L. Andersen, J.R. Andersen, O. Andersen, J.E. Jensen, A.M. Rasmussen, M.M. Pedersen, L. Damkjaer, H. Gilkes, and J. Petersen, The effect of protein intake and resistance training on muscle mass in acutely ill old medical patients - A randomized controlled trial. Clin Nutr, 2016. 35(1): p. 59-66.

107. Gade, J., A.M. Beck, C. Bitz, B. Christensen, T.W. Klausen, A. Vinther, and A. Astrup, Protein-enriched, milk-based supplement to counteract sarcopenia in acutely ill geriatric patients offered resistance exercise training during and after hospitalisation: study protocol for a randomised, double-blind, multicentre trial. BMJ Open, 2018. 8(2): p. e019210.

108. Pedersen, M.M., J. Petersen, N. Beyer, L. Damkjaer, and T. Bandholm, Supervised progressive crosscontinuum strength training compared with usual care in older medical patients: study protocol for a randomized controlled trial (the STAND-Cph trial). Trials, 2016. 17: p. 176.

109. Dirks, M.L., B.T. Wall, and L.J.C. van Loon, Interventional strategies to combat muscle disuse atrophy in humans: focus on neuromuscular electrical stimulation and dietary protein. J Appl Physiol (1985), 2017: p. jap009852016.

110. Dirks, M.L., B.B. Groen, R. Franssen, J. van Kranenburg, and L.J. van Loon, Neuromuscular electrical stimulation prior to presleep protein feeding stimulates the use of protein-derived amino acids for overnight muscle protein synthesis. J Appl Physiol (1985),2017.122(1):p.20-27.

111. Dirks, M.L., D. Hansen, A. Van Assche, P. Dendale, and L.J. Van Loon, Neuromuscular electrical stimulation prevents muscle wasting in critically ill comatose patients. Clin Sci (Lond), 2015. 128(6): p. 357-65.

112. Suetta, C., S.P. Magnusson, A. Rosted, P. Aagaard, A.K. Jakobsen, L.H. Larsen, B. Duus, and M. Kjaer, Resistance training in the early postoperative phase reduces hospitalization and leads to muscle hypertrophy in elderly hip surgery patients--a controlled, randomized study. J Am Geriatr Soc, 2004. 52(12): p. 2016-22.

113. Leenders, M., L.B. Verdijk, L. van der Hoeven, J. van Kranenburg, R. Nilwik, and L.J. van Loon, Elderly Men and Women Benefit Equally From Prolonged Resistance-Type Exercise Training. The journals of gerontology. Series A, Biological sciences and medical sciences, 2012. 
114. Suetta, C., P. Aagaard, A. Rosted, A.K. Jakobsen, B. Duus, M. Kjaer, and S.P. Magnusson, Traininginduced changes in muscle CSA, muscle strength, EMG, and rate of force development in elderly subjects after long-term unilateral disuse. J Appl Physiol, 2004. 97(5): p. 1954-61.

115. Suetta, C., J.L. Andersen, U. Dalgas, J. Berget, S.O. Koskinen, P. Aagaard, S.P. Magnusson, and M. Kjaer, Resistance training induces qualitative changes in muscle morphology, muscle architecture and muscle function in elderly postoperative patients. J Appl Physiol, 2008.

116. Lamb, S.E., J.A. Oldham, R.E. Morse, and J.G. Evans, Neuromuscular stimulation of the quadriceps muscle after hip fracture: a randomized controlled trial. Arch Phys Med Rehabil, 2002. 83(8): p. 1087-92.

117. Sakai, T., K. Maeda, H. Wakabayashi, S. Nishioka, and H. Seki, Nutrition Support Team Intervention Improves Activities of Daily Living in Older Patients Undergoing In-Patient Rehabilitation in Japan: A Retrospective Cohort Study. J Nutr Gerontol Geriatr, 2017. 36(4): p. 166-177.

118. Hegerova, P., Z. Dedkova, and L. Sobotka, Early nutritional support and physiotherapy improved long-term self-sufficiency in acutely ill older patients.Nutrition, 2015.31(1):p.166-70.

119. van de Bool, C., E.P.A. Rutten, A. van Helvoort, F.M.E. Franssen, E.F.M. Wouters, and A. Schols, A randomized clinical trial investigating the efficacy of targeted nutrition as adjunct to exercise training in COPD. J Cachexia Sarcopenia Muscle, 2017. 8(5): p. 748-758.

120. Deacon, S.J., E.E. Vincent, P.L. Greenhaff, J. Fox, M.C. Steiner, S.J. Singh, and M.D. Morgan, Randomized controlled trial of dietary creatine as an adjunct therapy to physical training in chronic obstructive pulmonary disease. Am J Respir Crit Care Med, 2008. 178(3): p. 233-9.

121. Miller, M.D., M. Crotty, C. Whitehead, E. Bannerman, and L.A. Daniels, Nutritional supplementation and resistance training in nutritionally at risk older adults following lower limb fracture: a randomized controlled trial. Clin Rehabil, 2006. 20(4): p. 311-23.

122. Sugawara, K., H. Takahashi, T. Kashiwagura, K. Yamada, S. Yanagida, M. Homma, K. Dairiki, H. Sasaki, A. Kawagoshi, M. Satake, and T. Shioya, Effect of anti-inflammatory supplementation with whey peptide and exercise therapy in patients with COPD. Respir Med, 2012. 106(11): p. 1526-34.

123. Zak, M., C. Swine, and T. Grodzicki, Combined effects of functionally-oriented exercise regimens and nutritional supplementation on both the institutionalised and free-living frail elderly (doubleblind, randomised clinical trial). BMC Public Health, 2009. 9: p. 39.

124. Suetta, C., U. Frandsen, A.L. Mackey, L. Jensen, L.G. Hvid, M.L. Bayer, S.J. Petersson, H.D. Schroder, J.L. Andersen, P. Aagaard, P. Schjerling, and M. Kjaer, Ageing is associated with diminished muscle re-growth and myogenic precursor cell expansion early after immobility-induced atrophy in human skeletal muscle. J Physiol, 2013. 591(15): p. 3789-804.

125. Beelen, J., N.M. de Roos, and L. de Groot, A 12-week intervention with protein-enriched foods and drinks improved protein intake but not physical performance of older patients during the first 6 months after hospital release: a randomised controlled trial. Br J Nutr, 2017. 117(11): p. 1541-1549.

126. Ziylan, C., A. Haveman-Nies, S. Kremer, and L.C. de Groot, Protein-Enriched Bread and Readymade Meals Increase Community-Dwelling Older Adults' Protein Intake in a Double-Blind Randomized Controlled Trial. J Am Med Dir Assoc, 2017. 18(2): p. 145-151.

127. Collins, J. and J. Porter, The effect of interventions to prevent and treat malnutrition in patients admitted for rehabilitation: a systematic review with meta-analysis. J Hum Nutr Diet, 2015. 28(1): p. 1-15.

128. Buckinx, F., F. Landi, M. Cesari, R.A. Fielding, M. Visser, K. Engelke, S. Maggi, E. Dennison, N.M. AlDaghri, S. Allepaerts, J. Bauer, I. Bautmans, M.L. Brandi, O. Bruyere, T. Cederholm, F. Cerreta, A. Cherubini, C. Cooper, A. Cruz-Jentoft, E. McCloskey, B. Dawson-Hughes, J.M. Kaufman, A. Laslop, J. Petermans, J.Y. Reginster, R. Rizzoli, S. Robinson, Y. Rolland, R. Rueda, B. Vellas, and J.A. Kanis, Pitfalls in the measurement of muscle mass: a need for a reference standard. J Cachexia Sarcopenia Muscle, 2018. 9(2): p. 269-278. 

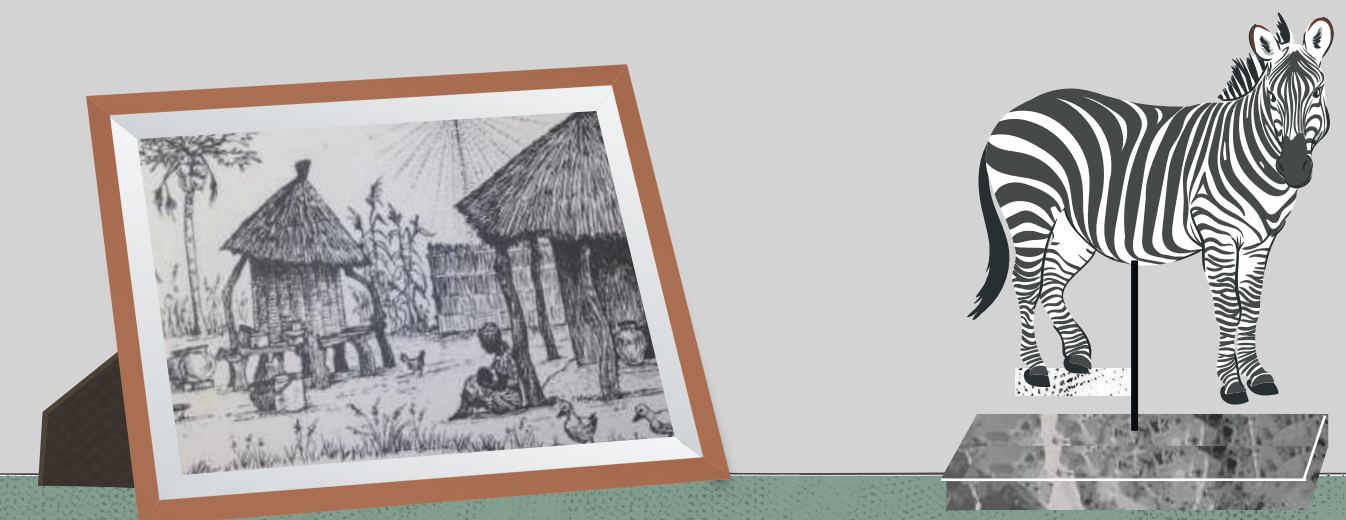


\title{
CHAPTER TEN
}

\author{
VALORIZATION \\ SUMMARY \\ SAMENVATTING \\ ACKNOWLEDGEMENTS \\ ABOUT THE AUTHOR
}




\section{VALORIZATION}

"Knowledge valorization refers to the process of creating value from knowledge, by making knowledge suitable and/or available for social (and/or economic) use and by making knowledge suitable for translation into competitive products, services, processes, and new commercial activities" (National Valorization Committee 2011:8).

\section{Relevance}

Due to the progressive aging of the population and the greater longevity, the subpopulation of older individuals is currently the fastest growing population in the developed world [1]. In the Netherlands, most recent predictions show that $33 \%$ of the population will be older than 60 in 2050, and nearly $10 \%$ aged over 80 years old $[2,3]$. The increasing aging population can be seen as a success for public health policies and socioeconomic development, but it also challenges society to improve health and functional capacity in older people and stimulate their social participation. Moreover, with the rise in the aged population there will be an increase in health care costs to cover the prevention, treatment, and hospitalization-associated costs of non-communicable and age-related diseases [2].

Hospitalization, often required due to illness or surgery, is associated with increased health care costs. For example, the cost of one hospital bed per day in the Netherlands is 500 euro, based on primary, secondary, and tertiary hospitals [4]. At present, the average hospitalization duration is 5 days [5]. However, the length of hospitalization increases with an advancing age from the age of 40 [5]. Short periods of bedrest or hospitalization have been shown to induce substantial muscle loss (chapter 2 and $[6,7])$. The amount of muscle tissue at time of hospital admission as well as the amount of muscle tissue lost during hospitalization predict mortality and clinical outcomes [8-10]. In addition, following a period of hospitalization, muscle disuse atrophy often carries over at home during the subsequent period of recovery. Importantly, it has been shown that recovery in older individuals is impaired when compared with younger individuals [11]. Subsequent (short) periods of muscle disuse atrophy in older individuals are therefore suggested to contribute to the age-related loss in muscle mass and strength, termed sarcopenia [6]. From 2016, sarcopenia has been recognized as a disease entity and has been given an ICD-10-CM code, meaning that there will be a demand for the availability of diagnostic tools, treatments, and intervention strategies to prevent and treat the emergence of sarcopenia.

\section{Health care implementation}

Nowadays, hospitals in the Netherlands have more daycare patients than in-patients. Moreover, patients are dismissed earlier, as evidenced by the reduction of average hospital length of stay from 7.5 days in 2003 to 5.2 days in 2013 [5]. This places a higher burden on the responsibility and the self-direction of the patient for recovery at home or in rehabilitation 
centers, as well as a multimodal approach for the integrated care to supervise patients from home, troughout hospitalization, back to home. Since more of the current health care is shifting from primary care towards secondary and tertiary health services, an efficient, multidisciplinary, integrated health care system is essential. Recently, more programs have been developed to prepare patients prior to a period of hospitalization by pre-habilitation training and nutritional support; examples of this are 'Fit4surgery' and 'Better in better out' concepts. Such a pre-habilitation program is not only an effective tool to increase physical and nutritional status of the patient; it also puts more accountability and motivation on patients. In addition, hospitals have introduced fast track surgeries and more daycare treatments for the fittest patients in order to be treated faster, on times outside regular hours, and to be dismissed earlier. This requests direct supervision during pre-habilitation and recovery in the home-based setting, including medical, nutritional, physical, social, and psychological support. Education towards the patients is essential in this case and all health care workers will have to carry out the same message in order to support integrated care.

This thesis provides insight in the absolute amount of muscle mass loss and nutritional intake during merely a few days of hospitalization in older patients (chapter $\mathbf{2}$ and 3). Even though there is an increasing amount of evidence on the negative health consequences of hospitalization in the older population, our findings have not yet been generalized and translated to the general public. Therefore, awareness amongst patients on the relevance of nutrition and physical activity should be created. Secondly, it is the task of physicians and health care workers to educate their patients on this. During hospital stay, patients spend about $80 \%$ of their day in bed, their food is served at the bedside, and appointments with physicians and health care workers take place in the patients' room [12, 13]. Indeed, older patients during hospitalization spend a mere 43 minutes per day standing or walking [12-14], and there is a clear role here for policy makers and the logistics in hospitals to encourage physical activity during hospitalization. Some hospitals in the Netherlands have started with creating attractive walking routes, gardens, and outside training equipment, which will be continued in more hospitals and nursing homes. The intrinsic motivation and patients' journey throughout hospitalization differs per patient, which does not require a one-size-fits-all advice and treatment. Therefore, a proper assessment of motivation, functional, and nutritional status in the pre- to post- clinical phase is essential to improve the treatment and supervision of the patient.

\section{Products and meal services}

The present thesis discusses several nutritional strategies to increase protein intake in older and clinically compromised individuals (chapter 6-8). The ingestion of dietary protein has been shown to stimulate muscle protein synthesis, and as such, is a key regulator in the maintenance of muscle mass with aging and in clinical populations. Acute changes in food intake can dramatically decrease protein intake and contribute to muscle mass and strength loss in the older and clinically compromised population. 
Pre-sleep protein ingestion can likely serve as an effective strategy to increase overall protein intake in the older population. We show in chapter $\mathbf{7}$ that protein ingested prior to sleep is effectively digested and absorbed and increases overnight muscle protein synthesis rates. The ingestion of $40 \mathrm{~g}$ protein significantly increased overnight muscle protein synthesis rates. Since $40 \mathrm{~g}$ of protein (e.g. $>1 \mathrm{~L}$ of milk) is likely difficult to consume prior to sleep by the general elderly population, technological advances towards protein-dense and low-volume products are necessary here to develop and improve pre-sleep protein products for healthy and diseased older individuals. Moreover, protein intake during hospitalization and institutionalization is generally reduced in the majority of the elderly. Still $40 \%$ of the patients are malnourished during hospitalization and in nursing homes [15, 16]. Pre-sleep protein ingestion can serve as an effective strategy to increase overall protein intake or cover energy and protein deficits during the first days of illness or in the pre- and peri-operative period. In addition, an evening serving round with protein-rich evening snacks can be relatively easily implemented in hospitals and nursing homes. However, here lies a call for product developers to produce specific pre-sleep nutritional products such as protein-rich snacks and drinks. The quality and attractiveness of meal services in hospitals and nursing homes is generally poor. New meal service concepts such as room service, buffet-style meals, meal orders upon request, mealtime assistance, and restaurant-style meal provisions have been developed [17-20]. Room service dining and attractive meals have been shown to increase food intake, improve patient satisfaction, and reduce food waste in hospitals [17, 18, 20,21]. Whilst these strategies provide interesting opportunities to decrease waste, more specific strategies to increase the protein content, source, taste, appearance, and timing of the meals are essential to increase the protein density of the diet. It is crucial that food intake is thoroughly monitored during hospitalization. With these new meal service concepts such as 'ordering upon request', food intake per patient can be directly monitored in order to tailor individualized dietary intake plans and directly advise towards the individual patient's needs and intake of that day. Nutritional assistants will have to play a central role in the nutritional support of the patient in order to provide patients with attractive meals and monitor nutritional intake.

\section{Recommendations}

The presented data in this dissertation provide many leads and targets for product development and innovations in the nutrition industry and health care. Since parts of this thesis have been conducted within the framework of TIFN, a public-private partnership, research findings have been shared with industrial partners throughout the last years. As such, a transparent platform is already in place for industries to directly implement the research findings into innovations.

To stimulate the implementation in health care, we present 10 key points on a separate flyer summarizing the main findings and recommendations from the present thesis. These will be distributed to several Dutch hospitals, nutritional companies, and Universities to be used as factsheets for health care professionals, patients, nutrition industry, and policy makers. 
The key recommendations from this thesis include:

1. Nutritional intervention strategies should be combined with more physical activity before, during, and after hospitalization.

2. Early pre-habilitation interventions that include exercise training and protein supplementation should be implemented to improve clinical outcomes during hospitalization in older patients.

3. Since $40 \%$ of the provided hospital meals is not consumed, more protein-rich foods and attractive meal service concepts need to be provided to the patient to increase protein intake.

4. To reach protein intake recommendation levels of $1.2 \mathrm{~g} \cdot \mathrm{kg}^{-1} \cdot \mathrm{d}^{-1}$ for older patients, a more protein-dense diet will be required.

5. More specific nutritional interventions throughout hospitalization are needed; nutritional supplementation can cover energy and protein deficits in the acute (operative) period while the subsequent days will require the focus on the increase in protein intake mainly through the diet.

6. Pre-sleep protein ingestion can be a useful strategy to provide extra protein on the evening prior to surgery and during evening rounds on the ward.

7. An attractive environment using walking routes and gardens could be offered in hospitals to encourage patients to be more physically active during hospitalization.

8. Hospital meals need to be attractive, adequately nutritious, and patient-specific.

9. Rehabilitation strategies need to be continued on the long term and should combine a functional exercise training regimen with proper nutritional support.

10. A multimodal approach will maximize the intrinsic motivation of the patient.

\section{Personal perspective}

Throughout my PhD trajectory, it became clear to me that there is an enormous amount of scientific research done on nutrition and muscle metabolism, however less is known on the practical implementation towards clinical health care. There is a gap between scientific research findings on one hand, and clinical bedside applicable research on the other hand. The collaboration between academic institutes and health care professionals as well as policy makers and nutrition companies is essential to investigate intervention strategies and facilitate the practical implementation. I am looking forward to, in the upcoming years, further conduct high quality research to gain knowledge on the role of (clinical) nutrition, that can be directly translated into practical advice and guidelines to dieticians, health care workers, and patients. I believe that dieticians, physicians, and scientists should collaborate to address research questions that are directly relevant to health care and patients, where a multimodal approach is key. Last but not least, there is currently enough insight to innovate health care and apply a more pro-active approach including pre- and post-hospitalization reconditioning of older patients. We should start today! 


\section{REFERENCES}

1. World Health Organization, National Institute on Aging and National Institutes of Health Publication Report on Global Health and Aging. no. 11-7737. October 2011.

2. Beard, J.R., A. Officer, I.A. de Carvalho, R. Sadana, A.M. Pot, J.P. Michel, P. Lloyd-Sherlock, J.E. EppingJordan, G. Peeters, W.R. Mahanani, J.A. Thiyagarajan, and S. Chatterji, The World report on ageing and health: a policy framework for healthy ageing. Lancet, 2016. 387(10033): p. 2145-2154.

3. United Nations, Department of Economic and Social Affairs, Population Division (2015). World Population Ageing 2015.

4. Stenberg, K., J.A. Lauer, G. Gkountouras, C. Fitzpatrick, and A. Stanciole, Econometric estimation of WHO-CHOICE country-specific costs for inpatient and outpatient health service delivery. Cost Eff Resour Alloc, 2018. 16: p. 11.

5. European Union, Hospital discharges and length of stay statistics. 2016 [cited 25-10-2017]. Available from: http://ec.europa.eu/eurostat/statistics-explained/index.php/Hospital_ discharges_and_length_of_stay_statistics\#Further_Eurostat_information

6. English, K.L. and D. Paddon-Jones, Protecting muscle mass and function in older adults during bed rest. Curr Opin Clin Nutr Metab Care, 2010. 13(1): p. 34-9.

7. Wall, B., M. Dirks, and L. van Loon, Skeletal muscle atrophy during short-term disuse: Implications for age-related sarcopenia. Ageing research reviews, 2013. 12(4): p. 898-906.

8. Welch, C. K.Z. Hassan-Smith, A.C. Greig, M.J. Lord, A.T. Jackson, Acute Sarcopenia Secondary to Hospitalisation - An Emerging Condition Affecting Older Adults. Aging Dis, 2018. 9(1): p. 151-164.

9. Morley, J.E., S.D. Anker, and S. von Haehling, Prevalence, incidence, and clinical impact of sarcopenia: facts, numbers, and epidemiology-update 2014. J Cachexia Sarcopenia Muscle, 2014. 5(4): p. 253-259.

10. Gariballa, S. and A. Alessa, Sarcopenia: prevalence and prognostic significance in hospitalized patients. Clin Nutr, 2013. 32(5): p. 772-6.

11. Suetta, C., U. Frandsen, A.L. Mackey, L. Jensen, L.G. Hvid, M.L. Bayer, S.J. Petersson, H.D. Schroder, J.L. Andersen, P. Aagaard, P. Schjerling, and M. Kjaer, Ageing is associated with diminished muscle regrowth and myogenic precursor cell expansion early after immobility-induced atrophy in human skeletal muscle. J Physiol, 2013. 591(15): p. 3789-804.

12. Brown, C.J., R.J. Friedkin, and S.K. Inouye, Prevalence and outcomes of low mobility in hospitalized older patients. J Am Geriatr Soc, 2004. 52(8): p. 1263-70.

13. Brown, C.J., D.T. Redden, K.L. Flood, and R.M. Allman, The underrecognized epidemic of low mobility during hospitalization of older adults. J Am Geriatr Soc, 2009. 57(9): p. 1660-5.

14. Schotanus, M.G.M., Y.F.L. Bemelmans, B. Grimm, I.C. Heyligers, and N.P. Kort, Physical activity after outpatient surgery and enhanced recovery for total knee arthroplasty. Knee Surg Sports Traumatol Arthrosc, 2017. 25(11): p. 3366-3371.

15. Kruizenga, H., S. van Keeken, P. Weijs, L. Bastiaanse, S. Beijer, G. Huisman-de Waal, H. Jager-Wittenaar, C. Jonkers-Schuitema, M. Klos, W. Remijnse-Meester, B. Witteman, and A. Thijs, Undernutrition screening survey in 564,063 patients: patients with a positive undernutrition screening score stay in hospital 1.4 d longer. Am J Clin Nutr, 2016. 103(4): p. 1026-32.

16. Tieland, M., K.J. Borgonjen-Van den Berg, L.J. van Loon, and L.C. de Groot, Dietary protein intake in community-dwelling, frail, and institutionalized elderly people: scope for improvement. European journal of nutrition, 2012. 51(2): p. 173-9.

17. Dijxhoorn, D.N., M.G.A. van den Berg, W. Kievit, J. Korzilius, J.P.H. Drenth, and G.J.A. Wanten, A novel in-hospital meal service improves protein and energy intake. Clin Nutr, 2017.

18. Doorduijn, A.S., Y. van Gameren, E. Vasse, and N.M. de Roos, At Your Request((R)) room service dining improves patient satisfaction, maintains nutritional status, and offers opportunities to improve intake. Clin Nutr, 2016. 35(5): p. 1174-80. 
19. Manning, F., K. Harris, R. Duncan, K. Walton, J. Bracks, L. Larby, L. Vari, K. Jukkola, J. Bell, M. Chan, and M. Batterham, Additional feeding assistance improves the energy and protein intakes of hospitalised elderly patients. A health services evaluation. Appetite, 2012. 59(2): p. 471-7.

20. Munk, T., A.M. Beck, M. Holst, E. Rosenbom, H.H. Rasmussen, M.A. Nielsen, and T. Thomsen, Positive effect of protein-supplemented hospital food on protein intake in patients at nutritional risk: a randomised controlled trial. J Hum Nutr Diet, 2014. 27(2): p. 122-32.

21. McCray, S., K. Maunder, R. Krikowa, and K. MacKenzie-Shalders, Room Service Improves Nutritional Intake and Increases Patient Satisfaction While Decreasing Food Waste and Cost. J Acad Nutr Diet, 2018. 118(2): p. 284-293. 


\section{SUMMARY}

Maintenance of skeletal muscle mass is of great clinical relevance in both health and disease. Having a low muscle mass at an older age increases the risk for hospitalization, impairs physical function, and results in a longer length of hospital stay, a worsened prognosis of disease, and higher mortality rates during hospitalization. A blunted response to the main anabolic stimuli of muscle mass regulation (coined anabolic resistance), i.e., dietary protein ingestion and physical activity, has been postulated to represent one of the driving factors explaining the generalized age-related muscle loss. Particularly in older and compromised clinical populations, acute changes in habitual physical activity level and food intake - often resulting from the development of various health issues - are likely the main cause of the accelerated skeletal muscle mass loss. Intervention strategies to maintain skeletal muscle mass are warranted to attenuate muscle loss with aging and during acute and chronic disease. The studies described in the present thesis aimed to gain further insight in the different factors that regulate muscle mass maintenance in older individuals, with a focus on nutritional aspects and clinical populations.

Older individuals experience multiple successive periods of hospitalization throughout the lifespan due to sickness, injury, and/or (elective) surgery. These successive periods likely contribute to the age-related loss of muscle mass and strength. To gain insight in the extent of muscle loss during a short period of hospitalization, the changes in skeletal muscle mass in older patients following elective hip replacement surgery were assessed in chapter 2. On average, 6 days of hospitalization resulted in a 3-4\% loss of muscle cross-sectional area in older patients. Likely, the impact of surgery, associated physical and mental stress, and reduced food intake during hospitalization further accelerate disuse-induced loss of skeletal muscle mass and function in clinical practice. In chapter 3, food intake in 101 hospitalized, older patients was measured and the amount of protein that was provided was compared with the amount of protein that was actually consumed in these patients. Protein intake during $\sim 6$ days of hospitalization was dramatically low, i.e. merely $\sim 0.6 \mathrm{~g} \cdot \mathrm{kg}^{-1} \cdot \mathrm{d}^{-1}$, in relatively healthy, older patients admitted for elective orthopedic surgery. In fact, 35-40\% of the provided hospital food was not consumed, resulting in extremely low energy and protein intake levels during hospital stay. Specific nutritional strategies including the provision of more proteindense meals, food fortification, supplementing oral nutritional supplements (ONS), and/or adjusting the timing of the provision of protein-rich meals and snacks are proposed to increase protein intake levels during hospitalization.

Since there is an accelerated loss of muscle mass in patients with metabolic diseases such as obesity, cardiovascular diseases, and type 2 diabetes, the hypothesis that older type 2 diabetes patients and obese individuals show impairments in muscle protein metabolism was examined in chapter $\mathbf{4}$ and $\mathbf{5}$. Using stable isotope tracer methodology, postabsorptive and postprandial muscle protein synthesis rates were assessed to determine potential alterations herein. Both postabsorptive and postprandial muscle protein synthesis rates following the ingestion of 20 
$g$ protein did not differ between older individuals with type 2 diabetes and healthy controls (chapter 4). As such, the more pronounced loss of skeletal muscle mass and strength in older type 2 diabetes patients does not seem to be attributed to a greater level of anabolic resistance. Chapter 5 examined postprandial protein handling in middle-aged males with morbid obesity and age-matched, lean controls. In contrast to our hypothesis, basal and postprandial muscle protein synthesis rates were not impaired in the obese state. We suggest that the relatively high level of habitual physical activity observed in the obese subjects may have protected from impairments in basal and postprandial muscle protein synthesis rates.

In chapters 6-8, several nutritional strategies are proposed to further stimulate postprandial muscle protein synthesis and, as such, to support muscle mass maintenance in healthy and clinically compromised older populations. In view of the recent interest in dietary nitrate as a nutritional compound to increase vasodilation and improve muscle tissue perfusion, the impact of ingesting a single bolus of dietary nitrate with protein on postprandial muscle protein synthesis rates was investigated in older, type 2 diabetes patients in chapter $\mathbf{6}$. The co-ingestion of sodium nitrate with $20 \mathrm{~g}$ protein did not result in higher muscle protein synthesis rates when compared with protein ingestion only in older individuals with type 2 diabetes. The ingestion of an additional protein meal prior to sleep provides an alternative strategy to stimulate muscle protein synthesis during a period where muscle protein synthesis rates are typically low. In chapter 7, the overnight muscle protein synthetic response to different amounts of protein ingested prior to sleep was assessed in 48 healthy, older males. Protein ingestion before sleep provided amino acids throughout the overnight period and subsequently served as precursors for de novo overnight muscle protein synthesis. The ingestion of $40 \mathrm{~g}$ protein only significantly increased overnight muscle protein synthesis rates when compared to a placebo. As physical activity can increase the anabolic response to protein intake, we subsequently investigated the surplus effect of physical activity performed in the evening to increase overnight muscle protein synthesis rates following pre-sleep protein ingestion in chapter 8. Performing physical activity prior to the $40 \mathrm{~g}$ pre-sleep protein ingestion increased overnight muscle protein synthesis rates to a greater extent. Therefore, we suggest that (both daytime and pre-sleep) nutritional strategies in older individuals should be combined with a certain amount of physical activity to further increase the muscle protein synthetic response to protein intake.

Finally, chapter 9 discusses different nutritional and physical activity intervention strategies to attenuate muscle mass and strength loss in older and clinically compromised populations. The pre-hospitalization period provides a window of opportunity to improve both nutritional as well as physical activity status and, as such, may improve clinical outcome during and following hospitalization. Intervention studies should focus on the combination of pre-habilitation training combined with nutritional support to augment muscle mass and strength prior to hospitalization. Since malnutrition during hospitalization is still present in $>40 \%$ of the patients, dietary strategies need to be developed to improve nutritional status and, thereby, attenuate muscle loss during subsequent hospitalization. The provision of high-protein ONS may compensate for the energy and protein intake deficit during the acute surgery period, 
whilst the provision of more protein-dense meals including pre-sleep protein ingestion may represent feasible nutritional strategies on the subsequent days of hospitalization. In order to obtain clinical evidence for the efficacy of such nutritional interventions, research studies need to assess more clinical and physiologically relevant outcome measurements. In the posthospitalization period, more evidence-based research is needed to confirm the overall benefits of (combined) nutritional and exercise interventions on the maintenance of muscle mass and function, overall quality of life in older patients, as well as the implementation of rehabilitation strategies in integrated health care. 


\section{SAMENVATTING}

Eén van de grootste uitdagingen in de huidige gezondheidszorg is de afname van spiermassa en de afname van fysiek functioneren die gepaard gaat met veroudering, ook wel sarcopenie genoemd. Een verlaagde spiermassa op oudere leeftijd vermindert het vermogen om dagelijkse activiteiten uit te kunnen voeren, verhoogt het risico op hospitalisatie en leidt bovendien tot een verlengde opnameduur, slechtere prognose, en verhoogde mortaliteit bij ziekenhuisopname. Spierbehoud wordt grotendeels gereguleerd door anabole stimuli zoals inname van eiwit via de voeding en fysieke inspanning. De respons op deze stimuli is echter verlaagd op oudere leeftijd (ook wel anabole resistentie genoemd), wat wordt gezien als één van de belangrijkste factoren die bijdragen aan het spiermassaverlies met veroudering. Naast de algemene afname van fysieke activiteit en voedingsinname met veroudering, krijgen veel ouderen te maken met acute klinische situaties waarbij verregaande inactiviteit en ondervoeding waarschijnlijk leiden tot een versneld verlies van spiermassa en -functie, bijvoorbeeld tijdens ziekenhuisopname. Recente inzichten suggereren dat dergelijke acute afnames in spiermassa in sterke mate bij kunnen dragen aan het ontstaan van sarcopenie. Interventiestrategieën om spiermassa te behouden zijn van groot belang om het verlies van spiermassa bij veroudering en gedurende acute en chronische ziekte te beperken. In dit proefschrift worden verschillende factoren beschreven die een rol spelen in de regulatie van spiermassa bij ouderen. Daarbij wordt specifieke aandacht besteed aan eiwitrijke voeding en verschillende klinische populaties.

Opeenvolgende periodes van ziekenhuisopname als gevolg van een ziekte, blessure, of (geplande) operatie dragen bij aan het leeftijdgerelateerde verlies van spiermassa en spierkracht. In hoofdstuk 2 werd het effect van een korte periode van ziekenhuisopname op het verlies van spiermassa onderzocht, door veranderingen in spiermassa te meten tijdens ziekenhuisopname bij 26 oudere patiënten die een nieuwe heup kregen. Een periode van ongeveer 6 dagen ziekenhuisopname resulteerde in een 3-4\% verlies van spiermassa bij oudere patiënten. Aangezien dit meer is dan de hoeveelheid spiermassa die verloren gaat tijdens een periode van fysieke inactiviteit zoals tijdens bedrust of immobilisatie bij gezonde mensen, impliceert dit, dat het effect van de operatie, de daaraan gerelateerde fysieke en mentale stress en een verminderde voedingsinname gedurende ziekenhuisopname waarschijnlijk bijdragen aan het versnelde verlies van spiermassa en -functie in de klinische praktijk. In hoofdstuk 3 is de dagelijkse voedingsinname van 101 oudere patiënten tijdens ziekenhuisopname voor een geplande knie- of heupoperatie gemeten, en daarbij werd met name gekeken naar het verschil tussen de hoeveelheid eiwit die werd aangeboden en datgene dat daadwerkelijk geconsumeerd werd. Eiwitconsumptie gedurende 6 dagen ziekenhuisopname was gemiddeld slechts 0.6 gram eiwit per kilogram lichaamsgewicht per dag, wat beduidend lager was dan de dagelijks aanbevolen hoeveelheid eiwit ( 0.8 gram per kilogram lichaamsgewicht per dag). In totaal werd $35-40 \%$ van de aangeboden voeding niet geconsumeerd, wat resulteerde in een extreem lage inname van energie en eiwit tijdens 
ziekenhuisopname. Specifieke voedingsstrategieën zoals het verrijken van de voeding, het gebruik van eiwitrijke voedingssupplementen en/of het aanpassen van het tijdstip van inname van eiwitrijke maaltijden en snacks zijn waarschijnlijk de meest geschikte strategieën om eiwitinname in patiënten tijdens ziekenhuisopname op peil te brengen.

Ouderen met chronische metabole aandoeningen zoals type 2 diabetes, cardiovasculaire ziekten en obesitas verliezen over het algemeen meer spiermassa tijdens veroudering. Daarom zijn in hoofdstuk $\mathbf{4}$ en $\mathbf{5}$ de hypotheses getest dat oudere patiënten met type 2 diabetes en personen met obesitas een verstoord spiereiwitmetabolisme hebben ten opzichte van gezonde personen. Door gebruik te maken van stabiele isotopen tracer methodologie kan spiereiwitsynthese (de snelheid van aanmaak van spiereiwitten) gemeten worden en de mogelijke verschillen tussen groepen worden aangetoond; zowel basaal (nuchter) als na inname van voedingseiwit. Zowel de basale spiereiwitsynthese als de spiereiwitsynthese na de inname van 20 gram eiwit waren niet verschillend tussen oudere patiënten met type 2 diabetes en gezonde ouderen (hoofdstuk 4). Het versnelde spiermassaverlies in ouderen met type 2 diabetes lijkt dus niet te kunnen worden verklaard door een verstoorde basale spieropbouw of een verminderde respons op eiwitinname (zogenaamde 'anabole resistentie'). In hoofdstuk $\mathbf{5}$ is de spieropbouw vergeleken voor en na de inname van $25 \mathrm{~g}$ eiwit tussen mannen van middelbare leeftijd met obesitas en mannen met een gezond gewicht. In tegenstelling tot de hypothese, werd ook in deze studie geen verminderde spiereiwitsynthese gemeten in obese proefpersonen in vergelijking met de mannen met een gezond gewicht. Hierdoor wordt verondersteld dat de relatief hoge mate van dagelijkse fysieke activiteit in de geïncludeerde obese proefpersonen beschermt tegen eventuele verstoringen in de basale en/of postprandiale spieropbouw.

In hoofdstuk 6-8 worden vervolgens verschillende voedingsstrategieën bestudeerd die de spiereiwitsynthese stimuleren en daardoor zouden kunnen bijdragen aan het behoud van spiermassa bij ouderen en klinische populaties. Nitraat heeft recentelijk veel aandacht gekregen als voedingscomponent aangezien het bijdraagt aan vaatverwijding en zodoende wellicht de doorbloeding van spierweefsel kan verbeteren. Daarom werd in hoofdstuk 6 het effect van de inname van nitraat in combinatie met een eiwitrijke drank op spiereiwitsynthese in ouderen met type 2 diabetes onderzocht. De gecombineerde inname van nitraat met $20 \mathrm{~g}$ eiwit leidde echter niet tot een hogere spiereiwitsynthese in ouderen met type 2 diabetes. Als alternatieve strategie om spiereiwitsynthese te stimuleren, in dit geval specifiek tijdens de nacht, is vervolgens gekeken naar de toevoeging van een extra eiwitrijke maaltijd voor het slapen. In hoofdstuk $\mathbf{7}$ is het effect van inname van verschillende hoeveelheden eiwit voor het slapen gaan in gezonde oudere mannen onderzocht. De inname van een eiwitrijke drank voor het slapen gaan zorgde ervoor dat aminozuren uit de drank beschikbaar kwamen in de circulatie gedurende de nacht en ook daadwerkelijk fungeerden als bouwstenen voor spiereiwitsynthese. Echter, de inname van $40 \mathrm{~g}$ eiwit voor het slapen gaan verhoogde de spiereiwitsynthese alleen significant ten opzichte van de placebo drank (zonder eiwit). Daarnaast is bekend dat fysieke inspanning in combinatie met voedingsinname leidt tot een verhoogde anabole respons op voeding. Daarom werd in hoofdstuk $\mathbf{8}$ het effect van fysieke 
inspanning voorafgaand aan de inname van $40 \mathrm{~g}$ eiwit voor het slapen gaan onderzocht bij 24 oudere mannen. Fysieke inspanning voorafgaand aan de inname van eiwit voor het slapen resulteerde in een hogere spiereiwitsynthese tijdens de nacht in vergelijking met eiwitinname alleen. Hieruit wordt geconcludeerd dat voedingsinterventies (in het algemeen als ook voor het slapen gaan) gecombineerd zouden moeten worden met fysieke inspanning om zo de impact op de spiereiwitsynthese verder te verhogen.

Dit proefschrift sluit af met een discussie van de onderzoeksresultaten (hoofdstuk 9) en de implicaties van verschillende interventiestrategieën op het verlies van spiermassa en spierkracht tijdens veroudering en bij klinische populaties. De periode voorafgaande aan ziekenhuisopname is een uitermate geschikte periode om zowel de voedingsstatus als fysieke status van de patiënt te optimaliseren en zo de klinische uitkomst tijdens en na hospitalisatie te verbeteren. Interventiestudies zullen zich allereerst moeten richten op de combinatie van pre-habilitatie training in combinatie met optimale voeding om spiermassa en spierkracht te verbeteren voorafgaand aan een ziekenhuisopname. Aangezien $40 \%$ van de patiënten in het ziekenhuis ondervoed zijn, dienen er daarnaast voedingsstrategieën ontwikkeld te worden om de voedingsstatus te verbeteren tijdens hospitalisatie, met als doel het spiermassaverlies te beperken. Veelbelovende strategieën hiervoor zijn het verstrekken van eiwitrijke supplementen op de dagen rondom een operatie of acute opname om het tekort aan energie en eiwit aan te vullen. Bovendien zal het aanbieden van eiwitrijke maaltijden in combinatie met een eiwitrijke snack voor het slapen gaan geschikt zijn om de voedingsinname te verhogen. Om bewijs voor de effectiviteit van bovengenoemde voedingsstrategieën te kunnen leveren, zullen interventiestudies zich moeten richten op klinisch en fysiologisch relevante uitkomstmaten. Tot slot is er ook in de periode na hospitalisatie meer bewijs nodig van de voordelen van gecombineerde voedings- en bewegingsinterventies op het behoud van spiermassa en functie, kwaliteit van leven, evenals de mogelijke implementatie van deze herstelstrategieën in de ketenzorg. Desalniettemin is de huidige kennis voldoende om vandaag al te starten met een verandering in de gezondheidszorg en de richting op te gaan naar een meer proactieve benadering in de begeleiding van oudere patiënten voor, tijdens en na hospitalisatie. 


\section{MEDE MDGELIJK GEMAAKT DODR}

$$
\begin{array}{r}
\text { Gru LUC VAN LODN } \\
\text { inspirator } \\
\text { Hijgend Hert } \\
4 \times 4 \text { canvay } \\
\begin{array}{r}
\text { co-pilout } \\
4 \text { P's }
\end{array}
\end{array}
$$

de deur die altijd open staat het leukste oppas adres

leescommissie PROF. JQS SCHOLS

PROF. ANNEMIE SCHDLS

DR. KAATJE LENNAERTS

PRDF. BEN WITTEMAN

DR. RENÉ KDOPMAN

corona PRDF. ILAV RODIJACKERS

PROF. QIM BEN SCHDUTEN

happy sidekicks MARLDU DIRKS

BIANCA VAN DER ZEE

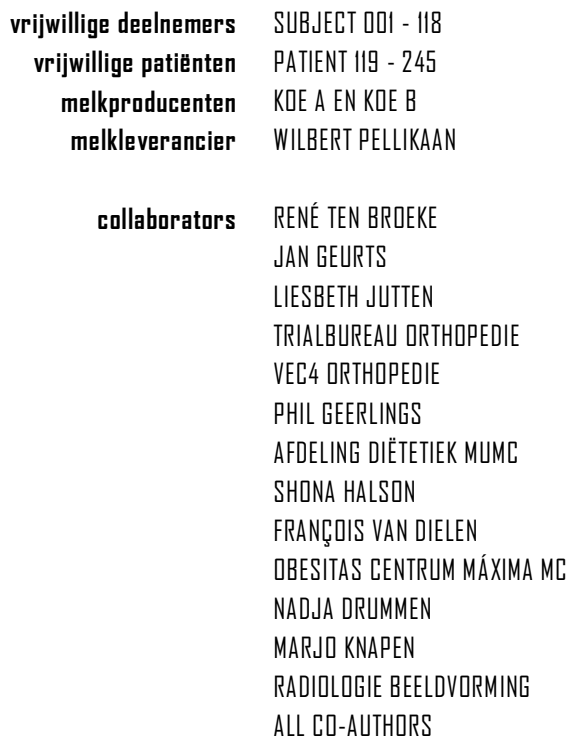

TiFN experts LISETTE DE GRODT

ELLEN VAN DEN HEUVEL

ARIE KIES

YVETTE LUIKING

IAN ROLLO

JAN STEIJNS

MICHAEL TIELAND

SJURS VERLAAN

biopt koningen en koninginnen

JACQUELINE BASTIAANSE

KIRSTEN VAN DER BEEK

BART GROEN

IRENE FLEUR KRAMER

JUEY SMEETS

\section{roomies}

$\begin{aligned} \text { window conversations } & \text { ANDY HOLWERDA } \\ \text { king imitator } & \text { CAS FUCHS } \\ \text { chacolate stash } & \text { MICHELE WEIJZEN }\end{aligned}$

Minions CINDY VAN DER AVQDRT

MILOU BEELEN

CAS FUCHS

STEFAN GDRISSEN

ANDY HOLWERDA

FLORIS HENDRIKS

WESLEY HERMANS

LISANNE HDUBEN

JEAN NYAKAYIRU

MAARTEN QVERKAMP

PHILIPPE PINCKAERS

JUEY SMEETS

TIM SNIJDERS

JORN TRDMMELEN

MICHELLE WEIJZEN

Emeritus Minions JAN-WILLEM VAN DIJK

BART GRDEN

HENRIKE HAMER

ASTRID HIRSTMAN

KRISTIN JUNVIK

IRENE FLEUR KRAMER

MARIKA LEENDERS

RACHEL NILWIK

TYLER CHURCHWARD-VENNE 


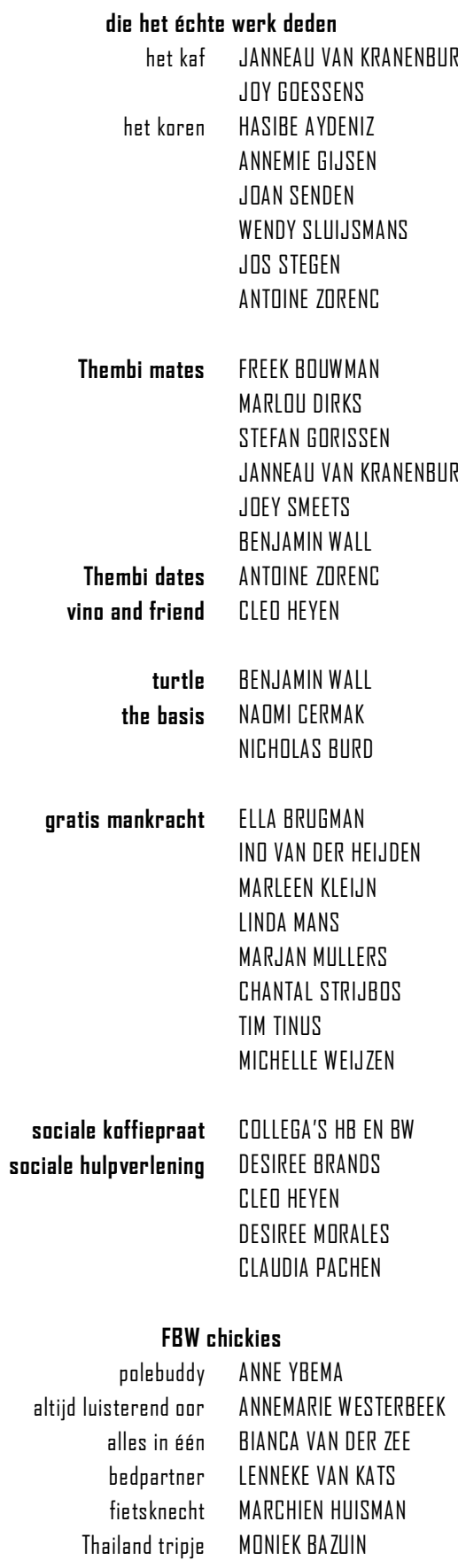

voor de nodige familieborrel NEVEN EN NICHTEN SCHOUTEN MIEKE EN JUEP VAN VALEN leukste nieuwe aanwinst YVETTE KRIST

interessebaak HAN EN SKA BEUMER-LEEUWERIK JUS EN ELLEN VAN HALST CLEMENCE HAMER LEQN EN KARIN DE JUNG-BEEN OPA EN IMA MEEUWSEN OUMS EN TANTES SCHDUTEN HANS QLE AND ASTRID SQRENSEN ANJA EN CEES VAN VALEN

the best is yet to come BART RENTMEESTER

voor altijd mijn grote broer WALTER mijn groutste trots PAPA EN MAMA 


\section{ABOUT THE AUTHOR}

Imre Kouw was born on 30 May 1986 in Goes, the Netherlands. She grew up with one older brother in a small village, Kortgene, in Zeeland. From her third until her sixth year she lived with her family in Niger, West-Africa, where her parents were working as teachers. In 2004, she graduated from secondary school, Buys Ballot College in Goes, the Netherlands. She obtained her Bachelors' degree in Nutrition and Dietetics at the Applied University of Amsterdam in 2010. During her BSc in Nutrition and Dietetics, she did a 20-week research project at Deakin University, Melbourne, Australia, and an internship as a dietician in clinical practice at Leiden University Medical Centre. To finalize her BSc degree, she wrote her thesis on "he impact of dietary protein on skeletal muscle mass in older individuals" at the Division of Human Nutrition at Wageningen University. In 2010, she studied at Karolinska Institute and Stockholm University, Sweden, and obtained her MSc in Nutrition Sciences in 2012. During her MSc, she conducted an internship in the Muscle Metabolism Maastricht (M3) group of Prof. Luc van Loon at the Department of Human Movement Sciences at Maastricht University, the Netherlands, and she started working as a research assistant in the M3 research group directly after obtaining her degree. Here, she worked on several research projects assessing the impact of dietary interventions on muscle protein metabolism in healthy volunteers, patients with type 2 diabetes, and frail older individuals, and she obtained experience in using stable isotope tracer methodology. In January 2013, she started her PhD under the supervision of Prof. Luc van Loon and Dr. Lex Verdijk, focusing on the impact of protein ingestion prior to sleep on muscle protein synthesis rates in older individuals. In the years that followed, she performed numerous human intervention studies that focused on nutritional strategies to attenuate muscle loss during hospitalization in older and clinical populations. Throughout her PhD, Imre was awarded with a European Society for Clinical Nutrition and Metabolism (ESPEN) Best Oral presentation in 2015 and a Travel Grant in 2015 and 2016, and a Gatorade Sport Science Institute (GSSI) Nutrition Award in 2016. In 2017, she visited the Royal Adelaide Hospital, Australia, to collaborate on an interventional study applying stable isotope tracers in the Intensive Care Research group of Prof. Marianne Chapman for 6 weeks. From January 2019 onwards, she will be working as a Postdoctoral Research Fellow with Prof. John Hawley in the Nutrition and Exercise Research Group at the Australian Catholic University in Melbourne, Australia. 


\section{List of publications}

1. Kouw IWK, Groen BBL, Smeets JSJ, Kramer IF, van Kranenburg JMX, Nilwik R, Geurts JAP, ten Broeke RHM, Poeze M, van Loon LC, Verdijk LB. One week of hospitalization following elective hip surgery induces substantial muscle atrophy in older patients. $J$ Am Med Dir Assoc. 2018 Aug 11. pii: S1525-8610(18)30356-6.

2. Trommelen J, Kouw IWK, Holwerda AM, Snijders T, Halson SL, Rollo I, Verdijk LB, van Loon LJC. Pre-sleep dietary protein-derived amino acids are incorporated in myofibrillar protein during post-exercise overnight recovery. Am J Physiol Endocrinol Metab. 2018 May 1;314(5):E457-E467.

3. Kouw IWK, Holwerda AM, Trommelen J, Kramer IF, Bastiaanse J, Halson SL, Wodzig WK, Verdijk LB, van Loon LJC. Protein ingestion prior to sleep increases overnight muscle protein synthesis rates in healthy older men: a randomized controlled trial. $J$ Nutr. 2017 Dec;147(12):2252-2261.

4. Nyakayiru J, Kouw IWK, Cermak NM, Senden JM, van Loon LJC, Verdijk LB. Sodium nitrate ingestion increases skeletal muscle nitrate content in humans. J Appl Physiol (1985). $2017 \mathrm{Sep} \mathrm{1;123(3):637-644.}$

5. Trommelen J, Holwerda AM, Kouw IWK, Langer H, Halson SL, Rollo I, Verdijk LB, van Loon LC. Resistance exercise augments postprandial overnight muscle protein synthesis rates. Med Sci Sports Exerc. 2016 Dec;48(12):2517-2525.

6. Gorissen SHM, Horstman AM, Franssen R, Kouw IWK, Wall BT, Burd NA, de Groot LC, van Loon LJC. Habituation to low or high protein intake does not modulate basal or postprandial muscle protein synthesis rates: a randomized trial. Am J Clin Nutr. 2017 Feb;105(2):332-342.

7. Kramer IF, Verdijk LB, Hamer HM, Verlaan S, Luiking YC, Kouw IWK, Senden JM, van Kranenburg JMX, Gijsen AP, Bierau J, Poeze M, van Loon LJC. Both basal and postprandial muscle protein synthesis rates, following the ingestion of a leucine-enriched whey protein supplement, are not impaired in sarcopenic older males. Clin Nutr. 2017 Oct;36(5): 1440-1449.

8. Klinkenberg $\sqcup$, Wildi K, van der Linden N, Kouw IWK, Niens M, Twerenbold R, Rubini Gimenez M, Puelacher C, Daniel Neuhaus J, Hillinger P, Nestelberger T, Boeddinghaus J, Grimm K, Sabti Z, Bons JA, van Suijlen JD, Tan FE, Ten Kate J, Bekers O, van Loon UC, van Dieijen-Visser MP, Mueller C, Meex SJ. Diurnal rhythm of cardiac troponin: consequences for the diagnosis of acute myocardial infarction. Clin Chem. 2016 Dec;62(12):1602-1611.

9. Kouw IWK, Cermak NM, Burd NA, Churchward-Venne TA, Senden JM, Gijsen AP, van Loon LJC. Sodium nitrate co-ingestion with protein does not augment postprandial muscle protein synthesis rates in older, type 2 diabetes patients. Am J Physiol Endocrinol Metab. 2016 Aug 1;311(2):E325-34.

10. Holwerda AM, Kouw IWK, Trommelen J, Halson SL, Wodzig WK, Verdijk LB, van Loon UC. Physical activity performed in the evening increases the overnight muscle protein 
synthetic response to presleep protein ingestion in older men. J Nutr. 2016 Jul; 146(7):1307-14.

11. Kouw IWK, Gorissen SHM, Burd NA, Cermak NM, Gijsen AP, van Kranenburg JMX, van Loon LJC. Postprandial protein handling is not impaired in type 2 diabetes patients when compared with normoglycemic controls. J Clin Endocrinol Metab. 2015 Aug; 100(8):3103-11.

12. Cermak NM, Hansen D, Kouw IWK, van Dijk JW, Blackwell JR, Jones AM, Gibala MJ, van Loon LJC. A single dose of sodium nitrate does not improve oral glucose tolerance in patients with type 2 diabetes mellitus. Nutr Res. 2015 Aug;35(8):674-80.

13. Kramer IF, Verdijk LB, Hamer HM, Verlaan S, Luiking Y, Kouw IWK, Senden J, van Kranenburg JMX, Gijsen AP, Poeze M, van Loon LC. Impact of the macronutrient composition of a nutritional supplement on muscle protein synthesis rates in older men: a randomized, double blind, controlled trial. J Clin Endocrinol Metab. 2015 Nov; 100(11):4124-32.

14. Burd NA, Cermak NM, Kouw IWK, Gorissen SH, Gijsen AP, van Loon LJ. The use of doubly labeled milk protein to measure postprandial muscle protein synthesis rates in vivo in humans. J Appl Physiol 2014 Dec 1;117(11):1363-70.

15. Kouw IWK, Tieland M, Gorissen SH. Journal club article. A step towards underpinning the molecular signaling events regulating muscle protein loss in critically ill patients. J Physiol; 2011; 589:5925-6.

\section{Awards and presentations}

2018: Invited speaker: Dutch Nutrition Conference, Ede, the Netherlands, 18 May 2018: "Nutrition and frailty"

Invited speaker: Exeter University, Exeter, Great Britain, 14 Feb 2018: "Nutritional strategies to support muscle maintenance in clinical populations"

Workshop speaker: Maastricht University Medical Centre+, 20 April 2018: Conference healthcare strategy: "Patient, nutrition and exercise: you are what you eat"

2017: Invited speaker: Nutrition and Dietetics Department, Alfred Hospital, Melbourne, Australia, 6 Dec 2017: "Anabolic resistance in ageing and clinical populations"

Speaker at Symposium: Australia Physiological Society AuPS meeting, 20-22 Nov 2017, Melbourne, Australia: "Anabolic resistance in ageing and clinical populations"

Oral presentation: Australia Physiological Society AuPS meeting, 20-22 Nov 2017, Melbourne, Australia: "Ingestion of $40 \mathrm{~g}$ protein prior to sleep stimulates overnight myofibrillar protein synthesis in healthy older men"

Oral presentation: Australia Physiological Society AuPS meeting, 20-22 Nov 2017, Melbourne, Australia: "One week of hospitalization leads to substantial muscle atrophy in older patients following elective hip surgery" 
Invited speaker: Centre of Research Excellence, Faculty of Health and Medical Sciences, the University of Adelaide, Australia, 1 Nov 2017: "Clogs, bicycles and radioactive cows-the regulation of skeletal muscle mass in clinical populations"

Invited speaker: Dutch Nutrition Conference, 10 Jan 2017, Ede, the Netherlands, Oral presentation: "Nutrition in the geriatric patient".

2016: Poster presentation: Annual NUTRIM day, Maastricht, 7 Dec 2016: "Basal and postprandial myofibrillar protein synthesis rates do not differ between lean and obese males"

Oral presentation: ESPEN Congress, Copenhagen 17-20 Sept 2016. Outstanding abstract: "Basal and postprandial myofibrillar protein synthesis rates do not differ between lean and obese males". Travel Grant winner 2016

Invited speaker: Nutricia Masterclass 7 June, 10 October, and 29 November 2016: "Sarcopenia: the importance of nutritional strategies and physical activity"

Oral Presentation: ECSS Congress, Vienna, 6-9 Jul 2016: "Ingestion of $40 \mathrm{~g}$ protein prior to sleep stimulates overnight myofibrillar protein synthesis in healthy older men". Gatorade Sport Sciences Institute (GSSI), Sports Nutrition Award: $1^{\text {st }}$ price oral presentation and selected for Young Investigators Award (YIA)

Invited speaker: Dietetics Department Maastricht MUMC+, 8 June 2016: "Muscle disuse atrophy during hospitalization; the role of nutritional interventions"

Invited speaker: Dutch Geriatric Society, 15 March 2016, Utrecht: "Sarcopenia: the importance of nutritional strategies and physical activity"

Invited speaker: Dutch Network Orthopedic surgery, 25 Feb 2016, Maastricht: "Nutritional strategies to maintain skeletal muscle mass"

Organizer Symposium and Oral presentation: Geriatrics, 's-Hertogenbosch, 18 Feb 2016, "The loss of skeletal muscle mass during hospitalization: the importance of nutritional interventions to support muscle mass"

2015: Invited oral presentation: Exeter University, 17 July 2015: "Dietary nitrate coingestion with protein does not enhance muscle protein synthesis in older, type 2 diabetes patients"

Oral presentation: ESPEN Congress, Lisbon, 5-8 Sept 2015. Best abstract winner: "Protein ingestion prior to sleep stimulates overnight protein synthesis in healthy elderly men". Travel Grant winner 2015

Oral Presentation: ESPEN Congress, Lisbon, 5-8 Sept 2015: "One week of hospital admission following elective hip surgery induces substantial muscle atrophy in older patients"

Oral presentation: ECSS Congress, Malmo, 24-27 June 2015: "Skeletal muscle disuse during hospitalization in older patients following elective hip surgery" 
2014: Oral presentation: ECSS Congress 2-5 July 2014, Amsterdam: Selected for YIA, Oral presentation: "The muscle protein synthetic response following a single bolus of dietary protein is not impaired in elderly men with type 2 diabetes"

Poster presentation: ESPEN Congress, 6-9 Sept 2014, Geneva: "Postprandial muscle protein synthesis is not impaired in elderly type 2 diabetes patients when compared with healthy, age-matched controls"

Oral presentation: Dutch Nutritional Science Days, 10-11 Oct 2014 "Protein ingestion prior to sleep stimulates overnight protein synthesis in healthy elderly men"

2013: Poster presentation: ECSS Congress Barcelona, 26-29 June 2013. Selected for YIA, Mini oral presentation: "Dietary nitrate co-ingestion with protein does not further enhance whole-body protein synthesis rates in older, type 2 diabetic men"

Poster presentation: ESPEN Congress, Leipzig, 31 Aug-3 Sept 2013: "Dietary nitrate co-ingestion with protein does not further enhance the muscle protein synthetic response in older, type 2 diabetic men"

2012: Poster presentation: ESPEN Congress Barcelona, 8-11 Sept 2012, "Neuromuscular electrical stimulation increases skeletal muscle protein synthesis rates in elderly, type 2 diabetic men" 

FINANCIAL SUPPORT FOR PRINTING THIS THESIS WAS

KINDLY PROVIDED BY
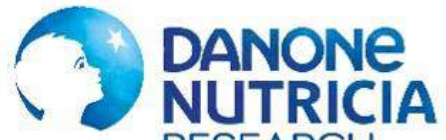
RESEARCH

NUTRICIA

RESEARCH
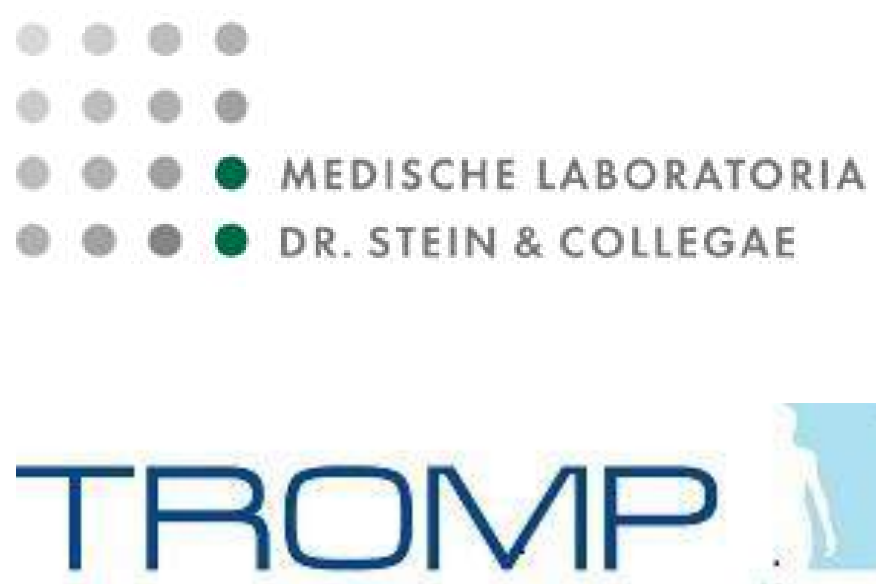
main Findings and ReCOMMENDATions from the PHD thesis:

NUtritional Strategies tO SUPPORT MUSClE maintenanCE in Clinical populations

IMRE KOUW, DECEMBER 2018

IMRE.KOUW@MAASTRichtuniversity.NL

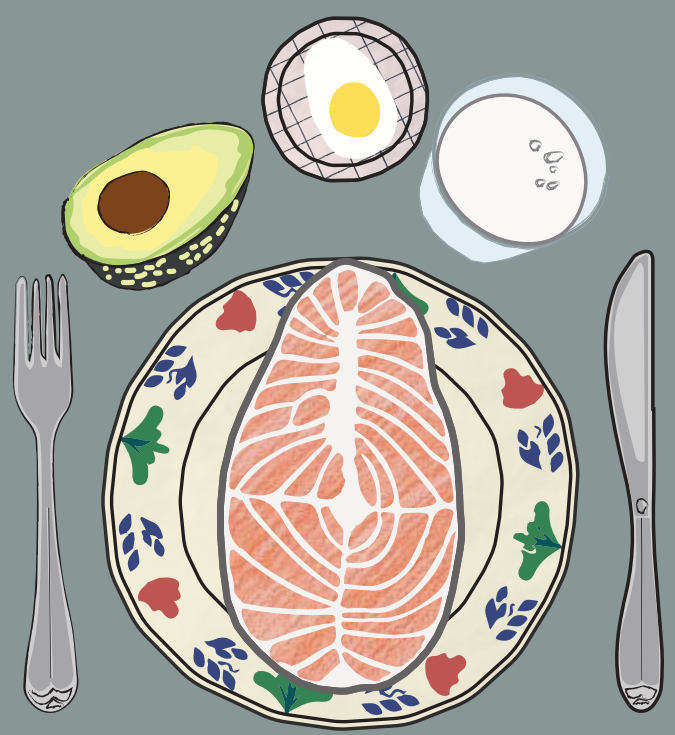


nutritional intervention strategies ShOUld be COMBined With more PHYSiCAL ACTivity BEFORE, DURiNG, AND AFter HOSPitalization.

\section{early pre-Habilitation interventions that include exercise}

2 TRAiNing AND PROTEIN SUPPLEMENTATION SHOULD bE IMPLEMENTED tO improve clinical OUtcomes during hospitalization in OLDER PATientS.

Since 40\% of the PROVIDED hospital MeALS is nOt CONSUMEd, MORE 3 PROTEIN-Rich FOODS AND ATTRACTIVE MEAL SERVICE CONCEPTS NEED tO be Provided tO the PATiENt tO inGREASE Protein intake.

4 TO REACH PROTEIN INTAKE RECOMMENDATION LEVELS OF 1.2 G.KG $G^{-1} \cdot 0^{-1}$ FOR older PATIENTS, A MORE PROTEIN-deNSE diet WILl be REQUiRED.

MORE SPECIFiC NUTRitional interventions throughOUt hOSPitalization are NEEDED; NUtRitional SUPPLEMENTATION CAN COVER

5 energy and protein deficits in the acute (operative) Period Whille THE SUBSEQUENT dAYS Will REQUiRE tHE FOCUS ON THE INCREASE iN PROTEIN INTAKE MAINLY THROUGH THE DIET.

PRE-SLeEp PRotein ingestion CAN BE A USEFUL Strategy to Provide 6 extra protein on the EVENing prior to surgery and during EVENing ROUNDS ON THE WARD.

AN ATtRactive ENVIRONMENT USing WALKING ROUTES AND GARDENS COULD

7 BE OFFEREO in HOSPITALS tO ENCOURAGE PATIENTS tO bE MORE PHYSiCally aCtive DURING HOSPITALizatioN.

8 hospital meals neEd to be attractive, adequately nutritious, and PATiENT-SPECIFIC.

rehabilitation Strategies nEed tO be CONTINUEO ON THE LONG teRM 9 AND SHOULD COMBinE A FUnCTiONAL EXERCiSE TRAining REGiMEN WITH PROPER NUTRITIONAL SUPPORT.

A MUttimodal approach will maximize the intrinsic motivation of THE PATIENT. 